MARIO DÖBERL, ALEJANDRO LÓPEZ ÁLVAREZ (HG.)

\title{
TRAGSESSEL IN EUROPÄISCHEN \\ HERRSCHAFTSZENTREN
}

VOM SPÄTMITTELALTER BIS ANFANG DES I8. JAHRHUNDERTS

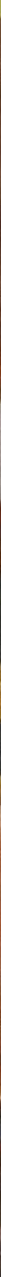


Mario Döberl - Alejandro López Álvarez (Hg.)

\section{Tragsessel in europäischen Herrschaftszentren}

Vom Spätmittelalter bis Anfang des 18. Jahrhunderts

BÖHLAU VERLAG WIEN KÖLN WEIMAR 


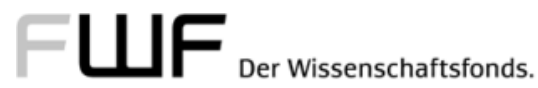

\section{Veröffentlicht mit Unterstützung des} Austrian Science Fund (FWF): PUB 637-G26

Open Access: Wo nicht anders festgehalten, ist diese Publikation lizenziert unter der Creative-Commons-Lizenz Namensnennung 4.0 siehe http://creativecommons.org/licenses/by/4.o/

Diese Publikation wurde einem anonymen, internationalen

Peer-Review-Verfahren unterzogen

Bibliografische Information der Deutschen Bibliothek:

Die Deutsche Nationalbibliothek verzeichnet diese Publikation in der Deutschen Nationalbibliografie; detaillierte bibliografische Daten sind im Internet über https://dnb.de abrufbar.

(C) 2020 by Böhlau Verlag GmbH \& Co. KG, Kölblgasse 8-ıо, A-ıо30 Wien

Die Herausgeber haben sich bemüht, für alle Abbildungen die Rechte umfassend einzuholen. In Fällen, wo dies nicht gelungen ist, bitten wir um eine Rückmeldung.

Umschlag: Michael Haderer, Wien

Umschlagabbildung: Das Hostienwunder von Bolsena (Detail). Raffael, I512.

Apostolischer Palast (Vatikan), Stanza di Eliodoro. (C) Scala Archives

Übersetzungen: Anatoli Adamidou, Catharina Dietrich und Mario Döberl

Bildbearbeitung: Michael Aumüller und Michael Eder

Satz: Bettina Waringer, Wien

Vandenhoeck \& Ruprecht Verlage | www.vandenhoeck-ruprecht-verlage.com

ISBN (Print) 978-3-205-20580-7

ISBN (PDF) 978-3-205-20966-9

Dieses Material steht unter der Creative-Commons-Lizenz Namensnennung 4.0 International. Um eine Kopie dieser Lizenz zu sehen, besuchen Sie http://creativecommons.org/licenses/by/4.0/.

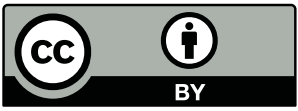




\section{Inhalt}

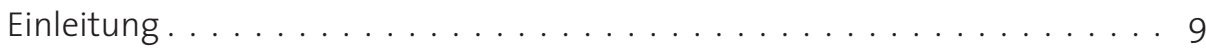

Claudia Märtl

Die sedia gestatoria der Päpste . . . . . . . . . . . . . . . . . . 17

I Die neuzeitliche Gestalt der sedia gestatoria: Bildquellen und erhaltene Tragethrone I7 - 2 Der erste Versuch einer historischen Erklärung: José Estefan (I578/I588) 20 • 3 Die Grundlegung des modernen Forschungsstandes: Gaetano Moroni (I853) 22 - 4 Methodische Probleme der historischen Herleitung 23 5 Die fehlgeleitete Suche nach einer mittelalterlichen Kontinuität der sedia gestatoria 25 - 6 Die „Erfindung“ der sedia gestatoria durch Papst Pius II. (I458-I464) 28 - 7 Die Etablierung der sedia gestatoria im päpstlichen Zeremoniell der Frührenaissance 32 - 8 Frühneuzeitliche Darstellungen der sedia gestatoria 34-9 Die Gestalt der sedia gestatoria in der Frühen Neuzeit 43 - IO Protestantische Bildpropaganda 44

\section{Farida Simonetti}

„The Streets are very narrow; so that they use here few Coaches, but many Sedans and Litters. "Tragsessel und Sänften in Genua vom 16. bis Anfang des 18. Jahrhunderts . . . . . . . . . . . . . . . . . . . . . . . 49

I Ein kostbarer Genueser Tragsessel von I67I 49 - 2 Weitere Tragevehikel des „goldenen Zeitalters" Genuas 56 - 3 Terminologische Aspekte und Ausstattungsvarianten 57 - 4 Luxusgesetze 65-5 Erhaltungskosten 65-6 Einsatzgebiete 67- 7 Straßen- und Verkehrsverhältnisse 68 
Alejandro López Álvarez

Zeremoniell, soziale Integration und Luxusgesetze: Tragsessel in der spanischen Monarchie des 16. und 17. Jahrhunderts . . . . . . . . . . . . . . . 71

I Vorwort 7I 2 Einleitung 7I - 3 Tragsessel im spanischen Königshaus 73 - 3.I Tragsessel Karls V. und Philipps II. (I556-I598) 73 - 3.2 Tragsessel im Hofstaat der Königinnen (I560-1707) 80 - 3.3 Tragsessel bei Taufen 96 4 Tragsessel in der spanischen Gesellschaft des I6. und I7. Jahrhunderts 99 - 4.I Tragsessel in Spanien und Amerika im I6. Jahrhundert 99 4.2 Tragsessel in Spanien und Amerika im I7. Jahrhundert Io9 - 5 Die Gesetzgebung zu Tragsesseln und Sesselträgern im I6. und 17. Jahrhundert I25 - 5.I Rechtliche Bestimmungen zur Tragsesselnutzung (I579 bis um I660) I26 - 5.I.I Die Anfänge der Gesetzgebung (I579-I603) I26 • 5.I.2 Die „Institutionalisierung“ der Tragsessel und ihre Folgen (I604 bis ca. I635) I31 - 5.I.3 Die Besteuerung von Tragsesseln und das Mietverbot (I635 bis ca. I660) I56 - 5.2 Gesetzliche Regelungen rund um die Ausstattung von Tragsesseln (I600-I69I) I60 - 5.3 Die Gesetzgebung zu Sesselträgern (I594-I69I) I66

Attilio Antonelli - Stefano Moscatelli - Ilaria Telesca

Portantine und sillas de manos im Hofzeremoniell Neapels . . . . . . . . . . . . 179

I Quellen I79 - 2 Terminologie I8I 3 Anthologie I9I

Mario Döberl

Tragsessel an den Höfen der österreichischen Habsburger . . . . . . . . . . 205

I Einleitung 205 - 2 Tragsessel an österreichischen Höfen bis zum Ende der Regierung Kaiser Leopolds I. (I705) 206 • 2.I Frühe Erwähnungen von Tragsesseln bis Anfang des 17. Jahrhunderts: Ein Transportmittel für gehbehinderte Fürsten 206 - 2.2 Ein Geschenk aus Florenz für Kaiserin Anna (I6I5): Tragsessel als Schutz für schwangere Fürstinnen und ihre ungeborenen Kinder 224 2.3 Zur Jagd im Tragsessel: Ein Präsent aus Mantua für Kaiserin Eleonora Gonzaga (I.) (I623) 23I • 2.4 Exkurs I: Nachrichten über frühe Tragsessel am Innsbrucker Hof 235 - 2.5 Königin und Kaiserin Maria Anna und ihre Tragsessel 237 - 2.6 Exkurs II: Tragsessel bei Tauffeiern und Hervorgängen von der 2. Hälfte des 17. Jahrhunderts bis Anfang der I740er Jahre. Nachhaltige Änderungen im Hofzeremoniell? 244 - 2.7 Gebrechliche Kaiser: Ferdinand II. und Ferdinand III. im Tragsessel 25I 2.8 Reformen im Hofmarstall und ihre Auswirkungen 
auf die kaiserlichen Sesselträger (I657) 259 - 2.9 Tragsessel am Hof Kaiser Leopolds I. (I657-1705) 262 - 3 Zu Herkunft, Gestalt und Ausstattung der kaiserlichen Tragsessel im I7. Jahrhundert. Mit einer Besprechung des ältesten erhaltenen Exemplars des Wiener Hofes 276 - 4 Die kaiserlichen Sesselträger: Sozialer Status, Anzahl, Herkunft, Rekrutierung und Dienstvorschrift 284 - 5 Die Einführung von Miettragsesseln in Wien 296-6 Quellenanhang 300 - 6.I Tragsessel in den kaiserlichen Marstallinventaren von I678 30I - 6.2 Vorschriften für kaiserliche Sesselträger (I682) 302 - 6.3 Überblick über die wechselnde Zahl der Hofsesselträger (I6I5-I7II) 304 - 6.4 Privileg für Miettragsessel in Wien (1703) 310

Gudrun Szczepanek - Friederike Ulrichs

„In- und außwendig mit Gold vertrefflichist außgeziert“.

Tragsessel am Münchner Hof . . . . . . . . . . . . . . . . . . . . . . 313

I Tragsessel im Münchner Marstallmuseum 313 • I.I Gala-Tragsessel von Kurfürstin Maria Antonia, um I684/85 313 - I.2 Tragsessel mit silber-blauem Lackdekor, um 1747 3I8 - 2 Quellen zu Gebrauch und Funktion der frühen Tragsessel am Münchner Hof 322 - 2.I Die Inventare des Münchner Marstalls 322 - 2.2 Erste Tragsessel unter Kurfürstin Maria Anna, I635 324 - 2.3 Die Tragsessel von Kurfürstin Henriette Adelaide, I650-I676 326 2.4 Tragsessel der Kurfürstinwitwe Maria Anna, I65I-I665 328 • 2.5 Der „Turinische Tragsessel“ im Kontext der Taufe von Kurprinz Max Emanuel, I662 329 - 2.6 Der Tragsessel Maria Antonias im Kontext der Taufe von Max III. Joseph, I727 333 - 3 Die Sesselträger 334 - 3.I Sesselträger am Münchner Hof 334 - 3.2 Instruktion für den Sesselmeister der Stadt München, I688 335 - 3.3 Türken als Sesselträger 337 - 4 Zusammenfassung 340 - 5 Quellenanhang 340 - 5.I. Übertragung des Marstallinventars von I656 340 5.2 Sesselträgerordnung von I688 (Abschrift) 34I

Marie Maggiani

Französische Tragsessel des späten 17. und frühen 18. Jahrhunderts. . . . . . . . 345

I Einleitung 345 - 2 Tragsessel im Machtzentrum der Monarchie 346 • 3 Beispiele aus sekundären Machtzentren und der Peripherie des Königreichs 352 - 4 Polsterung, Farben und Verglasung 363-5 Miettragsessel 366-6 Das Ansehen der Sesselträger 37I 
Mario Döberl

Résumé . . . . . . . . . . . . . . . . . . . . . 375

I Etablierung, Verbreitung, Einsatzgebiete und rechtliche Restriktionen $375 \cdot 2$ Typen, Ausstattungsvarianten und Verbreitungswege neuer Modelle $383 \cdot 3$ Miettragsessel 386

- 4 Sesselträger: Herkunft, Karriereverläufe, Reputation und gesundheitliche Aspekte 390

Abkürzungsverzeichnis . . . . . . . . . . . . . . . . 393

Verzeichnis der gedruckten Quellen und der Forschungsliteratur . . . . . . 395

I Gedruckte Quellen 395 - 2 Forschungsliteratur 4II 


\section{Einleitung}

Auf heutige Betrachter wirken Tragsessel wie ein Kuriosum einer längst vergangenen Epoche, ${ }^{1}$ das in trefflicher Weise soziale Unterschiede versinnbildlicht: Vertreter der Oberschicht ließen sich in oftmals aufwendig gestalteten Tragevehikeln in ihren Palästen oder auf den Straßen der Stadt von ihren in kostbare Livreen gekleideten Dienern transportieren, erhoben sich auf diese Weise über den unreinen Boden und entrückten sich damit auch symbolisch dem einfachen Volk. Die Sesselträger, deren Tätigkeit eine erhebliche Kraftanstrengung erforderte, übernahmen dabei jene Rolle, die bei anderen Transportmitteln Pferden oder Maultieren zufiel. Das Bild einer mächtigen Person, die sich im Tragsessel befördern lässt, ist von enormer Wirkkraft. Während es in früheren Zeiten in Anbetracht der damit verbundenen Prunkentfaltung wohl häufig Ehrfurcht und Staunen hervorrief, fördert es heute vermutlich eher ein Gefühl der Empörung über eine arrogante Zurschaustellung von Macht zu Tage und erregt Mitleid mit den in mehrfacher Hinsicht erniedrigten Trägern. Tatsächlich ist es aber noch gar nicht so lange her, dass Tragsessel aus dem zeremoniellen Kontext verschwunden sind: Erst nach dem kurzen Pontifikat von Johannes Paul I. im Jahr 1978 fand das Zeitalter der Tragsessel in Europa sein wohl endgültiges Ende. Politische Machthaber im Tragsessel sind heute selbst im traditionsbewussten Vatikan undenkbar und würden wohl einen öffentlichen Sturm der Entrüstung hervorrufen. $^{2}$

Zum Gegenstand der Forschung wurden Tragsessel bereits zu einem relativ frühen Zeitpunkt. Im Jahr 1737 veröffentlichte Carl Christian Schramm, Amtsrat der Reichsgrafen zu Solms, in Nürnberg ein Buch mit dem ausschweifenden Titel „Abhandlungen der Porte-Chaise oder Trage-Sänfften durch Menschen oder Thiere, in allen vier Theilen der Welt, nach der Critic, Mechanic, Historie, dem Recht, wie auch Cammer- und Policey-Wesen ausgeführet und erläutert mit Urkunden und Kupffern“. Schramm verfolgte mit seiner

I Ausgenommen von diesen Betrachtungen sind natürlich sesselartige Krankentragen, die bis heute von Rettungsdiensten und in Krankenhäusern verwendet werden.

2 Zur aktuellen Situation im Vatikan siehe auch den Beitrag von Claudia Märtl im vorliegenden Band. Hiervon nicht betroffen sind übrigens Politiker und Prominente unserer Zeit, die mit einer explizit ironischen Grundhaltung im Rahmen von Festveranstaltungen Sesselträgerdienste in Anspruch nehmen. Siehe hierzu die Kundenliste des österreichischen „Sänftendienstes“ „Flinker Hirsch“, der sich für Events unterschiedlichster Art buchen lässt: http://members.aon.at/saenftendienst/ (letzter Zugriff: 16.08.2016). 
gelehrten Abhandlung, die mit einem für seine Zeit überraschend modern anmutenden Anmerkungsapparat und zahlreichen Illustrationen aufwartet, den Plan, eine umfassende Geschichte von Tragevehikeln von der Antike bis in die Gegenwart zu verfassen. Sein Interesse ging dabei weit über den europäischen Kontinent hinaus und reichte bis nach Amerika, Asien und Afrika. Er stellte in seinem Werk nicht nur verschiedenste Erfindungen seiner Zeit vor - beispielsweise Tragsessel, die sich auch zum Stufensteigen eigneten, ohne dass die darin transportierte Person in Schieflage geriet -, sondern widmete sich auch verschiedenen zeitgenössischen Verordnungen, die den Gebrauch von öffentlichen Miettragsesseln regelten. Zwar ist Schramms Werk als Produkt seiner Zeit heute nur noch von eingeschränktem praktischem Nutzen für die Wissenschaft, es stellt aber dennoch ein erstaunliches frühes Zeugnis der theoretischen Beschäftigung mit Tragevehikeln dar. Bedauerlicherweise fand der deutsche Gelehrte für lange Zeit keine Nachfolger, die sein Werk in ähnlich umfassender Weise aktualisiert und vertieft hätten. Erst der aus Straßburg stammende, später in München tätige und historisch gebildete Wagenbauer Johann Christian Ginzrot setzte sich im ersten Drittel des 19. Jahrhunderts wieder in vergleichbarer Intensität mit der Geschichte von Tragsesseln und Sänften auseinander. ${ }^{3}$

Vorbildwirkung hatte Schramm für spätere Autoren - wie etwa Ginzrot - darin, dass er ganz unterschiedliche Vehikeltypen, die auch verschiedene Anwendungsgebiete hatten, gemeinsam behandelte und teilweise auch miteinander vermengte, nämlich einerseits Tragsessel, die häufig auch als „Porte-Chaisen“ bezeichnet wurden, und andererseits Sänften. ${ }^{4}$ Während es sich bei Tragsesseln um vorwiegend im urbanen Bereich verwendete, von Menschen beförderte Transportmittel für eine einzige Person handelte, wurden die größeren Sänften, die anders als Tragsessel gestaltet waren und meist auch zwei Personen Platz boten, in der Regel von Maultieren oder Pferden getragen und hauptsächlich auf Reisen eingesetzt, und dies bereits über weite Strecken des Mittelalters hin. An den Fürstenhöfen waren auch unterschiedliche Marstallabteilungen und Dienersparten für diese Transportmittel zuständig. Die erwähnte Vermischung liegt unter anderem auch darin begründet, dass damals allein in Teilen des süddeutschen Sprachraums - etwa in

3 Johann Christian Ginzrot, Die Wagen und Fahrwerke der Griechen und Römer und anderer alten Völker nebst der Bespannung, Zäumung und Verzierung ihrer Zug-, Reit- und Last-Thiere, 2 Bde. (München I817, Nachdruck Hildesheim/New York 1975), Bd. 2, S. 254-29I, Taf. LXVLXVII; Johann Christian Ginzrot, Die Wagen und Fahrwerke der verschiedenen Voelker des Mittelalters und der Kutschen-Bau neuester Zeiten nebst der Bespannung, Zäumung und Verzierung ihrer Zug-, Reit- und Last-Thiere, 2 Bde. (München I830, Nachdruck Hildesheim/New York 1979), Bd. I, S. I32-I48, Bd. 2, Taf. XXII, CXLVII.

4 Bereits wenige Jahre nach dem Erscheinen von Schramms Werk wurden auch im einflussreichen Zedler'schen Universallexikon beide Vehikeltypen unter dem Eintrag „Sänfte, Tragsessel“ abgehandelt. Johann Heinrich ZedLer, Universal-Lexicon, Bd. 33 (Leipzig/Halle 1742), Sp. 477. 
Österreich und Bayern - eine scharfe terminologische Trennung zwischen Sänften und Tragsesseln vorgenommen wurde, während in anderen Teilen des deutschen Sprachgebiets das Wort „Sänfte“ für beide Vehikeltypen Verwendung fand. Heute ist dieser synonyme Sprachgebrauch im Deutschen überall anzutreffen, sodass auch in wissenschaftlichen Werken zuweilen unklar bleibt, welche Vehikelart gemeint ist, wenn von „Sänften“ die Rede ist. In anderen europäischen Sprachen - etwa im Englischen, Französischen, Spanischen oder Italienischen - ist eine derartige terminologische Unschärfe für Tragevehikel weitgehend unbekannt. Um Missverständnisse zu vermeiden, wird in den Beiträgen dieses Buches der Begriff „Sänfte“ nur in Zusammenhang mit von Tieren beförderten Tragevehikeln verwendet.

Im vorliegenden Band stehen hauptsächlich Tragsessel im Vordergrund. In Privatbesitz und in musealen Sammlungen befindet sich bis heute eine überraschend hohe Zahl derartiger Transportmittel vergangener Zeiten. Der englische Hobbyforscher Stephen Loft-Simson, der eine provisorische und unveröffentlichte Liste ${ }^{5}$ aller ihm bekannten erhaltenen historischen Tragsessel anlegte, trug bislang Informationen zu insgesamt knapp IIоo Objekten europäischer Provenienz zusammen. In merkwürdigem Kontrast zur Fülle heute noch existierender Tragsessel und zu ihrer kunst- und kulturhistorischen Bedeutung steht bis heute das geringe Interesse, das die Forschung diesen Objekten entgegenbringt.

Seit Beginn des 20. Jahrhunderts waren es vor allem wissenschaftliche Bestands- und Ausstellungskataloge sowie Museumsführer, ${ }^{6}$ die in Europa - etwa in Belgien ${ }^{7}$, Deutschland ${ }^{8}$, Frank-

$5 \quad$ Ein entsprechender aktueller Überblick von Loft-Simson findet sich in den Akten der Kaiserlichen Wagenburg: KHM, Kaiserliche Wagenburg, Zl. 88/WGBG/20I5. Zahlreiche Tragsessel aus unterschiedlichen (auch außereuropäischen) Sammlungen sind auch aufgelistet in Claus Heinrich BILL, Kulturgeschichte der Portechaise. Soziale und kulturelle Aspekte des Sänftenwesens (München 20I3), S. 2I f.

6 Eine lückenlose Aufzählung dieser Publikationen ist hier allein schon deshalb unmöglich, weil die Zahl der an entlegenen Orten erschienenen Schlossführer und ähnlicher Veröffentlichungen, in denen oftmals nur ein einzelner Tragsessel behandelt ist, nicht zu überblicken ist.

7 Micheline Ruyssinck, Les voitures attelées aux XVIII et XIX ${ }^{e}$ siècles (Bruxelles 2002), S. 8, Abb. I2.

8 Tonio Schulze, Kutschenmuseum Schloss Augustusburg (Coburg o.J.), o.S.; Max Piende, Der fürstliche Marstall in Regensburg (Thurn und Taxis-Studien 4, Kallmünz 1966), S. I65-167; Mainfränkisches Museum Würzburg. Neuerwerbungen 1973-1978 (Würzburg 1978), S. 84, Abb. 93; Burkhardt Göres, Berliner Prunkschlitten, Kutschen und Sänften des Barock, Berlin, Kunstgewerbemuseum (1987), S. 17-19, 22 f., 26, 34 f.; Heinz Spielmann (Hg.), Reiseleben - Lebensreise. Zeugnisse der Kulturgeschichte des Reisens. Sammlung P.-J. van Tienhoven (Schleswig I994), S. 29, io8; Rudolf H. Wackernagel (Hg.), Staats- und Galawagen der Wittelsbacher. Kutschen, Schlitten und Sänfte aus dem Marstallmuseum Schloß Nymphenburg, 2 Bde. (Stuttgart 2002), Bd. I, S. 74-85, Bd. 2, S. 97-I05; Jörg Heinrich METZ, Inventarverzeichnis der Metz v. Tessin'schen Kutschensammlung (Tübingen 2002), S. 178 f.; Elisabeth Reissinger/Rudolf H. WaCKERNAGeL, Kutschenmuseum Auerstedt. Die historischen Wagen der Großherzöge von Sachsen-Weimar und 
reich $^{9}$, Großbritannien ${ }^{\mathrm{I0}}$, Italien (samt Vatikan) ${ }^{\mathrm{I1}}$, Österreich ${ }^{\mathrm{I2}}$, Polen $^{\mathrm{13}}$, Portugal ${ }^{14}$, Russland ${ }^{15}$,

Eisenach (Berlin/München 20II), S. 58 f.; Andres Furger, Die Kutschensammlung Heinz Scheidel Mannheim. Der Überblick: Fuhrwerke, Wagen, Reiten, Accessoires und Dokumente (Mannheim 20II), S. 204 f.; Claudia Meckel, Kutschen, Schlitten, Sänften (Stiftung Preußische Schlösser und Gärten Berlin-Brandenburg, Bestandskatalog der Kunstsammlungen, Berlin 2013), S. 177-213, 267 f., 370, 375, 379 .

9 Jean-Marie Moulin, Guide du musée national du château de Compiègne (Paris I992), S. 206 f.; Béatrix Saule, A Guided Tour of the Coach Museum (Versailles 1997), S. i8 f.; Emmanuel StarCKY u.a., Le Palais impérial de Compiègne (Paris 2008), S. II4 f. Für weitere Frankreich betreffende Literatur siehe auch den Beitrag von Marie Maggiani im vorliegenden Band.

io Ralph Straus, Carriages and Coaches. Their History \& their Evolution (London I9I2), S. 85-Io8.

II Luigi Belloni, La carozza nella storia della locomozione (Torino/Milano/Roma I90I), S. 45-50, 206 f.; Giuseppe Morazzoni, Carrozze e portantine a Napoli nel '700. In: Dedalo. Rassegna d'arte 8/3 (i927/28), S. 752-78i; Lucio Polo, C'era una volta una carrozza ... Il museo delle carrozze della Villa di Maser (Cittadella 1978), S. II3; Pietro Амато, Museum of the Papal Carriages in the Vatican (Recent Restorations of the Vatican Museums 5, Vatikanstadt 2006), S. I32-137; Louis Godart (Hg.), Le carrozze del Quirinale (Ancona 2009), S. 187, 191, 204-207; Jacques Charles-Gaffiot, Trônes en majesté. L'Autorité et son symbole (Ausstellungskatalog, Paris 20II), S. 312-317; Carrozze regali. Cortei di gala di papi, principi e re (Ausstellungskatalog, Reggia di Venaria, Milano 2013), S. I04-I09. In den im vorliegenden Band enthaltenen Beiträgen von Claudia Märtl, Farida Simonetti sowie von Attilio Antonelli, Stefano Moscatelli und Ilaria Telesca ist weitere Literatur zu italienischen Tragsesseln zitiert.

I2 Georg Kugler, Die Wagenburg in Schönbrunn. Hofwagenburg, Reiche Sattel- und Geschirrkammer der Kaiser von Österreich (Graz 1977), S. 46 und Tafel 25; Monica Kurzel-Runtscheiner, Die historischen Fahrzeuge der Schausammlung. In: Elisabetta Bresciani/Monica Kurzel-Runtscheiner/Elisabeth von Samsonow (Hg.), Schwanenhals und Goldkrepine. Höfischer Prunk und zeitgenössische Kunst - eine Konfrontation (Ausstellungskatalog, KHM, Wagenburg, 2004), S. 89-IO5, hier S. 94 f., 98, IOI, I03; Additionen. Neuerwerbungen des Kunsthistorischen Museums 1990-2008 (Ausstellungskatalog, Milano 2008), S. I6I f. Für weitere Literatur zu Tragsesseln in Österreich siehe auch den Beitrag von Mario Döberl im vorliegenden Band.

I3 Jerzy Żurawski/Zdzisław Postępski, Łańcut (Warszawa 1969), Abb. 6.

I4 Luciano Freire, Museu Nacional dos côches. Catálogo descritivo e ilustrado (Lisboa ${ }^{2}$ I928), S. 52 f.; Catálogo do museu nacional dos coches (Lisboa ${ }^{4}$ I964), S. 35 f., Abb. LIII und LIV; Silvana Bessone, Le musée national des carrosses Lisbonne (o.O. 1993), S. iro f.; Silvana Bessone, National Coach Museum. Guide (Lissabon 2002), S. 48, 90-92, 94-96, I03.

is Lyubov Kirillova, Royal Carriages. Treasures of the Armoury (Moskau 2000), S. I87-I89; Wladimir Tschernyschew, Vom kaiserlichen Marstallmuseum zur Wagensammlung der Eremitage in St. Petersburg - Kostbarkeiten des I8. und 19. Jahrhunderts. Geschichte und Bestand einer der weltweit wichtigsten Marstallsammlungen. In: Achse, Rad und Wagen. Beiträge zur Geschichte der Landfahrzeuge I2 (2004), S. 94-I05, hier S. 94 (Abb.) und IoI. 
Schweden ${ }^{16}$, der Schweiz ${ }^{17}$, Spanien ${ }^{18}$ oder Tschechien ${ }^{19}$ - einzelne Tragsessel mehr oder weniger genau behandelten. Im Vordergrund standen dabei aber vorrangig Objekte des I8. und 19. Jahrhunderts, also aus jenem Zeitraum, von dem sich auch die meisten Tragsessel erhalten haben. Publikationen, die sich in ausführlicher Weise mit Tragsesseln und ihrer Geschichte beschäftigten, blieben die Ausnahme. ${ }^{20}$

I6 The Royal Armoury. The assembling of royal relics, costumes arms, armour, uniforms and coaches from about 1500 to the present (Stockholm 1978), S. 23, 59.

I7 Andres Furger-Gunti, Kutschen und Schlitten aus dem alten Basel (Basel I982), S. 20 f.

I8 Isabel Turmo, Museo de Carruajes (Madrid ${ }^{2}$ I977), S. IoI-IO4; Carmen Rodrigo Zarzosa, Carruajes del Palacio de los Marqueses de dos Aguas. Museo Nacional de Cerámica. Catalogo (Valencia 199I), S. I05-IO8; Carmen Rodrigo Zarzosa, Evolución y tipología del carruaje desde I700. In: Historia del Carruaje in Espana (o.O. 2002), S. I82-205, hier S. 202, 204 f.; Eduardo Galán Domingo, El carruaje ceremonial y ciudadano en España: de 1700 al triunfo del automóvil. In: Historia del Carruaje in Espana (o.O. 2002), S. 24I-267, hier S. 24I, 263. In dem Beitrag, den Alejandro López Álvarez für den vorliegenden Band verfasst hat, ist weitere Literatur - auch von ihm selbst - zu Tragsesseln in Spanien zu finden.

I9 Jaroslav SojKA (Hg.), Zapřažená krása. Kočáry, saně a nosítka 18.-20. Století (Ausstellungskatalog, Praha 20I4), S. 8o-83, $88 \mathrm{f}$.

20 In Italien setzte sich schon früh Luigi Maria Majorca Mortillaro mit Tragsesseln auseinander. Sein Werk kann jedoch in vielerlei Hinsicht als veraltet gelten: Luigi Maria Majorca Mortillaro, Letthige, portantine e personaggi del Settecento. Ricerche storico-artistiche (Palermo ${ }^{3}$ I906, erstmals Palermo 1897). Eine ausführliche Beschäftigung mit italienischen Tragsesseln bietet der Ausstellungskatalog: Farida Simonetti/Marzia Cataldi Gallo (Hg.), Farsi Portare in carega, Portantine e livree per la nobiltà genovese (Ausstellungskatalog, Genova 1995). Ein Ausstellungskatalog über maltesische Tragsessel behandelt zwar gleich zwanzig Tragsessel und bildet diese auch großformatig ab, liefert bedauerlicherweise jedoch kaum Informationen zu den Objekten: Nicholas de Piro, The Sedan Chair in Malta - Is-Sugggetta. Great Exhibitions Revisited (Valetta 2007). Marie Maggiani setzte sich bislang am profundesten mit französischen Tragsesseln auseinander, über die sie auch ihre Dissertation verfasste: Marie MaGgiani, La parade citadine aux $17^{\text {ème }}$ et $18^{\text {ème }}$ siècles. Enquête méridionale sur la chaise à porteurs (ungedr. Dissertation, Universität Toulouse II 2007); Marie Maggiani, Les belles oubliées de la carrosserie: les chaises à porteurs. In: Béatrix SAULE/ Jean-Louis Libourel/Hélène Delalex (Hg.), Roulez carrosses! Le château de Versailles à Arras (Ausstellungskatalog, Paris 20I2), S. 63-73; La chaise à porteurs du château de Marsillargues, hg. von d. Direction régionale des affaires culturelles (DRAC) du Languedoc-Roussillon / Conservation régionale des monuments historiques (CRMH) (Montpellier 20I2). Weitere Spezialuntersuchungen zu französischen Tragsesseln stammen von Jean-Louis Libourel und jüngst von Esther van der Hoorn: Jean-Louis Libourel, Une chaise à porteur du XVIII ${ }^{\mathrm{ème}}$ siècle enrichit le Musée Georges Borias à Uzès. In: Uzès. Musée vivant 46 (2012), S. I5-24; Esther van der Hoorn, A Seventeenth-Century Drawing for a Chaise à Porteurs. In: The Rijksmuseum Bulletin 64/2 (2016), S. I0O-II9. Zu Tragsesseln in Wien arbeitete Gustav Gugitz: Gustav Gugitz, Die Sesselträger in AltWien. In: Jahrbuch des Vereines für Geschichte der Stadt Wien 8 (1949/50), S. 94-IO4. Für Großbritannien sind Artikel von Hugh Murray und Mary Anne Garry sowie ein schmaler Band von 
Wir - die beiden Herausgeber - beschäftigten uns unabhängig voneinander schon seit Längerem mit der Geschichte von Tragsesseln im I6. und I7. Jahrhundert, das heißt mit der noch weitgehend unerforschten Frühzeit dieser Tragevehikel, als ihre allmähliche Integration in das höfische Leben vonstattenging, ihre zeremonielle Verwendung ausgeformt wurde und sich in zahlreichen Städten auch ein Miettragsesselsystem etablierte. Wir hielten es jedoch für nötig, unsere eigenen Untersuchungen, deren räumlicher Schwerpunkt auf den Herrschaftsbereichen der spanischen beziehungsweise der österreichischen Habsburger liegt, in einen bereiteren europäischen Kontext zu stellen. So entstand die Idee für diesen Sammelband. Glücklicherweise gelang es uns, mehrere Forscherinnen und Forscher dafür zu gewinnen, Beiträge über die Geschichte von Tragsesseln in anderen europäischen Ländern zu verfassen. Ein Schwerpunkt liegt dabei auf Italien, das mit gleich drei Artikeln, über die Entwicklungen am päpstlichen Hof (Claudia Märtl), in Genua (Farida Simonetti) und Neapel (Attilio Antonelli, Stefano Moscatelli und Ilaria Telesca), vertreten ist. Der Grund dafür liegt in der großen Bedeutung italienischer Höfe und Städte für die Etablierung und Verbreitung von Tragsesseln in Ländern nördlich der Alpen. Weitere Beiträge widmen sich dem spanischen Herrschaftsgebiet (Alejandro López Álvarez), dem Münchner Hof (Gudrun Szczepanek und Friederike Ulrichs), den Höfen der österreichischen Habsburger (Mario Döberl) sowie Frankreich (Marie Maggiani). Die Autorinnen und Autoren setzen dabei unterschiedliche zeitliche Schwerpunkte innerhalb des vorgegebenen Zeitraums, der mit dem Spätmittelalter als unterer und dem Anfang des i8. Jahrhunderts als oberer Grenze festgelegt war. Auch die Variationsbreite des thematischen Zugangs ist vergleichsweise groß. Sie reicht von einer Analyse der Gestaltung und Ausstattung der Tragsessel über die Behandlung der mit ihrem Entwurf und Bau betrauten Künstler und Handwerker bis hin zur Untersuchung der Nutzung seitens der Mitglieder von Fürstenfamilien und Adelshäusern. Beleuchtet wird ebenso das Vorkommen von Tragsesseln an führenden Höfen wie auch in peripheren Zentren, ihr Einsatz als Miettragsessel sowie die Arbeitsumstände und der soziale Hintergrund von Sesselträgern. Während in einigen

Geoffrey Wilson zu nennen: Hugh MurraY, Sedan Chairs in York. In: York Historian I7 (2000), S. 30-45; Geoffrey Wilson, Poles Apart. The Public Sedans of Bygone London (Colchester 2002); Mary Anne GarRY, Sedan chairmen in eighteenth-century London. In: The Journal of Transport History 37/I (2016), S. 45-63. Jean Pierre Ducastelle organisierte in Ath (Belgien) eine Ausstellung über sogenannte Vinaigrettes, bei denen es sich um nahe Verwandte der Tragsessel handelt, die allerdings über zwei Räder verfügen: Jean-Pierre Ducastelle, Se déplacer en vinaigrette! Mobilité et transport du $\mathrm{I}^{\mathrm{e}}$ au $\mathrm{I}^{\mathrm{e}}$ siècle. In: Études et documents du Cercle royal d'histoire et d'archéologie d'Ath et de la région 20 (2009), S. 349-388. An einer Sozialgeschichte von Tragsesseln versuchte sich jüngst Claus Heinrich Bill. Seine anregende Untersuchung ist jedoch unter anderem deshalb problematisch, weil sie sich hauptsächlich auf veraltete Sekundärliteratur, jedoch kaum auf eigenständige Archivrecherchen stützt. BILl 2013 (wie Anm. 5). 
Beiträgen kunst-, sozial-, rechts- oder zeremonialgeschichtliche Ansätze dominieren, werden in anderen terminologische Fragen in den Fokus genommen. Die unterschiedlichen Fragestellungen und Zugänge spiegeln nicht nur die verschieden gelagerten Interessen der Forscherinnen und Forscher, sondern auch den Facettenreichtum des Untersuchungsgegenstands selbst wider. In einem letzten, knapp gehaltenen Kapitel sollen schließlich zentrale Erkenntnisse der im vorliegenden Band versammelten Beiträge zusammengefasst, Verbindungsfäden gespannt und parallele Entwicklungen sowie Sonderwege in den unterschiedlichen Herrschaftsgebieten Europas herausgestrichen werden.

Gerne hätten wir auch noch Beiträge aus anderen europäischen Ländern in den Band aufgenommen, jedoch war dies aus unterschiedlichen Gründen nicht möglich, meist, weil wir keine geeigneten Autorinnen und Autoren finden konnten. Besonders schmerzlich scheint uns das Fehlen eines Artikels über englische Tragsessel. Aber auch entsprechende Untersuchungen zu Skandinavien, den Niederlanden, Osteuropa oder dem einstigen Herrschaftsgebiet des Osmanischen Reichs bleiben vorerst ein Desiderat. So verbleibt uns die Hoffnung, dass der vorliegende Sammelband ein Anstoß zu weiterführenden Forschungen über die Geschichte von Tragsesseln in anderen Ländern Europas oder womöglich sogar in anderen Weltteilen sein könnte.

\title{
Mario Döberl und Alejandro López Álvarez
} Wien/Madrid, im November 2016

Die Entstehung der vorliegenden Publikation hat eine längere Geschichte. Manche der Beiträge wurden bereits im Jahr 20I4, die letzten 2016 abgegeben. Bedauerlicherweise kam es im Anschluss daran zu einer Verzögerung der Drucklegung. Dies ist auch der Grund, warum in den einzelnen Aufsätzen die jüngst erschienene Fachliteratur keine Berücksichtigung mehr finden konnte. Wir bitten diesen Umstand zu entschuldigen!

\author{
Mario Döberl und Alejandro López Álvarez \\ Wien/Madrid, im Juli 2019
}




\section{Die sedia gestatoria der Päpste}

Eine der berühmtesten Sequenzen in Federico Fellinis Film „Roma“ aus dem Jahr 1972 zeigt etwa zehn Minuten lang eine kirchliche Modenschau, bei der in zunehmend grotesker Übersteigerung Kleidung für Ordensleute und Kleriker präsentiert wird. Am Ende erscheint in Untersicht der Papst selbst, von dem nur Kopf und Schultern zu sehen sind, da er hinter einem hoch aufragenden Pult thront. Die ganze Szene ist in Weiß und Gelb, den heraldischen Farben der Kirche, gehalten, die Beleuchtung von hinten erinnert an das Fenster, unter dem in der Apsis des Petersdoms der von Gian Lorenzo Bernini gestaltete Thron des heiligen Petrus schwebt. Das Gesicht des Papst-Darstellers, der eine starke Ähnlichkeit mit Pius XII. (1939-I958) besitzt, bleibt völlig unbewegt, während die Straußenfederfächer zu beiden Seiten des Throns in einem Rhythmus schwanken, der die Bewegung des unmittelbar vorher abgelaufenen Defilees von Bischöfen aufnimmt. Die hysterisch verzückte Reaktion des Publikums im Film lässt den Zuschauer vor der Leinwand unsicher werden, ob sich mit der Erscheinung des Papstes der inszenierte Höhepunkt der Modenschau oder eine durch Lichteffekte, Weihrauch und Orgelmusik herbeigeführte Vision manifestiert. Obwohl der Sitz des Papstes im Film unsichtbar und damit undefinierbar bleibt, evoziert die in der Szene herrschende Ambivalenz von Bewegung und Unbewegtheit die Auftritte der Päpste auf der sedia gestatoria, deren Tage allerdings gezählt waren, als Fellini seinen Film ins Kino brachte.

Die neuzeitliche Gestalt der sedia gestatoria: Bildquellen und erhaltene Tragethrone

Die Suche nach historischen Bildquellen fördert rasch eine erstaunliche Vielzahl an Darstellungen von Päpsten auf der sedia gestatoria zu Tage, die nach der Mitte des I9. Jahrhunderts entstanden sind. Ihre Hochkonjunktur setzt mit Stichen von Pius IX. (I846-I878) ein und endet mit Fotografien von Johannes Paul I. (1978). Besonders viele Aufnahmen gibt es von Pius XII., der zu verschiedenen Gelegenheiten und in unterschiedlicher Kleidung auf dem päpstlichen Tragethron fotografiert wurde. Spitzenreiter in der Häufigkeit der Abbildung ist ein von oben im Petersdom aufgenommenes Farbfoto: Pius XII. wird, bekleidet mit dem 
päpstlichen mantum und der Tiara, von zwölf sediarii getragen; zu beiden Seiten des Throns ragen zwei Straußenfederfächer (flabella) empor. ${ }^{21}$ Im Gegensatz zu Fellinis Film ist die Szenerie nicht von den heraldischen Farben Weiß und Gelb, sondern von Weiß und Rot, den Farben des Papstes und der römischen Kirche, ${ }^{22}$ geprägt. Andere Fotos haben mit dem Film die steile Untersicht auf den Papst gemeinsam, die den Eindruck des erhabenen Thronens verstärkt, doch lassen viele Aufnahmen auch erkennen, wie Päpste auf der sedia gestatoria durch lebhafte Gestensprache versuchten, die hieratisch strenge Wirkung zu vermeiden oder zumindest abzuschwächen. Dazu gehören Filmaufnahmen aus dem letzten Lebensjahr Pius' XII., der leutselig in die Runde grüßt, ${ }^{23}$ ebenso wie Bilder Johannes Pauls I., der sich mit einem verschmitzten Lächeln oder offen lachend zum Publikum wendet.

Die Gestalt der sedia gestatoria lässt sich anhand der drei erhaltenen Tragethrone, die heute in einer Abteilung der Vatikanischen Museen im Lateranpalast zu besichtigen sind, für die Zeit seit dem Beginn des I9. Jahrhunderts gut nachvollziehen. Mit geringfügigen Anpassungen an den Zeitgeschmack entspricht sie jenen Sesseln, die aus den Papstporträts der Frühen Neuzeit bekannt sind, für die Raffael mit Bildnissen Leos X. und Julius' II. einen überaus erfolgreichen Prototyp schuf. ${ }^{24}$ Dank einer Ausstellung im Schloss zu Versailles ist die sedia gestatoria Pius' VII. (I800-I823) mittlerweile recht häufig im Internet zu finden (Abb. I), ${ }^{25}$ gelegentlich stößt man dort auch auf die sedia Pius' IX., ${ }^{26}$ und die sedia Leos XIII. (I878-1903)

2I Vgl. die Abb. in der englischsprachigen Wikipedia: https://en.wikipedia.org/wiki/Sedia_gestatoria (letzter Zugriff: 30.09.2019).

22 Zur Symbolik dieser Farben vgl. Agostino Paravicini Bagliani, Il corpo del papa (Torino 1994), S. II7-I25; (deutsche Übersetzung: DERS., Der Leib des Papstes. Eine Theologie der Hinfälligkeit [München 1997], S. 90-98); DERS., Le Chiavi e la Tiara. Immagini e simboli del papato medievale. Nuova edizione riveduta e aggiornata (Roma 2005), S. 65-67, S. 70 f.

23 Sie wurden in den nach Franz Werfels Roman von Ernst Marischka gedrehten Film „Der veruntreute Himmel“ integriert, der im Herbst 1958, nur wenige Wochen nach dem Tod Pius' XII., in die Kinos kam.

24 Vgl. zu diesen Gemälden und ihrem historischen Kontext: Raffaelo e il ritratto di papa Leone. Per il restauro del Leone X con due cardinali nella Galleria degli Uffizi (Milano 1996); Jochen SANDER (Hg.), Raffael und das Porträt Julius' II. Das Bild eines Renaissance-Papstes (Frankfurt a. M. 20I3).

25 Vgl. den Katalog: Jacques Charles-Gaffiot, Trônes en majesté. L'Autorité et son symbole (Ausstellungskatalog, Paris 20II), S. 312-315; eine Präsentation steht im Netz (www.trones.chateauversailles.fr), eine kurze Erläuterung der sedia Pius' VII. und eines Straußenfederfächers durch Hélène Delalex, Konservatorin in Versailles, auf YouTube (https://www.youtube.com/watch?v=KuuMFu2diMw [letzter Zugriff: 30.09.2019]). - In dem Film „Il marchese del Grillo“ von Mario Monicelli (198I) bringt die Hauptfigur, der römische Adlige Onofrio del Grillo, als sediarius Pius' VII. durch sein Stolpern die sedia gestatoria während einer Prozession kurz ins Wanken.

26 So etwa auf: www.orbiscatholicussecundus.blogspot.de/20II/o5/sedia-gestatoria.html (letzter Zugriff: 25.07.2014). 


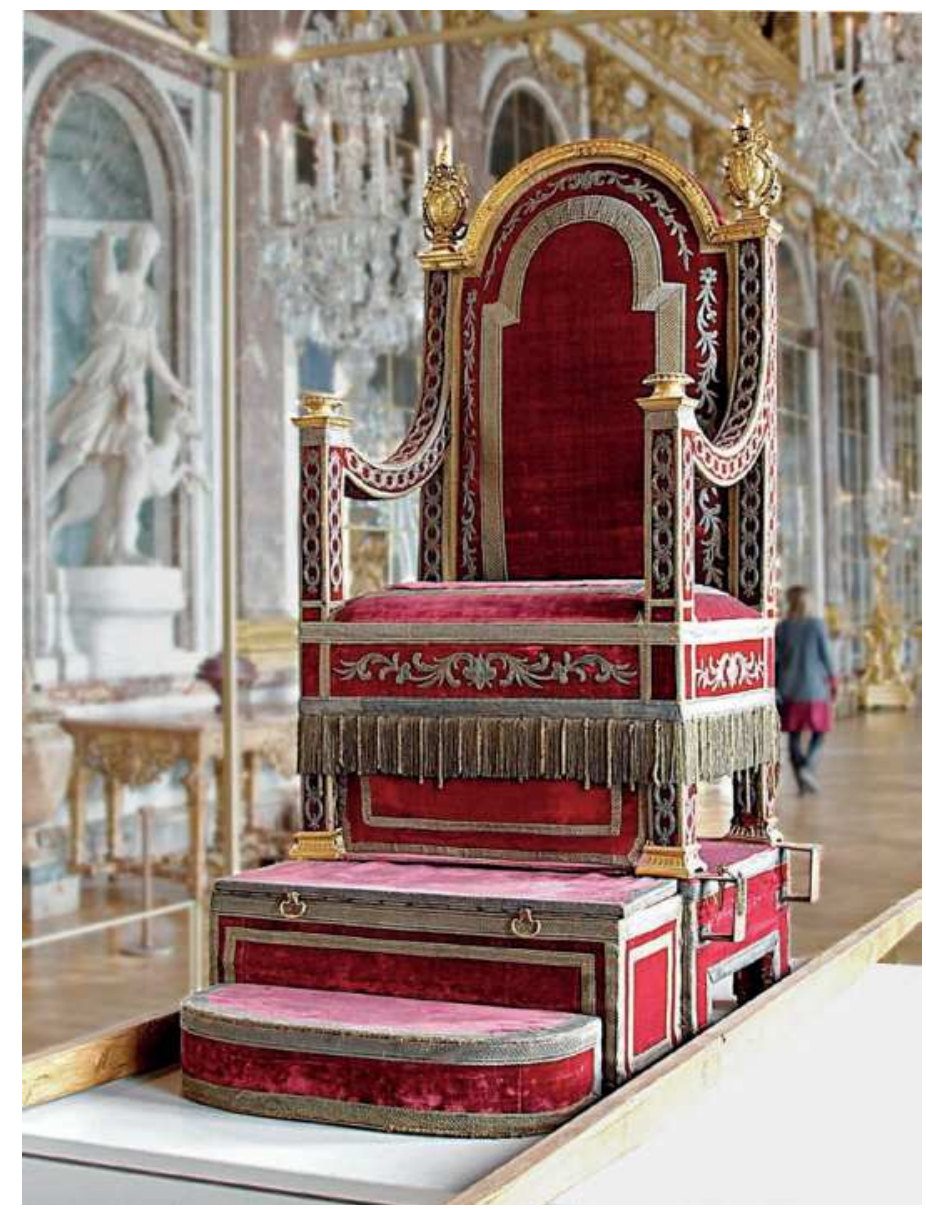

Abb. 1: Die sedia gestatoria Pius' VII. Vatikanische Museen (Rom), Museo Storico, Padiglione delle Carrozze. Foto: Vanzanten/Public Domain/Wikimedia Commons

wurde noch im 20. Jahrhundert benutzt, wie die erwähnten Aufnahmen erkennen lassen. Es handelt sich jeweils um einen massiven Thronstuhl mit vier Beinpfosten, Armstützen und gerader Lehne; mit der Vorderfront ist ein zweistufiger Schemel (suppedaneum) fest verbunden. Die ganze Konstruktion ist mit rotem Samt überzogen, der mit goldenen Ornamenten bestickt ist; Armlehnen und Kanten der Sitzfläche sind mit Fransen geschmückt; auf den vorderen Enden der Armstützen und oben auf den beiden Streben der Rückenlehne sitzen vergoldete geschnitzte Aufsätze. Auf der Rückseite der Lehne ist neben der Taube des Heiligen Geistes und den Petrusschlüsseln das Wappen des regierenden Papstes zu sehen.

An den Beinen der erhaltenen Tragethrone sind außen vier eiserne Halterungen angebracht, durch die Stangen geschoben werden können. Gaetano Moroni beschreibt um 
die Mitte des 19. Jahrhunderts jedoch, dass die sedia gestatoria auf einer „predella“ befestigt war, an der seitlich vergoldete Eisenringe für die Tragstangen angebracht wurden. ${ }^{27}$ In der Tat zeigen alle Stiche und Aufnahmen des 19. und 20. Jahrhunderts die Päpste auf einem Sitz, der auf einer Plattform montiert war, die mittels Stangen auf den Schultern der Träger lastete. Der Papst erschien dadurch in ganzer Figur über den Köpfen der Menge. Für das religiöse Empfinden des I9. Jahrhunderts unterstrich die gelegentliche Verwendung des Tragethrons zusammen mit einem Baldachin und Fächern, die damals noch aus Pfauenfedern bestanden, die Erhabenheit und Ehrwürdigkeit dieser Art der päpstlichen Fortbewegung. ${ }^{28}$ Beide Elemente wurden im 20. Jahrhundert aber immer öfter weggelassen, sodass bei Johannes Paul I. nur mehr der Tragethron auf der Plattform übrig geblieben war. Seit Johannes Paul II. (1978-2004) lehnen die Päpste die sedia gestatoria als unzeitgemäß ab. Auf vielen Websites, zumal solchen englisch-, italienisch- und deutschsprachiger Traditionalisten, herrscht heute eine gewisse nostalgische Sehnsucht nach diesem päpstlichen Fortbewegungsmittel, doch enttäuschte auch Benedikt XVI. (2004-2013), der nach einer vierzigjährigen Unterbrechung Mozzetta und Camauro wieder eingeführt hatte, entsprechende Hoffnungen, die im Jahr 2OII nach Nachrichten von Gehbeschwerden des Papstes aufgekeimt waren. Außerhalb traditionalistischer Kreise ist die Interpretation verbreitet, dass die Päpste die sedia gestatoria durch andere Transportmittel wie das „Papstmobil“ ersetzt hätten.

\section{Der erste Versuch einer historischen Erklärung: José Estefan (1578/1588)}

Historische Herleitung und Begründung des Einsatzes der sedia gestatoria folgen in den gängigen Nachschlagewerken ${ }^{29}$, neuerdings auch in digitalen Angeboten, häufig Denkmustern, die sich bereits in den Anfängen der Diskussion im I6. Jahrhundert herausbilde-

27 Gaetano Moroni, Sedia e sedie de' papi. In: DERs., Dizionario di erudizione storico-ecclesiastica, Bd. 63 (Venezia I853), S. 195.

28 Moroni i853 (wie Anm. 7), S. 196: „Pertanto riesce imponente e sublime tutto il complesso che si ammira nel vedere il papa portato in alto cosi decorosamente e con tanto splendore sul trono della sedia gestatoria." Es ist nicht klar, wann die bei Moroni noch eigens symbolisch gedeuteten Pfauenfedern der flabella durch Federn anderer Vögel - allem Anschein nach Straußenfedern - ersetzt wurden.

29 Vgl. nur in Auswahl: Philippe Levillain, Sedia gestatoria. In: Ders. (Hg.), Dictionnaire historique de la papauté (Paris 1994), S. I559 f.; Georg Kreuzer, Sedia (Sella) gestatoria. In: Lexikon des Mittelalters, Bd. 7: Planudes bis Stadt (Rus') (München 1995), Sp. I665 f.; Klaus Peter Dannecker, Sedia gestatoria. In: Lexikon für Theologie und Kirche, Bd. 9: San bis Thomas (Freiburg/Br. u.a. 32000), Sp. 365; Bernard Berthod/Pierre Blanchard, Trésors inconnus du Vatican. Cérémonial et liturgie (Paris 200I), S. $312 \mathrm{f}$. 
ten. Daher empfiehlt es sich, einen genaueren Blick auf die Argumentation des Stammvaters der Forschung zur sedia gestatoria zu werfen. José Estefan veröffentlichte im Jahr I588 eine Abhandlung „Über das Küssen der Füße des römischen Papstes“, der er eine „Disputation über die Krönung und das Heben oder Tragen des Papstes“ anhängte, mit der Zielsetzung, diese Zeremonien „gegen die Verleumdung der Häretiker mit vielen Argumenten und Zeugnissen der Väter sowie der Tradition“ "zu verteidigen..$^{30}$ Er stellte einen Zusammenhang her zwischen dem Auftritt des Papstes auf der sedia gestatoria und dem Brauch, neu gewählte Oberhäupter auf die Schultern oder auf Schilde zu heben, den er aus antiken Schriftstellern wie Tacitus, Ammianus Marcellinus oder Cassiodor belegte, wobei er betonte, dies sei nicht allein Sitte der Barbaren, sondern ebenso der Römer gewesen. Römische Priester und Vestalinnen hätten darüber hinaus das Vorrecht, auf Wagen zu fahren, besessen, und speziell die Pontifices hätten über eine sella gestatoria verfügt, die von lecticarii auf den Schultern getragen worden sei. Dies gehe aus einem sehr alten Ordo Romanus hervor, wo davon die Rede sei, dass der Pontifex von Diakonen empfangen werde, die ihm aus dem sellarium hülfen. Den Ausdruck sella/sellarium/sellare erklärt Estefan sodann mit Hilfe eines griechischen Glossars, das ihn als diphros übersetze und diphrophoroi (Träger) erwähne, womit eine Brücke zu Plutarch geschlagen wird, der diphros für sella curulis, den Sitz römischer Magistrate, verwende. Der Pontifex maximus sei also von Trägern ,in einem sellare, das heißt einer erhabenen sella curulis“, durch die Stadt getragen worden. Estefan ist auch der Meinung, dies könne „durch die Beispiele vieler Pontifices klar bewiesen“ werden. Als Belege führt er aber lediglich die Päpste Stephan II. (752-757), Hadrian II. (867-872), Leo VIII. (963-965) und Gregor IX. (I227-I24I) an, die alle getragen worden seien. Die sich andeutende Schwäche der Beweislage fängt der Autor mit dem Hinweis auf die Weissagung des Propheten Jesaja auf: „so werden sie deine Söhne in den Armen herbeibringen und deine Töchter auf den Achseln tragen“" (Jesaja 49,22). Abschließend argumentiert er noch pragmatisch, es sei nötig, den Papst „hoch erhoben zu tragen, damit er die Völker und ihm anvertrauten Schafe überblicke und sie mit heil-

30 (José Estefan), Iosephi Stephani Valentini episcopi Vestani de osculatione pedum Romani Pontificis ad Sanctissimum Dominum Nostrum Sixtum V. Pontificem Optimum Maximum, adiecta eiusdem auctoris disputatione de coronatione et levitatione seu portatione papae. Omnia nunc ex repetita praelectione multis ex partibus locupletata et aucta et ab haereticorum calumniis pluribus argumentis, patrum testimoniis et traditione defensa (Rom 1588). In der in Venedig 1578 erschienenen Erstauflage hatte Estefan dem Thema De elevatione. Cur Romanus Pontifex humeris deferatur drei Seiten (fol. 53v-54v) gewidmet, in der zweiten Auflage verwendete er darauf fünf Seiten (S. I70-I75). - Der aus Spanien stammende, in der Literatur unter verschiedenen Schreibungen, unter anderem als Giuseppe Stevani oder Stivani, auftauchende Kleriker war von 1586 bis I589 Bischof von Vieste in Apulien; vgl. Ludwig Schmitz-Kallenberg, Hierarchia catholica medii et recentioris aevi, Bd. 3 (Münster 1923), S. 332. 
bringendem Gebet segne“ und umgekehrt die Völker ihn erblicken „und ihren Hirten von Angesicht erkennen" könnten.

\section{Die Grundlegung des modernen Forschungsstandes: Gaetano Moroni (1853)}

Estefans Argumentationsstrategie bildet die Basis für die drei Jahrhunderte später entstandenen Ausführungen Gaetano Moronis. Dieser differenzierte den Überblick zu den päpstlichen Sitzgelegenheiten in seinem materialreichen Artikel über „den Sitz und die Sitze der Päpste“"3г, blieb jedoch dabei ganz in den gedanklichen Bahnen seines Vorgängers. Moroni unterscheidet einleitend zwischen der sella curulis antiker Amtsträger, Bischofsstühlen aus Marmor, dem vom Papst mitgeführten Faldistorium sowie den bei der Papsterhebung eine Rolle spielenden Porphyrsitzen im Lateran und befasst sich dann mit der Verwendung tragbarer Sitze durch die Päpste im I8. und frühen 19. Jahrhundert. Zu Moronis eigener Zeit bezeichnete der Ausdruck sella curulis jenen Sitz, den der Papst bei Umzügen in seiner Karosse benutzte. Daneben verwendeten die Päpste bei schlechtem Wetter für ihre Krönungsumzüge zum Lateran eine „überdachte sedia gestatoria “32, während die Päpste des I8. Jahrhunderts bei ihren Umzügen durch Rom eine offene sedia gestatoria, beim Krönungsumzug zum Lateran aber eine durch zwei weiße Kaltblutrösser getragene Pferdesänfte benutzt hätten. In den Krönungsumzügen sei am Übergang vom I5. zum I6. Jahrhundert eine sedia gestatoria mitgeführt worden, obwohl der Papst den Weg zu Pferd zurücklegte; den Päpsten des I8. Jahrhunderts, die sich in der Pferdesänfte zum Lateran begaben, sei ein solcher Tragethron vorangetragen worden. Die eigentliche sedia pontificale gestatoria ist in der Darstellung Moronis von der Pferdesänfte und anderen Transportmitteln klar zu unterscheiden. ${ }^{33}$ Der von zwölf sediari und palafrenieri getragene Thron kommt seinen Angaben zufolge an Mariä Lichtmess, bei Heiligsprechungen, am Palmsonntag und bei der Verleihung der Goldenen Rose zum Einsatz. Früher sei die sedia gestatoria auch bei Papstmessen im Palast verwendet worden, aber wegen der größeren Bequemlichkeit werde hier seit Langem eine normale portantina benutzt. Derartige Tragsessel seien im I8. Jahrhundert zudem außerhalb der feierlichen Anlässe, etwa während der Sommerfrische in Castel Gandolfo, in Gebrauch gewesen, während sich ein kränklicher Papst des I7. Jahrhunderts im Vatikanpalast in einem Rollstuhl34 bewegte.

3I Moroni 1853 (wie Anm. 7), S. I88-20I.

32 Ebenda, S. 193.

33 Ebenda, S. I94-20I. Den päpstlichen „Sänften“ widmete Moroni einen eigenen Artikel; Lectica. In: DERS., Dizionario di erudizione storico-ecclesiastica, Bd. 38 (Venezia I846), S. I47-I52. Moroni I853 (wie Anm. 7), S. 194 (Innozenz X., Dezember 1647). 
In seiner Begründung für den Gebrauch des Tragethrons folgt Moroni dem Argumentationsgang, den Estefan vorgezeichnet hatte: Keineswegs sei die sedia gestatoria aus Prunksucht, Eitelkeit und Stolz eingeführt worden, wie die Ketzer behaupteten, sondern es handle sich um einen Ausdruck der pastoralen Pflichten des Papstes, dessen Wachsamkeit auch durch die vielen Augen der Pfauenfederfächer symbolisiert werde; der Papst müsse auf einem erhabenen Thron getragen werden, um von allen gesehen werden zu können. In der historischen Herleitung versucht Moroni, über Estefan hinauszugelangen, indem er zum Teil die schon von diesem genannten Quellen ausführlicher oder nach anderen Drucken zitiert, zum Teil auch die Beispiele vermehrt. So geht er auf die im Petersdom aufbewahrte Cathedra Petri ein, die er mit dem von Estefan bei Ennodius von Pavia im 5. Jahrhundert entdeckten Ausdruck gestatoria sella apostolicae confessionis in Beziehung setzt, gibt frühmittelalterlichen Quellen aus dem fränkischen und angelsächsischen Raum mehr Platz als Estefan und bringt neben antiken Amtsträgern noch den Kaiser von China als Parallelfall. Den Übergang zum Mittelalter ab dem 8. Jahrhundert verschleiert Moroni ähnlich, wie es Estefan getan hatte. Das nach dessen Vorbild zitierte Beispiel Stephans II. führt bei ihm zu der raschen Überleitung, somit scheine es, als ob es sich mit diesem Papst eingebürgert habe, den Papst bei seinem Amtsantritt zu tragen, und zu Estefans Beispielen Hadrian II., Leo VIII. und Gregor IX. bemerkt er nur summarisch, sie seien schon von seinem Vorgänger behandelt worden. ${ }^{35}$ Dann macht Moroni einen großen Sprung in das 15 . Jahrhundert und nennt als nächsten Papst, der eine sedia gestatoria benutzte, Pius II. (I458-I464), worauf er eine ansehnliche Reihe von Päpsten des ausgehenden I5. Jahrhunderts und der Frühen Neuzeit folgen lässt, die zumindest bei ihren Krönungsfeierlichkeiten getragen wurden.

\section{$4 \quad$ Methodische Probleme der historischen Herleitung}

Estefans und Moronis bis heute nachwirkende Konstruktion einer in die Antike zurückreichenden kontinuierlichen Verwendung der päpstlichen sedia gestatoria ist im Hinblick auf die historische Quellenkritik mangelhaft. Teils hat Estefan bei seiner Suche nach frühen Formen der sedia gestatoria sich einige Verwirrung zuschulden kommen lassen, teils haben die Fortschritte der Forschung seine und Moronis Prämissen in Frage gestellt. Nicht bestritten sei, dass es in der christlichen Spätantike üblich gewesen sein mag, Bischöfe bei ihrem Antritt zu tragen. Auch hat es mobile Bischofsthrone gegeben, doch dienten diese zur Ausstattung von Räumen, nicht zum Tragen von Personen. ${ }^{36}$ Die in Sankt Peter aufbe-

$35 \quad$ Ebenda, S. I99.

36 Zur Verwendung von beweglichen Bischofssitzen in Spätantike und Mittelalter vgl. Nikolaus Gussone, Thron und Inthronisation des Papstes von den Anfängen bis zum I2. Jahrhundert. Zur 
wahrte Cathedra Petri muss als antike sedia gestatoria ausscheiden, handelt es sich doch um den Thron eines karolingischen Herrschers des 9. Jahrhunderts, vermutlich Karls des Kahlen. ${ }^{37}$ Daher ist es unzulässig, die bei Ennodius genannte gestatoria sella apostolicae confessionis auf diese Cathedra Petri zu beziehen. Aufgrund ihrer Form und Verwendungsweise kann auch die antike sella curulis nicht in die Ahnenreihe der päpstlichen sedia gestatoria eingereiht werden. Sie besaß als zusammenklappbarer Hocker mit scherenförmig überkreuzten Beinen keine Lehne und wurde römischen Magistraten als Amtsinsignie hinterhergetragen.$^{38}$ Ennodius wollte mit seinem Verweis auf einen „tragbaren Stuhl“ womöglich eine Parallele zwischen dem in Sankt Peter für Firmungen aufgestellten Sitz des Papstes und der sella curulis antiker Magistrate ziehen; ${ }^{39}$ ganz sicher wollte er aber nicht ausdrücken, dass der Papst auf diesem Stuhl getragen wird. Die Fortbewegung mit Hilfe von Trägern spielte gar keine Rolle bei den Prärogativen römischer Magistrate, für die vielmehr das Vorrecht, einen Wagen zu benutzen, wichtig war. ${ }^{40}$ Der von Estefan angeführte Ordo Romanus I ist ebenfalls kein Beleg dafür, dass die römischen Bischöfe auf einer sedia ges-

Beziehung zwischen Herrschaftszeichen und bildhaften Begriffen, Recht und Liturgie im christlichen Verständnis von Wort und Wirklichkeit (Bonner Historische Forschungen 4I, Bonn 1978), S. 83; zu beweglichen, sella genannten Sitzen des römischen Bischofs S. I4O, I5O, I89 f. Vgl. auch Agostino Paravicini Bagliani, Morte e elezione del papa. Norme, riti e conflitti. Il Medioevo (La corte dei papi 23, Roma 2013), S. 85. Zu beweglichen Papstthronen in der Neuzeit vgl. Berthod/ Blanchard 200I (wie Anm. 9), S. 332 f. und Charles-Gaffiot 201 (wie Anm. 5), S. 278-280.

Die beiderseits angebrachten Ringe dienten dazu, den seit dem Hochmittelalter als Reliquie des Apostelfürsten verehrten (leeren) Thron bei Prozessionen mitzuführen. Vgl. in unserem Zusammenhang Gussone 1978 (wie Anm. I6), S. 299 f.; ferner Jutta Dresken-Weiland/Wolfram Drews, Artikel Kathedra. In: Reallexikon für Antike und Christentum, Bd. 20 (Stuttgart 2004), Sp. 600-682, hier Sp. 659.

38 Vgl. den Artikel Sella, in: Paulys Realencyclopädie der classischen Altertumswissenschaft. Neue Bearbeitung begonnen von Georg WissowA, Bd. II, 4 (Stuttgart 1923), Sp. 1310-1315, und den Artikel Sella curulis, in: Der Neue Pauly, hg. von Hubert Cancik/Helmuth Schneider, Bd. II (Stuttgart/Weimar 200I), Sp. 37I f. Die sella curulis erweist sich somit als Vorläuferin des päpstlichen Faldistoriums. Zu „mobilen Thronen“ vgl. Charles-Gaffiot 201 (wie Anm. 5), S. 215-234, zum Faldistorium S. 218 und $308 \mathrm{f}$.

39 Gussone 1978 (wie Anm. I6), S. I24 f. hält die Ausdrucksweise des Ennodius für „etwas dunkel“ und schlägt die oben skizzierte Interpretation vor.

40 Vgl. Thomas Schäfer, Imperii Insignia. Sella curulis und fasces. Zur Repräsentation Römischer Magistrate (Mitteilungen des Deutschen Archaeologischen Instituts. Römische Abteilung, Ergänzungsheft 29, Mainz 1989), hier S. 24 f. und 63 ff. - Estefans Ausführungen zu diphros und sella curulis unterliegen teils einem Zirkelschluss, teils einer Verwechslung; vgl. den Artikel Lectica, in: Paulys Realencyclopädie der classischen Altertumswissenschaft. Neue Bearbeitung begonnen von Georg Wissowa, Bd. XII, I (23. Halbband, Stuttgart I924), Sp. I056-II28, hier Sp. I064, und den Artikel Diphros, in: Der Neue Pauly, hg. von Hubert Cancik/Helmuth Schneider, Bd. 3 (Stuttgart/Weimar 1997), Sp. 682. 
tatoria im neuzeitlichen Sinn getragen wurden; Aufgabe der Diakone war es gewiss auch, ihrem eintreffenden Oberhirten aus einer Sänfte oder aus dem Sattel zu helfen.

In terminologischer und methodischer Hinsicht stellte Moronis Unterscheidung einer sedia pontificale gestatoria von anderen päpstlichen Transportmitteln einen wichtigen Fortschritt dar. Das Alter und der Gesundheitszustand vieler Päpste machten es wahrscheinlich das ganze Mittelalter hindurch nötig, ihre Fortbewegung mit Hilfe von Wagen, Tragsesseln oder Bahren zu organisieren. Die Zeitgenossen hielten derlei Alltagsprobleme, die überdies nicht allein auf die Päpste beschränkt waren, selten für erwähnenswert; dass beispielsweise Bonifaz VIII. (I294-I303) für seine Reisen im Kirchenstaat einen Wagen mitführte, erfährt man nur aus seinen Rechnungen. ${ }^{4 \mathrm{I}}$ Es liegt auf der Hand, dass es nicht angeht, unter Missachtung des konkreten Zusammenhangs alle Hinweise auf Tragsessel oder Bahren unter sedia gestatoria zu subsumieren. Aus dem I9. Jahrhundert haben sich auch päpstliche portantine erhalten; sie ähneln Kabinen und wurden von zwei Männern, jedoch nicht auf den Schultern, sondern mit ausgestreckten Armen, getragen. ${ }^{42}$ Der von Moroni nicht weiter ausgeführte Unterschied dieser Tragsessel zum feierlichen Tragethron ist augenfällig. Die sedia gestatoria, deren Auftreten im päpstlichen Zeremoniell hier allein interessiert, kam in symbolisch höchst aufgeladenen Situationen zum Einsatz, in denen Rang und Autorität des Papstes inszeniert werden mussten. Anlässe hierzu ergaben sich bei den Feierlichkeiten seines Antritts, bei Treffen mit weltlichen Herrschern, beim Empfang des Papstes während seiner Reisen und nicht zuletzt auch bei herausragenden liturgischen Gelegenheiten, insbesondere solchen, die mit Prozessionen verbunden waren. Seit wann lässt sich der päpstliche Tragethron in diesen Kontexten nachweisen?

\section{Die fehlgeleitete Suche nach einer mittelalterlichen Kontinuität der sedia gestatoria}

Von den bei Estefan und Moroni angeführten Belegen für eine frühe Verwendung der sedia gestatoria bleiben allein jene bestehen, die sich auf das Zeremoniell des päpstlichen Amtsan-

4I Zwei Beispiele des I3. Jahrhunderts nennt bereits Moroni I846 (wie Anm. I3), S. I50; zu Bonifaz VIII. vgl. Agostino Paravicini Bagliani, La mobilità della corte papale nel secolo XIII. In: Sandro Carocci (Hg.), Itineranza pontificia. La mobilità della curia papale nel Lazio (secoli XII-XIII) (Nuovi studi storici 6I, Roma 2003), S. 3-78, hier S. 4I f. Worauf sich die bisweilen zu findende Behauptung (vgl. Levillain 1994 [wie Anm. 9] und Berthod/Blanchard 200i [wie Anm. 9]) gründet, die sedia gestatoria lasse sich in der Zeit des Papsttums in Avignon erstmals nachweisen, ist unklar.

$42 \mathrm{Zu}$ neuzeitlichen portantine vgl. Berthod/Blanchard 200 (wie Anm. 9), S. 282 f.; CharlesGaffiot $201 \mathrm{I}$ (wie Anm. 5), S. 226 mit fig. 173, S. 316 f. 
tritts beziehen. Die beiden Autoren verfolgen jedoch nicht nur das Anliegen, die sedia gestatoria möglichst weit zurückzudatieren, sie wollen auch beweisen, dass diese das ganze Mittelalter hindurch in Gebrauch war. Die Konstruktion einer kontinuierlichen Verwendung des päpstlichen Tragethrons von der Spätantike bis ins I5. Jahrhundert steht und fällt mit den von ihnen angeführten mittelalterlichen Beispielen. Hervorzuheben ist, dass auch Moroni nicht mehr als vier Beispiele bringt und dass er für diese keine anderen als die bereits bei Estefan auftretenden Quellen nennt, obwohl er sich sonst sichtlich um eine Verbreiterung und Aktualisierung der Literaturbasis bemüht. Estefan gebraucht nur bei den ersten beiden Belegen Synonyme für „tragen“, für Stephan II. deferre, für Hadrian II. deportare; beim dritten und vierten Beleg für Leo VIII. und Gregor IX. benutzt er hingegen „führen“ (ducere). ${ }^{43}$ Der Beweis einer Kontinuität erschöpft sich daher in den ersten beiden Zitaten, denn die anderen Beispiele belegen nur, dass diese Päpste im Rahmen ihrer Antrittsfeierlichkeiten durch die Stadt zogen; auf welche Weise sie dies taten, wird nicht gesagt. Der Versuch, den Sachverhalt anhand der heute gültigen Editionslage nachzuprüfen, führt zu einem interessanten Ergebnis. Estefans Quelle für Stephan II., das Buch der Papstviten von Platina, und dessen Vorlage, die Vita Stephans II. im Liber pontificalis, verwenden zwar nicht deferre, wohl aber dessen Synonym deportare, das sich auch in der Vita Stephans III. (768-772) findet und bei Hadrian II. noch einmal auftritt. ${ }^{44}$ Diese aus dem 8. und 9. Jahrhundert stammenden Lebensbeschreibungen stehen mit ihrer Wortwahl allerdings allein. Die Autoren der Papstviten des 7. bis 9. Jahrhunderts sprechen sonst des Öfteren davon, dass ein gewählter Kandidat „in den Bischofssitz des Lateran (ein)geführt“ worden sei, und bisweilen teilen sie mit, dass der Gewählte „mit Gewalt“ seinem neuen Amt zugeführt werden musste, ${ }^{45}$ da er sich aus löblicher Demut sträubte. In einem Fall wird deutlich, dass der Betreffende jedenfalls nicht getragen wurde; er wurde vielmehr auf das Pferd gesetzt, das seinem Vorgänger gedient hatte, und vom Lateran nach Santa Maria Maggiore „geführt“ . ${ }^{46}$ Von einer „Erhebung“ auf den apostolischen Stuhl ist erstmals bei Paschal I. (8I7-824) die

43 Estefan i588 (wie Anm. Io), S. I74 f.

44 Platynae historici Liber de vita Christi ac omnium pontificum (aa.I-I474), hg. von Giacinto GAIDA (Rerum Italicarum Scriptores² III,I, Città di Castello I913-I932), S. I29; Louis Duchesne (Hg.), Le Liber pontificalis, 2 Bde. (Paris I886-I892), Bd. I, S. 440 und 47I. Zu den "Wahlberichten“ der Viten des 8. und 9. Jahrhunderts vgl. Gussone 1978 (wie Anm. I6), S. I72 ff.; zur Entwicklung der Papsterhebung im Mittelalter vgl. die Synthese mit den wichtigsten Quellenbelegen bei PARAVICini Bagliani 2013 (wie Anm. I6), hier im Besonderen S. 82-85. Duchesne (I886-I892) (wie Anm. 24), Bd. I, S. 366, 371, 468, 470 und Bd. 2, S. 49, 87, Io7 usw. Vgl. Gussone 1978 (wie Anm. I6), S. I74 f.

46 Duchesne (I886-I892) (wie Anm. 24), Bd. 2, S. I43 f. zu Benedikt III. (855-858): „[...] eum super equum ovantes quem Leo praesul sedere consueverat posuerunt. Quem etiam magna populi praecedente caterva in basilica Dei genitricis quae Praesepe dicitur deduxerunt." 
Rede, mit dem Ausdruck elevare in sedem (apostolicam) ${ }^{47}$, der sich auch in den Viten von dessen Nachfolgern findet. Damit ist jedoch nicht die Verwendung einer sedia gestatoria gemeint, sondern die Inthronisation des Gewählten auf dem erhöht stehenden römischen Bischofsstuhl..$^{8}$

Falls es eine Tradition, den römischen Bischof im Rahmen seiner Amtseinführung zu tragen, gab, scheint sie das 9. Jahrhundert nicht überlebt zu haben. ${ }^{49}$ Mit der im späten 8. oder frühen 9. Jahrhundert entstandenen Konstantinischen Schenkung konzentrierte sich die Aufmerksamkeit auf das weiße Pferd, das Kaiser Konstantin als ehemals kaiserliches Vorrecht Papst Silvester und dessen Nachfolgern zugestanden haben soll. Die angebliche Verleihung kaiserlicher Ehrenvorrechte an Papst und römischen Klerus zielte nicht darauf ab, neue Tatbestände zu schaffen, sondern sanktionierte vielmehr bestehende Verhältnisse. Der Papst beanspruchte wohl schon vor der Konstantinischen Schenkung den kaiserlichen Schimmel. Im Hochmittelalter spielten weiße Pferde ${ }^{50}$ eine wichtige Rolle bei der Prozession, mit der die Päpste nach ihrer Weihe in der Peterskirche durch die Stadt zogen, um im Lateran das weltliche Zentrum ihrer Herrschaft in Besitz zu nehmen. Gregor IX., um im Rahmen der Beispielreihe Estefans und Moronis zu bleiben, ist mit Sicherheit auf einem Schimmel zum Lateran geritten, ${ }^{\text {II }}$ wie es die zu seiner Zeit bereits voll ausgeprägte Symbo-

47 Ebenda, S. 52. Vgl. Gussone 1978 (wie Anm. 16), S. 175-177; zu elevare in sedem in den Ordines des 9. Jahrhunderts ebenda, S. I84 und I88.

48 Vgl. Gussone 1978 (wie Anm. i6), hier bes. S. 85 ff. und i29 ff.; Paravicini Bagliani 2013 (wie Anm. 16), S. 94-97.

49 Gussone 1978 (wie Anm. I6), S. I3I, verweist auf Texte, die belegen, „daß der auswärts neu geweihte Bischof zum Abschluß der Feierlichkeit von seinen Amtsbrüdern in einem goldenen Sessel zu seiner Bischofskirche getragen wurde“; diese Quellen beziehen sich jedoch auf das Merowingerreich, nicht auf Rom. Zum Ablauf der Papstweihe und der Krönungsprozession im Mittelalter vgl. zusammenfassend Paravicini Bagliani 2013 (wie Anm. 16), S. 79-206, in übergreifender Perspektive zu Mittelalter und Neuzeit Maria Antonietta Visceglia, Cerimoniali romani: il ritorno e la trasfigurazione dei trionfi antichi. In: Luigi Fiorani/Adriano Prosperi (Hg.), Roma, la città del Papa (Storia d'Italia. Annali I6, Torino 2000), S. II3-I70, hier S. II3-I43.

so Zur Bedeutung des Pferdes im päpstlichen Zeremoniell vgl., ausgehend von den Bildquellen, Jörg Traeger, Der reitende Papst. Ein Beitrag zur Ikonographie des Papsttums (Münchner kunsthistorische Abhandlungen I, München/Zürich 1970), nachgedruckt in: DERS., Studien zur Renaissance, hg. von Christoph Wagner (Regensburger Studien zur Kunstgeschichte 2, Regensburg 2008), S. I5-I5I; zum Pferd als „Symbolträger“ im päpstlichen Zeremoniell des II. bis I5. Jahrhunderts vgl., ausgehend von den Textquellen, Agostino Paravicini Bagliani, Der Papst auf Reisen im Mittelalter. In: DERS., Il potere del papa. Corporeità, autorappresentazione, simboli (Firenze 2009), S. 315-333, bes. S. 330 ff. (Erstveröffentlichung 199I), und die oben in Anm. 2 genannten Arbeiten desselben Verfassers.

5I Vgl. die Vita Gregors IX. in: Paul Fabre/Louis Duchesne (Hg.), Le Liber Censuum de l'Église Romaine, Bd. 2 (Paris I910), S. I9: „equo [...] vectus“. 
lik päpstlichen Auftretens nahelegt. Bei Begegnungen zwischen Päpsten und Herrschern standen das päpstliche Reittier und der dem weltlichen Part abverlangte Strator- oder Marschalldienst im Fokus, ${ }^{52}$ der nach päpstlicher Auffassung in der Demutsgeste Kaiser Konstantins gegenüber Papst Silvester, die in der Konstantinischen Schenkung berichtet wird, sein Vorbild hatte. Die Bildquellen zeigen liegende, kniende, stehende, thronende und ab dem Hochmittelalter bisweilen auch reitende Päpste, ${ }^{53}$ doch Päpste, die auf Sitzen oder in Sänften getragen werden, kommen bis in das letzte Viertel des I5. Jahrhunderts als Bildmotiv nicht vor. Die normativen Texte zu Liturgie und Zeremoniell schweigen bis zum Jahr I488 über die sedia gestatoria. Die differenzierte Organisation des päpstlichen Hofs kennt bis zum Beginn des I6. Jahrhunderts nur palafrenieri, die das Reittier des Papstes zu satteln und am Zügel zu führen hatten, nicht jedoch sediarii. ${ }^{54}$

\section{Die „Erfindung“ der sedia gestatoria durch Papst Pius II. (1458-1464)}

Insgesamt sprechen die Schrift- und Bildquellen dafür, dass der päpstliche Tragethron im symbolisch aufgeladenen Sinn erst durch Pius II. in das päpstliche Zeremoniell eingeführt und dort von seinen Nachfolgern innerhalb eines Vierteljahrhunderts fest etabliert wurde. Dass Pius II. die sedia gestatoria „erfand“, verdankt sich einer besonderen Konstellation, in der das gesundheitliche Befinden des Papstes, Anforderungen des päpstlichen Zeremoniells und Interessen politischer Repräsentation in Einklang gebracht werden mussten. ${ }^{55}$ Eneas Silvius Piccolomini war bereits bei seiner Wahl schwer krank; ${ }^{56}$ insbesondere die durch Gicht verursachten Beeinträchtigungen seiner Bewegungsfähigkeit wurden sogar im Konklave

52 Vgl. Achim Thomas НACK, Das Empfangszeremoniell bei mittelalterlichen Papst-Kaiser-Treffen (Forschungen zur Kaiser- und Papstgeschichte des Mittelalters. Beihefte zu J. F. Böhmer, Regesta Imperii I8, Köln/Weimar/Wien I999), S. 504 ff.

Vgl. Gerhart B. Ladner, Die Papstbildnisse des Altertums und des Mittelalters, 3 Bde. (Città del Vaticano I94I, 1970, 1984); zur frühesten Darstellung eines reitenden Papstes (Ende des I2./Anfang des I3. Jahrhunderts) vgl. Bd. 3, S. 295 f., in Auseinandersetzung mit Traeger 2008 (Nachdruck, wie Anm. 30).

$54 \mathrm{Zu}$ den Aufgaben der palafrenieri vgl. zum Beispiel Paravicini Bagliani 2003 (wie Anm. 2I), S. 39. Möglicherweise ist das Wort sediarii eine Neuschöpfung des I6. Jahrhunderts.

Zum Folgenden vgl. Claudia Märtu, Papst Pius II. (I458-I464) in der Kapelle des Palazzo Medici Riccardi zu Florenz. Ein Beitrag zu Ikonographie und Zeremoniell der Päpste in der Renaissance. In: Concilium medii aevi 3 (2000), S. I55-183, hier bes. S. 160-169, mit einer Diskussion der Quellen (https://cma.gbv.de/dr,cma,003,2000,a,06.pdf [letzter Zugriff: 30.09.2019]).

56 Vgl. aus medizinhistorischer Sicht Antonia Whitley, Mind over matter. Living with ill health: the case of Pius II. In: Fabrizio Nevola (Hg.), Pio II Piccolomini: il Papa del Rinascimento a Siena. Atti del Convegno Internazionale di Studi, 5-7 maggio 2005 (Siena 2009), S. 269-279. 
gegen seine Kandidatur instrumentalisiert. Den Krönungsumzug zum Lateran absolvierte er am 3. September 1458 in herkömmlicher Weise hoch zu Ross, und es blieb ihm angesichts der laut gewordenen Bedenken gegen seine physische Leistungsfähigkeit auch gar nichts anderes übrig. Als er im Januar I459 zu dem von ihm in Mantua einberufenen Kongress aufbrach, bedurfte seine zeremonielle Einholung an den Stationen des Reisewegs sorgfältiger Planung, da es sich jeweils um den ersten adventus des neu gewählten Pontifex handelte. Einem verbreiteten Brauch entsprechend erhoben bei solchen Gelegenheiten bestimmte Personen oder Personengruppen Anspruch auf das Pferd und/oder den Baldachin, mit dem der Gast einritt, was zwar meist durch Geldzahlungen abgegolten wurde, doch in der Situation des Empfangs zunächst Unruhe schuf und oft sogar zu handfesten Auseinandersetzungen führte. Ebendies geschah bei einer der ersten Etappen, sodass der Papst beschloss, fortan zumindest nicht mehr auf einem Pferd einzuziehen, da der Streit um das Reittier ihn selbst in Gefahr bringen konnte. Dazu kam, dass ihm seine Gicht verstärkt zu schaffen machte. So ließ er sich jetzt auf dem mitgeführten päpstlichen Thron in die Städte tragen. Vor Florenz wurde deutlich, dass diese Art des Einzugs mit eigenen politischen und zeremoniellen Problemen verbunden war. Aufgrund der Rivalität zwischen Florenz und Siena, der Heimat des Papstes, war dieser adventus von vornherein eine diplomatisch sehr sensible Angelegenheit. Zudem hielten sich einige der Lehensleute der römischen Kirche aus der Romagna, die den Papst nach Mantua begleiten wollten, und der Sohn des mailändischen Herzogs, der ihn im Namen seines Vaters begrüßen sollte, bereits in der Stadt auf. Florenz war zwar nominell noch republikanisch verfasst, doch bestimmte der im Hintergrund agierende Cosimo de' Medici die Richtlinien der florentinischen Politik. Da Florenz I419/20 als Station eines mehrmonatigen päpstlichen Aufenthalts und von I439 bis I443 als dauerhafte Residenz der Kurie gedient hatte, besaßen die Florentiner durchaus Erfahrung mit dem kurialen Zeremoniell. Gemäß der Tradition hätte bei einem Einzug des Papstes zu Pferd der wichtigste in Florenz anwesende weltliche Machthaber das Reittier am Zügel führen und die Steigbügel halten müssen. Als Pius II. vor Florenz eintraf, war zum einen unklar, wer diesen Stratordienst leisten sollte, und zum anderen stellte sich die Frage, wie er kompensiert werden konnte, wenn der Papst nicht zu Pferd einzog. Für die florentinische Stadtregierung war das Ansinnen des Papstes, den Tragethron zu verwenden, ungewohnt; um die politischen Relationen der Beteiligten abzubilden, mussten neue Wege gefunden werden. Nach einem Aushandlungsprozess wurde die sedia gestatoria durch die - teils murrenden - Lehensleute der römischen Kirche und durch florentinische Bürger getragen, wobei der Sohn des mailändischen Herzogs eine kurze Strecke vor ihr schritt und in einer symbolischen Geste selbst Hand anlegte, als ob er mittrüge. Der Einzug ging mit solcher Geschwindigkeit vor sich, dass die Mitglieder der florentinischen Stadtregierung zuletzt hinterherlaufen mussten. Diese Vorgänge schürten auf beiden Seiten Animositäten; die Parteigänger der Medici sahen 
das florentinische Vorurteil einer besonderen Überheblichkeit der Sienesen bestätigt, der Papst wiederum fühlte sich in Florenz schäbig behandelt.

Die Gestaltung des Adventuszeremoniells integrierte seit jeher Elemente der Herrscherepiphanie und des Triumphs. In den Vorverhandlungen mit den Florentinern hatte Pius II. wohl ganz bewusst das Argument seiner schlechten Gesundheit in den Vordergrund gestellt, um diese Aspekte herunterzuspielen und die Verwendung des Tragethrons plausibel und akzeptabel zu machen. Nach seinem Einzug in Mantua auf der inzwischen schon gewohnten sedia gestatoria sind für die Dauer des Kongresses und bei der Rückreise hin und wieder Reparaturen an dem Möbelstück belegt. ${ }^{57}$ In den verbleibenden vier Jahren seines Pontifikats benutzte der Papst immer wieder den Tragethron, den er nach dem Zeugnis seiner Commentarii jetzt aber zunehmend als eine Insignie päpstlichen Triumphs verstand. Die Deutung, die er diesem Transportmittel gab, richtete sich nach dem Anlass des Einsatzes und den beteiligten Personen. Aufgrund seiner gesundheitlichen Probleme ließ sich Pius II. bei vielen Gelegenheiten tragen, doch triumphal gestaltete sich für ihn der Auftritt mit dem Tragethron vor allem bei Zeremonien, die großes Publikum anzogen: bei der Rückkehr nach Rom, der Fronleichnamsprozession, dem Empfang des Haupts des heiligen Andreas. ${ }^{58}$ Pius II. münzte damit seine eigene Schwäche in eine repräsentative Stärke des Papsttums um.

Die Entdeckung des Tragethrons als Mittel der Repräsentation fügt sich in eine Welle zeitgenössischen Interesses an antiken Triumphbräuchen ein. Bereits I443 war zum ersten Mal nach der Antike ein Triumphzug realisiert worden, mit dem Alfons V. seinen Einzug in Neapel feierte. ${ }^{59}$ Der gegebene Ort für Triumphzüge war jedoch Rom, wo, wie Flavio

57 ASR, Camerale I, I348 fol. I2v: "per aconciare una sedia per portare la santità de nostro signore“ (3I. August I459); fol. 99r: "per fare IIII bastoni a una sedia di nostro signore“ (3I. Januar I460, es handelt sich offenbar um die Tragstangen). Dasselbe Rechnungsbuch verzeichnet mehrmals den Ankauf von Nägeln und Eisenbeschlägen für die sedie des Papstes.

58 Zu den Transportmitteln Pius' II. vgl. Claudia MärTL, Alltag an der Kurie: Papst Pius II. (I458I464) im Spiegel zeitgenössischer Berichte. In: Zweder von Martels/Arjo Vanderjagt (Hg.), „Pius II, el più expeditivo pontifice“. Selected Studies on Aeneas Silvius Piccolomini (I405-I464) (Leiden/Boston 2003), S. 107-I45, hier S. 139 f.; zu seinen triumphalen Selbstinszenierungen zusammenfassend DIES., Pius II. (I458-I464), Offensive und defensive Strategien seiner Selbstdarstellung als Papst. In: Michael Matheus/Lutz Kuinkhammer (Hg.), Eigenbild im Konflikt. Krisensituationen des Papsttums zwischen Gregor VII. und Benedikt XV. (Darmstadt 2009), S. 63-87, hier S. 73-76.

59 Zu dem viel beachteten Präzedenzfall eines nachantiken Herrschertriumphs vgl. zuletzt ausführlich Philine Helas, Der Triumph von Alfonso d'Aragona 4443 in Neapel. Zu den Darstellungen herrscherlicher Einzüge zwischen Mittelalter und Renaissance. In: Peter Johanek/Angelika Lampen (Hg.), Adventus. Studien zum herrscherlichen Einzug in die Stadt (Köln/Weimar/Wien 2009), S. I33-228; zum Triumph in der Neuzeit zusammenfassend Yvonne RickerT, Triumph. 
Biondo am Ende seiner „Roma triumphans“ betonte, die Tradition der antiken Magistrate in der Kurie weiterlebte. Der päpstliche Sekretär prognostizierte in der Vorrede, mit der er sein Werk Pius II. widmete, dass die Kreuzzugsbemühungen des Papstes in einem Triumph der Christen enden würden. In dieser Perspektive konnte der päpstliche Tragethron als Pendant zum Wagen des Triumphators gesehen werden. Flavio Biondo, der im Rahmen seiner Ausführungen zu den Fortbewegungsarten der Römer auch auf die päpstliche sedia oder sella zu sprechen kommt, zieht allerdings einen anderen Schluss. Als sorgfältiger Antiquar achtete er auf das Detail, und so lag ihm eine andere Parallele näher, nämlich zum

Sitz der Ädile und Prätoren, auf dem diese, wenn sie Recht sprachen, durch die Stadt getragen wurden, so wie wir sahen, dass er für einige an Gicht leidende Pontifices unserer Zeit auf den Schultern von Menschen getragen wurde. ${ }^{60}$

Da Biondo einleitend den unüberbrückbaren Unterschied betont, der gerade auf diesem Feld zwischen der Antike und der eigenen Zeit herrsche, zielt dieser Vergleich nicht auf die Herstellung einer Tradition ab. Es geht dem Verfasser vielmehr um eine Analogie, die zudem nicht vollkommen ist, da die Päpste durch ihre Gicht dazu gezwungen werden, sich tragen zu lassen, während es sich bei den antiken Ädilen und Prätoren seiner Ansicht nach um normale Amtsausübung handelte. ${ }^{6}$ Diese Beobachtung unterstützt die herkömmliche Datierung des Abschlusses der „Roma triumphans“ auf I460: Flavio Biondo schrieb offenkundig noch vor den großen Inszenierungen Pius' II. mit ihrem Höhepunkt im Jahr I462.

In: Handbuch der politischen Ikonographie, hg. von Uwe FleCKner/Martin Warnke/Hendrik Ziegler, Bd. 2: Imperator bis Zwerg (München 2OII), S. 456-464.

60 Benutzt wurde das von der Bayerischen Staatsbibliothek digitalisierte Exemplar des Inkunabeldrucks Brescia I482 (http://daten.digitale-sammlungen.de/ db/ooo6/bsbooo65986/images/ [letzter Zugriff: 30.09.2019]); vgl. S. 336 (Beginn der Ausführungen zur observantia incedendi) und 338: „Sella magistratuum aedilis et praetoris sedes, qua per urbem ius dicentes comportabantur, quemadmodum aliquot ex nostris temporibus summis pontificibus podagra impeditis humeris hominum ea vidimus deferri." - Zu Flavio Biondo (I392-I463) vgl. den Artikel von Riccardo Fubini, in: Dizionario Biografico degli Italiani, Bd. Io (Roma I968), S. 536-559.

6I Flavio Biondo nimmt irrtümlich an, es habe zu den Vorrechten der Magistrate gehört, sich auf der sella curulis tragen zu lassen; siehe oben, Kapitel 6. Zur schlecht belegten sella quaestoria vgl. SCHÄFER I989 (wie Anm. 20), S. 107 ff. 


\section{$7 \quad$ Die Etablierung der sedia gestatoria im päpstlichen Zeremoniell der Frührenaissance}

Die Ausweitung der Verwendungsmöglichkeiten des Tragethrons nach der Rückkehr Pius' II. aus Mantua bereitete den Boden für die Integration der sedia gestatoria in das päpstliche Zeremoniell der Frühen Neuzeit, das Liturgie und Triumph verband. ${ }^{62} \mathrm{Zu} \mathrm{Be-}$ ginn des Pontifikats Innozenz' VIII. (I484-I492) war die sedia gestatoria im Zeremoniell des päpstlichen Amtsantritts bereits völlig eingeführt, wie aus dem Bericht des Zeremonienmeisters Johannes Burckard hervorgeht. ${ }^{63}$ Die sedes portatilis kam dabei erstmals nach der Altarsetzung in Sankt Peter zum Einsatz, als der neue Papst auf dem „tragbaren Sitz“ aus der Kirche in den Vatikanpalast getragen wurde. Zur Weihe wurde Innozenz VIII. aus dem Vatikanpalast herab und durch die mittlere Tür von Sankt Peter in die Kirche getragen; nach einer Gebetspause wurde er in die Kapelle des heiligen Gregor getragen; dann schritt er zu Fuß in einer Prozession zum Hauptaltar; nach der Weihe wurde er von dort zu einer für den päpstlichen Segen vor der Kirche aufgebauten Tribüne getragen. Den anschließenden Umzug zum Lateran bestritt er weitgehend zu Pferd, doch stieg er bei San Clemente auf die sedia gestatoria um. Dies sollte als Sicherheitsmaßnahme dem zu erwartenden Streit um das päpstliche Reittier beim Lateran vorbeugen, erwies sich aber als Fehlentscheidung, denn bei der Ankunft vor der Lateranbasilika entglitt der Zug der Kontrolle, und der Papst wurde hastig und tumultuarisch, unter Missachtung einiger zeremo-

62 Vgl. Visceglia 2000 (wie Anm. 29), S. I54-I70, bes. S. I55: „[...] il trionfo antico divenne, intrecciandosi a forme liturgiche christiane, una componente essenziale dei riti della sovranità papale“. Zum Forschungsstand vgl. Nikolaus Staubach, „Honor Dei“ oder „Bapsts Gepreng“? Die Reorganisation des Papstzeremoniells in der Renaissance. In: DERs. (Hg.), Rom und das Reich vor der Reformation (Tradition - Reform - Innovation. Studien zur Modernität des Mittelalters 7, Frankfurt a. M. u.a. 2004), S. 9I-I36; Günther WAssılowsky/Hubert Wolf (Hg.), Päpstliches Zeremoniell in der Frühen Neuzeit. Das Diarium des Zeremonienmeisters Paolo Alaleone de Branca während des Pontifikats Gregors XV. (I62I-I623) (Symbolische Kommunikation und gesellschaftliche Wertesysteme. Schriftenreihe des Sonderforschungsbereichs 496, 20, Münster 2007), S. II-24; Jörg BöLLING, Das Papstzeremoniell der Hochrenaissance. Normierungen - Modifikationen - Revisionen. In: Bernward Scнмidт/Hubert Wolf (Hg.), Ekklesiologische Alternativen? Monarchischer Papat und Formen kollegialer Kirchenleitung (I5.-20. Jahrhundert) (Symbolische Kommunikation und gesellschaftliche Wertesysteme. Schriftenreihe des Sonderforschungsbereichs 496, 42, Münster 2013), S. 273-307.

63 Enrico Celani (Hg.), Johannis Burckardi Liber Notarum ab anno MCCCCLXXXIII usque ad annum MDVI, 2 Bde. (Rerum Italicarum Scriptores², 32, Città di Castello I906-I9Io), Bd. I, S. 54, S. 72-82 (zu der bekannten Episode beim Lateran vgl. Visceglia 2000 [wie Anm. 29], S. I37 f.); die unten erwähnte Einholung der Heiligen Lanze: S. 356-358, S. 365-367. - Zum Verfasser vgl. Bernhard Schimmelpfennig, Johannes Burckard. In: Deutscher Humanismus I480-I520. Verfasserlexikon, hg. von Franz Josef Worstвrock, Bd. I (Berlin/New York 2008), Sp. 299-307. 
nieller Vorschriften, in die Kirche getragen, wo der Tragethron als Kompensation für das entgangene Pferd zerschlagen und verteilt wurde. Neben den Antrittsfeierlichkeiten gab es viele weitere Gelegenheiten für die Benutzung der sedia gestatoria. Diese war anscheinend schon unter Innozenz VIII. so üblich geworden, dass sie nicht jedes Mal von Burckard erwähnt wird. Der Zeremonienmeister übergeht etwa, dass Innozenz VIII. die ihm von Sul$\tan$ Bajezid übersandte Heilige Lanze auf der sedia gestatoria sitzend durch Rom trug, und spricht davon, dass dieser processionaliter ,in der üblichen Weise“ die Reliquie einholte. Aus Burckards Angabe, Innozenz VIII. habe die Zeremonie ganz nach dem Vorbild der Einholung des Hauptes des heiligen Andreas durch Pius II. gestalten wollen, lässt sich die Verwendung des Tragethrons nur indirekt erschließen; er wird jedoch durch eine bildliche Darstellung in den Grotten der Peterskirche vor Augen geführt.

Dem „Tagebuch“ des Zeremonienmeisters Burckard lässt sich die erste normative Fixierung des päpstlichen Zeremoniells an die Seite stellen, die Agostino Patrizi Piccolomini auf der Grundlage seiner Erfahrungen seit der Zeit Pius' II. verfasste und im Jahr I488 Innozenz VIII. widmete. ${ }^{64}$ Die sedia gestatoria wird darin, allerdings in Form einer Alternative zu anderen Arten der Fortbewegung, berücksichtigt. Der nächste Papst, Alexander VI. (I492-I5O3), verlegte den Gebrauch des Tragethrons noch um einen Schritt weiter nach vorn: Er wurde gleich nach seiner Wahl auf der sedia gestatoria in die Peterskirche getragen. Frühneuzeitliche Zeremonienmeister setzen die Verwendung des Tragethrons im päpstlichen Antrittszeremoniell vom Augenblick der Wahl bis zur Inbesitznahme des Laterans als Normalfall voraus, ${ }^{65}$ wenngleich viele Päpste den Weg zum Lateran, den sogenannten Possesso, immer noch zu Pferd absolvierten. Seit der Zeit Julius' II. (I5O3-I5I3) entwickelte sich der Possesso, der nun mit einigem zeitlichem Abstand auf Weihe und Krönung folgte, zu einer eigenständigen Zeremonie, bei der zusätzliche Inszenierungen, etwa das Aufstellen von Triumphbögen, die triumphalen Konnotationen verstärkten. ${ }^{66} \mathrm{Da}$

64 Vgl. zum Folgenden MärTL 2000 (wie Anm. 35), S. I66.

65 Vgl. die Schilderung des Antritts Gregors XV. durch Alaleone, WAssilowsky/Wolf 2007 (wie Anm. 42), S. 100-I08.

66 Vgl. Martine Borteux, Parcours rituels romains à l'époque moderne. In: Maria Antonietta VISCEGLIA/Catherine Brice (Hg.), Cérémonial et rituel à Rome (XVIe-XIX siècle) (Collection de l'École française de Rome 23I, Rome 1997), S. 27-87, hier S. 36-45; VisCEglia 2000 (wie Anm. 29), S. II3-I43; Irene Fosi, Court and City in the Ceremony of the Possesso in the Sixteenth Century. In: Gianvittorio Signorotto/Maria Antonietta Visceglia (Hg.), Court and Politics in Papal Rome, I492-I700 (Cambridge 2002), S. 3I-52; Birgit Емісн, Besitz ergreifen von der Kirche. Normen und Normkonflikte beim Zeremoniell des päpstlichen Possesso. In: Günther WAssılowsky/Hubert Wolf (Hg.), Werte und Symbole im frühneuzeitlichen Rom (Symbolische Kommunikation und gesellschaftliche Wertesysteme. Schriftenreihe des Sonderforschungsbereichs 496, II, Münster 2005), S. 83-99. 
die Päpste sich auch außerhalb ihres Antrittszeremoniells oft tragen ließen, begannen die Zeremonienmeister begrifflich zwischen dem auf einer Plattform montierten Tragethron und anderen Sitzen, auf denen der Papst getragen wurde, zu differenzieren. Den höchsten Ansprüchen an päpstliche Rangdemonstration genügte allein die sedia (gestatoria) maior, der Tragethron auf der Plattform, während die Verwendung der sedia minor oder parva, bei welcher der Sitz selbst mit Tragstangen versehen war, schon fast als Äußerung der Demut verstanden wurde. ${ }^{67}$

\section{Frühneuzeitliche Darstellungen der sedia gestatoria}

Dass die sedia gestatoria um die Wende vom I5. zum I6. Jahrhundert im päpstlichen Zeremoniell allgegenwärtig geworden war, erhellt nicht zuletzt aus ihrer Darstellung in Werken der bildenden Kunst, die in kurialem Auftrag entstanden. Die Maler zeigen sich dabei mit der Unterscheidung zwischen sedia maior und sedia minor wohlvertraut. Die anscheinend älteste erhaltene Darstellung einer sedia maior findet sich innerhalb des biographischen Zyklus zum Leben Sixtus' IV. (I47I-I484), der noch zu Lebzeiten dieses Papstes in Santo Spirito in Sassia ausgeführt wurde, und zeigt den Papst während der Feierlichkeiten seines Antritts mit Segensgestus auf dem Tragethron. ${ }^{68}$ Kurz nach der Wende zum I6. Jahrhundert ließ Kardinal Francesco Todeschini Piccolomini in der Libreria Piccolomini am Dom zu Siena das Leben seines Oheims Pius II. von Pinturicchio darstellen. Auf zwei Fresken erscheint der Papst auf der sedia gestatoria, zum einen im Rahmen seiner Krönungsfeierlichkeiten bei der Wergverbrennung in Sankt Peter (Abb. 2), zum anderen bei den Vorbereitungen zum Kreuzzug in Ancona (Abb. 3). Die Wiedergabe des Tragethrons - in beiden Fällen eine sedia maior - ist in Bezug auf die Lebensgeschichte Pius' II. eine Frucht künstlerischer Freiheit. Im Rahmen seiner Krönung hatte dieser den Tragethron noch nicht benutzt, der erst unter seinen Nachfolgern eine Rolle bei der Amtseinführung der Päpste spielte, und bei der Ankunft in Ancona war der Papst zu schwach gewesen, um sich der Öffentlichkeit zu zeigen; er wurde vielmehr in den Bischofspalast gebracht, wo er am I4./I5. August I464 starb. Die von Pinturicchio dargestellte Szene in Ancona verbildlicht eine ideale Vision des Wirkens Pius' II. für den Kreuzzug. Der Papst tritt hier nicht segnend, sondern eine

67 Vgl. MärTl 2000 (wie Anm. 35), S. I64 sowie die Stichwörter lectica und sedes mit der Differenzierung cooperta, gestatoria, ordinaria, privata, parva im Diarium des Alaleone, WAssILOwsKy/Wolf 2007 (wie Anm. 42), S. 395 und 405.

68 Vgl. Eunice D. Howe, Art and Culture at the Sistine Court. Platina’s „Life of Sixtus IV“ and the Frescoes of the Hospital of Santo Spirito (Studi e Testi 422, Città del Vaticano 2005), Abb. 30, S. 23I. 


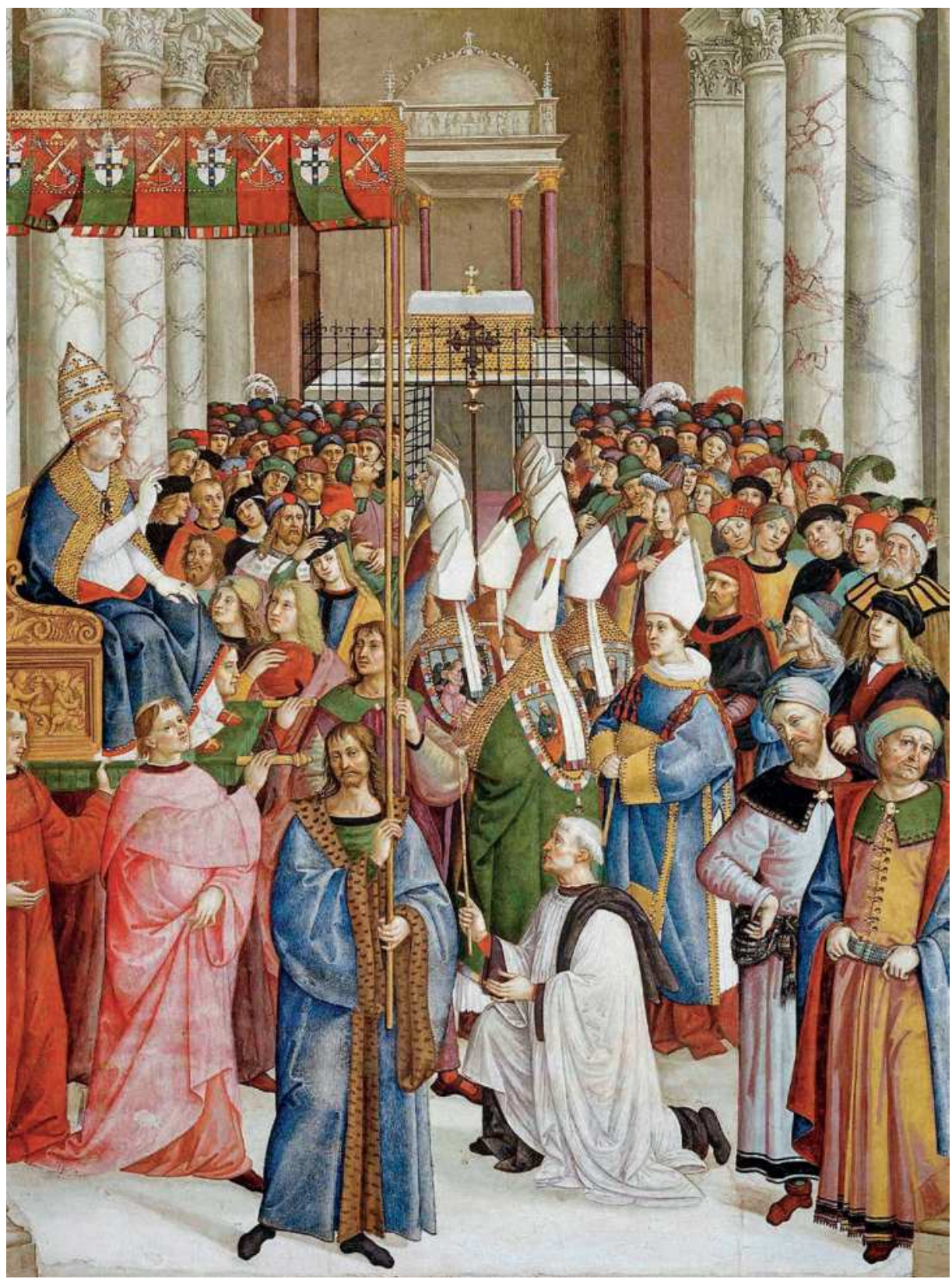

Abb. 2: Pius II. zieht auf der sedia gestatoria in die alte Peterskirche ein (Detail). Pinturicchio, Fresko, nach 1502. Libreria Piccolomini am Dom zu Siena. @ Scala Archives 


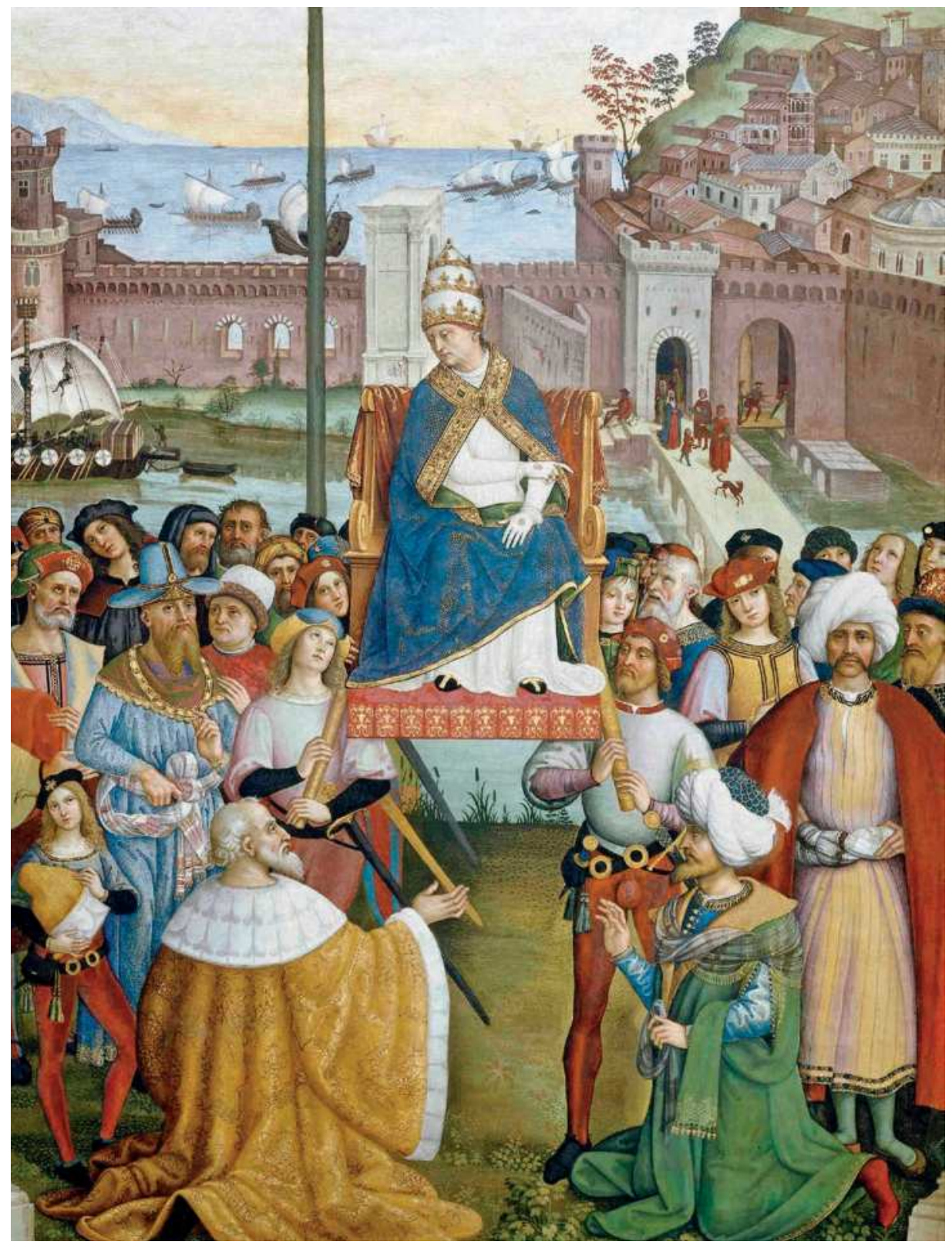

Abb. 3: Pius II. auf einer sedia gestatoria anlässlich der Kreuzzugsvorbereitungen in Ancona (Detail). Pinturiccho, Fresko, nach 1502. Libreria Piccolomini am Dom zu Siena. @ Scala Archives 


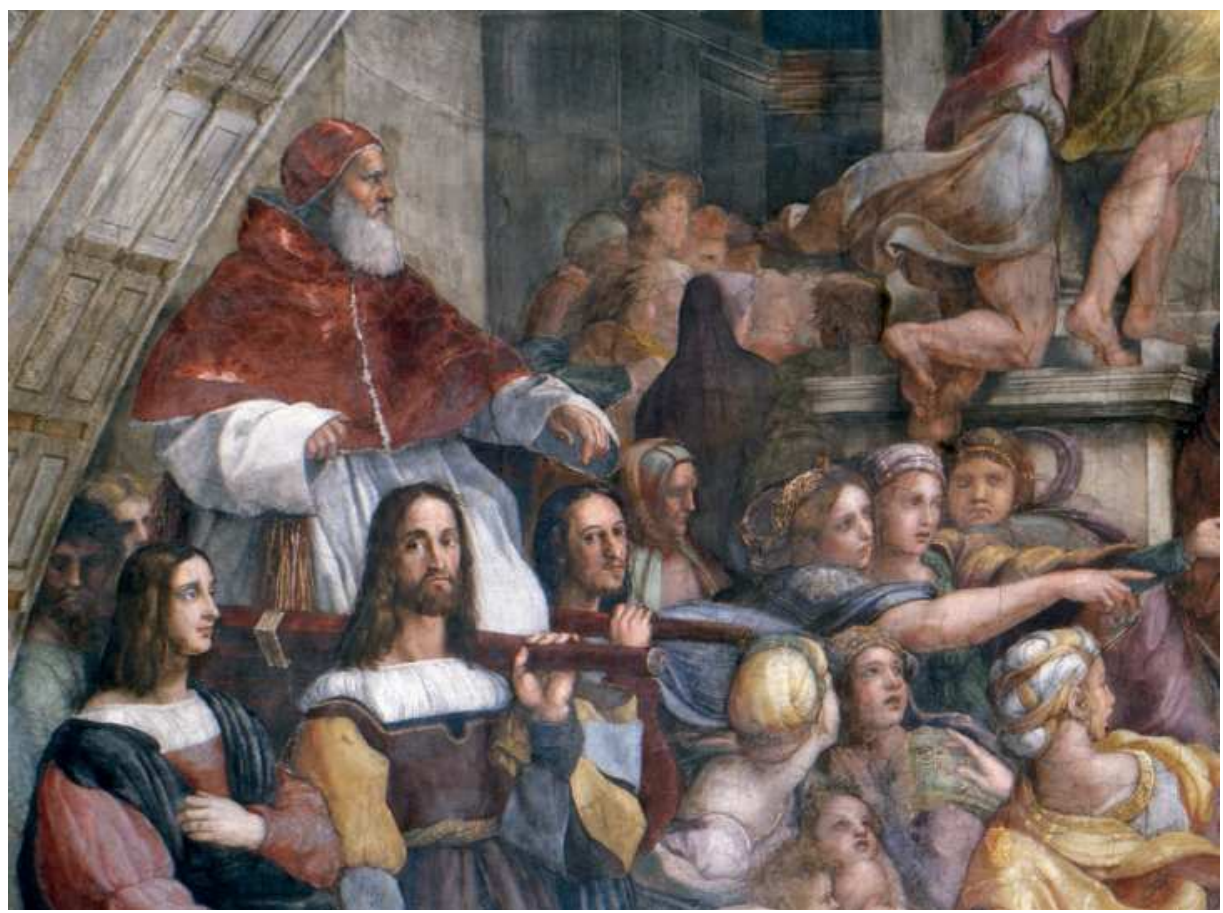

Abb. 4: Julius II. auf einer sedia gestatoria auf dem Fresko zur Vertreibung des Heliodorus aus dem Tempel (Detail), Raffael, 1511/12. Apostolischer Palast (Vatikan), Stanza di Eliodoro. @ Scala Archives

Anordnung erteilend auf, indem er den vor ihm knienden Dogen mit einem Fingerzeig auf einen orientalisch gekleideten Mann zu seiner Linken oder vielleicht auch auf den Hafen in seinem Rücken hinweist. Dass der Maler ihn dabei auf der sedia gestatoria thronen lässt, statt einen normalen Thronsessel darzustellen, unterstreicht die Ambivalenz dieses Transportmittels. Der Tragethron verdeutlicht zum einen die Leiden, die Pius II. für den Türkenkrieg auf sich genommen hatte, indem er trotz schlechter Gesundheit die Reise nach Ancona antrat; zum anderen drückt er einen religiös-politischen Führungsanspruch des Papstes aus, der sich auf die umstehenden Personen, die offenkundig unterschiedlichen Kulturen entstammen, richtet. Obwohl ihr Auftauchen in diesen Szenen historisch nicht korrekt ist, entspricht die Darstellung der sedia gestatoria maior in einem tieferen Sinn den Vorstellungen, die Pius II. selbst mit ihrer Verwendung verbunden hatte.

Auf die Darstellung der sedia minor spezialisierte sich hingegen Raffael. ${ }^{69}$ Er lässt Ju-

69 Zum Folgenden vgl. Jörg Traeger, Raffaels Stanza d'Eliodoro und ihr Bildprogramm. In: Römisches Jahrbuch für Kunstgeschichte I3 (1971), S. 29-99; DERS., Die Begegnung Leos des Grossen mit Attila. Planungsphasen und Bedeutungsgenese. In: Bibliotheca Hertziana - Musei Vaticani, 


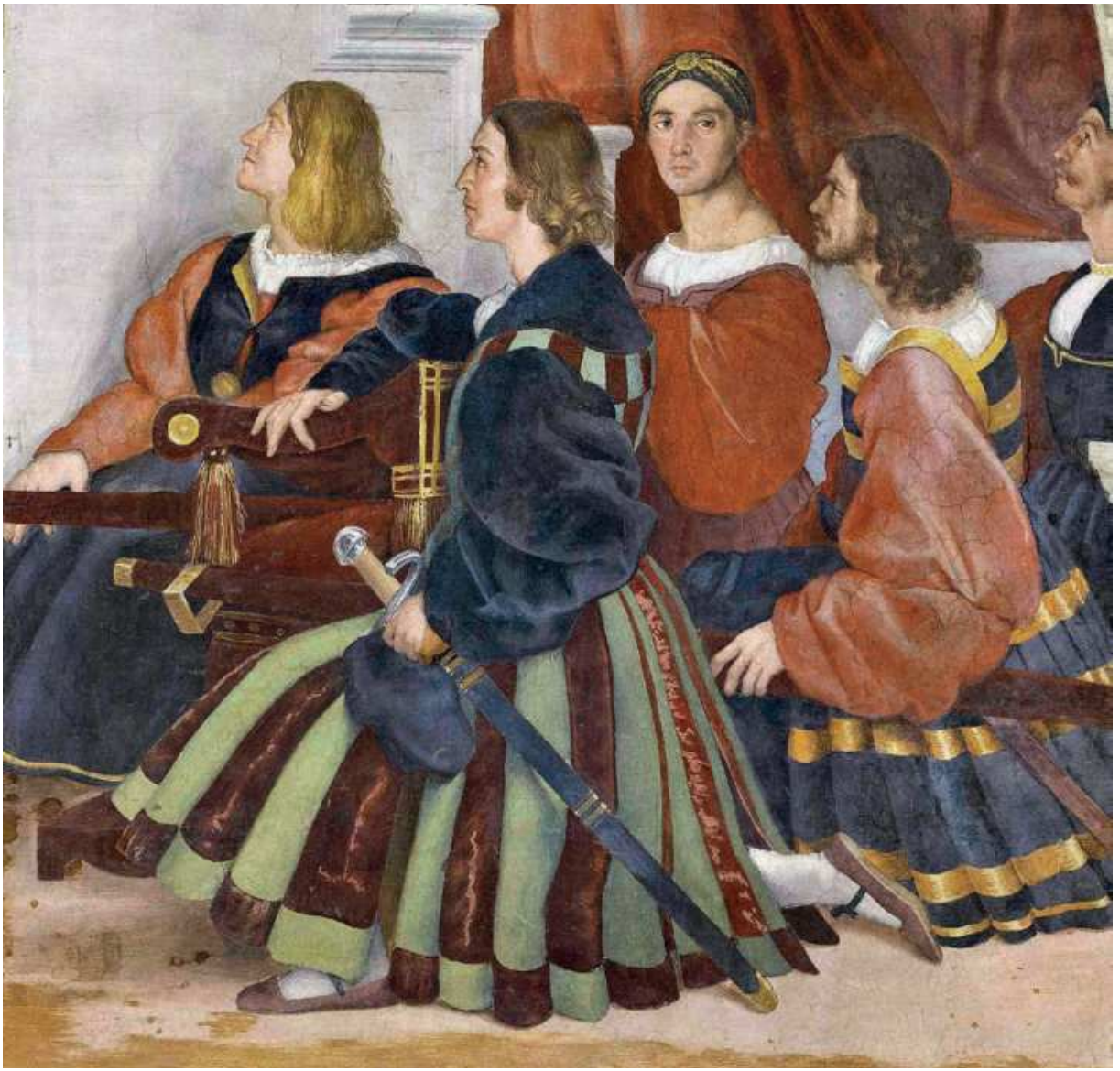

Abb. 5: Die leere sedia gestatoria Julius' II. auf dem Fresko zum Hostienwunder von Bolsena (Detail). Raffael, 1512. Apostolischer Palast (Vatikan), Stanza di Eliodoro. @ Scala Archives

lius II. auf einem solchen Tragsessel in der Stanza di Eliodoro zum Augenzeugen der Vertreibung des Heliodorus aus dem Tempel werden (Abb. 4) und platzierte eine sedia minor, von der ein Teil des Sitzes und die vorderen Enden der Tragstangen zu sehen sind, am

Raffaello a Roma. Il convegno del I983 (Roma 1986), S. 97-II6 (beide Beiträge sind nachgedruckt in DERs. 2008 [wie Anm. 30], S. 23I-337 und 339-368); Michael Rohlmann, „Dominus mihi adiutor“. Zu Raffaels Ausmalung der Stanza d'Eliodoro unter den Päpsten Julius II. und Leo X. In: Zeitschrift für Kunstgeschichte 59 (1996), S. I-28; DERS., Repräsentation von Künstler und Auftraggeber in den Fresken der Stanzen, der Madonna di Foligno und der Sixtinischen Kapelle. In: Raffael (wie Anm. 4), S. 25-37, hier S. 25-29 und 34, Abb. 20. 


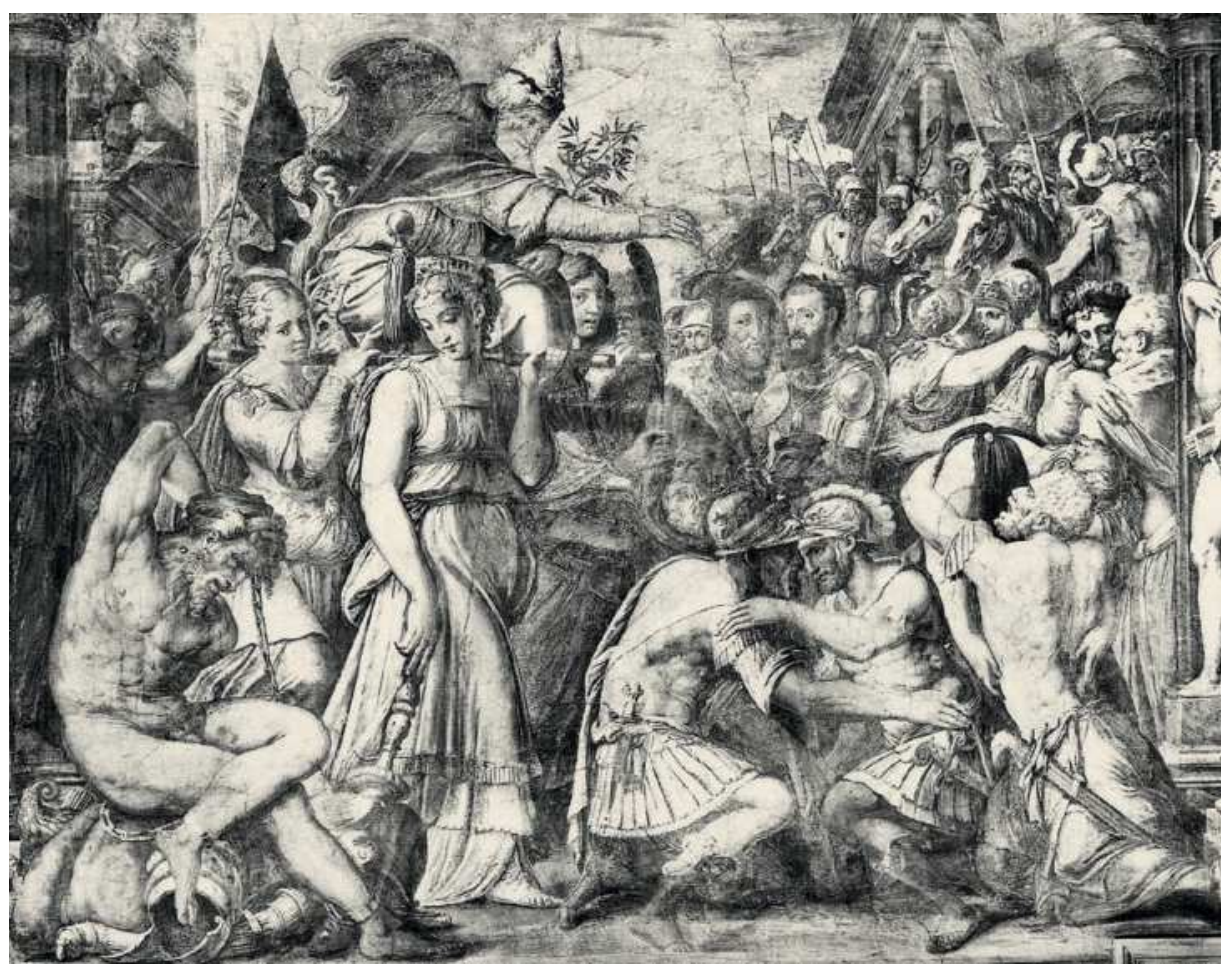

Abb. 6: Paul III. auf einer sedia gestatoria, getragen von Pax und Victoria. Giorgio Vasari, Fresko, 1546. Palazzo della Cancelleria (Rom), Sala dei Cento giorni. @ Fototeca Zeri

rechten Rand jenes Freskos, das denselben Papst, auf ein Faldistorium gestützt, beim Gebet angesichts des Hostienwunders von Bolsena darstellt (Abb. 5). Ein Entwurf von Raffaels Hand und Kopien seiner Vorzeichnungen zeigen, dass er daran dachte, auch Leo I. in der Gestalt Leos X. bei der Begegnung mit Attila auf einer sedia minor darzustellen; in der Ausführung setzte er den Papst dann aber doch auf einen Schimmel. Einige Varianten der Vorzeichnung zu einem nicht ausgeführten Fresko seines Schülers Giulio Romano in der Sala di Costantino lassen Papst Silvester I. auf einem Tragethron erscheinen, der als die Cathedra Petri im Petersdom zu identifizieren ist.

Nach diesem Höhepunkt künstlerischen Interesses an dem Bildmotiv sind ähnlich prominente und qualitativ hochstehende Darstellungen von Päpsten auf der sedia gestatoria in den folgenden Jahrhunderten dünn gesät. Giorgio Vasari verfertigte um die Mitte des 16. Jahrhunderts drei Fresken, in denen er dieses Thema aufnimmt. ${ }^{70}$ In der Sala dei Cento

70 Vgl. zum Folgenden Traeger 2008 (Nachdruck, wie Anm. 30), S. iıo f., und die Abb. bei Marco Pellegrini, Leone X. In: Enciclopedia dei papi, Bd. 3 (Roma 200o), S. 42-64, hier S. 6o; Mas- 


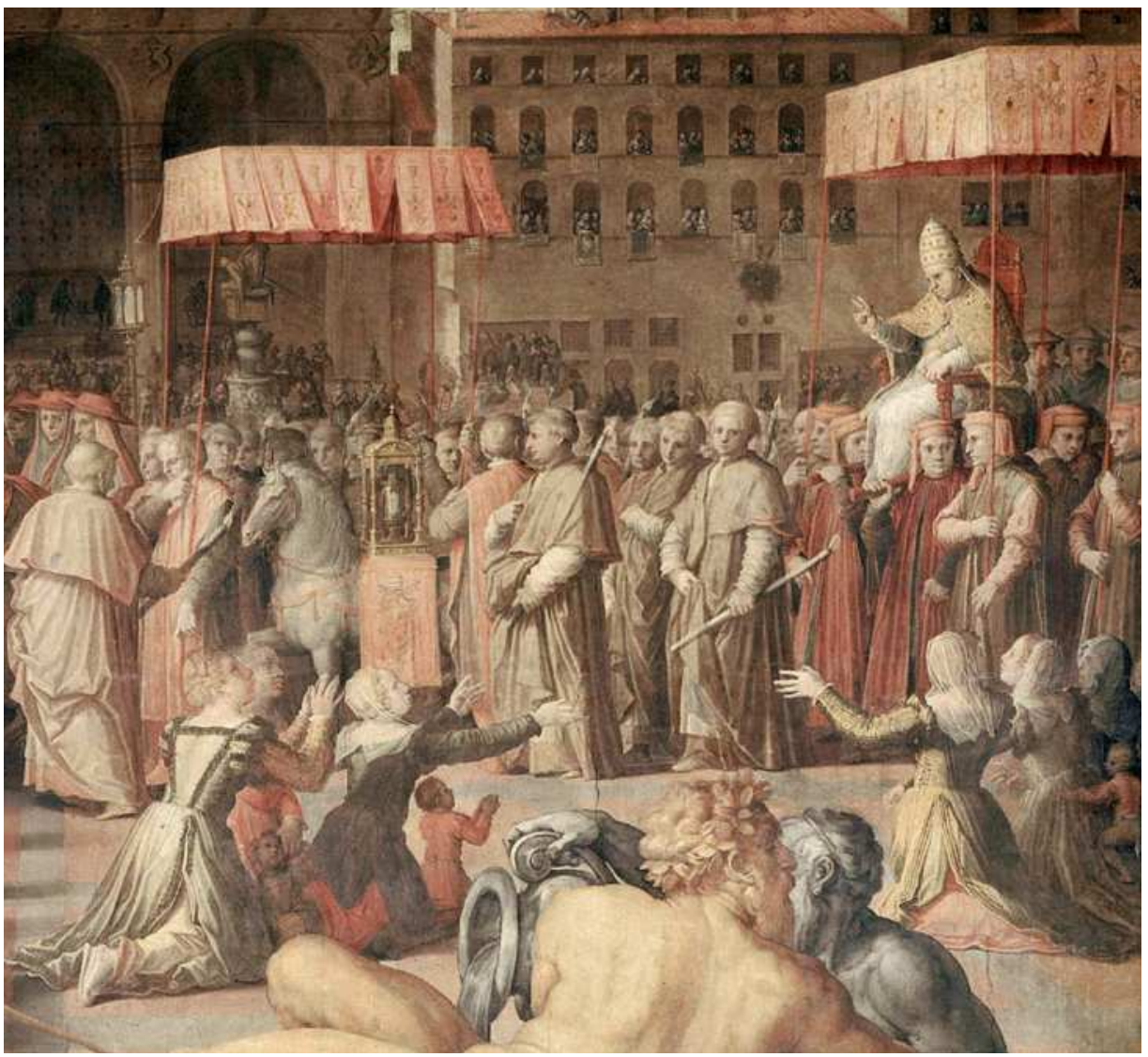

Abb. 7: Leo X. auf einer sedia gestatoria anlässlich seines Besuchs in Florenz im Jahr 1515 (Detail). Giorgio Vasari und Gehilfen, Fresko, 1555. Palazzo Vecchio (Florenz), Sala di Leone X. @ Scala Archives

giorni des römischen Palazzo della Cancelleria feierte er 1546 Paul III. als Stifter universalen Friedens: Der Papst wird von Pax und Victoria auf einer sedia minor getragen (Abb. 6). Im Jahr 1555 verewigte er (zusammen mit Mitarbeitern) den Besuch Leos X., der vierzig Jahre zuvor stattgefunden hatte, in der Sala di Leone $X$ des Palazzo Vecchio in Florenz durch eine Darstellung des segnend auf einer sedia maior einziehenden Papsts (Abb. 7). Und schließlich stellte er 1572/73 in der Sala regia der Vatikanischen Gemächer die Ankunft des auf einer sedia maior sitzenden Papstes Gregor XI. auf dem Petersplatz bei seiner Rückkehr von Avignon dar (Abb. 8). Am Ende des Jahrhunderts, im Jahr 1597, zeigte Rutilio Manetti in

simo Firpo/Fabrizio Biferali, „Navicula Petri“. L'arte dei Papi nel Cinquecento (Roma 2009), S. I74 und Tav. 26; Carlo Pietrangeli, Die Gemälde des Vatikan (München I996), S. 405, Nr. 38I. 
Abb. 8: Gregor XI. auf einer sedia maior auf dem Petersplatz bei seiner Rückkehr von Avignon (Detail). Giorgio Vasari, Fresko, 1572/ 73. Apostolischer Palast (Vatikan), Sala regia. c) Scala Archives

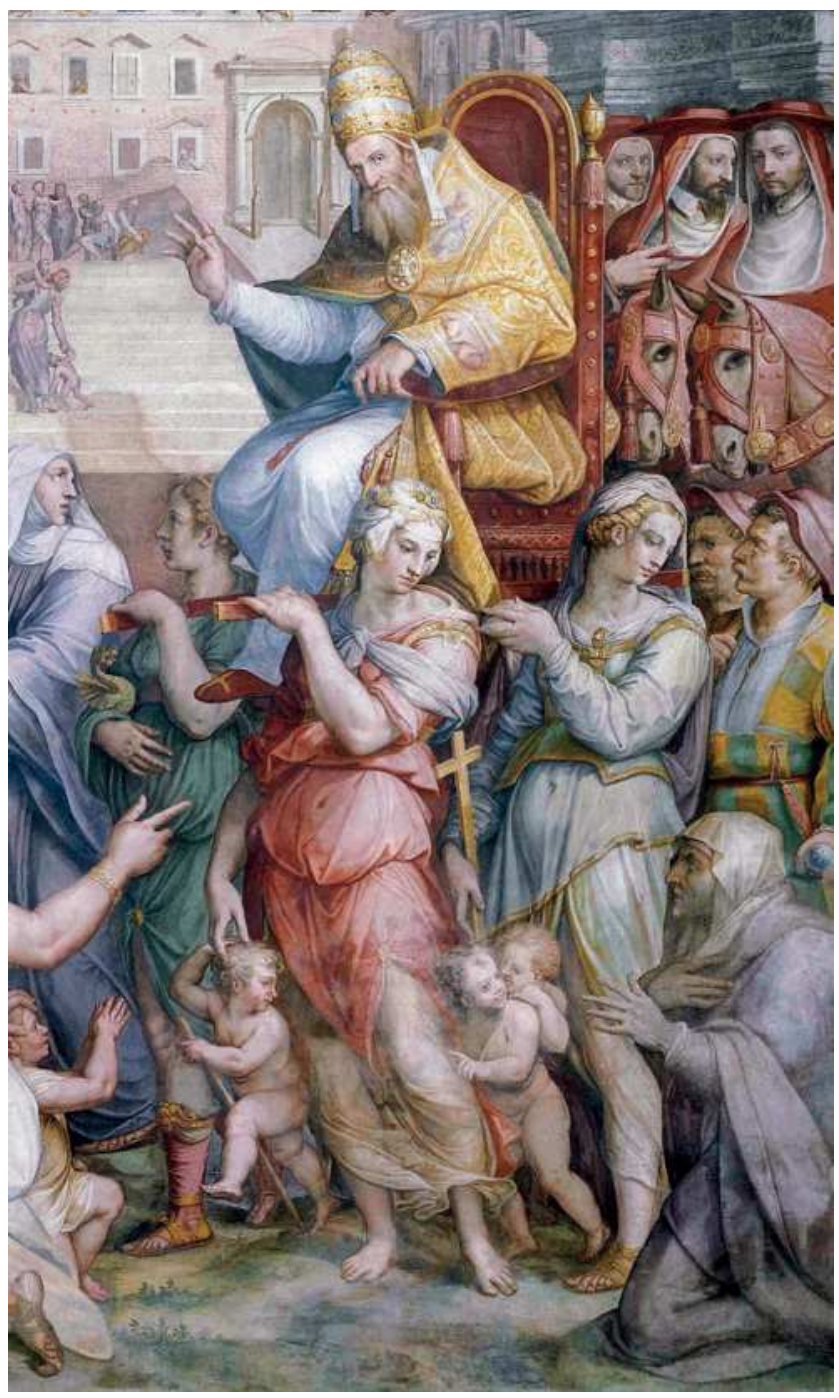

einer freskierten Lünette im Palazzo pubblico zu Siena dieselbe Szene, bei der er den Papst auf einer sedia minor, begleitet von Katharina von Siena, vor Sankt Peter erscheinen lässt. ${ }^{71}$ Der Großteil der bildlichen Darstellungen verwendete jedoch Techniken und Formate von geringerer Repräsentativität, die den Vorteil der Reproduzierbarkeit besaßen. Auf den verbreiteten frühneuzeitlichen Stichen zu den Krönungsumzügen der Päpste ist die sedia ges-

7I Vgl. Mauro Civai, La decorazione della Sala del Capitano del Popolo. In: Roberta Ferri (Hg.), Il Governo di Siena (Siena 2008), S. I29-162, hier Abb. S. I43 f. 


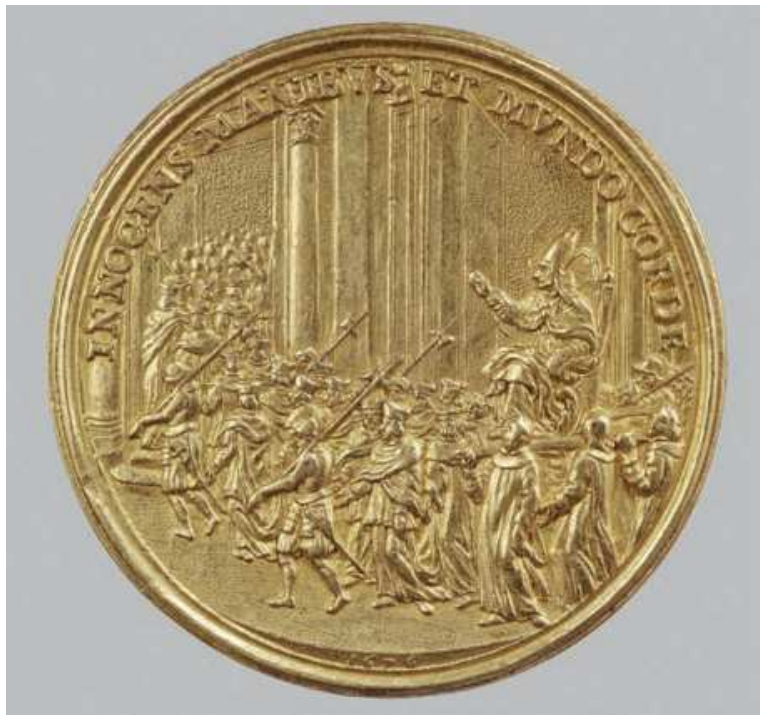

Abb. 9: Medaille zum Amtsantritt Innozenz' XI. im Jahr 1676, Revers. Medailleur Giovanni Hamerani, Gold (Prägung im Gewicht von 14 Dukaten), KHM, Münzkabinett,

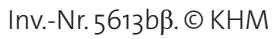

tatoria naturgemäß fast stets zu entdecken, sei es, dass sie vom Papst benutzt, sei es, dass sie ihm vorangetragen wird. ${ }^{72}$ Abgesehen von den Krönungsumzügen sind die Bildanlässe für Darstellungen des Tragethrons ziemlich variabel. Ein Stich, der anlässlich der Ausrufung des Jubeljahrs 1575 durch Gregor XIII. entstand, zeigt diesen auf einer sedia maior unter einem Baldachin auf dem Weg zur Eröffnung der Heiligen Pforte. ${ }^{73} \mathrm{Im}$ fortgeschrittenen I7. Jahrhundert entstanden zwei Medaillen, die jeweils auf dem Revers Päpste auf der sedia gestatoria präsentieren. Alexander VII. (I655-I667) ließ eine Bronzemedaille entwerfen, die auf der Rückseite die Prozession mit dem Papst auf der sedia gestatoria unter einem Baldachin zeigt; die ebenfalls dargestellten zwei Fächer verdienen besondere Beachtung, da sie sichtlich aus vielen Pfauenfedern zusammengesetzt sind. Die Medaille Innozenz' XI. (I676-I689) anlässlich seines Antritts trägt auf der Rückseite (Abb. 9) eine Szene, in der der segnende Papst auf der sedia gestatoria umgeben von einer großen Menge, darunter vier Hellebardenträger, vor monumentalen Säulen auftritt.

72 Zum späteren Verfall des Possesso-Zeremoniells, der sich unter anderem im Übergang zur Kutsche als Transportmittel des Papstes zeigt, vgl. Marina CAFfiero, La maestà del papa. Trasformazioni dei rituali del potere a Roma tra XVIII e XIX secolo. In: Visceglia/Brice 1997 (wie Anm. 46), S. 28I-3i6.

73 Vgl. die Abb. in Anton Haidacher, Geschichte der Päpste in Bildern (Heidelberg 1965), S. 440, und Simonetta Prosperi Valenti Rodinò, L’immagine degli anni santi nelle stampe. In: La storia dei Giubilei, Bd. 2: 1450-I575 (Roma 1997), S. 282-293, hier S. 282. 


\section{Die Gestalt der sedia gestatoria in der Frühen Neuzeit}

Während auf den Stichen Einzelheiten oft nur schwer zu erkennen sind, ist auf den Fresken Vasaris im Palazzo Vecchio zu Florenz und in der Sala regia im Vatikan die Form des päpstlichen Sitzes klar dargestellt: Er war von roter Farbe, hatte zwei Armstützen und eine hohe, über den Kopf des Papstes emporragende Lehne. Spätestens zur Zeit der Entstehung der Bilder, um die Mitte des I6. Jahrhunderts, hatte demzufolge der Thron auf der Plattform bereits die im 19. und 20. Jahrhundert übliche Gestalt eines Sessels nach dem Vorbild der „Staatsporträts“ der Päpste. Dies verdient deshalb Erwähnung, weil die um ein halbes Jahrhundert älteren Fresken Pinturicchios in der Libreria Piccolomini einen anderen Eindruck vermitteln. Pinturicchio gilt als ein äußerst genauer Schilderer des kurialen Zeremoniells, sodass seine Darstellung als Wiedergabe eines historischen Zustandes des päpstlichen Tragethrons um die Wende vom I5. zum I6. Jahrhundert Beachtung verdient. Die sedia gestatoria wird von Pinturicchio einmal von der Seite, das andere Mal von vorne dargestellt; bei genauer Betrachtung erweist sich, dass der Maler zwei verschiedene Sitze desselben Typs gestaltet hat. Der aus Holz gefertigte Thron besteht aus einem Block mit rechteckigem Grundriss, auf dem der Papst sitzt, und einer damit verbundenen Lehne, die einen Rückenteil und Seitenwangen aufweist. Deren oberer, zur Sitzfläche hin abgeschrägter Abschluss wird von zwei Voluten begrenzt, die sich in der Szene der Wergverbrennung gegenläufig, in der Szene in Ancona dagegen beide nach oben einrollen. In der Szene der Wergverbrennung ist die sedia an der sichtbaren Außenseite mit geschnitzten Reliefs verziert; auf dem Unterteil sind Putten, auf der Seitenwange ist ein Drache zu erkennen. Bei Pinturicchio wird also eine Kathedra auf der Plattform getragen, ${ }^{74}$ wobei für den oberen Abschluss der Seitenwangen mit gegenläufigen Voluten besonders der Vergleich mit dem Thron aufschlussreich ist, auf dem die von Arnolfo di Cambio gegossene Bronzestatue des heiligen Petrus in Sankt Peter sitzt. Es scheint aber, dass die Päpste von dieser symbolträchtigen Form ${ }^{75}$ aus welchen Gründen auch immer schnell Abschied nahmen; vielleicht wurde eine allzu deutliche Reminiszenz an Petrus angesichts der einsetzenden protestantischen Kritik, die im Kern immer den aktuellen Prunk der Päpste der Armut Christi und der Apostel gegenüberstellte, als nicht mehr opportun empfunden.

74 Ein ebenfalls in Siena entstandenes Kunstwerk, eine Tavoletta di Biccherna aus dem Jahr I598, stellt den Einzug Clemens' VIII. in Ferrara in diesem Jahr mit einer sedia gestatoria dar, die der von Pinturicchio gewählten Gestalt sehr ähnelt. Vgl. die Abb. in Haidacher I965 (wie Anm. 53), S. 497 und Luigi Borgia u.a., Le Biccherne. Tavole dipinte delle magistrature senesi (secoli XIII-XVIII) (Roma I984), S. 288 f. Nr. I24.

75 Vgl. Dresken-Weiland/Drews 2004 (wie Anm. i7), hier bes. Sp. 629-633, Sp. 638-640, Sp. $670 \mathrm{f}$. 
Anders als vielleicht zu erwarten wäre, bezieht sich die protestantische Bildpropaganda ${ }^{76}$ keineswegs besonders nachdrücklich auf das päpstliche Auftreten mit der sedia gestatoria, obwohl Martin Luther 1520 in seinem Aufruf „An den christlichen Adel deutscher Nation“ neben vielen anderen Phänomenen des Zeremoniells auch diesen Aspekt geißelte:

Der selben grosz ergerlichen hoffart ist auch das ein heszlich stuck / das der Bapst yhm nit lessit benugenn / das er reytten oder farenn muge / szondern / ob er wol starck und gesund ist / sich von menschen / als ein abtgot mit vunerhorter pracht / tragen lessit. Lieber wie reymet sich doch solch Lucifersche hoffart / mit Christo / der zufussen gangen ist / vnd alle seine Aposteln? ... Alszo geht es auch / wen er das sacrament in der procession vmbtregt / yhn musz man tragen / aber das sacrament stet fur yhm wie ein kandel weynsz auf dem tisch $[\ldots] .{ }^{77}$

Trotz dieser Steilvorlage nahmen protestantische Künstler viel lieber den ein aufgeputztes Pferd reitenden Papst aufs Korn und stellten ihn Christus auf der Eselin gegenüber. ${ }^{78}$ Es gibt nur wenige bedeutende Ausnahmen; die erste findet sich unter den Holzschnitten Lucas Cranachs zu der I52I auf Lateinisch veröffentlichten „Antithesis figurata Vitae Christi et Antichristi“ Philipp Melanchthons und Johann Schwertfegers, die im selben Jahr als "Passional Christi und Antichristi“ auch auf Deutsch erschien. Eines der dreizehn Bildpaare zeigt links den unter dem Kreuz zusammenbrechenden Christus und rechts den Papst auf einer sedia minor, kommentiert durch die Bildunterschrift: „Sic etiam fert crucem papa, ut baptisati Christiani cogantur eum humeris suis portare (Abb. IO). ${ }^{79}$ Der Papst trägt die Tiara, vollführt mit der rechten Hand einen Segensgestus und hält in der linken Hand

76 Vgl. zum Folgenden Staubach 2004 (wie Anm. 42), hier S. I25-I34; Carsten-Peter Warncke, Bildpropaganda der Reformationszeit. In: Barbara Stollberg-Rilinger/Thomas Weissbrich (Hg.), Die Bildlichkeit symbolischer Akte (Symbolische Kommunikation und gesellschaftliche Wertesysteme. Schriftenreihe des Sonderforschungsbereichs 496, 28, Münster 2010), S. I85-197; Marco Cavarzere, Rituale und Zeremonien zu Beginn der Reformation - zwischen Kritik und Innovation. In: Schmidt/Wolf 2013 (wie Anm. 42), S. 309-335, hier bes. S. 324-334.

77 Martin Luther, An den christlichen Adel deutscher Nation von des christlichen Standes Besserung, I520, bearbeitet von Karlheinz Blaschke (Martin Luther, Studienausgabe, hg. von Hans-Ulrich Delius, Bd. 2, Leipzig 1982), S. I30 f.

78 Traeger 2008 (Nachdruck, wie Anm. 30), S. I43-I48.

79 Benutzt wurde ein koloriertes Exemplar der Antithesis figurata Vitae Christi et Antichristi, Wittenberg I52I (Signatur: 3I.W.7I), das von der Österreichischen Nationalbibliothek digitalisiert und online gestellt wurde. 
das Patriarchenkreuz. Die sedia wird verdeckt von einem herunterhängenden gemusterten Tuch, das nach Art einer Kirchenfahne in drei gerundete Zipfel ausläuft; über geschnitzte oder gedrechselte Säulen ist ein Baldachin fest mit dem Sitz verbunden. Getragen wird der Sitz von vier Trägern in bodenlangen Gewändern, die durch ihre Kopfbedeckung, das Birett, als Universitätsgelehrte (Theologen?) ausgewiesen sind. Ein fünfter Mann in derselben Kleidung schreitet neben dem Sitz und scheint diesen mit einer Stange zu lenken. Wie eine Fortentwicklung dieses Holzschnitts mutet eine Verbildlichung der "proud primacie“ der Päpste an, die rund ein halbes Jahrhundert später den „Acts and Monuments“ des John Foxe ab der zweiten Auflage beigegeben wurde (Abb. II). ${ }^{80}$ Der Papst sitzt hier auf einer sedia maior, mit der ebenfalls ein Baldachin auf geschnitzten oder gedrechselten Säulen fest verbunden ist; er trägt die Tiara, vollzieht mit der rechten Hand einen Segensgestus und hält in der linken Hand die Petrusschlüssel. Von der Plattform der sedia hängt ein dreizipfliger Zierbehang herab. Getragen wird der Sitz von vier barhäuptigen Trägern in bodenlangen Gewändern. Die Überschrift suggeriert, es handle sich um eine Abbildung zum Text des päpstlichen Zeremoniells: „The P[ope] caried on mens shoulders, the Emp[eror] \& K[ings] going before him. Ex Li. Sacrar. Cer. lib. I." Damit folgt der Holzschnitt dem polemischen Kunstgriff Wenzeslaus Lincks, der I539 das unter Leo X. gedruckte Zeremonienbuch der römischen Kurie übersetzt und durch Auswahl der Texte, Überschriften und Randkommentare zu einer „Selbstoffenbarung des Antichrist“ umgestaltet hatte; ${ }^{81}$ allerdings hatte die sedia gestatoria für Linck keine Rolle gespielt, da er entsprechend seiner Vorlage bei den Antrittsfeierlichkeiten des Papsts nur das weiße Pferd erwähnt. Als Illustration für ein im Jahr I630 erschienenes historisches Werk imaginierte Matthäus Merian mit der Verspottung eines päpstlichen Umzugs durch Landsknechte eine Schlüsselszene des Sacco di Roma, ${ }^{82}$ in deren Gestaltung er wie der Illustrator der "Acts and Monuments“ durch Cranachs Stich beeinflusst scheint (Abb. I2). Der mit Paramenten und der Tiara an-

80 Vgl. die elektronische Edition: The Unabridged Acts and Monuments Online or TAMO (The Digital Humanities Institute, Sheffield 20II); https://www.dhi.ac.uk/foxe/ (letzter Zugriff: 19.07.2019). Der Holzschnitt findet sich in der Auflage von 1570 (S. 957), I576 (S. 79I), is83 (S. $8 \mathrm{i} 5)$.

8I Wenzeslaus LincK, Bapsts gepreng, auß dem Ceremonien Buch, von dem über den OPAC der Bayerischen Staatsbibliothek München mittlerweile je zwei Exemplare der Auflagen Straßburg I539 und Nürnberg 1565 digitalisiert einsehbar sind (letzter Zugriff: 30.09.2019). Vgl. STaubach 2004 (wie Anm. 42), S. I25-I27.

82 Joh. Ludw. GotTrRidi Historische Chronica, Oder Beschreibung der Fürnemsten Geschichten / so sich von Anfang der Welt / biß auff das Jahr Christi r6ı9 zugetragen (Frankfurt a. M. 1630), S. 720 ; benutzt in der Auflage von I7IO, die von der Österreichischen Nationalbibliothek digitalisiert wurde (http://data.onb.ac.at/rep/I06D7BF2 [letzter Zugriff: 30.09.2019]). Zum Verfasser Johann Ludwig Gottfried (um I584-I633) vgl. den Artikel von Lucas Heinrich WüTHRICH, in: Neue Deutsche Biographie, Bd. 6 (Berlin 1964), S. 677 f. 


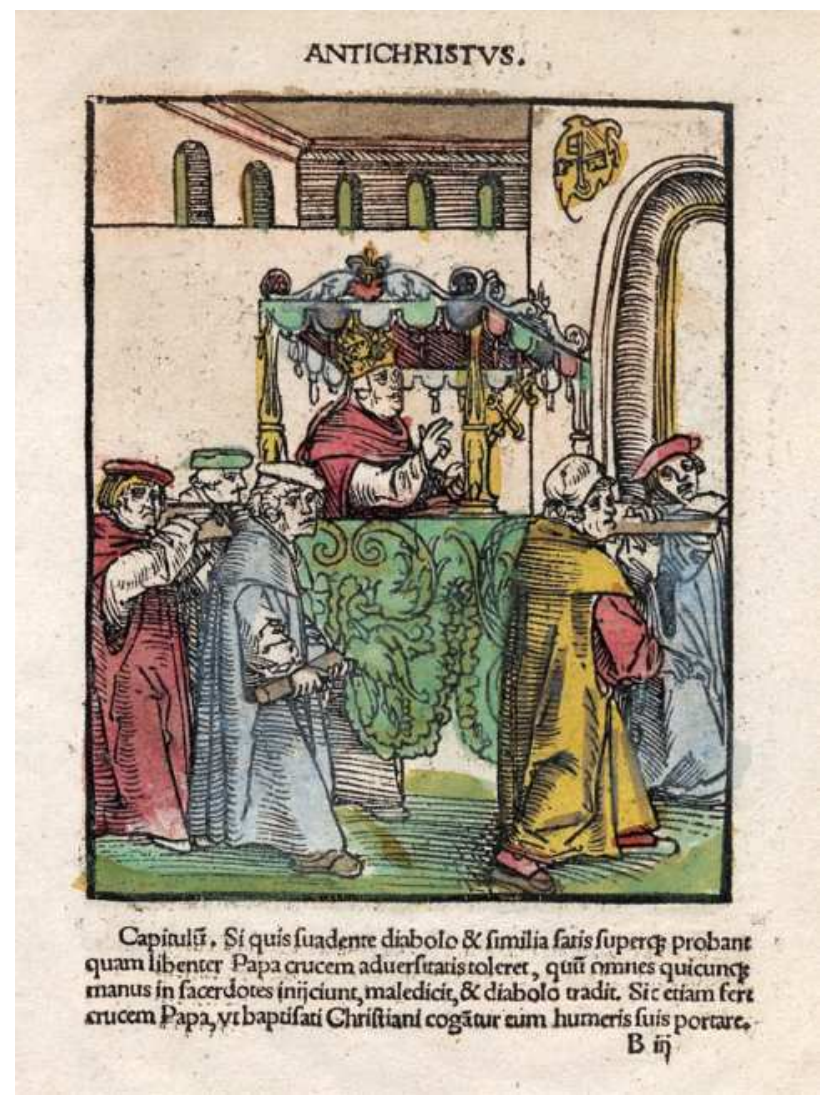

Abb. 10: Darstellung eines Papstes auf der sedia gestatoria. Lucas Cranach, Holzschnitt aus Antithesis figurata Vitae Christi et Antichristi (Wittenberg 1521). ÖNB, Sign. 31.W.71. (c) ÖNB

getane „Papst“ sitzt auf einer sedia maior, von deren Plattform ein Teppich herabhängt; er segnet mit der Linken und hält in der Rechten das Patriarchenkreuz. Der im Vergleich zu den ,ernsthaften“ Darstellungen der sedia maior relativ niedrige Sessel hat eine geschweifte Rückenlehne, an die sich der Sitzende nicht in aufrechter Haltung anlehnen kann, sodass er eher kauert als thront. Die Plattform wird durch Männer in Landsknechtskleidung getragen, von denen einer sich gerade abwendet. Es liegt auf der Hand, dass diese Darstellungen der sedia gestatoria nicht beabsichtigen, päpstliches Zeremoniell abzubilden, sondern vielmehr ,akzentuierte Interpretationen " ${ }^{\text {"83 }}$ bieten, die divergierende Positionen in kritischer oder polemischer Absicht zusammenspannen.

83 Warncke 20 Io (wie Anm. 56), S. i88 f., mit Bezug auf das „Passional Christi und Antichristi“. 


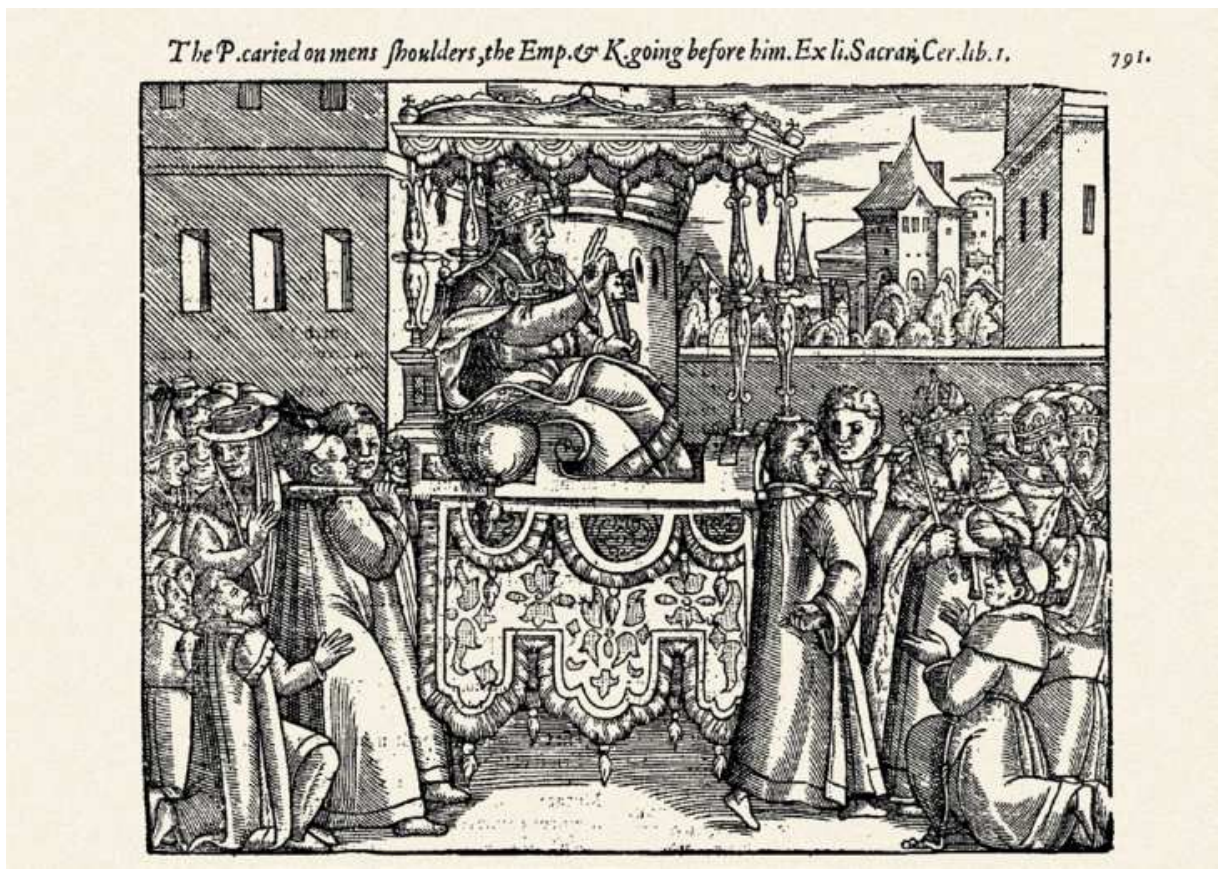

Abb. 11: Darstellung eines Papstes auf der sedia gestatoria. John Foxe, Acts and Monuments, Auflage von 1576, Buch 6, S. 957. The Unabridged Acts and Monuments Online or TAMO (The Digital Humanities Institute, Sheffield 2011); https://www.dhi.ac.uk/foxe/woodcuts/fo825w.gif (letzter Zugriff: 19.07.2019).

Nach dem Abklingen der konfessionellen Auseinandersetzungen kam es keineswegs zu einer nüchternen Untersuchung der historischen Ursprünge der sedia gestatoria. Je altertümlicher der Auftritt der Päpste auf der sedia gestatoria bei fortschreitender Zeit wirkte, desto bereitwilliger wurde unbesehen die Meinung akzeptiert, man habe es hier mit einem letztlich antiken Brauch zu tun: „Auch das Tragen des Papstes in Sanct Peter in Rom an hohen Kirchenfesten beruht natürlich auf alter Tradition" ${ }^{\text {"84 }}$. Es erstaunt, eine derartige Aussage in einem 1922 entstandenen und 1924 gedruckten Artikel der „Realencyclopädie der classischen Altertumswissenschaft" zu lesen, dessen Autor doch zuvor mit ungeheurem Quellenaufwand und überbordender Detailfreude die Formen der antiken Sänften und ihrer Benutzung zusammengestellt hatte. Vor allem mit dem Adverb „natürlich“ wird in diesem Monument des altertumskundlichen Positivismus die päpstliche sedia gestatoria rasch vereinnahmt. Dass die Quellenlage die Annahme einer ungebrochenen Tradition seit der Antike nicht zulässt, der Ursprung der sedia gestatoria in der Frührenaissance zu

84 Artikel Lectica, in: Pauly/Wissowa 1924, XII,I (wie Anm. 20), Sp. IIoo. 


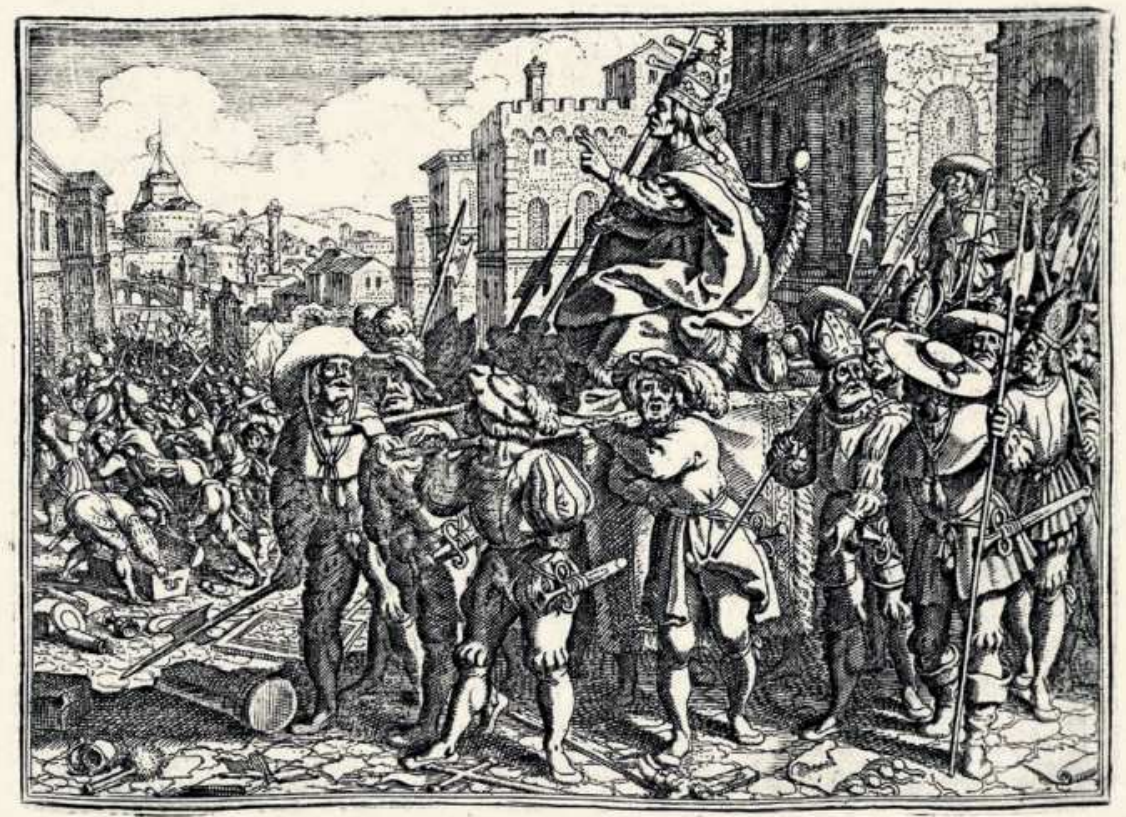

Abb. 12: Darstellung eines Papstes auf der sedia gestatoria. GotTrRIED (wie Anm. 62), S. 720 . @ ÖNB

verorten ist und Beziehungen zu antiken Bräuchen allenfalls über gelehrte Analogien hergestellt werden können, hätte um die Wende vom 19. zum 20. Jahrhundert angesichts der methodischen Entwicklung der historischen Wissenschaften bereits erkannt werden können. Die Bereitwilligkeit, mit der für die sedia gestatoria bis heute eine „uralte“ Tradition angenommen wird, lässt den Verdacht aufkommen, dass man es gar nicht anders wissen will. Die historischen Funktionen der sedia gestatoria als Medium triumphaler Repräsentation oder pastoraler Aufgaben des Papsttums treten vielleicht einfach zurück hinter ihrer Rolle als Relikt einer Zeit vor der „Entzauberung der Welt“ (Max Weber). 


\section{„The Streets are very narrow; so that they use here few Coaches, but many Sedans and Litters." Tragsessel und Sänften in Genua vom 16. bis Anfang des 18. Jahrhunderts}

Möchte man die Geschichte der Genueser Tragsessel des „goldenen Zeitalters“ der Republik - des 16. und I7. Jahrhunderts - erforschen, scheint es zunächst zielführend, von Quellen zur Familie Doria auszugehen. Das Haus Doria zählte zu den renommiertesten Familien Genuas und verfügte nicht nur über große politische Macht, sondern auch über eine dominante Rolle im sozialen Leben der Stadt, nicht zuletzt dank seiner Residenz in Fassolo ${ }^{\mathrm{r}}$, die nicht nur den Charakter eines Familiensitzes besaß, sondern auch als „Palast der Republik" fungierte. Als Sinnbild für die herausragende Stellung der Familie können die glanzvollen Hochzeitsfeierlichkeiten von 167I gelten, die damals die ganze Stadt in Atem hielten. Im Mittelpunkt des Festes standen der Bräutigam Giovanni Andrea III. Doria (1653-1737), ein Nachfahre des berühmten Admirals Andrea Doria und von dessen Erbe Gianandrea, sowie die Braut Anna Pamphilj (1652-1728)², Tochter der Olimpia

I Für die umfangreiche Literatur über den Palast, den Andrea Doria in der ersten Hälfte des I6. Jahrhunderts errichten ließ, und über die darin aufbewahrten Kunstwerke siehe Piero BocCardo, Andrea Doria e le arti (Roma 1989) sowie die in diesem Beitrag zitierten Werke von Laura Stagno, vor allem Laura STAGno, Feste barocche e „segni di allegrezza“: le nozze Doria-Pamphilj nel i67I nel Palazzo del Principe a Genova. In: Marcello Fagrolo (Hg.), Atlante tematico del Barocco in Italia. Le capitali della festa. Italia Settentrionale (Roma 2007), S. I49-I62, hier insbesondere Anm. I.

2 Siehe Stagno 2007 (wie Anm. I); Laura Stagno, Committenze artistiche per il matrimonio di Anna Pamphilj e Giovanni Andrea III Doria Landi (I67I). In: Stephanie C. Leone (Hg.), The Pamphilj and the Arts: Patronage and Consumption in Baroque Rome (Chestnut Hill [Massachusetts] 20II), S. 55-75. Für eine detaillierte Rekonstruktion dieses Ereignisses befinden sich im Archivio Doria Pamphilj in Rom folgende Schriftquellen: ADP, scaffale 79.55.9, Breve relazione di alcune cose più notabili seguite nel matrimonio dell'Ecc.mo Signor Principe Andrea 3 colla Sig.ra Principessa D. Violante Lomellina nella di lui morte, e minorità di suo figlio il Sr Principe Gio Andrea zzo sino al dì del matrimonio del medesimo; ADP, scaffale 39.3.31, Notizie del viaggio 
Aldobrandini Borghese und des zum Zeitpunkt der Eheschließung bereits verstorbenen Camillo Pamphilj, eines Neffen von Papst Innozenz X. Insbesondere dem Geschlecht der Doria versprach die Eheschließung enormes Prestige. Um sich vor der jungen Braut, die von ihrem römischen Elternhaus - dem luxuriösen Wohnsitz in der Via del Corso prunkvolle Empfänge gewohnt war und die neben einer Mitgift von I00.00o Scudi und kostbaren Juwelen auch die Aussicht auf ihren Erbteil der mütterlichen Güter ${ }^{3}$ in die Ehe einbrachte, keine Blöße zu geben, wurde für die Feierlichkeiten die unfassbar hohe Summe von insgesamt 208.375 Lire ausgegeben, ein Betrag, der damals der Fahrnis eines reichen Adeligen, wie etwa Gian Francesco II. Brignole Sale, entsprach.

Wie aus der von Antonio Merli im Jahr I87I veröffentlichen Transkription einer zeitgenössischen Hochzeitschronik hervorgeht ${ }^{4}$ und wie sich auch aus der direkten Lektüre der Schrift „Compendio delle spese sposalitie“" ersehen lässt - einer auch für den vorliegenden Beitrag zentralen Quelle, die sich im außerordentlich reichhaltigen Archiv der Familie Doria in Rom befindet -, kamen bei den verschwenderischen Feierlichkeiten einem Tragsessel und einer Karosse, die eigens für den Empfang der Braut in Genua und für ihre Fahrt zum Palast von Fassolo in Auftrag gegeben worden waren, zentrale Rollen zu.

Der Chronik ist zu entnehmen, dass die Braut unmittelbar nach der formalen Eheschließung, die am 25. Oktober I67I in Rom per procurationem in der Kapelle des Palazzo Pamphilj stattgefunden hatte, ihre Reise nach Genua antrat, wo für ihren Empfang ein außerordentlich großer Aufwand betrieben wurde: Nachdem vier Galeeren des Duca di

et incontro a Livorno del Principe mio Signore nella venuta di mia Signora Principessa Donna Anna Panfili Doria nel mese di novembre 1671, und vor allem ADP, scaffale 79.63, Compendio delle spese sposalitie dell'Eccellentissimo Prencipe Gio Andrea Doria Landi con la Eccellentissima Principessa Donna Anna Panfilia Aldobrandina del Anno i67I. Zur Hochzeit siehe auch Lauro Magnani, L'intaglio tra apparato e statuaria: l'idea di scultura di Filippo Parodi. In: La scultura a Genova e in Liguria dal Seicento al primo Novecento (Genova 1988), S. 127-134, S. 205 f.

3 Stagno 2007 (wie Anm. I), Anm. 25.

4 A[ntonio] Merli, Gio. Andrea III Doria Landi e Anna Panfili (Nozze Giglioli Masi) (Genova I87I), vor allem S. I5-20. Wie Laura Stagno bemerkte, publizierte Merli die Transkription einer Version mit Varianten der „Breve relazione [...].“ (ADP, scaffale 79.55.9). Vgl. STAGNo 2007 (wie Anm. I), Anm. 26.

5 ADP, scaffale 79.63, Compendio delle spese sposalitie dell'Eccellentissimo Prencipe Gio Andrea Doria Landi con la Eccellentissima Principessa Donna Anna Panfilia Aldobrandina del Anno I67I. Für ihre Unterstützung bei den Recherchen für diesen Artikel möchte ich mich bei Alessandra Mercantini, Archivarin im Archivio Doria in Rom, herzlich bedanken. Mein besonderer Dank gilt auch Laura Stagno, die mich großzügig mit vielen wertvollen Hinweisen versorgte. Bei den Quellenrecherchen in Genua unterstützten mich Simona Parigi im Archivio di Stato sowie Matteo Moretti und Marie Luce Repetto im Archivio Spinola. Auch ihnen möchte ich an dieser Stelle meinen Dank aussprechen. 
Tursi und die Kapitänsgaleere, auf der sich der Bräutigam befand, dem Schiff der Braut bis nach Livorno entgegengefahren waren, landete sie am 7. November I67I in Ponte Reale. Die unüberschaubare Menge der Menschen, die sich dieses Ereignis nicht entgehen lassen wollten, konnte von den Lakaien nur unter größten Anstrengungen unter Kontrolle gehalten werden. Der Braut, deren prachtvolle Kleidung mit Gold und Spitze geziert war, gelang es nur mit Mühe, die „bussola“ - womit der Tragsessel bezeichnet wurde - zu erreichen, in der sie nach ihrer Landung bis zur Piazza Banchi gebracht wurde, wo sie schließlich in eine Karosse umstieg. Begleitet von feiernden Menschenmassen und gefolgt von zahlreichen Kutschen und Sänften gelangte sie auf diese Weise zur Residenz der Doria. Zum prachtvollen Gefolge zählten der Bräutigam zu Pferd, eine größere Gruppe Kavaliere, zwei Lakaien, die die Wagenschläge flankierten, zwei Lakaien, die vor den Zugpferden schritten, vier, die auf Radhöhe den Wagen begleiteten, und sechs weitere, die dem Wagen folgten.

Besonderes Augenmerk schenkte unser Chronist der kostbaren Ausstattung und dem allegorischen Figurenschmuck des Tragsessels:

E' questa coperta di velluto cremisino con le aquile dell'Ecc.ma Casa in mezzo a due figure di fiumi intagliate ed altri ornamenti tutti dorati, stanno nel cielo ai lati quattro putti con vasi di fiori, e di dietro una figura grande sul mondo che è la figura della pace; è fasciata al di dentro di tela d'argento con ricamo rilevato d'oro molto vago e ricco e stimato assai, che è lavoro del Valente con bandinelle, e portello adorni di alamari d'oro rilevati [...].

Erwähnung fand auch, dass der Tragsessel von zwei Sklaven transportiert wurde, deren aus karmesinrotem Damast gefertigte Wämser dem Farbton des Vehikels angepasst waren. ${ }^{6}$

Merli fügte der Transkription des oben erwähnten Dokuments die lithographische Übertragung einer Entwurfszeichnung (Abb. I) bei, die er Filippo Parodi (I630-I702) zuschreibt, einem, wie er anmerkt, hervorragenden Schnitzer und Bildhauer, der für die Doria auch zahlreiche andere Arbeiten ausführte. ${ }^{8} \mathrm{Im}$ „Compendio“ ist Parodi nur als Schöpfer

6 ADP, 79.55.9, Breve relazione [...]. Merli bezeichnete Marc'Antonio Valente als „eccellentissimo ricamatore, socio ed allievo di un tal Rubato, servi lunga pezza la casa Doria“. Merli I87I (wie Anm. 4), S. I6, 26 (Anm. 7). Tatsächlich sind beispielsweise für das Jahr I639 Arbeiten Valentes an einem Bett und einem Baldachin dokumentiert. StaGno 20II (wie Anm. 2), S. 63.

7 Merli i87i (wie Anm. 4), S. 27, Anm. 8. Die Zeichnung, auf die er Bezug nimmt, befindet sich im Besitz des „Gabinetto Disegni e Stampe di Palazzo Rosso“ (Genua), Inv.-Nr. D339I, Bleistift, Feder und Tinte auf Papier, $408 \times 208 \mathrm{~mm}$.

8 Laura Stagno ist der Ansicht, dass die übrigen Arbeiten Parodis für das Haus Doria eine Folge dieses ersten Auftrages gewesen seien und deshalb zu einem späteren Zeitpunkt erfolgt sein müssen. Laura Stagno, L'attività di Filippo e Domenico Parodi per i Doria principi di Melfi. In: Rivista 
der Karosse erwähnt; Merli meint jedoch, er zeichne wahrscheinlich auch für die „bussola“ verantwortlich und habe wohl auch selbst deren Verzierungen geschnitzt, da daran Parodis persönlicher Stil zu erkennen sei. Trotz fehlender Belege für Zahlungen an Parodi oder an andere Künstler spricht für Merlis Annahme, dass Parodi die Kosten für die Vergoldung der Beschläge des Tragsessels übernahm, was in der Tat auf seine Beteiligung an der Ausführung hindeutet. Orlando Grosso schloss hingegen bereits 1942 hinsichtlich der Entwurfszeichnung aus, dass diese Parodi zuzuschreiben sein könnte. In diesem Punkt folgte ihm auch Piero Boccardo, der meinte, dass die dekorativen Elemente bereits im Régencestil gehalten und deshalb in die Jahre zwischen 1720 und 1730 zu datieren seien. ${ }^{9}$

Während also eine Beteiligung Parodis an der Herstellung des Tragsessels als ungesichert gelten muss, steht außer Zweifel, dass Giovanni Andrea ihn für die Gestaltung der Karosse heranzog. Ursprünglich hatte Giovanni Andrea jedoch in Betracht gezogen, andere Künstler mit diesem Auftrag zu betrauen, unter anderem, weil Mailand und Rom damals als Wagenbauzentren weitaus etablierter waren als Genua. ${ }^{\text {I0 }}$ So hatte er zunächst an einem Mailänder Karossenentwurf Gefallen gefunden, bei dem sich Putten und Adler

d'arte 5 (Juni 20I2), S. 353-386. Die derzeit aktuellste biographische Skizze zu Filippo Parodi samt einer umfassenden Bibliographie findet sich in Daniele SANGUineti, Scultura genovese in legno policroma (Torino 2013), S. 432-435.

9 Orlando Grosso, Le carrozze a Genova. In: Genova 22/12 (I942), S. 2I f.; Piero Boccardo vermutete, dass sich in Anbetracht der Möglichkeit einer späteren Datierung des Blattes die Entwurfszeichnung auf einen anderen Tragsessel beziehen könnte. Farida Simonetti/Marzia Cataldi Gallo (Hg.), Farsi Portare in carega, Portantine e livree per la nobiltà genovese (Ausstellungskatalog, Genova 1995), S. 68 f., Nr. 23. Laura Stagno räumt zwar ein, dass die Zeichnung später zu datieren sei, meint jedoch, dass sie sich trotzdem auf den Tragsessel von I67I beziehe, da dieser auch später noch von großer Bedeutung war. So wurde er etwa 1749 immer noch als das am besten geeignete Vehikel betrachtet, um Marie Louise Élisabeth de Bourbon, Herzogin von Parma, Piacenza und Guastalla, zum Wohnsitz der Doria zu geleiten. StaGno 2007 (wie Anm. I), S. I5I; Stagno 20II (wie Anm. 2), S. 74, Anm. I07.

StAGno 2007 (wie Anm. I), Anm. 42: ADP, scaffale 79.62.I, Registro delle lettere per Roma composte dal Principe mio signore: Giovanni Andrea schreibt, „in quanto alla carrozza o sia disegno di essa, desidero sia leggera, di grandezza mediocre, di luoghi sei, e vaga al possibile. In quanto al luogo di fabbricarla, non sono ancora risoluto, se debba elegger Milano, dove si lavora molto bene, o costi“. Ausgerechnet in Mailand wurden bereits 1626 für die Hochzeit von Giovanni Andrea II. und Maria Polissena Landi zwei Karossen zum Preis von 4200 Lire angekauft. Stagno 2007 (wie Anm. I), Anm. I4: ADP, Banc. 66.2. Laura Stagno stellte fest, dass neben der für das Haus Doria bestimmten Karosse für jene Zeit nur zwei weitere Beispiele von Wagenentwürfen ligurischer Künstler dokumentierbar sind, nämlich von Giovanni Andrea Carlone - aus dessen römischer Phase der I66oer Jahre, als er unter starkem Einfluss von Modellen Berninis stand - sowie von Baciccio, der I675 in Rom von der Familie Pamphilj den Auftrag für den Entwurf einer Karosse erhielt. Stagno 2007 (wie Anm. I), Anm. 44. 
Abb. 1: Entwurfszeichnung für einen Tragsessel. Anonymer Künstler, Genua, 1. Hälfte des 18. Jahrhunderts. Bleistift, Feder und Tinte auf Papier, 408 × 208 mm. Gabinetto Disegni e Stampe di Palazzo Rosso, Genua, Inv.-Nr. D3391. (C) Musei di Strada Nuova, Gabinetto Disegni e Stampe di Palazzo Rosso, Genua

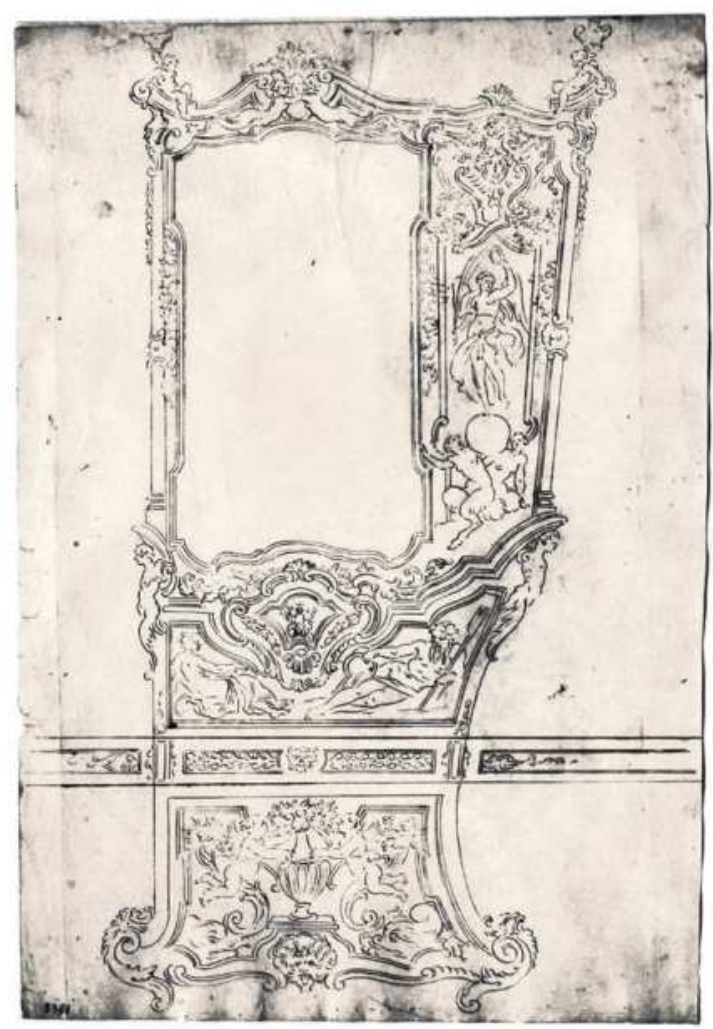

auf ansprechende Weise ineinander verschränkten. Schließlich fiel seine Wahl aber doch auf Parodi, der zu diesem Zeitpunkt schon über einen guten Ruf verfügte. Bereits in den I66oer Jahren hatte sich Parodi in Rom aufgehalten, um dort seine eigenen künstlerischen Fähigkeiten bei Bildhauern und Schnitzern aus dem Umkreis Berninis zu schulen. Er war deshalb der beste Garant dafür, dass die Karosse auch dem Vergleich mit Fahrzeugen standhalten konnte, die die römische Braut aus eigener Anschauung kannte. Bezeichnend ist in diesem Zusammenhang, dass sich der Vater der Braut, Camillo Pamphilij, wegen eines Wagenentwurfs an niemand Geringeren als Alessandro Algardi wandte. ${ }^{\text {II }}$

Laut Auftrag sollte Parodi eine Karosse „alla romana“ entwerfen, also in Form eines Triumphwagens, eines Modells, das bis dahin in Genua unüblich gewesen war. ${ }^{\mathrm{I2}}$ In $\mathrm{Zu}$ -

\footnotetext{
il Stagno $201 \mathrm{I}$ (wie Anm. 2), S. 63 f.; Stagno 2007 (wie Anm. I), Anm. 40; Magnani i988 (wie Anm. 2), S. I29.

i2 Stagno 201 (wie Anm. 2), S. 74, Anm. io8; ADP, scaffale 79.63, Compendio [...].
} 


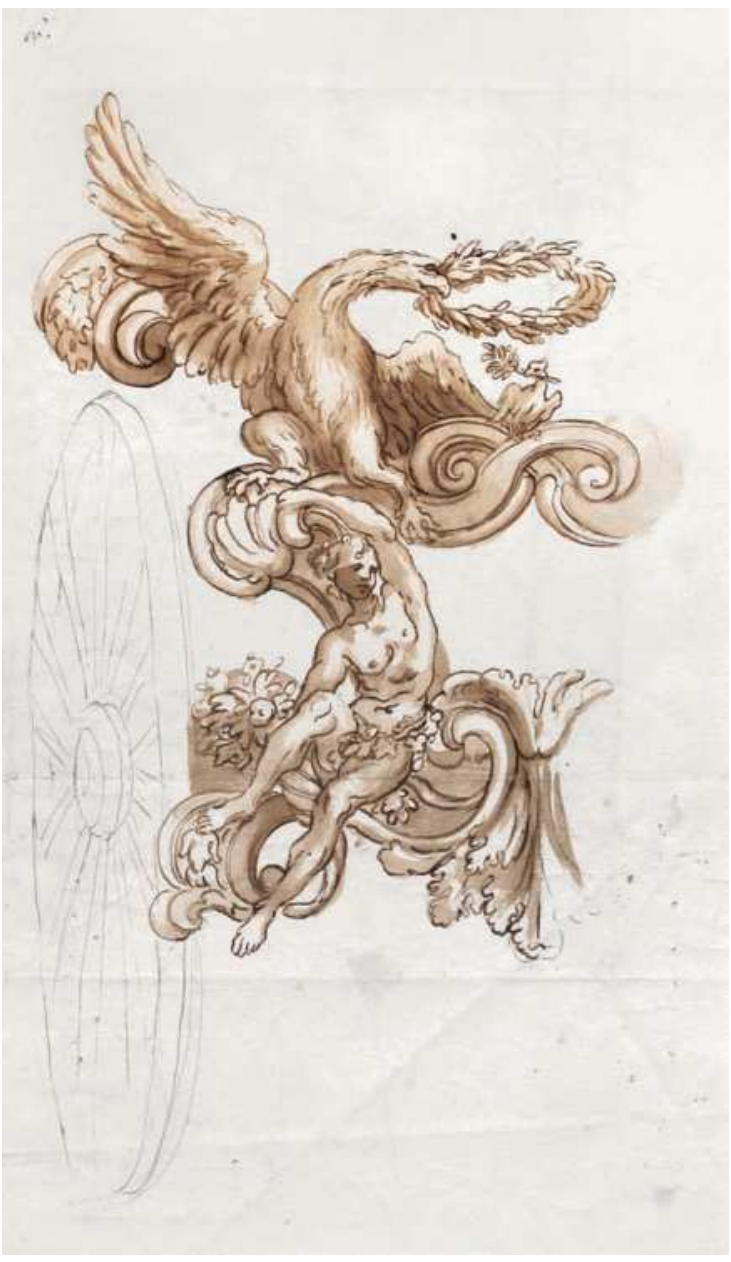

Abb. 2: Entwurfszeichnung für die Gestellbrücke einer Karosse. Anonymer Künstler, Genua, 1671. Bleistift, Feder und braune Tinte auf Papier, 552 × 207 mm. Gabinetto Disegni e Stampe di Palazzo Rosso, Genua. Inv.-Nr. 3393D. (c) Musei di Strada Nuova, Gabinetto Disegni e Stampe di Palazzo Rosso, Genua

sammenhang mit dieser Karosse steht eine andere Zeichnung ${ }^{13}$ (Abb. 2), die sich im Gabinetto Disegni e Stampe di Palazzo Rosso in Genua befindet und die Orlando Grosso erst Gregorio de Ferrari und später Filippo Parodi zuschrieb, der gemäß den Schriftquellen ja auch als Schöpfer des Brautwagens gelten kann. In jüngerer Zeit äußerte Piero Boccardo jedoch die Ansicht, Domenico Piola zeichne für die Entwurfszeichnung verantwortlich.

I3 Gabinetto Disegni e Stampe di Palazzo Rosso, Inv.-Nr. 3393D, Bleistift, Feder und braune Tinte auf Papier, 552 x $207 \mathrm{~mm}$. Alvar Gonzalez-Palacios betonte, dass bei einer Zuschreibung der Zeichnung jener Satz im „Compendio [...] " zu berücksichtigen sei, dem zufolge die Zahlung "per una carrozza di disegno di Filippo Parodi" erfolgt sei, womit suggeriert werde, dass sowohl der Entwurf als auch die Schnitzerei von Parodi stammten. Alvar Gonzalez-Palacios, Il mobile in Liguria (Genova I996), S. 95. 
Piola war nicht nur ein anerkannter Künstler, sondern auch Gregorios Schwiegervater, und Parodi vertraute ihm häufig die graphische Umsetzung eigener Ideen an. ${ }^{14}$ Die Zeichnung dokumentiert den atemberaubenden Entwurf für die Rückseite einer Karosse, mit Emblemen beider Adelshäuser, Adler und Taube, beide ineinander verschlungen und derart auf die prestigeträchtige eheliche Verbindung verweisend. Die in das Medium der Skulptur übersetzten Vögel waren gewiss vergoldet und verwandelten die Karosse zu einer prachtvollen Machtdemonstration auf Rädern, die die hohen Kosten von 9494 Lire, die am Io. Oktober I67I beglichen wurden, zweifellos rechtfertigte. ${ }^{\text {Is }}$

Liest man die von Merli wiedergegebene Beschreibung des Fahrzeugs, ${ }^{16}$ lässt sich erahnen, welch großes Staunen die Karosse wohl bei den Augenzeugen hervorrief:

[...] con diverse figure scolpite con tanta diligenza e in atto così naturale che paiono persone dorate, alle colonne stanno abbracciati putti che tengono in mano ghirlande di fiori così distinti e fatti al naturale che sembrano che non v'è cosa da correggere, ed è opera del famoso scultore Filippo Parodi [...]. Al di dentro resta tutta coperta di velluto carmisino, li sedili con suoi cuscini, bandinelle e di sotto il cielo circondati di tela d'oro molto ricca e vaga; la parte di sopra coperta di velluto simile al di dentro trinato d'oro abbondantemente, nelli lati ha 4 vasi di fiori di metallo dorato fatto a rame da perito artefice [...].

Eindruck hinterließen aber wohl ebenso die Kutscherlivreen sowie das Pferdegespann, das den Brautwagen nach Fassolo zog, wo sich die monumentale Residenz des Bräutigams befand:

[...] due bellissimi destrieri morelli generosi, guidati da un carrocciere vestito di panno verdone tutto trinato di trine d'oro.

I4 Piero Boccardo, Nota su Gregorio De Ferrari e Filippo Parodi: I progetti per la tomba del doge Francesco Morosini e alcuni inediti. In: Bollettino dei Musei Civici Genovesi 43-45 (gennaio-dicembre 1993), S. 39-52, hier S. 43 f. mit älterer Literatur.

I5 Marcello Fagioli, La festa a Roma dal Rinascimento al i870 (Torino I997), S. I82-I84; Magnani I988 (wie Anm. 2), S. 206 aus dem „Compendio [...]“.

i6 Merli i87i (wie Anm. 4), S. 17. Aus der Beschreibung geht hervor, dass die Karosse in Zusammenarbeit mehrerer Künstler entstand: Filippo Parodi aus Genua und der Römer Francesco Conti zeichneten für die Textilien verantwortlich; die Metallornamente schuf Filippo Fanelli, der am Kreuz der Kirche in Carignano mitgearbeitet hatte und vielleicht auch als Schöpfer der seitlichen Engel am Altar von Puget in der Kirche San Siro gelten kann, und den Kasten stellte schließlich Gio Antonio Pavia, der Stellvertreter von „Maestro Ambrioso“, her. Vgl. StaGno 2007 (wie Anm. I), Anm. 55: ADP, scaffale 79.63, Compendio [...], fol. I. 


\section{$2 \quad$ Weitere Tragevehikel des „goldenen Zeitalters“ Genuas}

Das im vorhergehenden Abschnitt behandelte Beispiel aus dem Jahr I67I ist natürlich nicht der früheste Beleg dafür, dass Mitglieder der Familie Doria prunkvolle Tragevehikel in Auftrag gaben: So bestellte etwa Giovanni Andrea (I540-I606), Gemahl der Zenobia Del Carretto, bereits 158I bei Gaspare Forlani aus Lucca ${ }^{17}$ eine Sänfte (lettiga). Forlani verpflichtete sich damals laut einer überlieferten Übereinkunft ${ }^{18}$ mit dem Haushofmeister Giovanni Pietro Ricardi nicht nur dazu, die ihm aufgetragene Handwerksarbeit zu erledigen, sondern darüber hinaus auch die zur Herstellung benötigten Gläser, Beschläge, das Holz und den Samt für die beachtliche Summe von insgesamt 40 Gold-Scudi zu liefern. Für die Bereitstellung von Seide, Leder, Wachsleinwand, Schnüren, Messingnägeln und für die Vergoldung sollte hingegen Ricardi selbst sorgen.

Gaspare Forlani war zu diesem Zeitpunkt bereits ein bekannter Schnitzer, dessen Fertigkeiten für verschiedenste Aufgaben, wie etwa für die Herstellung von Tabernakeln, Regalen, Kerzenständern, Hockern, Rückenlehnen, Truhen, Betten, Schmuckkästchen oder Bilderrahmen, ${ }^{19}$ herangezogen wurden. Dies belegen mehrere Schriftquellen, in denen Forlanis Beruf auf unterschiedlichste Art bezeichnet wird, etwa als „,bancalarius, faber lignarius, scultor lignaminum “ oder einfach nur als Bildschnitzer. ${ }^{20}$ Es waren Handwerker des Holz verarbeitenden Gewerbes, die mit der Anfertigung von Tragsesseln oder Sänften beauftragt wurden und die, wie auch dieser Fall belegt, an der Spitze einer Gruppe hochspezialisierter Handwerker mit unterschiedlichen Fachkenntnissen standen, die Techniken wie die fachgerechte Bearbeitung von Holz, die Bespannung mit Textilien oder das Anbringen von Beschlägen in Eisen oder vergoldeter Bronze umfassten.

Ganz deutlich geht dies aus einem Rechnungsbuch des Marcello Durazzo von I666 hervor, ${ }^{21}$ das einzelne Teilbeträge für die Herstellung einer Sänfte dokumentiert. Neben der

I7 Für biographische Informationen samt Literaturangaben siehe SANGUineTI 20I3 (wie Anm. 8), S. 407-4IO.

I8 Der vollständige Vertragstext ist abgedruckt in A[ntonio] MerL/L[uigi] T[ommaso] BeLgrano, Il Palazzo del Principe Doria (Genova 1874), S. 59.

I9 Von Forlanis vielfältiger Produktion sind heute leider nur Schnitzarbeiten an der linken Orgel der Kathedrale San Lorenzo in Genua sowie am I564 neu gestalteten Chorgestühl erhalten. Von seinen übrigen Tätigkeiten - so etwa auch von der Herstellung der Sänfte - zeugen nur noch Schriftquellen. Vgl. Sanguineti 2013 (wie Anm. 8), S. I25-I29.

20 Ebenda, S. 407.

2I Farida Simonetti, „La nostra città non è per le carrozze“. Portantine e lettighe per le strette vie di Genova. In: Simonetti/Cataldi Gallo 1995 (wie Anm. 9), S. 8-38, hier S. 28: ADGG, 522 , Manuale di Marcello Durazzo, I666 Juni i: Für eine „letica di vacchetta nera, un paro di coperte per mule e le sue selle [...] L. 1787.9 / L. 93 per 5 vachette in peso / L. 233.15 per palmi 85 damasco cremesile a L. 55 il palmo / L. 38.10 per palmi 7 veluto cremesile a L. 5.20 / L. 48.5 al merzaro per seta / L. 29 al 
Arbeit eines Tischlers, der den höchsten Betrag erhielt, sind in dieser Quelle unter anderem auch die eines Schmieds, eines Glasers, eines Stickers und eines Goldschmieds belegt. Eine weitere Rechnung der Doria berichtet von einer anderen Zahlung an einen Tischler, genannt „Gio bancalaro“, für die Herstellung einer „carega“, die von vier Männern getragen wurde und sich damit von Sänften unterschied, für deren Gebrauch Maultiere zum Einsatz kamen. ${ }^{22}$ Ein Schnitzer namens Domenico Steccone erhielt hingegen eine Zahlung für die Herstellung eines neuen Kastens für die „bussola“ der „signora marchesa“. ${ }^{23}$

\section{Terminologische Aspekte und Ausstattungsvarianten}

Wie einige bereits erwähnte Dokumente zeigen, wird in den Quellen zwischen mehreren Typen von Tragevehikeln unterschieden, nämlich zwischen der „lettiga“ (Sänfte), die meist von Maultieren, zuweilen aber auch von „Sklaven“ getragen wurde, der „cadrega“, die mittels Holmen von meist zwei, manchmal aber auch vier Männern transportiert wurde, und schließlich der „bussola“, ein Terminus, der laut Merli erst aufkam, nachdem Tragsessel mit Gläsern versehen worden waren, und der für jene Vehikel Anwendung fand, für die sich später die Bezeichnung ,portantina“ durchsetzen sollte. ${ }^{24}$

Als „bussole“ und „lettighe“ wurden beispielsweise jene Tragevehikel bezeichnet, die der „bancalaro“ (Tischler) Giovanni Fiorentino im Dezember 1590 für den kurz zuvor Witwer gewordenen Giovanni Andrea Doria schwarz ausschlagen musste, damit dieser in der

recamadore [Sticker] per pendone / L. I5.4 per palmi panno rosso / L. 467.13 per chiodi numero ... a prezzo ... l'uno e per indorar ferri / L. 4.26 per la stampa di essi / L. I02 per il pomo cioè L.72 a Gioachino orefice [Goldschmied] e L. 30 per 3 zechini / L. 44 al ferraro [Schmied] per ferri / L. 9 al vedraro [Glaser] per vetri / L. I2 per intaglio del cielo / L. 33 per indorarlo e dipingere l'arma / L. I6.4 al sellaro [Sattler] per li cossinetti di veluto / L. 6 per un paro di stanghe / L. Is3 al falegname [Tischler] per legname, fattura, et altre spesette / L. 47.3 per palmi I7 di panno per coperte delle mule a L. 25 la canna / L. 23.2 per 8 palmi panno rosso / L. 7.3 per palmi 26 tela larga per fodra di esse / L. 36.9 per frange e fenoggietto per esse / L. I4 per sete e filosella per ricamare / L. 20 al ricamatore [Sticker] per sua fattura / L. 50.8 per sei para di fiocchi per le testere / L. I6.I6 per fattura di esse / L. 266 al sellaro [Sattler] pelle nuove e fattura delle coperte."

22 ADP, Banc. 75.5, Libro di cassa, anni I579/80, c. I8, August I: „n. I05. per $£ 69.2$ pagate a m.o Gio bancalaro per le spese per manifatura della carega da portarsi da quattro homini".

23 ADP, Banc. 75.21, Manuale di cassa I7IO in I717, cc. n.n., I715 Mai 25: Dokumentation einer Zahlung von,$£ 295[\ldots]$ a Domenico Steccone intagliatore per lavori diversi da esso fatti d'ordine del sig. marchese n.ro". Darunter findet sich unter anderem zitiert: „scaffo nuovo di bussola per la signora marchesa".

24 Merli 187I (wie Anm. 4), S. 24, Anm. 6: „intorno al I588, aggiuntivi i cristalli, furono fatte eleganti quanto le letiche, e tosto presero il nome di bussole“. 
Trauerperiode über ein passendes Vehikel verfügte. ${ }^{25}$ „Carreghe“, also einfache Tragsessel, finden sich hingegen schon im Nachlassinventar des 1560 verstorbenen Andrea Doria. In diesem Inventar sind im Anschluss an verschiedene Maultiergeschirre (aus Gold- oder Silberstoff, Brokat und schwarzem Samt mit Gold- oder Silberfransen), die zu Sänften gehörten, insgesamt acht „carreghe“ aufgelistet, darunter eine „con sua spalletta coperta di veluto da donna con li pomi di lettoni indorati“, eine andere „ricamata a la granatina coperta di velluto verde“, eine weitere "del signor principe ornita di veluto verde con la spalla alta" und schließlich eine „carega alla medesima foggia coperta di velluto giallo“. ${ }^{26}$ Es wurde auch eine „carega“ aufgeführt, an der Pippo Santacroce ${ }^{27}$ im Jahr 1592 für 88 Lire Schnitzarbeiten verrichtete, die Adler, Wappen und Trophäen zeigten. Verwendet wurde dieses Vehikel von Giovanna Colonna anlässlich ihrer Vermählung mit Andrea II., dem Erstgeborenen des Giovanni Andrea Doria. ${ }^{28}$

All diese Tragevehikel scheinen nicht mit Gläsern verschlossen gewesen zu sein, auch wenn verglaste Transportmittel offenbar spätestens seit 1569 in Gebrauch standen, als der spanische Botschafter Gomez Suares de Figueroa eine „carrega“ mit „tribus vitre“ ${ }^{\text {“29 }}$ in Auftrag gab. Schon wenige Jahre später weist eine weitere Quelle auf die Existenz von verglasten Tragsesseln hin: 1588 erging ein Zahlungsauftrag der Doria an Lorenzo Brondo für „n. 9 cristalli a lire due l'uno per tre cadreghe a brazze“"30, wobei wir davon ausgehen können, dass an jedem Vehikel zwei Gläser an den Seitenwänden und ein Glas an der Frontwand des Gehäuses eingesetzt waren.

Eine indirekte Bestätigung dafür, dass „careghe“ geschlossene Passagierkästen aufwiesen, gibt auch ein Inventar von Giovanni Andrea I. von 1606, in dem unter der Rubrik „Textilien“ neben der inneren und äußeren Ausstaffierung eines derartigen Vehikels auch

25 Luigi Levati, I dogi di Genova e Vita genovese (dal I746 al I77I) (Genova I9I5), S. 287.

26 Boccardo 1989 (wie Anm. I), S. I69. Die komplette Transkription des Inventars findet sich ebenda, S. I65-175; ASG, Notar Agostino Lomellini Fazio, filza I4, anno I56I, n. 503, Inventarium rerum bonorum arnensium et suppeletilium Palaccij Ill.mo D. Andree D'Oria [...].

27 Sanguineti 2013 (wie Anm. 8), S. 446-448: Santacroce, ein Schnitzer aus Urbino, aktiv in Genua zwischen 1569 und seinem Tod im Jahr 1607, war insbesondere für seine feinen Korallen- und Elfenbeinschnitzereien bekannt. Zu seinen zahlreichen dokumentierten Arbeiten zählen unter anderem die Schnitzereien, die er in Zusammenarbeit mit Gaspare Forlani für eine neue, im Auftrag von Giovanni Andrea Doria entstandene Galeere schuf. Vgl. GonZalez-Palacios 1996 (wie Anm. I3), S. 44.

28 Levati i9is (wie Anm. 24), S. 287.

29 ASG, Notar Gio Andrea Monaco, scaffale 2799, n. 6, Inventario dei beni di Gomez Suarez de Figueroa, unter dem Schlagwort „,cadreghe“, in: SimonetTi 1995 (wie Anm. 2I), S. I2.

30 Merli 187I (wie Anm. 4), S. 26, gibt wieder, Brondo „aveva allora fatto in san Matteo l'occhio di vetri dipinti con quattro grandi arme ed un fregio di palmi quaranta, largo palmi uno e mezzo"; zit. nach Simonetti 1995 (wie Anm. 2I), S. I2. 
ein Himmel („cielo“) angeführt ist, also die Bedachung des Tragsessels. ${ }^{3 \mathrm{I}}$ Eine genaue Beschreibung liefert auch Fynes Moryson, der anlässlich eines Aufenthalts in Genua im Jahr I594 zu den dort verwendeten Tragsesseln bemerkte:

The chaires called Seggioli, whereof I spake in the discription of Naples, are also in use here, in which the Citizens of both sexes are carried upon two Porters shoulders, through the streetes lying upon the sides of hils, the chaires being covered with a curtaine drawne, and having glasse windowes, so as they may see all men, and themselves be unseene. Besides, in regard of the narrow streetes, and the steepe mountaines on all sides, they use horse litters here in stead of Coaches. ${ }^{32}$

Wenig später, gegen Ende des Jahres I599, machte der württembergische Hofbaumeister Heinrich Schickhardt (I558-I635) im Zuge einer Italienreise in Genua halt. In seiner Reisebeschreibung, die I602 im Druck erschien, vermerkte er mit spürbarer Verwunderung, dass das Transportwesen in Genau ganz anders funktionierte, als er das gewohnt war. Eine besondere Rolle nahmen dabei Tragsessel ein, die er wie Moryson einer recht genauen Beschreibung würdigte:

Ob nuhn woll dise Gassen Rein unnd Sauber gehalten werden so seind sie doch so schmal / das offt einer / wegen deß Volcks getrenge / schwerlich mit einem Pferd / durch kommen mag / dann sie seind gemeinglich nicht uber vier / oder 5. Schrit brait. Kein Wagen oder Karren wird in dieser Statt gesehen / sondern es werden alle Wahren / wie auch das Brenholz / so woll in der Statt alß auff dem land / auff Mauleseln unnd Pferdten geführt. Schwäre läst / alß lange Zimmerhöltzer / grosse Gütter Ballen / volle Faß / unnd dergleichen / werden gemeinglich durch 6. 8. Io. oder 20. Personen / nach dem der Last groß ist / getragen. Da alwegen 2. oder 4. ein stangen / an welche der Last / mit Sailern gehenckt

3I "Una coperta di panno negro per una carrega con una sola cortina tutta attacata col cielo fodrata di taffetà nero con due altre cortine nere una di damasco, l'altra di taffetä“. ADP, scaffale 77.50.I, Inventario dell'Heredità lasciata dal sig. Prencipe Gio: Andrea Primo - 1606, c. I03r. Aufgelistet sind außerdem: „Una carrega a cubba di veluto morello fodrata di taffetà morello con sua frangia e frangetta attorno in pezzi sette / Una carrega di feltro turchino di pezzi sette semplici / Una carrega di feltro morella con tutti suoi fornimenti da braccie con suoi [...] e fenogetto attorno di dentro è di veluto turchino in pezzi $n^{\circ}$ cinque / Sei cortine di carrega di veluto turchino fodrate di taffetà cioè le tre con sua frangia, et le altre senza con sue gassette / Una cortinetta di veluto morello fodrata di taffetä“. Ebenda, c. IO3r-v.

32 Fynes Moryson, An Itinerary Containing His Ten Yeeres Travell through the Twelve Dominions of Germany, Bohmerland, Sweitzerland, Netherland, Denmarke, Poland, Italy, Turky, France, England, Scotland \& Ireland, Bd. I (London I617, Nachdruck Glasgow 1907), S. 360. 
/ auff der Achsel tragen / mögen durch solche Mittel / ein grossen Last geschwind fortbringen. Was vermögliche Leuth sind / es seyen Weib oder Manspersonen) gehen nicht vil auff der Gassen / sonder lassen sich / in darzu gemachten Sesseln / welche inwendig mit gefarbtem Atlaß / oder Samat / außwendig aber / mit Gruen oder Schwartzem Tuch / wie ein Senffte / ubertzogen und bedeckt seind / von zweyen Männern in der Statt hin unnd wider getragen / die seind mit Thürlen eintweder gantz beschlossen / oder an etlich orten offen gelassen / haben auff all vier Seiten / schöne durchsichtige Glässer / dardurch sie / was inen begegnet / sehen mögen. Es lassen sich auch etliche in schönen Senfften / darin zween Maulesel gesetzt / also in der Statt hin unnd wider führen. Eins theils habens im brauch / in der Statt hin unnd her / ettwan auff Pferdten / etwan auff Mauleseln /ettwan auch woll zween auff einem Thier zureiten. ${ }^{33}$

In der handschriftlichen Version dieser Reisebeschreibung setzte Schickhardt an entsprechender Stelle an den Rand zwei Federzeichnungen (Abb. 3), die in der gedruckten Fassung nicht wiedergegeben sind. Die obere der beiden Skizzen zeigt zwei Männer, die mit Hilfe einer Tragstange einen Gegenstand befördern, die untere einen von zwei Männern transportierten Tragsessel. Es handelt sich dabei um die äußerst seltene Darstellung eines genuesischen Tragsessels aus solch früher Zeit. Das Passagiergehäuse ist mit einer tonnengewölbten Bedachung versehen und weist einen relativ kleinen, verhängbaren Seiteneinstieg auf. Auf der Vorderseite und an der Längsseite des Passagierkastens sind kleine rechteckige Fensteröffnungen dargestellt, die wir uns entsprechend der zitierten Beschreibung Schickhardts verglast vorstellen müssen.

Die für die Topographie Genuas so typischen engen Straßen waren gewiss ausschlaggebend dafür, dass sich Tragsessel gerade hier mit großem Erfolg durchsetzten. In der Stadt entwickelte sich ein lokales Gewerbe, das sich der Herstellung dieser Vehikel widmete, die im Unterschied zu den häufig auswärts angekauften Karossen zu den Exportgütern Genuas zählten. Merli berichtete etwa, dass die Verbreitung der mit Gläsern versehenen „bussole“ in anderen Ländern ursprünglich von Genua ausging beziehungsweise dass die

33 Heinrich Schickhart von Herrenberg, Beschreibung einer Reiß, welche [...] Friderich Herztog zu Würtemberg unnd Teck, [...] im Jahr 1599 [...] auß dem Landt zu Würtemberg, in Italiam gethan (Mömpelgard I602), S. 30 f. In der erhaltenen Handschrift des Reisetagebuchs ist diese Passage zwar nicht wortgleich, aber inhaltlich weitgehend identisch. Eine interessante Abweichung ist, dass bei der Beschreibung des Inneren des Tragsessels im Manuskript von ,atlas tuch wol mit rotem samat" die Rede ist. Stärker betont ist in der Handschrift auch die Tatsache, dass in Sänften - im Unterschied zu Tragsesseln - zwei Personen befördert werden konnten: „Andre, es seien weib oder man, haben solche senfte, darin ir 2 sizen megen, sezen 2 maulesel darin, [...]. "WLB, Handschriften, Cod. hist. qt. I48, b, fol. 6r. Den Hinweis auf diese beiden Quellen verdanke ich Mario Döberl. 


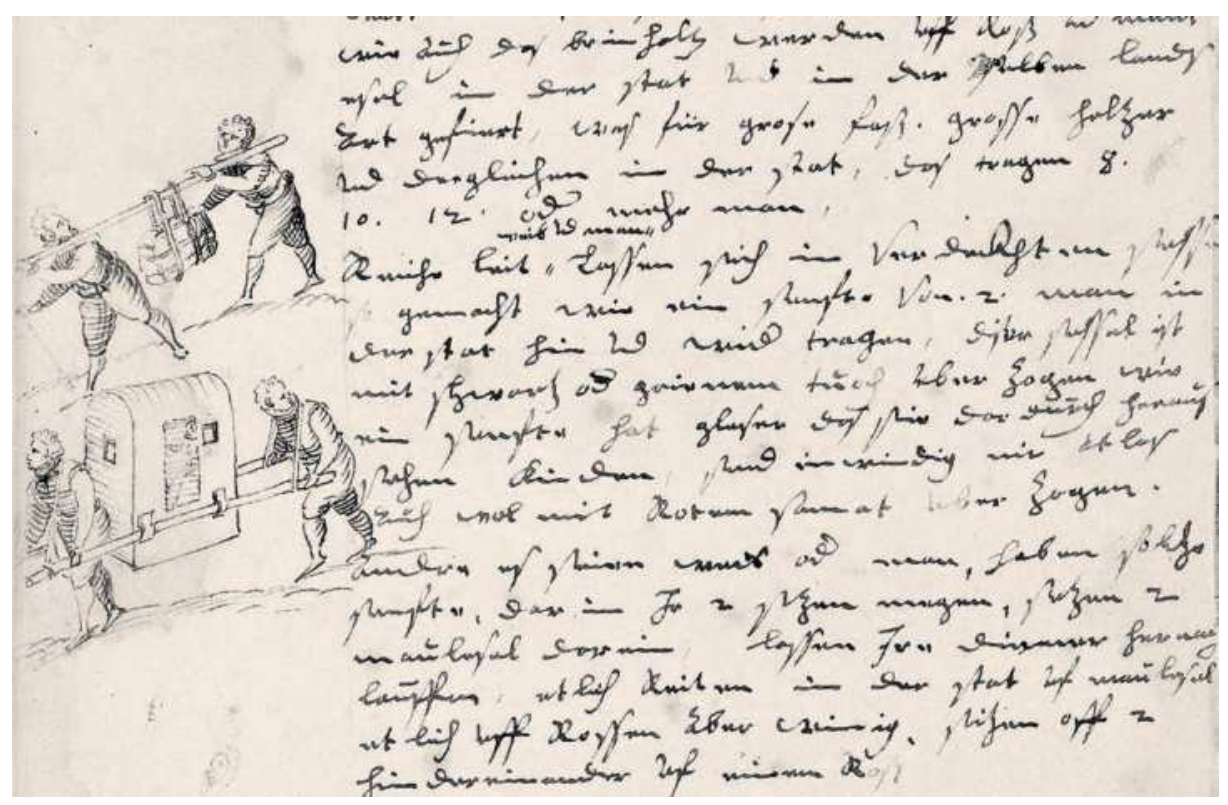

Abb. 3: Heinrich Schickhardt, Federzeichnungen einer von zwei Männern beförderten Tragstange und eines genuesischen Tragsessels samt Sesselträgern, 1599. WLB, Handschriften, Cod. hist. qt. 148, b, fol. 6r. (c) WLB

in Genua hergestellten Tragevehikel von besserer Qualität als andernorts gewesen seien. So wurden 1599 im Auftrag von Giovanni Andrea, dem Bräutigam Polissena Landis, zwei mit violettem Samt ausgeschlagene „bussole“ in Genua angefertigt, von denen er eine zum Herzog von Miranda nach Spanien und die andere, die für die Gräfin von Lemos bestimmt war, nach Neapel schicken ließ. ${ }^{34}$ Wie dieses Beispiel zeigt, galten derartige Vehikel demnach als bestens geeignete Geschenke für sozial hochstehende Persönlichkeiten, auch solche im vizeköniglichen Rang.

Wie bereits erwähnt, handelte es sich bei den Karossen Genuas häufig um „Importprodukte“. Dies demonstriert beispielsweise der Fall von Giovanni Andrea Doria, der sich 1579 eine Karosse samt zwei Pferden aus Prag bringen ließ. Dieser Transport wurde von zwei „Deutschen“ begleitet, die nach ihrer Ankunft in Genua in Giovanni Andreas Dienste übertraten. Ein anderes Beispiel betrifft Kardinal Ascanio Colonna, der 1592 auf dem Seeweg in Genua eintraf und für die Einfuhr einer Karosse Zollgebühren in der

34 Merli i87i (wie Anm. 4), S. 26, Anm. 6; Merli/Belgrano i874 (wie Anm. i8), S. 59. Der Herzog von Miranda war Juan de Zúñiga Avellaneda y Bazán, Vizekönig von Neapel zwischen 1586 bis I595, während die Gräfin von Lemos die Gemahlin des zwischen I599 und I60I amtierenden Vizekönigs von Neapel war. 
Höhe von 47 Lire bezahlen musste. ${ }^{35}$ Aber auch noch weitere Fälle belegen, dass Karossen häufig außerhalb Genuas beschafft wurden: Anlässlich der Hochzeitsvorbereitungen von Giovanni Andrea II. Doria und Maria Polissena Landi im Jahr I627 erscheint in Quellen des Vorjahres, die eine Generalüberholung von Ausstattungsgegenständen für das Brautpaar dokumentieren, unter anderem der Ankauf von zwei Karossen in Mailand zu einem Gesamtpreis von 4200 Lire. ${ }^{36}$ Im Jahr 1678 lieferte ein Mailänder Sattler eine neue Karosse an Ridolfo Brignole, wobei sich ein „deutscher“ Sattler um einzelne Materialien und Schmuckelemente wie Leder, Spiegelgläser und Borten kümmerte. Und schließlich kehrte Anton Giulio Brignole 1699 von seinem Romaufenthalt mit einer Karosse nach Genua zurück, die vergoldete Ornamente, Samtpolster, Damastvorhänge, Fiocken und Posamenteriearbeiten aufwies. ${ }^{37}$

Wo auch immer sie hergestellt sein mochten, Karossen, Sänften und „bussole“ - also Tragsessel - fehlten fast nie in den Inventaren des Genueser Adels. Aus dem I668 angelegten Nachlassinventar von Giovanni Andrea III. Doria († I654 ${ }^{38}$, dem Vater von Giovanni Andrea, der den vorerwähnten Tragsessel sowie eine Karosse in Auftrag gegeben hatte, geht etwa hervor, dass er neben zwei Karossen, von denen eine aus Loano stammte, einer Sänfte sowie drei Pferdesätteln auch neun „bussole“ besessen hatte. Letztere waren von grünem oder von karmesinrotem Samt oder aber auch in Schwarz gehalten, geschmückt mit Goldborten und im Inneren mit goldbordiertem Atlas in leuchtend roter Farbe ausstaffiert. Zudem wiesen sie auf ähnliche Weise gearbeitete Vorhänge auf, und in ihre Türen waren Kristallgläser eingesetzt. Andere „bussole“ waren wiederum mit grüner Wachsleinwand bespannt. Die Sänfte war außen schwarz und innen mit goldenem und karmesinrotem Brokat ausgestattet. Von den beiden Karossen war die eine außen mit schwarzem Rindsleder bespannt und wies innen eine karmesinrote Samttapezierung mit Goldfransen auf. Die andere, aus Loano stammende Karosse war mit hochrotem Samt ausstaffiert.

Aus dem 1627 angelegten Nachlassinventar des zwei Jahre zuvor verstorbenen Giovanni Battista Spinola geht hervor, dass dieser sowohl eine Karosse, deren Tapezierung und Vorhänge aus blauem Damast gefertigt waren, als auch einen lederbezogenen Tragsessel („una

35 Merli hält bezüglich der aus Prag kommenden Karosse fest, dass sich auf Basis der von ihm eingesehenen Quellen zwar nicht mehr ihr Preis rekonstruieren lässt, dafür aber die Transportkosten von Prag nach Novi (39 Taler) und von Novi nach Genua (96 Lire für die Karosse und 45,40 Lire für Diener und Pferde). Merli i87i (wie Anm. 4), S. 27, Anm. io.

36 Stagno 2007 (wie Anm. I), Anm. I4: ADP, Banc. 66.2

37 Laura TAGLiaferro, La magnificenza privata. „Argenti, gioie, quadri e altri mobili“ della famiglia Brignole Sale, secoli XVI-XIX (Collana di saggistica 66, Genova I995), S. Ioo f.

38 ADP, scaffale 77.50.4, Inventario dell'heredità del Signor Principe Andrea Doria 3 zo fatto dalla Signora principessa Donna Violante Lomellina [die Ehefrau] in atti del notaio Gio Stefano Ameglio I668 [† I654], Lettiche, carrozze, bussole et altro. 
bussola di coiro") besessen hatte. ${ }^{39}$ Sein Sohn Giovanni Maria Spinola konnte hingegen I666 neben drei Karossen und zwei Sänften gleich vier „bussole“ sein Eigen nennen, von denen eine vergoldet und mit karmesinrotem Damast ausstaffiert war und eine Rundumverglasung mit kleinen Vorhängen aufwies. ${ }^{40}$

Es ist jedoch abermals das an Informationen so reiche Archiv der Doria, das uns die wohl ausführlichste Beschreibung eines Genueser Adelsfuhrparks bietet. Die in dieser Quelle angeführten Transportmittel sind jenen anderer lokaler Adelshäuser zwar durchaus ähnlich, übertrafen diese jedoch durch ihre außerordentlich reiche Ausstattung. Das "Inventario moderno della Cavallerizza di Fassolo" von i708 umfasst Karossen, Tragsessel, Sänften, Reitpferde, Zugpferde für Karossen sowie Maultiere für Sänften. Unter den aufgelisteten elf Fahrzeugen befinden sich so unterschiedliche Typen wie „carrozze, stuffe, forloni, stuffette“, eine „birba“ sowie eine „carrozzetta“. Außerdem beinhaltet das Inventar vier Tragsessel („sedie“) und drei Sänften. ${ }^{4 \mathrm{I}}$ Die ersten beiden der angeführten Tragsessel sind wie folgt beschrieben:

[...] sedia verde ha il carro o scafo guarnito di vacchetta nera al di fuori e di vacchetta rossa al di dentro suo cuscino parecchio, con parafango di vachetta nera [...] sedia color di cinere ha il scaffo parecchio, il cielo di vacchetta nera, e dentro dipinta di rosso, cuscino e spalera simile con suo scozzale di vachetta nera, quattro cortine di baracano e suoi cristalli ai fianchi.

Von den drei Sänften waren die eine „indorata col cielo di damasco cremesi con cuscinetti di veluto, con quattro cortine bianche di seta con finochietto rosso, al di dentro con spalera di

39 Roberto Santamaria, Palazzo Doria Spinola. Architettura e arredi di una dimora aristocratica genovese da un inventario del 1727 (Recco 20II), S. 264: 1627, X februarii, inventario o sia repertorio de beni mobili, gioie, ori, argenti ed altro lasciati dal q. magnifico signore Gio Battista Spinola, c. Ior. Gio Battista Spinola (1575-1625).

40 Santamaria 201 (wie Anm. 39), S. 254: I666, a 5 luglio si principia l'inventario delle robe di Genova del q. Gio Maria Spinola (1602-I666), Sohn von Gio Battista, c. 5 r: vier „bussole“ („Bussola di damasco cremisile lavorata d'oro con le sue cortine piccole e cristalli all'intorno n. I. / Bussola di vachetta fodrata di damasco verde guarnita di seta n. I. / Altra simile vecchia n. I. / Altra di tela incerata fodrata di damaschetto con sue cortine n. I"), drei Karossen (,n. I Carozza grande di vachetta rossa n. I e più cortine s. I Carozzino di vachetta rossa fodrato di damasco verde con le sue cortine di panno, il suo incerato e più altra coperta di tela verde") und zwei Sänften (,n. I. Lettica di vachetta nera fodrata di damasco cremesile con sue cortine e cristalli. I Altra di tela incerata verde fodrata di ormesino con le sue cortine").

4I ADP, scaffale 75.88, I708, Inventario moderno della Cavallerizza di Fassolo, cc. 46-50. Unter den Karossen findet sich unter anderem eine „carozza nuova tutta dorata fuori che il carro ha il fondo verde e dorato la cascia dorata con pittura et il lato di vachetta nera, interno veluto verde ricamata fiorami bianchi e colorati persico". 
veluto", die zweite "rossa della Signora Maria col cielo di damasco cremisi, cuscinetti di veluto con quattro cortine di damasco cremisi, al di dentro con spalere di veluto" und die dritte schließlich „col cielo di damasco cremisi, cuscinetti di veluto con quattro cortine di damasco cremisi, al di dentro con spalera di veluto".

Am häufigsten begegnen uns in den Inventaren Tragsessel, die an den Außenwänden mit schwarzem Rindsleder bezogen waren. Reisende, wie etwa Grosley im Jahr I676, bemerkten, dass die Genueser Tragsessel fast immer einen in recht grober Weise ausgeführten schwarzen Anstrich gehabt hätten und nur zu feierlichen Anlässen auch Tragsessel mit Vergoldungen und Spiegelgläsern zum Einsatz gekommen seien..$^{22}$ Schwarz war auch ein I658 erwähnter Tragsessel von Gaspare Carroccio, nämlich eine „bussola“ von schwarzem Rindsleder, ausstaffiert mit karmesinrotem Damast und versehen mit Posamenteriearbeiten, Bandwerk, Kristallgläsern, Stangen und Tragegurten. ${ }^{43}$ Ebenso von schwarzer Farbe war eine „bussola“ von Paolo Girolamo Pallavicino, die in einem Inventar von I680 aufgelistet ist. ${ }^{44}$ Auch mehrere Sänften waren mit schwarzem Rindsleder bezogen, wie etwa jene, für die Marcello Durazzo im Jahr I673 1789,9 Lire bezahlte. ${ }^{45}$ Auch wenn uns schwarze „bussole“ in den Schriftquellen besonders häufig begegnen, verdienen dennoch auch die fallweise vorkommenden grünen oder roten „bussole“ Erwähnung, wie etwa jene von Francesco Maria Imperiale, der neben einer „bussola“ in schwarzem Rindsleder auch eine andere besaß, die mit roter Wachsleinwand bezogen war ${ }^{46}$ oder jene in grüner Wachsleinwand, die 1658 im Eigentum von Giovanni Battista Raggi stand. ${ }^{47}$

42 Vgl. Gonzalez-Palacios 1996 (wie Anm. 13), S. 345.

43 ASG, Notai Antichi 8833, Notaio Giuseppe Celesia, Inventario di Gaspare Carroccio, 1658 April 24 , fol. 4 .

44 ADGG, Archivio Pallavicini, Doc. Diversi 2, I649-I702, I680 Oktober 26, Inventario de mobili, ori, argenti della casa di Ge e Rivarolo divisi fra Giovanni Francesco e Giuseppe Pallavicino in conformità del testamento del q. Paolo Girolamo Pallavicino: „una bussola nera L. 30 in guardaroba con bronzi e altro". Zit. nach Simonetti 1995 (wie Anm. 2I), S. 36, Anm. 5 I.

ADGG, Cartulare di Marcello Durazzo I658-1673, I673 November 22. Zit. nach SimonetTi 1995 (wie Anm. 2I), S. 36, Anm. 50.

46 ASG, Notar Giuseppe Celesia, scaffale I040, fol. 2, 1634 November 25, Inventario de mobili di casa che il Francesco Maria Imperiale [...] prese in casa a Genova e li portò in Novi: „Una letica di tela incerata rossa; un'altra di vacchetta negra bordata di dentro [...] tre careghe di vacchetta con arma; due bussole negre vecchie [...] una carrozza con suoi fornimenti e cortine di baietta rossa". Zit. nach Simonetti 1995 (wie Anm. 2I), S. 22 f. und 36, Anm. 48.

47 ASG, Notai Antichi 8333, Notar Giuseppe Celesta, 1658 November 4, Inventario di Gio Batta Raggi q. Antonio: „Lettiche Carrozza e Sedia: Una lettica buona di vachetta nera con bandinell.e di damasco cremesile, et sopra un leone dorato; Altra lettica di tela incerata usata; Altra lettica di vachetta assai vechia; Un carrozzino piccolo; Una carrega di tela incerata verde con bandinelle d'ormesino e coperta turchina buona e moderna". 
Tragsessel entwickelten sich - ebenso wie Sänften - im Laufe der Zeit in zunehmendem Maße zu beliebten Mitteln der Luxus- und Prachtentfaltung. Um Exzessen einen Riegel vorzuschieben, wurden Tragevehikel mehrmals Zielscheibe von Verordnungen. Da die darin festgelegten Bestimmungen oftmals publiziert wurden, sind jedoch große Zweifel an ihrer Durchsetzungskraft angebracht. So wurden etwa I666 sämtliche Karossen, Sänften und Tragsessel verboten, an deren Stoffen, Fransen, Ornamenten und Stickereien Gold oder Silber vorzufinden waren. Jene, die in Hinkunft noch hergestellt würden, durften zudem auch keine Ziernägel oder -knäufe aufweisen. Innerhalb der Stadtmauern waren außerdem ab Inkrafttreten der Bestimmungen nur noch Tragsessel erlaubt, an denen sich keinerlei Gold- oder Silberornamente oder überflüssige Ziernägel befanden. ${ }^{4}$ Bereits 1672 wurde erneut ein öffentliches Verbot ausgesprochen, das wiederum Karossen, Sänften und Tragsessel ins Visier nahm. Untersagt war nun der Einsatz von Vehikeln mit folgenden Eigenschaften:

[...] veluto e con ricami e ornamenti di bordatura, al di fuori, d'argento o d'oro e resti parimenti proibito l'uso di coperte alli muli con riccamo di bordatura esclusi però quelli de suddetti vasi e coperte de muli che Cesare Pallavicino avessero ad adoperarsi per servigio del serenissimo Duce con dichiarazione che non resti proibita l'indoratura di dentro alli legnami di deti usi già fabbricati che però non se ne possa far di nuovi se non con doratura piana. ${ }^{49}$

Im Jahr I680 wurde diesem Verbot hinzugefügt, dass die innere Ausstaffierung in Leder, Wollstoff, Stoffen aus mit Seide durchwirkter Wolle sowie in reinem Seidenstoff ebenso wie Vergoldungen an nicht geschnitzten Holzteilen geduldet seien. Auch würden Vehikel mit vergoldetem Schnitzwerk toleriert, so ihr Herstellungsdatum vor dem Erlass von 1672 liege. ${ }^{50}$

\section{$5 \quad$ Erhaltungskosten}

Es versteht sich von selbst, dass nicht nur für die Herstellung aufwendig ausgestatteter Prunkvehikel - im Jahr I586 musste Giovanni Battista Spinola für den Kauf einer „ca-

48 ASG, Archivio Segreto 2943, I580-1778.

49 ASG, Archivio segreto 2943, 1675: „[... [ si permette ancora nell'interiore l'indoratura de legni i quali per quelli che si faranno nell'avvenire dovranno esser piani, senza intaglio veruno, tollerandosi i vari già fabbricati, e posti in uso tali quali sono, ancorché fossero dorati con intagli“.

50 Merli i87i (wie Anm. 4), S. 34, Anm. iI; Simonetti 1995 (wie Anm. 2i), S. 20 und 36, Anm. 44. 
rega" mit grünen Vorhängen aus Seidentaft IO2 Lire bezahlen ${ }^{\text {II }}$-, sondern auch für ihre Erhaltung hohe Kosten anfielen. Als Andrea Spinola von Leuten, die bereits eine Sänfte besaßen, in Erfahrung gebracht hatte, dass die laufend aufzubringenden Gelder für ein solches Tragevehikel jährlich etwa Iooo Lire betrugen, klagte er über derart hohe Ausgaben. Wer eine Sänfte sein Eigen nannte, musste deshalb auch damit rechnen, häufig mit dem Wunsch konfrontiert zu werden, diese auszuleihen. ${ }^{52}$ Dass die Erhaltungskosten für Tragevehikel beträchtlich waren, findet auch in den Rechnungsbüchern ${ }^{53}$ von Adelsfamilien Bestätigung. Ein diesbezüglich wichtiges Zeugnis stellt das Rechnungsbuch ${ }^{54}$ der Maria Caterina Durazzo dar, in dem Jahr für Jahr ihre Ausgaben detailliert angeführt sind. Ihre Sänfte und ihre Karosse verursachten in den I680er Jahren per annum Kosten in der Höhe zwischen 800 und 900 Lire. Zum Vergleich seien hier auch andere Ausgabeposten für das Jahr I683 angeführt. Für die Waschfrau und für Seife wurden damals 203 Lire aufgewendet, für Getreide, den Mahlstein und den Ofen 668 Lire und für Wein für die Tafel und die Dienerschaft, eingeschlossen die dafür anfallenden Steuern, 834 Lire. Im Jahr I688 machte der Lohn für die gesamten Hausangestellten rund 919 Lire aus. Darunter befanden sich auch die Besoldungen für den Sänftenknecht Antonio Fasce (I44 Lire), jene für den Oberpagen Michele Campodonico (64 Lire) und jene für den Koch (152 Lire). Zu den regelmäßig angeführten Kosten, die von Jahr zu Jahr nur geringfügig variierten, zählten außerdem Zahlungen an den Spengler, den Polsterer („parasoliere“) und den Tischler („,bancalaro"). Hinsichtlich der Sänfte fielen zudem Kosten für den Unterhalt der Maultiere an: Hafer, Geschirre, Zahlungen an den Hufschmied, für die Stallmiete und schließlich auch für den Priester, der die Tiere segnete. Außerdem waren neben den Lohnkosten auch noch weitere Ausgaben für Pagen und Sänftenknechte zu berücksichtigen, unter anderem für die Dienerlivree, die aus Hut, Hosen, Rock, Schuhen und Strümpfen bestand. Gab es in der Familie einen Trauerfall, fielen zusätzliche Ausgaben an, denn in solchen Fällen erhielt nicht nur das Personal neue Trauerkleider, sondern es mussten auch die Tragsessel und Sänften schwarz bezogen werden.

5I AS, n. 40, Libro dei conti di Gio Batta Spinola q. Antonio, c. 38.

52 Zit. in Merli/Belgrano i874 (wie Anm. I8), S. 59.

53 Als Beispiel seien hier nur einige Ausgabeposten der Familie Brignole Sale angeführt: 1678 Dezember 3I: "L. 274.I4 per il fornimento pittura ed altre spese in partite 9 per carrozza nuova.“; I68I Dezember 31: „L. 2I per due coperte per le mule al ricamatore; L. 17.2 spese e fattura per cappelletto di letica“; 1685 Dezember 23: „L. 23.4 sellaro e bancalaro per lettica; L. 45 al letichiero per salario“. ASCG, Archivio Brignole, Libro di conti di Ridolfo Maria Brignole Sale 1678-I685, zit. nach SImonetti 1995 (wie Anm. 21), S. 36, Anm 34.

54 AS, n. 192, Libro delle spese fatte e delli denari havuti dopo la morte della signora Maria Catterina Durazza Adorna i682-I690, I682, zit. nach Simonetti I995 (wie Anm. 2I), S. 30. 


\section{Einsatzgebiete}

Zwar existieren zahlreiche Schriftquellen, die im Besitz von Genuesen befindliche Tragsessel und Sänften erwähnen, weit seltener sind jedoch Passagen in Chroniken überliefert, die uns eine Vorstellung davon geben, auf welche Art und zu welchen Anlässen diese Transportmittel im Alltagsleben oder bei feierlichen Ereignissen eingesetzt wurden. Ein Beispiel für die Verwendung einer Sänfte in zeremoniellem Rahmen datiert von I578, als Giovanni Andrea Doria eine solche nach Voltaggio entsandte, um darin den Herzog von Braunschweig zum Familiensitz der Doria in Fassolo bringen zu lassen. ${ }^{5}$ Auch Margarete von Österreich, die Braut des spanischen Königs Philipp III., wurde während ihres Aufenthalts in Genua am II. Februar 1599 in einer Sänfte von Sampierdarena nach Fassolo transportiert. ${ }^{.6}$

Eher familiären Charakter hatte hingegen die Verwendung eines Tragsessels, der bei der Hochzeit von Giovanni Cesare Pallavicino im Jahr 1583 zum Einsatz kam. Pallavicino ließ seine Braut in Begleitung zahlreicher Adeliger in einer „carega“ zum Ort der Eheschließung bringen. ${ }^{77}$ In einer Sänfte ließ sich wiederum Lorenzo Sauli am I3. Juni I60o zum Hochzeitsbankett seines Schwagers Paolo Doria befördern. ${ }^{8}$ Ein Beispiel für die Verwendung eines Tragsessels auf einer verhältnismäßig langen Strecke bietet die Reise der Zenobia Doria von Massa nach Genua im Jahr 1590. Die Dame wurde dabei von sechs Sesselträgern („,camalli“) getragen, die für ihren elf Tage dauernden Einsatz einen Lohn in der Höhe von 75,40 Lire erhielten. ${ }^{9}$

Dass Tragsessel auch abseits festlicher Ereignisse Verwendung fanden, zeigt sich unter anderem daran, dass in Hinblick auf Tragsessel immer wieder zum Maßhalten im alltäglichen Gebrauch aufgerufen wurde. Die von den Behörden der Republik ausgesprochenen Appelle richteten sich zuweilen an konkrete Personen, etwa an Mitglieder der Familie Doria, die angehalten wurden, davon Abstand zu nehmen, ihrer „bussola“ Reitknechte voran-

55 Merli i87i (wie Anm. 4), S. 24.

56 Laura Stagno, Sovrani spagnoli a Genova: apparati trionfali e „hospitaggi“ alla corte dei Doria. In: Piero Boccardo/José Luis Colomer/Clario Di Fabio (Hg.), Genova e la Spagna. Opere, artisti, committenti, collezionisti (Genova/Cinisello Balsamo [MI] 2002), S. 73-87, hier S. 83; Giulio Sommariva, „Coronationi“ e solenni esequie, visite e „segni di allegrezza“: il potere in scena alla corte dei dogi. In: El siglo de los genoveses (Ausstellungskatalog, Milano I999), S. I30-I37.

57 Edoardo Grendi (Hg.), Inventione di Giulio Pallavicino di scriver tutte le cose accadute alli tempi suoi (1583-1589) (Genova 1975), S. 2: „Gio Cesare Pallavicino invitò la sua sposa e fecegli un banchetto con 58 persone molto sontuoso e vi si ballò tutto il giorno".

58 Marzia Cataldi Gallo, Rosso, oro e nero: colori e simboli di potere nella Repubblica di Genova. In: El siglo de los genoveses (Ausstellungskatalog Genua, Milano 1999), S. 78-87. Merli i87i (wie Anm. 4), S. 24, Anm. 6. 
gehen zu lassen, da das Zeremoniell dies nur für Botschafter vorsehe. ${ }^{60}$ Tatsächlich wurden Tragsessel im Alltag aber selbst für kürzeste Wegstrecken benutzt. Bartolomeo Paschetti hielt I602 fest, dass sich die Damen Genuas stets in einer „carega“ tragen ließen. Hätten sie diese Transportmittel einst nur verwendet, um nahe der Stadt gelegene Dörfer zu erreichen, würden sie sie mittlerweile auch innerhalb der Stadt bei Kirchgängen und Besuchen bei Verwandten oder Freunden benutzen. ${ }^{61}$ Im Jahr 1582 wurden Damen pauschal verdächtigt, sie würden nur deshalb zu Tragsesseln greifen, weil sie derart abends unerkannt das Haus verlassen könnten, was jedoch verboten sei. Aus diesem Grund wurde im selben Jahr mittels Dekret sowohl Frauen als auch Männern untersagt, sich in den frühen Nachtstunden in einer offenen oder geschlossenen „carega“ transportieren zu lassen. ${ }^{62}$

Die Gewohnheit, sich innerhalb Genuas im Tragsessel zu bewegen, war so weit verbreitet, dass auch Personen, die über keinen eigenen Tragsessel verfügten, einen solchen an mehreren festgelegten Standplätzen der Stadt mieten konnten. Zu den autorisierten Haltestellen zählten verschiedene stark frequentierte Knotenpunkte Genuas, etwa der Platz gegenüber der Kathedrale San Lorenzo, weiterhin Soziglia, Campetto, die Strada Nuova, der Ponte della Mercanzia, der Ponte degli Spinola oder die Porte di Vacca. Die Tarife, die je nach Distanz zwischen I und 4 Lire lagen, wurden alljährlich öffentlich bekannt gemacht, wobei zwischen dem Preis für die Sesselträger und jenem für die Miete des Tragsessels selbst unterschieden wurde. ${ }^{63}$

\section{Straßen- und Verkehrsverhältnisse}

Die Topographie Genuas ist von äußerst engen Gassen geprägt, was die Verbreitung von Tragsesseln offensichtlich stark beförderte. Dies unterstrich auch Hester Lynch Piozzi, die I789 über Genua schrieb:

60 ASG, Politicorum I663.17, 47, i689 Juli I8. Zit. nach Simonetti 1995 (wie Anm. 2I), S. I6 und 36, Anm. 39.

$6 \mathrm{I}$, „...] le nostre donne, [...] se non fussero cotanto vaghe di farsi portare in carega per ogni breve camino, che facciano [...]. Furono introdotte da principio nella vostra Città le lettiche, le seggiole invece dei cavalli, \& delle chinee, che usavano i vostri maggiori ne' tempi adietro per andar più agiatamente nelle ville discoste uno, ò due miglia dalla Città, ma hora si adoperano etiam dio per andare per la Città nelle Chiese, \& in visita di parenti, ò amici, \& l'usa hoggidi per certa vana grandezza ogni giovane donna, benche disposta, \& sana sia della pesona." Bartolomeo Paschetti, Del conservare la sanità e del vivere dei genovesi (Genova I602), S. I72.

62 Merli i87i (wie Anm. 4), S. 24; Grosso 1942 (wie Anm. 9), S. 23.

63 „[... intendendo però che per il porto di persone in bussola, ossia seggetta, si debba pagare il doppio fra tutti due li camalli e più soldi due per la piggione della bussola ossia seggetta". ASG, Arti, 176/32, Facchini, I624 August 28. Zit. nach Simonetti 1995 (wie Anm. 2I), S. 3I und 38, Anm. 88. 
The streets of the town are much too narrow for beauty or convenience - impracticable to coaches, and so beset with beggars that it is dreadful. A chair is therefore, above all things, necessary to be carried in, even a dozen steps [... ${ }^{64}$

Ähnliche Beobachtungen finden sich auch in älteren Reisebeschreibungen. So hielt etwa Maximilien Misson im Jahr I688 zu Genua fest:

[...] les carosses ne roulent-ils pas communément dans Génes: les Dames vont en litiere; $\&$ les hommes de qualité, ont ou de chaises, ou de petites caléches qu'ils ménent eux-mesmes. ${ }^{65}$

Auch Richard Lassels hob in seinem 1680 posthum erschienenen Bericht einer Italienreise in einer Passage über Genua hervor, wie ungünstig die Topographie der Stadt für den Gebrauch von Kutschen sei und dass man sich deshalb mit Tragsesseln und Sänften behelfe, was den angenehmen Nebeneffekt habe, dass dies den Lärm in den Straßen verringere:

The Streets are very narrow; so that they use here few Coaches, but many Sedans and Litters. This makes the noise in the streets less $[\ldots] .^{66}$

Der intensive Einsatz von Tragsesseln und Sänften auf den Straßen Genuas hatte jedoch auch unerfreuliche Konsequenzen, nämlich ein zu chaotischen Zuständen führendes hohes Verkehrsaufkommen, besonders in bestimmten Zonen und zu bestimmten Tageszeiten. Als Reaktion darauf versuchten die Behörden mehrmals die Zirkulation von Tragevehikeln mittels Erlassen zu regulieren, was sich jedoch meist als aussichtsloses Unterfangen herausstellte. So wurde etwa im Jahr I622 der Aufenthalt von Sänften und Tragsesseln auf den zum Hafen und zur Küste Genuas führenden Brücken zu bestimmten Zeiten untersagt („suonate le ore $\left.23^{“ \prime}\right){ }^{67}$ Trotz dieses Verbots fühlte man sich aber noch 1674 bemüßigt, mittels Dekret den Menschenauflauf vor dem Ponte Reale zu zerstreuen, der sich immer dann bilden würde, wenn die Damen von der Anlegestelle zurückkämen. ${ }^{68}$ Der Ponte Reale

64 Hester Lynch Piozzi, Observations and Reflections made in the course of a journey through France, Italy and Germany (London I789), Bd. I, S. 60.

65 Maximilien Misson, Nouveau voyage d'Italie, avec un mémoire contenant des avis utiles à ceux qui voudront faire le mesme voyage (La Haye ${ }^{4}$ I7O2), Bd. 3, S. 36.

66 Richard Lassels, The Voyage of Italy, or a Compleat Journey through Italy (Paris I670), S. 85.

67 ASG, Archivio Segreto, Politicorum, n. 48, 1662 August 25 (zit. nach SimonetTi 1995 [wie Anm. 2I], S. I4): Decreto con cui si incarica il Sergente Generale di dare li ordini opportuni che trovandosi lettiche e portantine sulli ponti che guardano il mare suonate le ore 23 siano levate.

68 ASG, Archivio Segreto I660, Politicorum n. 55, I674 Juni 27, Relatione degli Inquisitori di Stato 
zählte zu den sensibelsten Stellen im Stadtverkehr, weshalb die Verwendung von Sänften an diesem neuralgischen Punkt mehrmals verboten wurde. Zur einfacheren Durchsetzung dieser Maßnahme wurde 1682 per Dekret bestimmt, dass am Ponte Reale zwei Marmorsäulen mit eiserner Kettenabsperrung zu errichten seien, damit die Sänften sich den dort postierten Wachen fortan nicht mehr über Gebühr näherten. ${ }^{69}$ Als Begründung für dieses Vorgehen wurde angeführt, dass am Ponte Reale allabendlich ein großer Tumult entstehe und dies eines Tages einen plötzlichen, folgenschweren Unfall provozieren könne. Die Zahl der Sänften, die sich stets vor dem Tor zur Brücke befänden, sei so groß, dass nicht nur den Passanten der Durchgang erschwert werde, sondern - was als weit schwerwiegender angesehen wurde - auch die Wachen bei ihrer Arbeit behindert würden. ${ }^{70}$

Die in späteren Zeiten erfolgte Etablierung und stetige Verbreitung von Fahrzeugen, die von Zugtieren bewegt wurden, führte zu neuerlichen Verboten, die den Gebrauch von Vehikeln in manchen Straßen der Stadt gänzlich untersagten, einerseits, weil die Gefährte den Bodenbelag beschädigten, und andererseits, weil sie eine große Gefahr für Kinder, Alte, Handwerker und andere Personen darstellten. ${ }^{71}$ Die leise und bedächtige Welt der Tragsessel und Sänften gehörte damals bereits der Vergangenheit an, und die zu Tage tretenden Probleme ähnelten zunehmend jenen, die uns heute der Autoverkehr beschert.

Übersetzung aus dem Italienischen: MARIO DöBERL

tendente a togliere gli inconvenienti che insorger potessero dall'ingombramento le lettighe e bussole avanti Ponte reale allorchè ritornano dal barcheggio.

69 ASG, Archivio Segreto, Politicorum, n. II9, I682 Juni 3, Provvidenza per impedire l'ingresso delle letiche sul Ponte Reale; ASG, Archivio Segreto, Politicorum, n. 52.

70 ASG, Archivio Segreto, Politicorum, n. 94, 1692 Januar 30, Esposizione de Padri del Comune circa le Grida da pubblicarsi per le colonnette di marmo da riporsi in diversi siti della città per impedire il passaggio delle carrozze, carri, etc per prevenire gli inconvenienti che ne potrebbero succedere.

7I "Avendo i Ser.mi Collegi considerato che l'introduzione fatta da più anni in qua dell'uso delle carrozze, calessi, sedie rolanti, carri et altroi con ruote, che ordinariamente sono guidati da bestie, portano grossi danni al pubblico perché distruggono e rovinano le strade e ancora mettono in evidente pericolo i fanciulli, vecchi, artigiani et altre persone di poter essere da essi calpestati“. Ebenda. 


\section{Zeremoniell, soziale Integration und Luxusgesetze: Tragsessel in der spanischen Monarchie des 16. und 17. Jahrhunderts}

1 Vorwort

Für Prof. Peer Schmidt (1958-2009)

Während eines 2006 absolvierten Studienaufenthalts am Forschungszentrum Gotha für kultur- und sozialwissenschaftliche Studien der Universität Erfurt entstand die Idee, ein Buch über die Geschichte der Tragsessel in Europa zu schreiben. Diesem Thema widmete ich auch einige Seiten meiner Dissertation, die sich allerdings nur auf die spanische Monarchie bezogen. Im Anschluss an meine Zeit in Gotha nahm ich schließlich ein auf mehrere Jahre anberaumtes und zum gegenwärtigen Zeitpunkt noch nicht abgeschlossenes Forschungsprojekt über Tragsessel in Angriff, für das ich zahlreiche Quellen aus europäischen Archiven sammelte. Der vorliegende Beitrag ist ein Teilergebnis dieser wissenschaftlichen Untersuchung und letztlich auch ein Resultat meines Forschungsaufenthalts in Gotha. Er sei dem viel zu früh verstorbenen Professor Peer Schmidt gewidmet, der mich bei der Erlangung eines Forschungsstipendiums tatkräftig unterstützte, mir während meiner Zeit in Gotha stets freundlich zur Seite stand und mich in meinen wissenschaftlichen Vorhaben ermutigte.

\section{$2 \quad$ Einleitung}

Im Laufe des 16. Jahrhunderts fand in Europas Machtzentren ein tiefgreifender Wandel der Transport- und Repräsentationsformen statt. Dieser Prozess war durch das Entstehen und die Verbreitung einer Reihe von Vehikeltypen charakterisiert, die die Art und Weise, sich in der Öffentlichkeit zu zeigen, sich zu bewegen und zu reisen, erheblich und langfristig verändern sollten. In den meisten fürstlichen und herrschaftlichen Marställen waren unterschiedliche Transportmittel vorhanden: Sänften, das heißt radlose, von Tieren getragene Vehikel, weiterhin Schlitten, die mit Kufen versehen sind und ebenfalls durch 
die Kraft von Tieren bewegt werden, des Weiteren Tragsessel, das heißt von Menschen beförderte Vehikel, die über keine Räder verfügen, und schließlich Kutschen, Karossen oder ähnliche mit Rädern versehene und von Tieren gezogene Transportmittel. Diese vier Grundtypen stellen in ihrer Gesamtheit das dar, was wir unter dem Begriff „repräsentative Vehikel“ zusammenfassen wollen. Mit dieser Bezeichnung soll ihre Doppelfunktion zum Ausdruck gebracht werden, nämlich einerseits Menschen zu transportieren und andererseits repräsentative Aufgaben zu erfüllen.

Ein wesentlicher Grundzug des erwähnten Wandels war, dass sich repräsentative Vehikel - vor allem aber Kutschen und Tragsessel - im i6. und I7. Jahrhundert an sämtlichen Höfen und in allen großen Städten Europas verbreiteten und damit die Fortbewegungsweisen und Repräsentationsformen der politischen und sozialen Eliten revolutionierten. Diese Entwicklung fand nicht vorrangig deshalb statt, weil die neuen Fortbewegungsmittel schöner und bequemer als ihre Vorgänger waren (obwohl das zweifellos ihre Verbreitung begünstigte), sondern vor allem, weil ihre Etablierung in eine Epoche fiel, in der die Fürstenhäuser ihre Machtbasis stärken konnten. Die Einführung repräsentativer Vehikel fand zu einem Zeitpunkt statt, zu dem die dynastischen Monarchien Europas neue Instrumente benötigten, um all jene Personengruppen, die Politik betrieben und Teil der Hofgesellschaft waren, deutlich von der Masse der Untertanen abzuheben. Mit repräsentativen Vehikeln besaßen Fürsten und Hofleute nun adäquate Mittel zur sozialen Differenzierung und Distanzierung. Sie ermöglichten nicht nur eine schnellere und bequemere Art der Fortbewegung und des Reisens, sondern führten darüber hinaus zu einer radikalen Transformation des Marstalls, insbesondere hinsichtlich seiner Zusammensetzung und finanziellen Ausstattung sowie seines Anteils am Hofzeremoniell und an der Hofetikette: Kurz, die Marställe entwickelten sich von mittelalterlichen zu neuzeitlichen Institutionen. Durch die Verwendung repräsentativer Vehikel entstanden neue Formen der sozialen Kontrolle und Regulierung. Sie beförderten die Integration politischer Eliten und halfen dabei, die Macht, den Reichtum und den sozialen Status ihrer Besitzer zur Schau zu stellen. Die Ausbreitung von Kutschen und Tragsesseln, aber auch von Sänften und Schlitten lässt sich deshalb nicht von der Entstehung des Hofes als einer für die Gesellschaften der Neuzeit typischen Machtform trennen. Repräsentative Vehikel müssen daher für das I6. und I7. Jahrhundert als unverzichtbare Elemente der Fürstenmacht und als zentrales Attribut von Mitgliedern der höfischen Gesellschaft betrachtet werden.

Auf Basis dieser Überlegungen soll im Folgenden die Verwendung von Tragsesseln in der spanischen Monarchie für drei verschiedene Bereiche untersucht werden: Zunächst wird der Fokus auf die Einführung von Tragsesseln im Bereich des Königshauses selbst gelegt, wobei das Hauptaugenmerk auf die damit einhergehenden Änderungen im Hofzeremoniell gerichtet ist, im Besonderen auf Aspekte, welche die Königinnen und den Marstall 
betreffen. Anschließend soll erörtert werden, wie der Gebrauch von Tragsesseln seitens der Könige Vorbildwirkung für die gesamte höfische Gesellschaft entfaltete und wie sich diese Phänomene besonders ab Beginn des I7. Jahrhunderts in den verschiedenen Territorien der Monarchie ausbreiteten. Schließlich wird detailliert ausgeführt, wie man mittels einer spezifischen, vom Hof ausgehenden Gesetzgebung versuchte, diesen Prozess zu kontrollieren und den Gebrauch von Tragsesseln auf bestimmte soziale Gruppen zu beschränken: Nur wer Regierungsgewalt ausübte, einen entsprechend hohen sozialen Status besaß oder über die nötigen Beziehungen verfügte, sollte auch das Privileg genießen, Tragsessel zu benutzen. ${ }^{\text {. }}$

\section{3}

\section{Tragsessel im spanischen Königshaus}

Die Untersuchung des Gebrauchs von Tragsesseln im Rahmen des Königshauses hat zentrale Bedeutung, da ihm Vorbildwirkung für die gesamte höfische Gesellschaft zugemessen werden muss. Wir wollen deshalb zunächst die Verwendung von Tragsesseln durch die Monarchen selbst analysieren, uns anschließend ihrer Rolle im Hofstaat der Königinnen zuwenden und schließlich einen Blick auf ihre Funktion bei Taufen werfen. Die uns bekannten Informationen weisen darauf hin, dass die Etablierung von Tragsesseln in Spanien während der Herrschaft Karls V. vonstattenging, auch wenn sein Sohn, Philipp II., unter dessen Regierung das spanische Hofzeremoniell seine wesentliche Ausformung erhielt, weit intensiveren Gebrauch von ihnen machte. Was die Königinnen betrifft, so verwendeten sie Tragsessel zwar schon in den I56oer Jahren, von Relevanz wurde ihr Gebrauch allerdings erst um I600. Hinsichtlich des Zeremoniells wurde ihre Verwendung erst ab i620 definitiv formalisiert und blieb bis 1707 unverändert. Was die Verwendung von Tragsesseln bei fürstlichen Taufen anlangt, gehen wir davon aus, dass sich dieser Brauch im ersten Jahrzehnt des I7. Jahrhunderts etablierte und anschließend für lange Zeit Bestand hatte.

Wie bereits erwähnt, stammen die ersten Erwähnungen von Tragsesseln aus der Regierungszeit Karls V. ${ }^{2}$ Im Laufe der I55oer Jahre machte der Kaiser bei zahlreichen Gelegen-

I Zu Tragsesseln und Sesselträgern siehe Alejandro López Álvarez, Poder, lujo y conflicto en la Corte de los Austrias. Coches, carrozas y sillas de mano, I550-1700 (Madrid 2007), S. 565-616; Ders., Sillas de mano. In: Carlos Alvar (Hg.), Gran Enciclopedia Cervantina, bisher Io Bde. (Madrid 2005-20I7). Im Druck.

2 Für all jene, die mit der Genealogie der spanischen Habsburger nicht ausreichend vertraut sind, 
heiten von ihnen Gebrauch und griff damit auf ein Beförderungs- und Repräsentationsmittel zurück, das vielseitiger einsetzbar war als die bis dahin üblichen Sänften. Besonders während des Aufenthalts auf seinem Alterssitz im Kloster San Jerónimo in Yuste erlangten Tragsessel für die Beförderung Karls V. große Bedeutung. Der damals bereits stark gebrechliche Monarch bewegte sich in dieser seiner letzten Lebensphase nur noch in Ausnahmefällen selbstständig fort. Wie aus einem Schreiben seines Hofmeisters Luis Quijada an Juan Vázquez vom I2. November 1556 hervorgeht, benutzte Karl V. schon auf seinem Weg nach Yuste einen Tragsessel. Als er vor der Wahl stand, einen von zwei möglichen Wegen über die Berge nach Jarandilla zu nehmen,

entschied er sich für den kürzeren und unwegsameren. Er ist fest entschlossen, noch heute Jarandilla zu erreichen, das fünf Meilen schlechten Weges entfernt liegt. Seine Majestät wird die meiste Zeit über auf seine Sänfte verzichten und stattdessen im Tragsessel reisen müssen, denn er meint, dass ihm die Pferde nicht gut tun würden. Auf diese Weise spart er vier Tage gegenüber der flacheren Strecke. ${ }^{3}$

Aus der Zeit nach der Ankunft in Yuste häufen sich die Erwähnungen, dass Karl V. auch innerhalb der Klostermauern Tragsessel verwendete. Fray Hernando del Corral zufolge wurde er von zwei Edelleuten getragen und von Don Fernando Alvarez de Toledo, Duque de Oropesa, sowie von seinem Hofmeister Luis Quijada begleitet. ${ }^{4}$ Einer der Tragsessel ist auch im Nachlassinventar von Yuste angeführt. Im Abschnitt ,furriería" befinden sich „Zwei Sessel aus schwarzem Leder; auf den einen setzte sich Seine Majestät beim Essen, auf dem anderen, der über Tragstangen verfügte, ließ er sich hin und her tragen". Dazu waren „vier mit Federn gefüllte Ledersitzkissen“ vorhanden sowie ein „großes Lederpolster mit Gurten, womit Ihre Majestät auf Schultern getragen wurde“. Außerdem findet sich im

seien an dieser Stelle die Namen und Regierungszeiten der im hier behandelten Zeitraum herrschenden Monarchen angeführt: Kaiser Karl V. (I516-I556), Philipp II. (I556-I598), Philipp III. (I598-I62I), Philipp IV. (I62I-I665) und Karl II. (I665/I675-I700).

3 „[... le ha parescido escoger el más corto y más áspero, y ansi está determinado de llegar hoy a Jarandilla, que son cinco leguas de muy mal camino. Habrá S. M.tad de ir lo más fuera de su litera, en silla, porque dice que a caballo le haría mal, y ansi ahorra cuatro jornadas que habrá por el camino más llano". Louis Prosper GaChard, Retraite et mort de Charles-Quint au monastére de Yuste: lettres inédites d'aprés les originaux conservés dans les archives royales de Simancas, 3 Bde. (Bruxelles I854-I855), Bd. I, S. 38-4I, II9, I54, 217 und 316.

4 Fray Hernando del Corral, Historia breve y sumaria de cómo el emperador don Carlos V, nuestro señor, trató de venirse a recoger al monasterio de San Jerónimo de Yuste. In: Domingo SÁnchez Loro, La inquietud postrimera de Carlos V, 3 Bde. (Biblioteca Extremeña I7, Cáceres 1957-1958), Bd. 2, S. 7I-I54, hier S. 98. 
Inventar noch „ein kleiner, mit sayeta überzogener Lederkoffer, in dem der Feldsessel aufbewahrt wurde".

Aus all diesen Informationen lässt sich schließen, dass es sich bei den im Nachlassinventar erwähnten Tragsesseln um technisch anspruchlose Objekte in bescheidener Ausführung handelte. Dennoch brachten sie besonders für das Hofzeremoniell sowie für den Umgang mit dem Körper des Königs wichtige Neuerungen. Bemerkenswert ist zudem, dass die oben erwähnten Objekte der „furriería“ unterstellt waren, also jenem Amt, das unter anderem Möbel und anderen Hausrat verwaltete, und nicht dem Marstall, also jener kleinen Hofstaatsabteilung, in der sich während Karls V. Aufenthalt in Yuste mehrere Sänften befanden. ${ }^{6}$ Die Verwendung von Tragsesseln führte demnach zu keinen Änderungen im Bereich des Hofstaats, der nach Karls V. Rückzug aus dem öffentlichen Leben stark reduziert worden war. Offenbar wurden Tragsessel damals als eine Spielart von Möbeln betrachtet.

Am Hof Philipps II. nahm die Bedeutung von Tragsesseln in aufälliger Weise zu. Während seiner Regierung standen derartige Tragevehikel bereits in den Hofstaaten der Königinnen sowie bei den bedeutendsten Hofleuten in Gebrauch. Die Verwendung von Tragsesseln seitens des Monarchen selbst lässt sich nicht allein auf dessen gesundheitliche Probleme zurückführen, die ihn stark in seiner Bewegungsfreiheit einschränkten, sondern hat ihren Ursprung auch in seinem Interesse an symbolischer Selbstinszenierung. Dieser Aspekt lässt sich schon für das Jahr 1585 beobachten, als der König während eines Aufenthalts in Barcelona von Stadtvertretern mit mehreren Tragsesseln beschenkt wurde:

[...] um Seiner Majestät einen Gefallen zu erweisen, hatte [die Stadt] 48 auf eigene Kosten mit grünem Tuch bekleidete Männer geschickt, die zwölf gleichartig bezogene Tragsessel transportierten. In einem davon wurde Seine Majestät nach Flix getragen. ${ }^{7}$

Zweifellos begünstigten die gesundheitlichen Probleme des Monarchen jedoch die Verwendung von Tragsesseln, und es wurden auch mehrere davon für seinen persönlichen

$5 \quad$ „5... [ dos sillas de cuero negro, la una en que su majestad se asentaba para comer y la otra en que se hacía llevar de una parte a otra, con sus palos [...] cuatro cojines de cuero, llenos de plumas [...] un cojín de cuero, grande, con sus cinchas, en que llevaban a su majestad en los hombros [...] una maletilla de cuero, cubierta de sayeta, en que iba la silla de campo". SÁnchez Loro 1957-I958 (wie Anm. 4), Bd. 2, S. 467-540, hier, S. 5I5 f. Mit „sayeta“ wurde eine unbestimmte Art von Textilien bezeichnet.

6 SÁnchez Loro I957-I958 (wie Anm. 4), Bd. 2, S. 53I-533.

7 „[...] para hacer algún servicio a su magestad, habia enviado cuarenta y ocho hombres a su costa, vestidos de paño verde, desde los pies a la cabeza, para llevar doce sillas de mano aderezadas del mismo paño. En una de estas fue llevado su magestad de ellos a Flix“. Enrique Сock, Anales del año ochenta y cinco. In: José García Mercadal, Viajes de extranjeros por España y Portugal desde los tiempos más remotos hasta comienzos del siglo XX, 6 Bde. (Valladolid I999, erstmals Madrid I952-1962), Bd. 2, S. 535. 
Gebrauch angefertigt. Der bekannteste darunter ist der erst in jüngster Zeit rekonstruierte sogenannte „Gichtsessel“, der die durch die Gichterkrankung Philipps II. hervorgerufenen Schmerzen lindern helfen sollte. Der im Original leider nicht mehr erhaltene Gichtsessel wurde bereits 1595 gebaut, wie der in Diensten des Monarchen stehende Jehan Lhermite, von dessen Hand eine Zeichnung des Sessels überliefert ist (Abb. I), damals begeistert mitteilte. ${ }^{8}$ Über die Verwendung des „Gichtsessels“ berichteten auch mehrere Hofleute, wie etwa der Marqués de Velada, der dem Generalgouverneur der Spanischen Niederlande, Erzherzog Albrecht von Österreich, im Sommer 597 mitteilte: Philipp „isst und schläft sehr gut und lässt sich in seinem Gichtsessel durch seine Galerie tragen“. Vom Marqués de Velada erfahren wir auch, dass der König am Fronleichnamstag 1598, vor seiner Reise nach El Escorial, der Prozession vom königlichen Palast aus zusah, während „er in seinem Gichtsessel saß“. 9

Aufgrund seines hohen Wertes und seiner technischen Komplexität wurde der „Gichtsessel“ für Transporte in zwei Kisten aufbewahrt. ${ }^{10}$ Es handelte sich dabei aber durchaus nicht um die einzige Spezialanfertigung zur Beförderung des Königs; im Lauf der Zeit

8 Eine Rekonstruktion des verstellbaren Tragsessels befindet sich heute im Kloster von El Escorial (ME IOoI4I20). Siehe dazu: Felipe II un monarca y su época. Un príncipe del Renacimiento (Ausstellungskatalog, Madrid 1998), S. 456 und 547 f. Die Beschreibung Jehan Lhermites lautet wörtlich: „Ceste chayre des gouttes, [...] estoit un meuble des mellieurs et plus aysez que Sa Majesté pouvoit avoir, non en valeur ni estimation de richesse, mais bien en la grande commodité quil en reçoit en touttes ses maladies, et encores que fort n'estant que de bois, cuyer et ses ferremens ordinaires, vaillot dix fois davantaige qu'en or et argent ell pourroit peser. Quelle chose y a-t-il au monde pour un Prince et grand monarche plus estimable, que des biens et richesses que le bon Dieu luy a donné, en tyrer sa commodité principalement en temps de sa vieillesse, icelle chargé de grandes maladies comme ce bon Roy en eust bien sa part? Ceste chayre, doncques, luy servoit d'un grand repos et délassement de tous ses membres, touttes les fois quil en sortoit son lit de maladie, car sy tenoit dedans depuis le matin qu'il se levoit jusques au soir qu'il se couchoit [...]“. Jean Lhermite, Le passetemps, hg. von Charles Ruelens, 2 Bde. (Maatschappij der Antwerpsche Bibliophilen I7 und 20, Antwerpen I890-I896), Bd. I, S. 257 f. Für die spanische Übersetzung und die von Lhermite selbst angefertigte Abbildung des Tragsessels siehe: Jean Lhermite, El pasatiempos de Jehan Lhermite: memorias de un gentilhombre flamenco en la corte de Felipe II y Felipe III, mit einem Kommentar von Jesús Sáenz de Miera, Übersetzung von José Luis Checa Cremades (Aranjuez 2005), S. 25I f., 639 und Abbildung IX. Alle folgenden Zitate von Lhermite beruhen auf der spanischen Auflage.

9 Erstes Zitat: IVDJ, Envio 95, caja 173, doc. I22: „[... [ come y duerme muy bien y tráenle en su silla de gotas por su galería“. Das zweite Zitat stammt aus einem Schreiben, das der Marqués de Velada am 25. Juni 1598 an Don Pedro de Toledo richtete: ADMS, Villafranca, Leg. 4392, carta 84: „[...] estando en su silla de la gota".

io Francisco Javier Sánchez Cantón, Inventarios reales. Bienes muebles que pertenecieron a Felipe II, 2 Bde. (Archivo documental espańol publicado por la Real Academia de la Historia IO-II, Madrid 1959), Bd. 2, S. 380. 
$\{95$

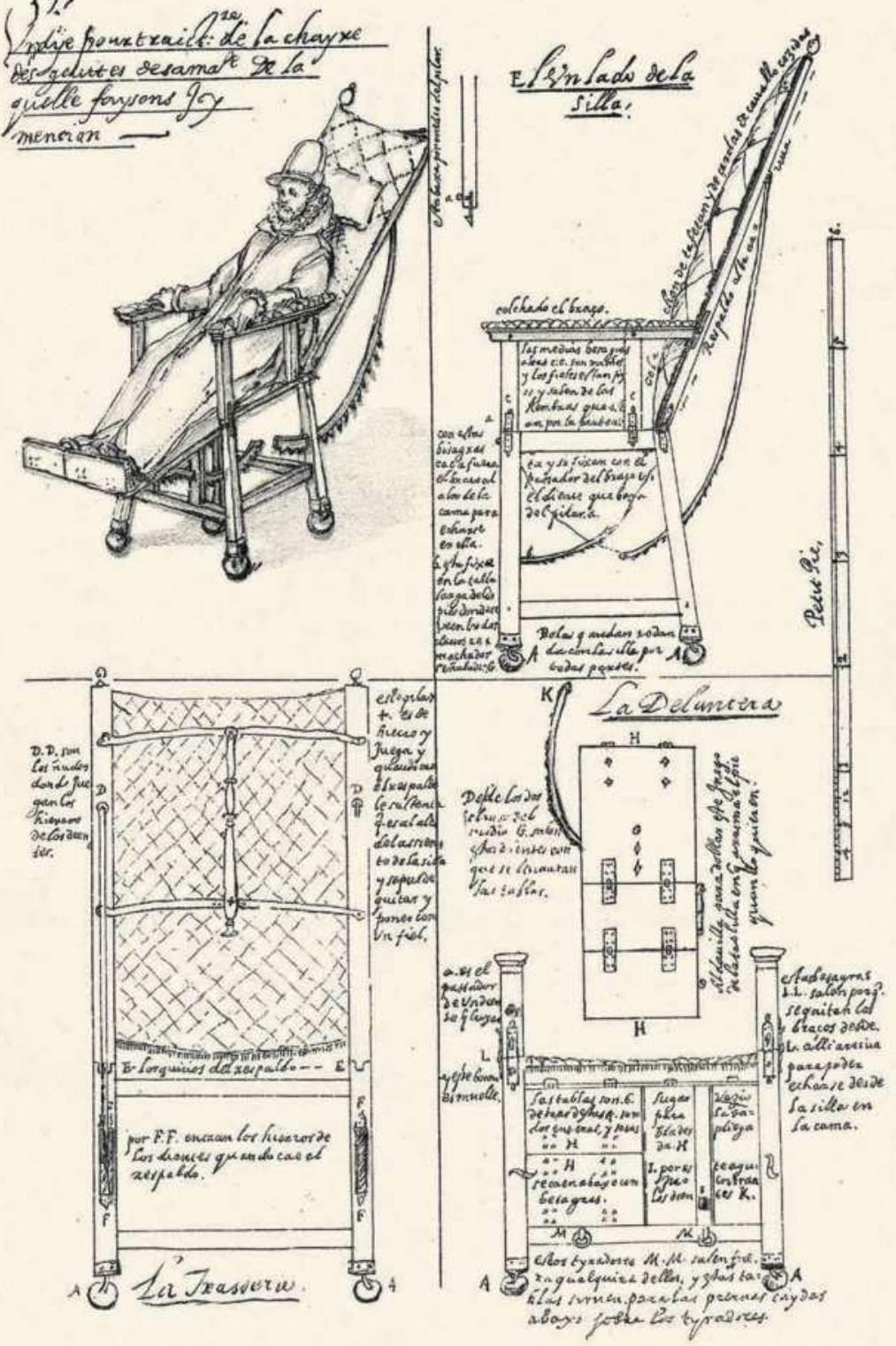

Abb. 1: Der „Gichttragsessel“ Philipps II., gezeichnet von Jehan Lhermite. Bild zit. nach LHERMITE 1890-1896 (wie Anm. 8), Bd. 1. @ ÖNB 
kamen weitere hinzu. Auf der letzten Reise des Monarchen, im Juni 1598, war er bereits so geschwächt, „dass er das Schwanken der Kutsche in keiner Weise ertragen konnte“, weshalb er sich „mit Hilfe der Arme mehrerer Männer in einem Stuhl tragen ließ, der speziell für diesen Zweck angefertigt wurde und der die Form einer kleinen Sänfte und fast sämtliche Annehmlichkeiten des Gichtsessels aufwies“. In diesem Transportmittel wurde Philipp II. von zwei aus der Gruppe seiner Lakaien ausgewählten Männern unter großen Anstrengungen befördert, und auf diese Weise besichtigte er auch ausgiebig San Lorenzo. ${ }^{\text {II }}$ Über die anderen Exemplare berichtete der päpstliche Nuntius in ausführlicher Weise. Er erzählte, dass sich der König kurz vor seinem Tod „eine Art von Tragbahre, die von zahmen Pferden befördert wurde“, anfertigen ließ. Weiterhin benutzte Philipp II. eine Art von Sessel, mit dem er innerhalb des Palastes

von vier Lakaien getragen wurde, einer auf jeder Seite, da er nicht in der eigens dafür angefertigten kleinen Sänfte ausgehen wollte, und wenn er um vier oder fünf Uhr nachmittags die Unterkunft verließ, ging einer mit einem Sonnenschirm oder -dach voraus, um Schatten zu spenden und derart den gesamten Sessel vor der Sonne zu schützen; weiterhin begleiteten ihn zehn, acht oder zwanzig Personen rundherum zu Fuß. ${ }^{\text {I2 }}$

Insgesamt besaß Philipp II. demnach neben dem „Gichtsessel“ auch eine kleine, von Menschen getragene Sänfte, eine Art Tragbahre, die mittels Pferden befördert wurde, sowie vermutlich einen von vier Lakaien getragenen Tragsessel, bei dem es sich um die von Lhermitte erwähnte „kleine Sänfte“ handeln könnte.

Andere Erwähnungen von nicht näher spezifizierten Tragsesseln sind in Briefen des kaiserlichen Botschafters Khevenhüller an Kaiser Rudolf II. zu finden. So schrieb Khevenhüller beispielsweise am 24. Februar I598 aus Madrid:

Den 19. hat der khunig die kayserin auf ain jagt, ain halbe meil weegs ungeverlich von

Madridt, nach dem össen durch den printzen und die infanta berueffen und plaitten laßen.

II „[...] que no podía soportar de todo punto el bamboleo del coche [...] llevar en brazos por varios hombres en una silla que se fabricó para esta finalidad y que tenía forma de litera pequeña y casi tenía las mismas comodidades que la silla de las gotas". Sáenz de Miera/Checa Cremades 2005 (wie Anm. 8), S. 398-400.

I2 „[...] cierta manera de camilla para yr en ella llevándola cavallos mansos. [...] la qual llevavan quatro lacayos, uno de cada parte, que no le pareció ir en la literilla que se havía hecho, y porque salía de las posadas a las quatro y cinco de la tarde, yba uno delante con un pavellón o guardasol grande que le hazía ombra y cubría toda la silla para defenderle del sol, y diez y ocho o veinte personas al rededor de a pie“. José Ignacio Tellechea IDígoras, El ocaso de un rey: Felipe II visto desde la nunciatura de Madrid, I594-I598 (Monografías 79, Madrid 200I), S. I77, 253 und 255. 
Der khunig hat ihr Mt. etc. und Dltt. unterwegen mit denn florentinischen leoparden und seinen falckhnern in ainem sößl, den zwen laggai zue tragen pflegen, gewardt. [...] Hernach die Khayserin durch ihre Dltt. widerumben zuehauß a las Descalzas plaidt worden. Der khunig aber ist strackhs in seinem sößl dem palatio zuezogen, dan sy sy [sic] numallen weder der gutschi noch senften geprauchen khin. Wie dem allem, so ertzaigen sy jetzo mehr gemuet, als sy woll vor etlich jharn gethan.

Am 30. Juni 1598 berichtete Khevenhüller, dass der König nur mit dem Tragsessel nach El Escorial befördert werden wollte und dass der Transport in einer Kutsche oder Sänfte zu anstrengend für ihn gewesen wäre:

Des khunigs sachen habben sy dermaßen wider mennigkhliches und der medicos selbs verhoffen gepösserdt, das sy sich anheut, unangesehen aller unglaublicher hitz, nach dem Escurial erheben. Und machen ihr erste nachtläger geen Carauantschel. Da sy sich ain tag oder zween verhalten. Khunen aber matigkhait halber weder ihn wagen noch der senft farn, laßen sy allain durch die laggai ihn sößl tragen und werden nein tagraißen von hier geen Escurial machen. Ihr Mt. nehmen dise raiß wider der medicos willen und ratt fur und hat sy durchaus nit alhie erhalten laßen wöllen. Was volgen, gibt die zeit. ${ }^{13}$

Zwei zusätzliche Aspekte sind für uns von besonderem Interesse: Einerseits, dass die Tragsessel, wie mehrere Quellen belegen, von Lakaien transportiert wurden. Da diese Diener dem königlichen Marstall zugeteilt waren, könnte dies ein Indiz dafür sein, dass Tragsessel damals entweder tatsächlich der Stallabteilung unterstellt waren oder dass sich zumindest allmählich die Ansicht durchsetzte, dass sie in diese für die äußere Repräsentation des Fürsten so bedeutende Sektion des Königshauses am besten passten. Der zweite, noch interessantere Punkt ist, dass zumindest der „Gichtsessel“ nicht nur ein praktisches, sondern auch ein repräsentatives Vehikel war. Dies lässt sich aus seinem Anwendungsgebiet schließen, etwa daraus, dass der König 1595 den Prinzen von Oranien im Tragsessel empfing, oder aus Berichten über die Hochzeitsvorbereitungen von Thronfolger Philipp und seiner zukünftigen Gemahlin Margarete, aus denen deutlich hervorgeht, dass Tragsessel hinsichtlich der Repräsentation ein höheres Ansehen genossen als ähnliche Transporthilfsmittel. Erwogen wurde damals etwa:

I3 Maria Stieglecker, „Wir haben dein gehorsames schreiben empfangen. “ Die Korrespondenz Rudolfs II. mit Johann Khevenhüller, seinem Gesandten in Spanien, I595-I598 (Dissertation, Universität Wien 2002), S. 343, 373. Den Hinweis auf diese Quelle verdanke ich Mario Döberl, bei dem ich mich auch für die kritische Lektüre des vorliegenden Beitrags herzlich bedanken möchte. 
[...] im Anschluss daran kann sich Seine Majestät im selben Gichtsessel zum Abendessen begeben, mitten durch die Festgesellschaft bis zum Treppenaufgang, wo er in einen Tragsessel umsteigen kann, wobei der Weg mit Tüchern zu verdecken sei, und so kann er, falls er nicht weiter an der Gesellschaft teilnehmen wollte, diese zu jedem Zeitpunkt auf selbem Weg wieder verlassen. ${ }^{\text {I4 }}$

Die Nutzung von Tragsesseln, die sich im I7. Jahrhundert noch weiter verbreitete, war mit Werten verbunden, die weit über rein praktische Motive hinausgingen. Der Monarch sollte durch seine Inszenierung als Vertreter Gottes auf Erden einen nahezu sakralen Status erhalten. In diesem Zusammenhang sei in Erinnerung gerufen, dass Saavedra Fajardo in einer seiner „Empresas politicas“ festhielt, dass die Autorität und der Ruf eines Fürsten auf mehrere Faktoren zurückzuführen seien. Unter anderem würden „die Kostbarkeit und der Glanz des Reitzeugs“ Bewunderung und Respekt hervorrufen, da das Volk „sich vom Äußeren leiten lässt, weil das Herz nicht weniger von den Augen als vom Verstand beraten wird“. Über den äußerlichen Luxus bemerkte er:

Wenn der höchste Pontifex die rechte Hand Gottes auf Erden ist, wenn er wie dieser mit Blitzen Kritik niederschmettert, so ist es angebracht (auch wenn die Pietätlosigkeit ihn dafür noch so kritisiert), dass er sich gleich Gott mit dem Glanz des Lichtes (der der Festschmuck des Himmels ist) schmückt, dass er sich mit irdischem Glanz umgibt und dass er sich tragen lässt. Dasselbe gilt für die Fürsten, die Statthalter Gottes im Zeitlichen. ${ }^{\text {Is }}$

\subsection{Tragsessel im Hofstaat der Königinnen (1560-1707)}

Wenngleich im I7. Jahrhundert auch die Könige Spaniens Tragsessel verwendeten, verwandelten sich diese doch im Lauf der Zeit in ein stark weiblich konnotiertes Gebrauchsobjekt,

I4 „[...] acabado esto podrá su majestad irse a cenar pasando por medio del sarao en la misma silla de la gota hasta la boca de la escalera donde podrá mudar silla teniendo tapado el callejón con los paños, si ya no fuese servido de asistir a parte del sarao pues a cualquier hora de él podrá hacer esta misma salida". AGS Estado, Leg. I82, unfol.; Sáenz de Miera/Checa Cremades 2005 (wie Anm. 8), S. 258. „Si el sumo pontífice es un brazo de dios en la tierra, si como él rayos, fulmina censuras, conveniente es (aunque más lo censure la impiedad) que, como Dios se adorna con resplandores de luz (que son las galas del cielo), se adorne el con los de la tierra, y se deje llevar en andas. La misma razón corre por los príncipes, vicarios de Dios en lo temporal". Diego de SaAvedra Fajardo, Empresas políticas (I642), hg., eingeleitet und kommentiert von Francisco Javier Díez de Revenga (Clásicos universales Planeta 16I, Autores hispánicos, Barcelona 1988), S. 206 f. 
wobei Tragsessel besonders im Hofstaat der Königinnen ${ }^{16}$ eine bedeutende Rolle erlangten. Bereits Elisabeth von Valois benutzte ein Vehikel, das als Vorläufer von Tragsesseln gelten kann, nämlich einen „Schultersessel, in dem die Königin getragen wurde ${ }^{{ }^{17}}$. Überliefert ist auch, dass Königin Anna von Österreich während ihrer ersten Schwangerschaft Tragsessel benutzte, denn der König ordnete an: „falls die Königin ausgehen will, so erinnert sie daran, dass sie den Tragsessel nehmen soll, damit sie nicht wieder stürzt ${ }^{\text {“18 }}$. Dennoch ist festzuhalten, dass im Hofstaat der Königinnen erst das I7. Jahrhundert als eigentliche Blütezeit für Tragsessel gelten kann.

Bevor wir auf dieses Thema noch näher eingehen, sei darauf hingewiesen, dass der Hofstaat der spanischen Königinnen nach dem von Königin Isabella der Katholischen eingeführten kastilischen Vorbild organisiert war. Für den Hofstaat der Königinnen waren zwei Ordnungen erlassen worden, nämlich eine im Jahr 1575 und eine zweite, die besonders prägend werden sollte, im Jahr I603. Tragsessel sind jedoch in beiden Schriften nicht erwähnt, einerseits, weil sie zum Zeitpunkt der Abfassung der ersten Ordnung verhältnismäßig selten verwendet wurden, andererseits aber auch, weil es Ende des I6. Jahrhunderts für beinahe zwanzig Jahre keine Königin in Kastilien gab. Das Zeremoniell allein würde aber ohnehin nicht ausreichen, um sich ein genaues Bild der Rolle von Tragsesseln im Hofstaat der Königinnen zu machen. Hierfür müssen andere Quellen und auch weniger offensichtliche Indizien in Betracht gezogen werden, da sich hinter den Zeremonialtexten häufig komplexe Realitäten verbergen und eine wörtliche Auslegung der vermeintlich kanonischen Texte ohnehin nur ein Zerrbild vom höfischen Leben bietet. Obwohl die Verwendung von Tragsesseln seitens der katholischen Königinnen den Anlass für eine Reihe sehr spezifischer zeremonieller Gewohnheiten lieferte, hinterließen die Tragevehikel kaum Spuren in den erwähnten Zeremonialwerken und blieben deshalb vorerst auch weitgehend im Dunkeln. ${ }^{19}$

I6 Die spanischen Monarchinnen waren damals: Kaiserin Isabella von Portugal (I526-I539), die beiden in Spanien lebenden Gemahlinnen Philipps II., nämlich Elisabeth von Valois (I559-I568) und Anna von Österreich (I570-I580), die Ehefrau Philipps III., Margarete von Österreich (I599-I6II), die Gattinnen Philipps IV., Élisabeth de Bourbon (I62I-I644) und Maria Anna von Habsburg (1649-1665/1696), und schließlich die Gemahlinnen von Karl II., Marie Louise d'Orléans (1679I689) und Maria Anna von Pfalz-Neuburg (I689-1700). Von I580-I598 und I6II-I62I gab es zwar keine Königin, jedoch waren gerade diese beiden Zeitperioden von fundamentaler Bedeutung für die Herausbildung des höfischen Zeremoniells, besonders hinsichtlich des Hofstaats des Königs.

I7 „[... silla de hombros en que traían a la Reyna“. AGS Casas y Sitios Reales, Leg. 79, fol. I28.

I8 „[...] si la reyna quiere ir fuera, recordadle que vaya en silla porque no vuelva a caer". Henry KAMEN, Felipe de España (Madrid 1997 [r. Auflage auf Spanisch]), S. 217.

I9 Kaum Erwähnung findet der Gebrauch von Tragsesseln in: La forma que tenía y guardava el rey $\mathrm{Nr}^{\circ}$ sr Don Phelipe Segundo quando havía de salir en público a Cavallo o en coche es la siguiente. $\mathrm{RAH}, 9 / 683$, fol. 196r-200v. 
Die Tatsache, dass es im ausgehenden r6. Jahrhundert für beinahe zwei Jahrzehnte keine Königin in Kastilien gab (Philipp II. blieb von 1580 bis zu seinem Tod I598 Witwer), war zweifellos ausschlaggebend dafür, dass sich die neuen repräsentativen und zeremoniellen Möglichkeiten, die sich durch Tragsessel boten, nur zögerlich entwickelten. Tatsächlich ist die große Bedeutung, die Tragsessel unter Königin Margarete von Österreich erlangten, ein deutlicher Hinweis darauf, dass zuvor allein das Fehlen einer entsprechenden Protagonistin eine raschere Entwicklung verhindert hatte. Um die Relevanz der Königin in diesem Prozess richtig einschätzen zu können, muss der Impuls berücksichtigt werden, der vom Königshaus und den königlichen Ratsgremien bei der Verbreitung von Tragsesseln ausging. Zunächst etablierten sich Tragsessel als Transport- und Repräsentationsmittel schwangerer Herrscherinnen. Dies ging so weit, dass Tragsessel sogar bei festlichen Stadteinzügen verwendet wurden. Bald darauf wurden Tragsessel auch in das Taufzeremoniell eingeführt, weshalb dieses auch partiell adaptiert werden musste. Parallel dazu wurde mittels Gesetzen versucht, den männlichen Gebrauch von Tragsesseln zu regulieren, ein Prozess, den wir als „Institutionalisierung“ der Tragsessel bezeichnen möchten. Eine Verordnung von I604 machte für Männer das Privileg, sich in einem Tragsessel befördern lassen zu dürfen, von der Erteilung einer Lizenz durch den Rat von Kastilien abhängig. In diesem Zusammenhang ist auch zu sehen, dass man in Madrid - und möglicherweise auch in anderen Städten Kastiliens - damit begann, die Arbeitsbedingungen jener Sesselträger, die gemietet werden konnten, strenger zu kontrollieren. Wie noch zu sehen sein wird, endeten die gesetzlichen Maßnahmen damit jedoch noch lange nicht. Die hier erwähnten Entwicklungsschritte verdeutlichen jedoch recht klar die gestiegene Wertschätzung, die Tragsesseln im frühen I7. Jahrhundert entgegengebracht wurde.

Die tatsächliche Integration von Tragsesseln in den Hofstaat der Königinnen fiel in die Zeit Margaretes von Österreich. Schon kurz nach ihrer Ankunft in Spanien begannen Tragsessel eine bedeutende Stellung einzunehmen. Anfänglich boten die Schwangerschaften der Königin den Anlass für die Verwendung der Tragevehikel. Hintergrund dafür war die weit verbreitete Meinung, dass zu ruppige Bewegungen eine Gefahr für schwangere Frauen darstellten. Zwar war diese Auffassung schon seit längerer Zeit etabliert, sie erhielt nun aber eine größere Bedeutung. Man nahm an, dass das Schwanken der Kutschen für das ungeborene Kind schädlich sei, ${ }^{20}$ weshalb man langsamere Transportmittel, wie Sänften oder Tragsessel, als geeigneter für eine schwangere Königin ansah. ${ }^{21}$ Fest steht, dass die

20 Im Jahr 1607 gebar die schwangere Königin nach einer rasanten Kutschenfahrt, für die sie den Tragsessel verlassen hatte, spontan ein Kind. Luis Cabrera de Córdoba, Relaciones de las cosas sucedidas en la corte de España, desde 1599 hasta I614 (Madrid I857), S. 314.

2I Eine in den ersten Jahrzehnten des Jahrhunderts verbreitete Anekdote spielte mit der Frage, ob die schwangere Duquesa de Uceda in einem Tragsessel oder in einer Sänfte nach Aranjuez getragen 
Königin aus Angst vor Erschütterungen unmittelbar nach Eintreten der ersten Schwangerschaftssymptome bis zur Geburt Tragsessel benutzte. Autoren und Chronisten erwähnten diesen Sachverhalt bei jeder sich bietenden Gelegenheit, sodass sich Tragsessel - ähnlich wie das damals auch bei Kutschen der Fall war - zu einem viel kommentierten Gegenstand des höfischen Lebens entwickelten. Cabrera de Córdoba berichtete im Juni ı6oI, dass die im sechsten Monat schwangere Königin während ihres Aufenthaltes in Valladolid „aus reinem Vergnügen regelmäßig Nonnenklöster und andere Orte im Tragsessel besucht". Einen Monat später vermeldete er, dass die Schwangerschaft gut voranschritt und die Monarchin sich mit großer Regelmäßigkeit zu Nonnenklöstern und außerhalb der Stadt gelegenen Gärten begab, um bei guter Gesundheit zu bleiben. Auch bei diesen Gelegenheiten ließ sie sich sicherheitshalber im Tragsessel transportieren. ${ }^{22}$ Die Gewohnheit, sakrale Orte im Tragsessel zu besuchen, sollte Margarete bis zu ihrem Tod beibehalten. Möglicherweise hatte dies - wie später noch eingehend untersucht werden soll - auch für die adelige Damenwelt Vorbildcharakter. Am IO. Juni I6II fand sich die Königin zur Grundsteinlegung für ein Kloster nahe dem Königspalast ein. Zu diesem Anlass wurde das Königspaar mit den Infanten in Tragsesseln zum Colegio de Doña María de Aragón befördert, wo die Geistlichen bereits mit Kreuz und Baldachin auf sie warteten. ${ }^{23}$ Die wichtigste Neuerung in Verbindung mit Tragsesseln war aber deren Aufnahme ins Zeremoniell im Rahmen königlicher Stadteinzüge. Cabrera de Córdoba erwähnte etwa, dass das Königspaar im März I60I nach einem vierzehntägigen Aufenthalt in Tordesillas nach Valladolid aufgebrochen war, „wo sie am 9. des Vormonats Einzug gehalten hatten. Die Königin verwendete wegen ihrer weiter fortschreitenden und nunmehr als gesichert geltenden Schwangerschaft einen Tragsessel." Allem Anschein nach gebrauchte sie Tragsessel auch auf Reisen, denn Cabrera de Córdoba schilderte wenig später, dass die nunmehr im dritten Monat schwangere Königin die Strecke von Valladolid nach Tordesillas im Tragsessel zurückgelegt hatte. ${ }^{24}$ Auch

werden sollte. Beatriz Chenot/Maurice Chevalier, Cuentos recogidos por Juan de Arguijo y otros (Publicaciones de la Excelentísima Diputación Provincial de Sevilla, Sección Literatura 3/2, Sevilla 1979), S. I88.

22 „sale muy de ordinario a monasterios de monjas y otras partes en silla, por divertirse [...]. [...] sale muy de ordinario en silla a visitar monasterios de monjas y a huertas fuera de la ciudad para hacer ejercicio y la llevan en silla para más siguridad". Cabrera de Córdoba 1857 (wie Anm. 20), S. IO2, IO7. Es sei hier daran erinnert, dass der Hof zwischen I60I und 1606 in Valladolid residierte.

23 Antonio de Capmany y Montpalau, Museo histórico, que comprende los principales sucesos de España y el extrangero, como asimismo toda la parte artística y monumental de los principales países, 2 Bde. (Madrid ${ }^{2} 1862$ ), Bd. 2, S. I4.

24 "donde entraron á los 9 del pasado, la Reina fue en silla de manos, á causa de su preñado, del cual se han continuado las señales de manera que se tiene ya por cosa muy cierta [...]. [...] en silla porque el preñado pasa adelante y va en tres meses". CABrera de Córdoba I857 (wie Anm. 20), S. $95,97$. 
bei darauf folgenden festlichen Stadteinzügen der Jahre I602 und I603 kamen erneut Tragsessel zum Einsatz. Beim feierlichen Empfang in León im Januar I602 zog das Königspaar unter einem Baldachin ein, wobei der König ritt und die Königin - vielleicht wegen einer vermuteten Schwangerschaft - getragen wurde. ${ }^{25}$ Dasselbe Bild zeigte sich im darauf folgenden Monat in Zamora und Toro und im Juni 1603 in Burgos ${ }^{26}$ Es würde wohl zu kurz greifen, das bei diesen Einzügen zu beobachtende Auftreten des Königspaars allein auf zufällige Entscheidungen oder Sicherheitsmaßnahmen zurückzuführen, noch dazu, da diese Zeremonien in einer komplexen politischen Phase stattfanden. Einzugszeremonien verfolgten Anfang des 17. Jahrhunderts zweierlei Ziele: Einerseits dienten sie dazu, die symbolische Unterwerfung der urbanen Eliten zu veranschaulichen, gleichzeitig sollten diese aber auch der Krone physisch nähergebracht werden. ${ }^{27}$ Ein derartiges Ritual trug nicht nur zur Verherrlichung der Königin und zur Erhöhung ihrer Würde bei, sondern führte auch zur Sakralisierung ihrer Person. Da wir davon ausgehen können, dass Vertreter lokaler Eliten den Tragsessel zu Fuß begleiteten, wurde so auf subtile Weise die erwünschte Nähe zur Königin hergestellt. Die Tatsache, dass sich die Königin in einem Vehikel präsentierte, das Affinitäten zu einer Monstranz, einem Tabernakel oder einem Thron aufwies, erinnert an eine Schilderung Diego de Guzmáns, der das Auftreten des Königspaars auf Reisen wie folgt beschrieb:

Dann brachen Ihre Majestäten in Richtung León und Zamora auf, wo sie unter einem Baldachin empfangen wurden, denn es handelte sich um ihren ersten Besuch [...]. Ihre Majestäten erbrachten in diesen Städten zahlreiche Beweise ihrer Pietät und Gläubigkeit, indem sie sich viel Zeit dafür nahmen, ihre königlichen Häupter über reich gestaltete Schreine aus Gold und Silber zu beugen, in denen zahlreiche kostbare Reliquien aufbewahrt sind, die sie mit großer Hingabe betrachteten, anbeteten und küssten. ${ }^{28}$

25 Relación que trata de la entrada que su magestad del rey, don Felipe nuestro señor y reina hicieron en la ciudad de Leon con el recibimiento y fiestas que se les hizo, en este ańo de mil y seiscientos y dos, en primero deste mes de febrero (Sevilla I602). RACMyP, 20.879 (62).

26 Cabrera de Córdoba i857 (wie Anm. 20), S. 74 f., I29 f., I34 f., i8i f.

27 Ebenda, S. 332, 34I f., 374. Für den politischen Kontext siehe María José del Río Barredo, Madrid, urbs regia. La capital ceremonial de la Monarquía Católica (Madrid 2000), S. 88-92.

„Luego partierô sus Magestades para la ciudad de Leô y Çamora, adonde los recibieron con Palio, por ser la vez primera [...]. Dieron sus Magestades muchas muestras de su piedad y religión en estos lugares, viendo, venerando, y besando muy de espacio con mucha devociô las muchas y preciosas reliquias que en estas ciudades ay en ricas arcas de oro y plata, metiendo sus Reales cabeças en ellas". Diego de GuzMán, Reyna católica. Vida y muerte de D. Margarita de Austria Reyna de Espanna (Madrid I6I7). BNE, R 25.370, fol. I3Ir-132r. 
Betrachten wir die Rolle der Königin im Rahmen des Hofzeremoniells nun etwas näher, so zeigt sich ein Kontrastbild zur traditionellen Vorstellung eines starren, von strenger Disziplin geprägten Hofzeremoniells, hinter dem die Monarchen als Personen zu verschwinden scheinen. ${ }^{29}$ Der Gebrauch von Tragstühlen veranschaulicht in deutlicher Weise, dass wir noch keine ausreichenden Informationen über das königliche Zeremoniell und seine Entstehung besitzen und dass uns vorgefasste Vorstellungen darüber nur bedingt weiterhelfen. An einem hohen Mobilitätsgrad der Königin kann kein Zweifel bestehen, und zum Leidwesen des Duque de Lerma begnügte sich die Monarchin weder auf den ständigen Reisen, die sie gemeinsam mit ihrem Gemahl zu den verschiedenen Residenzen in Valladolid, Ventosilla oder Lerma unternahm, noch bei den Stadteinzügen in Kastilien mit einer marginalen Rolle. Ihr Hofstaat und insbesondere ihr Marstall waren im Lauf ihres Lebens ständig in Bewegung, in den meisten Fällen, um ihrem Gemahl zu folgen, in selteneren Fällen aber auch für allein unternommene Lustreisen zu königlichen Residenzen oder für Landausflüge oder Ausgänge innerhalb Madrids. Der ständige Gebrauch von Vehikeln, seien dies Kutschen oder Tragsessel, steht jedoch auch für die Entstehung neuer Präsentationsformen für die Königin. Dabei handelt es sich um Phänomene, die in der bisherigen Forschung zum Bild und zur Außendarstellung der Herrscherinnen unbeachtet geblieben sind. Die Verwendung eines Tragsessels signalisierte fortan in allgemein verständlicher Weise den Auftakt von Schwangerschaften der Königin. Mittels Tragsessel ließ sich die „frohe Botschaft" visuell verkünden, und die Monarchin konnte sich als thronende, gut behütete Madonna in Szene setzen. Tragsessel leisteten somit einen wichtigen Beitrag zur klaren Trennung des Zeremoniells der Königin von jenem, das für den König Gültigkeit hatte..$^{30}$

Begleitet wurde die Änderung in der Nutzung von Tragsesseln von entsprechenden Reformen im Bereich des Marstalls, wo mit der Einführung von Sesselträgern nun auch eine neue Dienersparte entstand. In den Quellen tauchen Sesselträger erstmals I602 auf, als zwei von ihnen eingestellt wurden. Ihre Zahl erhöhte sich 1603 auf zehn, 1607 weiter auf zwölf und hielt sich anschließend bis zum Tod Margaretes konstant auf diesem Niveau. ${ }^{31}$

29 Siehe dazu Ludwig Pfandl, Felipe II. Bosquejo de una vida y de una época (Madrid 1942; Originalausgabe: Philipp II. Gemälde eines Lebens und einer Zeit [München 1938]), S. I30-167.

30 Zum Hofzeremoniell, zu dessen Änderungen unter der Regentschaft der verschiedenen Könige und zur Rolle der Vehikel dabei siehe: Alejandro López Álvarez, Some reflections on the ceremonial and image of the kings and queens of the House of Habsburg in the sixteenth and seventeenth centuries. In: René Vermeir/Dries Raeymaekers/José Eloy Hortal Muñoz (Hg.), A Constellation of Courts. The Courts and Households of Habsburg Europe, I555-1665 (Avisos de Flandes I5, Leuven 20I4), S. 267-32I.

3I José Martínez Millán/Santiago Fernández Conti (Hg.), La monarquía de Felipe II: la casa del rey, 2 Bde. (Madrid 2005), Bd. 2, S. 938. 


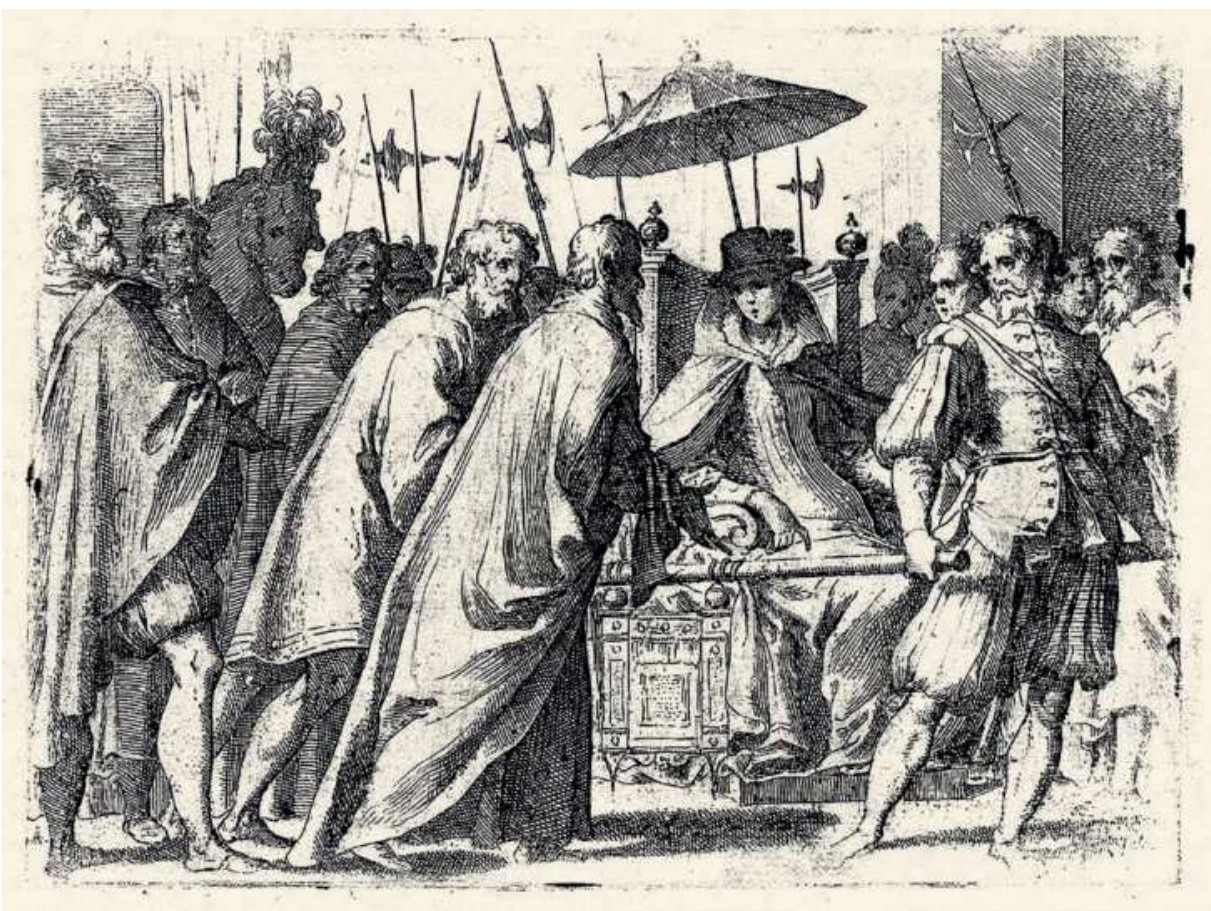

Abb. 2 : Königin Margarete im Tragsessel. Darstellung aus: Giovanni Altovit1, Essequie della Sacra Católica e Real Maestà di Marguerita d'Austria Regina di Spagna, celebrate dal Serenísimo don Cosimo II, Gran Duca di Toscana III (Firenze 1612), S. 15. BNE, R 22299. @ BNE

Offenbar fand man mit diesem Personalstand das perfekte Auskommen, denn auch Infantin Anna Maria, die Schwester Philipps IV. und spätere Ehefrau Kaiser Ferdinands III., führte bei ihrer Brautreise ins Reich „Reitknechte für Überlandreisen, einen Tragsessel samt zwölf Mauren, Sänften und alles, was sonst noch für ihre Belustigung nötig ist“, mit sich. $^{32}$

32 "[...] palafrenes para el campo, silla de manos con doze Moros, literas y quanto ha menester para su diuirtimiento“. Pedro de Robles, Relación verdadera del Acompañamiento, Recámara, y Riquezas que lleva la Magestad de la Sereníssima Reyna de Hungría, Títulos, Grandes, criados, y demás gente que viene en su servicio, Officios, y mercedes que se les ha hecho antes de partir, Riquezas y Ioyas de valor que el Rey nuestro seńor le ha dado a ella, como también para el Emperador, y Emperatriz sus cuñados (I630). In: José Simón Díaz, Relaciones breves de actos públicos celebrados en Madrid de I54I a I650 (El Madrid de los Austrias, Reihe: Documentación I, Madrid 1982), S. 395. In ähnlicher Weise wurde auch der Duque de Alburquerque in seiner Rolle als Obersthofmeister von Infantin Margarita Teresa auf deren Brautreise zu Kaiser Leopold I. mit einer beachtlich hohen Zahl an Dienern versehen. Zu seinem Marstallpersonal zählten damals unter anderem 
Vermutlich vereitelte der frühe Tod Königin Margaretes, dass Tragsessel schon zu einem früheren Zeitpunkt eine wichtigere Rolle im Rahmen des Hofzeremoniells einnahmen. Erst für Anfang der I62oer Jahre lässt sich schließlich ihre nachhaltige Integration in das königliche Zeremoniell beobachten. Dennoch soll das Augenmerk an dieser Stelle auf zwei Beispiele gelenkt werden, die zeigen, dass die Verwendung von Tragsesseln durch die Königin schon früher Resonanzen hervorrief. Das erste betrifft ein außergewöhnliches Gemälde ${ }^{33}$, das anlässlich der in Florenz abgehaltenen Trauerfeier für Königin Margarete entstand und das die Monarchin in einem Tragsessel zeigt, ein Motiv, das später in einem ähnlich gestalteten Stich übernommen wurde ${ }^{34}$ (Abb. 2). Das andere Beispiel, in dem sich die Bedeutung von Tragsesseln als zeremonielles Element von großer Symbolkraft manifestiert, betrifft den berühmten Prinzessinenaustausch von 16I5, ein Ereignis, bei dem Spanien und Frankreich einen intensiven Wettstreit auf zeremonieller Ebene austrugen, wobei klar zu Tage trat, welch außerordentliches Potential in dieser Hinsicht in Prunkvehikeln steckte. Gemäß den I6II festgesetzten Bestimmungen des Vertrags von Fontainebleau wurde im Jahr I6Is die spanische Infantin Anna mit dem französischen König Ludwig XIII. vermählt. Gleichzeitig reiste aus Frankreich Prinzessin Élisabeth de Bourbon an, um den zukünftigen König Philipp IV. zu heiraten. ${ }^{35}$ Interessanterweise bot dieses Ereignis die Bühne für eine Propagandaschlacht, bei der Vehikel eine bedeutende Rolle spielten. Duque de Lerma, der Favorit des Königs, der damals das Amt des Oberststallmeisters innehatte, nutzte dieses Ereignis in besonders eindrucksvoller Weise zur Prunkentfaltung: In Burgos, wo die Ehen per procurationem geschlossen wurden, ließ er sich von acht Sesselträgern in einem goldbestickten Tragsessel in die Kathedrale bringen. Begleitet wurde er dabei vom Marqués de Peñafiel, dem Marqués de Povar und den Condes de Paredes, Olivares und Oliva. Dem Tragsessel folgten eine Sänfte aus karmesinrotem Samt sowie eine reich

ein Oberkutscher, zwei Unterkutscher, ein Kammerkutscher, drei weitere Kutscher, drei Maultierknechte, sechzehn Lakaien und vierzehn Sesselträger. Noticias del viaje de la Infanta Da Margarita María, desposada con el Emperador Leopoldo I, desde Madrid hasta Roveredo (Tirol) en I666, zit. nach: Antonio Rodríguez Villa, Dos viajes regios (I679 y i666). In: Boletín de la Real Academia de la Historia 42 (1903), S. 379 f.

33 Zu beiden Bildquellen siehe ausführlich: Glorias efímeras. Las exequias florentinas de Felipe II y Margarita de Austria (Ausstellungskatalog, Madrid 1999).

34 Giovanni Altoviti, Essequie della Sacra Católica e Real Maestà di Marguerita d'Austria Regina di Spagna, celebrate dal Serenísimo don Cosimo II, Gran Duca di Toscana III (Firenze I6I2), BNE, R 22.299, S. I4 f.

35 María José del Rio BarRedo, Imágenes para una ceremonia de frontera: el intercambio de las princesas entre las Cortes de Francia y España en i6is. In: Joan Lluís Palos/Diana Carrió-Invernizzi (Hg.), La historia imaginada: construcciones visuales del pasado en la Edad Moderna (Madrid 2008), S. I53-184. 
verzierte Kutsche. ${ }^{36}$ In einer anderen Quelle wurde der Fokus hingegen verstärkt auf die öffentliche Erscheinung des Duque de Lerma und auf dessen Gefolge gelegt, der,

als er sein Haus verließ, von allen Menschen ob seiner Erhabenheit bestaunt wurde, die ihn wie einen wahrhaften Günstling des Königs erscheinen ließ. Aufgrund seiner Gebrechlichkeit wurde er in einem kostbaren Tragsessel von vorzüglicher Arbeit getragen, dessen Vornehmheit und geschmackvolle Gestaltung dem Getragenen selbst entsprach, denn in diesem Punkt kam ihm kein anderer gleich. [...] Es folgten zahlreiche Kavaliere, die ihn begleiteten, [...] und zahllose weitere Herren und Leute seines Hauses; der Tragsessel war von 30 Pagen umgeben, welche die königliche Livree trugen, ein Privileg, das ihm in seiner Funktion als Oberststallmeister zusteht. ${ }^{37}$

Das größte Interesse konzentrierte sich aber auf die beiden zukünftigen Königinnen Spaniens und Frankreichs, deren Fahrzeuge sehr detailliert geschildert wurden. So erfahren wir zum Beispiel, dass der Duque de Uceda für die zukünftige spanische Königin am Flussufer verschiedene Vehikel bereitgestellt hatte, nämlich

drei sehr kostbare Gegenstände, die der Prinzessin, unserer Herrin, auf ihrer Reise durch Spanien zur Verfügung stehen sollten, nämlich eine große Karosse, eine Sänfte und ein Tragsessel, allesamt in großzügiger Weise mit Gold, Brokatvorhängen und Silberrädern ausgestattet. Dazu gehörten sechs Zugpferde, zwei prachtvolle Maultiere sowie überreich gekleidete Lakaien, die den Tragsessel beförderten. ${ }^{38}$

36 Pedro Mantuano, Casamientos de España y Francia, y viage del Duque de Lerma llevando la Reyna Christianíssima Dońa Ana de Austria al paso de Beobia, y trayendo la princesa de Asturias nuestra señora (Madrid I6I8), BNE, R I1.067, S. I23-I25.

„[... s salió de su casa admirando el mundo con su grandeza, pareciendo verdaderamente privado de Rey, y por sus achaques, en una silla de preciosisima labor y riqueza, tan autorizado y galán como él mismo, porque no hubo otro que le excediese en esto [...] vinieron a acompañarle muchos caballeros; [...] y otros muchos señores y toda la gente de su casa, que era sin número; rodeando la silla 30 pajes, vestidos de la librea del Rey, que por Caballerizo Mayor le toca esta preeminencia“. Matías de NovOA, Historia de Felipe III, rey de España. In: Martín Fernández de Navarrete/Miquel Salvá/Pedro Sáinz de Baranda, Colección de Documentos Inéditos para la Historia de España, IIz Bde. (Madrid I842-I895), Bd. 6I, S. 2 f., 9.

38 „[...] tres cosas muy ricas para que la Prinçesa nuestra señora en passando a España hiziesse sus jornadas en ellas, que eran una gran Carroça, una Litera, y una silla, todas riquisimas quajadas de oro, cortinas de brocado, ruedas de plata, seis cavallos, y dos machos famosos, lacayos que llevassen la silla Riquísimam.te vestidos [...]. "Relación de la Jornada de las entregas de las Sereníssimas Señoras Doña Ana Reyna de Françia, y Doña Isabel Prinçesa de España, hechas en los meses de Otubre y Noviembre de este año de i6ıs (I6I5). BNE, Mss. 2.348, fol. 226r. 
Im Vergleich dazu fielen die Fahrzeuge der Franzosen stark ab. Ihre Wagen wiesen offenbar weniger Verzierungen auf und hatten auch kein solch majestätisches Erscheinungsbild wie die spanischen Vehikel. Vor allem aber machte sich auf französischer Seite das Fehlen von Tragsesseln bemerkbar:

Die Franzosen hielten an ihrer Uferseite eine rotsamtene Sänfte mit silbernen Holmen sowie ein gute Karosse für die Königin bereit; für alle übrigen standen zwei Karossen, jedoch keine Sänften zur Verfügung; und als sie übersetzten, wurde ihnen in unangenehmer Weise bewusst, was sie alles in Spanien zurückließen. ${ }^{39}$

Unser Berichterstatter betonte bei der Beschreibung des Empfangs der zukünftigen Königin Frankreichs mit Nachdruck die Unterlegenheit des französischen Hofes hinsichtlich des Zeremoniells. Besonders deutlich wird dies bei der Schilderung des Höhepunkts des Aufeinandertreffens, der Verabschiedung der Prinzessinnen:

[...] bei den Damen, die nach Frankreich übersetzten, gab es viele Tränen, und sie weinten auch mit gutem Grund, denn sobald sie auf der anderen Seite angekommen waren, standen sie alle herum und wussten weder, in welche Kutschen oder Sänften sie einsteigen sollten, noch, wer ihnen zu Diensten stehe. ${ }^{40}$

Quellen wie diese deuten darauf hin, dass schon vor der Erlangung der Königinnenwürde durch Élisabeth de Bourbon Tragsessel auch in Abwesenheit einer Monarchin eine bedeutende Rolle am Madrider Hof spielten. Das entsprechende Zeremoniell wurde schließlich während der Regierungszeit ihres Gemahls Philipp IV. geschaffen. Nachrichten, die uns über eine neuerliche Verwendung von Tragsesseln informieren, stehen in Zusammenhang mit einer Schwangerschaft der Königin. Einige davon betreffen Instandsetzungsarbeiten im Jahr 1622.4 Die Königin, die damals vermutete, guter Hoffnung zu sein, ließ sich anlässlich einer anstehenden Reise nach Aranjuez im Tragsessel transportieren. Sie benötigte

39 "Tenían los franceses en su orilla para la Reyna una Litera de terciopelo carmesi con pasamanos de plata y una carroça buena y para las demás dos Carroças y ninguna Litera, y quando passaron alli les pesó harto de lo que dejaron en España“. Ebenda, fol. 227r.

40 „[... [ huvo muchas lágrimas de las señoras que passaron a françia, y con razon lo podían hazer, según lo que les esperava, porque en acavando de passar se hallaron todas en el campo sin saver en que Coches ni Literas avian de ir, ni quién ayudasse dellas". Ebenda, fol. 228r.

4I Die Quellen erwähnen Restaurierungsarbeiten an einem Tragsessel aus Schildpatt sowie an einem Reisetragsessel. Zudem wurden im Juni und Oktober 1622 für beide Tragsessel neue Vorhänge angefertigt. AGP, Administrativa, Leg. 5985, unfol. 
für die sieben Meilen lange Strecke ganze fünf Tage. ${ }^{42}$ Weitere Details dieser Reise schilderte ein Madrider Handwerker, der seine Informationen möglicherweise aus einem unbekannten Bericht bezogen hatte. Allem Anschein nach war ursprünglich eine viertägige Reise geplant gewesen, die wie folgt in Madrid ihren Anfang nahm:

Am Montag, den I8. April 1622, brach an diesem Hofe um fünf Uhr nachmittags Ihre Majestät Königin Isabella mit dem Kardinalinfanten in Richtung Aranjuez auf, wo prunkvolle Feierlichkeiten für sie vorbereitet wurden. Es waren die ersten Festivitäten, die seit dem Tod Seiner Majestät (Gott habe ihn selig) ein Jahr zuvor stattfanden. Ihre Majestät wurde im Tragsessel getragen, da sie im dritten Monat schwanger war. Der Conde de Benavente begleitete sie in seiner Funktion als Hofmeister. Infantin Dońa María und alle Hofdamen befanden sich ebenfalls in ihrem Gefolge. ${ }^{43}$

Diese Beschreibung ist unter anderem deshalb von Interesse, weil darin mit dem Hofmeister nur ein einziger hoher Amtsträger im Gefolge der Königin erwähnt ist. Bald schon sollte sich die Komplexität des Zeremoniells erhöhen, als erneut Elemente des burgundischen Hofzeremoniells in jenes der spanischen Könige Eingang fanden. Anlass für die Änderungen gab ein Besuch des Prinzen von Wales, des zukünftigen Königs Karl I. von England, im Jahr I623. Beim Empfang des Prinzen, der beabsichtigte, die spanische Infantin Maria Anna zu heiraten, trat klar der Wunsch zum Vorschein, dem Zeremoniell der Königin größere Aufmerksamkeit zu schenken. Die Königin erschien am I. Juni zum Stierkampf auf der Plaza Mayor in Madrid im Tragsessel, umgeben von einem festlichen Gefolge. Ihren glänzenden Auftritt absolvierte sie

aufgrund ihrer Schwangerschaft im Tragsessel, in Begleitung sämtlicher Adeliger aus der Kammer des Königs, der Stall- und Hofmeister sowie des Conde de Olivares. Alle gingen zu Fuß zu beiden Seiten des Tragsessels, rechts der Conde de Benavente als Hofmeister der Königin und linker Hand der Marqués de Almazán als Oberststallmeister, und nahe dem Tragsessel fuhren auf einer Seite die Kutsche mit der Infantin und ihren Geschwistern und dahinter die Kutschen der Hofdamen. Kurz darauf folgte der König in seiner Kutsche, zu

42 Enrique Flórez, Memorias de las reinas Católicas, 2 Bde. (Valladolid 2002, erstmals Madrid I76I), Bd. 2, S. 939.

„Lunes, I8 de abril de I622 años, salió de esta corte, a las cinco de la tarde, su majestad de la señora reina madama Isabela con el Infante Cardenal al sitio de Aranjuez a unas fiestas muy grandiosas que le tenían prevenidas y fueron las primeras que se lucieron después de haber cumplido el un año que Su Majestad murió, que esté en el cielo. Llevaron a Su Majestad en silla de mano por estar preñada de tres meses. Iba el señor Conde de Benavente haciendo oficio de mayordomo. Iba también la señora infanta doña María y todas las damas". Antonio de Leon Soto, Noticias de Madrid, BNE, Mss. 2.395, fol. Iorr. 
seiner Rechten der Prinz von Wales, auf den vorderen Plätzen der Marqués de Boquingan und der Duque de Infantado, am rechten Trittbrett der außerordentliche Botschafter Englands und am linken der Marqués de Carpio. ${ }^{44}$

Am 26. Juni wurden Stierkämpfe und Pferdespiele („fiestas de cañas") auf der Plaza Mayor veranstaltet. Hunderte Reiter in glanzvollen Livreen nahmen daran teil, und die Königin erschien erneut „im Tragsessel, ihrer Schwangerschaft wegen, und der König in der Kutsche mit seinen beiden Brüdern Karl und Ferdinand“. Einige Wochen später, am I. August, nahmen die Majestäten in San Gil am Fest der Porciúncula teil, und erneut befand sich die Königin dabei „aufgrund ihrer Schwangerschaft im Tragsessel“. ${ }^{45}$ Ähnliches erfahren wir aus einem Bericht über die am 2I. August abgehaltenen Fiestas de Cañas:

Unsere Herrin, die Königin, kam im Tragsessel, mit der ihr eigenen Erhabenheit und Würde und unter den Segensrufen des Volkes; hinter ihr die schönen und galanten Hoffräulein und Damen, gleich dem Abendstern, dem die übrigen Gestirne folgen. ${ }^{46}$

Tragsessel gelangten auch in der darauf folgenden Zeit zum Einsatz, insbesondere bei Schwangerschaften. Am II. November I625 besuchte das Königspaar das Mercedarierkloster in Madrid, um in der Kapelle von Nuestra Señora de los Remedios für einen glücklichen Ausgang der sich dem Ende zuneigenden Schwangerschaft der Königin zu beten. Die Monarchin ließ sich zu diesem Anlass im Tragsessel transportieren und wurde dabei von einem großen Gefolge begleitet. Sie brachte eine Silberlampe als Opfergabe für eine glückliche Niederkunft dar. Der König und die Infantin saßen hingegen in einer Kutsche. ${ }^{47}$ Von

44 „...] en silla de manos por su preñado, acompañándola todos los Gentiles-hombres de la Cámara del Rey y caballerizos y mayordomos, y el Conde de Olivares: todos a pie; y a los lados de la silla, a la mano derecha el Conde de Benavente, como Mayordomo mayor de la Reina; y a la mano izquierda, el Marqués de Almazán, como Caballerizo mayor, y cerca de la silla a un lado, iba el coche de la Señora Infanta y sus hermanos, y detrás los coches de las Damas. De alli a un rato entró el Rey en coche, y a su lado derecho el Príncipe de Gales, y a la proa el Marqués de Boquingan y el Duque del Infantado, y al estribo derecho, el Embaxador extraordinario de Inglaterra, y al izquierdo, el Marqués del Carpio". Noticias de Madrid. I62I-I627, hg. von Ángel González Palencia (Madrid I942), S. XVII.

45 Ebenda, S. 61, 65, 70.

46 "La Reyna nuestra señora vino en silla de manos, con la grandeza y bizarría que suele, a quien seguian como al luzero las estrellas, Meninas y damas tan hermosas, como bizarras, llevándose las bendiciones del pueblo“. Juan Antonio de la Peña, Relación de las fiestas reales, y juegos de cañas, que su Magestad Católica del Rey nuestro señor hizo a los veynte y uno de Agosto deste presente año, para honrar y festejar los tratados desposorios del sereníssimo Príncipe de Gales, con la señora Infanta doña María de Austria, I623. In: Simón DíAz 1982 (wie Anm. 32), S. 24I-247, hier S. 24I.

Noticias de Madrid 1942 (wie Anm. 44), S. I26. 
da an scheint es zur Regel geworden zu sein, die Königin mit einem großen Gefolge zu umgeben. Dies wird auch aus einer nach 1628 entstandenen Reisebeschreibung Madrids aus der Feder des Franzosen Monconys ersichtlich, der dazu Folgendes anmerkte:

Pour la Reine elle se fait toûjours porter dans une petite litiere par deux hommes, accompagnée de sept ou huit carrosses, dans lesquels sont ses Dames; \& proche d'elle a pié quantité de Seigneurs qui l'accompagnent toûjours découverts. ${ }^{48}$

Aus den zuvor erwähnten Quellen wird evident, dass die zeremonielle Regelung der öffentlichen Ausgänge der Königin von jener Zeit herrührte. Das damals entwickelte Zeremoniell löste wohl die bis dahin praktizierten Gepflogenheiten ab und blieb die folgenden achtzig Jahre in Gebrauch. Als Konsequenz daraus erlangte der Oberststallmeister der Königin eine größere Bedeutung innerhalb ihres Gefolges, was die ohnehin schon vorhandene Tendenz, Elemente des burgundischen Hofzeremoniells in steigendem Maß zu integrieren, noch weiter verstärkte. In diesem Zusammenhang sei darauf hingewiesen, dass die Rolle des Oberststallmeisters in Burgund weit bedeutender war als in Kastilien. ${ }^{49}$ Auch wenn sich eine schriftliche Version des Zeremoniells bislang nicht auffinden ließ, ist seine Existenz doch durch mehrere Quellen belegt. Die damals erfolgte Normierung, die auch Einfluss auf andere Situationen im Leben der Königin hatte und die Adelige vermehrt zwang, zu Fuß zu gehen, rief Proteste hervor, etwa bei Francisco de Portugal, der in den I620er Jahren hinsichtlich des Vorrechtes von Kavalieren, Damen auf dem Trittbrett von Kutschen zu begleiten, verärgert feststellte, dass dieses Privileg durch den vermehrten Gebrauch von Tragsesseln seitens der Königin unterminiert würde. ${ }^{50}$

Die Gewohnheit, den Tragsessel der Königin zu begleiten, verfestigte sich in den darauf folgenden Jahren. So definierte eine Vorschrift von I638 genau, an welcher Stelle der

48 Balthasar de Monconys, Les Voyages De Monsieur De Monconys. Quatrieme Partie: En Espagne: Avec une Relation exacte sur la mort du Sultan Hibraim, Traitté pour connoître le poids des Liqueurs, Traitté de l'Algebre, un Recüeil de Poésies, \& un autre de Lettres; \& les Indices pour toutes les 4 Parties: Enrichie de Figures en taille douce (Paris 1695). WLB, Geogr. Oct. 474I, S. 79.

49 Siehe Félix Labrador Arroyo/Alejandro López Álvarez, Lujo y representación en la Monarquía de los Austrias: la configuración del ceremonial de la caballeriza de las reinas, I570-1600. In: Espacio, Tiempo y Forma. Historia Moderna 23 (2012), S. 19-39.

"Con los acompañamientos de la silla de la Reyna se venieron arastar sus privilegios, que el respeto de los validos rompió estos fueros bien desnecesariamente, que a los galanes, no los apea más que la cortezía, que aquella región queda izentada del poder". Francisco de Portugat, Arte de galantería (Lisboa I670), BNE, R 4.593, S. 5I f. Tatsächlich wurde der dem Buch zugrunde liegende Text schon lange vor dem Publikationsdatum verfasst. Francisco de Portugal besuchte noch den Hof Philipps IV. und verstarb bereits 1632 . 
Parade sich der Stallmeister der Cuartagos - Pferde von mittelgroßer Statur - einordnen sollte. ${ }^{\text {sI }}$ Auch Alonso Carrillo äußerte sich über das entsprechende Zeremoniell und berichtete, dass die Granden das Königspaar für gewöhnlich zu Fuß und zu Pferde begleiteten,

jedoch mit noch größerer gebotener Pflichtschuldigkeit zu Fuß den Königinnen voranschreiten, wenn diese sich in anderen Umständen befinden und zwecks sicherem Ausgang der Geburt sowie der Bequemlichkeit halber im Tragsessel befördert werden.

In einem ausführlicheren Kommentar dazu wird klar zum Ausdruck gebracht, dass der Tragsessel der Königin außerhalb Madrids zu Pferd, innerhalb der Stadt aber zu Fuß begleitet wurde:

Eines soll nicht unerwähnt bleiben: Wenn sich das Königspaar im Palacio de Buen Retiro aufhält und die Königin schwanger ist, so wird diese beim Einzug in Madrid (da der erwähnte Palast in einer gewissen, wenn auch nicht allzu großen Entfernung außerhalb der Stadt liegt) von den Granden zu Pferd begleitet, wobei sie sich hinter dem Tragsessel einreihen. Die übrigen Würden- und Amtsträger des Königshauses gehen dabei unverändert zu Fuß. Sobald jedoch die bewohnten Teile der Stadt erreicht werden (gelangt man von der Seite des Retiro nach Madrid, so gilt hierfür als Grenze das Kapuzinerkloster), steigen die Granden von ihren Pferden ab und reihen sich unmittelbar vor dem Tragsessel in die Fußbegleitung ein. ${ }^{52}$

Wie den an den späteren Hofmeister der Königin, Tomás Manrique de la Cerda, Conde de Paredes, gerichteten Anweisungen von September 1689 zu entnehmen ist, war dieser Punkt des Zeremoniells äußerst langlebig. Tomás Manrique de la Cerda, dem die Aufgabe zufiel, die anlässlich ihrer Vermählung mit König Karl II. anreisende Maria Anna von

5I Sobre el lugar que devía ocupar el Cavallerizo de los Quartagos en el acompañamiento de la Reina quand ${ }^{\circ}$. S. M. fuese sola. AGP, Histórica, Caja 49, exp. I3.

52 „[...] pero con más precisa, y devida obligación a las Reynas, caminando a pie delante de sus Majestades, quando están en cinta, y por mayor seguridad del parto, y comodidad de su salud son llevadas en silla. [...] No es de omitir, que si los Reyes se hallan en su Palacio del Buen Retiro, en ocasión que la Reyna nuestra Señora este preñada, quando su Magestad entra en Madrid (por estar aquel Palacio alguna, aunque no larga distancia de su población) los Grandes acompañan a su Magestad a cavallo, caminando detrás de la silla, no alterándose el acompañamiento de a pie, respeto de los demás Títulos, y Oficiales de la Casa Real, pero en llegando a lo poblado de la Villa (que en Madrid por la parte que mira al Retiro, es puesto señalado el Convento de los Capuchinos) dexan los Grandes sus cavallos, y se incorporan en el acompañamiento, tomando el puesto inmediato delante de la silla". Alonso CARRILlo, Origen de la dignidad de Grande de Castilla (Madrid I657), BNE, R 313.152/2, fol. 32 r. 
Pfalz-Neuburg zu empfangen, erhielt damals folgenden Auftrag, der erneut auf ein in der Stadt und auf dem Land unterschiedlich zu handhabendes Zeremoniell hindeutet:

Obwohl es in den Städten, durch die die Königin reist, üblich ist, sie mit dem Baldachin zu empfangen, habe ich aus Kostengründen beschlossen, dass die Einzüge unberitten zu bestreiten sind, und weise Euch im Voraus darauf hin, dass Ihr bei der Durchreise der Königin durch eine Stadt oder einen Ort zu Fuß neben ihrer Sänfte oder ihrem Tragsessel zu gehen habt, wie es auch am Hof Sitte ist, wenn die Königin im Tragsessel ausgeht; dies betrifft jedoch nur die Ortschaften, denn auf dem Land habt ihr aufgrund des unwegsamen Geländes (auch wenn die Königin im Tragstuhl reist) Pferde zu verwenden; dies gilt auch für alle Fälle, in denen sie in der Sänfte reist. ${ }^{53}$

Wahrscheinlich stand die zu Fuß erfolgende Begleitung des Tragsessels in Zusammenhang mit Traditionen, die damals bereits am Königshof etabliert waren. Es war dort nämlich gebräuchlich, Gäste höflichkeitshalber und als Zeichen der Wertschätzung zu Fuß bis zum Tragsessel zu geleiten. ${ }^{54}$ Eine am Königshof verbreitete Variante der Begleitung des Tragsessels war das Hofieren von Damen, ein Brauch, der zeitlich möglicherweise wesentlich länger zurückreicht, sich aber erst ab Mitte des I7. Jahrhunderts nachweisen lässt. So beschrieb im Juli I657 Barrionuevo detailliert, wie der König anlässlich einer im Schloss zu Buen Retiro veranstalteten Naumachie die Königin begleitete:

An jenem Abend und in jener Nacht gab es große Festlichkeiten, und der König begleitete seine im Tragsessel sitzende Gemahlin zu Fuß. Ihm folgten die Damen, die, ganz außer sich vor Freude, einander Körbchen und Sträußchen zuwarfen und Seiner Majestät zuriefen: „Wohin führt uns nur dieser rodrigón, zu Fuß und vor lauter Eile ganz erschöpft?" (dies war der Name für Knappen, die man für Feste anheuern konnte). Und sie alle gingen gleichzei-

53 „Aunque se estila que en las ciudades por donde ha de pasar la Reina se le haga el recibimiento con Palio, he resuelto que por excusar los gastos no haga entrada en público a caballo, previniéndoos que al pasar la Reina por alguna ciudad u otro lugar, habéis de ir a pie, al lado de la litera o silla en que viniere como se estila en esta Corte cuando la Reina sale en silla; lo qual debe entenderse dentro de los lugares, porque en el campo habeis de ir a caballo (aunque camine en silla la Reina) por algunos malos pasos; como también siempre que fuere en litera“. Adalbert Wittelsbach/Gabriel Maura Gamazo (Duque de Maura), Documentos inéditos referentes a las postrimerías de la Casa de Austria en España, 4 Bde. (Madrid 1929-1935), Bd. I, S. 203.

54 Wiser, der Sekretär der Königin, erwähnte im September 1693 gegenüber dem Kurfürsten von der Pfalz, dass er Zusammenstöße mit dem kaiserlichen Botschafter Lobkowitz vermeiden wolle und deshalb einige Tage zuvor dessen Frau bis zum Tragsessel begleitet habe, wie das in Madrid Brauch sei. Ebenda, Bd. 2, S. I29. 
tig zu Boden, und der König gab lachend zur Antwort: „Gehen wir langsamer voran, denn die Damen befehlen es so, und sie haben recht". 55

Mit Hilfe von Barrionuevo lässt sich auch gut dokumentieren, wie schnell sich die oben erwähnte galante Verhaltensweise in der Hofgesellschaft verbreitete. Für das darauf folgende Jahr berichtete er nämlich, dass die Condesa de Niebla beinahe täglich Zeit im Haus ihres Vaters verbrachte und ihr Gemahl

sie zu Fuß neben dem Tragsessel gehend hofierte; allein mit dieser Raffinesse hat sie ihn schon völlig betört, und man erwartet, dass sie noch große Dinge und Galanterien mit ihm vorhat. $^{56}$

Im Unterschied zu diesen Zeremonien mit öffentlichem Charakter halfen Tragsessel den Monarchinnen auch dabei, ihre eigene zeremonielle Präsenz zu differenzieren. Tragsessel, so wie auch andere Fahrzeuge, etwa Kutschen oder zum Beispiel die für den spanischen Barock so charakteristischen pasadizos ${ }^{57}$, ermöglichten ihren Benutzern, Einfluss auf das eigene Auftreten im öffentlichen Raum zu nehmen. Dazu gehörte auch die Option, sichtbar zu sein, ohne gesehen zu werden. Besonders deutlich geht diese Möglichkeit aus Versen des Hofpoeten Suarez Deza hervor. ${ }^{58}$ Wie wir später noch sehen werden, war die von den Monarchinnen praktizierte Vorgehensweise, mittels Verwendung von Tragsesseln auf die

55 „Aquella noche y tarde fue el festejo grande, acompañando el Rey a pie a su mujer, que iba en silla, y las damas tras él, locas de regocijo, tirándose las cestillas y ramilletes unas a otras, diciéndole a veces a Su Magestad: ¿¿Dónde nos lleva este rodrigón, molidas tan aprisa y a pie?' (éste es el nombre de los escuderos que se alquilan para fiestas), dejándose caer todas a la par y el Rey de risa, diciendo: ,Vamonos más despacio, que lo mandan las damas, y tienen razón “. Jerónimo Barrionuevo de Peralta, Avisos, hg. und kommentiert von Antonio Paz y Meliá, 2 Bde. (Biblioteca de Autores Españoles 22I-222, Madrid 1968-1969), Bd. I, S. 89.

56 „[... la va galanteando a pie al lado de la silla; con que le tiene loco solamente con esta fineza, y se espera ha de hacer con él grandes cosas y galanterías". Ebenda, S. 153 .

57 Alicia Cámara Muñoz, Pasadizos del Siglo de Oro: la arquitectura del símbolo. In: Revista de Occidente 73 (1987), S. 97-I08.

58 In der Beschreibung eines Stierkampfes, der am St.-Johannes-Tag in Anwesenheit des Königspaars stattfand, verglich Suarez Deza die in einem Tragsessel befindliche Königin mit Aurora, die dem Sonnenwagen - dem König - folgt: „En una silla de manos, / majestuosamente fina, / con ser de todos miradal fue de muy pocos bien vista./ Súbditos, nobles y grandes/ acompañaban la silla, / y hasta los que la llevaban/ eran de su compañia./ No te puedo decir más/ de que todos me decian/ que un pedazo de cristall engastado en coral iba“. Vicente Suárez de Deza, Romance. In: Esther Borrego GutiéRREZ, Un poeta cómico en la corte: vida y obra de Vicente Suárez de Deza (Teatro del siglo de oro. Estudios de literatura 70, Kassel 2002), S. 26-29, hier S. 26 f. 
eigene öffentliche Präsenz einzuwirken, auch unter anderen Mitgliedern der Hofgesellschaft verbreitet.

\subsection{Tragsessel bei Taufen}

Die Etablierung von Tragsesseln führte auch zu Neuerungen bei Tauffeiern am Königshof. Während in früheren Zeiten Taufpaten, die das neugeborene Kind zur Taufe brachten, zu Fuß gingen, wurde es mit Anfang des I7. Jahrhunderts gebräuchlich, bei dieser Zeremonie Tragsessel einzusetzen. Zum ersten Mal lässt sich die Verwendung eines Tragsessels bei der Taufe des späteren Königs Philipp IV. beobachten. Da die Taufpatin, Infantin Anna, die Schwester des Täuflings, nur wenig älter als der Prinz selbst war, erhielt der Duque de Lerma den Auftrag, das Neugeborene zu tragen. Diese zeremonielle Neuerung fand auch in höfischen Chroniken Widerhall:

[...] die durchlauchtige Infantin, seine Schwester und Patin, befand sich in einem offenen Tragstuhl, ohne Vorhänge und Himmel, in einem geschlitzten roten Satinkleid, gefüttert mit Silberstoff und einer Kopfbedeckung aus Goldsatin in derselben Farbe. Den Sessel trugen vier reposteros de camas der Königin. ${ }^{59}$

Wie eingangs bereits erwähnt, wurde später auch der Prinz selbst im Tragsessel befördert. Dass die dabei verwendeten Tragsessel thronähnliche Eigenschaften aufwiesen, wird aus einem Bericht über die Taufe von Baltasar Carlos im Jahr I629 deutlich. Bei dieser Zeremonie hatten der Duque de Olivares und seine Gemahlin, die die Aja des Täuflings war, zentrale Rollen inne. Beide näherten sich dem Neugeborenen in „anbetender“ und „huldigender“ Weise und unterstrichen dadurch den sakralen Charakter, der dem Kind zugemessen wurde. Der Tragsessel, der bei der Taufe zum Einsatz kam, war

verglast, mit rotem Samt bespannt und reich mit Gold verziert. Einen derartigen Schmuck

hält die Kunst allein für einen solch erhabenen Prinzen bereit. Im Tragsessel befand sich die

59 „[...] yua la s[erenísi]ma infanta, su hermana y madrina, en vna silla de manos descubierta, sin cortinas ni cielo, con un bestido de rasso encarnado acuchillado, forrado en tela de plata y vn capillo de rasso de oro del mismo color. Llebaban la silla quatro reposteros de camas de la reina“. Gerónimo GAscón DE Torquemada, Discurso sobre las fiestas que se hicieron en Valladolid por el dichoso nacimiento del Rey nuestro Señor Don Felipe IV y todo lo que sucedió en los dos meses siguientes, BL, Add. Ms io.236, fol. 292. Siehe auch Cabrera de Córdoba I857 (wie Anm. 20), S. 246. Für die Einführung von Tragsesseln, ihre Merkmale und Begleitung siehe auch die Korrespondenz zwischen Lerma und Franqueza: AGP, Histórica, 94/ı80. 
ehrwürdige Gräfin von Olivares, die, dem Prinzen mit besonderer Liebe und Verehrung zugetan, denselben in ihren Armen trug, denn einerseits liebte sie ihn aufrichtig, andererseits brachte sie ihm ihre Verehrung entgegen, wie es der Gehorsam von einer solch vornehmen Dame erforderte. Den Tragsessel transportierten reposteros und ayudas de Camara, und auf einer der Seiten packte auch der Conde-Duque [de Olivares] mit an, der dieser hohen Majestät besonders würdig war und ihr huldigte, indem er als weiterer Atlant jenes tragbaren Gebäudes fungierte [...]. An der Tür angekommen, hielt der Tragsessel an, und es wurden zu Schalmeienklängen verschiedene Krippenlieder gesungen. ${ }^{60}$

Dass sich Tragsessel zu einem zentralen Element bei Taufzeremonien entwickelt hatten und ihre Funktion dabei Ähnlichkeiten mit der einer Monstranz aufwies, geht aus einem anderen Taufbericht hervor, in dem das Tragevehikel folgendermaßen beschrieben ist:

[...] vom Sitz bis nach oben hin war alles verglast, mit Kristallgläsern von solch feiner Machart, dass diese kaum wahrgenommen werden konnten; ihre Ausschmückung war in Silber, woraus auch die vier Rahmen gefertigt waren. Oben war der Sessel mit einer Kuppel versehen, in der Art eines Turmes, etwa eine Spanne hoch, alles aus massivem, vergoldetem Silber. In diesem Tragsessel saß die Condesa de Olivares mit einem Fächer und [...] in den Armen der neugeborene Prinz [...]. Sie zeigte ihn mal zu einer, mal zur anderen Seite, denn sie wurde sehr langsam getragen, und zwar von vier Kammerdienern und vier moços de retrete, die Kleider mit fleischfarbenen Bändern und goldenen Spitzen anhatten. ${ }^{61}$

60 „[...] silla de cristal y terciopelo carmesí, toda estremada de oro, aliño, que sólo le pudo formar el arte para nicho de tan soberano Principe. Yba dentro della la Excelentissima señora Condesa de Olivares, llevándole en los braços, con tanto amor y respeto, que si por una parte le amava, por otra le prestaba adoración, digna de obediencia en tan noble señora. Llevaban la silla los reposteros, y ayudas de Camara, y a un lado el Excelentissimo señor Conde Duque, merecedor privado de tan alta Magestad, reverenciando su dueño otro Atlante de aquel portátil edificio [...]. Llegados pues a la puerta, donde paró la silla, tocaron las chirimias, cantando diversos villancicos". Segundas tres relaciones diferentes de las que han salido de la Entrada del Duque de Guastala, Embaxador del Rey de Hungría. Nombrando los nombres de los cavalleros, que le salieron a recibir, y joyas que presentó a la Reyna de Ungría. Con las estaciones que anduvo la Reyna Nuestra señora, por el feliz parto que tuvo. Fiestas y Máscaras, que se han hecho al nacimiento, y Bautismo del Príncipe nuestro seńor, nombrando por sus nombres las damas, y Grandes de España, que le acompañaron, con las ceremonias de la iglesia. In: Simón Díaz 1982 (wie Anm. 32), S. 379-381, hier S. 380.

6I „[...] del asiento arriba todo de bidrieras, de Christal tan finas que apenas se divisavan a vellas, la guarnicion dellas de plata, con cuatro cornejas de lo mismo, y encima de la dicha silla un cimbobo como a manera de torre, de cosa de un palmo de alto, todo de plata maciça sobre dorada. Dentro desta silla yva la señora Condesa de Olivares con abanico, y [...] en los braços el recién nacido Principe [...]. Yvale enseñando a una y otras partes, porque la llevavan muy poco a poco, pues la llevavan quatro ayudas de 
Seit damals fanden Tragsessel häufig bei fürstlichen Taufen Verwendung, so beispielsweise bei jener von Infantin Anna Maria Antonia im Jahre 1635, bei der ein besonders prachtvolles Exemplar zum Einsatz kam, ${ }^{62}$ oder auch 1638 bei jener von Infantin Maria Teresa. Eine Taufbeschreibung von I638 erwähnt, dass, nachdem das Gefolge das Zimmer der Königin verlassen hatte, der Duque de Melgar das Kind seiner Oberstkämmerin und Aja übergab, die mit dem Neugeborenen in den verglasten Tragsessel stieg und darin von vier Dienern bis zur Tür der königlichen Kapelle transportiert wurde, wo sie das Kind schließlich erneut dem Duque de Melgar überreichte. ${ }^{63}$

Ein Tragsessel fehlte auch nicht bei der Taufe des späteren Königs Karl II. im Jahr I66I. Der Infant wurde dabei von der Marquesa de los Vélez, seiner Aja, gehalten, die selbst in einem kostbaren, mit Korallen und Gläsern ausgestatteten Tragsessel getragen wurde. ${ }^{64}$ Diese für das 17. Jahrhundert zu beobachtende Praxis blieb auch noch im darauf folgenden Jahrhundert gebräuchlich und verschwand erst gegen Mitte des I8. Jahrhunderts. Spätestens ab I640 hatte sie auch Einfluss auf das Taufzeremoniell am Hof der österreichischen Habsburger gewonnen. ${ }^{65}$

Von besonderem Interesse scheint uns die Gleichsetzung des königlichen Tragsessels mit einer Monstranz zu sein, was auch an das gleichzeitige Phänomen der im I7. Jahrhundert so weit verbreiteten Tragevehikel für das Allerheiligste denken lässt. ${ }^{66}$ Signifikant ist aber auch das mit Hilfe von Tragsesseln vermittelte Bild von der Königin und den In-

Cámara, y quatro moços de retrete en cuerpo con vandas encarnadas y randas de oro". Segunda y más verdadera relación del Bautismo del Príncipe de España nuestro señor, Baltasar Carlos Domingo, con todos los nombres de los caballeros, y títulos que ivan en el acompañamiento. In: Simón Díaz 1982 (wie Anm. 32), S. 381-383, hier S. 382. Siehe auch: AGP, Histórica, 94, exp. 173.

62 Jerónimo de Cáncer y Velasco, Relación del nacimiento y bautismo de la Serenísima Infanta Doña Ana María Antonia de Austria, I635. In: Jerónimo de Cáncer y Velasco, poesía completa, hg. von Juan Carlos González Maya/José Cervera Baño/Javier Garau Amengual (Tesis doctorales „cum laude“, Serie L, Literatura 4I, Madrid 2007), S. I8I-19I, hier S. I85. Es ist bezeichnend, dass in einem mehr als ein Jahrhundert später erschienenen Werk an die Tragsessel der Infanten erinnert wurde. Dies unterstreicht die hohe Bedeutung, die den Tragevehikeln zugemessen wurde. Flórez 2002 (wie Anm. 42), Bd. 2, S. 930, 933.

63 „[...] a su Excelencia la Señora Camarera mayor, y Aya de sus Altezas, que entrándose en una silla de vidrieras de cristal, la passó en ella, llevándola quatro Reposteros de camas, hasta la puerta de la dicha Capilla Real, adonde se la entregaron segunda vez al referido Melgar". Relación verdadera de todo lo sucedido el día del Bautismo de la sereníssima Infanta, I638. In: Simón Díaz 1982 (wie Anm. 32), S. $45 \mathrm{I}-453$, hier S. 452 .

64 „[... que yba en una rica silla de manos de coral y xristales“. AGP, Histórica, Caja 94, exp. 190.

65 Siehe dazu den Beitrag von Mario Döberl im vorliegenden Band.

66 Diese waren Vorläufer der „Eucharistie-Karossen“. Isadora Rose-De VIEjo, „A honor y gloria del pan “: una silla de manos eucarística del siglo XVIII español. In: Archivo Español de Arte 67 (1994), S. $323 \mathrm{f}$. 
fanten. Die Funktion des Tragsessels entsprach nämlich sowohl der einer Monstranz als auch der eines Thrones, und die damit transportierten Hoheiten forderten eine dem entsprechende Verehrung. Der Gebrauch von Tragsesseln hatte somit zweifellos auch sakrale Facetten.

\section{$4 \quad$ Tragsessel in der spanischen Gesellschaft des 16. und 17. Jahrhunderts}

Im Laufe des I6. Jahrhunderts verbreitete sich in Spanien und dessen amerikanischen Kolonien die Verwendung von Tragsesseln stetig. Ihr Gebrauch war zunächst jedoch nur auf einige wenige Höflinge und finanziell gut ausgestattete Personenkreise beschränkt. Tragsessel standen zunächst im Ruf, von Männern hauptsächlich im Krankheitsfall benutzt zu werden und von Frauen, die einen höheren sozialen Rang vorspiegeln wollten. Ab etwa I600 lässt sich eine explosionsartige Ausbreitung von Tragsesseln beobachten, als im Rahmen eines seit den I580er Jahren im Gange befindlichen sozialen Umstrukturierungsprozesses der Zugang zu Tragsesseln und Kutschen auf jene Personen begrenzt wurde, die Regierungsgewalt ausübten, über beste Beziehungen zum Hof verfügten oder aber einen angemessenen sozialen Status vorweisen konnten. Ab Anfang des 17. Jahrhunderts entwickelten sich Tragsessel schließlich zum essentiellen Bestandteil des Hoflebens und zum Objekt der Begierde für all jene, die eine privilegierte soziale Stellung zur Schau stellen wollten.

\subsection{Tragsessel in Spanien und Amerika im 16. Jahrhundert}

Bereits aus den I520er und I530er Jahren datieren erste Hinweise auf die Existenz einer Art von Tragsesseln. Die entsprechenden Quellen lassen zwar einigen Interpretationsspielraum offen, deuten jedoch eindeutig auf das Vorhandensein spezieller Tragevorrichtungen zur Beförderung von Personen eines gewissen sozialen Ranges hin, und zwar in Situationen, in denen das Hochgehobenwerden in Zusammenhang mit einer Führungsrolle, der Verherrlichung eines Menschen oder der Ausübung von Befehlsgewalt steht. So trat beispielsweise unmittelbar vor einer drohenden Plünderung Toledos Maria Pacheco, die Witwe von Juan de Padilla, einem Anführer des Comuneros-Aufstandes, „aus ihrem Haus, gekleidet in Trauer, ihres Mannes wegen, in einem Sessel sitzend aufgrund einer Unpässlichkeit“, und konnte so die Niederschlagung des Aufruhrs herbeiführen ${ }^{67}$ Der bekannte Feldherr Antonio de Leyva

67 „[...] de su casa cubierta de luto, que traía por su marido, asentada en una silla por su indisposición“. Pedro de Alcocer, Relación de algunas cosas que pasaron en estos reinos desde que murió la reina 
wiederum ließ sich während der Schlacht von Pavia, von Schmerzen gequält, „in einem Tragsessel an einen Ort der Stadt bringen, von dem aus er bis zu tausend spanische und deutsche Soldaten befehligte", was schließlich einen bedeutenden Sieg für die kaiserlichen Truppen zur Folge hatte. ${ }^{68}$ Die erste spanischsprachige Erwähnung, in der zweifellos von einem Tragsessel die Rede ist, findet sich in einem anonymen Bericht aus dem Jahr I54I:

Der Duque de Béjar [...] litt an Schmerzen an einem Bein und kam deshalb nicht mit seiner Tochter, sondern wurde in einem Tragsessel vorangetragen, begleitet von vielen zu Fuß gehenden Edelmännern und seinem Sohn, Don Francisco. ${ }^{69}$

Zwar war die Verwendung von Tragstühlen für den Transport von kranken Personen üblich, nicht jedoch, die Vehikel eigens in einem Festbericht zu erwähnen. Hier zeigt sich eine neue, andersartige Bewertung dieser Objekte. Von Bedeutung scheint auch die Gleichzeitigkeit entsprechender zeitgenössischer Quellen zu sein, noch dazu, da es sich hierbei nicht um nachträglich niedergeschriebene Erinnerungen handelt. Von ihrer ersten Erwähnung an ist die Verwendung verschiedener Arten von Tragsesseln durch Adelige und

Católica Doña Isabel, hasta que se acabaron las Comunidades en la ciudad de Toledo, um 1539 (Sevilla I872), S. 67. Über Maria Pacheco berichtete auch Juan Ginés de Sepúlveda im Jahr 1536 Er schrieb, sie habe sich nach dem Tod ihres Gemahls in Trauerkleidung in einen Tragstuhl gesetzt und sei darin von ihrem Wohnhaus bis zum Alcazar gebracht worden: „[... la pusieron en una silla de manos y la transportaron desde la casa en que vivia al alcázar". Juan Ginés de SePúlveda, Historia de Carlos V, hg., bearb. und übersetzt von Elena Rodríguez Peregrina, mit einer historischen Untersuchung von Baltasar Cuart Moner, 6 Bde. (Obras completas I, Pozoblanco [Córdoba] I995-2010), Bd. I, S. 83.

68 „[... se hizo sacar en una silla a una parte de la ciudad y de ally mandó hasta mil soldados españoles y tudescos". Fr. Juan de Hoznaya, Historia de la guerra de Lombardía, batalla de Pavía y prisión del rey Francisco de Francia, 1544, BNE, Mss. 17.889, fol. 99v. Ein etwas jüngerer Bericht erwähnt ebenfalls den Gebrauch einer Art von Tragstuhl durch Antonio de Leyva. Als die Osmanen I532 Wien bedrohten, habe er in einem höchst gefährlichen Moment die Gemüter der Soldaten beschwichtigen können. Seine Autorität sei damals hochgeschätzt gewesen, obwohl er in einem Sessel getragen wurde: „cuya Autoridad aunq'lo trayan en una silla balió mucho“. Libro primero de la triunfante jornada q el ynbentísimo enperador Don Carlos hizo contra el turco Solimán en Biena, quando le hizo retirar (o.J.); Enrique Pacheco y de Leyva (Hg.) Carlos V y los turcos en 1532. La jornada de Viena. Según un manuscrito inédito del siglo XVI existente en la Biblioteca de El Escorial, y otros datos y documentos (Madrid 1909), S. 6I.

69 "El Duque de béjar [...] estava malo de una pierna y por eso fue en una silla de mano adelante y no con su hija fueron con el mucha copia de cavalleros todos a pie y don Franco su hijo". Memoria de la ida de la condesa de Niebla a su casa, 154I. BNE, Mss. 20.262/28; Amalio Huarte y Echenique (Hg.), Relaciones de los reinados de Carlos V y Felipe II, 2 Bde. (Sociedad de Bibliófilos Españoles. Segunda época I2, 25, Madrid I94I-I950), Bd. 2, S. I45. 
Geistliche gut dokumentiert. Dies gilt vor allem für Sevilla und Madrid. Von einem gewissen Don Juan Manuel heißt es etwa, dass er I54I - unmittelbar nach dem missglückten Angriff auf Algier - dem Kaiser die Hände küssen wollte, und dies, obwohl er das Haus sonst krankheitsbedingt nicht verließ:

Sie nahmen ihn an den Armen, brachten einen Sessel an den Eingang und trugen ihn darin mit Händen. ${ }^{70}$

Ein weiterer Augenzeugenbericht erwähnt, dass der Dekan Diego de Carmona aufgrund von Gichtbeschwerden einen Tragsessel verwendete, worüber sich - wohl aufgrund der ungewöhnlichen Neuheit - so mancher lustig gemacht haben soll. ${ }^{71}$

Auch an Universitäten begann man Tragsessel zu verwenden. Um I548 nahm der Anatom Bernardino Montaña an der medizinischen Fakultät Valladolids an von Alfonso Rodríguez de Guevara abgehaltenen Lehrsektionen teil: Der siebzigjährige, an Gicht leidende Montaña musste die Leichenöffnungen im Tragsessel besuchen. ${ }^{72}$ Ab 1560 scheint sich die Verwendung von Tragsesseln allmählich verbreitet zu haben, da sie von da an immer häufiger auf den Straßen Kastiliens anzutreffen waren. Zwar mangelt es für jene frühe Zeit an Zeugnissen, doch ist beispielsweise bekannt, dass um das Jahr I554 sogenannte „sillas literas" gebaut wurden, ${ }^{73}$ oder auch, dass im Jahr 1565 einer der ranghöchsten Kleriker der Diözese von Cordoba, der Dekan Juan Fernández de Córdoba, dessen Vater, Conde de Cabra, eine der mächtigsten Personen der Stadt war, einen Tragsessel besaß. Neben einer herkömmlichen Sänfte nannte er auch einen Tragsessel mit „vier neuen Polstern“ sein Eigen. Er war aus Nussholz gefertigt und mit schwarzem Leder, Eisenbeschlägen und Trageholmen versehen. ${ }^{74}$

70 „[...] le metieron por los braços, dejando a la entrada una silla en que le traían a mano“. Luis ZAPATA DE Chaves, Miscelánea. In: Memorial histórico español: colección de documentos, opúsculos y antigüedades que publica la Real Academia de la Historia, 50 Bde. (Madrid I85I-I963), Bd. II, S. 33. Melchor de Santa CruZ, Floresta española, I574, hg. von Maximiliano Cabañas (Madrid 1996), S. 580 .

72 „Septuaginta annos natus, misere infesstissima podagra vexatus, cum multas in medica facultate tulisset palmas, ut postremo de arrogantia triumpharet, continuo tecticula ductus lectionibus intererat". Rodríguez de Guevara, In pluribus ex ijs quibus Galenus impugnatur ab Andrea Vesalio in constructione \& vsu partium corporis humani, defensio (Conimbricae I559), BNE, R 29.358, Widmung. Ähnliches ereignete sich 1558 bei der Promotion von Diego Sobaños, dem Rektor der Universität von Alcalá. Alfonso García Matamoros, Pro adserenda hispanorum eruditione, I553, hg., übersetzt und kommentiert von José López de Toro (Revista de Filología Espańola, Anejo 28, Madrid 1943), S. 46.

73 Anastasio Rojo VegA, El Siglo de Oro. Inventario de una época (Valladolid 1996), S. 382.

$74 \ldots[$ „... cuatro colchones nuevos [...] de nogal y cueros negros, con sus hierros y varas para llevar". Antonio 
Das Jahr 1578 stellt einen Wendepunkt dar, denn damals wurde mittels Verordnung das Fahren von Kutschen mit weniger als vier vorgespannten Pferden untersagt. Die hohen Kosten für die Zugpferde - die wohl selbst die finanziellen Möglichkeiten vieler Vertreter der Oberschicht Kastiliens überstiegen - veranlassten so manche Personen, die sich weiterhin im öffentlichen Raum in einem Vehikel zeigen wollten, auf Tragsessel umzusteigen beziehungsweise auf Wagentypen auszuweichen, die man zu einem späteren Zeitpunkt als „carricoches“ bezeichnete und die nur entwickelt wurden, um die erwähnte Verordnung zu umgehen. ${ }^{75}$ Diese Neuerungen fanden sogar in der Literatur ein Echo, fällt doch auch die erste literarische Erwähnung von Tragsesseln in diese Zeit. Aber auch verschiedene in den Cortes vorgebrachte Äußerungen reflektierten die eingetretenen Änderungen. Zwischen I583 und 1585 fanden in Madrid Parlamentsversammlungen statt, in denen die Verbreitung von Tragsesseln angeprangert wurde. Mehrere Deputierte forderten König Philipp II. gar auf, ihren Gebrauch gänzlich zu verbieten. In den Capitulos Generales versuchten manche, ein umfassendes Verbot von Kutschen zu verhindern. Es wurde auch argumentiert, dass die Erlaubnis, zumindest in manchen Fällen Tragsessel zu verwenden, notwendig sei, da die Anforderung, den Kutschen vier Pferde vorzuspannen, einfach nicht von allen erfüllt werden könne. Als Lösung des Problems schlugen die Deputierten dem Monarchen die allgemeine Verwendung schlichterer und billiger dekorierter Fahrzeuge vor.

Auch in einer anderen Forderung der Capitulos Generales zeigt sich das Bestreben, Tendenzen der sozialen Differenzierung und ein Wetteifern um den Besitz prestigeträchtiger Fortbewegungsmittel zu unterbinden. Es wurde nämlich Kritik daran geäußert, dass sich nach der Einführung der obligatorischen Zahl an Zugpferden für Kutschen der Gebrauch von Tragsesseln vervielfacht habe, was unangemessene Ausgaben mit sich bringe und ganz allgemein als überflüssige Neuerung angesehen wurde:

Das Verbot von Kutschen, denen weniger als vier Pferde vorgespannt sind, hat dazu geführt, dass sich Frauen in mit Vorhängen versehenen Tragsesseln befördern lassen. Obwohl dies obrigkeitswidrig ist, lassen sich einige, die es sich leisten können, von einem solchen Vorgehen nicht abhalten, was wiederum andere, deren Möglichkeiten es übersteigt, zur Nachahmung anspornt. Verschlimmert wird dies noch durch die Tatsache, dass es allein

José Díaz Rodríguez, Las casas del deán don Juan de Córdoba: lujo y clientela en torno a un capitular del Renacimiento. In: Hispania Sacra 6I/123 (2009), S. 77-I04, hier S. 95 f.

Alejandro López Álvarez, Carricoche. In: Carlos Alvar (Hg.), Gran Enciclopedia Cervantina, bisher Io Bde. (Madrid 2005-2017), Bd. 2, S. I892-I895. Zusätzliche Details zu den Kutschen betreffenden Reformbestrebungen finden sich in López ÁlLVAREZ 2007 (wie Anm. I), insbesondere S. I45-3I6. Eine Zusammenfassung der Thematik bietet Alejandro López Álvarez, Coches, carrozas y sillas de manos en la Monarquía de los Austrias entre i600 y 1700: evolución de la legislación. In: Hispania 66/224 (2006), S. 883-908. 
religiösen Bildnissen vorbehalten ist, durch Straßen getragen zu werden, die mit Vorhängen geschmückt sind. Wir bitten Eure Majestät gnädigst darum, dies verbieten zu lassen.

Der Monarch bezog mit den Worten, er werde prüfen lassen, welches Vorgehen hierbei angemessen sei, in dieser Frage vorerst nicht Stellung. ${ }^{76}$

Eine neue Kutschenverordnung von 1593 beförderte abermals die Verbreitung von Tragsesseln. Ziel des Gesetzes war es, den Gebrauch von Kutschen weitgehend auf die adelige Führungsschicht einzuschränken. Aus diesem Grund wurde der Inhalt der Verordnung von 1578 hinsichtlich der für Kutschen verpflichtend vorgeschriebenen Zahl von vier Zugpferden auch auf sogenannte „carricoches “ und sämtliche anderen Fahrzeugtypen, die in Zukunft noch entwickelt werden würden, ausgedehnt. Gewiss trug diese Maßnahme nicht nur zur weiteren Verbreitung von Tragsesseln bei, sondern erhöhte wohl auch deren Ansehen als repräsentative Vehikel. Tragsessel konnten dabei helfen, die Kluft zwischen jenen, die eine Kutsche verwendeten, und jenen, die zu Fuß unterwegs waren oder ritten, zu überbrücken.

Es lässt sich beobachten, dass Tragsessel in den $1580 e r$ und $1590 e r$ Jahren in Mode kamen und dass sie auch dazu beitrugen, soziale Unterschiede zu unterstreichen. Dies deutete auch Nuntius Camillo Borghese an, als er 1594 festhielt, dass am spanischen Hof Frauen unterschiedlicher sozialer Schichten auch spezifische Fortbewegungsarten entsprachen:

Quando vanno le signore principale in volta, vanno in carrozza, overo si fanno portare in una sedia coperta alla genoesa; le altre poi di bassa conditione vanno a piedi, overo vanno a cavallo in un asino, e con loro menano un huomo. ${ }^{77}$

Zu den Personen, die befähigt waren, Tragsessel zu verwenden, zählten Räte, Minister, Adelige und Mitglieder der hohen Geistlichkeit, aber auch, wie die Deputierten in den Cortes beklagten, vom sozialen Wettstreit angestachelte Damen kastilischer Städte. Ver-

76 „El haver quitado los coches sino es con quatro cavallos, ha dado ocasión que las mujeres anden en sillas de manos con cortinas, y demás de ser desautoridad, aunque algunas tengan posibilidad para lo hazer, dan ocasión a que otras que no pueden tanto, lo hagan, quanto más que esto de cortinas por las calles sólo está reservado para las imágenes. Suplicamos a vuestra Magestad lo mande prohibir". Actas de las Cortes de Castilla. Publicadas por acuerdo del Congreso de los Diputados, a propuesta de su Comisión de Gobierno Interior, 68 Bde. (Madrid I86I-2006), Bd. 7, S. 834, § LXV.

77 Camillo Borghese, Diario in Relation del viaggio di Monsigr Camillo Borghese auditore della Rev. Camera da Roma in Spagna mandatovi Nuntio alla Corte straordinario da Papa Clemente Ottavo l'anno I594 al Re Philippo Secondo, I594. In: Alfred Morel-Fatio, L'Espagne au XVIe et au XVIIe siècle. Documents historiques et littéraires (Heilbronn I878), S. I6I-I93, hier S. 178. 
schiedene Bemerkungen weisen eindeutig darauf hin, dass Tragsessel als weiblich konnotierte Objekte angesehen wurden. So berichtete etwa Juan de Silva im Dezember 1578 in einem Brief an Gabriel de Zayas, er sei auf dem Weg von Gibraltar nach Sevilla streckenweise in einem für Damen bestimmten Tragsessel transportiert worden. ${ }^{78} \mathrm{Zu}$ den hochrangigen Hofleuten, die Tragsessel benutzten, zählte der Duque de Sessa. Über ihn berichtete Antonio Pérez 1578 in einem Schreiben an Don Juan de Austria, dass er für gewöhnlich darin zu den Ratssitzungen getragen werde. ${ }^{79}$ Unter den Tragsesselbesitzern am Hof befand sich auch der Marqués del Valle, in dessen Inventar von 1589 „ein Tragsessel mit Vorhängen aus karmesinrotem Damast mit einer Dacheinfassung aus Stoff und Fransen, mit einem Dach aus weißem Filz mit Fransen aus karmesinroter Seide und den dazugehörigen langen Trageholmen "Erwähnung findet. ${ }^{80}$ Auch der Duque de Alba verwendete Tragsessel, beispielsweise während der Eroberung Portugals. ${ }^{81}$

78 „[... en una silla de dueña [...]“. Aus anderen Schreiben von Juan de Silva geht hervor, dass Tragsessel sowohl für kurze Strecken als auch für längere Reisen benutzt wurden. Unbekannt ist allerdings, ob es für die verschiedenen Wegstrecken auch unterschiedliche Typen gab und, falls ja, inwieweit sie voneinander abwichen. Im Jahr 1578 teilte Juan de Silva Zayas mit, er lasse sich trotz eines Leidens „mit dem Tragsessel oder in der Sänfte zum Palast tragen“ („para ir a palacio me haré llevar en silla o en litera"). Anfang 1579 versicherte er Zayas, er habe von Gibraltar bis Sanlúcar „den halben Weg im Tragsessel zurückgelegt und den restlichen Weg in einer Kutsche“ („vine en una silla de manos la mitad del camino, y el resto en una carroza"). Fernández de NAVARRETe/ Salvá/Sáinz de Baranda I842-I895 (wie Anm. 37), Bd. 40, S. 98-IOI. Lizenziat Gregorio Tovar y Pizarro reiste im Jahr 1597 mit seiner im siebten Monat schwangeren Frau und einem zweijährigen Kind, das er auf dem Schoß hielt, von Pontevedra nach Tuy. Da sich wegen der vorherrschenden Pest keine Sänfte finden ließ, musste er fünf Tage lang teils in einem Tragsessel und teils von Feldarbeitern getragen werden. Antonio de PAZ y MeLIÁ, Un jurisconsulto del siglo XVI pintado por el mismo. Extractos de la autobiografía del Lic. Gregorio Tovar y Pizarro, su ascendencia y descendencia. In: Revista de Archivos, Bibliotecas y Museos I2 (1908), S. I8-36, hier S. 3I.

79 Raimundo A. Rodríguez Pérez, Un linaje aristocrático en la España de los Habsburgo: los marqueses de los Vélez (I477-I597) (Dissertation, Universidad de Murcia, 20IO), S. 4IO. Juan Rufo, der an diese Gewohnheit des Duque erinnerte, versicherte, dessen Gichtleiden sei seit vielen Jahren so stark ausgeprägt, dass er sich stets von Türken in einem Tragsessel befördern lassen müsse („estuvo muchos años tan impedido de la gota, que le traían siempre unos turcos en una silla de manos"). Las seiscientas apotegmas, I596. In: Juan Rufo, Las seiscientas apotegmas y otras obras en verso, hg. von Alberto Blecua (Clásicos Castellanos I70, Madrid 1972), S. 77.

80 "[... [na silla de manos con cortinas de Damasco carmesí, con gotera de tela e flocadura, con una cubierta de fieltro blanco con flocadura de seda carmesí, armada con sus palos largos". Documentos inéditos relativos a Hernán Cortés y su familia (Publicaciones del Archivo General de la Nación 27, México 1935), S. 423.

8I Antonio de Escobar, Recopilación de la felicíssima iornada que la Cathólica Real Magestad del Rey don Phelipe nuestro señor hizo en la conquista del Reyno de Portugal ansí en las cosas de la guerra como después en la paz antes que boluiesse a Castilla (Valencia I586), BNE, R 27.040, fol. $37 \mathrm{r}$ und 6ov. 
Auch in anderen Städten abseits des Madrider Hofes existierten Tragsessel. Sie waren vor allem im Besitz von Personen, die Beziehung zum Königshof unterhielten, wie dies etwa auf den Bischof von Barbastro, Carlos Muñoz Serrano, zutraf, der bei einer Visitation seiner Diözese in unwegsamem, für das Reiten zu Pferd ungeeignetem Gelände im Tragsessel befördert werden musste. ${ }^{82}$ Manche Leute von niedrigerem sozialen Stand, die aber ebenso auf die eine oder andere Art mit dem Hof verbunden waren, verwendeten gleichfalls Tragsessel, so etwa Diego Sarmiento, der 1597 anlässlich seiner Amtsübernahme als Vorsteher von Toro einen Tragsessel in Auftrag gab, damit seine Gemahlin damit alle Antrittsbesuche erwidern konnte, ${ }^{8_{3}}$ oder Ambrosio Cotes, ein an verschiedenen Krankheiten leidender Musiker der königlichen Kapelle Granadas, der in den $1580 e r$ Jahren auf ärztlichen Rat hin einen Tragsessel benutzte. ${ }^{84}$ Die Schwester des königlichen Günstlings Cristóbal de Moura konnte ihren Tragsessel nach vielen Jahren infolge einer Wunderheilung wieder verlassen, wie Fray Luis de Granada am 26. Mai 1585 in einem an den Erzbischof von Valencia gerichteten Brief mitteilte. ${ }^{85}$ Der Dichter Francisco de Rioja besaß neben zwei Kutschen samt entsprechender Anspannung auch einen Tragsessel, und Pedro Enríquez, Professor für Philosophie in Valladolid, nannte neben vielen anderen Dingen - wie etwa einer bestens ausgestatteten Bibliothek - auch einen Tragsessel sein Eigen. ${ }^{86}$

Da Tragsessel nicht nur repräsentative Zwecke erfüllten, sondern gleichzeitig auch Gegenstände von großem praktischem Nutzen waren, wurden sie auch häufig verwendet, um Krankentransporte bequemer zu gestalten, so etwa während Pestausbrüchen. Während der Pest, die Ende des I6. Jahrhunderts in Toledo wütete, erhielt eine Person den Auftrag, Tragsessel zu besorgen, damit Infizierte nächtens von einem Punkt der Stadt zu einem anderen transportiert werden konnten. Dem Arzt Francisco Gutiérrez wurden damals zwei Tragsessel samt vier Tagelöhnern zur Verfügung gestellt, um Kranke nach San Lázaro zu befördern. ${ }^{87}$

82 Saturnino López NovoA, Historia de la muy noble y muy leal ciudad de Barbastro y descripción geográfico-histórica de su diócesis, 2 Bde. (Faksimile der Ausgabe von Barcelona i86I, Barbastro I98I), Bd. I, S. I8I.

83 Carmen Manso Porto, Don Diego Sarmiento de Acuña, conde de Gondomar (I567-1626). Erudito, mecenas y bibliófilo (Santiago de Compostela 1996), S. I4.

84 José María Soler García, El polifonista villenense Ambrosio Cotes (Publicaciones del Instituto de Estudios Alicantinos I/49, Alicante 1979), S. 38.

85 Fray Luis de Granada, Epistolario, hg. von Álvaro Huerga (Obras completas de Fray Luis de Granada I9, Madrid I998), S. I49.

86 Francisco de Rioja, Poesías de Francisco de Rioja corregidas con presencia de sus originales, ańadidas e ilustradas con la biografía y la bibliografía del poeta por D. Cayetano Alberto de la BARRERA y Leirado (Sociedad de Bibliófilos Españoles 2, Madrid 1867), S. 82; Bartolomé Bennassar, Valladolid au siècle d'Or. Une ville de Castille et sa campagne au XVIe siècle (Civilisations et Sociétés 4, Paris 1967), S. 36r.

87 Julián Montemayor, Una ciudad frente a la peste: Toledo a fines el XVI. In: Emilio Sáez/Cristina 


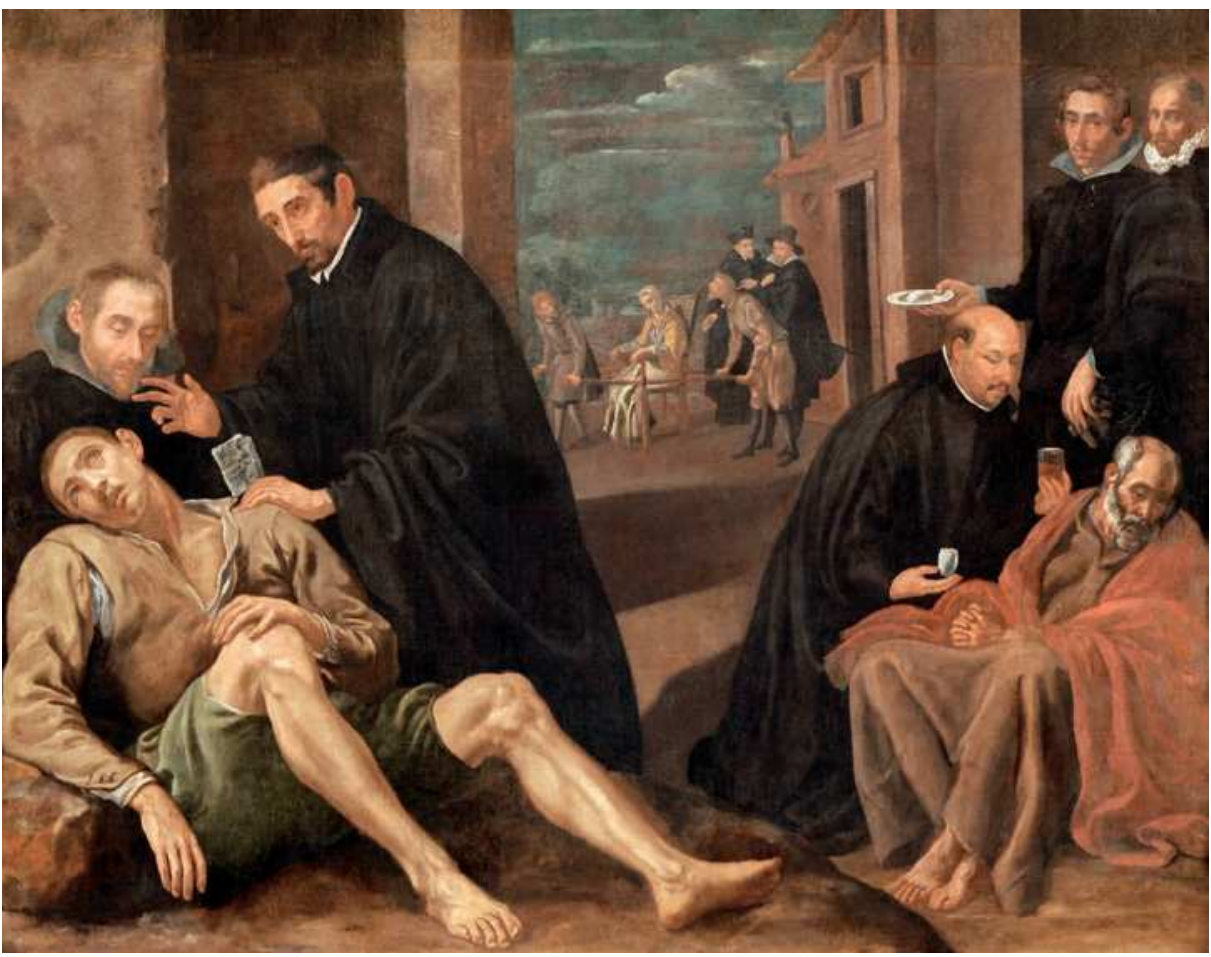

Abb. 3: Luis Tristán, La ronda de pan y huevo, 1624. Museo de Santa Cruz de Toledo, Inv.-Nr. 3376. Wie der Hintergrund dieses Gemäldes zeigt, zählte es zu den Aufgaben der in Toledo und Madrid gegründeten Hermandades del Refugio, Kranke im Tragsessel ins Hospital zu bringen. @ Museo de Santa Cruz de Toledo

In Cordoba wurde für Knechte, die Personen zum Hospital San Juan de Dios brachten, das Verbot ausgeprochen, die Stadt ohne Tragsessel zu betreten. ${ }^{88}$ Zur jener Zeit planten manche Städte sogar, einen dauerhaften Tragsesseldienst zur Beförderung von pflegebefürftigen Personen zum Hospital einzurichten, wie dies zum Beispiel 1599 in Valladolid geschah. ${ }^{89}$ Auch einige Bruderschaften folgten diesem Beispiel, etwa die I6I8 in Madrid gegründete Herman-

Segura Graíño/Margarita Cantera Montenegro (Hg.), La Ciudad hispánica durante los siglos XIII al XVI. Actas del coloquio celebrado en La Rábida y Sevilla del I4 al i9 de septiembre de I98I, 3 Bde. (Madrid 1985-1987), Bd. 2, S. II24.

88 Juan Ballesteros Rodríguez, La peste en Córdoba (Colección de estudios cordobeses 24, Córdoba 1982), S. 205 .

89 Siehe dazu die an den Hofmeister Jerónimo de Quintanilla geleisteten Zahlungen für Krankenhauskosten, darunter auch für einen Tragsessel zum Transport mittelloser Personen in das allgemeine Krankenhaus. AMV, CH 99-I8. Eine Kostenaufstellung für einen derartigen, 1682 in Cordoba für den Orden Tercera einzusetzenden Tragsessel findet sich in: AHMC, C-2107 und C-2108. 


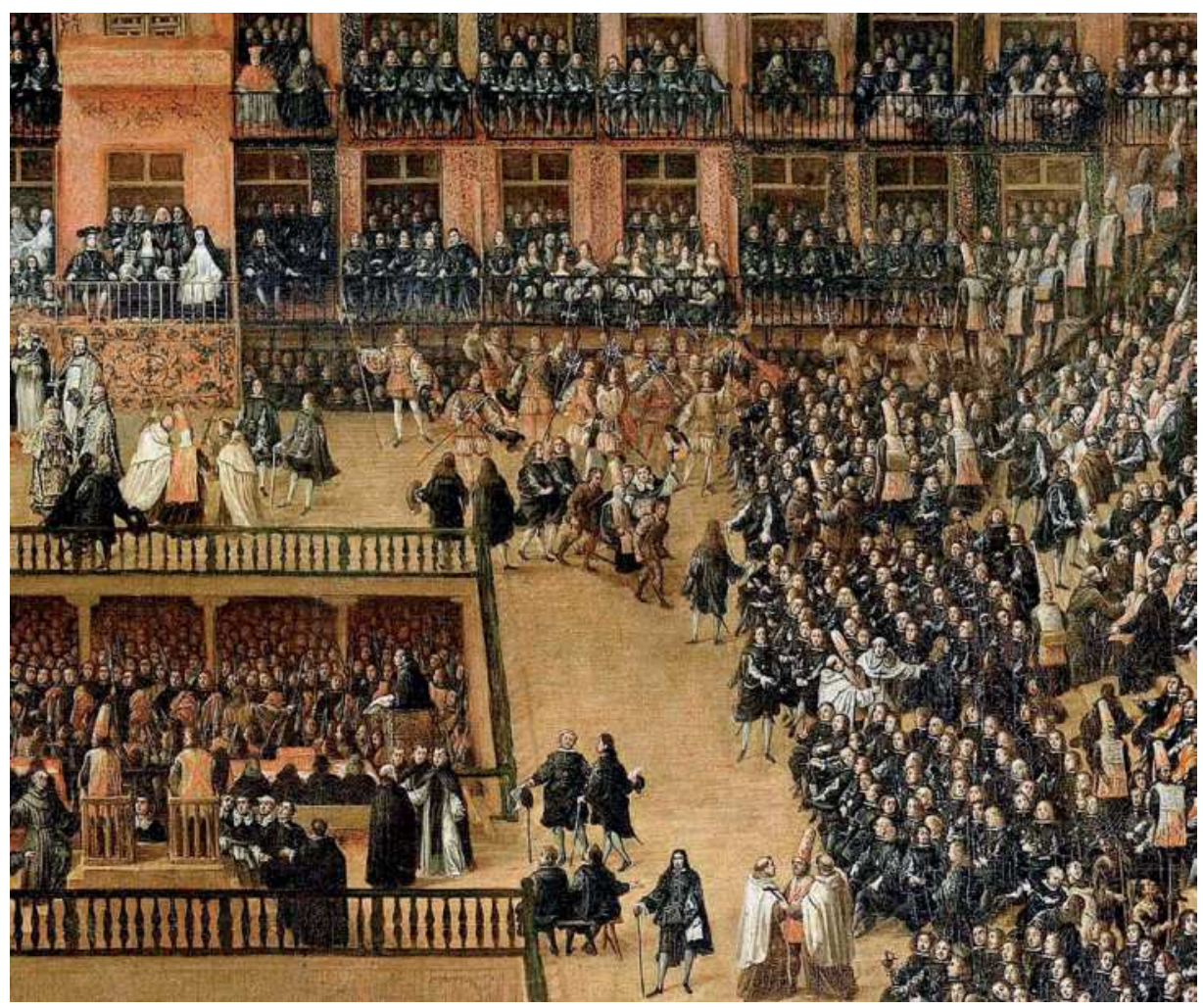

Abb. 4: Darstellung einer im offenen Tragsessel transportierten „reuigen Sünderin“ während eines in Madrid abgehaltenen Autodafés. Francisco Rizi, Autodafé auf der Plaza Mayor in Madrid (Detail), 1683. MNP, Inv.-Nr. Po1126. @ MNP

dad de Nuestra Señora del Refugio oder die bereits etwas früher in Toledo existierende Fraternität gleichen Namens ${ }^{\circ \circ}$ (Abb. 3). Selbst die Justiz verwendete Tragsessel, um alte und kranke Gefangene bequem und diskret befördern zu können. ${ }^{\text {rr }}$ So ist etwa auch auf einem Gemälde von Francisco Rizi, das ein I680 in Madrid abgehaltenes Autodafé zeigt, eine „reuige Sünderin" zu erkennen, die in einem offenen Tragsessel transportiert wird (Abb. 4).

90 Gerónimo de Quintana, A la muy antigua, noble y coronada villa de Madrid. Historia de su antigüedad, nobleza y grandeza, 2 Bde. (Reproduktion der Auflage Madrid I626, Madrid I980), Bd. I, S. 454. Zum Gemälde siehe Alejandro López Álvarez, Algunas notas sobre La ronda de pan y huevo de Luis Tristán (I624) y su copia anónima (I660). In: Laboratorio de Arte 3I (2019), S. 287-304.

9I Gabriel Maura Gamazo, Carlos II y su corte, 2 Bde. (Madrid I9II-I9I5), Bd. 2, S. ii6. 
Die hier skizzierten Entwicklungen lassen sich auch für Amerika beobachten, wo Spanier, die einen gewissen gesellschaftlichen Rang innehatten, ebenfalls Tragsessel verwendeten. Mehrere Berichte aus den I540er Jahren bestätigen, dass für die Beförderung Kranker Sessel mit Trageholmen ${ }^{92}$ beziehungsweise Tragsessel, die „vier Männer auf Schultern trugen “, eingesetzt wurden. ${ }^{33}$ Wahrscheinlich trugen auch die Unwegsamkeit vieler Straßen und der Komfort, den Tragsessel boten, zu ihrem Erfolg bei. So verlangte etwa ein Kranker die Anfertigung eines Tragsessels mit langen Holmen, weil er meinte, dass er darin komfortabler fortbewegt werden könne als auf einer Tragbahre. ${ }^{94}$ Nicht wenige Heerführer zogen in Übersee im Tragsessel in den Kampf, beispielsweise Pedro de Valdivia, der 1550 darin von vier Schwarzen getragen wurde, oder Villagra, der sich I56I in gleicher Weise auf das Schlachtfeld begab. ${ }^{95}$ Francisco Núñez de Pineda y Bascuñana erinnerte sich, dass sein Vater, nachdem er von vierzig Jahren Armeedienst in Chile schwere körperliche Schäden davongetragen hatte, einäugig und mit verkrüppelten Beinen ins Feld gesandt wurde und dabei einen Tragsessel verwenden musste. ${ }^{96}$

Bald begannen an den Höfen der amerikanischen Vizekönige auch gesellschaftlich höherstehende Personen Tragsessel zu benutzen und folgten darin den Modevorgaben Madrids. In Lima besaß beispielsweise Vizekönig Martín Enríquez in seinem Todesjahr 1583 einen Tragsessel „mit Vorhängen aus schwarzem Damast und Silberringen“97.

92 Gonzalo Fernández de Oviedo, Historia general y natural de las Indias (Biblioteca de Autores Españoles desde la formación del lenguaje hasta nuestros días I2I, Madrid I846-I999), S. I9.

93 "[... en hombros traían cuatro hombres“. Documentos relativos al licenciado Pedro Gasca sobre la comisión que le dio Carlos V en 1545 para ir a pacificar el Perú, sublevado por Gonzalo Pizarro y los suyos. In: Fernández de Navarrete/Salvá/Sáinz de Baranda i842-I895 (wie Anm. 37), Bd. 49, S. 302.

94 „[... que le hiciesen una silla, y en ella puestas unas varas algo cumplidas para en que fuese, porque él iría sentado en la silla mejor que en andas". Pedro de Cieza De León, Las guerras civiles peruanas, ca. I553-I584 (Obras Completas 2, hg. und kommentiert von Carmelo Sáenz de Santamaría, Madrid 1985), S. I20.

95 Augusto Miluán, Historia de la minería del oro en Chile (Santiago de Chile 200I), S. 45, 5 I.

96 „[... ${ }^{y}$ de esta suerte le mandaban asistir y gobernar los ejércitos, trayéndolo en una silla de manos". Francisco Núñez de Pineda y Bascuñán, Cautiverio feliz, hg. von Mario Federico Podestál Raïssa Kordic Riquelme, 2 Bde. (Biblioteca antigua chilena 5, Santiago de Chile 20oI), Bd. I, S. $75 \mathrm{f}$.

97 „[... [ con sus cortinas de damasco negra y sortijas de plata“. Carlos Alberto GonzÁLEz Sánchez, Dineros de ventura: la varia fortuna de la emigración a Indias (siglos XVI-XVII) (Universidad de Sevilla, Geografía e historia 9, Sevilla 1995), S. I86. 


\subsection{Tragsessel in Spanien und Amerika im 17. Jahrhundert}

Bis Anfang des 17. Jahrhunderts dominierte die Ansicht, Tragsessel seien allein ein Transportmittel für Frauen, Alte und Gebrechliche..$^{98}$ Diese Einschätzung änderte sich jedoch, als auch hochrangige Amtsträger am Hof begannen, nach dem Beispiel der Monarchen Tragsessel zu nutzen, um derart ihren hohen gesellschaftlichen Rang zu betonen. So besaß etwa der Duque de Lerma mehrere Tragsessel. Einige davon waren sehr aufwendig, andere hingegen vergleichsweise schlicht gestaltet. Für manche ist dokumentiert, dass er sie als Geschenk erhalten hatte. Seine Tragsessel waren unterschiedlichen Zwecken gewidmet. Unter anderem dienten sie dazu, sich ungesehen in den Gängen seines nahe Burgos gelegenen Palasts in Lerma fortzubewegen. ${ }^{99}$ Die Bedeutung seiner Tragsessel bei den 1615 zelebrierten Hochzeiten wurde bereits an anderer Stelle erwähnt. In den Genuss eines Tragsessels kam auch ein Günstling des Duque de Lerma, Don Rodrigo Calderón, der damit vom Palast bis in seine Unterkunft befördert wurde, nachdem im September I604 ein Attentat auf ihn verübt worden war. ${ }^{100}$ Der portugiesische Schriftsteller und Politiker Tome Pinheiro da Veiga erachtete Tragsessel als notwendig, um die Schicht der Herrschenden deutlich aus der Gruppe der übrigen Personen hervorzuheben, etwa den Conde de Miranda, Präsident des königlichen Rats von Kastilien, von dem Pinheiro berichtete, dass er, der entsprechend dem Machtgefüge der Monarchie die zweitwichtigste Position hinter dem König einnahm, stets Kutsche, Sänfte und Tragsessel hinter sich herbringen ließ. ${ }^{\text {Ior }}$

98 Die Quellen jener Zeit erwähnen für gewöhnlich, wenn Personen am Hof aufgrund einer Behinderung von Tragsesseln Gebrauch machten. So wurde im Februar 1599 berichtet, dass sich der gichtleidende Duque de Terranova dem Monarchen in einem Tragsessel näherte, um ihm die Hände zu küssen („como impedido de su gota [...] en la silla que le habian llevado"). Als sich $160 \mathrm{or}$ ein hoher militärischer Repräsentant anlässlich der Bestätigung von Friedensvereinbarungen zwischen Spanien und Frankreich im Tragsessel zur Kirche begab, wurde ebenfalls unterstrichen, dass er unpässlich gewesen sei. Und als Juan de Borja im Januar 1606 zum Obersthofmeister der Königin ernannt wurde, ist den Quellen zu entnehmen, dass er wegen eines Gichtleidens an den Beinen im Tragsessel zum Dienst erschien, um an den Ratssitzungen teilnehmen zu können. Schließlich wurde I608 erwähnt, dass der gehörlose Conde de Miranda im Tragsessel nach Alcalá kam, da ihn seine Leiden stark beeinträchtigten („muy impedido de sus achaques"). CABrera de Córdoba I857 (wie Anm. 20), S. 6, IO2, 269 und 332.

99 Luis Cervera Vera, El conjunto palacial de la villa de Lerma (Estudios de Urbanismo, Arquitectura y otras Artes I, Madrid 1967), S. 375 und 392; Luis Cervera Vera, Bienes muebles en el palacio ducal de Lerma (Estudios de Urbanismo, Arquitectura y otras Artes I, Madrid 1967), S. $48 \mathrm{f}$. und $\mathrm{I} 45 \mathrm{f}$.

ioo Cabrera de Córdoba i857 (wie Anm. 20), S. 227.

ioi Tomé Pinheiro da Veiga, Fastiginia. Vida cotidiana en la Corte de Valladolid, i605, hg. von Narciso Alonso Cortés (Valladolid 1973, I. Auflage 1916), S. I26 f. Siehe dazu auch die Satire von Bartolomé Leonardo de Argensola, Sátira del incógnito. In: Luis Cortés Vázquez, La vida estudiantil en la Salamanca clásica (Salamanca I996), S. 23. 
Dass die machtvolle Stellung des Präsidenten des Kastilischen Rates im Lauf der Zeit noch weiter an Bedeutung gewann, belegt die Tatsache, dass er regelmäßig im Tragsessel zu Ratssitzungen gebracht wurde und sich auch innerhalb der Sitzungszimmer und anderer Räume im Hofbereich darin befördern ließ. Hierfür waren im Zeremoniell verschiedene Regeln vorgesehen. Nach Abschluss der Audienz

begleiteten jene Herren Minister, die bis zur ersten Kammer ihren Dienst verrichten, den Herrn Präsidenten oder Gobernador bis zu jener Stelle, an der er in den Tragsessel steigt. Anschließend gehen zwei Kammertürhüter und zwei Hofgerichtsdiener voran und machen den Weg bis zur Vorhalle frei, wo er die Kutsche oder Karosse besteigt. Bleibt er jedoch im Tragsessel, so folgt ihm dieselbe Begleitung von Türhütern und Gerichtsdienern bis zu seiner Unterkunft. Die Plätze in der Ehrenkutsche nehmen in diesem Fall seine Kapläne und Mitglieder seines Anhangs ein. ${ }^{\text {IO2 }}$

Der Präsident konnte jedoch auch zu anderen öffentlichen Anlässen im Tragsessel erscheinen. „Stets dann, wenn er im Tragsessel ausging und wenn er in der Karwoche Kirchen besuchte", musste ihn auch ein Turhüter des Rates begleiten. ${ }^{103}$

Die Tatsache, dass ab I604 nur noch jene Männer Tragsessel besitzen durften, die sich im Besitz einer Lizenz befanden - ein Phänomen, das wir als „Institutionalisierung“ bezeichnet haben -, sowie der immer häufigere Gebrauch von Tragsesseln seitens der Königin führten zweifellos dazu, dass sich am Hof vermehrt auch Damen in Nachahmung des königlichen Zeremoniells tragen ließen. Dafür sprechen mehrere Indizien: Unter anderem wurde damals ein Zeremoniell verfasst, das das öffentliche Erscheinen von Damen am Hof regelte. Zwar existierten möglicherweise auch schon davor entsprechende Vorschriften, jedoch finden sich erst in Quellen von Anfang des I7. Jahrhunderts entsprechende Hinweise dazu. Das vielleicht wichtigste Werk über das Zeremoniell am spanischen Hof stammt aus der Feder von Yelgo de Vázquez. Anhand dieser Abhandlung, die übrigens dem Duque de Uceda - dem Sohn des königlichen Günstlings Duque de Lerma - gewidmet ist, lässt sich gut nachvollziehen, dass sich Tragsessel neben Kutschen zu den bevorzugten Vehikeln von Hofdamen entwickelt hatten. Die Damen wurden auf der Straße in ihren Tragsesseln von

IO2 „[...] los Señores Ministros, que asisten a la Sala primera, acompañan al Señor Presidente, o Gobernador hasta el sitio donde toma la Silla de manos; y después dos Porteros de Camara, y dos Alguaciles de Corte, van delante facilitando el paso hasta el Zaguán donde toma el Coche, o Carroza; pero sino dexa la Silla, lleva el mismo acompañamiento de Porteros, y Alguaciles hasta la Posada, y el Coche de respeto le ocupan sus Capellanes, y Familia“. Antonio Martínez SaLAzar, Colección de memorias, y noticias del gobierno general, y político del Consejo (Reproduktion der I. Auflage, Madrid I764, Madrid 2002), S. 3I f.

io3 Martínez Salazar 2002 (wie Anm. IO2), S. 3I-34, 40, 63, 199, 633 f. und 709 f. 
zahlreichen Bediensteten begleitet, die sie beschützten, gleichzeitig aber auch ihrem Auftritt größeren Glanz verleihen sollten. Auf diese Weise konnten die Damen einerseits vor aller Augen ihren sozialen Status demonstrieren, andererseits wurden auch ihre Unnahbarkeit gesteigert und ganz allgemein ihre Rolle im öffentlichen Raum weiter ausgebaut - Entwicklungen, die sich schon zuvor bei Männern am Hof beobachten ließen. Yelgo de Vázquez erteilte adeligen Herren die Anweisung, in Kutschen fahrende Damen zu Pferd zu begleiten. Sollten die Damen aber in einem Tragsessel ausgehen, so sollten die Herren an der Seite des Vehikels zu Fuß mitgehen, um zu verhindern, dass sich jemand dem Sessel näherte. Bei all dem darf nicht außer Acht gelassen werden, dass den Frauen auf diese Weise ein geschlossener Raum vorgegeben wurde, was eine kontinuierliche Überwachungssituation für sie und für jene Personen bedeutete, denen sie unterwegs begegneten. Hinsichtlich Besuchen gab Yelgo de Vázquez folgende Verhaltensrichtlinien:

[...] der Dame sollen sämtliche Edelleute und Amtsträger vorangehen [...]. Empfängt die Dame Besuch, so dürfen sie keinen Schritt vor das Haus setzen, sondern müssen warten, bis die Damen, die ihrer Herrin einen Besuch abstatten, wieder gehen. Beim Verlassen des Hauses haben sie voranzugehen und dürfen nicht zurückbleiben, selbst dann nicht, wenn die Herrin oder der Herr darauf bestehen sollten, vielmehr müssen sie sie bis zum Tragsessel oder zur Kutsche begleiten. ${ }^{\text {I04 }}$

Hinzu kommt, dass am Hof niemand in Konkurrenz zu den Damen treten durfte. Bereits im Jahr I600 wurde Prostituierten die Nutzung von Kutschen, Karossen und Sänften untersagt. ${ }^{\text {105 }}$ Dieses Verbot wurde I6II auch auf Tragsessel ausgedehnt, was deren gesteigerte

IO4 „[...] irán delante de la señora todos los Gentileshombres, y oficiales [...]. Y cuando la señora reciba visitas, no han de salir de casa un punto aguardando que salgan las señoras, que han venido a visitar a su ama, y en saliendo han de ir delante; y no se han de quedar, aunque más porfíe la señora, o señor, que se quede, hasta dejarlos en la silla, o coche“. Miguel Yelgo de VÁzquez, Estilo de servir a Príncipes con exemplos morales para servir a Dios (Madrid I6I4), BNE, R 2868, fol. IoIv-IO2r. Die Notwendigkeit, Damen im Tragsessel abzuschirmen, war keineswegs nur ein literarischer Allgemeinplatz, sondern hatte handfeste Gründe. Dies illustrieren folgende Beispiele aus Madrid: Im Jahr 166I stellte Francisco de Almaraz die Bitte, ihm eine vierjährige Haftstrafe in Afrika zu erlassen, die er nach einem Angriff auf die Dienerschaft der Condesa de Benavente erhalten hatte, als diese im Tragsessel durch die Gasse Callejuela del Postigo de San Martín ging. Ein anderes Beispiel datiert von I708, als Söhne des Marqués de Valdetorres Sesselträger erstachen, die ihnen den Vortritt verweigert hatten. Die Opfer hatten den leeren Tragsessel des Duque de Veragua befördert. AHN, Consejos, Leg. 4437/ 55 und Leg. 715I, unfol.

IO5 Das Gesetz lautete, dass "ninguna muger que públicamente fuere mala de su cuerpo, y ganare por ello, pueda andar en coche, ni carroça, en esta nuestra Corte, ni en otro algun lugar destos nuestros Reynos, sopena de quatro años de destierro della, con las cinco leguas, y de qualquier otros lugar y su jurisdicción 
Wertschätzung am Hof widerspiegelt. ${ }^{106}$ Mit dem Herrschaftswechsel von I62I verstärkten sich die Forderungen, Damen, die Tragsessel benutzen duften, von all jenen zu trennen, denen dies untersagt war. In diese Kerbe schlug beispielsweise Eugenio de Narbona, der die Auffassung vertrat, dass „zwischen ehrbaren Frauen und jenen, die dies nicht sind, unterschieden werden müsse. Letzteren dürfe nicht zugestanden werden, was Ersteren erlaubt sei." In seiner Argumentation berief er sich auf Sueton:

Die Römer unterschieden sich in vielerlei Hinsicht voneinander, und Domitian ordnete an, dass Frauen, die nicht Mitglied einer Senatorenfamilie waren, auch nicht in einem Tragsessel getragen werden durften. ${ }^{107}$

Die Definition von Tragsesseln als Gegenstände, die Hofdamen unmittelbar zugehörig waren, findet sich bei mehreren Autoren, die Tragsessel als eigentümlich weiblich betrachteten. ${ }^{108}$ Auch wenn man von derartigen Allgemeinplätzen absieht, lässt sich doch nicht

a donde anduviere en coche, o carroça, por la primera vez: y por la segunda sea trayda a la verguença públicamente y condenada en el dicho destierro". Premática en que se prohíben colgaduras y adereços de casas de brocados, y telas de oro y plata y bordado, y hechura de joyas de oro y pieças de plata, y se da la forma en ella contenida, y se permite traer cuellos de ochava con almidón, I60o, RAE, I3-A-23 (40).

Io6 Das Gesetz untersagte Prostituierten den Gebrauch von Kutschen, Karossen, Sänften und Tragsesseln bei einer Strafe von vierjähriger Verbannung beim ersten und von öffentlicher Anprangerung und Verbannung beim zweiten Verstoß. In: Nueva Recopilación (Madrid I775), Libro VI, Título XIV, ley VIII. Mit Hilfe eines geschlossenen Tragsessels ließen sich sowohl die darin sitzende Person als auch ihr sozialer Status gut verbergen. In anschaulicher Weise zeigt dies die mit einer aufklappbaren Papierlasche versehene Darstellung eines neapolitanischen Tragsessels. Ist die Lasche geöffnet, zeigt sich die im Tragevehikel sitzende Dame der Öffentlichkeit. Bei geschlossener Lasche ist der Vorhang des Tragsessels hingegen komplett zugezogen, und die transportierte Dame kann von Passanten nicht mehr gesehen werden. Siehe dazu Abbildung 5 im Beitrag von Attilio Antonelli, Stefano Moscatelli und Ilaria Telesca.

IO7 "Los Romanos tuvieron muchas cosas en que se diferenciavan, y Domiciano mandó que ninguna mujer que no fuesse de familia de senador, pudiera andar en silla de manos". Eugenio de NARBONA, Doctrina política civil, escrita por Aphorismos: sacados de la doctrina de los Sabios, y exemplos de la experiencia (Madrid I62I), BNE, 3/30.083, CCLXXVII, S. 99r. Narbona passte den Text den Bedürfnissen der Gegenwart an, denn bei Sueton ist zu lesen, Domitian habe „lasterhaften Frauen den Gebrauch von Sänften verboten“ („prohibió utilizar litera a las mujeres licenciosas"). Caius SuEtonius Tranquillus, Vidas de los doce césares [De vita Caesarum], übersetzt und kommentiert von Rosa María Agudo Cubas, 2 Bde. (Biblioteca clásica Gredos I67-I68, Madrid 1992), Bd. 2, S. 325 .

Io8 Hierzu seien einige Beispiele angeführt. Der Franzose Bassompierre berichtete etwa, dass bei einem auf eine Prozession folgenden Kirchgang nach dem Verstummen der Glocken „les carrosses cesent d'aller par la Ville. On ne va plus à cheval, ny les dames en chaise“. François de Bassompierre, Memoires 
abstreiten, dass es häufig Damen waren, die sich am Hof im Tragsessel und mit der dazugehörigen Begleitung zeigten. Dies machte auch der französische Reisende Brunel in folgenden Zeilen deutlich:

[...] geht man nachts durch den Ort, werden weder Fackeln noch Kerzen getragen; und ich habe keine Person - welcher Herkunft auch immer - gesehen, die in einer Karosse, zu Pferd oder zu Fuß unterwegs war, die welche mit sich geführt hätte; einzig und allein die hohen Damen machen von ihnen Gebrauch, vor allem jene des Hofes, die derart die Zahl ihrer Lakaien zur Schau stellen. Tatsächlich gehen Frauen hier mit größerem Pomp aus als ihre Männer, denn neben einer Vielzahl von Amtsträgern, die ihre Tragsessel umgeben, folgt ihnen stets auch ein Diener zu Pferd. ${ }^{\text {I09 }}$

Derartige Umzüge, bei denen die Damen mit ihrem großen Gefolge an Dienern und nicht zuletzt mit ihren Tragsesseln glänzten, wurden zu unterschiedlichen Anlässen veranstaltet, etwa auf dem Weg zum Palast und von dort wieder zurück in die eigene Unterkunft. Ein Beispiel hierfür ist der Empfang der Herzogin von Chevreuse im Jahr I637. Sie wurde von

denselben Damen, die sie in Tragsesseln, mit einer großen Zahl an berittenen Dienern sowie mit weiße Äxte tragenden Pagen, zum Palast begleitet hatten, anschließend auch wieder zu ihrem neuen Heim gebracht. ${ }^{\text {IIO }}$

du Mareschal de Bassompierre contenant l'histoire de sa vie de ce qui s'est fait de plus remarquable à la cour de France pendant quelques années, 3 Bde. (Cologne I665), BNE, 3/66.IOI, Bd. 2, S. I30. Antonio de Almansa y Mendoza erwähnte I624 „eine Überflutung des königlichen Schlosshofes mit Kutschen und Tragsesseln der Damen“ („una inundación de carrozas y sillas de las señoras"). Relación de capitulaciones de los señores Marqueses de Toral, y boda del señor Condestable de Castilla, máscara, y acompañamiento de su Magestad. In: Simón Díaz 1982 (wie Anm. 32), S. 294-302, hier S. 294. Am Ende des 17. Jahrunderts war die Gräfin von Aulnoy der Ansicht, dass in Madrid „pour de chaises l'on en autant que l'on veut; mais ce n'est guére la coûtume ici que les hommes se fassent porter en chaise, à moins qu'ils ne soient fort vieux ou fort incommodez", Marie Catherine LE JUMEL DE BARNEville d'Aulnoy, Relation du Voyage d'Espagne (Paris I69I), WLB, Geogr. Oct 255, S. I52.

I09 "[...] cuando se va por la villa, de noche, no llevan antorcha ni candela; y no he visto a ninguna persona, de cualquiera condición que sea, que las llevase, en carroza, a caballo o a pie; tan sólo las grandes damas se sirven de ellas, y sobre todo las de la corte, que hacen entonces alarde del número de sus lacayos. Verdad es que las mujeres salen aqui con más lustre que sus maridos, porque, aparte de la multitud de oficiales que van alrededor de sus sillas, llevan siempre siguiéndolas un escudero a caballo". García Mercadal 1999 (wie Anm. 7), Bd. 3, S. 295. „[...] las mismas señoras que la condujeron a Palacio a sillas de manos con mucho séquito de criados a caballo y pajes con hachas blancas, la llevaron a su nuevo hospicio". Venida de Madama Chevrosa a estos reinos, in Cartas de algunos Padres de la Compañía de Jesús sobre los sucesos de la Monarquía entre los años de i634 y i648. In: Memorial histórico español (wie Anm. 70), Bd. I4, S. 263-266. 
Auch das Ablegen des Ordensgelübdes durch ein Familienmitglied konnte Anlass sein, eine Parade mit Tragsesseln abzuhalten, wie dies etwa für den August I639 dokumentiert ist, als Doña Benita de Valladares, eine Nichte des Generalinquisitors, ins Kloster der Descalzas Reales eintrat. Als Paten waren der Duque de Villahermosa, der Conde de Ficallo und die Condesa-Duquesa de Sanlúcar anwesend. Darüber hinaus nahm auch das Königspaar an der Zeremonie teil

und infolgedessen auch alle Granden von Spanien: Die Braut und die Trauzeugin kamen in Tragsesseln, begleitet von der Dienerschaft ihrer Häuser, jener von Monterrey, Carpio, Alcañices sowie der ihrer Verwandten. ${ }^{\text {III }}$

Da der Conde-Duque de Olivares in jenen Jahrzehnten der bedeutendste Vertrauensmann des Königs war, kam auch seiner Gemahlin bei solchen Veranstaltungen eine entscheidende Rolle zu. Als am Tag des heiligen Benedikt im März I64I eine Kammerdienerin der Königin, Doña Ana María de Cerceda, eine Tochter von Doktor Roger, dem Vorsteher von Señorío de Molina, als Nonne in den Orden der Barfüßigen Karmeliterinnen eintrat, „stand das Königspaar Pate und die Condesa de Olivares führte sie im Tragsessel und mit großem Gefolge zum Kloster." Tragsesselumzüge am Königshof waren wichtige gesellschaftliche Ereignisse, bei denen adelige Damen ihre familiären Netzwerke und höfischen Beziehungen ins Spiel bringen konnten. Dies zeigt sich beispielsweise anlässlich der am 28. Mai 1642 erfolgten Eheschließung des Sohnes des Conde-Duque de Olivares, Felipe Enrique de Guzman, mit Juana de Velasco. Im Anschluss an die in der Palastkapelle abgehaltene Trauung

führte die Condesa Duquesa de Olivares die Braut spätabends in Tragsesseln und mit großem Gefolge zu ihrem Heim, das sich im Haus des Conde de Chinchón befand, wo die Hochzeit vollzogen wurde. ${ }^{112}$

Einem Bericht der Gräfin d'Aulnoy ist zu entnehmen, dass die Prozession mehr als fünfzig Tragsessel und ebenso viele Karossen umfasste, die den Weg vom Schloss der Duquesa

III „[... [ y en esa consecuencia toda la Grandeza de España: vinieron novia y madrina en sillas, acompañadas de los criados de las casas suya, Monterrey, Carpio, Alcañices, y todas las de la parentela“. Antonio VAlladares de Sotomayor, Semanario erudito, que comprende varias obras inéditas críticas, morales $[\ldots]$ y jocosas de nuestros mejores autores antiguos, y modernos, 34 Bde. (Madrid I787-I79I), Bd. 3I, S. 6I.

II2 „[... a la noche sacó la Señora Condesa Duquesa de Olivares en sillas y con acompañamiento grande, a la novia, a su casa, que es en las del señor conde de Chinchón, y se consumó el matrimonio". VAlLADares de Sotomayor i787-I79I (wie Anm. III), Bd. 3I, S. 6I, Bd. 32, S. i8 und 267. 
de Frías zu dem der Duques de Uceda einschlugen. Aulnoy machte auch nähere Angaben zum schlichten Aussehen der mit drei Gläsern versehenen Tragsessel der adeligen Damen, die von jeweils vier Lakaien befördert wurden, die einander streckenweise ablösten und stets zu zweit Dienst versahen. Aufgabe eines der Diener war es, den Hut des vorderen Sesselträgers zu halten. Die an Informationen überaus reiche Beschreibung Aulnoys sei hier ausführlich wiedergegeben:

[...] les Dames se visiten fort, $\&$ rien ne leur est plus aisé que de prendre una mante, d'entrer dans une chaise par la porte de derriere, $\&$ de se faire porter où elles veulent. [...]. [...] on les fait extrêmement grandes \& larges, \& pour q'elles soient moins Lourdes, elle ne sont que de simple étoffe tenduë sur un chassis de bois. Ces étoffes sont toûjours meslées d'or $\&$ d'argent, $\&$ fort magnifiques. Il y a trois grandes glaces, $\&$ le dessus est d'un cuir trés-mince, couvert comme le reste; il se leve pour que la Dame entre $\&$ sorte plus commodement. L'on a quatre porteurs que se relayent, un Laquais porte le chapeau du porteur de devant; car quelque mauvais temps qu'il fasse, il ne faut pas qu'il soit couvert devant la maistresse. La Dame est enchassée dans sa chaise comme un diamant dans son chaton. [...]. Il y a un carrosse à quatre mules, avec ses longues traits [...] qui suit la chaise au petit pas. Il est d'ordinaire rempli de deux vieux Escuyers \& de cinq ou six pages; car elles en ont toutes, [...]. Les Dames ne menent jamais aucune de leurs femmes, \& bien qu'elles se trouven plusieurs ensemble qui vont au même endroit, elles montent chacune dans leur chaise sans se mettre les unes avec les autres dans leur carrosse. Je me trouvais l'autre jour dans un embaras, \& je vis passer cinquante chaises \& cinquante carrosses à la file. L'on sortoit de chez la Duchesse de Frias, \& l'on alloit chez la Duchesse d'Uzeda. Je vous dirai pourquoi ells y alloient, quand je vous aurai dit que la Dame estant arrivée chez celle qu' elle va voir, ses porteurs la porte jusques dans l'anti-chambre. Les degrez sont faites exprés fort larges $\&$ fort bas pour qu'on les puisse Monter avec plus de facilité. ${ }^{\text {I3 }}$

Obwohl Tragsessel weiblich konnotiert waren und dem Frauen zugeschriebenen weichen und sanften Wesen entsprachen, ${ }^{\text {Ir } 4}$ ließen sich auch zahlreiche Männer nicht davon abhalten, selbst Tragsessel zu verwenden. Fest steht, dass ab I604 viele Männer versuchten, in den Besitz eines Tragsessels zu gelangen, um jene nachzuahmen, die dieses Privileg bereits genossen, namentlich hochrangige Herren, Diener des Königs sowie die mächtigsten Kle-

ii3 Le Jumel de Barneville d’Aulnoy i69i (wie Anm. io8), S. 235-239.

II4 Sich im Tragsessel befördern zu lassen wurde auch als „Übung für Schwache“ („exercicio para los flacos") betrachtet. Juan Sorapán de Rieros, Medicina española contenida en proverbios vulgares de nuestra lengua (I6I6), hg. von Antonio Castillo de LuCAs (Biblioteca clásica de la medicina espańola ı6, Badajoz ı99i [Faksimile der Erstausgabe, Madrid I6ı6]), S. 389. 
riker der Monarchie. Damit setzte eine Entwicklung ein, die einige Jahrzehnte später eine massive Ausprägung finden sollte. ${ }^{\text {Is }}$ Tragsessel fanden sukzessive Eingang in die Marställe der meisten Adeligen und der einflussreichsten Geistlichen. ${ }^{116}$ Diese Personen zeigten sich zu verschiedensten Anlässen öffentlich in ihren Tragevehikeln. So berichtete der französische Botschafter in Spanien über seinen im März I62I erfolgten Empfang in Madrid durch den Duque de Osuna:

En suite le Duc d'Ossuna me vint salüer en apparat extraordinaire: car il estoit porté en chaise [...]. Plus de vingt carosses le suivant, remplis de Seigneurs Espagnols, ses parents $\&$ amis, ou de Seigneurs Napolitains: a l'entour de sa chaise plus de cinquante Capitaines, Tenientes ou Alfereces reformados, Espagnols ou Napolitains. ${ }^{\text {II7 }}$

Am königlichen Hof entwickelten sich Tragsessel zum Mittel der Selbstdarstellung. Sie wurden als Zeichen von Macht und Prestige der Öffentlichkeit vorgeführt. In diesem Sinne erregte der Hofmeister der Königin, Marqués de Velada, bei seiner Abreise aus Madrid großes Aufsehen. Er zog mit einem großen Gefolge aus, bei dem in Anschluss an Kutschen, Sänften und eine Chaise-Roulante auch „der in Grün und Gold gehaltene Tragsessel Seiner Exzellenz mit sechs Sänftenknechten folgte “" ${ }^{\text {"I8 }}$. Aber nicht nur am Hof selbst

II5 Die Vorliebe der Aristokratie für Tragsessel illustriert ein Kommentar Barrionuevos über das Pferd des Conde de Peñaranda, das „ihn kopfüber abwarf und ihn gewiss zur Strecke gebracht hätte, wäre er nicht von Dienern umringt gewesen, die ihn auffingen“ („,le echó por las orejas, y a no hallarse tan rodeado de criados, que le recogieron en los brazos, se tiene por cierto que acabara con él"). Das Tier, so Barrionuevo, sei wohl „verärgert darüber gewesen, ihn stets - gleich vielen anderen - wie eine Dame im Tragsessel zu sehen, und entledigte sich deshalb seiner Last“ („de enfadarse de verle andar siempre en silla de manos como dama, como hacen otros muchos, y desechó la carga facilmente"). Barrionuevo de Peralta i968-I969 (wie Anm. 55), Bd. 2, S. 9.

II6 Dies geht aus Stallmeister-Instruktionen hervor, die die gewachsene Bedeutung von Sesselträgern belegen. Dieses Dienstpersonal bedurfte nun auch einer besonderen Kontrolle. In den Anordnungen für einen herzoglichen Stallmeister wurde dieser etwa dazu angehalten, dafür zu sorgen, dass die Sesselträger nicht mit der ihnen übergebenen Livree das Weite suchten, sondern ihre volle Dienstzeit leisteten und nach ihrer Entlassung ihr Dienstkleid wieder rückerstatteten, damit es anschließend ihren Nachfolgern weitergegeben werden könne (,[... con las libreas sino que den seguridad de servir el tpo que están obligados y quando alguno se despidiere se le a de quitar la librea para dar al que entrare en su lugar"). La orden que a de tener el cavallerizo en el exerçiçio de su officio (I6I9), AZ carpeta 292/24.

ii7 Bassompierre i665 (wie Anm. io8), Bd. 2, S. I07.

II8 „[... la silla de manos de Su Excelencia, verde y oro, y seis Esclavos Litereros“. Relación de la forma en que salió desta Corte, e Imperial Villa de Madrid el Excelentíssimo Sr Marqués de Velada, y Astorga, Mayordomo Mayor de la reyna nuestra señora D. María Luisa de Borbón, en 26 de Setiembre deste año I679. llevando la Real Casa de su Magestad al Viaje de Irún, por la Reyna nuestra Señora (Madrid I679), BNE, R 24.575, fol. 242r-v. 
benutzten Adelige ihre Tragsessel, sondern auch in ihren eigenen Herrschaftsgebieten, wo sie ihre Machtstellung wie an keinem anderen Ort zur Entfaltung bringen konnten. Der Franzose Bertaut schilderte etwa mit Erstaunen die Ausstattung adeliger Marställe, die er bei einer Corrida im nahe Sevilla gelegenen Ecija in Augenschein nehmen konnte: Während der Marqués de Priego mit einem mittelgroßen Gefolge auftrat, erschien der Duque de Osuna

mit drei sechsspännigen und zwei vierspännigen Maultierkarossen; seine Frau wurde im Tragsessel getragen; hinzu kamen noch zwölf oder fünfzehn Männer zu Pferd oder Maultier sowie zwei Trompeter. ${ }^{\text {II }}$

Auch bei der Hochzeit des Duque de Braganza mit der Tochter des Duque de Medina Sidonia im Jahr I633 wurde ein außergewöhnlicher Aufwand betrieben. Der Bräutigam hatte seiner Braut eine von äußerst prachtvollen Pferden gezogene Karosse, die mit vergoldeten Bauteilen aus Silber versehen war, für ihren Einzug in Elvas bereitgestellt. Außerdem hatte er ihr einen von zwei groß gewachsenen Schwarzen („dous negros grandes") getragenen Tragsessel zugesandt, einen weiteren von zwei Maultieren beförderten Tragsessel sowie viele Sänften und Kutschen („muitas Liteiras; e Coches“). Am Hochzeitstag kam die Duquesa in einer Karosse und in Begleitung von zwei Kammerdienern ihres zukünftigen Gemahls bei der Kathedrale von Elvas an. Nachdem sie das Gefährt verlassen hatte, stieg sie in den von den beiden Schwarzen bedienten Tragsessel und ließ sich in den Kirchenraum bringen. Nach Beendigung der Trauungszeremonie verließ die Duquesa in gleicher Weise wieder die Kirche und begab sich zum Bischofspalast, wo ein Bankett gegeben wurde. ${ }^{\text {I20 }}$ Im Jahr I640 kam es zu einer Eheschließung zwischen Mitgliedern der herzoglichen Häuser von Medina Sidonia und Priego. Unmittelbar nach der Hochzeit in Montilla begab sich das Brautpaar auf den Weg nach Cádiz und machte unterwegs in Ecija halt, wo die beiden Jungvermählten in einer Karosse einzogen und darin bis zum Rathaus fuhren. Dort angelangt, stieg das Paar aus dem Wagen, und der Duque begleitete seine Gemahlin „zum dort schon bereitstehenden Tragsessel, und so stiegen sie hinauf zum Balkon", wo sie von den in großer Zahl versammelten Einwohnern begrüßt wurden. ${ }^{121}$

II9 „[... [ con tres carrozas de seis mulas y dos de a cuatro; su mujer llevada en una silla, doce o quince hombres a caballo o sobre mulas y dos trompetas". García Mercadal 1999 (wie Anm. 7), Bd. 3, S. 427 f. und 445 .

I20 Relassao do Cazamento do Duque de Barganca Dom Joà̀ segundo deste nome com a senhora Dona Luiça Francisca de Gusman filha do Duque de Medina Çidonia e de tudo o que passou na ocaziao e seu reçebimento (I639), BNE, Mss. I8.633/53, unfol.

I2I „[...] a la silla de manos, que para este efecto estava allí prevenida, y subieron al balcón“. Antonio de Chirino Bernárdez, Panegírico nupcial. Viaje del Excelentísimo señor don Gaspar Alonso Pérez 
Ganz gleich, ob sich adelige Herren in einer Kutsche oder in einem Tragsessel befördern ließen: Ihre Macht erstrahlte aus einer Distanz schaffenden, schützenden Hülle. Aber nicht nur Vertreter der Aristokratie stellten in Madrid und in anderen Städten ihre Tragsessel als Machtsymbole zur Schau. Auch Kleriker taten es ihnen gleich, obwohl die Kirche derartige Zeichen der Verschwendung oftmals verurteilte. ${ }^{\text {I22 }}$ Alles deutet darauf hin, dass die Prachtentfaltung mittels Tragsesseln unter hochrangigen Geistlichen weit verbreitet war. So ließ etwa der Patriarca de las Indias anlässlich der Taufe des späteren Königs Karl II. im Jahr I66I neben drei außerordentlich prunkvoll ausgestatteten Karossen auch einen Tragsessel anfertigen. Er war mit weißem, goldgeblümten Mailänder Seidenstoff und geteilten Vorhängen versehen, mit goldenen Ziernägeln beschlagen und verfügte über kristallene Gläser. ${ }^{\mathrm{I} 23}$ Einem Reisebericht ist wiederum zu entnehmen, dass das Gefolge des Kardinals von Aragon die gesamte Straße einnahm. Der Kardinal selbst ließ sich in einem äußerst prachtvollen Tragsessel befördern. Das Prunkvehikel wurde von sechs einander gelegentlich abwechselnden, livrierten Dienern getragen und von mindestens achtzehn bis zwanzig Lakaien begleitet. ${ }^{124}$ Stadteinzüge oder die Übernahme eines Bistums boten für Kleriker passende Gelegenheiten, sich in reich verzierten Vehikeln zu zeigen. Ein Beispiel hierfür ist eine viermonatige, enorm kostspielige Reise des neu ernannten Erzbischofs von Granada, Fray Alonso de los Ríos y Guzmán, der sich zuerst von Ciudad Rodrigo nach Madrid und anschließend nach Granada begab. Zu diesem Zweck wurden eine große Karosse und eine Sänfte angeschafft, die zusammen 20.00o Golddukaten kosteten. Für den Empfang in Granada wurden zusätzlich Tragsessel angekauft. ${ }^{125}$ Der schon in anderen Zusammenhängen erwähnte Brauch, hochrangige Personen bis

de Guzmán, duque de Medina Sidonia, [...] en las bodas con la Excelentísima señora dońa Juana Fernández de Córdoba, hija del excelentísimo seńor marqués de Priego, duque de Feria (1640), BNE, Mss. I8.653/18, fol. 246-26I.

I22 So hebt ein in huldvollem Ton gehaltenes Werk über den Erzbischof von Sevilla lobend hervor, dass dieser in der Fastenzeit weder eine Karosse noch einen Tragsessel verwendete und auch nicht von Dienern begleitet werde. Vielmehr gehe er - gleich einem Mönch - zu Fuß in die Kirche, begleitet allein von einem einzigen Gefährten. (,[...] a pie, sin carroza, silla, ni criados, sino como dos Religiosos"). Fray Antonio de Lorea, El siervo de Dios Fr. Pedro de Tapia, de la Orden de Predicadores, Obispo de Segovia, Siguenza, Córdova y Arzobispo de Sevilla istoria de su apostólica vida y prodigiosa muerte (Madrid I676), BNE, 2/37.598, S. 313.

I23 „[... [na silla de manos de tela passada de Milán, blanca, con flores de oro, cortinas de dos hazes, clavazón dorada, y vidrieras cristalinas". Descripción del magestuoso aparato, con que se celebró el Bautismo del Príncipe Don Carlos Ioseph, nuestro seńor (que Dios guarde) el Lunes 2I de Noviembre de I66I. In: Eulogio VArela Hervías, Gazeta Nueva i66I-I663 (Notas sobre la historia del periodismo español en la segunda mitad del siglo XVII, Madrid 1960), S. XCV-CI, hier S. XCVI.

I24 García Mercadal 1999 (wie Anm. 7), Bd. 4, S. 484.

I25 Manuel Garzón Pareja, Diezmos y tributos del clero de Granada (Granada 1974), S. I7. 
zum Tragsessel zu begleiten, war auch unter führenden Klerikern verbreitet. Ein Beispiel hierfür bietet Kardinal Portocarrero, der im Jahr I682 nach Beendigung der ersten Sitzung des Konzils von Toledo den feierlichen Segen erteilte, zu Chormantel und Birett griff und

sich in Begleitung in den Innenhof begab, wo der Tragsessel stand. Dort entließ er die Mitglieder des Domkapitels und ließ sich im Tragsessel in sein Quartier bringen. ${ }^{126}$

Im öffentlichen Raum war das Zeremoniell etwas komplexer. Dies demonstriert der Fall des Generalinquisitors, der sich I680 nach einem abgehaltenen Autodafé öffentlich im Tragsessel zeigte. Gegen neun Uhr am Abend, nach Beendigung des Gottesdienstes, wurden ihm die Messgewänder abgenommen und

in Anbetracht der fortgeschrittenen Stunde und da er die Rückkehr zum Rat auf dieselbe Weise und mit gleichem Gefolge bestreiten wollte wie zuvor den Hinweg, beschloss er, seinen Tragsessel aus violettem Plüsch zu nehmen. Begleitet wurde er von seinen Dienern nämlich vier Sesselträgern und davor und dahinter zwölf Lakaien mit dem Beil -, die eine dazu passende Livree trugen, sowie von Don Juan de Ocampo, dem Stallmeister Seiner Exzellenz und Schätzmeister des Rates, der hinter dem Tragsessel ritt und dem eine rund geformte coche de respeto sowie zwei weitere Kutschen folgten, in denen sich Kapläne und Pagen Seiner Exellenz befanden. ${ }^{\text {I27 }}$

Der Einsatz von Tragsesseln war jedoch keineswegs nur auf Mitglieder der kirchlichen Elite beschränkt. Vielmehr scheinen Tragsessel zu besonderen Anlässen auch von einfachen Priestern und Nonnen benutzt worden zu sein, wie etwa bei der Gründung oder feierlichen Eröffnung religiöser Einrichtungen. Ein Beispiel hierfür datiert vom 29. Juni I638,

I26 „... [ salió con el acompañamiento hasta el patio donde estaba la silla de manos, y despidiendo los comisarios del Cabildo de su Santa Iglesia ciudad y a los demás, subió en ella a su cuarto". Sínodo diocesana del arzobispado de Toledo celebrada en Abril de i682 por el Excelentisímo Señor Don Luis Manuel de Portocarrero añadida con varios edictos (Madrid I849), S. XXVIII.

I27 „[... [ viendo la incomodidad de la hora, para que pudiese volver al consejo en forma con el acompañamiento que habia venido, resolvió volverse, como lo egecutó, en su silla de manos de felpa morada, correspondiente a la librea, con cuatro silleteros, doce lacayos con hachas delante y detrás, y don Juan de Ocampo, caballerizo de S. E. y tasador de papeles del consejo, a caballo siguiendo la silla, y después un coche redondo de respeto, a quien sucedian dos coches en que fueron los capellanes y pages de S. E." José del Olmo, Relación histórica del auto general de fe que se celebró en Madrid este año de I680 (Madrid I820), BNE, R 36.963, S. 7I. 
als „die ehrwürdigen Geistlichen in einer von Sevillas Adel begleiteten Prozession in Tragsesseln zu ihrem neuen Hospital“ transportiert wurden. ${ }^{128}$

Tragsessel und das mit ihnen in Verbindung stehende Hofzeremoniell gelangten auch in die Vizekönigreiche von Peru und Neuspanien, insbesondere an die Höfe von Lima und Mexiko, wo das königliche Zeremoniell getreulich nachgeahmt wurde und sich zum zentralen Element der Herrschaftsrepräsentation entwickelte. Obwohl Tragsessel, ganz genau wie am Hof von Madrid, auch hier vorrangig weiblich konnotierte Gegenstände waren und ihre Verwendung häufig mit den Vizeköniginnen in Zusammenhang stand, ließen sich nachweislich doch auch Vizekönige in Tragsesseln transportieren. ${ }^{129} \mathrm{Wie}$ in der spanischen Metropole waren auch die Tragsessel der Vizekönige ein bedeutender Bestandteil bei offiziellen Besuchen. ${ }^{130}$ Tragsessel halfen einerseits beim dosierten, stufenweise erfolgenden Erscheinen des Vizekönigs in der Öffentlichkeit, wobei das rituelle Verbergen des Königs als Vorbild herhielt, ${ }^{\mathrm{I} 3 \mathrm{I}}$ andererseits konnten durch die Verwendung eines Tragsessels auch der Reichtum und die Macht des königlichen „Alter Ego“, das die Kolonialterritorien im Namen des habsburgischen Monarchen regierte, betont werden. ${ }^{132}$

I28 „[... [en sillas de manos, procesionalmente, asistidos de la nobleza de Sevilla, los venerables sacerdotes a su nueva casa hospital". Justino Matute y Gaviria, Noticias relativas á la Historia de Sevilla que no constan en sus anales, recogidas de diversos impresos y manuscritos (Sevilla I886), S. I39.

I29 In einigen Fällen erhielten die Vizekönige eine königliche Lizenz, Tragsessel nach Amerika bringen zu dürfen. So wurde dem Duque de Escalona I632 die Genehmigung erteilt, mehrere Karossen, eine Sänfte und zwei Tragsessel nach Neuspanien zu verfrachten. Diese Lizenz wurde anscheinend am 22. Januar 1640 erneut und zu denselben Bedingungen ausgestellt. AGI, Indiferente, 452 Libro I4, fol. I8or-v und AHN, Toledo, Frías, Caja I24, doc. 84.

I30 José GÁlveZ, Estampas limeñas (Lima I966), S. 83.

I3I In diesem Zusammenhang sei auf die Verwendung eines Tragsessels seitens des Sohnes des Vizekönigs von Neapel hingewiesen, die unmittelbar nach dessen Tod im Jahr I6or erfolgte. Damals besuchten die Mitglieder des vizeköniglichen Hauses allmorgendlich die Trauernovene. Der Sohn des verstorbenen Vizekönigs verließ dabei sein Zimmer im verdeckten Tragsessel, ganz allein und ohne Diener, um inkognito zu bleiben, da er niemanden stören wollte. („[...] salía de su quarto en silla cubierto, solo y sin criados, por yr de incógnito. [...] y esto por no disturbar los puestos, y assientos de la Casa".) Isabel Enciso Alonso-Muñumer, Linaje, poder y cultura. El virreinato de Nápoles a comienzos del XVII. Pedro Fernández de Castro, VII conde de Lemos (ungedr. Dissertation, Universidad Complutense de Madrid 2002), S. 476-484. Zu Neapel siehe auch den Beitrag von Attilio Antonelli, Stefano Moscatelli und Ilaria Telesca im vorliegenden Band.

I32 Als der Duque de Montalto I652 als neuer Vizekönig in Valencia eintraf, zog er zu Pferd in die Stadt ein, stellte jedoch seinen Tragsessel und seine Kutsche leer zur Schau und ahmte derart die königlichen Einzüge nach: „[...] dahinter folgte ein über alle Maßen kostbarer Tragsessel, mit Drillich bedeckt und von vier sich abwechselnden Mauren befördert, die mit Röcken und Strümpfen jener Livrée versehen waren, die auch die Lakaien trugen“. („[... luego se seguia la silla de manos jarifamente costosa, cubierta con su terliz, y conducida alternativamente de quatro Moros con casacas, y calçones de la misma librea de los lacayos".) Relación de la iornada que hizo a Espańa el 
Doch standen - wie bereits erwähnt - vor allem die Vizeköniginnen im Mittelpunkt des Tragsesselzeremoniells.

Die Ankunft eines neuen Vizekönigs gab dessen Gemahlin Gelegenheit, ihre eigene Position durch einen Besuch bei der Familie des scheidenden Amtsinhabers zu unterstreichen. Dies lässt sich etwa für den Mai 1629 beobachten, als der Marqués de Guadalcázar die Leitung des Vizekönigreichs abgab und die neue Vizekönigin seinen Töchtern in einem reich verzierten Tragsessel im Beisein der gesamten Garde und mit prächtigem Gefolge einen Besuch abstattete. ${ }^{33}$ Genau wie die Königin am spanischen Hof wurde auch die Vizekönigin von verschiedenen hohen Herren zu Fuß begleitet. Als die Condesa de Salvatierra, die Witwe des kurz zuvor verstorbenen Vizekönigs von Peru, am 28. Januar I660 ihr Haus verließ, um sich nach Spanien einzuschiffen, wurde sie vom neuen Vizekönig wie folgt begleitet:

[...] sie kam in einem Tragsessel, der von zwei spanischen Lakaien transportiert wurde: und auf einem der Tragsesselgurte ruhte die Hand des Herrn Vizekönigs, Conde de Alba de Aliste, und auf dem anderen jene von Don Juan Enríquez, seinem Sohn. Sie wurde vom Herrn Erzbischof, Don Pedro de Villagómez, allen hohen Beamten der hiesigen Real Audiencia und sämtlichen adeligen Herren dieser Stadt bis zum Pier begleitet. ${ }^{\mathrm{I} 4}$

Weitere zeremonielle Ereignisse, bei denen Vizeköniginnen nach Vorbild der Königinnen in Madrid öffentliche Auftritte im Tragsessel bestritten, waren laut zeitgenössischen Quellen feierliche Begleitungen, Kirchgänge, Taufen oder Hervorgänge nach Geburten. ${ }^{135}$

Selbstverständlich machten in Übersee auch kirchliche Amtsträger Gebrauch von Tragsesseln. Sie wurden darin durch die Stadt getragen und statteten damit Besuche $a b .{ }^{136}$ In manchen Fällen griffen sie zu Tragsesseln, um ihre Sichtbarkeit zu erhöhen, in anderen

excelentíssimo señor Príncipe Duque de Montalto, quando vino por virrey, y capitán general del reyno de Valencia, el año M.DC.LII. In: Genaro Alenda y Mira, Relaciones de solemnidades y fiestas públicas de España, 2 Bde. (Madrid I903), Bd. I, Nr. II28.

I33 „[...] fue en una silla muy ricamente aderezada a vissitar a las señoras hijas del Sr. Marqués de Guadalcázar con toda la guardia y acompañamiento abentajado". Juan Antonio SuARdo, Diario de Lima: I629-1634, hg. von Rubén Vargas Ugarte, 2 Bde. (Lima 1936), Bd. I, S. 3.

I34 „[... [ salió en una silla de manos, que la cargaron dos lacayos españoles; y por la una banda de la silla llevaba puesta su mano el señor virrey Conde de Alba de Aliste, y por la otra parte, D. Juan Enríquez, su hijo. Y más, le acompañaron hasta la planchada, el señor Arzobispo D. Pedro de Villagómez, todos los oidores de esta Real Audiencia y toda la nobleza de los caballeros desta ciudad". Josephe de MuGaburu/Francisco de Mugaburu, Diario de Lima: I640-I694, hg. von Carlos A. Romero (Lima I935), S. 35 .

I35 Einige Beispiele hierzu finden sich in: ebenda, S. 49 f., 91, 94 f., I03, II7, I48 und I77.

I36 Ebenda, S. 169 und 218. 


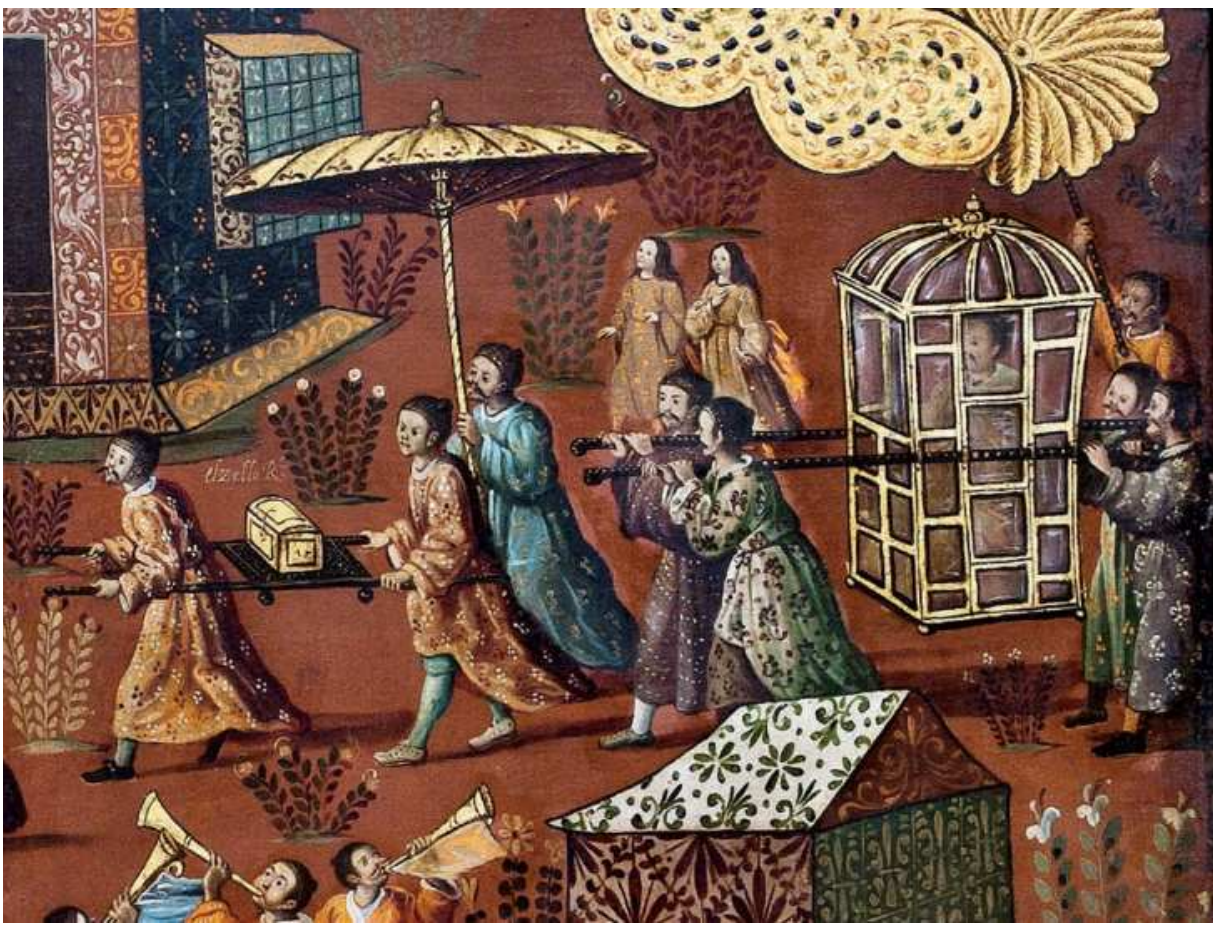

Abb. 5: Darstellung eines geschlossenen Tragsessels auf einem in orientalisierendem Stil gehaltenen mexikanischen Wandschirm des 17. Jahrhunderts. Der Kasten und sein Dach scheinen komplett verglast zu sein; der kleinteilige konstruktive Rahmen des Vehikels ist vergoldet. MA, Inv.-Nr. 2013/04/01.C4. @ MA. Ministerio de Educación, Cultura y Deporte

hingegen, um sich zu verbergen, wie dies vom Erzbischof von Mexiko überliefert ist, der während der Unruhen von I624

sein Haus in einem Tragsessel verließ und deshalb auch von sich behaupten konnte, verdeckt unterwegs zu sein. Tatsächlich verursachte er dadurch - ohne vorangetragenes Kreuz und ohne die sonst übliche Karosse - ein umso größeres Aufsehen. ${ }^{137}$

I37 „[... salió de su casa en una silla, y aunque por ser en esta forma pudo decir que iba encubierto, la verdad fue que el verle así, y sin llevar su cruz delante, y no en carroza como siempre, causó mayor alteración“. S. C., Documentos históricos pertenecientes al reinado de Felipe IV. Manuscritos inéditos. In: Revista mexicana. Periódico científico y literario I (I835), S. IO7-I2I, hier S. IO8. 


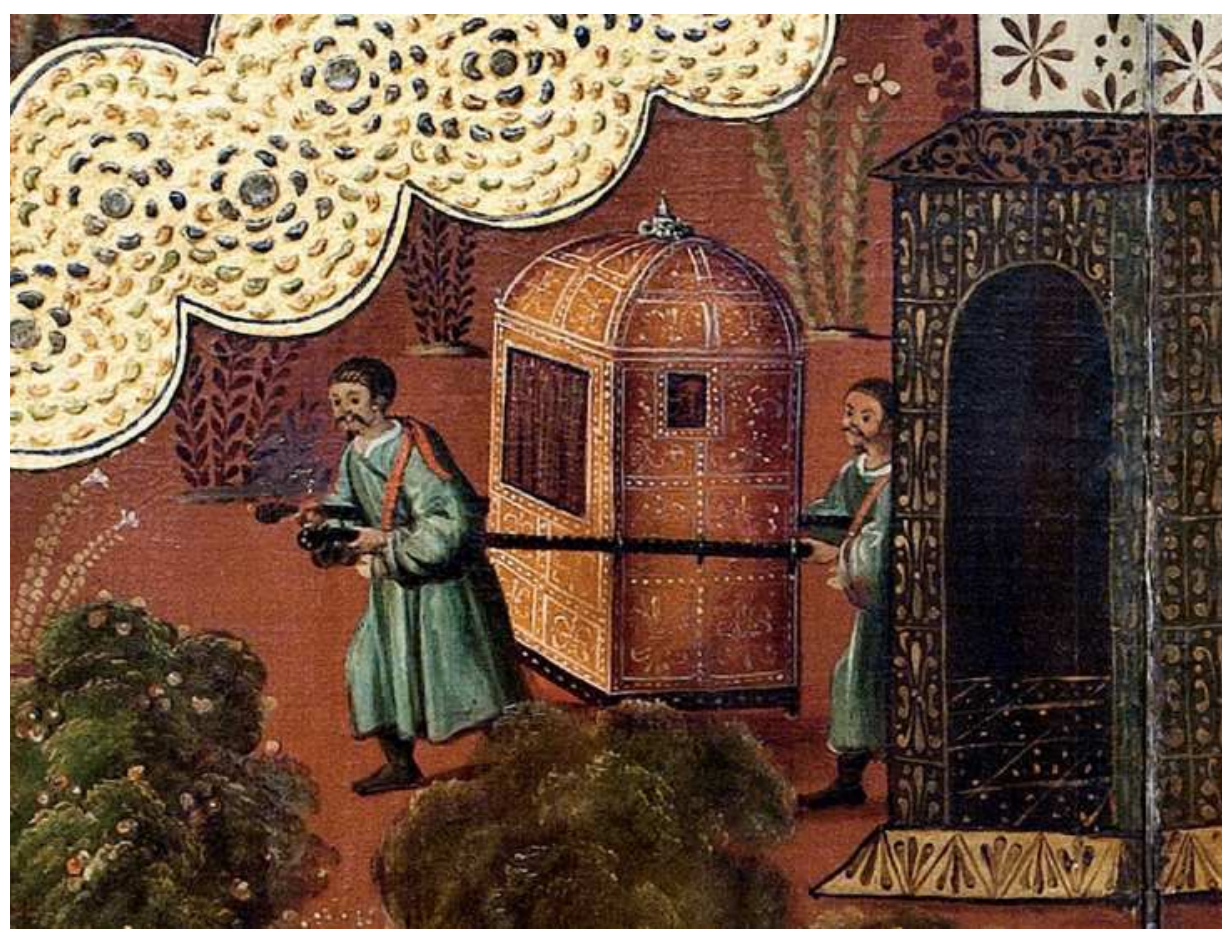

Abb. 6: Darstellung eines weiteren geschlossenen Tragsessels auf demselben mexikanischen Wandschirm wie in Abb. 5. Die Kastenwände scheinen hier mit Leder bezogen und mit Ziernägeln versehen zu sein. MA, Inv.-Nr. 2013/04/01.C6. @ MA. Ministerio de Educación, Cultura y Deporte

An den vizeköniglichen Höfen von Mexiko und Lima griffen nicht nur die höchsten Würdenträger zu Tragsesseln, sondern auch Mitglieder der lokalen Aristokratie, ${ }^{138}$ Landbesitzer ${ }^{139}$ oder Vertreter der Stadtverwaltung. Ja, die Verwendung von Tragsesseln war so weit verbreitet, dass sie zusammen mit anderen repräsentativen Vehikeln ab Anfang des I7. Jahrhunderts das Stadtbild prägten. Bernardo de Balbuena brachte in einer Beschreibung der Stadt Mexiko den Status des vizeköniglichen Hofes mit der großen Zahl seiner Vehikel in Verbindung:

I38 Gustavo Curiel Méndez, El efímero caudal de una joven noble. Inventario y aprecio de los bienes de la marquesa Doña Teresa Francisca María de Guadalupe Retes Paz Vera. (Ciudad de México, I695). In: Anales del Museo de América 8 (2000), S. 65-IOI, insbesondere S. 98.

I39 Guillermo Lohman Villena/Enriqueta Vila Vilar, Juana de Rojas: una mujer emigrante empresaria y matriarca del siglo XVII. In: Pilar Gonzalbo Aizpuru/Berta Ares Queija (Hg.), Las mujeres en la construcción de las sociedades iberoamericanas (Sevilla/México 2004), S. 87-IOI, im Besonderen S. 99. 
[...] und, hinsichtlich Machtstellung und Edelmut / Kutschen, Karossen, Tragsessel und Sänften. ${ }^{140}$

Die wenigen uns überlieferten Bildquellen, die Auskunft über das Aussehen und die Verwendung von Tragsesseln geben, deuten darauf hin, dass es sich bei den Tragsesseln in den spanischen Überseebesitzungen zumindest fallweise um äußerst luxuriös und extravagant gestaltete Vehikel handelte. Dies lässt etwa ein mexikanischer Wandschirm erahnen, auf dem gleich zwei Tragsessel abgebildet sind (Abb. 5 und 6). ${ }^{41}$

Einen Hinweis auf die Verwendung von Tragsesseln in Lima gibt unter anderem eine Beschreibung der dort ansässigen Kreolen. Darin wird die Schönheit ihrer Erscheinung, ihres Schmuckes und ihrer Kleidung in höchsten Tönen gelobt. Erwähnung findet nebenbei auch, dass sie

Tragsessel besitzen, in denen sie bei Messgängen oder Besuchen von Schwarzen befördert werden; auch haben sie sehr prächtige und gute Karossen, die von Maultieren und Pferden gezogen und von schwarzen Kutschern gelenkt werden. ${ }^{\text {I42 }}$

I40 „[... y para autoridad y señorío / coches, carrozas, sillas y literas“. Bernardo de Balbuena, Grandeza mexicana, I604, hg. von José Carlos González Borxo (Roma 1988), S. 78. In ähnlicher Weise äußerte sich auch Arias de Villalobos über die Vehikel der Stadt Mexiko: „[...] Coches, carrozas, literas, sillas cerradas y abiertas, de gran costa y gala“. Canto intitulado Mercurio. Dase razón en él, del estado y grandeza de esta gran ciudad de México Tenoxtitlán, desde su principio, al estado que hoy tiene: con los príncipes que le han gobernado por nuestros reyes, I623. In: Genaro García, Documentos inéditos o muy raros para la historia de México (México 1975, erstmals 1907), S. 367.

I4I MA, Inv. Nr. 2013/04/or.C4 und Inv. Nr. 2013/04/or.C6. Siehe dazu auch Teresa Castelló YTurbide/Marita Martínez del Río de Redo, Biombos mexicanos (México I970), S. I2O-I22. Hinsichtlich spanischer Tragsessel in der Frühen Neuzeit ist ein eklatanter Kontrast zwischen den zahlreichen vorhandenen Schrift- und den spärlichen Bildquellen zu bemerken.

I42 „[... [ tienen sillas de mano en que las llevan los negros quando van a misa y a sus visitas; $y$ tienen carrozas ricas y muy buenas y mulas y caballos que las tiran y negros cocheros que las guian“. Boleslao LEwIN, Descripción del virreinato del Perú. Crónica inédita de comienzos del siglo XVII (Rosario 1958), S. 39. Zur Bedeutung repräsentativer Vehikel für das Bild der vizeköniglichen Stadt siehe Alejandro López Állvarez, Los vehículos representativos en la configuración de la Corte virreinal: México y Lima, I590-I700. In: Enrique García Santo-Tomás (Hg.), Materia crítica: formas de ocio y de consumo en la cultura áurea (Biblioteca áurea hispánica 58, Madrid/Frankfurt a. M. 2009), S. 269-29I. 
Tragsessel wurden natürlich nicht nur in den vizeköniglichen Machtzentren verwendet. Auch in Städten minderer Bedeutung, wie etwa Buenos Aires ${ }^{143}$, Santiago de Chile ${ }^{144}$, Quito $^{\mathrm{I45}}$, Havanna ${ }^{\mathrm{I} 46}$, Santafé de Bogotá ${ }^{\mathrm{I47}}$ oder Mérida ${ }^{\mathrm{I} 48}$, benutzten zahlreiche Personen, die sozial hochgestellten Gruppen angehörten, derartige Vehikel. Zuweilen fielen hinsichtlich der Verwendung von Tragsesseln aber alle sozialen Schranken: Laut Anklageschrift der Inquisition sei Mitte des I7. Jahrhunderts in Cartagena de Indias eine „Hexe“ in kostbarer Kleidung und ohne Bußkleid in einem Tragsessel unterwegs gewesen und habe in derartiger Aufmachung einen hohen Geldbetrag verdient. ${ }^{\text {I4 }}$

\section{Die Gesetzgebung zu Tragsesseln und Sesselträgern im 16. und 17. Jahrhundert}

Ein wesentlicher Aspekt der Geschichte des Tragsessels ist die rund um seinen Gebrauch entstandene Luxusgesetzgebung. Diese lässt sich in drei Bereiche unterteilen, nämlich

I43 Mehrere diesbezügliche Fälle sind dokumentiert in: Raúl A. Molina, Historia de los divorcios en el período hispánico. La familia porteńa en los siglos XVII y XVIII (Buenos Aires I99I), S. 35; Raúl A. Molina, Antón Higueras de Santana. El andaluz de las cuatro estancias. Vecino fundador de Buenos Aires. In: Genealogía. Revista del Instituto Argentino de Ciencias Genealógicas I2 (1957), S. 2I-46, hier S. 33; Leopoldo de la Rosa Olivera, Una familia aventurera luso-canaria en el Nuevo Mundo. In: Francisco Morales Padrón (Hg.), II Coloquio de historia Canario-Americana, 2 Bde. (Ediciones del Excelentísimo Cabildo Insular de Gran Canaria III Geografía e Historia, Las Palmas de Gran Canaria 1977), Bd. I, S. 99-II8, hier S. I09.

I44 Melchor Jufrè del Aguila, Compendio historial del descubrimiento i conquista del Reino de Chile seguido de dos discursos: Avisos prudenciales de Govierno i Guerra, de la Astrología judiciaria (Santiago de Chile i897), S. 34I; Raïssa Kordic Riquelme/Cedomil Goic, Testamentos coloniales chilenos (Biblioteca indiana 5 / Biblioteca antigua chilena 6, Madrid/Frankfurt a. M. 2005), S. 230.

I45 Adriana Pacheco Bustillos, Historia del Convento del Carmen Alto (Quito 2000), S. 46.

I46 Ismael Sarmiento Ramírez, Cuba entre la opulencia y la pobreza. Población, economía y cultura material en los primeros 68 ańos del siglo XIX (Madrid 2004), S. 86.

I47 María del Pilar López Pérez, El objeto de uso en las salas de las casa de habitación de españoles y criollos en Santafé de Bogotá. Siglos XVII y XVIII en el Nuevo Reino de Granada. In: Anales del Instituto de Investigaciones Estéticas 2I/74-75 (1999), S. 99-I34, hier S. II2; Fray Nicolás de Freitas, Relación del descubrimiento del País y ciudad de Quivira, hecho por D. Diego Dionisio de Peñalosa, Briceño y Verdugo, Ocampo y Valdivia, señor de las villas de Guarina y de Farara y sus once pueblos, I662. In: Memorias de la Real Academia de la Historia, I4 Bde. (Madrid I796-1914), Bd. Io (1885), S. 33-4I, hier S. 34.

I48 Adriana del Carmen Quintero González, Repertorio léxico en testamentos merideños del siglo XVII (Mérida 2006), S. 35.

I49 María Cristina Navarrete, Génesis y desarrollo de la esclavitud en Colombia. Siglos XVI y XVII (Cali 2005), S. 345. 
erstens in Anordnungen zur Einschränkung und Kontrolle der Tragsesselbenutzer, wobei diese Regelungen eng mit jenen für die Nutzung von Kutschen verbunden waren, zweitens in Vorschriften hinsichtlich der Ausstattung von Tragsesseln und drittens in Bestimmungen, welche die Sesselträger selbst betrafen. Obwohl all diese Vorschriften in enger Verbindung miteinander stehen, werden sie im Folgenden getrennt behandelt.

\subsection{Rechtliche Bestimmungen zur Tragsesselnutzung (1579 bis um 1660)}

Die Gesetzgebung rund um Tragsessel lässt sich in drei Etappen gliedern. In der Anfangsphase zwischen 1579 und I603 wurden erste Versuche gestartet, den Gebrauch einzuschränken. Der zweite Zeitraum, der von I604 bis um I635 reicht, war von einem Prozess der „Institutionalisierung“ geprägt, und im dritten, I635 beginnenden Abschnitt wurde erst versucht, die Verwendung von Tragsesseln durch deren Besteuerung zu drosseln, und später, ihre Vermietung zu unterbinden. Da durch diese Maßnahmen die Ausbreitung von Tragsesseln nur unmerklich verringert werden konnte, lag das Augenmerk der Gesetzgeber schließlich in erster Linie darauf, Einfluss auf den Grad an Luxus in der Ausstattung zu erlangen und Kontrolle über die Sesselträger auszuüben. ${ }^{\text {Is }}$

\subsubsection{Die Anfänge der Gesetzgebung (1579-1603)}

Die ersten rechtlichen Maßnahmen, die Tragstühle beziehungsweise vergleichbare von Trägern geschulterte Transportmittel betrafen, wurden von 1535 an in Amerika getroffen. ${ }^{\text {ISI }}$ Es sollte jedoch noch bis Ende der I570er Jahre dauern, bis auch Gesetze im engeren Sinn über Tragsessel in Kraft traten. Diese legislativen Schritte standen zunächst in engem Zusammenhang mit Verordnungen, die für Kutschen Gültigkeit hatten. In den Überseebesitzungen wurde die erste Kutschen betreffende Verordnung am 24. November 1577 erlassen. Darin wurde ihr Gebrauch in sämtlichen amerikanischen Territorien der spanischen Monarchie grundsätzlich untersagt. ${ }^{152}$ Diese Verordnung war weit restriktiver als das Anfang

I5O Zur Gesetzgebung über Tragsessel und Sesselträger siehe auch López ÁlvVAREZ 2007 (wie Anm. I), S. 174-177 und 565-573.

I5I Siehe hierzu Alejandro López Álvarez, La introducción de los coches en la corte hispana y el Imperio. Transfers tecnológicos y culturales, I550-1580. In: José Martínez Millán/Rubén GonzÁlez Cuerva (Hg.), La dinastía de los Austria: las relaciones entre la Monarquía Católica y el Imperio, 3 Bde. (Madrid 20II), Bd. 3, S. 1885-1928, hier S. I893, Fußnote II.

i52 Joaquín F. Pacheco/Francisco de Cárdenas/Luis Torres de Mendoza, Colección de documentos inéditos relativos al descubrimiento, conquista y organización de las antiguas posesiones españolas en América y Oceanía, sacados de los Archivos del Reino, y muy especialmente del de 
I578 für die Königreiche von Kastilien erlassene Verbot, Kutschen mit weniger als vier vorgespannten Pferden zu verwenden, eine Maßnahme, die den Gebrauch von Kutschen als Privileg des Adels etablieren sollte, dem Philipp II. eine stärkere Führungsrolle im Rahmen der Monarchie zugedacht hatte. Es scheint, dass das für Amerika ausgesprochene Verbot den dort damals bereits weit verbreiteten Tragsesselgebrauch stark beförderte. Dies lässt sich einerseits aus manchen in literarischen Werken geäußerten Beschwerden schließen, ${ }^{53}$ andererseits aber auch aus kurzer Zeit später erlassenen Verordnungen, deren Ziel es war, Kontrolle über Tragsesselnutzer auszuüben. Darin wurde verboten, verhüllte Tragsessel zu verwenden, da eine Identifizierung der Insassen stets gewährleistet bleiben müsse. Ein vizeköniglicher Beschluss vom I3. November 579 schrieb außerdem vor, dass Indios keine Sesselträgerdienste leisten dürften:

Keine Person, egal ob Mann oder Frau und welchen Ranges auch immer, darf in den Städten und Dörfern von Neuspanien einen Tragsessel verwenden und darin getragen werden, wenn dieser verdeckt oder das Gesicht mit einem Umhang verhüllt ist. Vielmehr muss das Gesicht frei von Putz oder Maske bleiben, sodass zu erkennen ist, wer darin befördert wird: Sie dürfen auch außerhalb der Städte nicht von Indios getragen werden, auch nicht zu den Gärten und Einsiedeleien, weder verdeckt noch unbedeckt noch in irgendeiner anderen Weise. Und dasselbe gilt auch für kleine Sänften oder andere Erfindungen, die auf Schultern oder Armen getragen werden, bei einer Strafe von fünfzig Pesos für jeden, der dagegen verstößt, wobei ein Drittel davon an den Richter geht, eines an den Informanten und eines an das Hospital de los indios de México. ${ }^{154}$

Indias, 42 Bde. (Madrid I864-I884), Bd. I8, S. II6-II8. Zum Kutschenverbot und seinem Erfolg in Mexiko bis zum Jahr I59I siehe: AGI, México/22/86.

I53 Die erste literarische Erwähnung eines Tragsessels in spanischer Sprache findet sich in einem in Amerika erschienenen Werk. Darin reist Doña Murmuración in Begleitung eines Pagen in einem von zwei Indios beförderten Tragsessel und beklagt sich in bitterem Ton: „Da man die Kutschen verboten hat, bin ich auf die Eingeborenen angewiesen; ich bin in ihrer Hand wie eine Ladung Mist“. („Como quitaron los coches, ando entregada a la gente de la tierra; como carga de basura voy en su poder".) Francisco González de Eslava, Coloquios espirituales y sacramentales, ca. I578, hg. von José Rojas Garcidueñas, 2 Bde. (Colección de escritores mexicanos 74 und 75, México 1958), Bd. I, S. 22 f. und Bd. 2, S. 216-220.

I54 "Que ninguna persona, hombre o muger de qualquier calidad que sea, pueda ir o ser llevada en Silla de manos dentro de las Ciudades y Villas de la Nueva España, yendo la tal silla cubierta, y el manto sobre la cara, sino descubierto el rostro, y sin ningún paramento ni rebozo; de manera que se pueda ver y conocer quien fuere en ellas: $Y$ no las lleven con Indios fuera de dichas Ciudades yendo de camino, aunque vayan a Huertas o Hermitas, cubiertas o descubiertas ni en otra manera. Y lo mismo se entienda en quanto a las literillas o otra invención que hubiere de llevarse a hombros o en brazos, pena de cincuenta pesos a quien contraviniere a ello, para el Juez, Denunciador y Hospital de los indios de México, por tercias 
Dieselbe Strafe war für verschiedene Amtsträger (Alcaldes Mayores, Tenientes und Justicias) vorgesehen, die sich selbst mit Frauen und Kindern von Dorf zu Dorf oder zur Messe von Indios in Tragsesseln oder kleinen Sänften transportieren ließen. Darüber hinaus sollten sie ihr Amt verlieren und für zehn Jahre von weiteren Ämtern ausgeschlossen bleiben. ${ }^{155}$ Das Gesetz hatte eine präventive Funktion, denn man nahm an, dass das Kutschenverbot zu einem Anstieg der Zahl von Tragsesseln führen würde. Angesichts dessen versuchte man einerseits moralische Appelle an die Nutzerinnen von Tragsesseln zu richten, andererseits aber auch die Indios davor zu bewahren, Sesselträgerdienste zu verrichten, eine Maßnahme, die in Zusammenhang mit Verordnungen stand, die Jahrzehnte zuvor für sänftenartige Tragevehikel erlassen worden waren. Um der Einführung von neuartigen Erfindungen, mit denen Personen „auf Schultern oder Armen“ getragen werden konnten, einen Riegel vorzuschieben, wurde auch verordnet, dass die Insassen erkennbar bleiben mussten. Aus all diesen Hinweisen geht klar hervor, dass derartige Maßnahmen andere Gründe hatten, als allein den Verkehr in den Städten zu regulieren, wie dies bereits andernorts angemerkt wurde. ${ }^{156}$ Verordnungen des Konzils von Toledo im Jahr 1582 stellten einen weiteren Versuch dar, den Gebrauch von Tragsesseln durch moralische Argumente zu limitieren. Vermutlich waren diese Beschränkungen als notwendig erachtet worden, weil die Zahl der Tragsessel in Kastilien seit der Reglementierung der Kutschennutzung von 1578 deutlich angestiegen war. Damals, im Jahr 1582, wurde daran erinnert, dass bereits auf dem vorhergegangenen Konzil Klerikern, die Hand in Hand mit Frauen gingen oder in weiblicher Begleitung auf einem Pferd ritten, die Exkommunikation angedroht worden war. Nun wurde Klerikern auch untersagt, Frauen zu Fuß zu begleiten, die sich in Tragsesseln durch die Städte oder Dörfer bewegten. Sowohl zuwiderhandelnde Geistliche als auch Frauen, die sich nicht an die Verordnung hielten, hatten die Exkommunikation latae sententiae zu erwarten. ${ }^{157}$

partes". Eusebio Bentura Beleña, Recopilación sumaria de todos los autos acordados de la Real Audiencia y Sala del Crimen de esta Nueva España, y Providencias de su superior Gobierno, 2 Bde. (México 1787), BNE, 2/47.629, Bd. I, S. Ios f.

I5s Ebenda, S. Ios f.

is6 Carmen Purroy Turrillas, Las ordenanzas de Martín Enríquez de Almansa, virrey de México. In: Memoria del X Congreso del Instituto Internacional de Historia del Derecho Indiano, 2 Bde. (Instituto de Investigaciones Jurídicas, Reihe C, Estudios Históricos 50, México 1995), Bd. 2, S. I285-I323, hier S. I30I.

157 „Además se probibe que acompañen a pie a las mugeres que se conduzcan por la ciudad o poblaciones en silla de manos. Y los que no obedecieren estos decretos, bien sean clérigos, bien sean las mugeres que permitan que estos les presten tales servicios, incurran en la misma excomunión latae sententiae“. Colección de cánones y de todos los concilios de la Iglesia española traducida con notas é ilustraciones por D. Juan Tejada y Ramiro, 5 Bde. (Madrid I849-I862), Bd. 5, S. 472, \$3. XXXVI. Diese Verordnung wurde auch in nachfolgenden Konzilen wiederholt festgehalten. 
Die in den Machtkreisen entstandene und stetig wachsende Besorgnis, die Zahl der Tragsessel könnte noch weiter ansteigen, führte ein Jahrzehnt später zu drastischen Maßnahmen. Eine Verordnung des Jahres I594 versuchte die Zahl der Sesselträger sowie deren Preistarife zu regulieren, was zeigt, wie notwendig die Kontrolle des Tragsesselgebrauchs erschien. Leider ist in diesem Punkt aber nur wenig über weitere Entwicklungen bekannt.

Unterdessen sorgte der Gebrauch von Tragsesseln in manchen gesellschaftlichen Bereichen weiterhin für Aufsehen, wenngleich in etwas diffuser Art und Weise. Dies lässt sich verschiedenen in den Cortes eingebrachten Anträgen entnehmen. Die Hauptsorge galt dabei in erster Linie nicht den Tragsesseln selbst, sondern billigen, zweispännigen Kutschen. Anfang 1598 wurde ein nur ungenügend begründeter Antrag eingebracht, bei dem es sich wohl um ein wenig überzeugendes Täuschungsmanöver handelte. Verlangt wurde eine Abstimmung darüber, ob man den König auffordern sollte, in den wichtigsten Ortschaften Turniere und Ritterspiele zu genehmigen, wobei man jedoch Männern unter siebzig Jahren den Gebrauch von Tragsesseln und Kutschen untersagen wollte. ${ }^{158}$ Der Antrag, der folgenlos blieb, ist in einem größeren, komplexen Zusammenhang zu sehen. Er stellte den Versuch dar, erneut zweispännige Kutschen in Kastilien einzuführen. Die vorgeschlagene Einschränkung des Gebrauchs von Tragsesseln war dabei nur Nebensache. Es existieren aber auch Indizien, die darauf hinweisen, dass sich der Gebrauch von Tragsesseln signifikant intensiviert habe und dass als Gegenreaktion bereits Reformen in Planung gewesen seien, um ihre Nutzung einzuschränken. Entsprechende Beschwerden lagen auch aus weit abgelegenen Herrschaftsgebieten der spanischen Monarchie vor. Antonio de Morga etwa berichtete damals zur allgemeinen Lage auf den Philippinen Folgendes:

[...] hinsichtlich der Behandlung und Kleidung von Männern und Frauen gibt es zahlreiche Ausschweifungen und ein großes Durcheinander, denn sowohl Arme als auch Reiche, bedeutende wie unbedeutende Personen möchten sich selbst und ihre Frauen mit Tragsesseln, Dienern, Kirchenpodesten und ähnlichen überflüssigen Dingen versehen, was zu zahlreichen Missständen führt: es ist daher angebracht, in dieser Sache so weit als möglich Abhilfe zu schaffen. ${ }^{59}$

I58 „[... hombres en sillas ni en coches sino fueren de setenta años". Actas de las Cortes de Castilla I86I-2006 (wie Anm. 76), Bd. I5, S. 766.

I59 „[... [en el tratamiento y trages de hombres y mugeres hay mucho esceso y confusión, porque igualmente pobres como los ricos, los principales como los que no lo son, quieren vestirse y arrear sus mugeres con sillas, escuderos, estrados en las iglesias y otras demasias, de que nacen muchos inconvenientes: que es justo se remedie de ello lo que más se pueda“. Antonio de MorGA, Relación hecha por el Dr. Antonio de Morga para S. M. de lo que se le ofrece sobre el estado de las Islas Filipinas, tanto en lo secular como en lo eclesiástico, I598. In: Antonio de Morga, Sucesos de las Islas Filipinas, hg. von Wenceslao Emilio Retana (Madrid I909), S. I-588, hier S. 253 f. 
Aus anderen Quellen wissen wir, dass die Verwendung von Tragsesseln in Städten und Dörfern Kastiliens immer üblicher wurde. Selbst wenn wir in Betracht ziehen, dass die zuvor erwähnten in den Cortes geäußerten Stimmen letztlich Interessen der kastilischen Eliten repräsentierten, die damals noch vom Wunsch besessen waren, an billigere Kutschen zu gelangen, ${ }^{160}$ verdient doch ein Vorschlag Beachtung, den Juan Serrano in einem Gesuch vom I2. Mai I603 vorbrachte. Serrano verlieh darin seiner Ansicht Ausdruck, dass in Gegenden außerhalb Madrids, Valladolids, Granadas und Sevillas von Maultieren gezogene Kutschen genehmigt werden sollten, weil dadurch eine größere Zahl an Arbeitskräften verfügbar würde:

[...] viele Menschen, die für die Feldarbeit nützlich wären, befördern Tragsessel, denn fast überall sind diese in großer Zahl vorhanden und werden zum Transport von allem Möglichen eingesetzt. Dies könnte mittels Maultierkutschen vermieden werden, denn selbst wenn es in einem Stadtviertel oder einer Straße nur eine einzige Kutsche eines Edelmanns und seiner Frau gäbe, würden sich Nachbarinnen hinzugesellen und gemeinsam in dem Fahrzeug ihre Besuche und Landausflüge unternehmen, sodass Sesselträger eingespart werden könnten. Und da besonders zu Beginn der Reform viele Leute dieses Gewerbes arbeitslos würden [...], scheint es angebracht, Eure Majestät zu bitten, die Strafen gegen Herumtreiber zu erhöhen, damit diese aus Furcht vor der Härte des Gesetzes beginnen, sich jener Tätigkeit zuzuwenden, die erwünscht ist. ${ }^{161}$

Nachdem sich das Gerücht verbreitet hatte, dass man erneut zum Gebrauch vierspänniger Kutschen zurückkehren wolle, stimmten die Cortes am 22. Juli I604 darüber ab, ob vom König nicht gefordert werden sollte, die Verwendung von Kutschen mit nur zwei vorgespannten Maultieren in allen Gebieten des Königreichs - mit Ausnahme des Hofes - zuzulassen. Dem positiven Votum zufolge verlangte man schließlich unter Punkt 30 der dem König vorgelegten Capitulos, dass man mit Ausnahme der zum Hof gehörigen Städte

I60 Seit I600 war es erlaubt, zweispännige Kutschen zu fahren. Die kastilischen Eliten bevorzugten jedoch Kutschen mit zwei Maultieren, da diese für den Ackerbau nützlicher, billiger in der Haltung und einfacher zu lenken waren.

I6I „[... [ mucha gente muy útil para el campo, que andan a traer sillas, porque pocos son los lugares donde no las haya en mucho número, y las que pueden y las que no, las traen, que se excusaria con los coches de mulas, porque aunque en un barrio o calle no hubiese más de un coche de un caballero con su mujer, se juntan las vecinas a la fiesta y van a sus visitas y al campo y ahorran mozos de silla. Y porque especialmente a los principios de la reforma destos oficios habría mucha gente desocupada dellos [...] parece sería conveniente suplicar a S.M. se aumentasen las penas contra los vagamundos para que con el temor dellas, siendo rigurosas, comenzasen desde luego a trabajar en lo que se pretende“. Actas de las Cortes de Castilla I86I-2006 (wie Anm. 76), Bd. 2I, S. 380 f., Bd. 22, S. 445. 
(Valladolid, Granada, Sevilla und Madrid) Kutschen in allen Territorien und mit jeglicher Anspannung von Pferden oder Maultieren fahren dürfe. Mit einem Gedränge auf den Straßen sei aufgrund der geringen Zahl an Kutschen nicht zu rechnen. Die Vorteile einer solchen Regelung seien hingegen beträchtlich, denn

es wird in den Königreichen gewiss viele Einwohner geben, die sich mit einer Kutsche für die Festtage begnügen, an den übrigen Tagen aber auf den Feldern, in den Weinbergen und den Olivenhainen mit Maultieren arbeiten würden. Auf diese Weise könnten viele Leute, die in den besagten Orten mit dem Transport von Tragsesseln beschäftigt sind, für die Arbeit auf den Feldern freigestellt werden, wo große Not am Mann ist. ${ }^{162}$

Kurz zusammengefasst sollten Tragsessel durch Kutschen ersetzt und derart zusätzliche Arbeiter für die Landwirtschaft gewonnen werden. Der Arbeitskräftemangel zählte damals zu den dringendsten Problemen der Monarchie und wurde sowohl von Arbitristen als auch von anderen Reformern heftig beklagt.

\subsubsection{Die „Institutionalisierung“ der Tragsessel und ihre Folgen (1604 bis ca. 1635)}

Ob die oben erörterten Argumente den Rat von Kastilien von der Notwendigkeit überzeugten, eine Verordnung zu erlassen, oder ob unabhängig davon damals bereits an einer solchen gearbeitet wurde, lässt sich heute nicht mehr mit Sicherheit feststellen. Entscheidend ist jedoch, dass der Ende I604 gefasste Beschluss dazu führte, die rund um Tragsessel entstandenen Probleme - zumindest teilweise - zu lösen, und zwar in innovativer Weise, nämlich mittels ihrer „Institutionalisierung“. Wenn hier nur von einer partiellen Lösung die Rede ist, dann deshalb, weil die getroffenen Maßnahmen ausschließlich den männlichen Bevölkerungsteil berührten: Seit I604 war es Männern ausdrücklich untersagt, ohne eine vom Kastilischen Rat erteilte Lizenz Tragsessel zu verwenden.

Der Einführungsprozess für Tragsessel am spanischen Hof hatte mit der Verordnung von 1604 seinen Abschluss gefunden. Die „Institutionalisierung“ brachte mehrerlei Konsequenzen mit sich: Sie führte im Kontext eines allgemeinen Bereinigungsprozesses am Königshof dazu, dass der Gebrauch von Tragsesseln fortan nur noch bestimmten sozialen Gruppen vorbehalten war. Das auf Männer beschränkte, allgemeine Verbot, Tragsessel zu verwenden, sollte das Reiten stärken und führte zu einer zunehmend weiblichen Kon-

162 „[...] habrá muchos naturales destos reinos que se contenten con coche las fiestas, y los dias de trabajo labrarán con las mulas tierra, viñas y olivares, y se desocupará mucha gente que en los lugares particulares se ocupan en llevar sillas, y acudirán a las labores del campo, de que hay tanta necesidad". Actas de las Cortes de Castilla I86I-2006 (wie Anm. 76), Bd. 2I, S. 380 f., Bd. 22, S. 375 und 445. 
notation der Tragevehikel. Dieser Punkt geht auch deutlich aus Argumenten hervor, die Ratsmitglieder zur Unterstützung des Verbots ins Feld führten. Neben anderen Nachteilen habe man auch erkannt, dass

der seit einigen Jahren zu beobachtende exzessive und ungeordnete Gebrauch von Tragsesseln durch Männer jeden Alters, der ohne jegliche Notwendigkeit und nur zum reinen Vergnügen erfolgt, anstößig ist und zu Exzessen und Konfusion geführt hat. Dadurch geriet die lobenswerte und notwendige Übung im Reiten in Vergessenheit. ${ }^{163}$

Die Verordnung schrieb vor, dass

kein Mann, egal welchen Alters, Ranges oder Standes er auch sei, ohne eine von uns erteilte schriftliche Lizenz im Tragsessel befördert werden darf.

Zuwiderhandelnde wurden nach einer Schonfrist, die sechzig Tage nach Veröffentlichung der Verordnung endete, mit einer Strafe bedroht, die in der Beschlagnahmung des Tragsessels sowie einer Geldbuße in der Höhe von 20.000 Maravedis bestand. ${ }^{164}$ Der „Institutionalisierungsprozess" begann damit faktisch mit Anfang I605 und dauerte bis ungefähr 1635. Im Folgenden wollen wir besonders die Jahre zwischen I605 und I62I eingehend analysieren. Dieser Zeitraum lässt sich in zwei Abschnitte gliedern, da das Jahr I6II einen Einschnitt mit sich brachte. Damals wurde nämlich ein „Institutionalisierungsprozess“ für Kutschen in Gang gesetzt, was wiederum die Umsetzung des Gesetzes von I604 erheblich beeinflusste ${ }^{\mathrm{I} 65}$ (Abb. 7).

163 „El excesso y desorden que ay en andar en silla de mano los hombres de todas las edades, sin necesidad, ni otra causa alguna, por solo su regalo, que de pocos años a esta parte se a introduzido, siendo cosa tan indecente, y que por ello se va olvidando el loable y necesario exercicio de los cavallos". Premática en que se prohibe andar a los hombres en silla de mano, BNE, VE 40-75, unfol. Die am 27. Oktober I604 im nahe Valladolid gelegenen Ventosilla unterzeichnete Verordnung wurde am 30. Oktober in Valladolid veröffentlicht.

I64 „[... [ingun hombre de qualquier edad, calidad y condicion que sea, pueda andar ni ande en silla de manos, si no fuere teniendo licencia nuestra por escrito y no en otra manera". Premática en que se prohibe andar a los hombres en silla de mano, BNE, VE 40-75, unfol. Zum Vergleich: Die Gehälter von in Madrid tätigen Maurern schwankten in den ersten Jahrzehnten des 17. Jahrhunderts

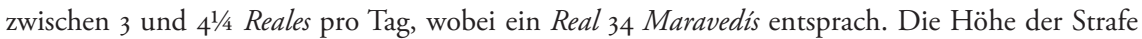
kam demnach etwa dem Lohn für circa I40 bis 198 Arbeitstage gleich.

I65 Zu den Lizenzen sind einige Erläuterungen notwendig: Unser Quellenkorpus basiert für den Zeitraum von I604 bis I62I auf unterschiedlichen Archivbeständen. Ein Teil umfasst Bittgesuche, die an die Kammer von Kastilien gerichtet waren. Ein kleinerer Teil davon befindet sich in Madrid im AHN, Consejos, Legs. 4417-4422. Eine größere Zahl an Bittschriften, die auch reichere In- 
Abb. 7: Titelblatt der 1604 vom Kastilischen Rat erlassenen Verordnung, die Männern ohne entsprechende Lizenz die Beförderung in Tragsesseln untersagte. Gedruckt in Valladolid vom königlichen Buchdrucker Luys Sánchez, 1604. BNE, VE 4O-75. @ BNE

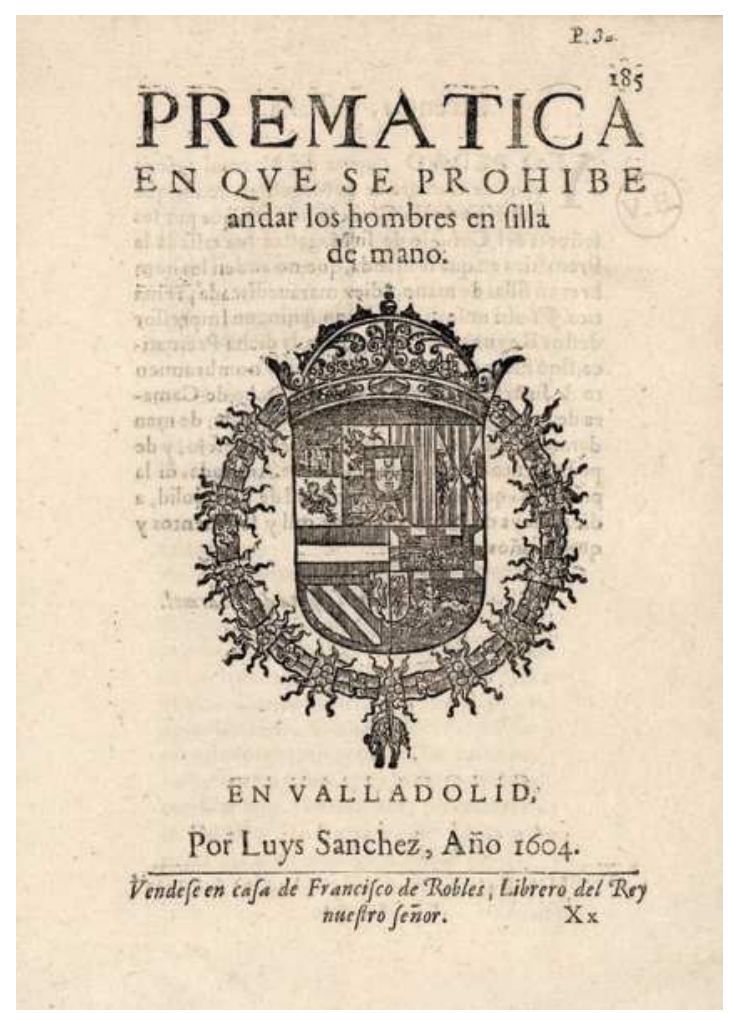

Der folgende Abschnitt mit seinen langen, vielleicht repetitiv erscheinenden Zusammenstellungen von Namen und Daten wird vielleicht auf so manche Leser und Leserinnen ermüdend wirken. Wir halten diese Passagen aber dennoch für essentiell, da sie anschau-

formationen liefern, werden in Simancas im AGS CC, Legs. 997-IO73 (jedes Jahr umfasst dabei rund zehn Aktenbündel) aufbewahrt. Die Lizenzen selbst finden sich in mehreren Büchern registriert, die sich ebenfalls in Simancas befinden, und zwar unter den Signaturen AGS CC, Libros I78, I79 und I8I-I90. Hinzu kommt, dass manche Originalausfertigungen von Lizenzen in anderen Archiven erhalten sind. Erschwert wird die Arbeit zusätzlich dadurch, dass für gewöhnlich weder in den Lizenzen noch in den Bittgesuchen der Beruf, der soziale Stand oder der Ort, für den sie Gültigkeit hatten, angegeben ist, weshalb die konkreten Personen hinter den Namen manchmal nur schwer greifbar sind. Nur mittels tiefgehender und umfassender Recherchen ist es daher möglich, die Bittsteller und Lizenzempfänger im sozialen Koordinatensystem richtig einzuordnen. Um den Umfang der Fußnoten nicht zu sprengen, werden nur der soziale Status der einzelnen Personen genannt und das Datum sowie der Quellenstandort der Lizenzerteilung angegeben. Zusätzlich enthalten einige Fußnoten Kommentare mit exemplarischen Begründungen, die zu den Bittgesuchen geführt hatten. Außerdem werden fallweise auch einige Termine von Ratssitzungen erwähnt, die zeigen, wie schnell beziehungsweise langsam der Rat über die Gesuche entschied. 
lich demonstrieren, dass die Luxusgesetzgebung - zumindest im Bereich der spanischen Monarchie - keineswegs dazu diente, das Maß an Luxus einzuschränken oder äußere Zeichen sozialer Autorität zu eliminieren, wie dies häufig suggeriert wird. Vielmehr wurde Letztere mittels gesetzlicher Maßnahmen legitimiert. Die Luxusgesetze halfen dabei, soziale Unterschiede zu verstärken. Personen, die der politischen beziehungsweise religiösen Elite kastilischer Städte angehörten und die darüber hinaus über gute Beziehungen zum Hof verfügten, durften fortan Tragsessel verwenden, während allen anderen dieses Privileg mangels Lizenz verwehrt blieb. So lässt sich zusammenfassend feststellen, dass mit Hilfe von Gesetzen ganz bewusst und gezielt Luxuspolitik betrieben wurde.

Infolge des Verbots beantragten ab i605 zahlreiche Personen beim Rat von Kastilien eine Lizenz. Die etwa achtzig zwischen I605 und I6Io erteilten Lizenzen entsprachen einem Durchschnitt von rund dreizehn pro Jahr, was in Anbetracht der großen Nachfrage eine geringe Bewilligungsrate bedeutet. Hinsichtlich der sozialen Zuordnung der Lizenzempfänger lässt sich feststellen, dass es sich bei dreizehn davon um Träger von Adelstiteln handelte. Die Hälfte dieser Lizenzen war keiner zeitlichen Einschränkung unterworfen. Ab I606 waren hingegen fast alle erteilten Lizenzen mit einer Befristung verbunden. Die ersten Begünstigten waren - in chronologischer Reihenfolge - der Marqués Alejandro Malespina, der infolge einer durch einen Kanonenschuss hervorgerufenen Verletzung beidseitig beinamputiert war, der Condestable von Kastilien Conde de Chinchón, der Duque de Sessa, der Conde de Olivares, der Duque de Infantado, der Marqués de las Navas, dessen Lizenz nur für zwei Jahre Gültigkeit hatte, der Marqués de la Algaba, der eine einjährige Lizenz erhielt, und der Conde de Nieva. Dem Marqués de Estepa wurde eine für zwei Jahre gültige Lizenz ausgestellt, die allerdings nur in seinen eigenen Territorien galt, während der Marqués de Cusano eine Lizenz für vier Jahre erhielt. Don Francisco de Borja, Príncipe de Esquilache, bekam eine einjährige Lizenz zugesprochen, der Marqués de Auñón eine für zwei Jahre und der Marqués de Almazán eine für nur sechs Monate. Auch der Duque de Alburquerque erhielt eine Lizenz. ${ }^{166}$

Mindestens achtzehn Lizenzen wurden nachweislich Personen erteilt, die in den königlichen Räten dienten, nämlich als Ratsmitglieder, Buchhalter, Richter oder Sekretäre. Unter den zehn Ratsmitgliedern befanden sich - in chronologischer Reihenfolge - Francisco Álvarez de Rivera vom Italienischen Rat, dessen Lizenz auf ein Jahr befristet war, Lizenziat Andrés de Arbizul vom Inquisitionsrat, Lizenziat Núñez de Bohórquez vom Königlichen Rat und vom Kammerrat, der die Lizenz bis zur Wiedererlangung seiner Gesundheit erhielt, Lizenziat Juan de Alderete vom Königlichen Rat, dessen Lizenz für die Dauer einer Behinderung galt, Domingo de Zabala vom Finanzrat, Lizenziat Juan de Acuña, Präsident des Finanzrats, Juan de Ibarra vom Italienischen Rat, Juan Bautista de Tassis vom Kriegs-

I66 Siehe dazu AHN, Consejos, Leg. 44I7, Nr. 65, I56, I74, I92 und 200-202, Leg. 44I8, Nr. I6, 26, 30, 33, 69, 264 und 268; AGS CC, Libro I79, fol. I2. 
rat, der eine zweijährige Lizenz erhielt, Esteban de Ibarra vom Kriegs- und Finanzrat und schließlich Lizenziat Diego Fernández Ruíz de Alarcón vom Königlichen Rat, der die Lizenz für die Dauer von zwei Jahren genehmigt bekam. ${ }^{167}$

Eine weitere Gruppe von Personen, die in die Gunst von Tragsessellizenzen gelangten, umfasste Buchhalter, unter denen uns mindestens fünf Fälle bekannt sind. Die erste Lizenz bekam Luis de Torregrosa im Jahr I605 zugesprochen; zwei Jahre später erhielten Gabriel de Santa Cruz eine zweijährige und Sancho Méndez de Salazar eine dreijährige Lizenz. Juan López de Alui wurde I608 eine für drei Jahre gültige Lizenz ausgestellt. Auch der zum damaligen Zeitpunkt bereits pensionierte Diego Pérez de Salcedo suchte auf Anraten ehemaliger Kollegen im Jahr I6ıo um eine Lizenz an. Im Zusammenhang mit diesem Fall erklärte der Kammerrat gegenüber dem König, dass man mit den Genehmigungen sparsam umginge und von den zahlreichen Anträgen nur solche für Leute mit „hohem Ansehen und bei denen tatsächlich ein Bedürfnis vorlag" genehmige, weshalb die Räte dem Monarchen empfahlen, Pérez de Salcedo eine Lizenz für Messgänge und den Weg zu seiner ehemaligen Arbeitsstätte zu bewilligen, da er trotz seiner Pensionierung weiterhin seinen früheren Arbeitsplatz aufsuche. ${ }^{168}$

Unter den Richtern mit einer Tragsessellizenz befanden sich Lizenziat Luis de Santillán von der Contaduría Mayor des Finanzrats, dessen Lizenz Ende I607 auslief, und Tana de Zárate, Richter der Audiencia von Valladolid, der mit einer zweijährigen Lizenz bedacht wurde. Francisco de Idiáquez, Sekretär des Staatsrats, wurde eine dreijährige Lizenz zugesprochen, ${ }^{169}$ und Diego Fernando de Alarcón, Richter des Königlichen Rats, erhielt ebenfalls eine dreijährige Lizenz, wobei er um eine zweijährige Verlängerung ansuchen durfte. ${ }^{170}$

$\mathrm{Zu}$ den Lizenzinhabern, die ebenfalls mit dem Verwaltungsapparat der Monarchie verbunden waren, gehörten auch Doktor Hernán Rodríguez, oberster Richter der Herrschaft von Bizkaia, sowie der zum Gobernador von Galizien ernannte Luis Enríquez. ${ }^{171}$ Lizenziat Berrio, der offenbar ebenfalls im Dienst der Monarchie gestanden hatte, erhielt eine auf sechs Monate befristete Lizenz. ${ }^{172}$

Mit rund einem Dutzend Lizenzen bildeten Kleriker die drittgrößte Gruppe von Lizenzinhabern. Es handelte sich dabei - in chronologischer Ordnung - um Pedro González

I67 AHN, Consejos, Leg. 44I7, Nr. II4; AHN, Consejos, Leg. 44I8, Nr. I2, 2I, 35, 57, 64, 65, I84, 245 und $25 \mathrm{I}$.

I68 „[... [ mucha calidad y q tenga precisa necesidad dellas“. AHN, Consejos, Leg. 44I7, Nr. 197; AHN, Consejos, Leg. 4418, Nr. 96, I56 und I78; AHN, Consejos, Leg. 4419, Nr. 56.

169 AHN, Consejos, Leg. 4418, Nr. 20, 130 und 132.

I70 I6Io November 6; AGS CC, Libro 179, fol. I52v. Die zweijährige Verlängerung der auf drei Jahre befristeten Lizenz erfolgte am 5. Juni I608.

I7I AHN, Consejos, Leg. 44I7, Nr. I78; AHN, Consejos, Leg. 44I8, Nr. I42.

I72 I607 Februar I4; AHN, Consejos, Leg. 44I8, Nr. 27. 
de Mendoza, Prior von Hibernia, Juan de Velasco, Erzdiakon von Valpuesta, und Don Miguel Enríquez, Oberkaplan von Cuenca. Sie erhielten alle eine zweijährige Lizenz. Tragsessellizenzen wurden auch dem Bischof von Badajoz sowie dem Patriarchen und Generalinquisitor erteilt. Eine einjährige Lizenz wurde außerdem Lizenziat Canseco de Quiñones, Inquisitor in Granada, und eine zweijährige dem Bischof der Kanarischen Inseln zugesprochen. Auch der Bischof von Plasencia wurde mit einer Lizenz bedacht. ${ }^{173}$ Wahrscheinlich wurden einige dieser Lizenzen später verlängert, wie dies etwa beim Lizenziaten Sebastián de Covarrubias Horozco, Oberlehrer und Kanoniker von Cuenca, der Fall war, der die Lizenz I608 vorerst für ein Jahr erhielt. Nach einer einjährigen Verlängerung, die I609 erfolgte, wurde ihm die Lizenz schließlich im Mai I6II für weitere zwei Jahre bewilligt. ${ }^{174}$ In ähnlicher Weise erhielt Francisco Martínez de Lerma, Kanoniker von Burgos, zunächst eine einjährige Lizenz, die wohl prolongiert wurde, bis ihm schließlich nach einer weiteren, I6I6 erfolgten Verlängerung im Jahr I6I8 erneut eine Lizenz erteilt wurde. ${ }^{175}$

Weitere Personengruppen, die in den Genuss von Tragsessellizenzen kamen, waren Ratsherren und Veinticuatros kastilischer Städte. Bekannt ist ein halbes Dutzend derartiger Fälle: Antonio de Salazar, Ratsherr in Burgos, Gabriel de Galarza aus Madrid, ${ }^{176}$ Antonio de Vargas Manrique, Ratsherr in Toledo, mit einer zweijährigen und nur für diese Stadt gültigen Lizenz, ${ }^{177}$ Lorenzo de Ribera, Veinticuatro in Sevilla, mit einer Lizenz, die zunächst nur für ein Jahr Gültigkeit hatte und später mehrmals verlängert wurde, ${ }^{178}$ sowie Alonso de Peralta, Ratsherr und königlicher Schatzmeister von Toledo, mit einer einjährigen Lizenz. ${ }^{179}$ Lorenzo Cataneo, der mit den Eliten Cuencas eng verbunden war und dessen Sohn dort als Ratsherr fungierte, erhielt eine zweijährige Lizenz. ${ }^{180}$

Einer heterogeneren Gruppe von Lizenzempfängern gehörten Personen an, die entweder im königlichen Hofstaat arbeiteten oder die zumindest nachweisen konnten, diesem Dienste geleistet zu haben. Unter den königlichen Dienern befanden sich Pedro Porto-

173 AHN, Consejos, Leg. 44I7, Nr. 66; AHN, Consejos, Leg. 44I8, Nr. 2, I99, II, 56 und I6I; AHN, Consejos, Leg. 4419, Nr. 2 und 8I.

174 AHN, Consejos, Leg. 4418, Nr. I3I; AGS CC, libro 178, fol. 259.

175 AHN, Consejos, Leg. 4418, Nr. 44; AGS CC, Libro 183, fol. 436v; AGS CC, Libro I86, fol. 409; AGS CC, Leg. I064/32; AHN, Consejos, Leg. 442I/97.

1761607 September I2; AHN, Consejos, Leg. 44I8, Nr. I8I; 1606 November I3; AHN, Consejos, Leg. 44I7, Nr. II7.

177 I608 Mai I; AHN, Consejos, Leg. 44I8, Nr. 66.

178 I609 August 29; AHN, Consejos, Leg. 44I8, Nr. I23; AGS CC, Libro 178, fol. 260 und fol. 452, Leg. 999/62, Leg. IoIO, unfol., Leg. I00I/75. Veinticuatros waren in Andalusien die höchsten Vertreter einer Stadt oder Gemeinde und deren Einwohner.

179 I609 Oktober 4; AHN, Consejos, Leg. 44I8, Nr. I4O.

I80 I606 November 22; AHN, Consejos, Leg. 4417, Nr. I22; AGS CC, Libro 178, fol. 352. 
carrero, Gentilhombre de Boca, der eine zweijährige Lizenz erhielt, Diego Sillero, königlicher Baumeister, dessen Tragsessel „schlicht und unbedeckt“ sein sollte, sowie Cristóbal Perea, Contino des Königs, der in den Genuss einer zweijährigen Lizenz kam. ${ }^{181}$ Martín de Alagón, Gentilhombre de la Cámara, wurde ebenfalls eine Lizenz zugesprochen, wie auch Pedro de Espinosa, Gentilhombre de la casa-acroys, dessen Lizenz später verlängert wurde. ${ }^{182}$

Rund ein Dutzend Tragsessellizenzen ging an Personen, die der Krone in Regierungsämtern gedient oder andere Aufgaben für sie erfüllt hatten, wie Jerónimo de Labastida aus Valladolid, der als Corregidor in mehreren Städten tätig gewesen war und der eine Lizenz für die Dauer von drei Jahren erhielt. Miguel de Vargas, Ritter des Santiagoordens und Komtur von Castilleja de la Cuesta, war ebenso Lizenzempfänger wie Juan de Gaviria, Komtur des Calatravaordens in Las Casas de Talavera, der eine einjährige Lizenz erhielt, die jedoch auf Messgänge beschränkt war. ${ }^{183}$

Bedeutende Dienste für den König leisteten auch der aus Aachen stammende Deutsche Giraldo Paris, der dank seiner Kenntnisse auf den Gebieten des Bergbaus und der Alchemie eine Lizenz für ein Jahr erhielt, und Pedro López de Vilanova, der in Flandern Dienste verrichtete und der eine dreijährige Lizenz erhielt. ${ }^{184}$ Militärische Dienste als Maese de Campo leistete Alonso de Luzón, dem man I608 eine Lizenz für zwei Jahre ausstellte, die I6ı zunächst für sechs Monate und im April I6I schließlich für zwei weitere Jahre verlängert wurde, was sehr enge Beziehungen zum Hof vermuten lässt. ${ }^{\text {.85 }}$

Unter den mit Lizenzen ausgestatteten Personen fehlte es auch nicht an Bankiers und Kaufleuten, die der Krone wohl mit ihrem Vermögen aushalfen, etwa der in Sevilla ansässige, aus Genua stammende Asentista Cosme Centurión, der eine einjährige Lizenz erhielt. ${ }^{186}$ Adam Becquer, einem ebenfalls in Sevilla wohnhaften flämischen Kaufmann, wurde I607 eine zweijährige Lizenz ausgestellt, die I6I für die Dauer einer Erkrankung verlängert wurde. ${ }^{187}$ Auch Fabio Neli de Espinosa, Bankier aus Valladolid, erhielt I6Io eine Lizenz. Er beantragte später eine Lizenz auf Lebenszeit, erlangte schließlich im Jahr I6II

I8I AHN, Consejos, Leg. 44I7, Nr. I70, 54; AHN, Consejos, Leg. 44I8, Nr. 9I.

I82 I6Io Februar I5; AGS CC, Libro I79, fol. I5v; I6II April I6; AGS CC, Libro 179, fol. 209v.

I83 AHN, Consejos, Leg. 44I7, Nr. 43 und I25; AHN, Consejos, Leg. 44I8, Nr. 250. In der spanischen Monarchie war der Corregidor ein Vertreter des Königs, der dem Regidor gegenüberstand, welcher die städtischen Interessen vertrat.

I84 AHN, Consejos, Leg. 44I8, Nr. I5 und I30.

I85 AHN, Consejos, Leg. 44I8, Nr. 82; AGS CC, Libro I79, fol. $201 \mathrm{f}$.

I86 AHN, Consejos, Leg. 44I7, Nr. I53. Asientos waren Verträge, die zwischen der kastilischen Regierung und Bankiers oder Kaufleuten abgeschlossen wurden. Dabei handelte es sich um kurzfristige Vorschüsse, die meist mittels Anweisung auf in Sevilla ankommende Edelmetallieferungen beglichen wurden.

I87 AHN, Consejos, Leg. 44I8, Nr. I33; AGS CC, Libro 178, fol. 300. 
jedoch nur eine auf zwei Jahre befristete Genehmigung. ${ }^{188} \mathrm{Zu}$ den Asentistas zählten auch Ambrosio Espinola, der eine einjährige Lizenz erlangte, die mehrmals verlängert wurde, sowie Hector Picamilo, der eine zweijährige Lizenz erhielt. ${ }^{189}$ So manche Person ausländischer Herkunft, die sich Verdienste um die Monarchie erworben hatte, kam ebenfalls in den Genuss einer Tragsessellizenz, so etwa der genuesische Botschafter Juan Francisco Francesqui, der im Jahr I606 eine Lizenz zugesprochen bekam, oder Camilo Medea, der anführte, bedeutende Mailand betreffende Geschäfte zu führen, was wohl dazu beitrug, dass seine Tragsessellizenz mehrmals verlängert wurde. ${ }^{190}$

Um in den Besitz einer Tragsessellizenz zu kommen, waren persönliche Beziehungen zum Hof von großem Vorteil, auch wenn solche nicht immer nachweisbar sind. Nutznießer solcher Beziehungen waren eindeutig Marco Antonio Padilla, der zweitgeborene Sohn des Adelantado Mayor von Kastilien, sowie Juan Garcés de Marcilla, ein Neffe des Großmeisters des Johanniterordens. Die Kammer schlug vor, Garcés de Marcilla eine Lizenz auf ein Jahr zu erteilen, da er „ein sehr enger Verwandter des Großmeisters des Johanniterordens war und deshalb von den Ordensrittern geschätzt wird und weil er ein vornehmer Herr ist ". ${ }^{991}$

Schließlich wurde auch eine Reihe von Lizenzen vergeben, über deren Inhaber wir nur wenig aus den Quellen erfahren. Sie waren unterschiedlicher sozialer Herkunft und stammten allesamt aus dem urbanen Umfeld Kastiliens. ${ }^{192}$ Zweifellos pflegte mancher die-

I88 AHN, Consejos, Leg. 44I9, Nr. 5; AGS CC, Libro I78, fol. 25Iv; AGS CC, Libro 179, fol. IIv.

I89 I607 März I8 und Dezember 8; AHN, Consejos, Leg. 44I8, Nr. 52 und 252; BPR, II/2395, fol. II2r-I34r.

190 I606 Dezember 27; AHN, Consejos, Leg. 44I7, Nr. I40. Die Lizenz für Medea von 7. März I6I5 findet sich in AGS CC, Libro I83, fol. II5. Zu den Verlängerungen siehe AGS CC, Leg. IOI2/II6; AGS CC, Leg. I047/53.

I9I „[... $q$ hera muy pariente del gran maestre de San Juan y que como tal le estiman los cavalleros de la orden y que es hombre noble“. 1606 Januar I4; AHN, Consejos, Leg. 4417, Nr. 4 und I6; I607 Dezember; AHN, Consejos, Leg. 44I8, Nr. 267.

192 Beispiele hierfür sind etwa Doktor Aguiar, Professor in Valladolid (einjährige Lizenz für Messgänge), Lucas Jiménez, ebenfalls aus Valladolid (einjährige Lizenz), Nicolás de Escobar aus Madrid (einjährige Lizenz mit der Einschränkung, dass sein Tragsessel keine Vorhänge haben durfte), Andrés de la Cerda (einjährige Lizenz), Manuel de Castañoso Sarmiento aus Ocaña (einjährige Lizenz für einen Tragsessel ohne Vorhänge) und Antonio Rodríguez de la Banda aus Salamanca (einjährige Lizenz mit der Begründung, er sei „caballero principal y mayorazgo“). Lizenzen wurden auch vergeben an den alten und blinden Pedro de Espinosa (dreijährige Lizenz), an Francisco Peroni (zweijährige Lizenz), an Doktor Pedro de Sosa (sechsmonatige Lizenz) sowie an Jerónimo de Silva, Ritter des Santiagoordens (einjährige Lizenz). I60s November 26; AHN, Consejos, Leg. 44I7, Nr. I48; AHN, Consejos, Leg. 44I8, Nr. 158; I608 August 30; AHN, Consejos, Leg. 44I8, Nr. I2I; I608 November 7; AHN, Consejos, Leg. 44I8, Nr. I26 und I27; I609 Januar 16; AHN, Consejos, Leg. 44I8, Nr. 6; I609 Juni I5; AHN, Consejos, Leg. 44I8, Nr. 89; I606 Februar I4; AHN, Consejos, Leg. 44I7, Nr. 20; I607 Juni 3; AHN, Consejos, Leg. 44I8, 
ser Begünstigten gute Beziehungen zum Hof, was sich etwa für Felipe Montenegro y Sotomayor nachweisen lässt, einen Einwohner von Pontevedra, der mit dem renommierten Diplomaten Sarmiento de Acuña verkehrte und der wohl nicht zuletzt deshalb eine zweijährige Lizenz zugesprochen bekam. ${ }^{193}$ Gegen Ende des Jahres I608 kam der König zu der Ansicht, dass die Zahl der ausgestellten Lizenzen unangemessen hoch sei. Dieser Meinung verlieh er anlässlich der Erteilung einer Lizenz an Pedro Alderete de Haro, einen Bewohner Salamancas, Ausdruck, der sich laut eigenen Angaben aufgrund einer schweren Erkrankung weder zu Pferd noch in der Kutsche fortbewegen konnte. Der König forderte anlässlich dieses Falls seine Räte auf, bei den Ratssitzungen größeren Eifer bei der Überprüfung der Anträge an den Tag zu legen. ${ }^{194}$ Die Vorgänge rund um die „Institutionalisierung“ der Kutschen führten jedoch zu einem verstärkten Interesse an Tragsessellizenzen und in der Folge auch zu einer Zunahme der ausgestellten Lizenzen.

Tatsächlich lässt sich ab dem Jahr I6II ein solcher Anstieg beobachten. Zwischen I6II und I62I, in jenen Jahren, denen wir nun besonderes Augenmerk schenken wollen, wurden 280 Lizenzen erteilt. Zu Beginn dieses Zeitraums schwankte die Zahl der jährlich ausgestellten Lizenzen relativ stark. Im Jahr I6II wurden mehr als vierzig registriert, in den Jahren I6I2 und I6I3 hingegen weniger als zwanzig - auch wenn bekannt ist, dass I6I3 weitere Lizenzen vergeben wurden, allerdings ging das entsprechende Quellenmaterial dazu verloren. Schon I6I4 erhöhte sich die Zahl wieder auf mehr als dreißig. In der Folgezeit wurden bis I620 jährlich stets mehr als zwanzig Lizenzen vergeben. Ab I620 sank diese Zahl dann rasch ab. Nach einer in den frühen I620er Jahren erreichten Talsohle lässt sich wieder ein Anstieg verzeichnen. Bis Mitte der I63oer Jahre wurden schließlich insgesamt rund 500 bis 600 Tragsessellizenzen vergeben.

Die 280 im Zeitraum zwischen I6II und I62I erteilten Lizenzen geben eine solide Basis für eine soziale Einordnung der Lizenzempfänger. Wie bereits im vorhergehenden Zeitabschnitt waren auch nun viele der Begünstigten Träger von Adelstiteln, allerdings verdreifachte sich die Zahl der für sie bestimmten Lizenzen auf dreiunddreißig. Zahlreiche Vertreter dieser Gruppe, nämlich einundzwanzig, bekleideten entweder Ämter im Hofstaat des Königs beziehungsweise der Königin oder in den Räten der Monarchie. Angehörige des königlichen Hofstaats waren neben Pedro Lasso de la Vega, Conde de Arcos, Hof-

Nr. I20; I609 August 23; AHN, Consejos, Leg. 44I8, Nr. II2; I6Io Januar I8; AHN, Consejos, Leg. 44I9, Nr. 9 .

I93 I608 Oktober 4; AHN, Consejos, Leg. 44I8, Nr. I40; BPR, II/2IO9, doc. I6I.

I94 „[... [ mirese en q vengan ciertas estas relaciones de fuera y esto se haga assi“. 1607 Dezember 8; AHN, Consejos, Leg. 44I8, Nr. 259. 
meister des Königs, ${ }^{195}$ auch der Kämmerer Francisco de Rivera, Marqués de Malpica, ${ }^{196}$ weiterhin der Duque de Uceda, Sohn des königlichen Favoriten und seit I6I2 Kämmerer, dessen Lizenzgesuch von seinem Vater unterstützt wurde, ${ }^{197}$ sowie Rodrigo Calderón, Marqués de Sieteiglesias, Komtur von Ocaña, Kapitän der Deutschen Garde und Vertrauter des königlichen Favoriten, der auch die Lizenzvergabe an Calderón unterstützte. ${ }^{198}$ Unter den Adeligen, die der I6II verstorbenen Königin gedient hatten und die Lizenzen erhielten, befanden sich der frühere Hofmeister Marqués de La Laguna, weiterhin der Conde de Alcaudete, der seit I6ı das Amt des Hofmeisters der Köngin innehatte, wie auch der Conde de Priego sowie Rui Méndez de Vasconcelos, Conde de Castelmellor, die gleichfalls zu Hofmeistern berufen worden waren. ${ }^{199}$ Bernardino de Velasco, Conde de Salazar, diente erst König Philipp II. als Hofmeister und bekleidete ab I6I2 dasselbe Amt auch im Hofstaat des Infanten, ${ }^{200}$ ebenso wie Juan, Conde de Castro. ${ }^{201}$ Unter den Adeligen, die Posten im Regierungsapparat der Monarchie bekleideten, befanden sich mehrere Ratsmitglieder, wie etwa der Marqués de Santa Cruz, Antonio de Quintanadueñas, Marqués de la Floresta und Carlos de Tapia, Marqués de Belmonte, die allesamt Mitglieder des Italienischen Rates waren. Lizenzempfänger waren auch der Präsident des Indienrates, Marqués de Salinas, jener des Ordensrates, Marqués de Caracena, und jener des Portugiesischen Rates, Carlos de Borja, Duque de Villahermosa. Im Kriegsrat diente Bernardo González de Avellaneda, Conde de Castrillo, und im Kastilischen Rat der Conde de Chinchón. ${ }^{202}$ Einige Adelige hatten militärische Ämter inne, wie etwa der Marqués de Cadereyta, General der Armada de la Guarda de la Carrera de Indias und Gentilhombre de la Boca, ${ }^{203}$ und vermutlich auch

I95 I6II März 6; AGS CC, Libro 178, fol. 235v.

I96 I6r7 Mai I9; AGS CC, Libro I85, fol. I78; AHN, Consejos, Leg. 442I/380; AGS CC, Leg. I075/98.

197 I613 April 27; AGS CC, Libro I8I, fol. I44v; AGS CC, Leg. IOI4/83; AGS CC, Leg. I027/20.

198 I6I4 September 27; AGS CC, Libro I83, fol. 22v; AGS CC, Leg. I035/49.

199 I6II März 6; AGS CC, Libro I78, fol. 235v; I6II März I3; AGS CC, Libro I79, fol. 196v; I6II August 20; AGS CC, Libro 179, fol. 273v; I6II August 20; AGS CC, Libro 179, fol. $273 \mathrm{v}$.

200 I6I7, Konsultation I6I7 Oktober 28; AHN, Consejos, Leg. 4421/188.

201 I6I6 Mai 7; AGS CC, Libro I83, fol. 436v; AHN, Consejos, Leg. 4420/6; AGS CC, Leg. Io64/33.

202 I6II Februar I5; AGS CC, Libro I78, fol. 23Ir; AHN, Consejos, Leg. 4419/4; I6I6 Mai 25; AGS CC, Libro I82, fol. 420v; AHN, Consejos, Leg. 4420/3I; I6I8 Juni I5; AGS CC, Libro I87, fol. 90; AHN, Consejos, Leg. 4421/70; I6II Dezember 9; AGS CC, Libro 179, fol. 333v; I6I6 Mai 7; AGS CC, Libro 183, fol. 436v; AHN, Consejos, Leg. 4420/2; AGS CC, Leg. 1064/36; I618 März 19; AGS CC, Libro I86, fol. 255; AHN, Consejos, Leg. 442I/8; AGS CC, Leg. I087/I84; I6I7 August I9; AGS CC, Libro I85, fol. 295; AHN, Consejos, Leg. 442I/ı2I; AGS CC, Leg. I077/88; I6I4 März I3; AGS CC, Libro I8I, fol. 322v; AHN, Consejos, Leg. 4420/I4; AGS CC, Leg. I029/II5. I620 März I3; AGS CC, Libro I88, fol. 270v; AHN, Consejos, Leg. 442I/19. Die Carrera de Indias war zwischen dem 16. und I8. Jahrhundert das spanische Konvoysystem zur Sicherung der Atlantiküberquerungen. 
der Marqués de Santa Ágata, Conde de Potenza. ${ }^{204}$ Andere bekleideten wiederum einflussreiche Regierungsposten, wie der Duque de Monteleón, der von I603 bis I6ıo Vizekönig von Katalonien war, ${ }^{205}$ oder der Marqués de la Hinojosa, der seine Lizenz kurz nach seinem Amtsende als Gouverneur Mailands erhielt. ${ }^{206}$ Unter ähnlichen Umständen gelangte auch Juan Hurtado de Mendoza, Marqués de Montesclaros, im Jahr I6I7 an eine Lizenz. Er war von 1603 bis 1607 Vizekönig von Neuspanien gewesen, hatte anschließend dasselbe Amt von I607 bis I6I5 in Peru ausgeübt und war schließlich I6I6 nach Spanien zurückgekehrt. ${ }^{207}$

Unter den Adeligen die eine Lizenz erhielten, befanden sich auch einige prominente Persönlichkeiten, wie etwa der Príncipe de Esquilache, ${ }^{208}$ der Conde de Cifuentes, ${ }^{209}$ der Marqués de Mondéjar, ${ }^{210}$ der Marqués de Cañete ${ }^{211}$ oder der Conde de Monsanto, ${ }^{212}$ während andere weniger traditionsreichen Adelshäusern entstammten, wie etwa der Marqués de Estepa,${ }^{213}$ der Conde de Villaverde ${ }^{214}$ und der Marqués de Toral, ${ }^{215}$ was veranschaulicht, wie breit gestreut die königlichen Gunstbezeugungen waren. Manche Adelige bewarben sich um eine Lizenz für die Dauer ihrer Geschäftstätigkeiten, wie bespielsweise Pedro Portocarrero, Conde de Medellín, der in Granada Prozesse führte, ${ }^{216}$ oder der Duque de Alcalá, der Gleiches am Hof tat. ${ }^{217}$ Ebenso suchte der Príncipe de Sansever um eine Tragsessellizenz an, um sich in Madrid seinen Geschäften widmen zu können. ${ }^{218}$

Die siebenundvierzig Kleriker, die mit Erfolg um eine Lizenzen ansuchten, lassen sich in mehrere Gruppen unterteilen, nämlich erstens die Träger hoher Würden, die

204 I6I5 August 8; AGS CC, Libro I82, fol. I8I; AHN, Consejos, Leg. 4420/7I.

205 I620 September I2; AGS CC, Libro I89, fol. I34; AHN, Consejos, Leg. 442I/90.

206 I6I6 September I7; AGS CC, Libro I84, fol. 48; AHN, Consejos, Leg. 4420/ıi4; AGS CC, Leg. I067/215.

207 I6r7 April I8; AGS CC, Libro I84, fol. 307v; AHN, Consejos, Leg. 442I/22; AGS CC, Leg. 1074/105.

208 I6I April 5; AGS CC, Libro I79, fol. 207.

209 I6I3 Juni 3; AGS CC, Leg. I020/54.

2IO I6I4 Juli 20; AGS CC, Libro I8I, fol. 4I6v; AHN, Consejos, Leg. 4420/57; AGS CC, Leg. IO33/II3.

2II I6I6 Januar 29; AGS CC, Libro I82, fol. 3II; AHN, Consejos, Leg. 4420/I58; AGS CC, Leg. I06I/68.

2 I2 I6Ir März I3; AGS CC, Libro I79, fol. I96v.

213 I6I2 September 22; AGS CC, Libro I8I, fol. 38; AGS CC, Leg. Ioo4/43.

$2 I 4$ I6I6 Juli 6; AGS CC, Libro I82, fol. 457v; AHN, Consejos, Leg. 4420/44; AGS CC, Leg. I065/7.

215 I6I4 Februar I8; AGS CC, Libro I8I, fol. 309; AHN, Consejos, Leg. 4420/6; AGS CC, Leg. IO28/II3.

216 I6II und I6I3; AHN, Consejos, Leg. 4419/54.

217 I6I5 Mai 30; AGS CC, Libro I82, fol. I26; AHN, Consejos, Leg. 4420/46 und 50; AGS CC, Leg. I049/ unfol.; AGS CC, Leg. I050/34.

218 I6I7 Mai 6; AGS CC, Libro I84, fol. 320v; AHN, Consejos, Leg. 442I/39; AGS CC, Leg. I074/60. 
eine kleine Gruppe darstellten, da die meisten von ihnen automatisch mit Kutschenlizenzen versehen waren, zweitens das Personal bedeutender kastilischer Kathedralen, insbesondere jener von Toledo, Santiago, Cuenca, Granada und - in geringerem Umfang - Sevilla, und schließlich Personen, die im königlichen Dienst standen. Die Zahl der Kleriker, die keiner dieser Gruppen angehörten und die dennoch eine Lizenz erhielten, ist vernachlässigbar. Zu den hohen Würdenträgern, die in den Genuss einer Lizenz kamen, zählten der Erzbischof von Burgos und Präsident des Rates von Kastilien, der Erzbischof von Granada und die Bischöfe von Guadix, Badajoz sowie von Bona, Juan de la Sal. ${ }^{219} \mathrm{Zu}$ den Kathedralen, deren Mitglieder mehrere Lizenzen erhielten, gehörte jene von Toledo, die den ersten Rang in der spanischen Kirche einnahm und bei der acht Personen mit Tragsessellizenzen zu finden sind: Francisco de Acuña, Vorsänger und Kanoniker, ${ }^{220}$ die Kanoniker Francisco de Oria, ${ }^{221}$ Andrés de Villegas, ${ }^{222}$ Álvaro de Quiroga y Monsalve, ${ }^{223}$ Juan de Monsalve y Quiroga, ${ }^{224}$ der vom königlichen Favoriten protegierte Gaspar Yáñez Tofiño ${ }^{225}$ sowie Lizenziat Mancio de Villafañe, Oberkaplan der Mozaraber Toledos. ${ }^{226}$ Hinzu kamen der Kanoniker Francisco Chacón, der auch Erzdiakon von Calatrava war, ${ }^{227}$ und Doktor Gabriel Suárez de Toledo, der gleichzeitig das Amt eines Erzdiakons von Madrid innehatte. ${ }^{228}$ Unter den Kanonikern der Kathedrale von Santiago de Compostela erhielten zumindest sechs Personen Lizenzen, darunter Gonzalo Barba

219 I6I7 Juli I5; AGS CC, Libro I85, fol. 26Iv; AHN, Consejos, Leg. 442I/IO2; I6I2 Juli 2; AGS CC, Libro 179, fol. 452v; AHN, Consejos, Leg. 4419/88; AGS CC, Leg. IooI/I20; I6II September Io; AGS CC, Libro 179, fol. 285r, Lizenz bis auf Widerruf des königlichen Willens; I613, AGS CC, Leg. I0I2/55; I6I4 Januar 24; AGS CC, Libro I8I, fol. 288; AGS CC, Leg. I022/80.

2201620 August I2; AGS CC, Libro I89, fol. I2Iv; AHN, Consejos, Leg. 442I/85.

22I I6I9 September 22; AGS CC, Libro I88, fol. I39v; AHN, Consejos, Leg. 442I/74.

222 I6I5 September I2; AGS CC, Libro I83, fol. 267.

223 I6II Dezember I8; AGS CC, Libro I78, fol. 38I.

224 I6I5 September I2; AGS CC, Libro I83, fol. 267; AHN, Consejos, Leg. 4420/98; AGS CC, Leg. I053/55.

225 I613; AGS CC, Leg. IO2I/I45.

226 I6II Juni I8; AGS CC, Libro I78, fol. 275v; AHN, Consejos, Leg. 4419/65; AGS CC, Leg. IOI2/53.

227 I6II Juni 31; AGS CC, Libro I78, fol. 282. Chacón, der eine einjährige Lizenz erhielt, litt an Herzund Leberleiden, und „nach dem Verbot der Kutschen wurde er in Armen nach Hause getragen“" („después q se prohibieron los coches le an llevado a su casa en braços“). AHN, Consejos, Leg. 4419/96. I6I4 beantragte er schließlich mit Erfolg eine unbefristete Lizenz. AGS CC, Leg. I032/38.

I6I5 Mai 30; AGS CC, Libro I82, fol. I26; AHN, Consejos, Leg. 4420/55. Der mit über achtzig Jahren älteste Pfründner der Kirche konnte aufgrund diverser körperlicher Leiden weder ein Maultier noch eine Kutsche benutzen und bat daher unter Verzicht auf seine Lizenz für Kutschen um eine Tragsessellizenz. I6I5 April 6; AGS CC, Leg. 1058/24. 
de Figueroa, ${ }^{229}$ Lizenziat Espinosa, der auch als Kontrollor des Bistums fungierte, ${ }^{230}$ der Prior Gaspar de Garnica, ${ }^{231}$ der Dechant Francisco Antonio Juárez ${ }^{232}$ sowie Lizenziat Pedro de Espinosa Mondéjar. ${ }^{233}$ In anderen bedeutenden Domkapiteln Kastiliens wurden ebenfalls Lizenzen an Kanoniker erteilt, wenn auch in geringerer Zahl, etwa in Cuenca, wo der Erzdiakon Luis de Castilla, ${ }^{234}$ der Erzpriester Pedro Suárez Franco ${ }^{235}$ und Damián Suárez ${ }^{236}$ zu den Lizenzempfängern zählten. Der Kirche Cuencas gehörte auch der Priester und Lizenziat Lucas de Marquina an. ${ }^{237}$ In Granada erhielten der mit Sicherheit gute Verbindungen zur Krone unterhaltende Kanoniker Doktor Salinas de Mercado ${ }^{238}$, der Kanoniker Alonso de Zayas ${ }^{239}$ sowie der Inquisitor Pedro Hurtado de Gaviria Lizenzen. ${ }^{240}$ In Burgos kam der Kanoniker Doktor Jerónimo del Río in den Genuss einer Tragsessellizenz. ${ }^{241}$ Zwei Kanoniker erlangten in Sevilla eine Lizenz, nämlich Lizenziat Serafino Costa, Erzdiakon von Carmona, ${ }^{242}$ sowie Juan Hurtado. ${ }^{243}$ In weit geringerer Zahl wurden Lizenzen an Mitglieder anderer Domkapitel vergeben, etwa an Hernando Gutiérrez Calderón, Erzdiakon in Valladolid, ${ }^{244}$ an Gonzalo de Villasante, Erzdiakon in Tordesillas, ${ }^{245}$ an Pedro Gudiel, Domscholast und Kanoniker in Ciudad Rodrigo, der

229 I6Is April 2; AGS CC, Libro I83, fol. 306v; AHN, Consejos, Leg. 4420/I22; AGS CC, Leg. I054/II8.

230 I6I7 Juli I5; AGS CC, Libro I85, fol. 26rv; AHN, Consejos, Leg. 442I/Ior. Er gab an, dass er nur im Tragsessel oder mit Hilfe von Krücken die Kirche besuchen könne. I6r7 Juni 5; AGS CC, Leg. I076/187. I6r8 Juni I5; AGS CC, Libro I87, fol. 90v; AHN, Consejos, Leg. 442I/66; AGS CC, Leg. I085/I43. 1620 November 2I; AGS CC, Libro 190, fol. 44; AHN, Consejos, Leg. 442I/I2I. I620 September I9; AGS CC, Libro I89, fol. I39; AHN, Consejos, Leg. 4421/94. I6I3 Juni 23; AGS CC, Libro I8I, fol. I79v. I617 Mai 6; AGS CC, Libro I84, fol. 320v; AGS CC, Leg. I074/54. I6I6 Januar 29; AGS CC, Libro I82, fol. 3II; AHN, Consejos, Leg. 4420/158; AGS CC, Leg. I06I/65.

237 I6I8 August I8; AGS CC, Libro I86, fol. 409; AHN, Consejos, Leg. 442I/90.

238 Konsultation I6I8 August 30; AHN, Consejos, Leg. 442I/II2.

239 I6I8 Mai 26; AGS CC, Libro I86, fol. 319; AHN, Consejos, Leg. 442I/68.

240 I6I2 März 27; AGS CC, Libro I79, fol. 399v; AHN, Consejos, Leg. 4419/22; AGS CC, Leg. 997/74.

24I Für del Río: I6ı2 April 8; AGS CC, Libro 178, fol. 438. Er gab an, älter als sechzig Jahre zu sein und an Unterleibsschmerzen, Nierensteinen und Gicht zu leiden. AHN, Consejos, Leg. 4419/26; AGS CC, Leg. 997/I3. Für den bereits erwähnten Kanoniker Francisco Martínez de Lerma, der ebenfalls in Burgos eine Lizenz erhielt, siehe Anm. I75.

242 I618 Juni I5; AGS CC, Libro 187, fol. 90v; AHN, Consejos, Leg. 4421/64.

243 I62I Februar 4; AGS CC, Libro I89, fol. 222; AHN, Consejos, Leg. 442I/I57.

244 I6II April 29; AGS CC, Libro 179, fol. 2IIv; AHN, Consejos, Leg. 4419/38.

245 I6I2; AHN, Consejos, Leg. 4419/159; AGS CC, Leg. I005/unfol.; AGS CC, Leg. I004/69. Er gab an, blind und über achtundsiebzig Jahre alt zu sein. 
sie für sein Erscheinen am Hof erbat, ${ }^{246}$ wie auch an Jerónimo de Sota, Erzpriester von Saragossa, der sich im Auftrag des Erzbischofs in Madrid aufhielt. ${ }^{247}$

Neben diesen Kathedralkirchen zugehörigen Geistlichen erhielten auch einige Kleriker Lizenzen, die dem Königshaus eng verbunden waren, allen voran königliche Beichtväter und Prediger. Zu diesen Lizenzempfängern zählten beispielsweise Gonzalo de Peñacarrillo, königlicher Kaplan und Ritter des Santiagoordens, ${ }^{248}$ Pedro de Araques, königlicher Kaplan und Kanoniker in Saragossa, der seine Lizenz mit der Unterstützung Lermas zugesprochen bekam, ${ }^{249}$ Fray Francisco de Barreda de Rivera, königlicher Kaplan, Prior von Porcuna, Granada und Alhama und Ritter des Ordens von Calatrava, ${ }^{250}$ der königliche Kaplan Doktor Francisco Sánchez de Villanueva, ${ }^{251}$ Lizenziat Fray Antonio de Valencia, Obersakristan in Alcántara, der mit Hilfe des Marqués de Povar in den Besitz einer Lizenz gelangte, ${ }^{252}$ und schließlich Lizenziat Miguel de Sosa, Kaplan bei den königlichen Edelknaben. ${ }^{253}$ Andere hochrangige königliche Diener, die eine Tragsessellizenz erhielten, waren Fray Plácido de Tosantos, Ordensgeneral der Benediktiner, königlicher Beichtvater und Calificador des Inquisitionsrats, ${ }^{254}$ sowie Fray Luis de Aliaga, königlicher Beichtvater und Generalinquisitor. ${ }^{255}$ Offenbar außerhalb der engeren Hofkreise - jedoch gewiss mit hilfreichen Beziehungen zu denselben - befanden sich andere Kleriker, die ebenfalls in den Genuss einer Tragsessellizenz gelangten, wie etwa Lizenziat Juan Delgado y Agüero, Vikar von

246 I6II Oktober 22; AGS CC, Libro I78, fol. 348; AHN, Consejos, Leg. 4419/180.

247 Seinen Angaben zufolge war er zweiundsechzig Jahre alt und außer Stande, in einer Kutsche zu fahren oder ein Maultier zu reiten. Er bat deshalb um eine Lizenz für die Dauer seines Aufenhaltes am Hof. Die Kammer befürwortete die Vergabe einer zweijährigen Lizenz. I6ı3; AGS CC, Leg. IOI2/86.

248 I6I9 September 22; AGS CC, Libro I88, fol. I39v; AHN, Consejos, Leg. 442I/75.

249 I6I4 Dezember 7; AGS CC, Libro I82, fol. 33; AGS CC, Leg. I039/15.

250 I6I6 Februar I2; AGS CC, Libro I82, fol. 322v; AHN, Consejos, Leg. 4420/163; AGS CC, Leg. I062/I4.

25I I6I7 März I9; AGS CC, Libro I85, fol. I2I; AHN, Consejos, Leg. 442I/II. Er war krank und benötigte einen Tragsessel, um predigen und die königliche Kapelle besuchen zu können. AGS CC, Leg. $1074 / 98$.

252 I6I6 August 27; AGS CC, Libro I82, fol. 482v; AHN, Consejos, Leg. 4420/76; AGS CC, Leg. I066/ 82.

253 I6I3 September 23; AGS CC, Leg. I020/48. Laut Konsultation vom 30. September I6I3 sollte er eine auf zwei Jahre befristete Lizenz erhalten.

254 I6I2 September I5; AGS CC, Libro I8I, fol. 32; AHN, Consejos, Leg. 4419/122. Die Aufgabe eines Calificador lag in der Erstellung von Gutachten.

255 I619 April 7; AGS CC, Libro 188, fol. 36. 
Alcalá, ${ }^{256}$ Lizenziat Francisco de Salcedo, apostolischer Inquisitor Aragoniens, ${ }^{257}$ Andrés de Cañizares y Uribe, apostolischer Notar des bischöflichen Gerichts von Cuenca, ${ }^{258}$ sowie der Priester Pedro de Reinoso, der gleichzeitig auch Dorfherr war, ${ }^{259}$ und Doktor Gaspar Ruíz de Montalbán, Priester und Vikar der Kirche San Justo in Madrid ${ }^{260}$.

Unter den knapp zwei Dutzend königlichen Dienern mit Tragsessellizenzen befanden sich mehrere Gentileshombres und Ärzte, auch wenn die Zahl der Diener, die andere wichtige Ämter - wie etwa Hofmeister - ausübten oder die Kleriker waren, ebenfalls nicht zu vernachlässigen ist. Zu den königlichen Hofmeistern zählte beispielsweise Iñigo de Cárdenas. ${ }^{261} \mathrm{Zu}$ den Gentileshombres gehörten unter anderem Enrique Enrrig ${ }^{262}$, Alonso Fernández de Córdoba ${ }^{263}$, Juan de Castro y Castilla, ${ }^{264}$ Pedro Fernández de Córdoba, Komtur des Ordens von Calatrava in Torres und Jimena, ${ }^{265}$ Gaspar Girón, Komtur von Estremera, ${ }^{266}$ Tello de Guzmán ${ }^{267}$ sowie Dalmau de Rocabertii ${ }^{268}$, die allesamt Gentileshombres de Boca waren, während Antonio Pessoa als Gentilhombre de la Casa diente ${ }^{269}$.

Von den königlichen Ärzten durften Doktor Paulo de Salinas (Leibarzt), ${ }^{270}$ der kurz vor Erhalt der Lizenz zum königlichen Chirurgen ernannte Lizenziat Martín Castellanos, ${ }^{271}$

256 I6III August 20; AGS CC, Libro 179, fol. 273v. Da er unter gesundheitlichen Problemen litt und seit Erlass des Kutschenverbots seinen Pflichten nicht mehr nachkommen konnte, schlug die Kammer die Erteilung einer zweijährigen Tragsessellizenz vor. AHN, Consejos, Leg. 4419/118.

257 I6I8 Dezember 29; AGS CC, Libro I87, fol. 265v; AHN, Consejos, Leg. 4421/I5I.

258 I6I8 Mai 26; AGS CC, Libro I86, fol. 319. Aufgrund seiner Erkrankung wurde ihm die Nutzung eines Tragsessels mit kleinem Dach („silla de toldillo“) gewährt. AHN, Consejos, Leg. 442I/38.

259 I6I5 Januar 3I; AGS CC, Libro I82, fol. 56v; AHN, Consejos, Leg. 4420/187; AGS CC, Leg. I040/8I.

260 I617 September 8; AGS CC, Libro I85, fol. 321; AHN, Consejos, Leg. 4421/127. Er litt an einer Harnwegserkrankung und an großen Schmerzen, weshalb ihm seine Ärzte verboten hatten, auf Maultieren oder Pferden zu reiten. AGS CC, Leg. I077/23.

26I I6I6 Mai 7; AGS CC, Libro I83, fol. 436v; AHN, Consejos, Leg. 4420/6; AGS CC, Leg. 1064/38.

262 I6II März 22; AGS CC, Libro 179, fol. I99v; AHN, Consejos, Leg. 4419/2I.

263 I6I2; AHN, Consejos, Leg. 44I9/82; AGS CC, Leg. I00I/24.

264 I6I8 Mai 26; AGS CC, Libro I86, fol. 319; AHN, Consejos, Leg. 442I/39.

265 I619 Dezember 17; AGS CC, Libro I89, fol. 18; AHN, Consejos, Leg. 442I/97.

266 I620 September I2; AGS CC, Libro I89, fol. 134; AHN, Consejos, Leg. 4421/90.

267 I617 Juni 3; AGS CC, Libro I84, fol. 359; AHN, Consejos, Leg. 442I/54. Er hatte ein Augenleiden, und die Ärzte meinten, er solle sich im Tragsessel fortbewegen, um sich so vor Wind und Sonne zu schützen. AGS CC, Leg. 1075/80.

268 I629 August I2; AGS CC, Libro I89, fol. I2Iv; AHN, Consejos, Leg. 4421/85.

269 I6II Oktober 22; AGS CC, Libro 178, fol. 347v; AHN, Consejos, Leg. 4419/212.

270 I6II Februar 28; AGS CC, Libro I79, fol. I90v.

27I I6I2 Mai II; AGS CC, Libro I79, fol. 42I. Er suchte um einen Lizenz für eine Kutsche oder einen Tragsessel an. Die Kammer entschied sich für die Bewilligung einer Tragsessellizenz. AHN, Consejos, Leg. 4419/58; AGS CC, Leg. 999/27. 
Doktor Valle (Leibarzt), ${ }^{272}$ Doktor Álvarez de Perea (Leibarzt und Protomédico) ${ }^{273}$ und Doktor Soto (königlicher Arzt) Tragsessel verwenden. ${ }^{274}$ Vertreter anderer Dienerkategorien im Hofstaat erhielten nur in Einzelfällen Lizenzen, etwa Antonio de Robles, Aposentador del Libro, ${ }^{275}$ Antonio Martínez, der in der königlichen Kapelle diente, ${ }^{276}$ und Pedro Alosa, Fourier-Gehilfe und Sohn des königlichen Oberkochs, eine Tatsache, die ihm bei der Erlangung seiner Lizenz gewiss von Nutzen war. ${ }^{277}$ Welche Tätigkeit Jorge de Mendoza ausübte, der einfach nur als „Diener Seiner Majestät“ bezeichnet wurde und der ebenfalls eine Tragsessellizenz erhielt, entzieht sich unserer Kenntnis. ${ }^{278}$

Der Großteil der erteilten Genehmigungen, nämlich mindestens sechzig, wurde Personen ausgestellt, die Regierungsämter innehatten, und zwar entweder in den Räten oder in den Gerichten der Monarchie. Hinsichtlich der Räte lässt sich beobachten, dass die Mehrheit der Lizenzen zwar an den Kastilischen Rat ging, jedoch auch Lizenzvergaben an Mitglieder anderer Ratsgremien nicht unüblich waren. Die Amtsträgern des Kastilischen Rats erteilten Genehmigungen waren bestimmt für Álvaro de Benavides, Komtur von Montalbán, Ritter des Santiagoordens und Mitglied des Königlichen Rates sowie des Kammerrates, ${ }^{279}$ für Lizenziat Molina de Medrano, ebenfalls Ritter des Santiagoordens, ${ }^{280}$ für Doktor Antonio Bonas, Ritter des Alcántaraordens, ${ }^{281}$ für Lizenziat Juan de Frías, ${ }^{282}$ für

272 I6I3 September 28; AGS CC, Libro I8I, fol. 232; AHN, Consejos, Leg. 44I9/IIO; AGS CC, Leg. IOI9/29.

273 I6I5 August 22; AGS, Libro I83, fol. 246v; AHN, Consejos, Leg. 4420/74; AGS CC, Leg. I052/66. Das Protomedicato war das Kollegium der königlichen Ärzte.

274 I6r9 März I8; AGS CC, Libro I87, fol. 342; AHN, Consejos, Leg. 442I/9.

275 I6I5 September I2; AGS CC, Libro I83, fol. 267; AHN, Consejos, Leg. 4420/74. Er konnte sein Haus weder zu Fuß verlassen noch in der Kutsche, „da deren Stöße ihm erhebliche Schmerzen bereiteten" (,[...] ni en coche porque le hacen notable daño los golpes del $[\ldots]$ "). Auch war es ihm nicht möglich, die Messe zu besuchen. AGS CC, Leg. I053/58.

I6I5 Mai I8; AGS CC, Libro I83, fol. I56v; AHN, Consejos, Leg. 4420/49. Er war sechzig Jahre alt und litt an Lähmung und Wassersucht. Das Ansuchen um Bewilligung einer Lizenz wurde durch Lizenziat Magán eingebracht. AGS CC, Leg. I04I/64.

277 I6I3; AGS CC, Leg. 1020/58.

278 I619 März I8; AGS CC, Libro 187, fol. 342; AHN, Consejos, Leg. 442I/8.

279 I6I2 April 8; AGS CC, Libro I78, fol. 438; AHN, Consejos, Leg. 4419/33; AGS CC, Leg. 997/rio. Der Kastilische Rat wurde auch Königlicher Rat genannt. Zu ihm zählte auch der Kammerrat. $280 \quad$ I6I6 Juli 6; AGS CC, Libro I82, fol. 457; AHN, Consejos, Leg. 4420/44; AGS CC, Leg. 1065/6. 28I I6I6 Juli 6; AGS CC, Libro I82, fol. 457v; AHN, Consejos, Leg. 4420/44; AGS CC, Leg. 1065/7. 282 I616 September 17; AGS CC, Libro I84, fol. 48; AHN, Consejos, Leg. 4420/Ir4. Er suchte um eine Tragsessellizenz an, um pünktlich und besser als bisher zum königlichen Dienst erscheinen zu können, da er bei Unpässlichkeit oder Krankheit auf solche Tragevehikel angewiesen sei. AGS CC, Leg. $1067 / 218$. 
Diego de Santoyo, Receptor de las penas de Cámara, ${ }^{283}$ für Martín de Córdoba vom Königlichen Rat und Generalkommissar der Santa Cruzada, ${ }^{284}$ für Gil Ramírez de Arellano, Mitglied des Rats von Kastilien und des Kammerrats, ${ }^{285}$ für Lizenziat Melchor de Molina, ${ }^{286}$ für Lizenziat Diego López de Ayala, Ritter und Komtur des Alcántaraordens und Mitglied des Kastilischen Rates sowie des Kammerrates, ${ }^{287}$ für Luis de Padilla, der ebenfalls dem Kastilischen Rat und dem Kammerrat angehörte, ${ }^{288}$ sowie für weitere Mitglieder des Kastilienrates wie Francisco Mena de Barrionuevo ${ }^{289}$ oder Lizenziat Pedro de Tapia. ${ }^{290}$ Vom Italienischen Rat erlangten folgende Personen Tragsessellizenzen: Lanz, der dem Rat vorstand, ${ }^{291}$ Doktor Jerónimo Caymo, ${ }^{292}$ Doktor Mario Cañizaro, ${ }^{293}$ Felipe de Haro, ${ }^{294}$ Carlos de Aragón, als Mitglied und Archimandrit von Messina, ${ }^{295}$ sowie der Referent Doktor Diego López de Salcedo. ${ }^{296}$ Im Portugiesischen Rat wurden an die Ratsmitglieder Hernando de Matos, ${ }^{297}$ Lizenziat Francisco Noguera ${ }^{298}$ und Pedrálvares Pereira ${ }^{299}$ Lizenzen erteilt. Weitere Lizenzen erhielten der Protonotar Agustín de Villanueva vom Aragonesischen Rat, ${ }^{300}$ Pedro Mejía de

283 Er sollte die Lizenz schließlich nicht mehr erhalten, da er vorzeitig starb. I6ı2; AHN, Consejos, Leg. 44I9/III; AGS CC, Leg. IOOI/II.

284 I6I3; AGS CC, Leg. I022/78.

285 I6I4 Februar 8; AGS CC, Libro I8I, fol. 299. Aufgrund seiner Gichterkrankung und seines hohen Alters war es ihm unmöglich, zu Fuß zu gehen. Auch Fahrten in der Kutsche konnte man ihm nicht mehr zumuten. Mit Hilfe eines Tragsessels aber, so der Bittsteller, könne er dem König weiterhin dienen. AGS CC, Leg. IO29/25.

286 I6I7 November 20; AGS CC, Libro I86, fol. I27; AHN, Consejos, Leg. 442I/I84; AGS CC, Leg. $1080 / 36$.

287 I6I2 Februar I6; AGS CC, Libro 179, fol. 380v.

288 I6I3; AGS CC, Leg. IоI3/Io.

289 I6I4 Oktober 23; AGS CC, Libro I8I, fol. 475; AHN, Consejos, Leg. 4420/132; AGS CC, Leg. I037/46.

2901616 August I7; AGS CC, Libro I82, fol. 475v; AHN, Consejos, Leg. 4420/58; AGS CC, Leg. $1065 / 44$.

29I I6I2 September I5; AGS CC, Libro I8I, fol. 32; AHN, Consejos, Leg. 4419/II3.

292 I620 April 3; AGS CC, Libro I88, fol. 297; AHN, Consejos, Leg. 4421/22.

293 I616 September I6; AGS CC, Libro I82, fol. 492v; AHN, Consejos, Leg. 4420/78; AGS CC, Leg. I066/22.

294 I6I6 Mai 25; AGS CC, Libro I82, fol. 421; AHN, Consejos, Leg. 4420/27; AGS CC, Leg. I064/30.

295 Konsultation I6ı9 März I8; AHN, Consejos, Leg. 4421/35.

296 I6I4; AHN, Consejos, Leg. 4420/30; AGS CC, Leg. I030/I2I.

297 I6II Februar I5; AGS CC, Libro I78, fol. 232.

298 I6Ir März I3; AGS CC, Libro 179, fol. 196v; AHN, Consejos, Leg. 4419/22.

299 I620 Mai 19; AGS CC, Libro I89, fol. 79. Konsultation I620 Februar 29; AHN, Consejos, Leg. $442 \mathrm{I} / 30$.

$300 \quad$ I620 August I2; AGS CC, Libro I89, fol. I2Iv. 
Tovar, Ritter des Santiagoordens, vom Finanzrat, ${ }^{301}$ Agustín Mejía vom Kriegs- und Staatsrat $^{302}$ sowie Martín de Aróstegui, Sekretär im Kriegsrat. ${ }^{303}$ Im Ordensrat wurde ein Ratsmitglied, nämlich Lizenziat Antonio de Pedrosa, ${ }^{304}$ mit einer Lizenz bedacht, während im

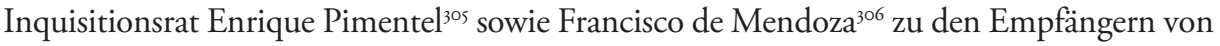
Tragsesselgenehmigungen zählten. In enger, jedoch nicht mehr klar zu rekonstruierender Verbindung zu den verschiedenen Ratsgremien standen auch einige andere Lizenzempfänger, wie etwa die königlichen Sekretäre Pedro de Contreras ${ }^{307}$ und Agustín de Oviedo ${ }^{308}$, der Buchhalter Marcos de Plaza ${ }^{309}$, der königliche Schreiber Martín de Araco ${ }^{310}$ und der königliche Sekretär Bartolomé Anaya Villanueva ${ }^{311}$.

Auch an Mitglieder verschiedener Gerichtshöfe der Monarchie wurden Lizenzen vergeben. Dies gilt insbesondere für die Reales Chancillerías von Granada und Valladolid und die Casa de la Contratación in Sevilla sowie für weitere, weniger bedeutende königliche Institutionen. In der Chancillería Valladolids erhielt der bereits pensionierte Lizenziat Diego Velázquez, Alcalde de Hijosdalgo, ${ }^{312}$ eine Lizenz, ebenso wie ein weiterer bereits im Ruhestand befindlicher Anwalt, Lizenziat Gaspar Rodríguez, ${ }^{313}$ während in der Chan-

301 I6I4 September 9; AGS CC, Libro I8I, fol. 45I; AHN, Consejos, Leg. 4420/II6; AGS CC, Leg. I034/IO.

302 I6r9 Februar II; AGS CC, Libro I87, fol. 288v. Konsultation I6I8 Dezember 4; AHN, Consejos, Leg. 442I/I6I.

303 I6I8 April 5; AGS CC, Libro I87, fol. 32v. Konsultation I618 Februar Io; AHN, Consejos, Leg. $442 \mathrm{I} / 2 \mathrm{I}$.

304 I6II August 20; AGS CC, Libro 179, fol. 273v. Er erhielt zunächst eine zweijährige Lizenz. AHN, Consejos, Leg. 4419/II7. Im Jahr I6I3 bescheinigten zwei Ärzte, dass er krank sei, weshalb seine Lizenz ohne weitere zeitliche Befristung verlängert wurde. AGS CC, Leg. Ior7/unfol.

3051616 August 17; AGS CC, Libro 182, fol. 475v; AHN, Consejos, Leg. 4420/58. Nach Ansicht der Ärzte sollte er so selten wie möglich in Kutschen fahren. AGS CC, Leg. 1065/49.

306 1615; AHN, Consejos, Leg. 4420/62; AGS CC, Leg. I051/37.

307 I6I5 Juli I8; AGS CC, Libro I82, fol. I62v. Konsultation I6I5 Mai 30; AHN, Consejos, Leg. $4420 / 64$.

308 I6r9 Dezember 17; AGS CC, Libro I89, fol. I8. Konsultation I6r9 September 30; AHN, Consejos, Leg. 442I/98.

309 Er erhielt eine zweijährige Lizenz. Konsultation I613 November 30; AGS CC, Leg. 1020/59.

3 IO I6I2 März 20; AGS CC, Libro 179, fol. 397v. Er litt unter Lähmungen und konnte deshalb weder zu Fuß gehen noch reiten. Die Kammer schlug für ihn eine auf zwei Jahre befristete Lizenz für einen Tragsessel ohne Vorhänge (,sin cortinas") vor. AHN, Consejos, Leg. 4419/7; AGS CC, Leg. $996 / 45$.

3II I6I8 November 21; AGS CC, Libro I87, fol. 226. Konsultation I6I8 Oktober I4; AHN, Consejos, Leg. 442I/I43.

312 I6Ir November 29; AGS CC, Libro 179, fol. 312; AHN, Consejos, Leg. 4419/175. Er war blind und litt an Gicht. Die Alcaldes de Hijodalgo waren für Hidalgo-Prozesse zuständige Richter.

313 I6I7 Juni 25; AGS CC, Libro 185, fol. 236. Er war alters- und krankheitsbedingt pensioniert und 
cillería Granadas dem Anwalt Doktor Juan Bravo, ${ }^{314}$ dem Präsidenten Martín Fernández Portocarrero $^{315}$ und dem Lizenziaten Juan de Zuazo, der als Berichterstatter diente, Lizenzen zugesprochen wurden. ${ }^{36}$ Als Strafrichter war Lizenziat García de Medrano, Ritter des Santiagoordens, ebenfalls der Chancillería verbunden. ${ }^{37}$ Auch er kam in den Genuss einer Tragsessellizenz. In der Casa de la Contratación Sevillas erhielten sowohl der Buchhalter Juan López de Ibartola ${ }^{318}$ als auch Richter und Oberbuchhalter Antonio López de Calatayud eine Lizenz. ${ }^{319}$ Eine solche wurde auch Gonzalo Pérez erteilt, der beim Zollamt von Sevilla diente und der in seinem Ansuchen von einigen Repräsentanten der Stadt unterstützt wurde. ${ }^{320}$ Auch Amtsträger weniger bedeutender königlicher Institutionen konnten eine Tragsessellizenz erlangen, wie das Beispiel von Doktor Feliciano de Solís zeigt, der als Alcalde Mayor des Königreichs Galizien diente. ${ }^{321}$

Unter den Lizenzempfängern befanden sich auch auffallend viele Corregidores, die in ihren Lizenzansuchen häufig explizit darauf hinwiesen, dass sie dieses Amt innehätten. Zahlreiche Corregidores übten im Laufe ihrer Karriere auch Ämter bei Gericht oder beim Militär aus. Dies trifft zum Beispiel auf den Lizenziaten Alonso de Castro zu, der in seinem Antrag vierzigjährige Dienste in Gerichtsämtern und als Corregidor von Tarifa und Quesada anführte, ${ }^{322}$ auf Alonso Ramírez de Arellano y Zúñiga, der viele Jahre

wurde von einem Gichtleiden geplagt. Konsultation I6r7 Mai 24; AHN, Consejos, Leg. 442I/89; AGS CC, Leg. 1075/196. I6I5 April I6; AGS CC, Libro I82, fol. I03; AHN, Consejos, Leg. 4420/36; AGS CC, Leg. I059/I.

315 I6r6 August 17; AGS CC, Libro 182, fol. 475v. Konsultation I6r6 Juni 5; AHN, Consejos, Leg. $4420 / 58$.

316 I6I8 August I4; AGS CC, Libro I86, fol. 40I. Konsultation I6I8 Juni 5; AHN, Consejos, Leg. 442I/94.

317 I6I2 Dezember 2I; AGS CC, Libro I8I, fol. 84.

318 I6I3 Dezember II; AGS CC, Libro I8I, fol. 269v. Er erhielt I6I3 eine zweijährige Lizenz, die I6I6 auf vier Jahre verlängert wurde. AGS CC, Libro I82, fol. 454; AGS CC, Leg. I022/85; AGS CC, Leg. 1065/7I.

319 I6r9 August 3; AGS CC, Libro I88, fol. IIo. Konsultation i6r9 Juni 30; AHN, Consejos, Leg. $442 \mathrm{I} / 67$.

320 I6I2 Dezember 2; AGS CC, Libro I8I, fol. 84. Er erhielt eine zweijährige Lizenz. AHN, Consejos, Leg. 4419/I52. Pérez war über fünfundsiebzig Jahre alt, litt an Beschwerden beim Harnlassen und hatte überdies ein Gichtleiden. Es hieß, er sei eine hochrangige Person ,y como tal se trata“. AGS CC, Leg. I005/23. Das Amt des Asistente entsprach in einigen andalusischen Städten dem eines Corregidor.

321 I6I6 Oktober I; AGS CC, Libro I84, fol. 94. Konsultation I6I6 September I0; AHN, Consejos, Leg. 4420/138. Laut Akten war er alt und krank, konnte sich weder in der Kutsche noch in der Sänfte befördern lassen und war betrübt, weil er ohne Tragsessel die Messe nicht besuchen konnte. AGS CC, Leg. I069/182.

322 I6I4 Juli 26; AGS CC, Libro I8I, fol. 4I8v; AHN, Consejos, Leg. 4420/90; AGS CC, Leg. I033/80. 
Kriegsdienste geleistet hatte und in mehreren Corregimientos tätig gewesen war, ${ }^{323}$ oder auf Hernando de Quesada Ulloa, den ehemaligen Corregidor und Capitán de guerra von Cádiz. ${ }^{324}$ Aber auch andere im Bereich der königlichen Verwaltung tätige Personen erhielten Lizenzen, wie etwa der Receptor Francisco de Orozco, ${ }^{325}$ der Buchhalter Antolín de la Serna ${ }^{326}$ oder der in der Inquisitionsverwaltung dienende Lope Osorio de Mercado, $A l$ guacil Mayor der Inquisition des Königreichs Galizien. ${ }^{327}$ Eine Reihe von Lizenzen war für Amtsträger bestimmt, die mit der Verwaltung oder dem Einziehen von Abgaben betraut waren, so etwa Jerónimo de Torrellas, Veedor de la guerra in Katalonien, ${ }^{328}$ der Proveedor de armadas Miguel de Oviedo ${ }^{329}$ oder Lizenziat Rodrigo Yáñez Dovalle, Juez de puestos y cosas vedadas. ${ }^{330}$ Womöglich nicht direkt in der Verwaltung beschäftigt, aber bestimmt mit guten Kontaken zu dieser versehen waren einige andere Lizenzempfänger, wie etwa Juan López de Vitoria, der offenbar für die Einhebung des Seezehents zuständig war, ${ }^{331}$ Juan de Hervás, der als Buchhalter bei den beschlagnahmten Gütern der Morisken Granadas diente, ${ }^{332}$ oder Gaspar de Guevara, der unter anderem das Amt eines Veedor de las guardias y caballería bekleidete. ${ }^{333}$

Andere königliche Bedienstete, die mit der Erlaubnis, Tragsessel zu verwenden, bedacht wurden, waren Amtsträger bei Ritterorden, wie etwa Bernabé Centurión, Aposentador und Schatzmeister der Mesa maestral des Santiago- und des Calatravaordens, ${ }^{334}$ und Francisco

323 I6I7 Januar 30; AGS CC, Libro I85, fol. 77v; AHN, Consejos, Leg. 4420/209; AGS CC, Leg. $1069 / 74$.

324 I619 Januar 29; AGS CC, Libro 187, fol. 283; AHN, Consejos, Leg. 4421/163.

325 Er konnte weder gehen noch reiten noch Kutsche fahren, ohne sich dabei gesundheitlichen Gefahren auszusetzen. I6I3; AGS CC, Leg. IOI2/46. Receptores waren für das Eintreiben der von der Kammer verhängten Strafen zuständig.

326 I6I9 August 3; AGS CC, Libro I88, fol. IIo; AHN, Consejos, Leg. 442I/6I.

327 I6I6 Februar I9; AGS CC, Libro 183, fol. 376v; AHN, Consejos, Leg. 4420/I47; AGS CC, Leg. I062/IO2.

328 I6I4 August 6; AGS CC, Libro I8I, fol. 426; AHN, Consejos, Leg. 4420/86; AGS CC, Leg. I033/65.

329 I6II November 29; AGS CC, Libro I79, fol. 312. Es hieß, er sei siebzig Jahre alt, leide an der Gicht und wolle nach Sevilla reisen, um dort in königliche Dienste zu treten. Dies sei ihm ohne Tragsessel aber nicht möglich. AHN, Consejos, Leg. 4419/217.

330 Laut Akten litt er an der Gicht und konnte zeitweise weder gehen noch reiten noch in einer Kutsche fahren. I613; AGS CC, Leg. IOIs/88.

33I I6I4 Dezember 7; AGS CC, Libro I83, fol. 50; AHN, Consejos, Leg. 4420/I49. Der Zehent wurde an der Zollstelle der kantabrischen Küste erhoben.

332 I620 August I2; AGS CC, Libro I89, fol. I2Iv. Konsultation I620 Juni 20; AHN, Consejos, Leg. $4421 / 85$.

333 I6I7 November 20; AGS CC, Libro I86, fol. I27; AHN, Consejos, Leg. 442I/I88; AGS CC, Leg. I080/47.

334 I6I4 Februar I8; AGS CC, Libro I8ı, fol. 309. Da er an Füßen und Händen gelähmt sei, könne 
Bravo de Acuña, Adelantado von Zerrenate und Generalvisitator des Alcántaraordens. ${ }^{335}$ Dem königlichen Dienst zwar verbunden, jedoch mit nicht eindeutig zuordenbaren Aufgaben betraut, waren der königliche Diener Francisco de la Peña, der bei der Contaduría de la villa beschäftigt war, ${ }^{336}$ Juan Antonio de Araiz, der „Seiner Majestät gedient hat “"337, sowie Francisco Venegassi, der dasselbe von sich behauptete. ${ }^{338}$

Weitere Lizenzen, nämlich etwa achtundzwanzig, gingen an Ratsherren großer Städte Kastiliens beziehungsweise an Personen, die zu einem früheren Zeitpunkt Mitglieder eines Stadtrats gewesen waren. ${ }^{339}$ Ebenso erhielten einige Personen eine Lizenz, weil sie früher an den Cortes teilgenommen hatten, was sich - dies nur nebenbei - auch für die Vergabe von Kutschenlizenzen beobachten lässt. Ein Großteil der Lizenzen für Ratsherren oder Veinticuatros wurde in Granada vergeben, aber auch für Sevilla, Madrid, Valladolid und Segovia sowie in geringerem Maße für Burgos, Zamora, Cádiz, Toledo, Mérida und Gibraltar finden sich derartige Empfänger von Tragsessellizenzen. In Granada erhielten Melchor Ruíz de Canales, Veinticuatro und Vertreter bei den Cortes, ${ }^{340}$ die Veinticuatros Cristóbal Fernández de Córdoba, ${ }^{341}$ Diego de Ágreda, Santiagoritter und Bruder von Doktor Alonso de Ágreda, Mitglied des Kastilien- und des Finanzrates, ${ }^{342}$ Hernando de Haro, Veinticuatro und Vertreter bei den kurz zuvor abgehaltenen Cortes, sowie Rodrigo Monte ${ }^{343}$ und Alonso Castellano, der als Jurado im Stadtrat gedient hatte, Tragsessellizenzen. ${ }^{344}$ Egas Venegas de Córdoba bekam als Herr von Luque und als Alférez Mayor von Granada eine Lizenz zu-

er sich weder zu Fuß fortbewegen noch reiten. Er bat deshalb um eine Tragsessellizenz für Messbesuche, da er sonst nicht in die Kirche gelangen könne. AGS CC, Leg. I028/109.

.6II; AHN, Consejos, Leg. 4419/47.

336 I6I2; AHN, Consejos, Leg. 4419/I66; AGS CC, Leg. IoII/Ioo. Mit Villa ist hier Madrid gemeint.

337 I620 März I3; AGS CC, Libro I88, fol. 270v. Konsultation I620 Februar 2; AHN, Consejos, Leg. $442 \mathrm{I} / 20$.

338 I6II Juni I2; AGS CC, Libro I78, fol. 268v; AHN, Consejos, Leg. 4419/64

339 Wie bereits an anderer Stelle erwähnt, handelte es sich bei den Regidores oder Ratsherren um die höchstrangigen Vertreter einer Stadt oder eines Dorfes und deren Einwohner. In Andalusien wurden sie Veinticuatros gennant.

340 I6I2 März 27; AGS CC, Libro I79, fol. 400; AHN, Consejos, Leg. 4419/24; AGS CC, Leg. 997/75.

34I I6I4 Juli 26 und I6ı8 Juli 7; AGS CC, Libro I8I, fol. 4I8v; AGS CC, Libro I86, fol. 359; AHN, Consejos, Leg. 4420/89; AGS CC, Leg. I033/8I; AGS CC, Leg. I044/unfol.

342 I6I4 Mai 27; AGS CC, Libro I8I, fol. 369v; AHN, Consejos, Leg. 4420/4I; AGS CC, Leg. IO27/28.

343 I6I5 August 22; AGS, Libro I83, fol. 246v; AHN, Consejos, Leg. 4420/74 und 78. Beide kümmerten sich seit dreißig Jahren „con particular amor y voluntad“ um den königlichen Dienst betreffende Angelegenheiten. AGS CC, Leg. I052/6I und 69.

344 I6I7 August 5; AGS CC, Libro I85, fol. 275v; AHN, Consejos, Leg. 442I/I54; AGS CC, Leg. I077/I9I. Auch Jurados waren Mitglieder der Ratsgremien kastilischer Städte. 
gesprochen, ${ }^{345}$ ebenso wie die beiden Veinticuatros Pedro González de Castilla ${ }^{346}$ und Mateo de Oviedo. ${ }^{347}$ In Segovia befanden sich unter den Lizenzempfängern Andrés de Ximena, ein ehemaliger Vertreter bei den Cortes, ${ }^{348}$ sowie die beiden Ratsherren Tomás Núñez de Vergara $^{349}$ und Lizenziat Manuel Martínez. ${ }^{350}$ In Sevilla kamen einige Veinticuatros und mehrere Jurados in den Genuss von Lizenzen. Während Antonio Rodríguez de Salamanca zur ersten Gruppe zählte, ${ }^{351}$ waren Marco Antonio de Alfaro ${ }^{352}$ und Pedro López de Verastegui ${ }^{353}$ Teil der zweiten Gruppe. Für Valladolid liegen Informationen über zwei Lizenzen vor, nämlich jene für García de Vera y Paz, der dort als Correo Mayor diente, ${ }^{354}$ und jene für den ehemaligen Ratsherren Hernando Muñoz de Castro. ${ }^{355}$ Ganz ähnlich verhielt es sich in Madrid, für das sich nicht mehr als zwei Lizenzen für Ratsherren nachweisen lassen, nämlich für Miguel Martínez de Sel und für Francisco Martínez. ${ }^{356}$ Auch in Cádiz wurden zwei Genehmigungen erteilt, und zwar für Juan de Soto y Avilés, Capitán alférez mayor

345 I620 März I3; AGS CC, Libro I88, fol. 270v. Konsultation I620 Januar Io; AHN, Consejos, Leg. 442I/4. Zu den Pflichten eines Alférez Mayor zählten unter anderem die Organisation der Milizen, die Aufbewahrung und das Tragen des Stadtbanners und die Aufsicht über Fahnen und Trommeln für militärische Umzüge.

346 I6I4 Februar I8; AGS CC, Libro I8I, fol. 308v; AGS CC, Leg. I029/I2.

347 I616 September 17; AGS CC, Libro I84, fol. 48; AHN, Consejos, Leg. 4420/94; AGS CC, Leg. I067/166.

348 I6II August 20; AGS CC, Libro I79, fol. 273v. Er erhielt eine Genehmigung, die erst durch königlichen Widerruf erlöschen sollte. Andrés de Ximena war über siebzig Jahre alt, krank und hatte - wie bereits sein Vater - in den Cortes gedient. Der Corregidor von Segovia berichtete über ihn, er sei "hombre principal y tiene 2000 ds de renta y los gasta en hospitales limosnas y obras de Caridad". AHN, Consejos, Leg. 4419/136.

349 I6I4 August 6; AGS CC, Libro I8I, fol. 426; AHN, Consejos, Leg. 4420/85; AGS CC, Leg. 1033/46. 350 I6I4 Juli 20; AGS CC, Libro I8I, fol. 4I7; AHN, Consejos, Leg. 4420/72; AGS CC, Leg. I033/II2.

35I I6I4 August 6 und I6I6 August 27; AGS CC, Libro I8I, fol. 426; AGS CC, Libro I82, fol. 482; AHN, Consejos, Leg. 4420/87, Leg. 4420/49; AGS CC, Leg. I033/69; AGS CC, Leg. I066/77; AGS CC, Leg. I044/unfol.

352 I6II Juni I2; AGS CC, Libro I78, fol. 269; AHN, Consejos, Leg. 4419/62.

353 I6I7 Januar Io; AGS CC, Libro I85, fol. 55; AHN, Consejos, Leg. 4420/192; AGS CC, Leg. 1069/132.

354 I620 Juni 6; AGS CC, Libro 189, fol. 86v. Konsultation 1620 April 24; AHN, Consejos, Leg. $4421 / 53$.

355 I620 August I; AGS CC, Libro I89, fol. I07. Konsultation I620 Mai I8; AHN, Consejos, Leg. $4421 / 75$.

356 I6I4 Juli 26; AGS CC, Libro I8I, fol. 4I8v; AHN, Consejos, Leg. 4420/88; AGS CC, Leg. I033/82. Für Martínez siehe I6I4 Juni I5; AGS CC, Libro I8I, fol. 38I; AHN, Consejos, Leg. 4420/64; AGS CC, Leg. $1032 / 98$. 
der Stadt, ${ }^{357}$ und für den Stadtschreiber Esteban de Vivero. ${ }^{358}$ In anderen Städten wurden ebenfalls nur in Einzelfällen Lizenzen vergeben, etwa in Burgos an Juan Rodríguez de Salamanca, Alcalde mayor und Ritter des Santiagoordens, ${ }^{359}$ in Mérida an den Ratsherren Fernando de Vera y Vargas, ${ }^{360}$ in Zamora an Jerónimo de Bargas, Ratsherr und Depositario general der Stadt, ${ }^{361}$ in Toledo an den Jurado Juan Bautista de Úbeda ${ }^{362}$ und in Gibraltar an Andrés de Villegas, Alférez mayor der Stadt und Señor de vasallos. ${ }^{363}$ Es entzieht sich unserer Kenntnis, ob die Lizenz für Fernando Chumacero, einen auf Lebzeiten bestellten Ratsherrn in Valencia und Ritter des Alcántaraordens, in Zusammenhang mit seiner Tätigkeit in Valencia stand. Mit Sicherheit war es für die Erlangung seiner Lizenz jedoch hilfreich, dass mit seinem Vetter, dem Lizenziaten Chumacero, der Mitglied des Königlichen Rats war, ein enger Verwandter einen einflussreichen Posten bekleidete. ${ }^{364}$ Bei Diego de Cabrera Sotomayor, einem Einwohner Córdobas, dem I6I3 aufgrund seines schlechten Gesundheitszustands eine Tragsessellizenz erteilt wurde, lässt sich nicht mehr feststellen, ob er Beziehungen zu Regierungskreisen der Stadt unterhielt. ${ }^{365}$

Neben den bereits angeführten sozialen Gruppen existierte auch eine Reihe anderer Lizenzempfänger, bei denen sich die Genehmigung, einen Tragsessel benutzen zu dürfen, bei genauerer Betrachtung mit erwiesenen Diensten an der Monarchie, mit engen familiären Beziehungen oder mit einer eindeutigen sozialen Vormachtstellung in Verbindung bringen lässt. Die Rede ist von Angehörigen des Militärs, Verwandten königlicher Bediensteter, Mitgliedern von Ritterorden sowie von bedeutenden Asientistas, Bankiers, Geschäftsleuten oder Bediensteten hochrangiger Persönlichkeiten. Dass manche Lizenzempfänger in ihren

357 I616 September 17; AGS CC, Libro I84, fol. 48; AHN, Consejos, Leg. 4420/II4; AGS CC, Leg. I067/219.

358 I6I4 März I3; AGS CC, Libro I8I, fol. 323; AHN, Consejos, Leg. 4420/I4; AGS CC, Leg. Ior6/59. Er war gelähmt und gebrechlich und bat deshalb um eine Lizenz für einen geschlossenen Tragsessel. AGS CC, Leg. IO20/42 und IO29/II8. I6I7 April I8; AGS CC, Libro I84, fol. 307v; AHN, Consejos, Leg. 442I/29; AGS CC, Leg. I074/132.

360 I6I4 April 26; AGS CC, Libro I8I, fol. 354; AGS CC, Leg. I022/I07.

36I I618 Juni I5; AGS CC, Libro I87, fol. 90v; AGS CC, Libro I86, fol. 409; AHN, Consejos, Leg. 442I/57 und 88. Beim Depositario general handelte es sich um den königlichen Aufseher über die städtischen Finanzen, der auch mit der Verwaltung der Geldmittel betraut war.

362 I6I8 Mai 26; AGS CC, Libro I86, fol. 318v. Konsultation I6I8 Februar 16; AHN, Consejos, Leg. $442 \mathrm{I} / 29$.

363 I6I5 Oktober 3; AGS CC, Libro I83, fol. 289v; AHN, Consejos, Leg. 4420/98; AGS CC, Leg. I053/124.

364 I6I7 Februar 17; AGS CC, Libro I85, fol. 87; AHN, Consejos, Leg. 4420/229; AGS CC, Leg. I069/25.

365 Genehmigung der Lizenz I6r3 Dezember 31; AHMV Viana, Empleos y Honores, Leg. 50, exp. 46. 


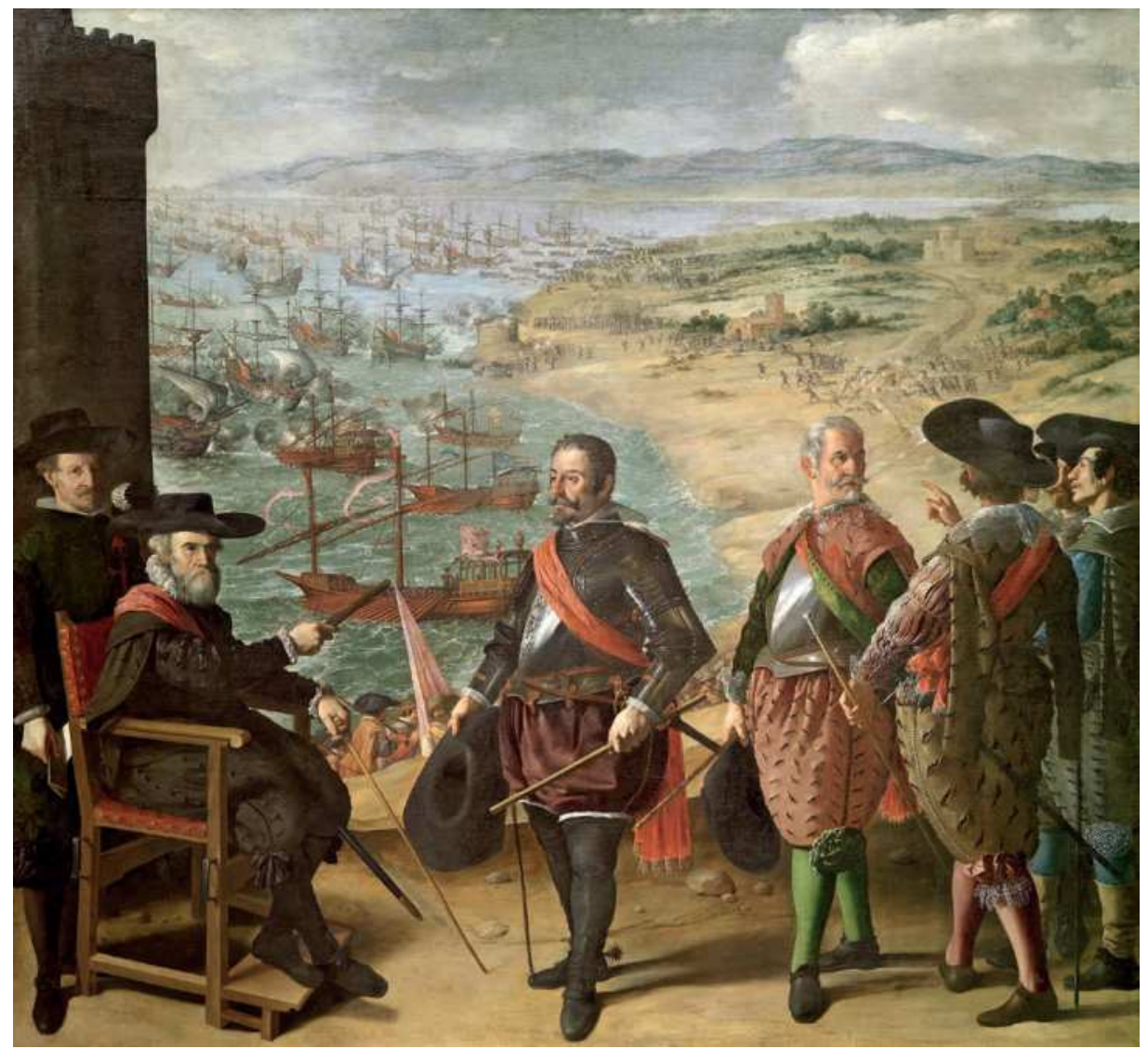

Abb. 8: Darstellung von General Fernando Girón im Tragsessel. Er befehligte auf diese Weise im Jahr 1625 die Manöver zur Verteidigung von Cádiz gegen das englische Geschwader. Francisco de Zurbarán, Die Verteidung von Cádiz, 1634-1635, MNP, Inv.-Nr. Poo656. @ MNP

Anträgen auf ihre Kriegsdienste verwiesen, wurde bereits erwähnt. Bei folgenden Militärs wurde jedoch das Privileg, einen Tragsessel zu benutzen zu dürfen, explizit als Belohnung für solche Dienste gewährt. Dies traf etwa auf den Capitán general de la armada del mar océano Luis Fajardo zu, ${ }^{366}$ aber auch auf den Maese de campo Pedro Cortes de Monroy, ${ }^{367}$

366 I6I5 August 22; AGS, Libro I83, fol. 246v; AHN, Consejos, Leg. 4420/74; AGS CC, Leg. I052/62. 367 I6I4 März I3; AGS CC, Libro I8I, fol. 323; AHN, Consejos, Leg. 4420/I4. Er war achtzig Jahre alt, von denen er mehr als fünfzig in Kriegsdiensten gestanden hatte. Dabei hatte er allein sieben Schussverletzungen am rechten Bein und weitere an anderen Stellen des Körpers erlitten. AGS CC, Leg. 1029/126. 
auf Diego López de Zúñiga, Teniente general und Gobernador de la gente de guerra an den Küsten des Königreichs Granada, ${ }^{368}$ auf den Ritter des Santiagoordens Jerónimo de Portugal y Córdoba, der als General der Armadas in Amerika gedient hatte, auf Gómez Mesía de Figueroa, der in Flandern, in La Goulette, in Italien und auf der See in königlichen Diensten gestanden war, ${ }^{369}$ auf den Capitán Rafael Bayarte, ${ }^{370}$ auf den altgedienten Militär Fray Antonio Centeno, Bailio del sepulcro de Toro und Komtur von Tocina, der dem Johanniterorden angehörte, ${ }^{371}$ sowie auf den von seinen Kriegsdiensten gesundheitlich stark mitgenommenen Santiagoordens-Komtur von Paloma, Pedro Zapata de Cárdenas ${ }^{372}$ (vgl. Abb. 8).

Einige der einfachen Mitglieder und Komture von Ritterorden, die eine Tragsessellizenz erhielten, wurden bereits unter anderen Gruppierungen angeführt. Noch nicht erwähnt wurden hingegen Sancho Briceño el Tronco, Komtur des Johanniterordens, der in seinem Lizenzantrag von Lerma unterstützt wurde, der Komtur von Castronuño, Antonio Centeno, sowie Diego Esteban de Carvajal, Ritter des Santiagoordens und Komtur von Castroverde. ${ }^{373}$ Die Mehrheit der mit einer Tragsessellizenz versehenen Ordensritter war dem Santiagoorden zugehörig, wie Francisco de Menchaca, Lope Cerón de Valenzuela, Juan Pérez de Saavedra und Diego del Castillo Carvajal, ${ }^{374}$ während Bernardino de Zúñiga Ritter des Johanniterordens war. ${ }^{375}$

Wie bereits für mehrere Fälle erwähnt, spielten bei den Lizenzvergaben familiäre Beziehungen häufig eine große unterstützende Rolle. Dafür können auch noch weitere Beispiele angeführt werden, die klar zeigen, wie bedeutend der Einfluss von Verwandten auf den Ausgang einer Beratung über die Ausstellung einer Lizenz tatsächlich war. Die Unterstützung seitens Familienangehöriger war etwa entscheidend in den Fällen von Juan de

368 I6I8 Juni I5; AGS CC, Libro 187, fol. 90v. Konsultation 8. Mai I6I8; AHN, Consejos, Leg. 442I/65. 369 I6I8 März I9; AGS CC, Libro I86, fol. 255; AHN, Consejos, Leg. 442I/5; AGS CC, Leg. I083/III.

3701620 September 19; AGS CC, Libro I89, fol. 139. Konsultation 20. August 1620; AHN, Consejos, Leg. 442I/94.

37I I6I4 Januar 24; AGS CC, Libro I8I, fol. 288; AGS CC, Leg. I027/77.

372 I6I4; AHN, Consejos, Leg. 4420/135. Er war über siebzig Jahre alt und litt an Kriegsverletzungen. AGS CC. Leg. $1036 / 66$.

373 I6I3 Mai I8; AGS CC, Libro I8I, fol. I67v; AGS CC, Leg. I0I5/54. Für Centeno siehe I6I8 August I8; AGS CC, Libro I86, fol. 409; AHN, Consejos, Leg. 442I/8o. Für Carvajal siehe I6ı;; AHN, Consejos, Leg. 442I/55.

374 I6Ir April 29; AGS CC, Libro 179, fol. 2IIv; AHN, Consejos, Leg. 44I9/39. Für Valenzuela siehe I6r3 Februar 2; AGS CC, Leg. Ior3/29. Für Saavedra, der krank und behindert war, siehe AHN, Consejos, Leg. 44I9/I39; AGS CC, Leg. I002/37. Für Carvajal siehe I6I8 November 2I; AGS CC, Libro I87, fol. 226; AHN, Consejos, Leg. 442I/I47.

375 I6I3 Dezember 3I; AGS CC, Libro I8I, fol. 28Iv. Er litt an zahlreichen körperlichen Beschwerden und verschiedensten Erkrankungen. AGS CC, Leg. I022/33. 
Zúñiga, dem Bruder von Don Bernardino de Zúñiga, ${ }^{376}$ von Juan Vallejo de Cabañas, einem Verwandten von Pedro Vallejo Cabañas, Diener des Duque de Medina Sidonia, ${ }^{377}$ von Fernando Enríquez de Ribera, Onkel des Duque de Alcalá, ${ }^{378}$ und von Francisco de Tapia, Sohn des Marqués de Belmonte. ${ }^{379}$ Zur letzten Gruppe von Lizenzempfängern, auf die wir näher eingehen wollen, zählten Bankiers, Asentistas und Geschäftsleute, die der Krone oder einflussreichen Höflingen Dienste leisteten. Zu dieser Gruppe gehörten der aus Genua stammende Bankier Carlos Strata, der Asentista Juan María Corbari, der ebenfalls genuesischer Herkunft war, ${ }^{380}$ und Geschäftsträger diverser Adelshäuser, wie etwa der Capitán Francisco Maya, der im Auftrag der Dietrichsteins tätig war, Alonso de Aibar, der für den Conde de Lemos und Montesclaros agierte, und schließlich Pedro Vallejo Cabañas, ein Bediensteter des Duque de Medina Sidonia. ${ }^{381}$

Die Auswertung unserer umfangreichen Datenansammlung zeigt, dass etwa 73 Prozent und damit eine klare Mehrheit der Lizenzempfänger entweder im Verwaltungsapparat der Monarchie beschäftigte Personen, Mitglieder der königlichen Hofstaaten, Angehörige der Kirchenelite oder lokale Machthaber waren. Somit lässt sich festhalten, dass - zumindest zwischen I605 und I635 - die Beförderung eines Mannes im Tragsessel eindeutig dessen herausragende soziale Position und seine guten Beziehungen zum Hof signalisierte. Vor diesem Hintergrund sind die in weiterer Folge erlassenen, für Tragsessel bestimmten Gesetze zu sehen, die vor allem darauf abzielten, den Status quo aufrechtzuerhalten.

\subsubsection{Die Besteuerung von Tragsesseln und das Mietverbot (1635 bis ca. 1660)}

Der „Institutionalisierungsprozess“ war für Tragsessel und Kutschen im Jahr I635 abgeschlossen. Damals setzte jedoch eine neue Entwicklung ein, nämlich ihre Besteuerung, was bedeutete, dass für die Verwendung von Kutschen und Tragsesseln Abgaben unterschied-

376 I6II Juni I2 und I6I3 September 28; AGS CC, Libro I78, fol. 269, Libro I8I, fol. 232; AHN, Consejos, Leg. 4419/63. Sein Bruder bat um eine unbefristete Verlängerung der Lizenz. AGS CC, Leg. IOI9/I54.

377 Konsultation I6I5 September 19; AHN, Consejos, Leg. 4420/ı22.

378 I616 August 27; AGS CC, Libro I82, fol. 482; AHN, Consejos, Leg. 4420/82; AGS CC, Leg. I066/68.

379 I6I8 Juni I5; AGS CC, Libro I87, fol. 90.

$380 \quad$ I6I5 Januar 31; AGS CC, Libro I82, fol. 56; Konsultation I6I4 Dezember 20; AHN, Consejos, Leg. 4420/187. Für Corbari siehe I6I9 Februar I8; AGS CC, Libro I88, fol. 5, Konsultation I6I8 Oktober 24; AHN, Consejos, Leg. 442I/I46.

38I I6I3 April I; AGS CC, Libro I8I, fol. I40; AGS CC, Leg. Ior3/I6. Für Aibar siehe I6I2; AHN, Consejos, Leg. 4419/137; AGS CC, Leg. I08I/unfol. Für Cabañas siehe I6I5 April 2; AGS CC, Libro I83, fol. 306v; AGS CC, Leg. 1054/118. 
lichster Art eingehoben wurden. Zwar war die Idee, Kutschen zu besteuern, in den Cortes auch zuvor schon mehrmals zur Sprache gebracht worden, ${ }^{882}$ jedoch stets ohne Folgen nach sich zu ziehen. Dies änderte sich erst im Dezember 1635, als bei der Debatte rund um die Durchsetzung der sogenannten „Neun-Millionen-Steuer“ die Procuradores, die stets nach neuen Finanzierungsmöglichkeiten Ausschau hielten, den Antrag mit aufnahmen, Männern den Gebrauch von Kutschen, Sänften und Tragsesseln gesetzlich zu untersagen. Gleichzeitig sollte das Verbot aber in bestimmten Fällen aufgehoben werden, nämlich „für Personen, denen es aufgrund ihrer Würde, ihres Dienstes, ihres Alters oder aufgrund von Gebrechlichkeit gegen eine einmalige Zahlung von roo Dukaten in Silberdublonen gestattet sein muss", die betroffenen Vehikel zu verwenden. ${ }^{383}$ Das Inkrafttreten der Verordnung wurde für die nächstfolgende Zeit in Aussicht gestellt. Tatsächlich wurde sie schon bald darauf in Sevilla, Valladolid und anderen Städten veröffentlicht, nicht jedoch in Madrid, wo höhere Einnahmen zu erzielen gewesen wären. Dies schränkte die Wirksamkeit der gesetzlichen Maßnahme erheblich ein. Die Verordnung traf von Anbeginn an auf Widerstand. Zu ihren Gegnern zählte nicht zuletzt der Procurador del estado eclesiástico, der sich über das, was er als „neue Steuer“ bezeichnete, heftig beklagte. Selbst der Rat von Kastilien wandte sich am 27. Januar mit kritischen Worten an den Monarchen:

Den Gesetzen und Verordnungen, die im königlichen Namen Eurer Majestät erlassen werden und die dem allgemeinen Wohl der Republik dienen sollen, müssen die Prinzipien Dauerhaftigkeit und Akzeptanz zugrunde liegen. Da es aber den Anschein hat, als ob dieser Beschluss des Königsreichs nicht das Verbot von Kutschen, Sänften und Tragsesseln bezwecke, sondern den Verkauf von Lizenzen zu einem bestimmten Preis, ist es nicht angebracht, ein gesetzliches Verbot zu erlassen, das vor seinem Inkrafttreten bereits über den Preis seiner Übertretung informiert. ${ }^{384}$

382 Actas de las Cortes de Castilla I86I-2006 (wie Anm. 76), Bd. 49, S. 483, Bd. 50, S. 22, Bd. 54, S. 464.

383, „... [ en las perssonas a quien se deve permitir por su dignidad exercicio hedad o enpedimentos pagando Ioo ducados en plata doble por una vez". Actas de las Cortes de Castilla I86I-2006 (wie Anm. 76), Bd. 55, S. I8I f., 197.

384 „Las leyes y Pragmáticas q autoriça el Rl nombre de VM y se encaminan al vien universal de la República deven tener por uno de los principales atributos la perpetuidad y observancia y ansí pareçe q siendo el fin q el Reyno a tenido en este acuerdo no la prohivición de los coches literas y sillas, sino el bender por çierto preçio las Liçençias no será conveniente promulgar una ley prohibitiva $q$ antes de pronunciarse tenga prevenido el precio de la transgresión“. AHN, Consejos, Leg. 5I.438/I. 
Das Vorgehen sorgte für heftige Debatten im Rat, auf die wir hier nicht weiter eingehen können. Zwar sollte das Verbot schließlich nicht in Kraft treten, ${ }^{385}$ jedoch lässt sich nachweisen, dass damals der Verkauf von Lizenzen einsetzte. Auch wenn die Datenlage zu diesem Phänomen äußerst dürftig ist, deuten dennoch einige Informationen darauf hin, dass verschiedene Personen mit dem Privileg ausgestattet wurden, Kutschenlizenzen zu verkaufen, wobei hier besonders der Conde de Castrillo hervorzuheben ist. ${ }^{386}$ Ein analoges Privileg für den Verkauf von Tragsessellizenzen erhielt Fernando Pizarro im Jahr I635. ${ }^{387}$ Der Verkauf von Kutschenlizenzen lässt sich auch für das darauf folgende Jahrzehnt beobachten. ${ }^{38}$ In Anbetracht des großen Interesses und der erheblichen Schwierigkeiten, in den Genuss entsprechender Lizenzen zu gelangen, liegt die Vermutung nahe, dass viele Personen, denen zuvor eine Genehmigung für die Benutzung von Tragsesseln oder Kutschen versagt geblieben war, nun danach strebten, mittels Zahlung eines Geldbetrages derartige Vehikel legal zu benutzen. Während der Verkauf von Lizenzen voranschritt, nahmen die Debatten darüber kein Ende, auch wenn nach Abschluss des „Institutionalisierungsprozesses" keine der widerstreitenden Parteien mit ihrer Position die Oberhand gewann.

Im Jahr I637 stellte der Conde-Duque de Olivares in einer Consulta hinsichtlich Kut-

385 Auch der Schriftsteller Quevedo sprach das Scheitern der gesetzlichen Maßnahme in einem Schreiben vom 22. Januar 1636 an: „Paguen, que es muy justo, los poltrones que se mecen y arrullan las panzas". Kurz darauf hielt er fest, dass die Verordnung an vielen Orten veröffentlicht worden war, nicht jedoch in Madrid. Luis Astrana Marín, Epistolario completo de D. Francisco de Quevedo. Edición crítica (con anotaciones, apéndices, documentos inéditos y una acabada bibliografía) (Madrid 1946), S. 282 f., 374.

386 Erwähnt sei die Lizenz, die er an den Príncipe de Mélito, Duque de Pastrana, verkaufte, die diesem I636 gestattete, nach Belieben und frei von jeglicher Strafe „eine oder mehrere von zwei oder vier Maultieren gezogene Kutschen zu fahren oder mit sich zu führen, wenn diese ihm gehören, sowie Kutschen mit zwei oder vier vorgespannten Pferden sowie Sänften und Tragsessel“ zu verwenden („[...] pueda ruar y traer unol o más coches de dos o quatro mulas siendo propias suyas [...] coches de dos/ o quatro cavallos literas y sillas de manos"). Zudem durfte „alles, oder auch nur ein Teil davon, nach Belieben verliehen werden, selbst in seiner Abwesenheit, ohne dass Einwände oder Behinderungen seitens der Justiz befürchtet werden müssen“ („[...] prestarlo todol o parte dello como quissiere aunqueste aussente de su cassa sin que ningunas justiçias se lo impidan ni estorven"). AHN Nobleza, Osuna, Leg. 1977, Nr. 35/2.

387 Siehe dazu Luis VÁzquez Fernández, Memoria de Gracias que Puede otorgar Don Fernando Pizarro, del Consejo de Castilla, en Virtud de la Comisión que de su Majestad Felipe IV tiene (De un documento inédito). In: Coloquios Históricos de Extremadura (2000), Weblink: http://www. chdetrujillo.com/memoria-de-gracias-que-puede-otorgar-don-fernando-pizarro-del-consejo-decastilla-en-virtud-de-la-comision-que-de-su-majestad-felipe-iv-tiene-de-un-documento-inedito/ (letzter Zugriff: I6.08.2016). Zu diesen Gracias zählte die Erlaubnis, Lizenzen für den Gebrauch von Kutschen und Tragsesseln zu verkaufen.

López ÁlvVarez 2007 (wie Anm. I), S. 269-277. 
schen eine interessante Überlegung an, die auch Tragsessel berührte. Er war der Ansicht, dass der exzessive Gebrauch von Kutschen von Nachteil sei, und plädierte deshalb dafür, Kutschen generell aus dem Verkehr zu ziehen. Auch wenn Olivares auf einer drastischen Einschränkung des Gebrauchs von Kutschen und anderen Vehikeln bestand, war er sich gewiss bewusst, dass ihre Verwendung schon zu weit verbreitet war, als dass sein Plan auch in die Tat hätte umgesetzt werden können. So lautete sein recht naiver Vorschlag:

[...] und für die Minister, Alten und Kranken bleiben die Tragsessel, die nicht so kostspielig wie die Kutschen sind, weil sie über keine kostbaren Dekorationen verfügen und die Sesselträger auch als Lakaien, Speisekammerdiener oder an anderen unverzichtbaren Stellen dienen können. ${ }^{389}$

Kutschen und Tragsessel waren mittlerweile so fest in der höfischen Gesellschaft verankert und die Interessen rund um ihren Gebrauch so stark angewachsen, dass ihre völlige Abschaffung unrealistisch schien. Beide Vehikeltypen hatten sich zu untrennbaren Bestandteilen des höfischen Lebens und zu fundamentalen Attributen von Höflingen entwickelt.

Nur wenige Monate nach Olivares' Debattenbeitrag, in dem er einen verstärkten Einsatz von Tragsesseln befürwortete, wurde die Beschlagnahmung von Sklaven zu Kriegszwecken veranlasst, was auch auf zahlreiche Sesselträger Auswirkungen hatte, wobei unklar ist, ob die beiden zeitlich nahe beeinander liegenden Umstände in einem Zusammenhang stehen, und falls ja, in welchem. Am 20. März I638 wurde angeordnet, dass alle Sklaven Madrids registriert werden sollten. Nachdem viele von ihnen daraufhin untergetaucht oder geflohen waren, zwang man ihre Herren zu einer Meldung. Es hieß, die Sklaven würden dringend für Ruderdienste auf den Galeeren benötigt. Einige Damen, die sich Sklaven für Sesselträgerdienste hielten, wandten sich infolgedessen an Olivares und baten ihn, ihr eigenes Personal von der Verordnung auszunehmen. Sie erhielten jedoch zur Antwort, dass

er seine eigenen auslieferte und dass dies auch dringend notwendig war: Tragsesselknechte gebe es in Madrid schließlich im Überfluss. ${ }^{390}$

389 „[... [ y para los ministros, viejos y enfermos quedan las sillas, las cuales no son tan costosas como los coches, porque no tiene aderezos que hacer considerables, los mozos de sillas sirven de lacayos, despenseros y todos los otros oficios necesarios". John H. Elliott/José F. de la PeÑA, Memoriales y cartas del Conde Duque de Olivares, 2 Bde. (Madrid I978), Bd. 2, S. I6I f. López Álvarez 2007 (wie Anm. I), S. 284-286.

390 „[... que él daba los suyos, y que la necesidad era grande: hartos mozos de sillas habia en Madrid". Cartas de algunos Padres de la Compañía de Jesús sobre los sucesos de la Monarquía entre los años de I634 y i648. In: Memorial histórico español (wie Anm. 70), Bd. I5, S. 216. 
Schon kurze Zeit später lenkte der Rat sein Augenmerk auf die Sesselträger selbst. Am I2. April I639 wurde konstatiert, dass auf Basis verschiedener Verordnungen der Gebrauch von Miettragsesseln einem grundsätzlichen Verbot unterliege, und da eine Nichtbeachtung dieser gesetzlichen Bestimmungen inopportun sei, würden mit I4. April der Besitz und die Verwendung von Miettragsesseln untersagt. Sesselträger, die Miettragsessel besaßen oder betrieben, würden fortan nicht nur ihre Vehikel durch Beschlagnahmung verlieren, sondern müssten zudem einen vierjährigen Strafdienst in den Festungen gewärtigen. Sollten sie aber zum wiederholten Mal das Verbot übertreten, drohe ihnen ein sechsjähriger Galeerendienst, und dies ohne jegliche Möglichkeit einer Strafumwandlung oder -minderung. ${ }^{391}$ Vermutlich diente diese Maßnahme, die zu einem Zeitpunkt getroffen wurde, zu dem die Vergabe von Lizenzen freigiebiger gehandhabt wurde, dazu, den Gebrauch von Tragsesseln allein auf jenen Personenkreis zu beschränken, der dazu eine formale Berechtigung besaß. Unbekannt ist, ob die Maßnahme, die vermutlich auf Madrid beschränkt blieb, von Erfolg gekrönt war. ${ }^{392}$

Von da an gab es allem Anschein nach keine weiteren Verordnungen mehr, die die Nutzer von Tragsesseln selbst berührt hätten. Die in der Folge erlassenen gesetzlichen Bestimmungen bezogen sich zunächst auf die Ausstattung der Tragevehikel und später auf die Zahl der Sesselträger, was wiederum bestätigt, dass Tragsessel damals bereits vollends in das Hofleben integriert waren. Einen Ausnahmefall scheint jedoch Bilbao darzustellen, wo I657 in einer Ratssitzung beklagt wurde, dass einige Personen den verbotenen Brauch, sich im Tragsessel durch die Straßen tragen zu lassen, erneut einführen wollten. ${ }^{393}$

\subsection{Gesetzliche Regelungen rund um die Ausstattung von Tragsesseln (1600-1691)}

Angesichts der Tatsache, dass Kutschen betreffende Verordnungen zu einer vermehrten Verwendung von Tragsesseln geführt hatten und dass auch der Hofstaat der Königinnen und andere Machtinstanzen immer häufiger Tragsessel gebrauchten, ist es nicht weiter verwunderlich, dass diese in zunehmendem Maße mit kostbaren Materialien und prachtvollen Verzierungen ausgestattet wurden. Dieser Prozess hatte bereits Ende des I6. Jahr-

39I AHN, Consejos, Libro I224, fol. 70r-v.

392 In Sevilla wurden I642 die Tarife für Kutscher und Sesselträger festgelegt. Sesselträger sollten „für einen halben Tag zwei Reales, für einen ganzen Tag, an dem nur einer einzigen Person gedient wird, vier Reales und für eine einzige Strecke eineinhalb Real" (,por medio día dos reales, y por un día entero sirviendo a una persona, quatro reales, y por un viaje solo, real y medio") erhalten. Siehe dazu BNE, VE/208-45.

393 Teófilo Guiard y Larrauri, Historia de la noble villa de Bilbao (I300-1600) (Bilbao I905), Bd. I, S. $529 \mathrm{f}$. 
hunderts seinen Anfang genommen. Nachdem sich am spanischen Hof kritische Stimmen erhoben hatten, die forderten, diesen Entwicklungen Einhalt zu gebieten, erging schließlich im Oktober des Jahres 5999 ein Gesuch an den neuen Monarchen Philipp III., die Zahl der begleitenden Dienerschaft zu reduzieren, die Einhaltung bereits existierender Kleiderordnungen strenger zu kontrollieren, den Gebrauch von Seide einzuschränken sowie Verordnungen für „Betten, Behänge, Tragsessel, Kutschen und anderen profane Dingen zu erlassen, damit diese weder Gold, Silber, feine oder unechte Metallfäden noch Stickereien aufwiesen "394. Als Reaktion darauf wurde am 2. Juni I600 eine Verordnung veröffentlicht, in der hinsichtlich Tragsesseln verboten wurde, dass diese

mit Brokat, Gold-, Silber- oder diese Metalle beinhaltendem Seidenstoff ausgestattet sind, auch darf das Futter mit keinerlei Stickereien verziert werden; sie dürfen ausschließlich mit Samt, Damast oder Seide versehen sein; erlaubt sind Fransenbesätze und Zierschnüre aus Seide, nicht aber aus Gold oder Silber; die Pfosten der Tragsessel dürfen weder Gold- oder Silberborten noch Seidenposamenterie oder Ziernägel aufweisen. ${ }^{395}$

Tragsessel, die vor Inkrafttreten der Verordnung angefertigt worden waren, durften weiterhin genutzt, repariert und veräußert werden, jedoch war es verboten, ihr Aussehen zu verändern. Darüber hinaus mussten sie binnen sechs Monaten den zuständigen Justizstellen der Städte und Dörfer gemeldet werden. Zuwiderhandelnden Handwerkern drohte beim ersten Verstoß eine vierjährige Verbannung sowie eine Strafzahlung von 20.000 Maravedis. Beim zweiten Übertreten verdoppelte sich die Strafe, und beim dritten wurde der öffentliche Ehrverlust sowie eine zehnjährige Verbannung über den Gesetzesbrecher verhängt. ${ }^{396}$

Am 3. Januar I6II wurde im Rahmen allgemeiner Verbotsgesetze auch erneut eine gesetzliche Regelung hinsichtlich der Dekoration von Tragsesseln veröffentlicht. Der Text war beinahe mit jenem von I6oo identisch, mit der Ausnahme, dass Tragsessel nunmehr auch Seidenposamenterie und Ziernägel an den Pfosten aufweisen durften. Jedoch wurden

394 „...] camas colgaduras sillas coches y en las demás cosas del serviçio profano de modo q no puedan tener tela de oro ni de plata ni hilo fino ni falso ni ser bordadas". Exposon de io puntos q se tocaron en villete q se embió al Rey Nsor D. Phe $3^{\circ}$ año I599, BNE, Mss. 2346, fol. 65.

395 „[...] de brocado, ni tela de oro, o plata, ni de seda alguna q lo lleve, ni puedâ ser bordados los aforros dellas de cosa alguna, y no se puedan hazer sino de terciopelo, o damasco, o otra qualquier seda; y puedâ llevar flocaduras, y alamares della, y no de oro, ni plata, y los pilares de las dichas sillas no puedan ser guarnecidos de trencillas de oro, ni de plata, ni de passamanos de seda, ni de tachuelas". Premática en que se prohíben colgaduras y adereços de casas de brocados, y telas de oro y plata y bordado, y hechura de joyas de oro y pieças de plata, y se da la forma en ella contenida, y se permite traer cuellos de ochava con almidón, I600, RAE, I3-A-23 (40).

396 Ebenda. 
die Strafen nun deutlich erhöht: Ein Handwerker hatte beim ersten Verstoß mit einer Geldstrafe von 50.000 Maravedis zu rechnen, beim zweiten mit 100.000 Maravedis und beim dritten mit fünf Jahren Galeerendienst sowie fünf Jahren Verbannung. ${ }^{397}$

Die Gesetzgebung über die Ausstattung von Tragsesseln scheint damit ihren Abschluss gefunden zu haben. Die Tragsessel am Hof wurden dennoch immer teurer und aufwendiger in ihrer Gestaltung, wofür mehrere Faktoren ausschlaggebend waren: der sie betreffende „Institutionalisierungsprozess“, ihre gewachsene Bedeutung im Rahmen des königlichen Zeremoniells und nicht zuletzt der für die Epoche so typische Wettstreit mit Luxuswaren. Die gesetzgebenden Institutionen scheinen den Tragsesseln bis zu einer Verordnung von September I657 jedoch keine weitere Beachtung geschenkt zu haben. In dieser Verordnung wurde unter Punkt 20 die Ausstattung von Tragsesseln im Wortlaut von I6II behandelt. Die Verordnung brachte jedoch im Vergleich zu vorangegangenen gesetzlichen Bestimmungen auch einige Neuerungen mit sich. So wurde unter Punkt 22, der in den Verordnungen von I600 und I6Ir allein die äußere Gestaltung von Kutschen und Sänften behandelt hatte, nunmehr auch jene von Tragsesseln geregelt, was abermals als Beleg dafür gelten kann, dass ihr Luxuswert enorm gestiegen war. Laut den Bestimmungen war es verboten, Tragsessel außen mit Seide zu versehen. Darüber hinaus durften Sänften und Tragsessel weder mit gesteppten Oberflächen - auch nicht bei Kalbs- oder Korduanleder - ausgeführt sein noch Verzierungen aus Lederstickerei aufweisen. Vehikel, die vor Inkrafttreten der Verordnung hergestellt worden waren, durften nur noch für zwei weitere Jahre verwendet werden. Um die Zahl der zum damaligen Zeitpunkt vorhandenen Vehikel exakt bestimmen zu können, war gemäß Punkt 23 der Verordnung eine Registrierung verpflichtend. Jenen Meistern und Handwerkern, die bei Reparaturen von Kutschen, Sänften oder Tragsesseln deren Ausstattung entgegen den Bestimmungen der Verordnung erneuerten, wurde gemäß Punkt 24 beim ersten Verstoß die Beschlagnahmung des Vehikels und eine Geldstrafe in der Höhe von 50.000 Maravedis und beim zweiten Mal eine vierjährige Verbannung und eine doppelt so hohe Geldstrafe angedroht. Dies waren jedoch nicht die einzigen Neuerungen. Im Zuge einer verstärkten Reglementierung der Ausgaben für Lakaien, Kutscher und Sesselträger wurde in Punkt I4 festgelegt, dass für deren Livreen einzig und allein Tuch verwendet werden dürfe, ohne jegliche Verzierung wie etwa Posamente, Borten, Bauchbinden oder Absteppungen an den Säumen; vielmehr hatte dass Tuch ganz glatt zu sein und einfache Knöpfe an den Mantelvorderseiten aufzuweisen. Kragen von Umhängen, Wehrgehänge und Ärmel durften aus einfachem oder mehrfarbigem Samt gearbeitet sein, der jedoch aus dem spanischen Herrschaftsgebiet stammen musste. Für Strümpfe war farbige Wolle, nicht jedoch Seide gestattet. Livreen, die gegen diese Verordnung verstießen, wurden eingezogen; die dafür verantwortli-

397 Pragmática, y nueva orden, cerca de las colgaduras de casas, y hechura de joyas de oro, y piedras, y pieças de plata, y en la forma que se han de hazer labrar, y traer, y otras cosas, I6II, RAE, 40-III-32. 
chen Schneider wurden bestraft und das damit eingekleidete Dienstpersonal mit einer Geldstrafe von 6000 Maravedis und zweijähriger Verbannung belegt. ${ }^{398}$

Die in der Verordnung von I657 vorgesehene zweijährige Frist schien den Verantwortlichen unmittelbar vor ihrem Ablauf zu kurz, weshalb in einer Ratssitzung vom I9. September I659 eine Fristverlängerung gefordert wurde, „um die Kosten, die durch die Anschaffung neuer Kutschen, Tragsessel und Sänften zwangsweise entstehen würden, zu vermeiden." Das geltende Verbot für die Herstellung neuer Vehikel sollte jedoch seine Gültigkeit behalten. Der König stimmte dieser Forderung zu, und die Frist wurde bis Ende des Jahres I66I verlängert, damit die durch das Gesetz verbotenen Vehikel noch einige Zeit weiter genutzt werden konnten. ${ }^{399}$ Wie schon in anderen Fällen früherer Zeiten wurde durch das Herstellungsverbot für luxuriös ausgestattete Vehikel beabsichtigt, ihre Vermehrung zu verhindern. Durch die Erlaubnis, die bereits vorhandenen Prunkvehikel weiter zu nutzen, wurden wiederum zusätzliche Ausgaben unterbunden.

Mit Anfang der I670er Jahre setzte der Kastilische Rat neue Impulse zur Kontrolle von Luxusausgaben am spanischen Hof. Im Jahr I67I wurde in Ratssitzungen eine umfassende Reform der entsprechenden Regelungen für Kleider und andere Objekte in Erwägung gezogen. Der Hof sollte dabei dem gesamten Königreich als Beispiel vorangehen. In zwei einschlägigen Consultas vom 7. Oktober I67I und 27. April I672 wurde der schwere Schaden betont, der in Madrid durch die übermäßig große „Zahl an Lakaien und die Kostspieligkeit von Kutschen und Tragsesseln" entstehe. Um den Erfolg der Reform nicht zu gefährden, plante man allerdings, nicht alle angestrebten Punkte auf einmal umzusetzen, sondern zunächst mit jenen zu beginnen, die aller Voraussicht nach die geringste Unruhe am Hof hervorrufen würden. Auf eine Anfrage der Königin hin sprach der Rat etwas später die Empfehlung aus, angesichts der im ganzen Königreich zu beobachtenden Exzesse bei Kleidungen und Festen die Verordnung von 1657 wieder einzuführen. Allerdings, so die Räte, wäre das Augenmerk dabei auf die tatsächliche Durchsetzung der dort festgelegten Bestimmungen zu legen, damit kein schlechtes Licht auf die Gerichtsbarkeit falle. Zwar seien die Verbote „einige Zeit lang befolgt [worden], bis durch die Unachtsamkeit der zuständigen Minister eine Auflockerung um sich zu greifen begann." ${ }^{400}$ Nachdem die Angelegenheit fürs Erste im Sand verlaufen war, griff man sie zwei Jahre später erneut auf. Im Februar I674 fragte die Königin beim Rat an, welche Waren angesichts des unangemessen hohen

398 Premática que su Magestad manda publicar sobre conservacion del contravando, revocación de las permissiones, prohibición del uso de las mercaderías, y frutos de los Reynos de Francia, Inglaterra, y Portugal, y reformación de trajes, vestidos, y otras cosas, I657, BNE, R 23.879 (9).

399 AHN, Consejos, Leg. 7255/95.

400 „[... tubo observançia algún tiempo, hasta que faltando el cuidado de los ministros que la tenían a su cargo, fue tomando fuerças la relaxaçión“. AHN, Consejos, Leg. 718I, unfol.; ebenda 7137/I2. 
Aufwands im Bereich der Lakaien und der Ausstattung von Kutschen und Tragsesseln verboten werden könnten, „ohne gegen die Artikel des Friedensabkommens zu verstoßen“ - sie bezog sich dabei auf eine am 30. Januar desselben Jahres publizierte Verordnung, die den Handel mit allen aus Frankreich stammenden Waren untersagte. In einer Ratssitzung vom I5. Februar wurden daraufhin Reformen erörtert, die sowohl Vehikel als auch die ausufernde Zahl an Lakaien betreffen sollten. Damals wurde vorgeschlagen, die Einhaltung der Gesetze entschiedener als bisher zu überwachen und in diesem Punkt auch die verschiedenen Räte stärker in die Pflicht zu nehmen. Die Königin zeigte sich damit einverstanden und ordnete die Ausarbeitung einer entsprechenden Verordnung an. Schon am Io. März war die Reform fertig abgefasst. Wie die in den Ratssitzungen geführten Debatten erahnen lassen, sollte die neue Verordnung auf jenen der Jahre 1657 und I60o basieren..$^{401}$ Allein die Etablierung und internationale Verbreitung eines neuen französischen Fahrzeugtypus - der sogenannten Carrosse moderne - führte zu neuen Aspekten im Gesetzestext. ${ }^{402}$ Wenngleich der Kastilische Rat ausdrücklich auf der Einhaltung der Verordnung bestand, ließen einige ihrer Punkte eine lockere Auslegung zu. Zudem wurde ihr Inkrafttreten mehrmals verschoben. Die ursprünglich einjährige Frist (März 1675) wurde schließlich auf zwei Jahre verlängert (Mai 1676). Allerdings durften auch schon davor bereits existierende Vehikel weder neu vergoldet noch bemalt noch in einer anderen Art als bisher äußerlich verziert werden. Das für die Fristverlängerung ins Feld geführte Argument lautete, dass man die in der vorhergegangenen Verordnung geforderten Änderungen an den Vehikeln zwar umgesetzt habe, aber zu wenig Zeit vergangen sei, um die adaptierten Vehikel auch tatsächlich zu nutzen. Eine zu kurze Frist würde deshalb zusätzliche Ausgaben für den Bau neuer Vehikel verursachen. ${ }^{403}$ Als drei Jahre später die Verordnung schließlich tatsächlich in Kraft trat, wurde sie von mehreren Personen einfach ignoriert. Dies hatte neuerlich Debatten im Rat zur Folge, bei denen verschiedene Gegenmaßnahmen diskutiert wurden, etwa die Androhung hoher Geldstrafen, eine strenge Mahnung an die königlichen Bediensteten, mit der Botschaft, die Königin fordere die pünktliche Befolgung der Gesetze seitens ihrer Diener und deren Verwandter, oder aber die konsequente Inpflichtnahme unterschiedlichster Ratsgremien bei der Kontrolle von Gesetzesübertretungen. Schließlich wurde im August I677 aber nur eine Verordnung veröffentlicht, die einfach die Bestimmungen von I674 unverändert wiederholte. ${ }^{404}$

\footnotetext{
4OI AHN, Consejos, Leg. 5I.438/I.

402 Pragmática que su Magestad manda publicar sobre la reformación en el excesso de Traxes, lacayos, y coches, y prohibición del consumo de las mercadurías de Francia [...] y otras cosas, I674, BNE, R 23.879 (I8), fol. 5v-7r; AHN, Consejos, Leg. 5I.438/r.

403 AHN, Consejos, Leg. 5I.438/I, Libro I260, fol. 28-29; ebenda, Libro I26I, fol. 65.

404 AHN, Consejos, Libro I262, fol. I09, II3v-II5r; Vando del Rey para que se cumpla la pragmática
} 
Zusammenfassend lässt sich festhalten, dass die aus der Zeit zwischen I640 und I670 datierenden Reformen, die auf die Verwendung von Vehikeln - und insbesondere Kutschen - Einfluss nahmen, nicht ausreichten, um ihren weiteren Aufstieg zu bremsen. ${ }^{405}$ Sie wurden zunehmend opulenter gestaltet, und auch ihr Anwendungsbereich weitete sich stetig aus. Erst in den I670er Jahren wurden hinsichtlich der Ausstattung der Vehikel restriktive Verordnungen erarbeitet, ein Phänomen, das mit dem Auftauchen der französischen Carrosses modernes am spanischen Hof in Verbindung steht. Die in jenem Jahrzehnt in Kraft getretenen gesetzlichen Maßnahmen blieben jedoch weitgehend erfolglos. Damals wurde auch immer häufiger Kritik an der hohen Zahl von Tragsesseln geübt, die als Beleg für einen exzessiven sozialen Wettbewerb gewertet wurde. Ein anonymer Arbitrist klagte während der Regentschaft Maria Annas:

Tragsessel und Sesselträger, die einst allein auf vornehmere Damen beschränkt waren, sind heutzutage weit verbreitet und wohl auch reicher geschmückt als früher. Sie finden sich in den Häusern zahlreicher hoher Beamter und Schreiber, werden von Pagen und Reitknechten begleitet und von solchen Damen verwendet, für die es völlig ausreichen würde, zu Fuß und in Begleitung von nur einem Diener auf der Straße zu erscheinen. ${ }^{406}$

Die Situation änderte sich jedoch erst, als im Anschluss an den von großen Konfusionen geprägten Zeitabschnitt zwischen I668 und I677 der Hochadel in allen Bereichen der Monarchie eine Vorrangstellung erlangte. Zwar könnte durchaus auch die Verordnung von 1674 als Beginn einer neuen Reformperiode betrachtet werden, jedoch sorgten vor

el 8 de marzo de 1674 que se había contravenido sobre la reforma de trajes, lacayos y coches, tanto en esta corte como fuera de ella, y para que se ejecuten sentencias a los trangresores, I677, BNE, R 23.879 (I8/2).

$405 \mathrm{Zu}$ diesem Thema siehe López Álvarez 2007 (wie Anm. I), im Besonderen S. 283-299.

406 "Las sillas y silleteros de que se contentaban en otro tiempo las señoras de más porte son oy comunes, $y$ quizás más adornadas en casa de muchos togados, y plumistas con el acompañamiento de paxes y escuderos a cavallo para ir sirviendo a las que no parecieran mal por la calle a pie con una criada". Anonym, Achaques de la Monarquía, BNE, Mss. 8180, fol. 66. Siehe dazu auch die Meinung eines Alcalde de Corte aus der Zeit um 1670, in: Antonio Domínguez Ortiz, Aspectos del vivir madrileño durante el reinado de Carlos II. In: Anales del Instituto de Estudios Madrileńos 7 (197I), S. 229-252, hier S. 245. Damals kritisierte auch ein namentlich nicht bekannter Arbitrist, der sich 1677 an Juan José de Austria wandte, um diesem die Probleme der Monarchie darzulegen, das Verhalten der Alcaldes de Corte sowie die Tragsessel ihrer Ehefrauen. Rosa Isabel SÁnchez Gómez, Delincuencia y seguridad en el Madrid de Carlos II (Dissertation, Universidad Complutense, Madrid 1994), S. 72 f. Ein anderer Autor beklagte, dass mit Sekretären oder Buchhaltern verheiratete Gastwirtstöchter sich nur im Tragsessel zur Messe begeben würden, selbst dann, wenn die Kirche gegenüber ihrem Haus lag. Julián Juderías, España en tiempo de Carlos II el Hechizado (Madrid I9I2), S. I55. 
allem die in den Jahren darauf erfolgenden Veränderungen am Hof für unerwartete und weitreichende gesetzliche Einschränkungen auf dem Gebiet der Luxusgüter, insbesondere hinsichtlich des Zugangs zu Kutschen. Die Restriktionen erreichten in den letzten beiden Jahrzehnten des I7. Jahrhunderts ihren Höhepunkt, als die Granden die Kontrolle über die Regierungsgeschäfte der Monarchie ausübten. ${ }^{407}$ Damals ging man mit Nachdruck gegen soziale Distinktionsbestrebungen vor, die sich des Einsatzes von Vehikeln bedienten. Zu diesem Zweck wurden bereits früher eingeleitete Reformen wiederholt, vertieft und erweitert. So wurde etwa am 9. Oktober I684 die Verordnung von I674 mit fast identischem Wortlaut wieder in Kraft gesetzt. ${ }^{408}$ Als sie am 26. November I69I erneuert wurde, war ihr Text in entscheidenden Punkten abgeändert worden. ${ }^{409}$ Neben dem Verbot, sechs Maultiere oder Pferde als Zugtiere für Kutschen zu verwenden, war die bedeutendste Neuerung der Ausschluss von Vertretern mehrerer Gewerbesparten vom Recht, in Kutschen zu fahren. Hinsichtlich der Tragsessel wurden die bereits früher getroffenen Maßnahmen nahezu im Wortlaut wiederholt. Gemäß einer neuen Bestimmung sollte es fortan jedoch nur noch Witwen gestattet sein, schwarze Tragsessel zu benutzen, eine Regelung, die auch für die Überseegebiete der Monarchie gelten sollte. ${ }^{40}$ Ebenfalls neu war der Versuch, die Zahl der Sesselträger gesetzlich zu beschränken, eine Thematik, die weder I674 noch 1684 aufgegriffen worden war und auf die wir im Folgenden noch näher eingehen möchten.

\subsection{Die Gesetzgebung zu Sesselträgern (1594-1691)}

Wie bereits mehrfach erwähnt, gehen wir davon aus, dass die Kutschen-Verordnungen von 1578 und I593, durch die der Zugang zu Kutschen erschwert worden war, zu einem

407 Antonio Álvarez-Ossorio Alvariño, El favor real: liberalidad del príncipe y jerarquía de la república (i665-I700). In: Chiara Continisio/Cesare Mozzarelli, Repubblica e virtù. Pensiero politico e Monarchia Cattolica fra XVI e XVII secolo (Biblioteca del Cinquecento 67, Roma 1995), S. 393-453, im Besonderen S. 434-437.

408 Pragmática que su magestad manda publicar para que se guarde, execute, y observe la que se publicó el año de 1674 sobre la reforma en el Excesso de Trages, Lacayos, y Coches, y otras cosas en esta contenidas, I684, BNE R 23.879 (23).

409 Pragmática que su magestad manda publicar, para que se guarde y execute y observe la que se publicó el año de I684 sobre la reformación en el excesso de Trages, Coches, y otras cosas en esta contenidas, I69I, BNE, R 23.879 (26).

$4 \mathrm{IO}$, „... [ pero no traer coche negro en manera alguna“. Antonio Muro Orejón, Cedulario americano del siglo XVIII. Colección de disposiciones legales indianas desde I680 a I800, contenidas en los Cedularios del Archivo General de Indias, 3 Bde. (Publicaciones de la Escuela de Estudios Hispano-Americanos de Sevilla 99, 185 und 242, Sevilla 1956-1977), Bd. I, S. 493. Zu den entsprechenden Ergebnissen dieser Maßnahmen siehe López Álvarez 2007 (wie Anm. I), S. 308-3i6. 
verstärkten Gebrauch von Tragsesseln seitens der Stadtbevölkerungen Kastiliens führten, was wiederum eine vermehrte Nutzung von Miettragsesseln zur Folge hatte. Um dieser Entwicklung entgegenzuwirken, wurde im Jahr 1594 die erste uns bekannte Verordnung erlassen, die Sesselträger direkt betraf. Die darin festgehaltenen Bestimmungen hatten nicht nur für Madrid Gültigkeit, sondern auch für andere Städte des Königreichs, möglicherweise sogar für ganz Kastilien. Zweck der Verordnung war es, das Heer mittelloser Personen, die unter anderem versuchten, Arbeit als Sesselträger zu finden, unter Kontrolle zu bringen. Am 6. Februar 1594 fasste die Junta Grande folgenden Beschluss:

Aufgrund des Überangebotes an Sesselträgern, die am Hof für den Transport von Personen gemietet werden können, und wegen ihrer überzogenen Preise unterbreiteten die Alcaldes de Corte dem Kastilischen Rat infolge der aufgetretenen Missstände den Vorschlag, dieses Gewerbe zu regulieren. Der Rat gelangte zur Auffassung, dass diese Männer keine Tragsessel mehr vermieten dürfen und dass für eine einfache Strecke nicht mehr als ein Real und für den Rückweg ebenfalls nur ein Real verlangt werden dürfe. Sollte der Weg etwas weiter sein, dürfe auch etwas mehr verlangt werden, sollte sich der Benutzer damit einverstanden erklären. ${ }^{4 I I}$

Infolgedessen wurden einerseits das Gewerbe mit nicht angemeldeten Tragsesseln verboten und andererseits verbindliche Tarife für Sesselträgerdienste festgesetzt. Vom Versuch, unabhängige Gewerbetreibende zu kontrollieren, waren allem Anschein nach Sesselträger in privaten Haushalten ausgenommen, blieben diese doch in der Ratssitzung unerwähnt. Interessant sind in diesem Zusammenhang Verse, die ebenfalls I594 in Sevilla veröffentlicht wurden. Darin wird Tragsesselnutzern empfohlen, auf Sklavendienste zurückzugreifen:

Sollen es ihre eigenen gekauften / nicht gemietete oder geliehene sein / um Dukaten zu sparen / nehmen sie fremde Leute. ${ }^{412}$

$4 \mathrm{II} \quad$ „.... [os alcaldes de Corte viendo el excesso que en ella ay de moços que se alquilan para llevar personas en sillas y la demasía de precio, consultaron al con ${ }^{\circ}$ se les tasasse, y visto en él parece que se devría mandar que estos hombres no tengan sillas para alquilar por los inconvenientes que resultan, y que por cada visita que fueren en silla de yda, y buelta no puedan llevar más q un real cada uno, o, algo más siendo lexos a voluntad del que las alquila“. Die Stellungnahme des Königs lautete: „Am besten wäre es wohl, diese Tragsessel durch ein Verbot zu eliminieren, und so soll es dem Rat auch mitgeteilt werden“" („,...] parece que lo más acertado será prohibir que no aya estas sillas, y responderlo assí al Cons ${ }^{\circ "}$ ). IVDJ, Envío 43 (II), 448. Offenbar verfügten einige Sesselträger bereits über eine entsprechende Genehmigung. Andere scheinen hingegen ohne Erlaubnis ihre Dienste angeboten zu haben.

4I2 "Que sean suyos comprados, / no alquilados ni prestados, / que por ahorrar ducados / se sirven de gente ajena". Aquí se contiene un milagro que el glorioso San Diego hizo con una devota suya, a los 
Die getroffenen Maßnahmen führten auf der einen Seite zu einer Verknappung des Angebots an Miettragsesseln und erschwerten somit für viele Menschen den Zugang zu diesen Vehikeln; andererseits wurden Personen, die mit Sesselträgerdiensten ihr tägliches Brot verdienten, einer stärkeren Kontrolle unterworfen. Gleichzeitig wurde aber auch der Zugang zu Tragsesseln für all jene erleichtert, die sich den Unterhalt eigener Diener und Sklaven leisten konnten. Die Gruppe vagabundierender Sesselträger, die jedermann ihre Dienste anboten, wurde durch die Registrierungspflicht schärfer überwacht, und bereits bestehende soziale Unterschiede erfuhren eine Konsolidierung. Zwar sind uns die konkreten Folgen der Verordnung von 1594 unbekannt, fest steht jedoch, dass die Bestrebungen der Städte Kastiliens und des Kastilischen Rats, das Sesselträgergewerbe zu regulieren, auch in den darauf folgenden Jahren nicht nachließen. Als der Hof nach Valladolid verlegt wurde, erneuerte man am 2. April I6or auch die Verordnung aus dem Jahr I594. Damals wurde bestimmt, dass Mietsesselträger für den Hin- und Rückweg nicht mehr als einen Real pro Kopf von den beförderten Personen verlangen beziehungsweise erhalten sollten; andernfalls drohten ihnen hundert Peitschenhiebe und eine vierjährige Verbannung vom Hof außerhalb eines Umkreises von fünf Meilen. ${ }^{433}$ Anlässlich der Rückkehr des Hofes nach Madrid wurde dieselbe Maßnahme getroffen, jedoch wurden nun sowohl die Tarife erhöht als auch die Strafen verschärft. Mit 20. Februar I607 wurde Sesselträgern untersagt, mehr als anderthalb Real pro Person für einen Hin- und Rückweg innerhalb des Stadtgebiets von Madrid zu verlangen. Weiterhin wurde streng verboten, dieses Gewerbe ohne Registrierung und Genehmigung auszuüben. Zuwiderhandelnden wurden der öffentliche Ehrverlust, eine vierjährige Verbannungs- sowie eine Geldstrafe in der Höhe von 20 Dukaten angedroht. ${ }^{414}$ Der hier zu beobachtende Mechanismus, ein Gewerbe zu kontrollieren, basierte auf der Eingliederung in eine Zunft, auf der Registrierung der Gewerbetreibenden und auf der Überwachung durch eine Aufsichtsbehörde. Dies entsprach dem Vorgehen, das in der Vergangenheit schon auf anderen Gebieten von den Gemeinden und dem Rat mit Erfolg erprobt worden war. ${ }^{415}$

25 de febrero de este presente año de mil y quinientos y noventa y quatro, juntamente de la gran justicia que en la ciudad de Lisboa se hizo de un inglés luterano y de otras personas, y lleva al cabo una letrilla nueva al tono de la zarabanda sobre la nueva premática. Compuesto en verso castellano por Benito Carrasco, vecino de Ávila. In: Bartolomé José Gallardo, Ensayo de una biblioteca espańola de libros raros y curiosos [...], 4 Bde. (Madrid I863-I889), Bd. 2, S. 238 f., hier S. 239. „[...] no pueda llevar ni lleve más de tan solamente un real cada uno, de yda y vuelta, a la parte donde llevare a la persona que los alquilare sopena de cien açotes, y de quatro años de destierro, de la corte y cinco leguas". Pregón general para la gobernación desta corte, Valladolid I6oI, BNE, VE I54-30, fol. 9v. AHN, Consejos, Libro I20I, fol. I43.

4I5 José Antolín Nieto Sánchez, Artesanos y mercaderes. Una historia social y económica de Madrid, I450-1850 (Ciencia 297, Serie „Sociología“, Madrid 2006), S. 174. 


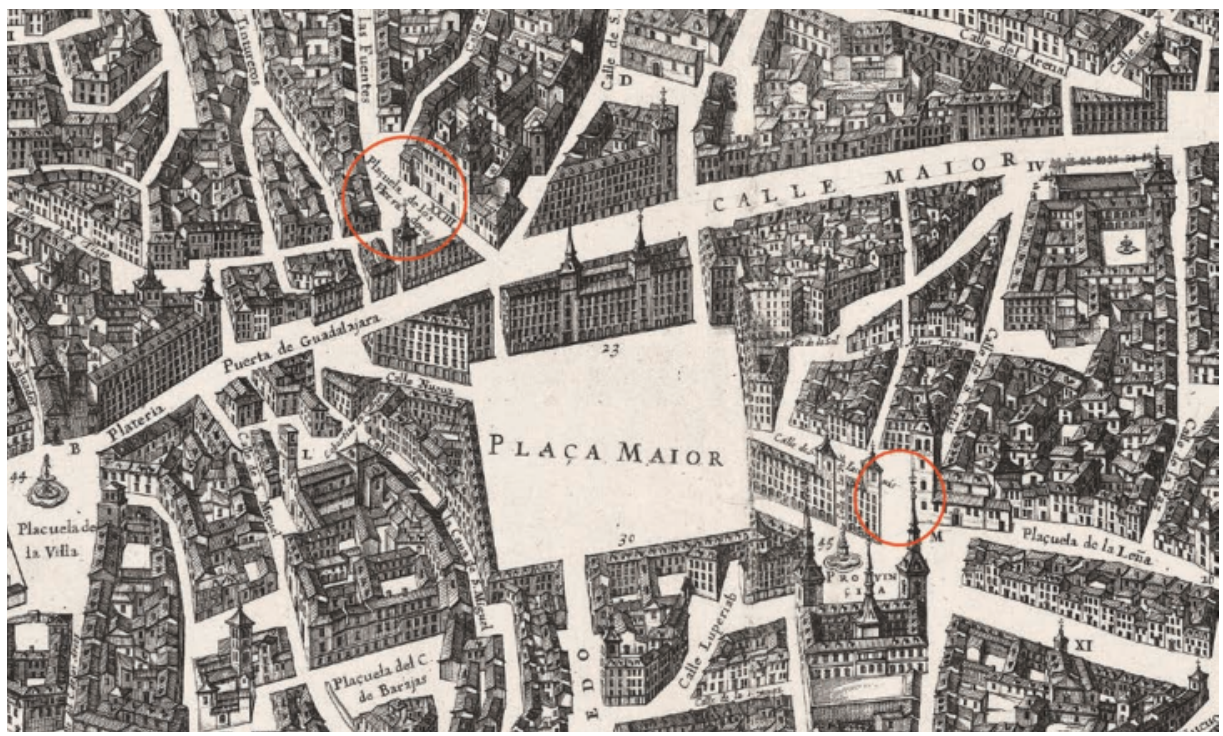

Abb. 9: Detail eines historischen Stadtplans von Madrid, auf dem nordwestlich der Plaza Mayor die Plaza de Herradores und östlich die Plaza de Santa Cruz mit Kreisen markiert sind. Auf diesen Plätzen hatten Sesselträger im 16. und 17. Jahrhundert ihre Standplätze. Pedro Texeira und Salomon Savery, Topographia de la Villa de Madrid, Antwerpen, 1565. BNE, INVENT/23.233. @ BNE

Im Zuge des damals bereits eingeleiteten „Institutionalisierungsprozesses“ wurde in Konformität mit Entwicklungen der vergangenen Jahre der Status von Sesselträgern am Hof reguliert. Dabei war man bestrebt, mittellose Personen vom Hof fernzuhalten, um so den sozialen Frieden auf den Straßen aufrechtzuerhalten. Der Zugang zu einem für viele erschwinglichen Luxusgut sollte beschränkt bleiben. Am 23. Juni i609 verordneten die Alcaldes de Corte, dass sämtliche Sesselträger ihre Dienste fortan nur noch auf der Plaza de Herradores anbieten dürften, nicht aber auf anderen Plätzen.

Um als Sesselträger identifiziert werden zu können und damit sich keine Vagabunden in ihre Reihen einschleichen, soll der von ihnen für den Dienst benötigte Tragriemen offen über der Schulter getragen werden. ${ }^{416}$

416 „[...] y para que sean conocidos y no aya bag[abun]dos ayan de traer y traigan cada uno el correón con que lleban la silla echado al hombro descubierto [...]“. AHN, Consejos, Libro I208, fol. II-19, hier fol. I4r. 
Die Nichtbeachtung dieser Regel wurde mit öffentlichem Ehrverlust und einer zweijährigen Verbannung vom Hof geahndet. Bei den Sesselträgern traf diese Bestimmung auf Widerstand. Schon kurze Zeit später machten die registrierten Sesselträger Joan de Feira, Bartolomé Riviera, Francisco de Montejo und weitere Schicksalsgefährten vor dem Rat geltend, dass sowohl sie als auch ihre Vorgänger seit mehr als zwanzig Jahren auf der Plaza de Santa Cruz ihren Standplatz gehabt hätten. Für das Recht, dort die Vorhallen beziehungsweise die Plaza de Herradores nutzen zu dürfen, hatten sie bereits eine Kaution hinterlegt. Ein Aufgeben des Standorts Santa Cruz bedeute Veränderungen, die ihren Kunden erhebliche Unannehmlichkeiten bereiten würden (Abb. 9). Aufgrund der Größe des Hofes, so die Beschwerdeführer, bestehe Bedarf an zwei Standplätzen für Sesselträger. Mit nur einem einzigen Standort würde es den Damen infolge der dadurch hervorgerufenen Verzögerungen erschwert, ihre Besuche im Tragsessel bequem und pünktlich abzustatten. Noch heftiger fielen die Proteste gegen die Pflicht aus, die Riemen um die Schulter hängend tragen zu müssen,

denn das Umlegen von Tragriemen über der Kleidung ist nie üblich gewesen; es ist weder zweckmäßig noch bequem, selbst dann nicht, wenn die Riemen nicht offen sichtbar getragen würden. ${ }^{417}$

Die Sesselträger versicherten, die Tragriemen an Bändern beziehungsweise ihren Hosenbünden hängend oder aber in ihren Rocktaschen mit sich zu führen. Würde man sie nun aber dazu verpflichten, die Tragriemen um den Hals zu tragen,

wäre das sehr auffällig, sie würden wie Haussklaven erscheinen, und keiner hätte mehr das Verlangen, als Sesselträger zu dienen. ${ }^{418}$

Im darauf folgenden Rechtsstreit gaben fünf Zeugen Auskunft über die Tätigkeiten und das Verhalten der Sesselträger. Der im Anschluss daran gefasste Entschluss war gegen die Interessen der Sesselträger gerichtet. ${ }^{49}$ Sie hatten behauptet, der Wegfall eines ihrer Standplätze, nämlich der Plaza de Santa Cruz, würde den Bewohnern der Stadtviertel San Jerónimo, San Sebastián und Lavapiés den Zugang zu Tragsesseln erschweren. Der Beschluss der Sala de Alcaldes scheint jedoch nicht ohne Hintergedanken gefasst worden zu sein,

$4 \mathrm{I} 7, \ldots[$, porque el traer correas del oficio encima de los vestidos nunca se a usado ni es cosa conveniente ni menos de no traer los dichos correones descubiertos se sigue inconveniente [...]“. Ebenda, fol. $155 \mathrm{r}-\mathrm{v}$.

$4 \mathrm{I} \quad$ „[... [ sería mucha nota de andar como los esclavos particular y ning ${ }^{\circ}$ querría servir de mozo de sillas [...]“. Ebenda, fol. I6r.

419 Für nähere Informationen dazu siehe López Álvarez 2007 (wie Anm. I), S. 567-569. 
denn in den beiden letztgenannten Stadtteilen hielten sich zahlreiche Schauspieler und Prostituierte auf. Die Entscheidung bezweckte demnach, die Sesselträger auf einen einzigen Raum zu konzentrieren, wobei die Pflicht, die Tragriemen um die Schulter zu legen, zu ihrer besseren Identifizierung und Beaufsichtigung beitragen sollte. Außerdem wollte man damit die Exklusivität eines für privilegierte Schichten bestimmten Luxusgutes bewahren, während anderen sozialen Gruppen der Zugang zu Tragsesseln erschwert werden sollte, eine Zielrichtung, die auch die Einführung der Lizenzen im Jahr I6os verfolgt hatte. Das verhängte Verbot, auf der Plaza de Santa Cruz zu arbeiten, blieb auch in der Folge bestehen. Darauf deutet eine Beschwerde der Tuchscherer im Jahr I6I7 hin, die sich damals über die Präsenz verschiedener Geschäftsaktivitäten auf der Plaza de Herradores beklagten, vor allem derjenigen der Schlosser, Lakaien und Sesselträger. ${ }^{420}$ Fest steht, dass die Registrierungspflicht für Sesselträger in der Folgezeit wieder zwingend wurde. So wurde am 7. April i6II verordnet, dass

keine Person an unserem Hof als Mietsesselträger arbeiten dürfe, ohne im Besitz einer entsprechenden Lizenz zu sein, ohne festgelegten Preistarif und ohne Registrierung bei der vom Kastilischen Rat bestimmten Behörde. Dies gilt auch für alle anderen Diener, die Tragsessel befördern. Auch sie sollen sich bei den entsprechenden Justizstellen der Städte, Dörfer und Ortschaften eintragen lassen. ${ }^{421}$

Im Mai I6I3 wurde eine Verordnung publiziert, die neuerlich eine Registrierung sämtlicher Sesselträger durch die Alcaldes binnen drei Tagen forderte. Gleichzeitig wurde abermals Personen ohne entsprechende Lizenz die Ausübung dieses Gewerbes untersagt. Zuwiderhandelnden wurden der öffentliche Ehrverlust sowie vier Jahre Galeerendienst angedroht. ${ }^{422}$ Im Jahr I629 unternahm man einen weiteren Versuch, die Sesselträger einer schärferen Kontrolle zu unterwerfen, indem sie neuerlich dazu verpflichtet wurden, an der Plaza de Herradores zu arbeiten und ihre Tragriemen sichtbar über der Schulter zu tragen. In einer Verordnung vom I5. Juni desselben Jahres wurden die Sesselträger angehalten, sich in der ältesten Kammerkanzlei eintragen zu lassen, andernfalls drohe ihnen eine zweijährige Verbannungsstrafe sowie die Zahlung von 20 Dukaten für Anwaltskosten und

\footnotetext{
420 AVM, Secretaría, 2-245-I4.

$42 \mathrm{I}$, „.... ninguna persona pueda ser mozo de sillas alquilado en esta nuestra Corte, sin tener licencia para ello, y habiéndole tasado lo que hubiere de llevar, habiéndose de registrar ante quien nombrará el consejo, lo qual se entienda con los que tiran sillas siendo criados; y en las ciudades, villas y lugares se registren ante las Justicias de ellas". Novísima Recopilación (Madrid 1775 und I805), Libro VI, Título XIV, ley VII.

422 AHN, Consejos, Libro I204, fol. 3r.
} 
Aufwendungen für notleidende Gefangene. ${ }^{423}$ Zweifellos waren all diese Maßnahmen Ausdruck der Bemühungen, Kontrolle über Sesselträger zu erlangen, den Zugang zu diesem Luxusgut zu reglementieren und so manchem auch den Zugang dazu zu ermöglichen.

Parallel zu den gesetzlichen Mitteln, die ergriffen wurden, um den Zugang bestimmter Gesellschaftsgruppen zu Tragsesseln sowie die Sesselträger selbst zu kontrollieren, und gleichzeitig mit dem bereits erörterten „Institutionalisierungsprozess“, der verstärkten Integration von Tragsesseln in das königliche Hofzeremoniell und dem auf dem Sektor der Luxusvehikel ausgetragenen sozialen Wettbewerb erschien auch eine Reihe von Publikationen aus der Feder von Moralschriftstellern und anderen Autoren. Ihr Anliegen war es, jene Probleme anzuprangern beziehungsweise zu beseitigen, die durch die um sich greifende Verarmung von am Hof lebenden Personen hervorgerufen worden waren. Da die Maßnahmen zur Kontrolle der Sesselträger und Kutscher offenbar nicht die erwünschten Erfolge gezeitigt hatten, unter anderem, weil in jenen Jahren der soziale Druck, sich mit Kutschen und Tragsesseln auszustatten, enorm war, setzten diese Autoren Sesselträger und Kutscher auf die Liste jener Berufe, die sie abgeschafft wissen wollten. Es scheint plausibel, dass sich die Zahl der Tragsesselbenutzer analog zu früheren Entwicklungen im Bereich der Kutschen im Zuge des „Institutionalisierungsprozesses“ erhöht hatte und infolgedessen auch die Zahl jener Personen, die ihren Lebensunterhalt als Mietsesselträger verdienen wollten, gewachsen war. Vor diesem Hintergrund ist ein Schreiben der Junta de Reformación an den König vom 23. Mai I62I zu sehen, in dem die Übervölkerung am Hof beklagt und gleichzeitig die Notwendigkeit betont wurde, den Adel dazu zu bewegen, Madrid zu verlassen, um in ärmere, dünn besiedelte Gebiete zu ziehen:

[...] all die Herren scharen Diener, Angehörige, Gehilfen und andere Handwerker um sich, die ihre Häuser verlassen haben und hierher an den Hof gekommen sind, weil sie zu wenig zu arbeiten hatten, um sich ihr tägliches Brot zu verdienen, und die deshalb nun als Pagen oder Knappen dienen. Zu dieser Entwicklung trägt in nicht unbeträchtlichem Maß der üble Brauch bei, dass jede Dame ihrem Tragsessel ein Geschwader an Dienern folgen lässt und sich der Hof auf diese Weise mit Müßiggängern füllt, die Grund zur Sorge und Beunruhigung sind. Andere wiederum umgeben sich mit Lakaien, Kutschern, Sessel- und Wasserträgern sowie anderen nutzlosen Leuten, Personen, die hier vollkommen überflüssig sind, in ihren Heimatorten aber gut gebraucht werden könnten, um die Felder zu bewirtschaften und zu kultivieren, was schließlich auch die Hauptaufgabe und das Rückgrat der Republik ist. ${ }^{424}$

423 AHN, Consejos, Libro I2I4, fol. 222r-v.

$424,[. .$.$] los señores con los criados y allegados y offçiales y otros menestrales que llevarán tras sí, los quales se$ han venido a esta Corte y dexado sus casas por no tener en qué trabajar ni ganar de comer en ella, dando 
Auch der weithin bekannte Pedro Fernández de Navarrete schrieb über Gewerbesparten, die seiner Ansicht nach zur Entvölkerung der Landstriche beigetragen hätten. Er meinte, dass all jene, die keine Anstellung als Pagen oder Knappen fänden, unter anderem als Lakaien, Kutscher und Sesselträger dienen würden. Verantwortlich dafür sei zu einem erheblichen Teil

die schädliche Gewohnheit, die sich seit einigen Jahren eingeschlichen hat, dass sich nämlich jede Dame in ihrem Tragsessel von einer ganzen Eskadron unerfahrener Infanteristen begleiten lässt, die nicht nur kaum angegraut sind, sondern sogar wallenderes Haar als die Knappen zu Zeiten unserer Großmütter tragen, was, abgesehen vom Übel, dass jene, die solche Dienste ausführen, Kriegsdienste leisten oder anderen Beschäftigungen nachgehen könnten, auch in vielerlei anderer Hinsicht von großem Schaden ist. ${ }^{425}$

Auch in den Cortes vernahm man ähnliche Beschwerden, ${ }^{426}$ die zweifellos damit zusammenhingen, dass das königliche Zeremoniell rund um die Tragsessel - insbesondere ab

unos en pages y escuderos, a que no convida poco el pernicioso uso de traer cada señora un escuadrón de infantería junto a su silla, llenándose la Corte de gente holgaçana, ques la que la inquieta y perturba, y otros en lacayos, cocheros, moços de sillas y aguadores, y otros oficios ynútiles, gente que haze mucha sobra aqui y mucha falta en sus naturales, donde pudieran labrar y cultivar la tierra, ques el offçio principal en que consiste el nervio de la República“. Ángel González Palencia, La Junta de Reformación. Documentos procedentes del Archivo Histórico Nacional y del General de Simancas transcritos por Ángel González Palencia publicados por la Academia de Estudios Histórico-Sociales de Valladolid (Colección de documentos inéditos para la historia de España y de sus Indias 5, Valladolid I932), S. 8I.

425 „[... el pernicioso uso, que de pocos años a esta parte se ha introducido, de traer cada señora junto a su silla un escuadrón de infantería bisoña, con menos canas y más guedejas de las que solían traer los escuderos en tiempo de nuestras abuelas, en que sin el inconveniente de ocuparse en este ministerio los que pudieran y debieran servir en la guerra, y en otras ocupaciones, hay otros infinitos daños". Fernández de Navarrete klagte auch über die durch die in Überfülle vorhandene Dienerschaft am Hof (zu der auch die Sesselträger zählten) hervorgerufene verheerende Übervölkerung des Machtzentrums: „Der Schaden, der durch die Aufgabe der Feldarbeit ensteht, wurde bereits erwähnt; ich füge nur noch hinzu, zu welch hässlichem, scheußlichem und glanzlosem Ort diese Leute den Hof machen" („[... el daño que se sigue de que éstos desamparen el trabajo del campo, queda ponderado; y sólo añado, cuán fea, asquerosa y deslustrada está la Corte con ellos"). Pedro Fernández de Navarrete, Conservación de Monarquías, I626, hg. von Michael D. Gordon (Madrid 1982), S. I08 und 218.

426 Der Procurador Francisco Maldonado aus Granada beschuldigte im Juli 1626 die „cortados“ genannten Sklaven dafür, dass sie zwar „Weizen, Wein und Tragsessel befördern, Tragstangen schultern und Kleinkram verkaufen, dies alles aber keine rechte Arbeit ist und eine geringe Auslastung bedeutet.“ („[...] pasan el trigo, vino, sillas de manos, traen la palanca y venden muchas menudencias, que todo es de poco trabajo y mucho aprovechamiento".) Aus diesem Grund herrsche in der Landwirtschaft und bei der Viehzucht ein bemerkenswerter Arbeitskräftemangel. Actas de las Cortes de Castilla 186I-2006 (wie Anm. 76), Bd. 35, S. 222 f. 
I62I - zunehmend komplexer geworden war. Wie bereits erwähnt, hatte dies in den vorhergegangenen Jahren dazu geführt, dass Hofdamen nicht nur durch die Ausstattung ihrer Tragsessel, sondern vor allem auch durch die Zahl ihrer Begleiter glänzen und sich voneinander abheben wollten, wie dies auch Lisón y Biedma im Jahr I630 kritisierte. Er schilderte, wie er sich im Traum an den Conde-Duque de Olivares wandte, um ihm Strategien und Ideen für einen Ausweg aus dem Niedergang Spaniens zu unterbreiten. Unter anderem schlug er ihm vor, dass für die Begleitung von Tragsesseln ältere Personen herangezogen werden sollten, um keine jüngeren Arbeitskräfte zu vergeuden:

[...] noch vor nicht allzu langer Zeit wurde es als würdevoll erachtet, zehn oder zwölf alte Männer vor dem Tragsessel vorangehen zu lassen, wobei der Älteste von ihnen der beförderten Person den Arm darbot. Auf diese Weise könnten die kräftigen jungen Männer, die heute als Begleiter fungieren, andere, der Öffentlichkeit nützlichere Tätigkeiten verrichten, bis sie schließlich in einer Verfassung sind, in der sie sich Begleitdiensten widmen könnten, denn vor Erreichen der Altersschwäche sind sie von Geburt an verpflichtet, dem König und der Republik zu dienen. ${ }^{427}$

$427,[. .$.$] que no es muy añeja la memoria de cuando era aumento de la gravedad, el llevar diez o doce hom-$ bres ancianos delante de la silla y ser el bracero el más antiguo dellos, con que la lozana juventud de los que hoy acompañan se daría a otras ocupaciones útiles al público bien, hasta llegar a estado que pudiesen ocuparse de esta, para que en toda edad, antes de llegar a la decrepitud, sirviesen al rey y a la república, a quien nacieron obligados". Lisón sprach sich auch dafür aus, Personen, die sich Tragsessel aufgrund ihrer sozialen Stellung nicht leisten konnten, den Zugang dazu zu verwehren. Er forderte außerdem, dass für Ehefrauen von Handwerkern die Zahl der Begleiter gekürzt werden sollte, damit die Standesunterschiede sichtbar blieben. Auch empfahl er, dass nur ältere Personen als Begleiter eingesetzt werden sollten, um so einen Verlust junger Arbeitskräfte zu vermeiden: „[...] und gleichzeitig zu verordnen, dass keine dieser Frauen mit einem Knappen ausgehen darf, denn abgesehen von den vielen Besoldungen und Taglöhnen, die dafür aufgewendet werden, gebührt es sich auch, dass ein Unterschied zwischen ihnen und jenen, die vornehm sind, besteht; und dass tageweise gemietete oder für ein Jahr angestellte Knappen bereits ergraut sein sollten, denn es ist eine Schande, so viele junge Männer, die arbeiten könnten, Schlampen und Huren den Arm reichen zu sehen." (,[...] y juntamente mandar que ninguna destas mujeres pueda salir con escudero, porque, demás de los muchos salarios y jornales diarios que en esto se gasta, conviene que también haya diferencia entre las que son principales y ellas; y que los escuderos que se alquilan por días o asalarian por año, hayan de ser, por lo menos, que ya pinten canas; porque es cosa vergonzosa el ver tan gran numero de hombres mozos, que podrian trabajar, ocupados en ser braceros hasta de tusonas y cantoneras".) Mateo de Lisón y Biedma, El Tapaboca que azotan. Respuesta del bachiller ignorante, al Chitón de las taravillas, que hizieron los Licenciados Todo se sabe, y Todo lo sabe, I630. In: Luis Astrana Marín, La vida turbulenta de Quevedo (Madrid 1945), S. 583-620, hier S. 603 f. 
Diese und andere Schmähschriften ${ }^{428}$ nahmen wohl Einfluss auf die von Philipp IV. am 2I. Februar I634 erlassene Verordnung, in der bestimmt wurde, dass keine Frau von mehr als vier Knappen begleitet werden dürfe und dass hinsichtlich der Lakaien die bereits erlassenen Vorschriften einzuhalten seien:

Wir verfügen, dass keine Frau, unabhängig von ihrem Stand, Rang oder ihrer Eigenschaft, egal ob es sich um eine Frau mit Adelstitel handelt oder ob sie zu den Granden zählt, sich von mehr als vier Knappen oder Gentileshombres begleiten lassen darf, weder in der Funktion eines Dieners, Verwandten oder Angehörigen noch in irgendeiner anderen Eigenschaft oder unter anderem Vorwand, und dass weder die oben Erwähnten noch irgendeine andere von ihnen zu Fuß, zu Pferd oder auf irgendeine andere Weise von mehr als der erwähnten Zahl an Gentileshombres oder Knappen begleitet werde, unabhängig davon, in welcher Form auch immer die oben Erwähnten ausgehen, ob sie das Haus nun in Tragsesseln oder Kutschen verlassen.

Überzählige Begleitpersonen hatten mit einer zweijährigen Haftstrafe zu rechnen. Jene Personen aber, die sich vorschriftswidrig begleiten ließen, mussten für den Unterhalt ihrer inhaftierten Begleiter sorgen und erhielten zusätzlich eine Strafe, die sich beim ersten Verstoß auf 60.000 Maravedis und beim zweiten auf 100.000 Maravedis belief und bei der dritten Übertretung schließlich eine einjährige Verbannung bedeutete. ${ }^{429}$ Ließ sich der hohe Aufwand, der sich bei den Begleitungen eingebürgert hatte, auf diese Weise eindämmen? Bereits erwähnte Augenzeugenberichte der I640er Jahre legen das Gegenteil nahe. Mehrere Darstellungen veranschaulichen deutlich, dass die Zahl der am Hof tätigen

428 Ein anderer Autor, der der Frage nachging, welchen Gefahren sich Sesselträger und Sänftenknechte aussetzten, merkte an: „Sollen andere es berurteilen; ich begnüge mich damit, darauf hinzuweisen, was Tertullian über Christenfrauen sagte, die mit Ungläubigen sprachen, nur weil diese ihnen versicherten, sie in Tragsesseln tragen und von zahlreichen Knappen von reckenhafter Gestalt, mit geschmückten Locken und Haarschöpfen, begleiten zu lassen, und dass der Stifter solcher Ehen der Teufel selbst sei“. („Ponderenlo otros; que yo sólo me contento con referir lo que dixo Tertuliano, hablando de las mugeres Christianas, que hablaban con infieles, sólo porque las prometían que las traerían en sillas, $i$ acompañadas con número de escuderos de gallardos talles, i de adornadas Guedejas, i copetes; i que el demonio era el casamentero de semejantes bodas".) Gutierre MARquÉs de CAREAGA, Invectiva en discursos apologéticos contra el abuso público de las guedejas (Madrid I637), BNE 2/58578, fol. 44r-v.

429, „... [. Mandamos que ninguna mujer de cualquier estado, calidad y condición que sea, aunque sea $o$ haya sido mujer de título, o grande, pueda acompañarse con más de 4 escuderos o gentileshombres, ni con título de criados, ni de parientes o allegados, ni con otro título ni pretexto alguno, ni acompañen a las susodichas, ni a ninguna dellas a pie, ni a caballo, en cualquiera manera que las susodichas salgan, o anden fuera de sus casas en silla o coche, o en otra forma, más gentileshombres o escuderos que hasta el dicho número". Novísima Recopilación (Madrid I775 und I805), Libro VI, Título XVI, ley 6. 
Sesselträger keineswegs abnahm. Viele Autoren klagten zudem über die ausländische Herkunft der Sesselträger. Um die Mitte des I7. Jahrhunderts häuften sich die Beschwerden über ihre große Zahl. Dies betraf sowohl Sesselträger mit einer Festanstellung in einem Adelshaus als auch solche, die auf Mietbasis ihr Geld verdienten. Pérez del Barrio schätzte, dass jedes Jahr „mehr als zwanzigtausend Ausländer aus aller Herren Länder“ in Spanien eintrafen, unter denen sich auch zahlreiche „Lakaien, Kutscher und Sesselträger“ befänden. ${ }^{430}$ Martínez de Mata behauptete wiederum, dass die mehr als I20.00o Franzosen, die nach Spanien gekommen seien, verschiedene Dienersparten - darunter auch das Gewerbe der Sesselträger - usurpiert und die Spanier daraus verdrängt hätten. ${ }^{431}$ Mexía de las Higueras meinte, bei diesen Personen handle es sich um Vagabunden, die man zur Arbeit verpflichten sollte, um auf diese Weise Ordnung im höfischen Raum zu schaffen:

Von einer anderen Sorte von Leuten gibt es zu viele am Hof, nämlich von verheirateten Lakaien, Kutschern und Sesselträgern, deren Frauen in den Straßen herumstreunen und neben der Wirtshaustüre stehen [...] und derart zur Völlerei und Trunksucht animieren. ${ }^{432}$

In der zweiten Hälfe des I7. Jahrhunderts, als der Reformeifer seinen Höhepunkt erreichte, wurde mittels einer I69I erlassenen Verordnung versucht, die Zahl der Sesselträger auf höchstens vier zu beschränken, ein Vorhaben, mit dem sich die Verordnungen von I674 und I684 noch nicht befasst hatten. Den überzähligen Sesselträgern wurden der Verlust ihrer Livree sowie eine vierjährige Verbannung nach Afrika beim ersten Verstoß und sechs Jahre Galeerendienst beim zweiten Zuwiderhandeln angedroht. ${ }^{433}$ Es handelt sich hierbei um den ersten Versuch seit längerer Zeit, den bei öffentlichen Auftritten von Vertretern der Oberschicht zu beobachtenden maßlosen Luxus zurückzudrängen. Diese Bemühungen standen in Einklang mit Maßnahmen, die im selben Jahr hinsichtlich der Ausstattung von Kutschen getroffen

430 „[...] más de veinte mil extranjeros, de todas naciones [...] lacayos, cocheros y mozos de silla“. Gabriel Pérez del BARrio Angulo, Secretario y consegero de señores y ministros: cargos, materias, cuydados, obligaciones y curioso agricultor de quanto el Gouierno y la Pluma piden para cumplir con ellas (Madrid I645), BNE, R II.4I4, S. I87.

43I Francisco Martínez de Mata, Memorial en razón de la despoblación, i65o. In: Gonzalo Anes, Memoriales y discursos de Francisco Martínez de Mata (Madrid 197I), S. 287-330, hier S. 309.

„[...] Otro género de gentes biben en la corte en gran abundancia que sobran muchos lacayos, cocheros, moços de silla casados, que las mugeres de estos bagando por las calles, y a las puertas de las tabernas [...] dan pasto a la gula y a los bebedores". Vgl. Carmelo ViñAS y MeY, El problema de la tierra en la España de los siglos XVI-XVII (Madrid I94I), S. I86, 229 f.

433 Pragmática que su magestad manda publicar, para que se guarde y execute y observe la que se publicó el año de 1684 sobre la reformación en el excesso de Trages, Coches, y otras cosas en esta contenidas, I69I, BNE, R 23.879 (26), fol. 4-6. 


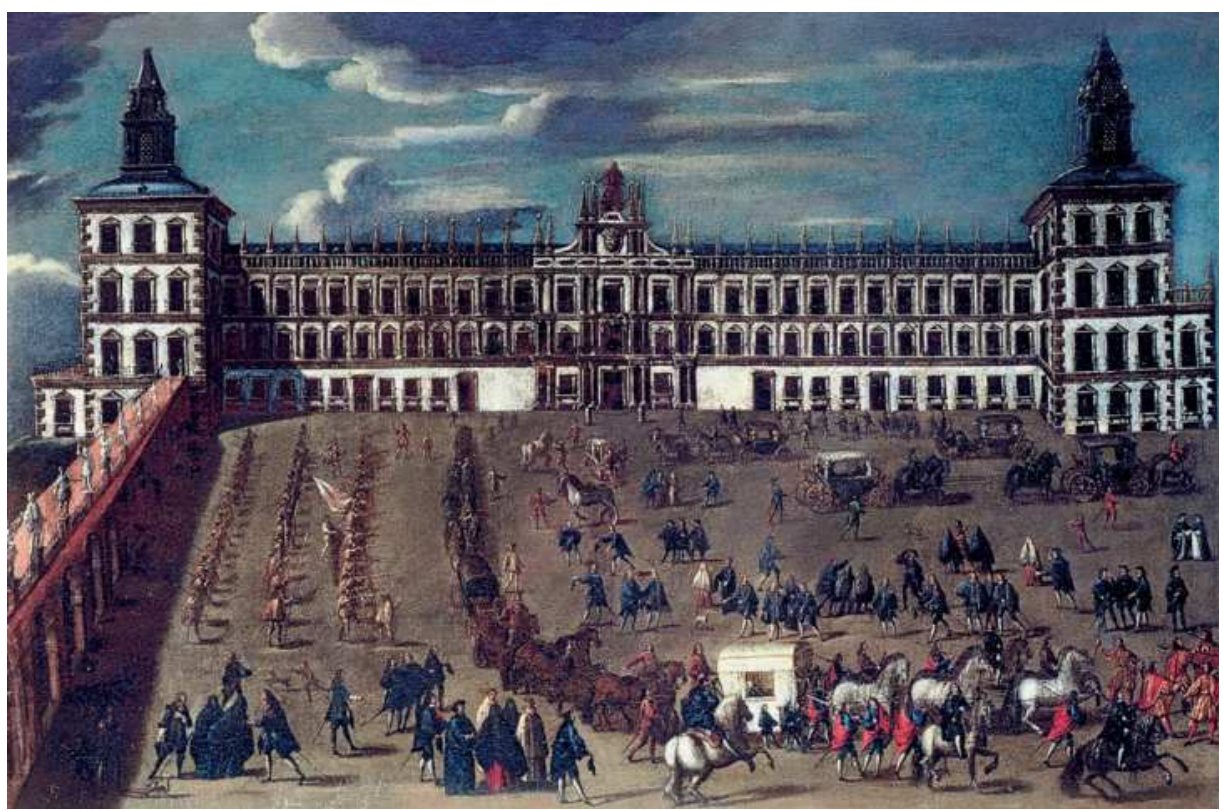

Abb. 10: Zu den äußerst seltenen Madrider Stadtansichten des 16. und 17. Jahrhunderts, auf denen ein Tragsessel dargestellt ist, zählt dieses Gemälde eines anonymen Madrider Meisters: Ausfahrt König Karls II. vom Madrider Alcázar, 1677. Sammlung Abelló (Foto: Joaquín Cortes). @ Colección Abelló, Madrid

wurden. Die rechtlichen Schritte wurden jedoch von der Realität eingeholt: Tragsessel hatten sich zu fundamentalen Bestandteilen des Hofes entwickelt. Es war unmöglich geworden, sie abzuschaffen, und es schien ein hoffnungsloses Unterfangen, ihre Ausstattung und die Anzahl ihrer Begleiter zu reglementieren (Abb. Io). Dies zeigt sich allein schon in der Tatsache, dass auch im Anschluss an die Verordnung von I69I noch weitere, vergleichbare rechtliche Schritte als notwendig erachtet wurden, bis hinein in die Regierungszeit der Bourbonen, von der noch eine entsprechende Verordnung aus dem Jahr 1723 bekannt ist. ${ }^{434}$ Die scheinbaren Widersprüche in diesem Reformprozess demonstrieren, dass die Machthaber gesetzliche Maßnahmen flexibel auslegen mussten, um auch weiterhin einen gewissen Grad an sozialer Mobilität zu gewährleisten. Davon blieb jedoch der Endzweck der Reformen unberührt, nämlich die Beschränkung von Tragsesseln und anderen repräsentativen Vehikeln auf einen kleinen Zirkel der höfischen Elite, ein Bemühen, das langfristig auch von Erfolg gekrönt war.

Übersetzung aus dem Spanischen: AnAtoli Adamidou

434 Pragmática sanción, que su magestad manda observar, sobre Trages, y otras cosas, I723, RAE, RM VAR-467, im Besonderen $\$$ II. 


\section{Attilio Antonelli -Stefano Moscatelli - Ilaria Telesca* \\ Portantine und sillas de manos im Hofzeremoniell Neapels}

Lleuaua el cauallerizo mayor un cauallo cubierto con dos lacayos, que le lleuauan de diestro, tras de la carroza o silla de respetto, por lo que pudiesse succeder y por la grandeza que conuiene que lleuen los virreyes.

Díez DE Aux

\section{Quellen}

Schon seit einigen Jahren arbeitet das italienische Kulturamt Soprintendenza per i beni architettonici, paesaggistici, storici, artistici ed etnoantropologici di Napoli e provincia an der Herausgabe mehrerer bislang unveröffentlichter Handschriften, die sukzessive in der Reihe I cerimoniali della corte di Napoli (Die Zeremonialschriften des Neapolitanischen Hofes) erscheinen. Die Manuskripte, die im Staatsarchiv von Neapel aufbewahrt sind und dort die Signaturen I483 bis I493 tragen, ${ }^{\text {I }}$ decken einen Zeitraum von insgesamt drei Jahrhunderten ab, der von der Zeit des spanischen Vizekönigreichs bis Anfang des I9. Jahrhunderts reicht, als Neapel von den Bourbonen regiert wurde. Eine wertvolle Ergänzung zu diesen für die Geschichte der Stadt und des Königreichs Neapel neuen historischen Quellen sind die Schriften zweier Hofzeremoniäre, nämlich jene von Miguel Díez de Aux² für die Jahre

Attilio Antonelli, der als Kunsthistoriker bei der Soprintendenza per i beni architettonici di Napoli e provincia, Palazzo Reale di Napoli tätig ist, koordinierte die Arbeiten am vorliegenden Beitrag; Stefano Moscatelli, der an der Universität Neapel Federico II das Studium der Neuphilologie absolvierte, stellte hauptsächlich die Schriftquellen zusammen; Ilaria Telesca, die an derselben Universität ein Diplom in Archäologie erwarb, kümmerte sich vorrangig um die Sammlung und Auswertung der Bildquellen.

Für genauere Angaben zur Chronologie der Handschriften siehe einen entsprechenden Überblick in Attilio Antonelli (Hg.), Cerimoniale del viceregno spagnolo e austriaco di Napoli, I650-1717 (I ceremoniali della corte di Napoli I, Soveria Mannelli 20I2), S. 19. Die Zeremonialschriften mit den Signaturen 1483 bis I489 (ihr genauer Standort lautet ASN, Maggiordomia maggiore, IV inventario, cerimoniali) sind im zitierten Werk zur Gänze oder zumindest teilweise ediert.

2 Miguel DíEz De Aux, Libro en que se trata de todas las ceremonias acostvmbradas hazerse en el Pa- 
von I558 bis I622 und jene von José Renao3, der die Zeit zwischen I535 und I637 behandelte.

Eine Untersuchung des Zeremoniells, das einerseits Kontrollfunktionen erfüllte, andererseits aber auch Regeln formulierte, eröffnet der Forschung über den vizeköniglichen Hof Neapels, der gleichsam ein Projektionsfeld für die Macht des abwesenden Monarchen darstellte, gänzlich neue Perspektiven und ermöglicht die Analyse historischer Ereignisse aus der Perspektive eines unkonventionellen, neue wissenschaftliche Erkenntnisse versprechenden Standpunkts. Die in den Zeremonialschriften erörterten Themen sind in mehrfacher Hinsicht von nicht zu unterschätzender Bedeutung. Sie werfen ein Licht auf längst außer Gebrauch gekommene Festlichkeiten und liefern zudem politische Kurzbiographien der einzelnen Vizekönige samt einer Auswahl bedeutsamer während ihrer Amtszeit realisierter Vorhaben und vorgefallener Ereignisse. Die Schriften schildern in chronologischer Ordnung die im Jahreskreis wiederkehrenden Zeremonien und Riten samt der dabei vorgeschriebenen Etikette. Für die Machthaber stellte die regelkonforme Teilnahme an Prozessionen sowie an anderen weltlichen oder religiösen Zeremonien eine willkommene Gelegenheit dar, ein konsensuales Vertrauensverhältnis zur Bevölkerung beziehungsweise zur weltlichen und geistlichen Oberschicht zu begründen und zu festigen. Öffentliche Zeremonien boten dabei den Rahmen, in dem in Momenten kollektiver Selbstbestätigung die Begegnung zwischen einer Kultur der Macht und den unteren sozialen Schichten stattfinden konnte.

In unseren Handschriften, in deren Mittelpunkt die Sitten und Bräuche des Hofes von Neapel stehen, wird häufig auch die Verwendung von Tragsesseln erwähnt. ${ }^{4}$ Bei diesen Ve-

latio Real del Reyno de Nápoles, y del govierno, edificios y memorias hechas por los virreyes, desde el gran capitán a esta parte. Dirigido all'illustrísimo y eccellentísimo señor don Antonio Álvarez de Toledo, dvche de Alva, puesto en luz y en su punto por Miguel Díez de Aux, contino y entretenido por Su Magestad el año MDCXXII, Sevilla, Biblioteca Capitular y Colombina, mss. 59-2-9. Eine Edition dieser Handschrift, die im vorliegenden Beitrag der Einfachheit halber als „Díez de Aux“ bezeichnet wird, erscheint in der Reihe I cerimoniali della corte di Napoli.

3 José Renao, Libro donde se trata de los virreyes lugartenientes del Reino de Nápoles y de las cosas tocantes a su grandeza, como mas largamente se verá en la hoja siguiente. Compilado per Joseph Renao, portero de cámara de S.E. que ha ejercitado y al presente exercita el officio de maestro de cerimonias de los señores virreyes duque de Alba y conde de Monterrey. Año de I534 [I634], BNE, ms. 2979. Dieser Text wird hier hinkünftig einfach als „Renao“ bezeichnet. Er liegt auch gedruckt vor als: José Renao, Libro donde se trata de los vireyes [...], hg. von Eustaquio Fernández de Navarrete (Colección de documentos inéditos para la historia de Espańa 23, Madrid I853 und Madrid ${ }^{2}$ I966); José RenaO, Etiquetas de la Corte de Nápoles, hg. von A. PAZ y Meliá. In: Revue Hispanique 27 (I9I2), S. I-284.

4 Besonders häufig finden Tragsessel bei Díez de Aux und Renao Erwähnung, die beide großen Wert auf die Wiedergabe der am Hof geltenden Regeln legten. Die Zeremonialschrift I483 fokussiert hingegen etwas stärker auf die Beschreibung von Ereignissen. 
hikeln handelte es sich nicht nur um äußerst nützliche Transportmittel, sondern auch um Machtsymbole, die bestehende soziale Strukturen besonders deutlich zu Tage treten ließen. Nicht zuletzt deshalb wird ihre Rolle in den Quellen des hier behandelten Untersuchungszeitraums, der mit Ende des I6. Jahrhunderts beginnt und sich über das gesamte I7. Jahrhundert erstreckt, oftmals eigens hervorgehoben. Es erscheint deshalb geboten, eine Zusammenstellung der Quellen, in denen der Terminus Tragsessel (portantina) und seine Varianten (silla, silleta, silla de mano oder - wenn auch nur am Rande - lettiga) vorkommen, zu liefern und anhand der darin beschriebenen Einsatzgebiete eine differenzierte Typologie herzuleiten. ${ }^{5}$ Die Auswertung der schriftlichen Zeugnisse soll zusätzlich von einer Untersuchung zeitgenössischer Bildquellen begleitet werden. Bevor wir uns aber der Anthologie zuwenden, wollen wir zunächst der Frage auf den Grund gehen, was Tragsessel überhaupt sind, was sie von anderen Transportmitteln unterscheidet und wofür sie im Lauf der Geschichte verwendet wurden.

2

\section{Terminologie}

Eine portantina ist im allgemeinen Wortsinn ${ }^{6}$ ein Sitzmöbel, das in einen schützenden Kasten eingebettet ist. Der Kasten verfügt für gewöhnlich über eine kleine Tür und wird mittels seitlich fixierter Holme getragen. Luxuriöse Modelle wiesen zudem Vorhänge oder eine Verglasung sowie Verzierungen auf, deren Aussehen je nach Zeitgeschmack variierte. Bis Ende des 19. Jahrhunderts fanden derartige der Personenbeförderung dienende Transportmittel auf kurzen Strecken Verwendung. ${ }^{7}$ Als Anschauungsbeispiel möge hier eine typische portantina dienen, die in einer nach dem Marchese Mario d'Alessandro di Civitanova benannten Kutschensammlung ${ }^{8}$ aufbewahrt wird. Die Kollektion erfuhr erst kürzlich eine Neuaufstellung und ist nun im alten Marstallgebäude der Villa Pignatelli in Neapel öffentlich zugänglich (Abb. I).

In einigen bildlichen Zeugnissen von Ende des I6. Jahrhunderts bestehen Tragsessel aus einer mit Trageholmen versehenen hölzernen Plattform, auf der ein Sessel befestigt ist. Die

5 Die Darstellung folgt keiner strengen Chronologie, da innerhalb des Untersuchungszeitraums keine signifikanten Veränderungen in Hinblick auf den Gebrauch von Tragsesseln im Rahmen des Hofzeremoniells zu beobachten sind.

6 Darin stimmen die entsprechenden Einträge in den beiden Nachschlagewerken Salvatore BATTAGlia (Hg.), Grande dizionario della lingua italiana (I96I-2002) und N. Tommaseo/B. Bellini, Dizionario della lingua italiana (I86I-I874) überein.

7 Einen guten Überblick über die baulichen Eigenschaften von Tragsesseln bietet Farida SimONETTI/ Marzia Cataldi Gallo (Hg.), Farsi portare in carega. Portantine e livree per la nobiltà genovese (Ausstellungskatalog, Genova i995), S. 40-45.

8 Denise Maria Pagano (Hg.), Museo delle carrozze a Villa Pignatelli (Napoli 20I4). 


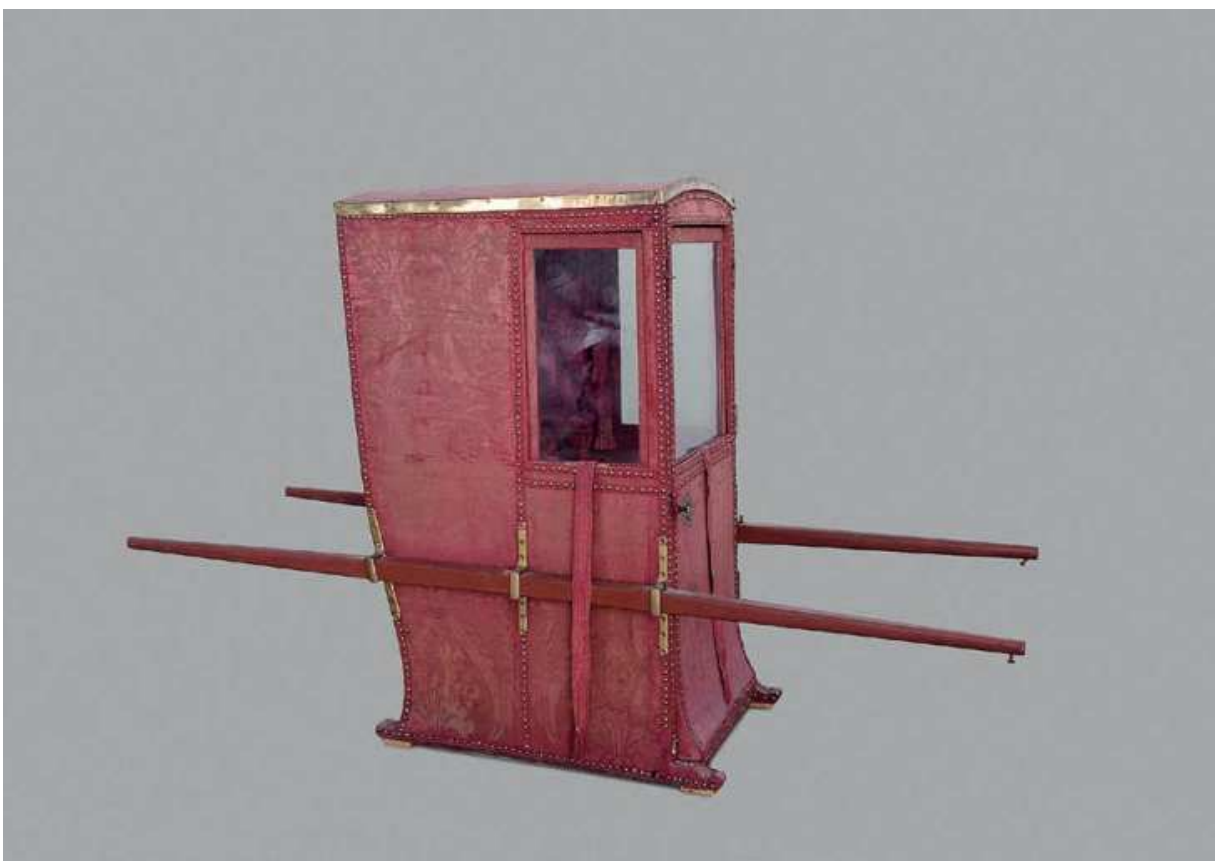

Abb.1:Tragsessel (portantina), Süditalien, Mitte des 18. Jahrhunderts. Napoli, Villa Pignatelli, Museo delle carrozze. Foto: Mario Milo. ๑ Archivio Arte’M, Napoli / Fototeca del Polo Museale della Campania

gesamte Konstruktion ist mit reichem, von Goldfransen bordiertem Samt bedeckt und verhängt und wird von Männern befördert, die mit Tragegurten ausgestattet sind. (Abb. 2-3)

Marchese Gioan Battista del Tufo (Neapel, ca. I548-ca. I600) schwelgte im Jahr I588 in Mailand in Erinnerungen an seine ferne Heimatstadt Neapel und gedachte nostalgisch der Leidenschaft seiner Landsleute für luxuriöse Transportmittel. Del Tufo widmete in seinen Reminiszenzen auch den Tragsesseln Neapels eine liebevolle, in Versform gefasste Beschreibung:

Onde allor, quando vuole, / se dal parto gentil gravar si sente, / uscir quel vivo sole / ch'afflitto e mesto già s'affanna e duole, / se li prepara allor la segia a posta, / per lei sola disposta, / o di feltro infodrata, / di tela inargentata, / o dentro o fuor di ricco drappo ornata; / così come del legno / non ve vedeste un segno, / se non che 'l suo lavoro / tutto è ben fatto a ricco argento o d'oro'

9 Gioan Battista Del Tufo, Ritratto o modello delle grandezze, delizie e maraviglie della nobilissima città di Napoli (I588), hg. von Olga Silvana CaSAle/Mariateresa Colotti (Roma 2007), Ragio- 


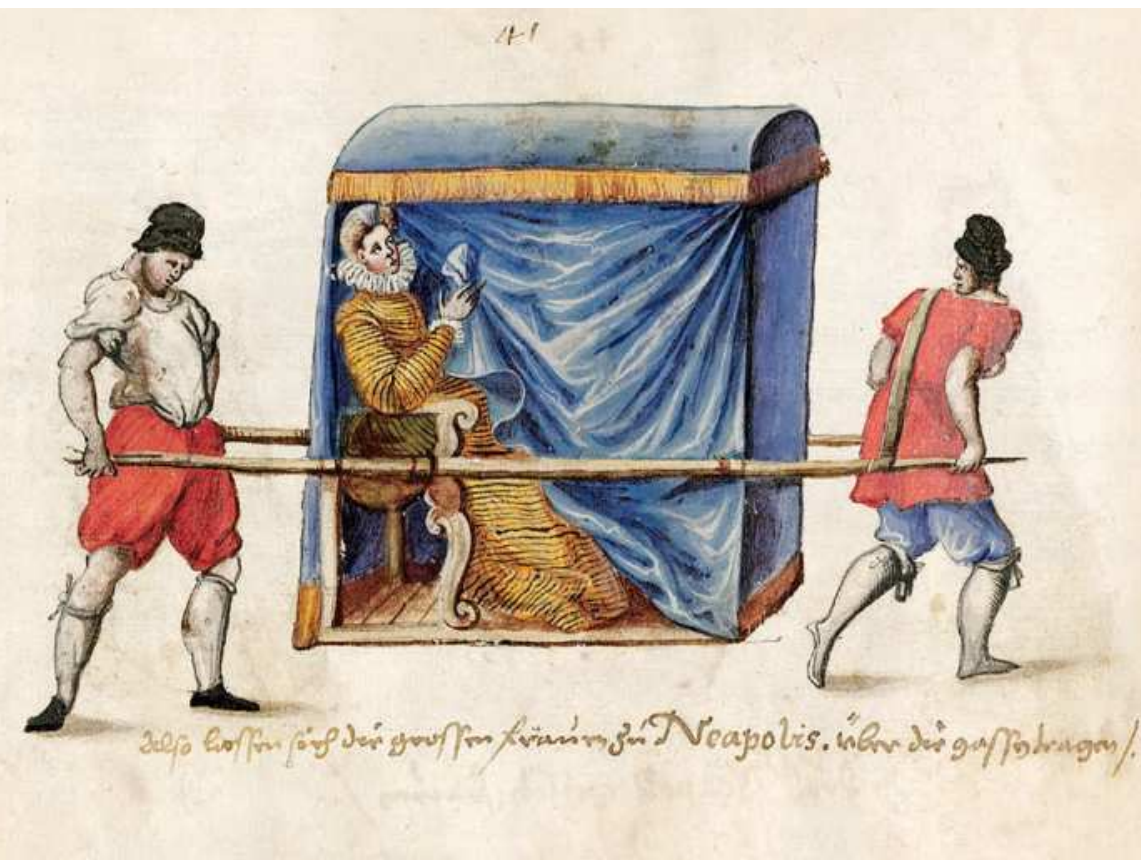

Abb. 2: Darstellung einer Neapolitanerin im Tragsessel mit der Bildunterschrift „Also lassen sich die grossen frauen zu Neapolis über die gassn tragen.", aus einem Codex mit Kostümen und Sittenbildern des 16. Jahrhunderts aus West- und Osteuropa, dem Orient, der Neuen Welt und Afrika, entstanden in Augsburg (?) im 4. Viertel des 16. Jahrhunderts. Bayerische Staatsbibliothek, Cod. icon. 361, fol. 39v. @ Bayerische Staatsbibliothek

Die Gestalt von Tragsesseln und ihre Rolle im Hofzeremoniell wurden mit großer Wahrscheinlichkeit von zwei Transportmitteln des antiken Rom beeinflusst: der lectica und der sedia gestatoria. Die lectica (von lectus, Bett) entstand als Trage für Götterstatuetten. Ihr Gebrauch dehnte sich schließlich auch auf Herren und Damen im Senatsrang aus, die darauf auf Matratzen und Polstern liegend kurze, innerstädtische Strecken zurücklegten. ${ }^{\text {Io }}$ Ursprünglich war die lectica unbedacht, allmählich wurde sie aber mit einem Bal-

namento Quarto, Vers I328-I340. In den Versen des Autors möchte die Dame trotz widriger Umstände nicht auf ihren gewohnten Ausgang verzichten und lässt sich deshalb in einem Tragsessel befördern, dessen reiche Ausstattung ausführlich geschildert wird: Er ist mit Filz oder Silbertuch bespannt, innen und außen mit Behängen versehen und derart dicht mit Silber- und Goldstoffen bedeckt, dass sich von der hölzernen Oberfläche der konstruktiven Teile nichts mehr erkennen lässt. Es war übrigens auch nicht unüblich, die Livree der beiden für den Tragedienst bestimmten Personen auf die Farben des Vehikels abzustimmen. Ebenda, Vers I34I-I350.

io Luigi Maria Majorca Mortillaro, Lettighe, portantine e personaggi del Settecento. Ricerche storico-artistiche (Palermo ${ }^{\mathrm{I}} \mathrm{1} 897$ ), S. Io. 


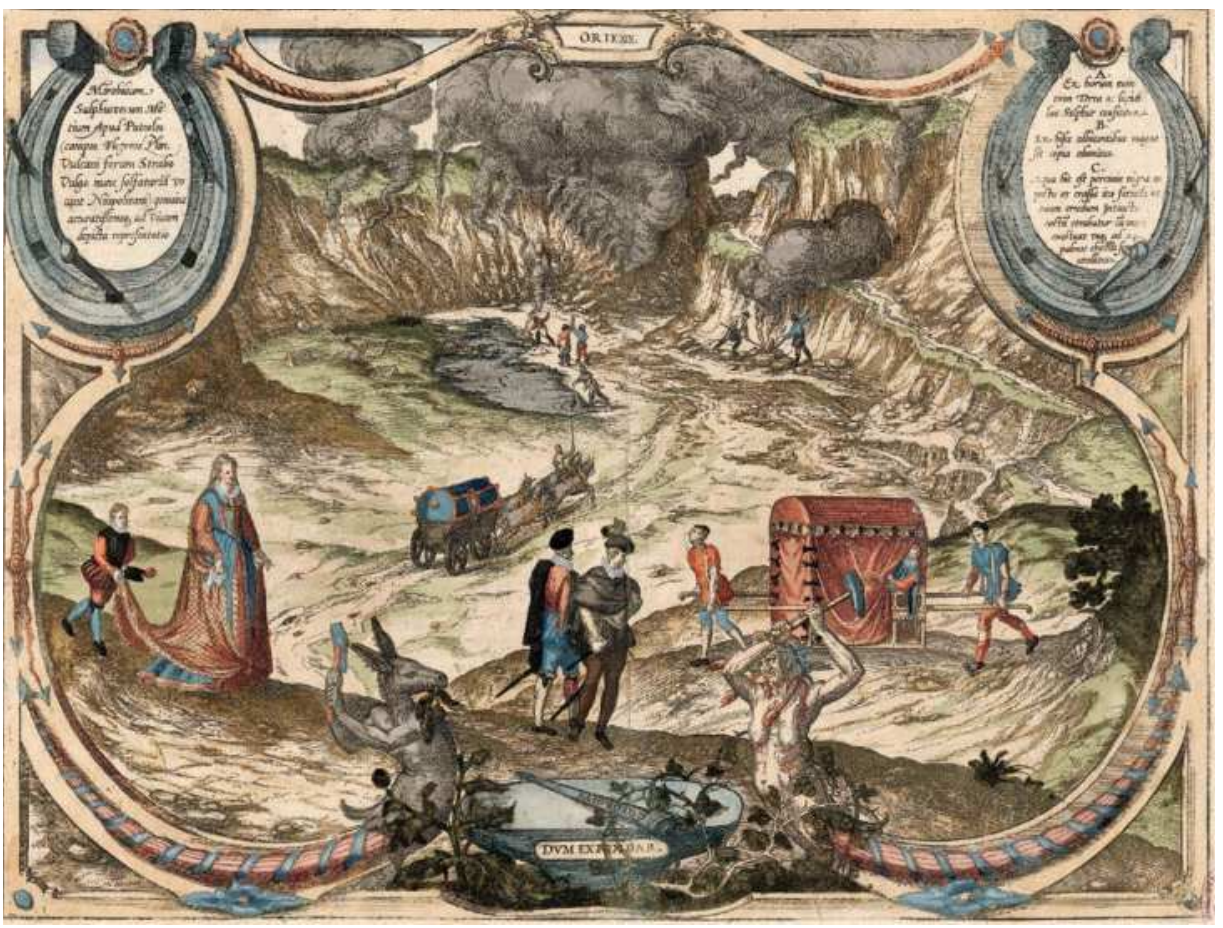

Abb. 3: Joris Hoefnagel, Mirabilium Sulphureorum [...]. Stich aus dem Band Georg Braun/Franz HoGenBERG, Civitates Orbis Terrarum, Urbium Praecipuarum Totius Mundi: Liber Tertius (Köln 1593). @ BNE

dachin und umlaufenden Vorhängen versehen, und zwar vorrangig, um die Privatsphäre der derart beförderten Damen zu schützen. An der lectica waren lange Holme befestigt, an denen vorne und hinten lecticarii anpackten, die zuweilen auch Schultergurte zu Hilfe nahmen. Die Anzahl der Träger variierte je nach sozialem Status der transportierten Damen und Herren und konnte bis zu acht Personen betragen. ${ }^{\text {II }}$

Im Laufe der Zeit wurden die lecticarii schließlich meist von Lasttieren wie Pferden, Eseln, Maultieren oder Ochsen abgelöst, die an die Vorder- und Hinterseite des Vehikels gespannt waren. ${ }^{12}$ Die lectica kam nun meist auf längeren Strecken zum Einsatz und wies auch sonst andere Eigenschaften als die portantina auf. Erstere bot der transportierten Per-

II Je höher die Zahl der Träger, desto größer war auch die Bedeutung der beförderten Person. Ein vergleichbarer Indikator war Jahrhunderte später die Zahl der Pferde, die einer Kutsche vorgespannt wurden.

I2 Luigi Maria Majorca Mortillaro, Lettighe, portantine e personaggi del Settecento. Ricerche storico-artistiche (Palermo ${ }^{3}$ I906), S. 22-25. 
son vergleichsweise mehr Platz und und größeren Komfort, ${ }^{13}$ und ihr Aufbau erinnert an die „Verbindung zweier gespiegelt angeordneter Tragsessel“. Dies erlaubte es den Insassen zwar nicht, sich darin völlig ausgestreckt hinzulegen, ermöglichte jedoch mehr als nur einer Person, darin Platz zu nehmen, und bot somit die Gelegenheit, unterwegs ein Gespräch zu führen. ${ }^{4}$

Die Sänfte (span. litera) findet in den Zeremonialschriften nur selten Erwähnung. Sie wurde beispielsweise von der Vizekönigin verwendet, allerdings nicht für Ortsveränderungen innerhalb des städtischen Raums, sondern auf längeren Reisen. Einen solchen Fall erwähnte etwa Díez in seiner Beschreibung der Obbedienzgesandtschaft des Conde de Lemos von Neapel an den päpstlichen Hof im März des Jahres I6oo. Die Vizekönigin legte damals die weite Strecke in einer litera zurück, die eigens für diesen Anlass hergestellt worden war. Ihr persönliches Vehikel unterschied sich von jenen der sie begleitenden Damen durch die Qualität der eingesetzten Materialien - es war mit karmesinrotem Samt bezogen und mit goldenen Borten versehen -, weiterhin durch eine entfernbare Bedachung sowie durch ein außen angebrachtes, mit Samt tapeziertes Trittbrett, das ein müheloses Auf- und Absteigen ermöglichte. ${ }^{\text {Is }}$

In Hinblick auf die Terminologie sind die Zeremonialtexte sowohl im Italienischen als auch im Spanischen oft mehrdeutig, da die Begriffe "portantina“, „silla“, „silla de manos“ (und zuweilen auch „lettiga“) darin häufig und ohne weitere Differenzierung dieselben Transportmittel bezeichneten. In manchen Fällen erlaubt nur der Kontext die Identifikation eines bestimmten Vehikeltypus. ${ }^{16}$ Der Begriff, der mit Abstand die größten Schwierigkeiten bereitet, ist „silla“: Er ist in allen uns zur Verfügung stehenden Zeremonialtexten omnipräsent und wird sowohl zur Bezeichnung eines gewöhnlichen Sessels als auch einer sedia a mano, einer portantina oder manchmal gar eines Pferdesattels verwendet. Der Aus-

i3 Majorca Mortillaro i897 (wie Anm. io), S. in f.

I4 Vgl. Simonetti/Cataldi Gallo i995 (wie Anm. 7), S. i3.

I5 „Mandóse hazer una littera aforrada en terciopelo carmessi toda guarnecida y bordada de oro y que el cielo de encima fuesse leuadizo con su tablilla guarnecida de lo mismo para que suniesse a dicha littera la virreyna. [...] Venía luego la littera de la virreyna con ella dentro, quitado el cielo de encima, para que pudiesse uer y ser uista, y a su lado yzquierdo, yua en un famosso y rico cauallo con un riquíssimo vestido de campaña el señor conde de Lemos lleuando delante de la littera doze lacayos descubiertos y en cuerpo y al lado yzquierdo del virrey yva el paje de lança con su sayo vaquero, banda y sombrero como queda dicho, lleuando arbolado el guionzillo, desuiado un cuerpo de cauallo de Su Excelencia“. Díez DE Aux I622 (wie Anm. 2), S. IOI-IO5.

I6 Glücklicherweise nimmt die Zeremonialschrift mit der Signatur I489 - eine jener Handschriften, die für den vorliegenden Beitrag nicht ausgewertet wurde - eine sprachliche Vermittlerrolle ein, da sie den gesamten Inhalt des Manuskripts I483 zusammenfasst und übersetzt und auf diese Weise die italienische Terminologie des I8. Jahrhunderts etwas erhellt, was uns wiederum dabei helfen kann, terminologische Fragen rund um Tragsessel zu klären. 


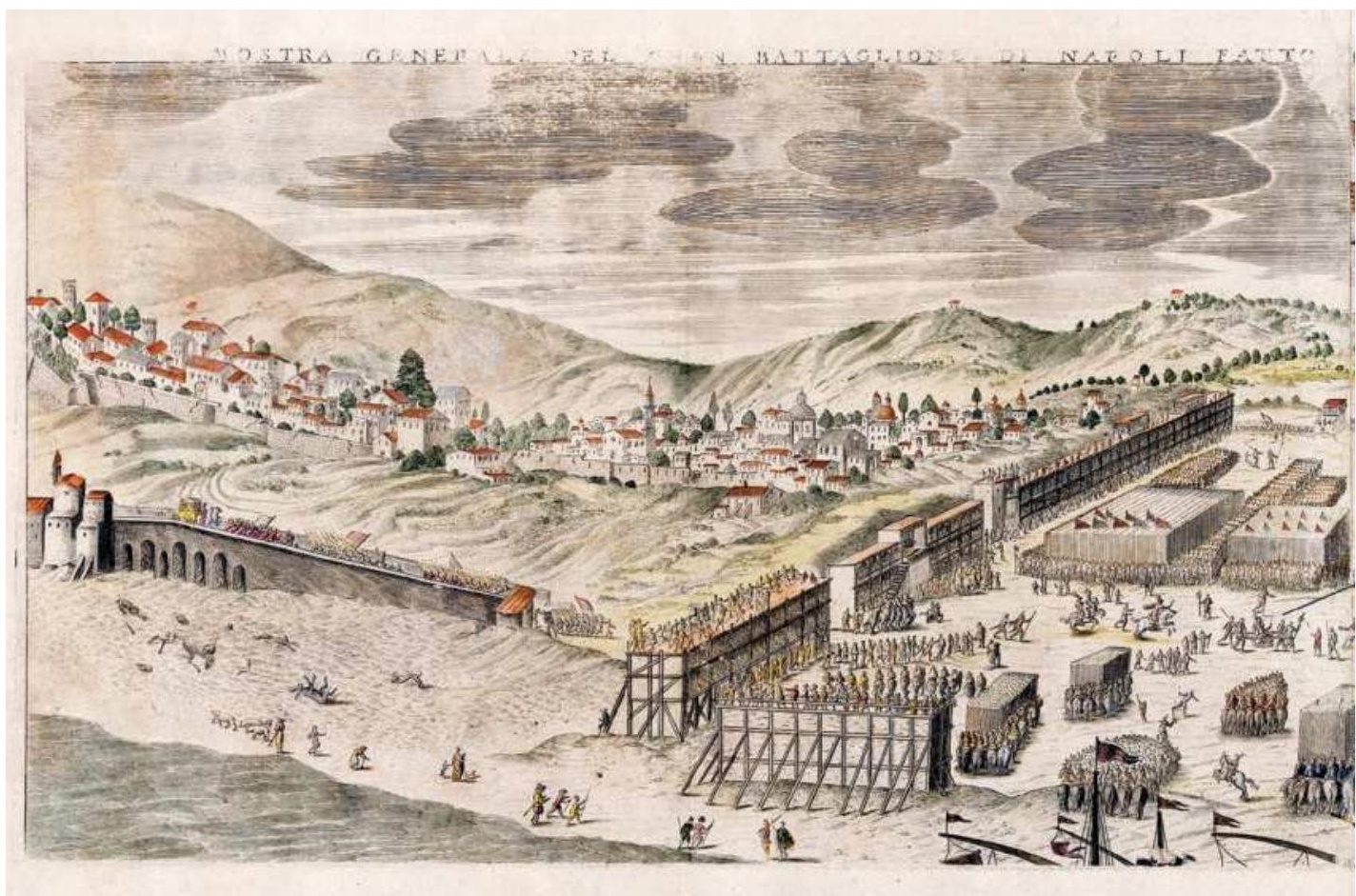

Abb. 4: Giulio Cesare Fontana/Alessandro Baratta, Mostra generale del Gran battaglione di Napoli fatto da l'Ecc.mo Sig.re don Antonio Alvarez de Toledo duca d'Alba, kolorierter Stich, ca. 1625. Museo e Certosa di San Martino (Neapel), collezione della Fondazione Alisio. Foto: A. D’Antonio, R. De Simone, L. Basagni, F. Speranza - Lab. fotogr. Sopr. Rechts oben ein vergrößertes Detail mit dem in einer silla getragenen Vizekönig, Duque de Alba. @ Fototeca del Polo Museale della Campania

druck „,illa de manos“ (zuweilen abgekürzt als „,silleta“, was wiederum einen Widerhall im italienischen Wort „seggetta“ findet) wurde hingegen benutzt, um sowohl eine sedia a mano als auch eine portantina zu bezeichnen. Den geringsten Interpretationsspielraum bietet schließlich die ,litera“, die - wie bereits erwähnt - meist mit einem von Tieren getragenen Transportmittel zu identifizieren ist, auch wenn der Kontext in Einzelfällen erahnen lässt, dass es sich auch hierbei um ein von Menschen transportiertes Vehikel - gleich dem Tragsessel - handeln konnte.

Trotz der erwähnten Vorbehalte können wir jedoch davon ausgehen, dass der ohne weitere Spezifizierung verwendete Begriff „Sessel“ (ital. sedia, span. silla) im Allgemeinen einen geschlossenen Tragsessel bezeichnete, wofür unter anderem die weite Verbreitung dieses Vehikeltypus spricht. Die silla de manos (in den Quellen meist als sedia a mano, sedia a 


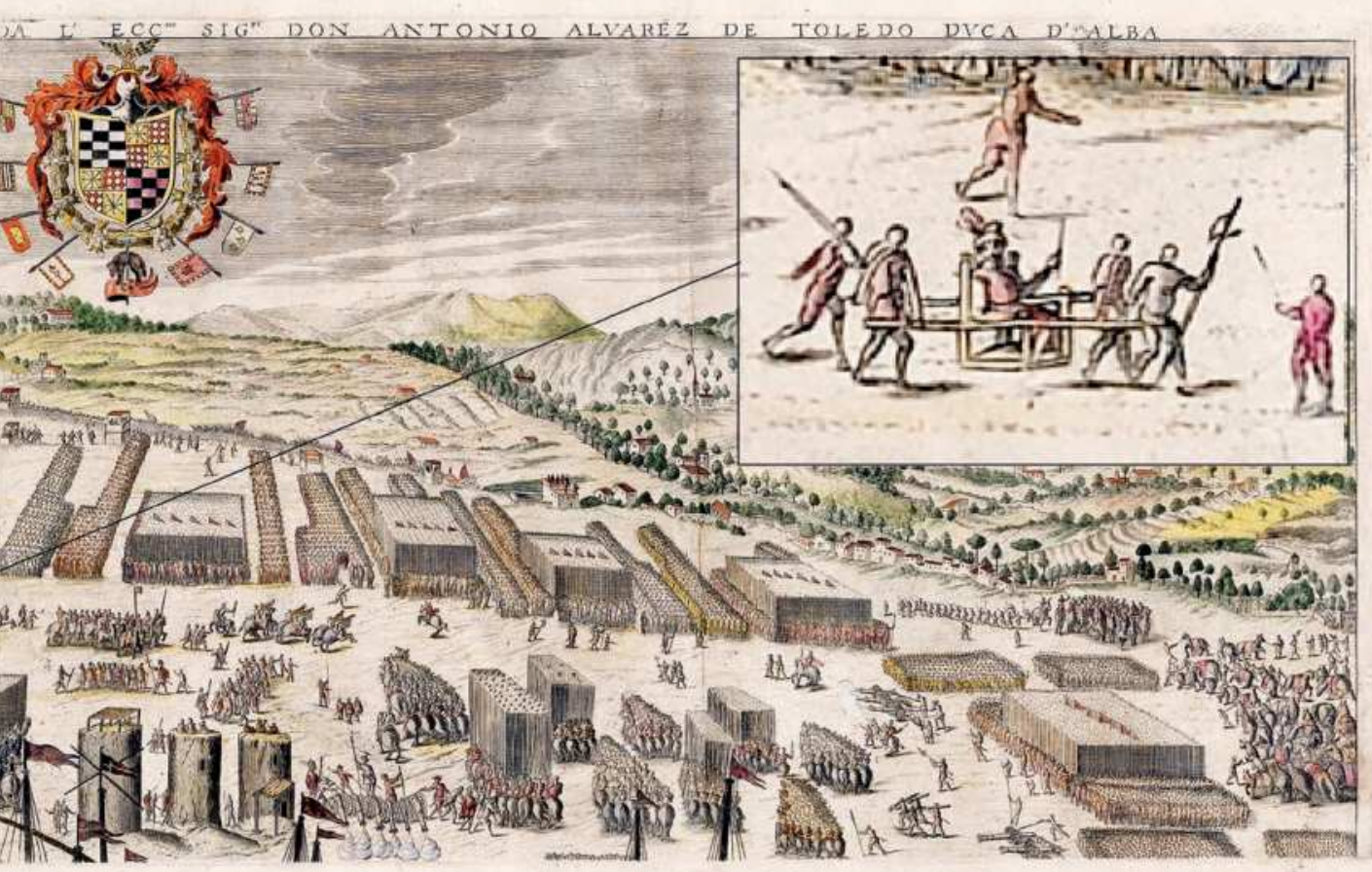

braccia oder als portantina aus dem Spanischen ins Italienische übersetzt) ist in unseren Zeremonialtexten der direkteste Nachkomme der sedia gestatoria. Zwar stand Erstere der Letzteren im Prunk nach, war dafür aber leichter zu handhaben. ${ }^{17}$ Es handelte sich dabei um einen offenen, unbedachten Sessel, der häufig aus einfachsten Materialien hergestellt und mit Trageholmen versehen war. In der Regel war dieses Vehikel für adelige Personen vorgesehen, die sich damit beispielsweise im Inneren von Palästen von einem Stockwerk ins andere tragen ließen, was in den Quellen als salire oder scendere in sedia beschrieben wird. ${ }^{18}$

In Abbildung 4 ist zu sehen, wie eine äußerst schlicht gestaltete, vermutlich hölzerne silla de manos am I8. November I625 bei einer Militärparade von Vizekönig Antonio Álvarez de Toledo (I622-I629), Herzog von Alba, benutzt wurde. Auch wenn diese Parade

I7 Die römische sedia gestatoria ist eine Art mobiler Thron und stets unbedacht (im Gegensatz dazu können Tragsessel sowohl offen als auch geschlossen sein). Sie wurde früher zum Tragen des Papstes verwendet, damit dieser während öffentlicher Zeremonien besser von der Masse der Gläubigen gesehen werden konnte.

I8 Der Vollständigkeit halber soll hier nicht unerwähnt bleiben, dass die ausgewerteten Quellen fallweise auch auf eine Verwendung von geschlossenen Tragsesseln in Treppenhäusern hindeuten. 
in unseren Schriftquellen keine Erwähnung findet, soll sie dennoch an dieser Stelle etwas näher besprochen werden, da sie ein Beispiel für ein besonderes Einsatzgebiet einer silla de manos darstellt. Die mostra general bot dem Vizekönig die Gelegenheit, seine volle Identifikation mit der Politik des Hauses Habsburg zur Schau zu stellen (der Herzog war in jenen Jahren persönlich darum bemüht, finanzielle und personelle Ressourcen für die Krone bereitzustellen) und die spanische Machtpräsenz im Königreich zu verkörpern. Die Graphik gibt sowohl spanische als auch italienische Fußtruppen und Kavallerieeinheiten wieder, die in Richtung Küste Salven abschießen. Sie zeigt auch Tribünen, von denen aus das gesamte Geschehen beobachtet werden konnte. Über all dem steht das Wappen des Duque de Alba. ${ }^{19}$

Im Unterschied zum schlichten Tragevehikel, dessen sich der Vizekönig bei der Parade bediente, waren Tragsessel in ihrer „klassischen“ Form mit einem kuppel- oder tonnenförmigen Dach versehen und seitlich mit Vorhängen - oder später auch mit Gläsern - geschlossen. Es handelte sich dabei um das bevorzugte Fortbewegungsmittel hochrangiger Personen. Der aus Neapel stammende del Tufo erinnerte sich in seinen Versen auch an „tausend“ Tragsessel, die anlässlich eines zeremoniellen Ereignisses eigens für Vertreter der Oberschicht bereitstanden und von Sklaven, Trägern oder Dienern geschultert wurden (,mille seggiette a posta accomodate, / sugli omeri portate / da schiavi, d'i facchini o servitori I di quei miei gran signori““2o). Fynes Moryson, ein englischer Reisender, der gegen Ende des I6. Jahrhunderts verschiedene Länder Europas besuchte und deren Gebräuche schriftlich festhielt, merkte zu Neapel überrascht an, dass es in den engen Straßen der Stadt von rundum geschlossenen Tragsesseln nur so wimmelte und dass diese volkstümlich „Seggioli di Napoli“ genannten Vehikel gleich jenen in Genua gestaltet seien. ${ }^{2 \mathrm{I}}$

I9 Giancarlo Alisio/Nicola Spinosa (Hg.), Vedute Napoletane della Fondazione Maurizio e Isabella Alisio (Napoli 200I), S. 96-98. Eine ausführliche Beschreibung der Parade findet sich bei Capaccio, der jenes Schreiben wiedergibt, das Gomez de Campo an den königlichen Architekten Giulio Cesare Fontana schickte. Gomez de Campo war ein spanischer Militär, der den Auftrag hatte, einen kurzen Bericht und eine Reihe von Skizzen zu erstellen, womöglich, damit Fontana auf dieser Grundlage das Ereignis darstellen konnte. Vgl. die Edition von „Il forastiero“ von Giulio Cesare CapaCcio, hg. von Memofonte (Die Fondazione Memofonte kümmert sich um die Online-Publikation schwer zugänglicher Schrift- und Bildquellen. Die derart herausgegebenen Texte werden im vorliegenden Beitrag hinkünftig mit dem Zusatz „Memofonte“ und dem entsprechenden Erscheinungsjahr angegeben. Für weitere Informationen dazu siehe die Internetseite http://www.memofonte.it, letzter Zugriff: I6.08.20I6). Giulio Cesare CAPACCIO, Il forastiero, hg. von Stefano De Mieri/Maria Toscano (Napoli 1634, Memofonte 2007), S. 365-371.

20 Del Tufo, 2007 (wie Anm. 9), Ragionamento Quarto, Vers I324-I327.

2I Fynes Moryson, An Itinerary Containing His Ten Yeeres Travell through the Twelve Dominions of Germany, Bohmerland, Sweitzerland, Netherland, Denmarke, Poland, Italy, Turky, France, 

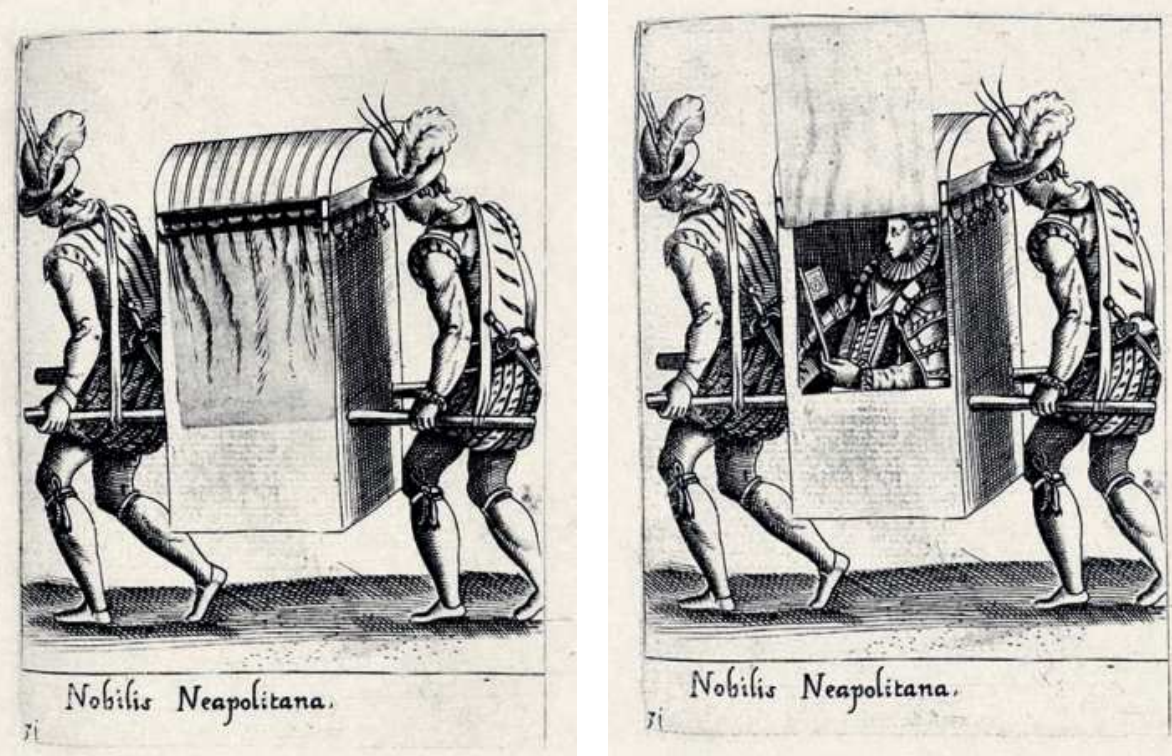

Abb. 5: Unbekannter Künstler des späten 16. Jahrhunderts, „Nobilis Neapolitana“. Zu sehen sind hier beide möglichen Ansichtsvarianten, nämlich einmal mit zugezogenem und das andere Mal mit geöffnetem Vorhang. Aus: Pietro BERTELI, Diversarum nationum habitus centum et quattuor iconibus in aere incisis diligenter expressi, 3 Bde. (Padova 1594). @ BNE

Etwas weniger wohlwollend stand der venezianische Botschafter Girolamo Ramusio den Gewohnheiten und Bräuchen der Neapolitaner gegenüber. In einem Bericht von seinem zwischen 1594 und 1597 datierenden Aufenthalt in der Stadt kritisierte er, dass der Adel schädliche Standesdünkel hege und dass das verwöhnte Volk ohne jeden Anstand mehr Geld ausgebe, als ihm zur Verfügung stehe. Niemand, so Ramusio, sei in Neapel willens, zu Fuß zu gehen, und die Zahl der Kutschen und Karossen übersteige I500, jene der Tragsessel $300 .{ }^{22}$

England, Scotland \& Ireland, Bd. I (London I617, Nachdruck Glasgow 1907), S. 239.

22 „[...] onde il numero dé cocchi e carrozze è più di I500, e le seggette 300“. Girolamo Ramusio, Relazione del Regno di Napoli (Venezia 1597). In: Alessandra Rullo (Hg.), Tre relazioni del Regno di Napoli composte da diplomatici veneziani (Memofonte 2013), S. 58-105, hier S. 77. Cristina Anna Addesso, „Voler descrivere il sito di Napoli in una lettera non è egli cosa temeraria?“ Alcune descrizioni epistolari della città di Napoli tra Quattro e Cinquecento. In: Studi rinascimentali 7 (2009), S. 89-106. 


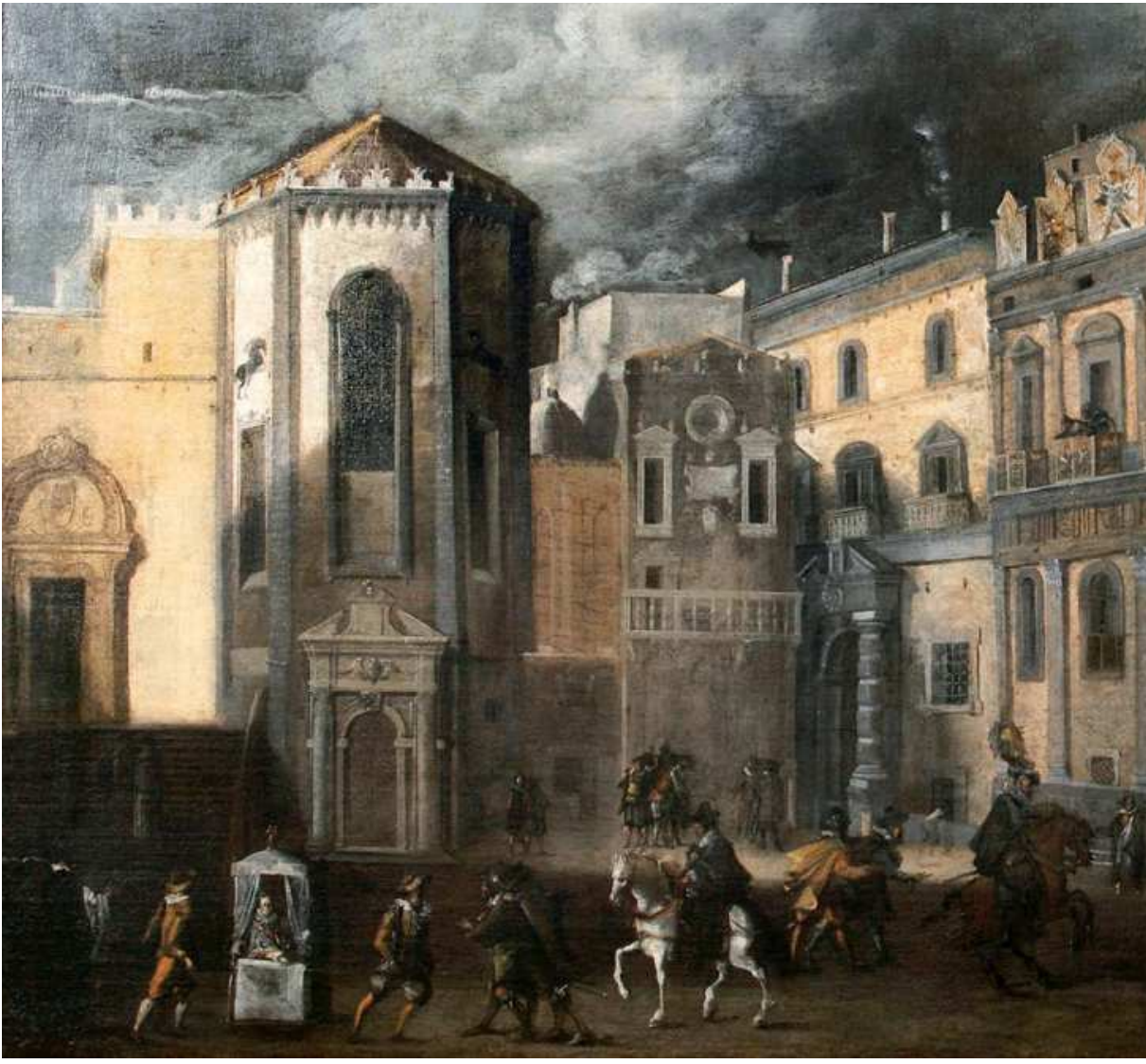

Abb. 6: Unbekannter Künstler des 17. Jahrhunderts, Largo San Domenico Maggiore (Detail). Öl auf Leinwand, um 1650. Napoli, Certosa e Museo di San Martino. @ Fototeca del Polo Museale della Campania

Auch wenn sich die Urteile über derartige Usancen widersprachen, ist doch unstreitig, dass es in Neapel allgemein üblich war, sich in einer seggietta tragen zu lassen. Del Tufo berichtete, dass es besonders unter adeligen Frauen und anderen Damen weit verbreitet war, sich „wunderschöner“ Tragsessel zu bedienen, in denen man sich auf den Straßen der Stadt von seiner besten Seite zeigen konnte, ohne auf Bequemlichkeit verzichten zu müssen und Gefahr zu laufen, dass die Kleidung oder die Frisur dabei litten. ${ }^{23}$ (Abb. 5-7). Nach Klärung der terminologischen Fragen wollen wir nun zur Anthologie übergehen.

23 „[... [ sedia bellissima, ove poter essere trasportata senza maltrattarsi l'acconciatura delle vesti e del capo, ed ove senza scomodarsi potere fare bella mostra di sé nelle vie cittadine“. Del Tufo, 2007 (wie Anm. 9), Vers I35I-I368; Majorca Mortillaro 1906 (wie Anm. I2), S. iO7 f. 


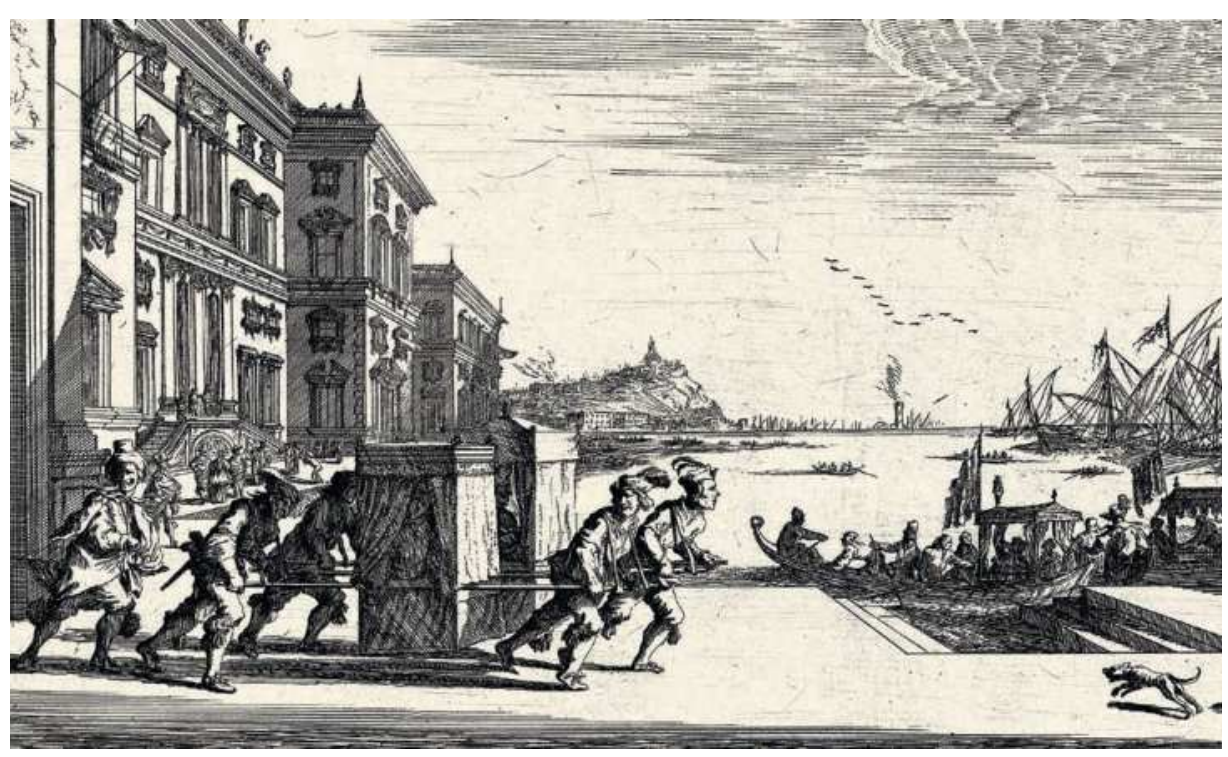

Abb. 7: „Wie man die Seggie zu Neapoli zu tragen pflegt“ (Detail). Johann Wilhelm Baur (Inventor)/Melchior Küsel (Stecher), Radierung, erstmals Augsburg $1670 \odot$ Privatsammlung

\section{Anthologie}

Die Zeremonialschriften belegen in zahllosen Passagen, dass Tragsessel am Hof Neapels sowohl vom Vizekönig ${ }^{24}$ als auch von anderen vornehmen Personen benutzt wurden. Die prächtigsten Tragsessel waren Vertretern der obersten Gesellschaftsschichten vorbehalten und in Einzelfällen sogar für den alleinigen Gebrauch des Vizekönigs bestimmt. Ihre hölzerne Grundstruktur war mit einer goldenen Fassung versehen und mit kostbaren Materialien wie Samt oder Seidentaft bespannt. Mit Hilfe eines Tragsessels konnten vom Königspalast aus rasch nahe gelegene Ziele erreicht werden, wie etwa der Hafen, das Zeughaus oder Castel Nuovo. Aber auch etwas längere Strecken ließen sich damit zurücklegen, etwa zu den in der Umgebung der Via Toledo befindlichen Häusern des neapolitanischen Adels,

24 Del Tufo berichtete etwa, dass die Bevölkerung Neapels den Vizekönig und die Vizekönigin häufig morgens und abends auf den Straßen der Stadt in zwei nebeneinander beförderten, mit Filzbespannung versehenen Tragsesseln zu Gesicht bekam. Der Vizekönig musste nicht befürchten, dass dies negative Auswirkungen auf das Dekorum haben könnte, da ein derartiges Vehikel, so del Tufo, das geeignete Transportmittel für einen Mann seines Standes sei: „[... [e perché ancor sovente / v’è visto da la gente / andarvi il Vicerè, sera e mattina, I con la Viceregina, I a paro a par in due di feltro insieme, I non dubita né teme, / sendo luogo appregiato, / perder la gravità quel titolato." DeL Tufo, 2007 (wie Anm. 9), Vers I369-1379. 
zur Kirche San Gregorio Armeno, zum Dom, zur Piazza Mercato, nach Piedigrotta sowie zu den am Rande der Stadt gelegenen Gärten.

Aufgrund ihrer geringen Größe und guten Manövrierbarkeit eigneten sich Tragsessel auf unwegsamem Boden und in schmalen Gassen besser als Karossen, weshalb Tragsessel auch bei festlichen Anlässen häufig Verwendung fanden. Sie ermöglichten aber nicht nur ein schnelles und bequemes Fortkommen, sondern auch einen glanzvollen Auftritt. Dies ließ sie als Machtsymbole besonders geeignet erscheinen. Der Vizekönig, und in der Folge auch Vertreter des Adels, waren bestrebt, Fußwege so kurz wie möglich zu halten. Karossen und Tragsessel waren deshalb unverzichtbare Transportmittel, die durchaus dem hohen Rang eines Vizekönigs entsprachen. Dies geht besonders deutlich aus dem diesem Beitrag vorangestellten Motto hervor, das der Feder von Díez de Aux entstammt. Weltliche Macht ließ sich aber nicht nur mittels der gezielten Wahl bestimmter Transportmittel versinnbildlichen, sondern auch durch das Gefolge, etwa durch die Zahl der Sesselträger, der Garden, die den Tragsessel gegebenenfalls begleiteten, sowie durch zusätzliche vergleichbare Transportmittel.

Bislang konnten wir sehen, dass Tragsessel ihren festen Platz im Hofleben Neapels hatten und für ihre praktischen Eigenschaften geschätzt wurden. Aber nicht alle standen ihnen wohlwollend gegenüber. Renao etwa äußerste sich mehrfach kritisch über sie. Er war der Ansicht, dass bei ihnen nicht nur höchste Maßhaltung angebracht sei, sondern dass sie sogar nur dann verwendet werden sollten, wenn sich dies gar nicht vermeiden ließe. Renaos Haltung gegenüber Tragsesseln war zum Teil wohl auch seinen eigenen persönlichen Vorlieben geschuldet. Wie später noch zu sehen sein wird, sah er im Tragsessel ein Objekt, das der Würde eines Vizekönigs abträglich sei beziehungsweise das sich nur schlecht für die zeremoniellen Zwecke und das Bild, das vom Herrschenden vermittelt werden sollte, eigne.

Wie bereits erwähnt, lag die Erfolgsgeschichte des Tragsessels auch darin begründet, dass es sich dabei sowohl um ein schnelles als auch um ein praktisches Transportmittel handelte. Dies verdeutlicht eine Anekdote, in deren Zentrum Vizekönig Perafán de Ribera steht. Der Vizekönig weilte in der Nacht des I5. August I570 im Haus des Fürsten von Stigliano (heute Palazzo Cellamare), als Türken völlig überraschend einen Raubzug an der Küste von Chiaia durchführten. Alarmiert von Schreien und Kampfgeräuschen brach Perafán de Ribera sofort auf, um in der Festung des alten Königspalasts Zuflucht zu suchen. Um den Weg durch die Gassen der Stadt raschestmöglich zurückzulegen, ließ er sich in einem Tragsessel befördern. ${ }^{25}$

25 „Succedió en su tiempo que tres galeras turquescas, noche de la Sanctíssima Assunción, año I570, vieron encima en tierra en el burgo de Chaya, el qual saquearon y cautiuaron nouenta y ocho personas; estando Su Excelencia en casa del principe de Astillano sobre la puerta de Chaya, y sintiendo el rumor y gritos de 
Ein Fortkommen war auch deshalb im Tragsessel komfortabler als in einer Karosse, weil aufgrund der Enge vieler Straßen Neapels mit den behäbigeren Wagen häufig Umwege genommen werden mussten. Eine Stelle in der Zeremonialschrift I486 erwähnt einen Fall, in dem ein Weiterkommen in der Karosse gar nicht mehr möglich war und der Vizekönig schließlich aus dem Wagen steigen und ein Stück des Weges zu Fuß gehen musste. Dies brachte wiederum den Zeremonienmeister völlig aus dem Konzept, da ihm kein entsprechender Präzedenzfall bekannt war, der als Leitfaden hätte dienen können. ${ }^{26}$ Die Bequemlichkeit von Tragsesseln wird auch in einer Passage der Zeremonialschrift I483 evident, die zeigt, dass man sich in einem solchen Transportmittel sogar an Bord einer Galeere bringen lassen konnte, ohne den Fuß auf den Boden setzen zu müssen:

Baxó Su Exçelençia en público por el Muellecillo en silla, allí fue por dentro del Arsenal y salió a la Dársena [...] Subió Su Exçelençia con su silla, ençima la capitana y al salir de la silla le puço el bastón en la mano que se lo regaló; Su Exçelençia estubo un ratto dentro la popa y se boluió a poner en silla y se fue por el mismo camino, quedando el señor general a la bocca de su capitana. ${ }^{27}$

Da Tragsessel Transportmittel und Kennzeichen der oberen Gesellschaftsschichten waren, stellte man sie als Zeichen des Respekts und aus Höflichkeitsgründen auch gerne hochgestellten Personen zur Verfügung. Für illustre Gäste des Hofes schrieb das Zeremoniell eine solche Vorgehensweise sogar explizit vor. Wurde hoher Besuch erwartet, mussten am Tor des Arsenals Tragsessel bereitstehen, damit der Gast darin in den Königspalast geleitet werden konnte. ${ }^{28}$ In solchen Fällen wurden Tragsessel auch über die Wendeltreppe ${ }^{29}$ („,ca-

la gente que huya, tomó una silleta y se entró en su Palacio Real". DíEz DE Aux I622 (wie Anm. 2), S. 67. Siehe dazu auch Renao I634 (wie Anm. 3), c. 20 Ir.

26 „Nell'ultima sera delli lumi, havendo andato per li mercanti ed orefici Sua Eminenza, perché la carrozza per la [st]rettezza de' vicoli non poteva andare avanti, volse per ivi andare a piedi; dal maestro di cerimonie se li disse che non si era tal cosa stilato, al che rispose che ogni novità se portava poi per esemplare e così camminò a piedi tutte le strade d'orefici". Attilio Antonelli (Hg.), Cerimoniale del viceregno austriaco di Napoli, I707-I734 (I ceremoniali della corte di Napoli 2, Napoli 2014), S. 213, Cc. I25r-I25v. Die hier beschriebene Szene fand im Jahr I724 statt.

27 Antonelli 2012 (wie Anm. i), S. 478, c. I56r.

28 „El día siguiente tiene de boluer la visita, viniendo con sus galeras y apeándose a la puerta del Attaracenal donde con sus galeras Su Excelencia acompañado de todo su baronaje, Colateral, Tribunales y continos, teniendo preuenido el cauallerizo mayor, silletas de respecto por si acaso se offreciesse hauer algun impedimiento". DíEz de Aux i622 (wie Anm. 2), S. 3.

29 Tragsessel waren so weit verbreitet, dass ihre Maße sogar bei der Planung von Treppenhäusern und Durchgängen in Palästen berücksichtigt werden mussten. In einer Quelle des 17. Jahrhunderts, in der die umfassenden von Vizekönig Conde de Ońate (1648-1653) in Auftrag gegebenen Renovie- 
racó ) der Residenz getragen, wie Renao dies anlässlich der Abreise von Vizekönig Kardinal Borgia $^{30}$ schildert:

A los 22 de deciembre 1622 pribadamente salió por el caracol en una silla, y por el parque se fue a embarcar. ${ }^{31}$

Eine analoge Vorgehensweise lässt sich schließlich auch bei der Verabschiedung von Gästen beobachten. ${ }^{32}$ Die Höflichkeitsbezeugungen beschränkten sich zuweilen nicht nur auf die Bereitstellung eines Tragsessels, sondern umfassten auch die Begleitung des Gastes bis zum Tragsessel selbst und das Schließen von dessen Tür unmittelbar vor dem Aufbruch. ${ }^{33}$ Selbstverständlich zählte die Bereitstellung von Tragsesseln neben jener von Pferden und Karossen auch zu den Formen der Courtoisie, die bei Besuchen von Repräsentanten königlicher Häuser zur Anwendung kamen. ${ }^{34}$ Aber auch Mitglieder des neapolitanischen Adels kamen in den Genuss von bereitgestellten Tragsesseln, wie eine Stelle der Zeremonialschrift 1485 zeigt:

A 3 de henero 167I bolvió la visita pública el señor duque de Fernandina al señor don Pedro [de Aragón], y de Palaçio se le enbió todo el reçado de coches y sillas de manos de respetto, lleuando con él tres cavalleros dentro del coche. ${ }^{35}$

rungs- und Erweiterungsarbeiten am Königspalast von Neapel beschrieben sind, ist auch von einer „escalera grande que pueda dar buelta la silla“ die Rede. Vgl. Cartas de assunto de Nápoles el año de i65ı, BNE, Mss. I432, fol. I3r; M. A. De Cunzo, Palazzo Reale di Napoli. In: Il Palazzo Reale di Napoli (Napoli 1995), S. I7-19.

30 Gaspar de Borja y Velasco (I580-I645).

3I Renao I634 (wie Anm. 3), c. 35r.

32 "Y acauado ésto, se podrán yr a despedir de la virreyna, yéndose a embarcar él que ha venido, donde I terrán preuenidas sillas al parque salido todo lo que es Palacio, hasta adonde saldrá acompañarle, conforme le reciuió y puesto en su silla, se yrá a embarcar porque no se acostumbra acompañar más adelante. $Y$ en caso que él que presidiere fuesse cardenal, le reciuirá con las mismas ceremonias, pero tiene de lleuar siempre mejor lugar por ser cardenal". Díez De Aux I622 (wie Anm. 2), S. 5.

33 „Su Exelencia lleuó al dicho embaxador a su casa, subió arriba donde estaua la señora marquesa, la uisitó y después se puço en silla y el embaxador se la cerró y se bino a Palaçio“. ANTONELli 2012 (wie Anm. I), S. 426, c. I27v. In einem anderen Fall begleitete der Gastgeber seinen Besucher erst zum Tragsessel und brach dann gleichzeitig mit diesem auf. „A I 8 dicho Su Exçelençia fue en casa del señor cardenal en silla a uisitarle. El señor cardenal lo reçibió a la puerta de la antecámara, Su Exçelençia salió de la silla, se hiçieron las acostumbradas çeremonias [...] y el señor cardenal acompañó a Su Ex̧̧elençia hasta la silla, Su Exçelençia se puço en ella y se fueron todos dos a un tiempo". Ebenda, S. 440, c. I36r.

34 Vgl. Renao I634 (wie Anm. 3), c. 201 r.

35 Antonelli 2012 (wie Anm. I), S. 280, 282, c. 99 r. 
Eine in der Zeremonialschrift 1483 festgehaltene Episode aus der Regierungszeit des Marchese di Astorga (I672-I675) zeigt, dass die Bereitstellung eines Tragsessels manchmal auch in den Komplex jener Verhaltensweisen fiel, die das Verhältnis zwischen Männern und Frauen regelten. Als der Vizekönig wie gewöhnlich an der feierlichen Zeremonie teilnahm, bei der eine Novizin den Ordenseid ablegte, wollte es der Brauch, dass nach Beendigung der feierlichen Handlung der Vizekönig die frisch gebackene Nonne zum Tor des Konvents begleitete. Da damals aber ein heftiges Gewitter niederging, beschloss man, der Nonne und ihrer Mutter die Tragsessel des Vizekönigs und des Kapitäns der deutschen Leibgarde zur Verfügung zu stellen, um die beiden Damen entlang der kurzen Wegstrecke zwischen der Kirche San Gregorio Armeno und dem Konvent vor dem Regen zu schützen. ${ }^{36}$

Es war auch üblich, Adeligen und Regierungsmitgliedern, denen aus gesundheitlichen Gründen das Stufensteigen innerhalb der Palastmauern Probleme bereitete, die Verwendung eines Tragsessels zu gestatten, damit sie ohne Mühe zum Treffpunkt gelangen konnten. ${ }^{37}$ Höflichkeitshalber zur Verfügung gestellte „silletas de respetto“ befanden sich auch im Gefolge des Conte di Benavente und dessen Gemahlin, als das Paar in der Karwoche in Begleitung einer großen Zahl von Dienern, Garden und Damen in den Kirchen des Quartiers rund um den Vizekönigspalast die sogenannten „Sepolcri“ besuchten, bei denen es sich um geschmückte Altäre handelte, auf denen am Gründonnerstag Brot und Wein für die Karfreitagsliturgie aufbewahrt wurden. ${ }^{38}$ Dies führt uns zu einem anderen Aspekt des Hofzeremoniells, nämlich zur Position von Tragsesseln innerhalb feierlicher Prozessionen und zum Gefolge, von dem sie bei derartigen festlichen Ereignissen umgeben waren. Je nach Bedeutung und Charakter der Veranstaltung begleiteten unterschiedliche Personen die Tragsessel in genau festgelegter Form und gingen ihnen entweder voraus, folgten ihnen nach

36 "En tiempo del señor de Astorga se puço monja la hija del prinçipe de Furino a Santo Ligorio, y fue allá Su Exçelençia, y entretanto se acabó la funçión, bino un agua grandiosa en tal forma que no dio lugar a Su Exçelençia, que podiesse lleuar la tal señora a la portería, y assi la fue seruiendo hasta la puerta de la iglesia, y hiço poner la monja en su silla y su madre en la silla del capitán de la guardia, y las lleuaron a la portería de las monja“. Ebenda, S. 242, c. 56v.

37 „Entran lugo por su orden y con sus precedencias los señores de los Siete Officios, principes, duques, marqueses, condes, Colateral, arçobispos y obispos por su antigüedad y hauiendo alguno destos señores impedidos de alguna enfermedad entra con silleta y se hallará Su Excelencia debaxo de su dosel sentado, y sientraren [sic] arrimados les mandará dar silla por el impedimento que tuniere". DíEz DE AuX I622 (wie Anm. 2), S. I8 f.

38 „Después de hauer comido, yvan a uisitar los monumentos de todo el quartel y Santiago a pie con todos sus criados, continos y guarda. Y la virreyna con sus dueñas y damas yva detrás de Sus Excelencias, el cauallerizo mayor, coches y silletas de respetto. El guardaropa y moço de estrado lleuauan dos almohadas para arrodillarse los virreyes los quales les daua el vger mayor. Tanbién yva el limosnero mayor y Su Excelencia mandaua acabado de adorar la cruz se diessen muy largas limosnas". Ebenda, S. 2I4. 


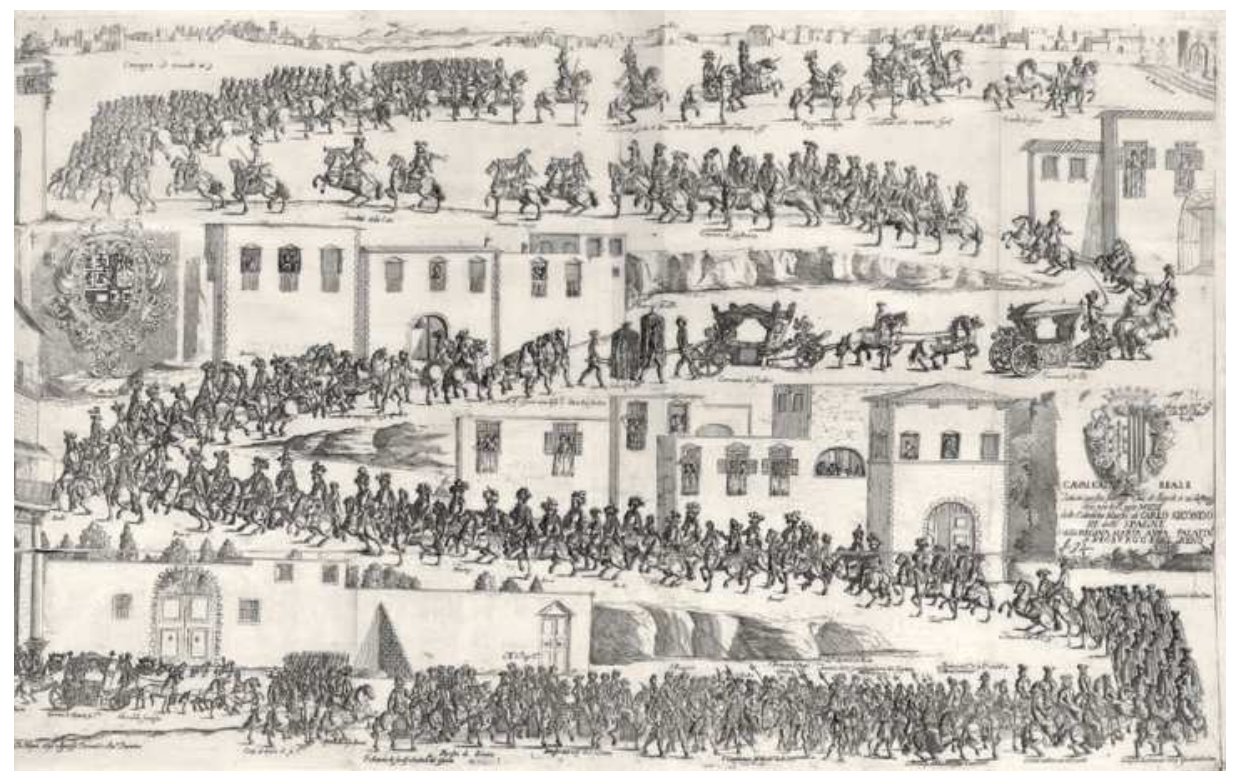

Abb. 8: Luca Antonio di Natale/Francesco de Grado, Cavalcata Reale. @ Anne S.K. Brown Military Collection, Brown University Library. Der Stich stammt aus dem Werk: Domenico Antonio Parrino, L'ossequio tributario della fedelissima città di Napoli per le dimostranze giulive nei Regii Sponsali del monarca Carlo secondo colla principessa Maria Anna di Neoburgo [...] (Napoli 169o). Der Zug, der sich rechts oben in Richtung des erzbischöflichen Sitzes bewegt, setzt sich unter anderem aus folgenden Bestandteilen zusammen: „cavalli di rispetto, la carrozza di Sua Eccellenza, la carrozza del sindaco, la sedia del sindaco, la sedia di Sua Eccellenza, due cavalli di rispetto (uno di Sua Eccellenza e l'altro del sindaco), cavalli da maneggio di sua Eccellenza, una carrozza di offerta di Sua Eccellenza, le altre carrozze della famiglia, cavalleria".

oder blieben an ihrer Seite. Bei einer Kavalkade im Jahr I70I, die anlässlich der Huldigung Philipps V. als König von Spanien stattfand und die durch die wichtigsten Straßen Neapels führte, befanden sich im langen und abwechslungsreichen Zug auch zwei leere Tragsessel de respetto, von denen einer dem Vizekönig und der andere dem Bürgermeister der Stadt gehörte. Der den Tragsesseln zugewiesene Platz befand sich genau zwischen der vierspännigen Kutsche des Bürgermeisters, die dem sechsspännigen Wagen des Vizekönigs nachgereiht war, und den Trompetern der Stadt, die den vizeköniglichen Trompetern vorausgingen. Dabei ist bemerkenswert, dass auch der Bürgermeister von Neapel einen eigenen Tragsessel im Zug mitführte und dass dieser unmittelbar jenem des Vizekönigs folgte. ${ }^{39}$ Eine hierzu

39 „El coche de Su Exçelençia a seis. El coche del sindico a quatro. / La silla de manos de Su Exçelençia. La silla de manos del sindico. Las trompettas de la Çiudad Las trompettas del rey". ANTONELLI 2012 (wie Anm. I), S. 490, cc. I6or-160v. 
passende Bildquelle zeigt eine anlässlich der Hochzeit Karls II. im Jahr I690 abgehaltene königliche Kavalkade, bei der ebenfalls diese beiden Tragsessel de respetto im Festzug vertreten waren und jeweils mit einem kostbaren Tuch bedeckt dargestellt sind (Abb. 8).

Aus der Regierungszeit des Marchese di Astorga stammt die Vorschrift, den Tragsessel des Vizekönigs zur Rechten des Tragsessels seiner Gemahlin zu befördern, wenn beide durch die Straßen der Stadt zogen. Ihre jeweiligen Stallmeister hatten dabei hinter ihnen zu reiten:

[...] quando el virrey y virreyna saliessen en sillas, los caualleriços, assí de Su Exçelençia como de la virreyna, han de ir a cauallo detrás de las sillas, lleuando él de Su Exçelençia a mano derecha..$^{4}$

Bei Zeremonien mit einem gewissen offiziellen Charakter ließ sich der Vizekönig häufig von einer Kompanie Lanzenträger begleiten. Dies war beispielsweise der Fall, als sich Marchese del Carpio zur Chiesa del Carmine begab, um die Einnahme Budas im Jahr I686 zu feiern..$^{4}$ Noch öfter aber führte der Vizekönig seine deutsche Leibgarde in seinem Gefolge mit ${ }^{42}$ oder ließ eine Kavalleriekompanie vorangehen, wenn sein Ziel in großer Entfernung von seinem Palast lag:

Su Eminençia respondió que Su Exçelençia era patrón y assí Su Exçelençia fue allá a las tres de la tarde, se uajó por la puerta secreta, se puço en silla, pero delante de la silla iba una compañía de cauallos que assí se suele estilar, quando se ua en parte lexa, estaua a Piedegrutta. ${ }^{43}$

40 Ebenda, S. 230, c. 5 Ir.

4I „Su Exçelençia fue luego por la mañanitta al Carmin y tubo capilla real, se cantó el Te Deum, hubo salua real de todos los castillos, esquadrón de cauallería y infantería y lleuó la compañia de lanças detrás de su silla". Ebenda, S. 394, c. II2v.

42 „Al istante el señor duque de Medinaçeli enbió un gentilhombre en casa del señor duque de Escalona a deçirle que quería ir a berlo; el duque de Escalona respondió que era patrón y assi Su Exçelençia fue en silla con su guardia alemana, el señor duque de Escalona lo reçibió hasta la silla". Ebenda, S. 500, c. I66r. Wie hier zu beobachten ist, war es üblich, den Gast bis zum Tragsessel zu begleiten und anschließend sofort aufzubrechen. Auch eine andere Textstelle (ebenda, S. 420, c. I24v) demonstriert, dass der Erwiderung eines Besuchs und der Begleitung des Gastes durch den Gastgeber bis zum Transportmittel allein zeremonielle Aspekte innewohnten: „A 20 de setiembre dicho, bino el capelo al señor cardenal Carrafa y se hiço la funçión de dicho cardenal, con que Su Exçelençia le fue a uisitar en silla a veinte y tres dicho lleuando su guardia alemana como al sólito, y el otro le correspondió la uisita a 26 dicho y uino en silla y se hiçieron las acostumbradas çeremonias [...] y a la despedida Su Exçelençia le acompañó hasta la silla y aguardó que se puçiesse en ella y partieron todos dos a un tiempo". 
Wie uns der Verfasser des Zeremoniells I483 zu verstehen gibt, blieb es dem Vizekönig überlassen, welchen Charakter seine Ausgänge hatten: geheim ${ }^{44}$, öffentlich oder inkognito; jede einzelne Variante folgte dabei einem ganz eigenen Zeremoniell:

A 30 dicho fueron los embaxadores a darle la hora buena [...]; en este mismo día que bienen los embaxadores el gouernante ha de ir a despedirse del cardenal y suele ir en silla, pero puede ir como mandaré en público, o en secreto, que esto está en su arbitrio. ${ }^{45}$

Dem Vizekönig stand es auch frei zu entscheiden, auf die Begleitung durch die deutsche Leibgarde ganz zu verzichten und für sich und seinen Gast sillas zum Palast kommen zu lassen, was erneut die große Bedeutung unterstreicht, die Tragsesseln im Rahmen des Zeremoniells zukam:

Por la tarde el señor duque de Escalona le quiso pagar la uisita y fue en silla, pero sin guardia alemana; la silla y coches se les enbiaron de Palaçio. ${ }^{46}$

Aber nicht nur das: Dem Vizekönig war es auch möglich, sich bei seinen Ausgängen im Tragsessel von bestimmten Personen seiner Wahl begleiten lassen. So befand sich etwa der Zeremoniär Miguel Díez de Aux an der Seite des Vizekönigs Conte di Benavente, wenn sich dieser an Feiertagen, die auf einen Montag oder Mittwoch fielen, auf Rundgänge zu den Märkten Neapels begab, um die Steuern auf Waren zu überprüfen und die Ordnung auf den Straßen zu kontrollieren. ${ }^{47}$ Bei länger dauernden Ausgängen von größerer zeremo-

Neapels. Um diese Vergnügungsorte zu erreichen, wurden neben Karossen und Pferden auch Tragsessel verwendet: „Assimismo quando salía por su recreación fuera a los arrabales, jardines y huertos y campaña con la condesa y sus hijas assi en carrozas como en sillas, lleuaua siempre una azémila con toda la friambrera, conseruas, frutas, vinos y aguas para si quisiessen merendar en puño estuuisse a punto el mayordomo y maestro sala para dársela; lleuaua el cauallerizo mayor un cauallo cubierto con dos lacayos que le lleuauan de diestro tras de la carroza o silla de respetto por lo que pudiesse succeder y por la grandeza que conuiene que lleuen los virreyes". Díez De Aux I622 (wie Anm. 2), S. 234.

44 Geheim war beispielsweise der Besuch einer Komödie, die 1684 im Haus des Duca di Maddaloni aufgeführt wurde. „Su Exçelençia mandó que aquel día este general le aguardasse en casa de Matalón y la noche fue allá / Su Exçelençia de secreto en silla y halló al general y se subieron en el palquette a oyr la dicha comedia, pero Su Exçelençia se tomó el primer lugar, hubo muchos dulçes y gran frutta. Acabada la comedia Su Exçelençia se despidió del tal general, se puço en silla y se bino a Palaçio". Antonelli 2012 (wie Anm. I), S. 382, c. I07v.

45 Ebenda, S. 280, c. $74 \mathrm{v}$.

46 Ebenda, S. 500, c. I66r.

$47 \ldots[. .$.$] los lunes y viernes que caj́an en fiesta, yva en una silleta, priuadamente, solo con su guarda y$ Miguel Diez de Aux, uisitando y mirando el mercado y todas las plaças y tiendas que vendian cosas 
nieller Bedeutung war es auch üblich, Wagner, Schlosser und Tischler im Gefolge mitzuführen, um bei Bedarf schadhafte Wagen und Tragsessel in Stand setzen zu können.

Aus den Quellen geht weiterhin hervor, dass die Vizekönigin bei ihren öffentlichen und privaten Ausgängen neben Sänften auch regelmäßig Tragsessel benutzte. Im Gebrauch von Tragsesseln lassen sich Unterschiede zwischen dem Vizekönig und der Vizekönigin beobachten, und zwar bei der Länge der damit zurückgelegten Wegstrecken: Häufig ließ sich die Vizekönigin im Tragsessel bis in die Beletage der Paläste oder zumindest bis ins Innere der Gebäude bringen, und zwar auch in Fällen, in denen das Reglement für den Vizekönig ein früheres Aussteigen vorsah.

A la puerta de la iglesia la virreyna se ha de boluer y se despide de la damas, estas se bueluen a entrar en la iglesia y Su Exçelençia se pone en silla y se uan con preuençión que la silla de la virreyna ha de estar dentro de la puerta de la iglesia y aquella de Su Exçelençia fuera de ella. $4^{8}$

Der Vizekönig verließ in diesem Fall den Tragsessel bereits außerhalb des Kirchenportals, während sich die Vizekönigin bis in das Innere des Sakralraums tragen ließ. Diese Vorgehensweise lässt sich darauf zurückführen, dass Damen im Allgemeinen ein größeres Maß an Diskretion auferlegt wurde, um das Dekorum zu wahren, was sich unter anderem durch sparsam dosierte Auftritte in der Öffentlichkeit erreichen ließ. Möglicherweise waren es dieselben Beweggründe, die den Vizekönig in anderen Fällen dazu veranlassten, in die Sänfte seiner Gemahlin zu steigen, um ein Gespräch unter vier Augen mit ihr führen zu können. ${ }^{49}$

Tragsessel boten bei Bedarf willkommene Rückzugsorte, die ein anonymes Fortkommen in der Stadt ermöglichten. Der transportierten Person stand es frei, mit offenen Vorhängen zu reisen und sich sehen zu lassen oder aber die Vorhänge geschlossen zu halten, um sich so unerwünschten Blicken der Passanten zu entziehen beziehungsweise um sich vor widrigen Witterungseinflüssen wie Sonne oder Regen zu schützen. ${ }^{\circ \circ}$ Bildliche Quellen

comestibles, preguntando el precio de cada cosa, llamando a los capitanes de las dichas Plaças para que le hiziessen relación de lo que passaua cada uno en su quartel". DíEz DE Aux I622 (wie Anm. 2), S. 92.

48 Antonelli 2012 (wie Anm. I), S. 222, c. $47 \mathrm{v}$.

49 „La virreyna salió de su silla y se puço en littera sola, la qual littera era del señor marqués de Astorga, y se fue adelante [...]; s[e ba] xó del coche y se puço en littera con la virreyna, y se fueron a Pu[çol] lleuando dos compañias de cauallos". Ebenda, S. 288, c. IO3v. Kurz darauf (ebenda, c. I04r) ist festgehalten, dass der Vizekönig aus der Sänfte stieg, um in seinem Tragsessel Platz zu nehmen.

50 Die geschlossenen Vorhänge verhinderten allerdings auch die Sicht nach außen. Dies führte etwa im Jahr 1676 dazu, dass sich Vizekönig Los Velez plötzlich aufgrund eines Missverständnisses mit seinen eigenen Sesselträgern irrtümlich im Haus des Fürsten von Piombino anstatt im Haus des Herzogs von Grottella befand: „A la salida que hiço Su Exçelençia del castillo, dixo el caualleriço que quería 


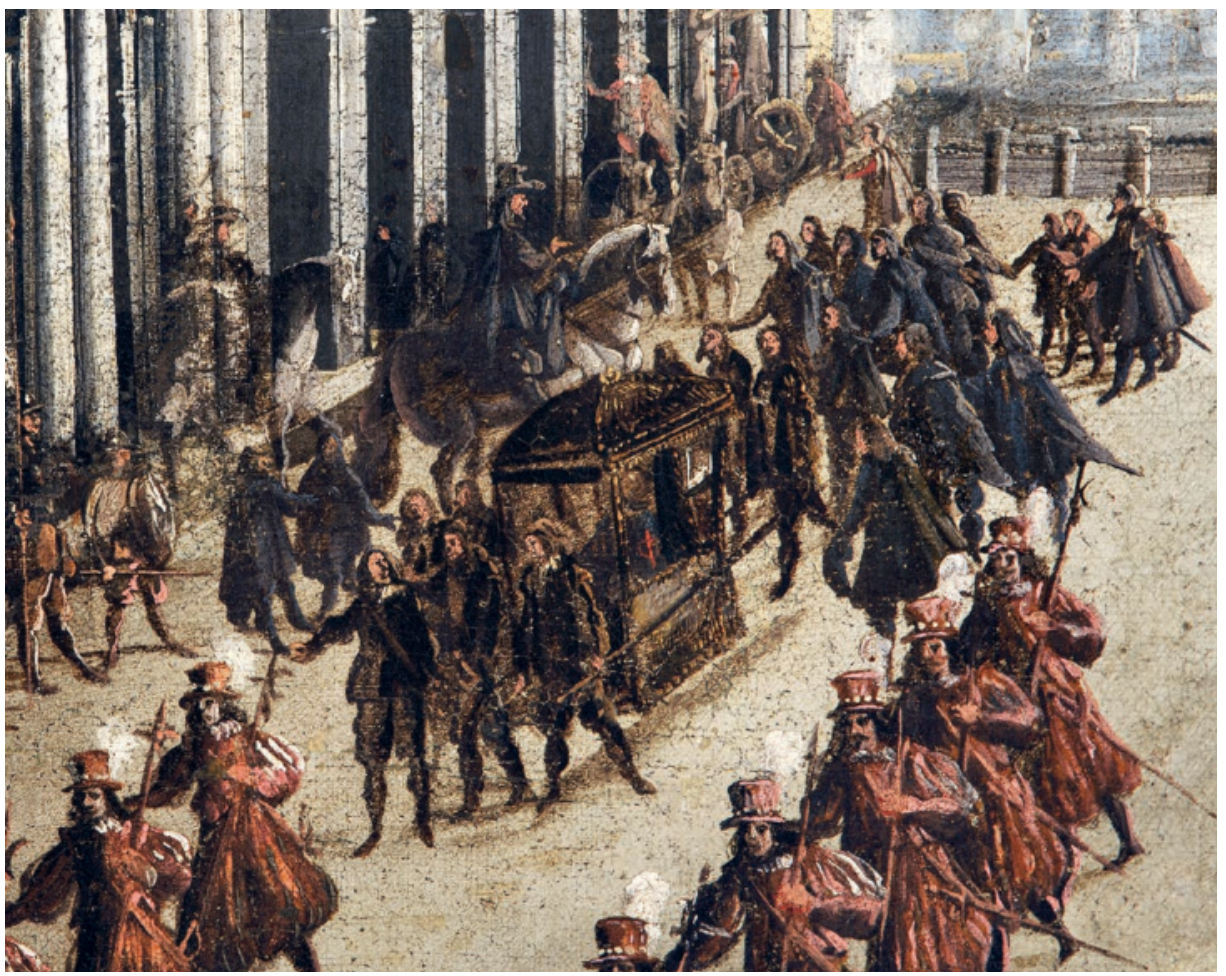

Abb. 9: Auszug des Vizekönigs aus dem königlichen Palast Neapels (Detail). Anonymer Künstler, Öl auf Leinwand, um 1650. Napoli, Certosa e Museo di San Martino. Foto: A. D’Antonio, R. De Simone, L. Basagni, F. Speranza - Lab. fotogr. Sopr. (c) Fototeca del Polo Museale della Campania

(Abb. 9) liefern uns zudem Informationen über das hohe Maß an Luxus, das manche Tragsessel - besonders jene des Vizekönigs - kennzeichnete: Erlesene Hölzer, Tücher und mit Seide und Taft bezogene Polsterungen sowie ornamental gestaltete Dachaufsätze ${ }^{\text {II }}$ machten

uisitar al prínçipe de Pomblín, que era general de las galeras de Nápoles, y biuía al largo de castillo, en la casa grande del duque de las Grotolelas, y assí oyendo esto los tudescos y lacaios y silleteros creieron que $S u$ Exçelençia hauia de hazer la uisita al prínçipe, porque oyeron mal, que el caualleriço era aquel que hauia de uisitar, no Su Exçelençia. Se fueron derecho a la casa del prínçipe y subieron arriba, y como haçia mucho frio, Su Exçelençia se hauia tirado las cortinas de la silla, y por adentro no miraua donde lo lleuauan, subieron arriba los silleteros con la silla; auisaron los criados a la prinçessa quando uieron que la guardia alemana hauia entrado en el pattio, la prinçessa quedó admirada y salió luego fuera a la antecámara, paró la silla Su Exçelençia pensando que estubiesse en Palaçio y, al abrirla, se quedó cortado, no sabía que le hauía suçedido uiéndose de golpe en casa de Ponblin". Ebenda, S. 298, c. 77v.

Dank einer Passage in der Zeremonialschrift I483 wissen wir, dass die Tragsessel sogar bei Trauer- 
sie zu äußerst vornehmen Objekten, an denen die Kunstfertigkeit mehrerer Handwerkssparten (Schlosser, Schnitzer, Vergolder, Sattler, Tapezierer, Spengler, Tischler und so fort) sichtbar wurde. Tragsessel waren deshalb auch passende Geschenke für illustre Personen und unverzichtbare Ausstattungsstücke bei bedeutenden diplomatischen Missionen.

Während des gesamten I7. Jahrhunderts und auch noch darüber hinaus umgab Tragsessel eine gravitätische, von großer Formalität geprägte Aura, und dies trotz der erwähnten Abneigung Renaos, der im Anschluss an Miguel Díez de Aux das Amt des obersten Zeremonienmeisters bekleidete und als solcher bemüht war, das Einsatzgebiet von Tragsesseln für den Vizekönig und dessen Gemahlin so weit als möglich einzuschränken. Bei Renao lassen sich zahllose Passagen finden, in denen er minutiös festhielt, auf welche Art Tragsessel bei Ausgängen zu verwenden seien. Dies lässt ein eigenartiges Bild entstehen: Für Renao waren Tragsessel Objekte, die stets verfügbar sein mussten; sie hatten allerdings immerzu im Hintergrund zu bleiben, da sonst ihr Einfluss auf das Zeremoniell allzu stark geworden wäre. Der Zeremonienmeister war der Ansicht, dass Reittiere oder Karossen gegenüber Tragsesseln stets bevorzugt werden sollten. Kam aber dennoch ein Tragsessel zum Einsatz, ließ Renao es sich nicht nehmen, die genauen Verwendungsumstände zu beschreiben und zuweilen auch seinen persönlichen Widerwillen gegenüber der Entscheidung des Vizekönigs zugunsten des Tragevehikels zu unterstreichen.

Sowohl bei Ausgängen außerhalb der Palastmauern als auch in den Treppenhäusern der königlichen Residenz führte der Vizekönig einen Tragsessel mit sich. ${ }^{52}$ Benutzte er diesen schließlich auch, war sein Gefolge angehalten, ihm stets zu folgen:

Advirtiendo que tomando silleta, se tiene de mandar se vaya todo el acompañamiento, atento no tienen puesto; pero saliendo a pié tiene de ir cada uno en su lugar. ${ }^{53}$

Die Ausgänge des Vizekönigs sind in den Quellen in aller Ausführlichkeit überliefert. Nur er hatte dabei das Recht, einen geschlossenen Tragsessel und einen sechsspännigen Wagen

fällen geschmückt blieben: „El aposento donde Su Exçelençia reçibió las paredes blanca, dosel y sillas moradas de la misma manera estaua compuesto el quarto de la señora virreyna, no poniendo lutto, ni a gentileshombres, ni a pajes, lacayos, coches, silla de manos ni a los tudescos". Ebenda, S. 474, c. I54r. „[...] al canton de la escalera adonde reciuio a sus Excelencias, y esto por yr en silla la Virreyna, que si fuera a pie, hania de salir a recibirla adonde se apeaua". Renao I634 (wie Anm. 2), c. I6Ir. An späterer Stelle ist erwähnt, dass auch die Mitglieder des Consiglio collaterale, des höchsten politisch-juridischen Organs im Königreich Neapel, in derartigen Fällen verpflichtet waren, sich dem Geleit anzuschließen: "Quando el Virrey va acompañando á la Virreyna a pie y ella en silla y se hallan algunos del Colateral, el puesto que han de tener, es delante del Virrey y no detras". Ebenda, c. I69r. Ebenda, c. 8Ir. 
zu verwenden. ${ }^{54}$ Bei feierlichen Anlässen musste sein Tragsessel mit Seidentaft ausstaffiert sein. 55 In Fällen, in denen sowohl der Vizekönig als auch die Vizekönigin Tragsessel benutzten, durfte kein Adeliger sie begleiten. Ausgenommen davon waren Fälle, in denen sich nur die Vizekönigin tragen ließ, der Vizekönig aber zu Fuß ging. ${ }^{56}$ In Räumen, die mit einem Dorsale versehen waren, galt ein allgemeines Verbot für Tragsessel. Aber auch hierfür sind Ausnahmen dokumentiert, nämlich dann, wenn Kardinäle ${ }^{57}$ den vizeköniglichen Palast aufsuchten, was mit der Bequemlichkeit der Tragevehikel begründet wurde:

[...] porque esto de el venir en silla se hace por mayor comodidad suya [...] tanto el Virrey como el Cardenal..$^{8}$

Dennoch bleibt unübersehbar, dass Renao die Verwendung von Tragsesseln grundsätzlich als schwerwiegenden Missstand betrachtete, wie er in zwei Gelegenheiten explizit hervorhob. Der erste Fall betraf eine Kavalkade:

[...] si el Virey se metiere en silla (que es muy grave inconveniente) el síndico ha de tener otra, y si en carroza, mete al síndico al lugar del cochero. ${ }^{59}$

Der zweite Fall beschreibt die Rückkehr vom Hafen, wohin zuvor der scheidende Vizekönig begleitet worden war:

Si buelue en silla (que es muy grande incombeniente) el síndico ha de yr tambien con silla; [...] se tiene de tener preuenida otra para el sindico, porque seria impossible y no liçito que Su Excelencia boluiesse solo á Palaçio y dexasse alli el síndico. ${ }^{60}$

54 "Silla cubierta ni tiro de seis no lo puede llevar otro que los Vireyes". Renao I634 (wie Anm. 3), c. 83r. Renao präzisiert auch: "Solo las sillas de mano de sus Excelencias Virrey y Virreyna tienen de yr cubiertas y otra ninguna no, aunque sean de sus proprios hijos", ebenda, c. I69r.

55 Ebenda, c. I20v. Siehe auch ebenda, c. I46r.

56 "Siempre que sus Excelencias salieren fuera yendo en sillas, no tienen de permitir que titulo ninguno les acompañe, ni persona particular. Pero en caso que la Virreyna fuese en silla y el Virrey a pie, tiene de dexar que le vayan acompañando todas las personas que se hallaren, assi Titulos como personas particulares". Ebenda, c. I69r. "No se tiene de permitir que en ninguna sala que haya dosel este silla de manos, solo la de algun cardenal que huniesse venido a visitar á Sus Excelencias". Ebenda, c. I69r.

58 Ebenda, c. I64v.

59 Ebenda, c. 83 r.

60 Ebenda, c. I26r. 
Die von Renao offen zur Schau gestellte Ablehnung von Tragsesseln könnte vielleicht mit der verbreiteten Meinung in Zusammenhang stehen, die Verwendung eines Tragsessels oder einer Sänfte durch den Vizekönig sei als Zeichen mangelnder Männlichkeit (,falta de masculinidad ${ }^{\text {"(6I) }}$ zu werten und dass es ihm bei hochrangigen zeremoniellen Anlässen deshalb besser anstünde, sich zu Pferd oder zu Fuß zu zeigen.

Eine Stelle der Zeremonialschrift I483 fasst abschließend in anschaulicher Weise verschiedenste Einsatzbereiche für Tragsessel im Rahmen des Zeremoniells zusammen. Die Passage beschreibt den im Tragsessel zurückgelegten Weg von den königlichen Appartements über die Korridore des Palasts zum Ankunftsort eines illustren Gasts und im Anschluss daran die erneute Abreise des Besuchers. Dabei verlief alles nach den im Zeremoniell festgelegten Regeln:

La misma mañana Su Exçelençia le fue a uisitar en silla con la guardia alemana. Hecha la uisita Su Exçelençia quiso passar al quarto de la señora condessa: el señor conde le acompañó hasta la silla. Su Exçelençia se puço en ella y passó al quarto de la señora condessa y lo reçibió a la puerta en donde fue la uisita, y Su Exçelençia entró con la silla hasta la dicha puerta. [...] Por la tarde uino el señor conde a restituir la uisita a Su Exçelençia, pero de Palaçio se le enbió la silla para su persona, decano y lacayos, coche a seis de respetto y otros dos para la familia. [...]. Subió arriba en silla hasta la sala de los títulos, allí Su Exçelençia le reçibió; [...] Su Exçelençia le acompañó hasta la silla que estaua preuenida en la antecámara de los títulos, se puço en silla y se fue, acompañándole los capitanes y criados de Su Exçelençia hasta la última escalera del pattio, y se fue. ${ }^{62}$

Tragsessel zählten im Königreich Neapel während des I6. und I7. Jahrhunderts mit Fug und Recht zu den bedeutendsten Transportmitteln und standen im Rang allein den Karossen nach. Der massive Einsatz von Tragsesseln lässt sich jedoch nur für den oben erwähnten Zeitraum beobachten. Schon für die Regierungszeit der österreichischen Vizekönige ist in den Quellen ein starker Rückgang bei der Verwendung von Tragsesseln zu bemerken. ${ }^{63}$

Die vorliegende Untersuchung zeigt, dass Zeremonialschriften nicht nur eine einfache Beschreibung von komplexen höfischen Regeln sind, sondern auch eine reiche Informationsquelle für interdisziplinäre Forschungen darstellen. Im vorliegenden Fall liefern sie

6I Für Herren schickte es sich nicht, über Gebühr auf Tragsessel zurückzugreifen, da diese als Transportmittel für Damen und Kranke galten und deshalb nicht mit dem gängigen Männlichkeitsbild in Einklang zu bringen waren. Vgl. Cristina Bravo Lozano/Roberto Quirós Rosado (Hg.), En tierra de confluencias: Italia y la Monarquía de España. Siglos XVI-XVII (Valencia 2013), S. 313.

62 Antonelli 2012 (wie Anm. I), S. 504, cc. I68r-I68v.

63 Vgl. Antonelli 2014 (wie Anm. 26). 
umfangreiches Material zur Geschichte von Tragsesseln, aber auch für verschiedene andere Themenbereiche, von der Schneiderei über die Polsterei bis hin zur Tischlerei und Vergoldung.

Übersetzung aus dem Italienischen: MARIo DöBERL 


\section{Tragsessel an den Höfen der österreichischen Habsburger}

\section{$1 \quad$ Einleitung}

Wie an den meisten Höfen Europas standen auch in den Residenzen der österreichischen Habsburger jahrhundertelang Tragsessel in Verwendung, von denen sich einige bis heute erhalten haben. In der „Kaiserlichen Wagenburg Wien“ werden sieben Tragsessel aus dem I8. und 19. Jahrhundert aufbewahrt. Sechs davon stammen ursprünglich aus kaiserlichem

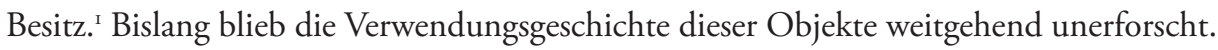
Ebenso war bisher unbekannt, seit wann es Tragsessel und Sesselträger am Kaiserhof gab, zu welchen Anlässen diese zum Einsatz kamen und wie die Vorgängermodelle der erhaltenen Tragsessel gestaltet waren.

Ziel des vorliegenden Beitrags ist es deshalb, ein wenig Licht in die im Dunkeln liegenden Anfänge dieses repräsentativen Tragevehikels zu bringen und nachzuverfolgen, wie es schrittweise in das kaiserliche Hofzeremoniell integriert wurde. Mit ergänzenden Seitenblicken auf andere Hofstaaten österreichischer Habsburger, vor allem auf jene der Tiroler Seitenlinie, soll versucht werden, die sukzessive Ausbreitung von Tragsesseln am Kaiserhof in einen breiteren Kontext zu stellen. Die wichtigsten Vergleichsbeispiele liefern jedoch zweifellos die in diesem Buch versammelten Beiträge, die die Verwendung von Tragsesseln in

Die diesem Beitrag zugrunde liegenden Quellen wurden großteils im Rahmen des zwischen 2008 und $201 \mathrm{I}$ vom Verfasser des vorliegenden Beitrags durchgeführten und vom österreichischen „Fonds zur Förderung der wissenschaftlichen Forschung“ (FWF) finanzierten Forschungsprojekts „Die Einführung von Fahrzeugen in das kaiserliche Hofzeremoniell“ (Р20316) gesammelt. Für eine kritische Lektüre des Beitrags sowie wertvolle Anregungen und Hinweise möchte ich mich bei Alejandro López Álvarez und Elisabeth Hassmann bedanken.

I Kaiserliche Wagenburg Wien, Inv.-Nrn. W 92-W 97. Der siebte Tragsessel (Inv.-Nr. W I47) gehörte einst den Fürsten Kinsky. Alle diese Tragsessel - bis auf Inv.-Nr. W 97 - sind abgebildet und kurz besprochen in Monica Kurzel-Runtscheiner, Die historischen Fahrzeuge der Schausammlung. In: Elisabetta Bresciani/Monica Kurzel-Runtscheiner/Elisabeth von Samsonow (Hg.), Schwanenhals und Goldkrepine. Höfischer Prunk und zeitgenössische Kunst - eine Konfrontation (Ausstellungskatalog, KHM, Wagenburg 2004), S. 89-105, hier S. 94 f., 98, IOI, I03. 
anderen Teilen Europas behandeln. Ferner wird der Versuch unternommen, die vielen verstreuten Informationen zum Aussehen und zur Ausstattung der kaiserlichen Tragsessel zu sammeln und den ältesten erhaltenen Tragsessel des Kaiserhofs zeitlich einzuordnen. Besonderes Augenmerk soll im vorliegenden Aufsatz auch den kaiserlichen Sesselträgern selbst geschenkt werden. Sie zählten zu jener großen Gruppe einfacher, niederrangiger Hofdiener, über die die Quellen des I7. Jahrhunderts für gewöhnlich schweigen und von denen sie bestenfalls die Höhe ihrer Besoldung beziehungsweise biographische Eckdaten preisgeben, hinter denen die Funktionsträger jedoch nur selten als Individuen mit eigener Geschichte hervortreten. Durch einen glücklichen Zufall haben sich in einem privaten Adelsarchiv mehrere Bittgesuche kaiserlicher Sesselträger erhalten, die Informationen zu ihrer Herkunft, ihren Karriereverläufen und ihren privaten Nöten liefern. Diese Schreiben werden in einem eigenen, den Sesselträgern gewidmeten Abschnitt ausgewertet. Behandelt wird außerdem die Einführung von Miettragsesseln in der kaiserlichen Residenzstadt Wien, die dort wesentlich später als in vielen anderen europäischen Machtzentren vonstattenging. Der zeitliche Rahmen der vorliegenden Untersuchung erstreckt sich hauptsächlich vom I6. Jahrhundert bis zum Tod Kaiser Leopolds I. im Jahr I705, wobei punktuell auch Rückblicke ins Spätmittelalter und Ausblicke in die Zeit bis Mitte des I8. Jahrhunderts gemacht werden. Zwar stellt die obere zeitliche Begrenzung mit dem Ableben Leopolds I. für die Geschichte der Tragsessel am Kaiserhof keineswegs eine Zäsur dar, jedoch lässt sie sich als Schlusspunkt für eine Untersuchung der Frühzeit dieser Tragevehikel vertreten, da Tragsessel bis dahin sowohl im Rahmen des Hofzeremoniells als auch in Form mietbarer Verkehrsmittel im Straßenbild der kaiserlichen Residenzstadt Wien ihren festen Platz gefunden hatten.

\section{Tragsessel an österreichischen Höfen bis zum Ende der Regierung Kaiser Leopolds I. (1705)}

2.1 Frühe Erwähnungen von Tragsesseln bis Anfang des 17. Jahrhunderts: Ein Transportmittel für gehbehinderte Fürsten

Eine Suche nach dem exakten Zeitpunkt, an dem Tragsessel an den Höfen der österreichischen Länder erstmals aufschienen, bliebe wohl vergebens. Es ist vielmehr davon auszugehen, dass altersschwache und gehbehinderte Mitglieder des Hauses Habsburg immer schon zu Hilfsmitteln wie Tragsesseln griffen, um ihre Mobilität zu erhalten beziehungsweise wiederzuerlangen, denn ohne diese war die Wahrnehmung herrschaftlicher Pflichten und eine Teilnahme am gesellschaftlichen Leben kaum denkbar. Fürsten, denen es aus gesundheitlichen Gründen verwehrt war, Wege zu Fuß oder auf dem Rücken eines Pferdes 


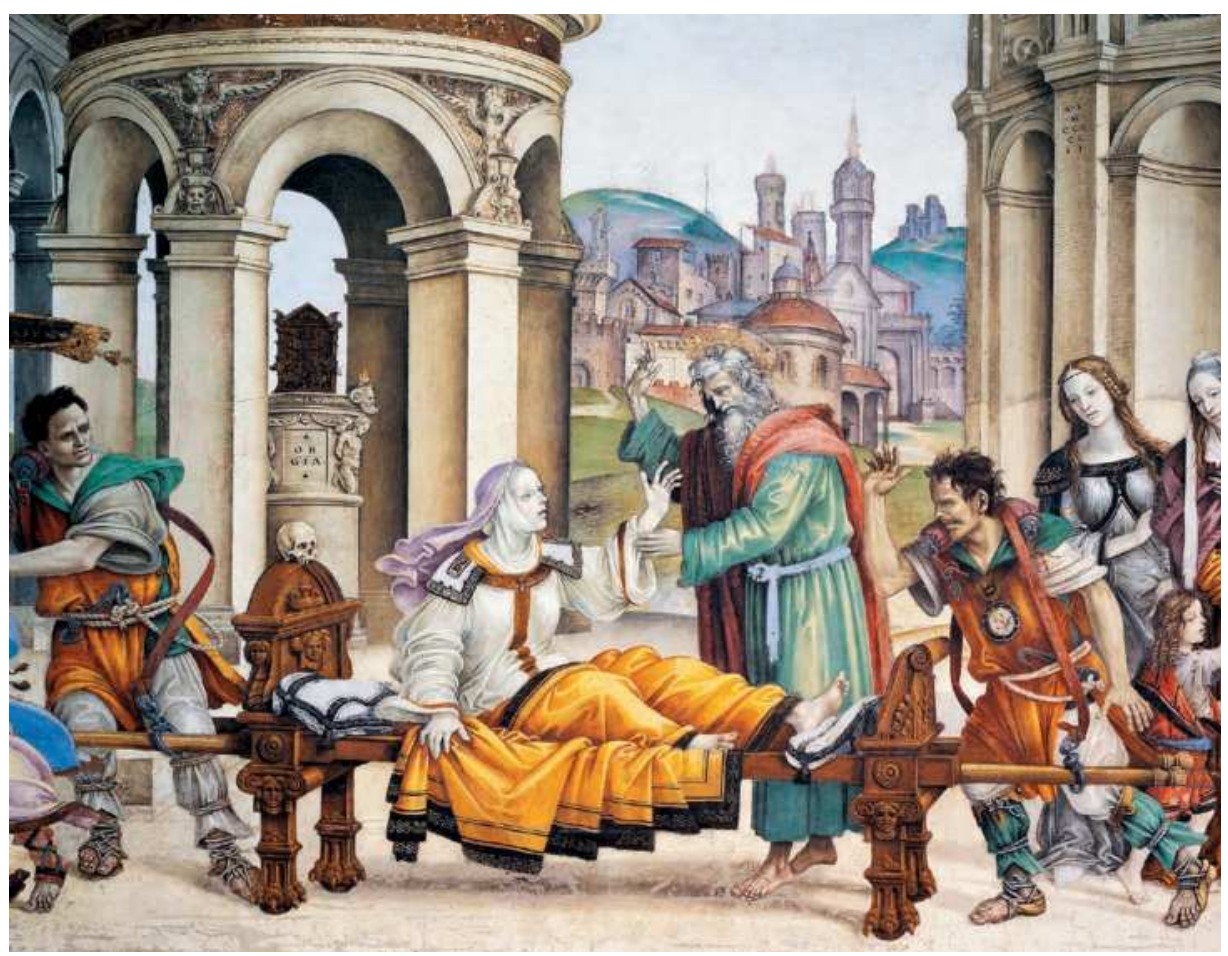

Abb. 1: Repräsentative Krankenbahre um 1500. Ausschnitt aus dem Wandfresko „Auferweckung der Drusiana durch Johannes den Evangelisten" in der Cappella Strozzi in Santa Maria Novella, Florenz. Filippino Lippi, um 1487/1502. Foto: DeAgostini Picture Library/Scala, Florenz

zurückzulegen, ließen sich bereits im Mittelalter auf kurzen Wegen im Freien oder auf längeren Überlandreisen in Pferdewagen beziehungsweise in Maultier- oder Pferdesänften befördern. In geschlossenen Räumen, etwa in Palästen oder Kirchen, war der Einsatz von Transportmitteln, die mit Hilfe der Zug- oder Tragkraft von Tieren bewegt wurden, jedoch nicht praktikabel. Es lag deshalb nahe, Fürsten, denen das Gehen schwerfiel oder sogar gänzlich unmöglich war, im Inneren von Gebäuden mittels menschlicher Muskelkraft zu bewegen. Dabei bot es sich an, die transportierte Person eine sitzende Haltung einnehmen zu lassen, da ihr auf diese Weise - im Unterschied zur Beförderung in liegender Position, welche die körperliche Hinfälligkeit besonders deutlich vor Augen führt (vgl. Abb. I) - ein verhältnismäßig hohes Maß an Würde belassen werden konnte. Zwar wurden bereits im ausgehenden Mittelalter Vorformen von Rollstühlen entwickelt, ${ }^{2}$ am Wiener

2 Fritz Hörber, Auf Kufen und Rädern. Die Geschichte des Krankentransports und der Krankenfahrzeuge (München 1976), S. II f. Zu mit Rollstühlen vergleichbaren Vehikeln des Spätmittel- 
Hof scheint es solche aber erst ab der ersten Hälfte des i8. Jahrhunderts gegeben zu haben. ${ }^{3}$ Relativ unkompliziert war es, gehbehinderte Personen in einem von Männern getragenen Sessel transportieren zu lassen, da auf diese Weise die Überwindung kleinerer oder größerer Niveauunterschiede wie Türschwellen oder Treppen einfach zu bewerkstelligen war. Im besten Fall erinnerte ein Fürst, der in einem Sessel getragen wurde, sogar an ein positiv konnotiertes Bild, nämlich an einen thronenden Herrscher.

Mehrere habsburgische Fürsten des Spätmittelalters waren zumindest zeitweise gehbehindert und deshalb gezwungen, Tragevehikel zu verwenden. Herzog Albrecht II. von Österreich (I298-I358), der von der Historiographie auch mit dem Beinamen „der Lahme“ versehen wurde, litt von 1330 an bis zu seinem Tod - also beinahe drei Jahrzehnte lang unter Lähmungen an Armen und Beinen. Nahm man früher an, dass sein Leiden von einer Vergiftung herrührte, zeigten jüngere Untersuchungen an seinem Skelett, dass er an einer stark ausgeprägten Polyarthritis litt. ${ }^{4}$ Wie stark seine Bewegungsfähigkeit tatsächlich eingeschränkt war, demonstriert eine Anekdote des Geschichtsschreibers Johann von Viktring (ca. I270-I347), eines Zeitgenossen Albrechts II. Er schilderte ein Zusammentreffen im Jahr 1342 in Wien zwischen dem gelähmten Herzog und König Johann von Böhmen, der seinerseits die Sehkraft zur Gänze verloren hatte. Die beiden auf unterschiedliche Weise behinderten Fürsten führten dabei in einem geschlossenen Raum eine vertrauliche

alters und der Frühen Neuzeit siehe auch Ernst HAUTSCH, Der Nürnberger Zirkelschmied Johann Hautsch (1595-1670) und seine Erfindungen. In: Mitteilungen des Vereins für Geschichte der Stadt Nürnberg 46 (1955), S. 533-556, hier S. 535; Jörg Jochen Berns, Die Herkunft des Automobils aus Himmelstrionfo und Höllenmaschine (Kleine kulturwissenschaftliche Bibliothek 54, Berlin I996), S. $72 \mathrm{f}$.

3 Vgl. den Rollstuhl von Kaiserin Elisabeth Christine im Hofmobiliendepot - Möbel Museum Wien. Christian Witt-Dörring, Die Möbelkunst am Wiener Hof zur Zeit Maria Theresias I740-1780 (ungedr. Dissertation, Universität Wien 1978), S. 204-206; Eva B. Ottillinger, Kaiserliches Hofmobiliendepot (Wien 2000), S. I3. Zwei vergleichbare Rollstühle des preußischen Hofes aus dem I8. Jahrhunderts wurden bis zum Zweiten Weltkrieg im Hohenzollernmuseum in Schloss Monbijou ausgestellt und sind seither verschollen. Siehe dazu (mit Abbildungen) Claudia Meckel, Kutschen, Schlitten, Sänften (Stiftung Preußische Schlösser und Gärten Berlin-Brandenburg, Bestandskatalog der Kunstsammlungen, Berlin 2013), S. 237 f.

$4 \mathrm{Zu}$ ihm und seiner gesundheitlichen Beeinträchtigung siehe Erika ElOGA, Albrecht II. Herzog von Österreich. Eine Monographie (ungedr. Dissertation, Universität Wien 1952), im Besonderen S. 34-37; Alphons Lнотsку, Geschichte Österreichs seit der Mitte des I3. Jahrhunderts (I28I-I358) (Veröffentlichungen der Kommission für Geschichte Österreich I, Wien I967), S. 310-375, im Besonderen S. 310 f.; Günther HöDL, Habsburg und Österreich I273-I493. Gestalten und Gestalt des österreichischen Spätmittelalters (Wien/Köln/Graz 1988), S. 75-92, im Besonderen S. 83; Winfried Stelzer, Albrecht II., „der Weise“, der „Lahme“. In: Brigitte Hamann (Hg.), Die Habsburger. Ein biographisches Lexikon (Wien 1988), S. 34-35; Alois Niederstätter, Die Herrschaft Österreich. Fürst und Land im Spätmittelalter (Österreichische Geschichte I278-I4II, Wien 200I), S. I32-I45. 
Unterredung unter Ausschluss von Zeugen. Als das Gespräch zu Ende war, bemühte sich der blinde Gast, den Ausgang zu finden. Als Albrecht II. sah, wie sich Johann von Böhmen vergeblich die Wand entlangtastete, versuchte er diesem mit Worten den Weg zur Tür zu weisen, da er ihm aufgrund seiner eigenen Gehbehinderung nicht zu Hilfe eilen konnte. Nachdem seine mündlichen Hinweise aber nicht das erwünschte Resultat erbracht hatten, erfassten außerhalb des Raumes wartende Diener die für beide Herrscher höchst unangenehme Situation und befreiten sie aus ihrer misslichen Lage. ${ }^{5}$

Trotz seines körperlichen Gebrechens ließ sich Albrecht II. nicht von ausgedehnten Reisen abhalten. So begab er sich etwa im Jahr 1337 auf eine circa fünf Monate dauernde Wallfahrt nach Aachen und Köln, die ihn auf dem Rückweg über das Elsass, Augsburg und Konstanz führte, bevor er schließlich wieder nach Wien zurückkehrte. ${ }^{6}$ Natürlich musste sich der Herzog, dem seit 1330 weder das Gehen noch das Reiten möglich war, dabei eines Vehikels bedienen. Johann von Viktring nannte das vom Herzog verwendete Transportmittel „sella gestatoria"7, womit - im Unterschied zur von Maultieren oder Pferden getragenen „lectica“ (Sänfte) - in der Regel ein von Menschen beförderter Tragsessel bezeichnet wurde. Bemerkenswert ist in diesem Zusammenhang auch, dass für das Jahr 1355 in den Quellen ein gewisser „Johannes portator ducis“ als Besitzer von Weingärten vor den Toren Wiens dokumentiert ist. Womöglich fungierte er als Sesselträger Albrechts II. und kann somit vielleicht als erster namentlich bekannter, im Dienst des Hauses Habsburg stehender Sesselträger gelten. ${ }^{8}$

Aus der ersten Hälfte des I4. Jahrhunderts ist auch ein frühes, sehr ungewöhnliches Beispiel für die Verwendung eines Tragevehikels beim Einzug eines römischen Königs auf dem Weg zur Kaiserkrönung dokumentiert. Sigismund von Luxemburg (I368-I437) ${ }^{9}$

5 Fedor Schneider (Hg.), Iohannis abbatis Victoriensis. Liber certarum historiarum, 2 Bde. (Scriptores rerum Germanicarum in usum scholarum ex Monumentis Germaniae Historicis separatim editi, Hannover/Leipzig 1909-I910), Bd. 2, S. 225.

6 Ebenda, Bd. 2, S. 169-172, 204-206.

7 „Dux vero Albertus, membrorum compage contracta, ad opera militaria impotens quoad manuum et pedum virtutem, sella gestatoria mira preditus sapiencia et industria circumfertur [...]." Ebenda, Bd. 2, S. 136. An anderer Stelle schreibt Johann von Viktring im selben Zusammenhang von einem „Tragevehikel“: „[...] in vehiculo gestatorio semper vectus [...].“ Ebenda, Bd. 2, S. IO2.

8 Richard MüLLER, Wiens höfisches und bürgerliches Leben im ausgehenden Mittelalter. In: Geschichte der Stadt Wien, hg. vom Alterthumsvereine zu Wien, Bd. II/2 (Wien 1907), S. 626-757, hier S. 652.

$9 \mathrm{Zu}$ ihm siehe Jörg K. Hoensch, Kaiser Sigismund. Herrscher an der Schwelle zur Neuzeit I368-I437 (München 1996). Zu seinem Romzug und zu seinen gesundheitlichen Problemen siehe ebenda, S. 37I-399, 457-46I, 628 f.; allgemein zu Kaiser Sigismund siehe außerdem Michel Pauly/ François Reinert (Hg.), Sigismund von Luxemburg. Ein Kaiser in Europa. Tagungsband des internationalen historischen und kunsthistorischen Kongresses in Luxemburg, 8.-IO. Juni 2005 
war bereits alt und von der Gicht geplagt, als er Ende I43I nach Italien reiste, um sich in Rom vom Papst zum Kaiser krönen zu lassen. Seine Reise an den päpstlichen Hof dauerte außergewöhnlich lange und wurde von zahlreichen längeren Aufenthalten in italienischen Städten unterbrochen. Die Ankunft in diesen Städten erfolgte häufig in Form festlicher Einzüge. Als Sigismund am 9. Mai 1433 Viterbo erreichte, war er aus gesundheitlichen Gründen gezwungen, bei seinem Einzug von einer Pferdesänfte Gebrauch zu machen, die die Form eines Sessels hatte. Offenbar wurden die Tragetiere vor oder während der Zeremonie aber ausgespannt und der Sessel des Kaisers unter einem Baldachin von einer größeren Anzahl an Männern transportiert, die sich dabei zweier langer, runder Trageholme bedienten. ${ }^{\text {Io }}$ Dieses Beispiel zeigt, dass die Grenzen zwischen Pferde- beziehungsweise Maultiersänften und Tragsesseln zuweilen durchlässig waren und Erstere fallweise zu Letzteren umfunktioniert werden konnten.

Meist ist in den Quellen, die von Fürsten berichten, denen weder das Reiten noch das Gehen möglich war, jedoch nicht von Tragsesseln, sondern von Sänften oder Wagen die Rede. Von den österreichischen Herzögen Albrecht IV. (I377-I404) ${ }^{\mathrm{II}}$ und seinem Sohn Albrecht V. (als Kaiser Albrecht II., I397-I439) ${ }^{\text {I2 }}$ ist beispielsweise überliefert, dass sich beide während ihrer letzten Lebenstage, an der Ruhr erkrankt und vom Tode gezeichnet,

(Mainz 2006); Karel Hruza/Alexandra KaAr (Hg.), Kaiser Sigismund (I368-I437). Zur Herrschaftspraxis eines europäischen Monarchen (Forschungen zur Kaiser- und Papstgeschichte des Mittelalters. Beihefte zu J. F. Böhmer, Regesta Imperii 3I, Wien/Köln/Weimar 20I2).

„Lì vi andò incontro tutto il popolo di Viterbo con un drappo di fin oro, lo quale posero con certe aste sopra il capo dellimperatore, e con grandissimo onore lo remisero dentro alla porta di S. Lucia della città, e smontò a S. Francesco. Lo detto imperatore venia sopra una sedia, che si posava sopra dui corsieri, e molti omini aiutavano a portarla con dui legni lunghi e tondi." Nicola Della Tuccia, Cronache di Viterbo e di altre città. In: Ignazio Ciampi (Hg.), Cronache e statuti della città di Viterbo (Documenti di storia italiana publicati a cura della R. deputazione sugli studi di storia patria per le provincie di Toscana, dell'Umbria e delle Marche 5, Firenze i872), S. I-272, hier S. I24. Vgl. Dazu auch Achim Thomas HaCK, Das Empfangszeremoniell bei mittelalterlichen Papst-Kaiser-Treffen (Forschungen zur Kaiser- und Papstgeschichte des Mittelalters. Beihefte zu J. F. Böhmer, Regesta Imperii 18, Köln/Weimar/Wien 1999), S. 347; Claudia Märtu, Papst Pius II. (I458-I464) in der Kapelle des Palazzo Medici Riccardi zu Florenz. Ein Beitrag zu Ikonographie und Zeremoniell der Päpste in der Renaissance. In: Concilium medii aevi. Zeitschrift für Geschichte, Kunst und Kultur des Mittelalters und der Frühen Neuzeit 3 (2000), S. I55-183, hier S. I63.

II Zu ihm Gerda Mraz, Albrecht IV. In: Hamann 1988 (wie Anm. 4), S. 38 f.

I2 Zu ihm Wilhelm Wostry, König Albrecht II. (I437-I439), 2 Bde. (Prager Studien aus dem Gebiete der Geschichtswissenschaft I2-I3, Prag 1906-1907); Gerda Koller, Princeps in Ecclesia. Untersuchungen zur Kirchenpolitik Herzog Albrechts V. von Österreich (Archiv für österreichische Geschichte 124, Graz/Wien/Köln 1964); Günther HöDL, Albrecht II. Königtum, Reichsregierung und Reichsreform I438-I439 (Forschungen zur Kaiser- und Papstgeschichte des Mittelalters. Beihefte zu J. F. Böhmer, Regesta Imperii 3, Wien/Köln/Graz 1978), im Besonderen S. 36. 
jeweils in einer Sänfte („letica“ beziehungsweise „lectica“) transportieren ließen. ${ }^{13}$ Auch Kaiser Maximilian I. (1459-I5I9) hatte in den letzten Jahren seines Lebens mit gravierenden gesundheitlichen Problemen zu kämpfen, die es ihm immer wieder verunmöglichten, auf Reisen oder bei öffentlichen Auftritten zu reiten. ${ }^{14}$ So musste er sich etwa im Jahr I5I5 beim Einzug anlässlich des Wiener Fürstenkongresses in einer Pferdesänfte transportieren lassen, die mit schwarz und scharlachrot kariertem Samt bezogen war. ${ }^{15}$ Das genaue Aussehen dieser Sänfte ist uns leider nicht bildlich überliefert, sie ähnelte aber womöglich jener, die seine Tochter Margarete (I480-I530) im gleichen Jahr beim Einzug ihres Neffens Karl V. in Brügge verwendete (Abb. 2). ${ }^{16}$ Siegmund von Herberstein war Augenzeuge, als Maximilian I. ein anderes Mal eine Sänfte verwendete. Herberstein traf den bereits vom nahenden Tod gezeichneten Kaiser, als dieser gegen Ende des Jahres 1518, nur wenige Wochen vor seinem Ableben, durch Salzburg reiste. Dabei wurde er laut Angaben Herbersteins in einer Sänfte getragen. ${ }^{17}$ Die letzte Station im Leben des bereits dahinsiechenden

I3 Thomas Ebendorfer, Chronica Austriae, hg. von Alphons Lhotsky (Monumenta Germaniae Historica, Scriptores rerum Germanicarum, Nova series I3, Berlin/Zürich 1967), S. 321, 378.

I4 $\mathrm{Zu}$ den Krankheiten des Kaisers, die zeitweise zu Gehbehinderungen führten, siehe Hermann Wiesflecker, Kaiser Maximilian I. Das Reich, Österreich und Europa an der Wende zur Neuzeit, 5 Bde. (Wien 197I-I986), Bd. 4: Gründung des habsburgischen Weltreiches. Lebensabend und Tod I508-1519 (Wien 198I), S. 629-632.

I5 Wo und wie Ro. Kay. Maiestat und die Kunig von Hungern, Poln und Peham zusammen kumen und zu Wienn eingeritten sendt (o.O. o.J., aber Wien I5I5), o.S.; (Johannes Cuspinianus), Der nambhaftigen kay. Ma. und dreyer Kunigen zu Hungern Beham und Poln zamenkumung und versamlung so zu Wienn in dem Heymonat [...] MDXV. jar geschehen [...] (o.O. o.J. aber Wien I5I5), o.S.; Marino Sanuto, I Diarii, Bd. 20 (Venezia I887), Sp. 48I f.; Wiesflecker I97I-I986 (wie Anm. I4), Bd. 4: Gründung des habsburgischen Weltreiches. Lebensabend und Tod I508-1519 (Wien 198I), S. I86-I89. Am Wiener Hof scheinen zu jener Zeit für Sänften Pferde und nicht Maultiere verwendet worden zu sein. Vgl. dazu auch Anneliese GATT, Der Innsbrucker Hof zur Zeit Kaiser Maximilians I. I493-1519 (ungedr. Dissertation, Universität Innsbruck 1943), S. I02; Thomas Fellner/Heinrich Kretschmayr, Die österreichische Zentralverwaltung I/2 (Veröffentlichungen der Kommission für neuere Geschichte Österreichs 6, Wien 1907), S. I44; ÖStA, FHKA, NÖHA, W 6I/a/36/a, fol. 28v.

I6 Wenn wir einer unmittelbar nach dem Einzug Karls entstandenen Buchmalerei, die diesen Einzug zum Thema hat, Authentizität zuschreiben können, handelte es sich dabei um eine von zwei Schimmeln getragene Sänfte mit schwarzer Kobelbespannung, goldenen Verzierungen und einem Einstieg an der Längsseite, dessen Verdeck sich zurückschlagen ließ. Ihr tonnengewölbtes Dach wurde an den Schmalseiten von einer vergoldeten Maßwerkstruktur gestützt. Zur Entstehung des Codex, in dem sich die Darstellung befindet, siehe Franz Unterkircher, Die datierten Handschriften der Österreichischen Nationalbibliothek von I50I bis I60o (Katalog der datierten Handschriften in lateinischer Schrift in Österreich 4, Wien 1976), S. 23.

I7 Th[eodor] G. von Karajan (Hg.), Johannes Tichtel's Tagebuch MCCCCLXXVII bis MCCCCXCV, Sigmunds von Herberstein Selbstbiographie MCCCCLXXXVI bis MDLIII, Jo- 


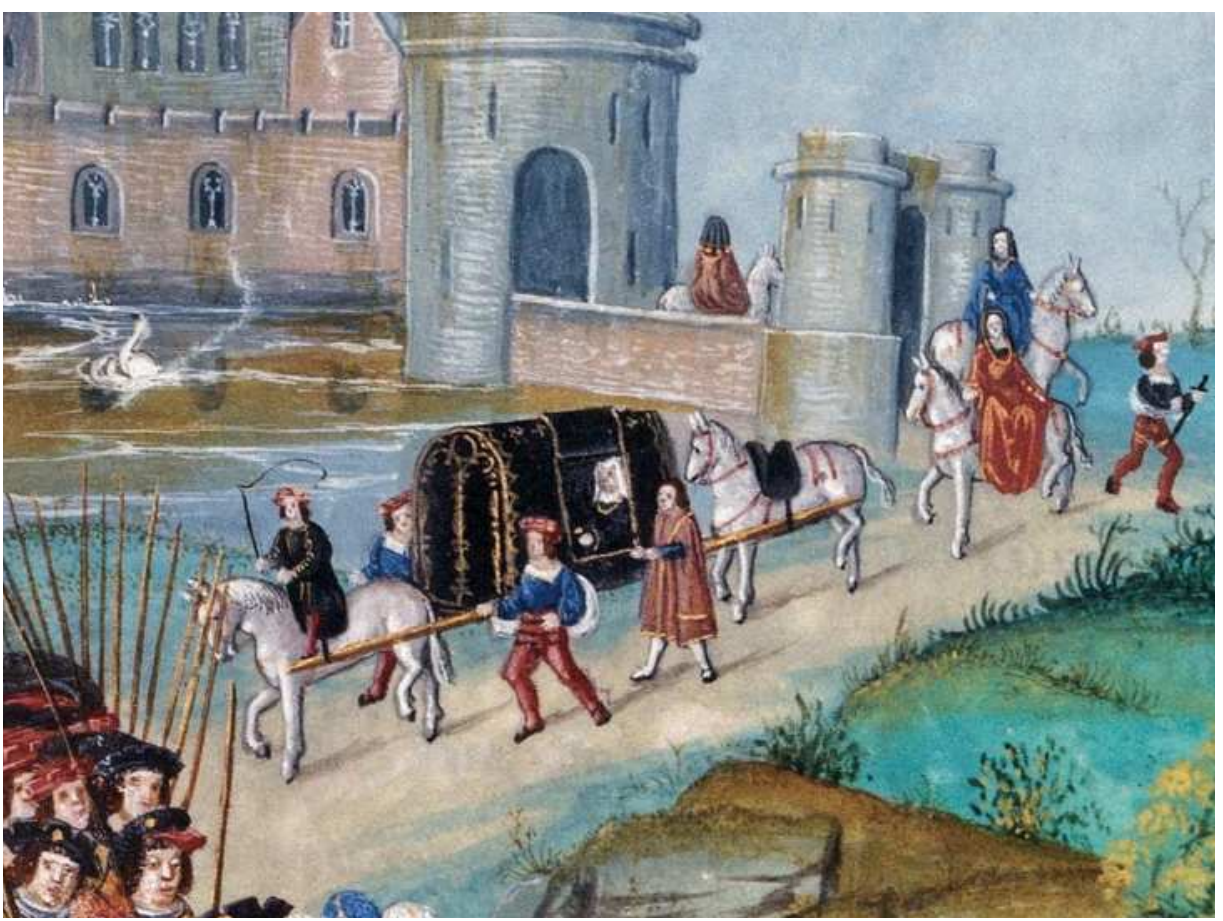

Abb. 2: Die Statthalterin der habsburgischen Niederlande, Margarete von Österreich, in einer Pferdesänfte beim am 18. April 1515 erfolgten Einzug ihres Neffen, des späteren Kaisers Karl V. (Detail). ÖNB, Cod. 2591, fol. 7. (C) ÖNB

Monarchen war Wels. Dort ließ er sich täglich auf einem Krankenstuhl zur Messe befördern. ${ }^{18}$

Wie wir uns einen solchen für Krankentransporte vorgesehenen Tragsessel aus jener Zeit vorstellen können, zeigt ein Holzschnitt, dessen in den Jahren vor I520 entstandene Vorlage von einem bis heute nicht identifizierten und deshalb mit dem Hilfsnamen „Petrarca-Meister “' ${ }^{\text {‘9 }}$ bezeichneten Künstler stammte (Abb. 3). Bei diesem auf dem Holzschnitt

hannes Cuspinian's Tagebuch MDII bis MDXXVII und Georg Kirchmair's Denkwürdigkeiten MDXIX bis MDLIII (Fontes rerum austriacarum I/I, Wien I855), S. I4I.

I8 Wiesflecker I97I-I986 (wie Anm. I4), Bd. 4: Gründung des habsburgischen Weltreiches. Lebensabend und Tod I508-1519 (Wien I98I), S. 423 f.

I9 Zu ihm und der Bildserie, der dieser Holzschnitt entstammt, siehe Wilhelm Fraenger, Altdeutsches Bilderbuch. Hans Weiditz und Sebastian Brant (Leipzig 1930); Walther Scheidig, Die Holzschnitte des Petrarca-Meisters zu Petrarcas Werk: von der Artzney bayder Glück des guten und widerwärtigen - Augsburg 1532 (Berlin 1955); Hans-Joachim Raupp, Die Illustrationen zu Francesco Petrarca, „Von der Artzney bayder Glueck des guten vnd widerwertigen“ (Augsburg I532). 


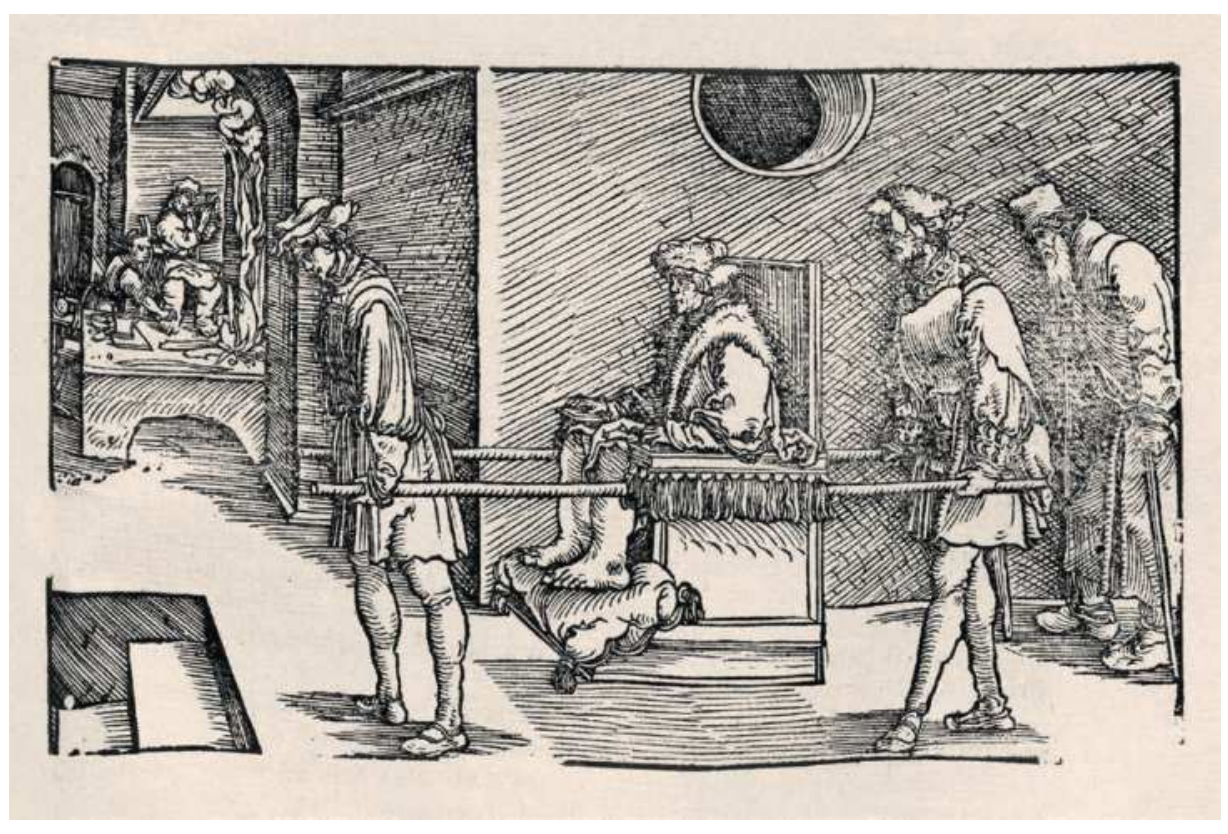

Abb. 3: Ein an den Beinen erkrankter Mann wird von zwei Männern in einem Tragsessel transportiert. Ausschnitt aus einem Holzschnitt. Petrarca-Meister, um 1520. Aus: Francesco Petrarca, Trostspiegel in Glück und Unglück. [...] zwey Trostbücher / Von Artznei und Rath [...] Jetzund von newem widerumb zügericht und in Truck verfertiget (Frankfurt a. M. 1572), fol. 182 r. @ ÖNB

dargestellten von zwei Männern beförderten Tragsessel handelt es sich um einen einfachen Armlehnstuhl. Er ist auf einer Plattform fixiert, die dem Kranken zum Abstützen der Beine diente. Die einzige sichtbare Verzierung des Sessels bilden von den Armstützen herabhängende Fransen, die verbergen, wie die beiden Trageholme an den Seitenwänden befestigt waren. Ein in dieser Schlichtheit vergleichbarer Tragsessel, der ohne jegliche Polsterung und textilen Schmuck auskommt, dafür aber mit Schnitzdekor versehen ist und eine ornamental durchbrochene Rückenlehne aufweist, hat sich in der Schweiz erhalten (Abb. 4). ${ }^{20}$

In: Wallraf-Richartz-Jahrbuch 45 (1984), S. 59-II2.

20 Solothurn, Museum Blumenstein, Inv.-Nr. 1986.77. Siehe dazu Rudolf H. Wackernagel (Hg.), Staats- und Galawagen der Wittelsbacher. Kutschen, Schlitten und Sänften aus dem Marstallmuseum Schloß Nymphenburg, 2 Bde. (Stuttgart 2002), Bd. I, S. 76, Abb. 78. Dieser Tragsessel lässt sich aufgrund der in die Lehne geschnitzten Jahreszahl mit 1647 datieren und stammt vermutlich aus dem Besitz von Emanuel Hermann, Landvogt in Saanen (I608-I664). Es handelt sich dabei um den einzigen bislang bekannten offenen Tragsessel des I7. Jahrhunderts, der die Zeiten überdauert hat. 


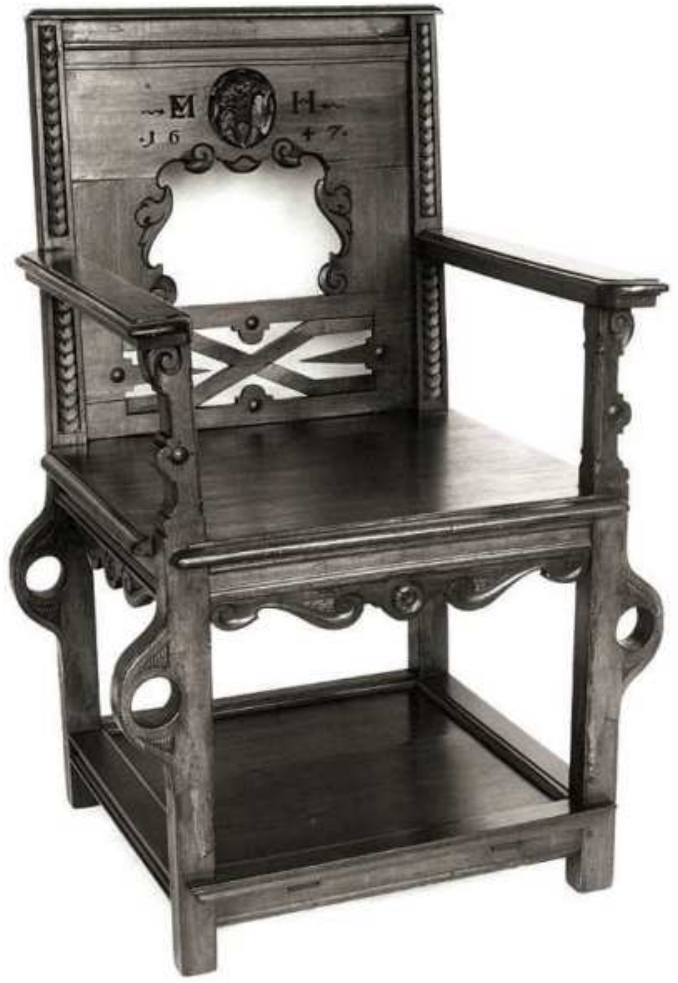

Abb. 4: Tragsessel, vermutlich aus dem Besitz von Emanuel Hermann, Landvogt von Saanen. Vermutlich Schweiz, 1647. KHM, Kaiserliche Wagenburg, Bildarchiv

Die für die letzten Lebensjahre Kaiser Maximilians I. vermehrt zu beobachtende Verwendung von Sänften hinterließ auch in seinem Hofstaat Spuren. Ein unmittelbar nach dem am I2. Januar I519 in Wels erfolgten Tod des Kaisers erstelltes Hofstaatsverzeichnis führt unter anderem vier Sänftenknechte und zwei Stallbuben für die Sänftenpferde an. Ein fünfter Sänftenknecht Maximilians I. war in Innsbruck zurückgeblieben. ${ }^{21}$ Sesselträger sucht man in seinem Hofstaat jedoch vergeblich. ${ }^{22}$

Ein ähnliches Bild zeigt sich auch für die darauf folgenden Jahrzehnte. Im Zeitraum zwischen I519 und Anfang des I7. Jahrhunderts lässt sich in den erzherzoglichen, königlichen und kaiserlichen Hofstaaten der in den österreichischen Ländern regierenden Fürsten zwar zumeist Personal zur Bedienung von Sänften nachweisen, Hinweise auf die Beschäf-

2I Fellner/Kretschmayr i9O7 (wie Anm. I5), S. I44.

22 Vgl. ebenda, S. I39-I47. 
tigung von Sesselträgern fehlen dort jedoch zur Gänze. ${ }^{23}$ Auch die spärlichen Informationen, die über die Fuhrparks habsburgischer Höfe vom Spätmittelalter bis zu Anfang des I7. Jahrhunderts vorliegen, deuten darauf hin, dass Tragsessel zu jener Zeit keineswegs zur Standardausstattung von Haushalten österreichischer Fürsten und Fürstinnen zählten. Hierfür seien einige Beispiele angeführt. Herzogin Katharina (um I42O-I493), die Schwester Kaiser Friedrichs III., erhielt etwa anlässlich ihrer 1447 erfolgten Hochzeit für die Reise zu ihrem Bräutigam nach Baden vier teils äußerst prunkvolle Wagen, aber keinen Tragsessel zur Verfügung gestellt. ${ }^{24}$ Auch zur Stallausstattung, welche die beiden Prinzessinnen Maria von Ungarn (I505-I558) und Anna Jagiello (I503-I547) im Jahr I52I für ihre Brautreisen zu Ludwig II. Jagiello (I506-I526) beziehungsweise Erzherzog Ferdinand (I503-1564) erhielten, zählten zwar jeweils eine Pferdesänfte und fünf Wagen, von denen einige äußerst kostbar ausgeführt waren, jedoch ebenfalls keine Tragsessel. ${ }^{25}$ Relativ

23 Vgl. etwa die zahlreichen handschriftlichen Hofstaatsverzeichnisse von I5I9 bis I6I5 in ÖStA, HHStA, OMeA, SR, K. I8I-I84; ergänzend dazu die gesammelten Hofstaatsverzeichnisse Kaiser Rudolfs II. in Jaroslava Hausenblasová, Der Hof Kaiser Rudolfs II. Eine Edition der Hofstaatsverzeichnisse I576-I6I2 (Fontes Historiae Artium 9, Prag 2002). Die vollständigsten und zuverlässigsten Informationen zu den besoldeten königlichen und kaiserlichen Hofdienern finden sich in den Hofzahlamtsbüchern der Jahre I543 bis I622 (die nachfolgenden Hofzahlamtsbücher liefern nur unzureichende Informationen zum am Kaiserhof beschäftigten Personal) in ÖStA, FHKA, HZAB, Bd. I-7I. Das die Frauen der Fürsten bedienende Stallpersonal war in der Regel im Hofstaat des Herrschers inbegriffen. Aber auch die wenigen erhaltenen Hofstaatsverzeichnisse von Frauen aus dem I6. Jahrhundert führen keine Sesselträger an. Vgl. etwa den Hofstaat von Kaiserin Bianca Maria Sforza (I472-I5IO) von I504, in GaTT 1943 (wie Anm. I5), S. 38; oder den Hofstaat von Maria von Spanien, der Frau des späteren Kaisers Maximilian II., aus dem Jahr 1560, in ÖStA, FHKA, NÖHA, W 6r/a/36/a, fol. 469-473. Auch auf Tragsessel selbst bieten die Quellen bis zur Regierung Kaiser Matthias' keine Hinweise. Durchgesehen wurden in diesem Zusammenhang unter anderem die Protokoll- und Indexbände der königlichen- beziehungsweise kaiserlichen Hoffinanz: Für die Zeit von I53I-1575 und I6I2-16I9 vgl. ÖStA, FHKA, Hoffinanz Österreich, Bd. I80-320, 635-69o. Für den dazwischenliegenden Zeitraum siehe Lydia GröвL/Herbert HaupT, Kaiser Rudolf II. Kunst, Kultur und Wissenschaft im Spiegel der Hoffinanz. Teil I: Die Jahre I576 bis I595. In: Jahrbuch des Kunsthistorischen Museums Wien, Bd. 8/9 (2006/2007), S. 205-353; Herbert Haupt, Kaiser Rudolf II. Kunst, Kultur und Wissenschaft im Spiegel der Hoffinanz. Teil II: Die Jahre I596 bis I612. In: Jahrbuch des Kunsthistorischen Museums Wien, Bd. Io (2008), S. 227-399.

24 Herbert Haupt, Der „goldene Wagen“ der österreichischen Herzogin Katharina (I420-I493). In: Livrustkammaren I4/7-8 (1977), S. I73-194. ÖStA, FHKA, NÖHA, W 6r/a/36/a, fol. 17-44; ÖStA, FHKA, NÖHA, W 6r/a/rI/b, fol. 3-18. Siehe dazu auch Orsolya RÉTheLYI, „... Maria regina ... nuda venerat ad Hungariam ...“. The Queen's Treasures. In: Orsolya Réthelyi/Beatrix F. Romhányi/Enikö SpeKner/András VÉgh (Hg.), Mary of Hungary. The Queen and Her Court I52I-I53I (Ausstellungskatalog, Budapest History Museum/Slovenská národná galéria, Budapest 2005), S. I2I-I27; Orsolya RÉTHELYI, Die 
ausführliche Informationen liegen auch zum Fuhrpark von Erzherzogin Elisabeth (I526I545) vor, die 1543 den polnischen König Sigismund II. August heiratete. Auf der Liste der Stallgegenstände, die sie von Wien auf ihre Brautreise nach Krakau mitnahm, sind allein zwei prachtvolle Wagen samt Zubehör und Pferdegespann erwähnt, aber keinerlei Tragevehikel. ${ }^{26} \mathrm{Im}$ Jahr 1553 vermählte sich Sigismund II. August in dritter Ehe mit Erzherzogin Katharina (I533-I572), der Schwester seiner ersten Frau Elisabeth. Nachdem sich herausgestellt hatte, dass die Ehe kinderlos bleiben würde, wandte sich Sigismund II. August von seiner Frau ab, woraufhin diese 1566 Polen verließ und sich nach Linz zurückzog. ${ }^{27}$ Weder in einem von 1568 datierenden Inventar all ihrer Textilien, das unter anderem verschiedenste Wagen- und Sänftendecken, Wagenpolster und -teppiche, Matratzen für Sänften und Wagen sowie Schlittendecken und Ähnliches verzeichnet, noch in ihrem Nachlassinventar, das ebenfalls derartige Gegenstände auflistet, und auch nicht in den testamentarischen Verfügungen der Erzherzogin, in denen sie mehrere Mitglieder ihres Hofstaats mit Fahrzeugen bedachte, finden sich Hinweise auf etwaige in ihrem Besitz befindliche Tragsessel..$^{28}$

Der älteste bisher bekannte vollständige Überblick über den Fuhrpark eines habsburgischen Fürsten des österreichischen Familienzweigs findet sich im Nachlassinventar von Ferdinand II. von Tirol (I529-I595) ${ }^{29}$ aus dem Jahr I596..$^{\circ 0}$ Dieses Inventar umfasst nicht

Anfänge der Ofener Hofhaltung der Königin Maria von Ungarn. In: Martina Fuchs/Orsolya RÉThelyi (Hg.), Maria von Ungarn (I505-1558). Eine Renaissancefürstin (Geschichte in der Epoche Karls V. 8, Münster 2007), S. 22I-243.

Hans von Voltelini, Urkunden und Regesten aus dem k. und k. Haus-, Hof- und Staatsarchiv (Fortsetzung). In: Jahrbuch der kunsthistorischen Sammlungen des Allerhöchsten Kaiserhauses, Bd. II (I890), S. I-LXXXIII, hier Reg. 6360. Die Fahrzeuge werden auch in der Autobiographie des Siegmund von Herberstein erwähnt, der Elisabeth als Hofmeister nach Polen begleitete: KaraJAN I855 (wie Anm. I7), S. 355 .

27 Walter Pillich, Königin Katharina von Polen in Linz. In: Historisches Jahrbuch der Stadt Linz I966 (I967), S. I69-198; Anna Sucheni-Grabowska, Zu den Beziehungen zwischen den Jagiellonen und den Habsburgern. Katharina von Österreich, die dritte Gemahlin des Königs Sigismund August. Ein Forschungsbeitrag. In: Historisches Jahrbuch der Stadt Linz 1979 (1980), S. 59-100. ÖStA, FHKA, NÖHA, W 6I/a/36/b, fol. 528-533; TLA, Inventare, A I/28; PILlich 1967 (wie Anm. 27), S. 169-198.

$29 \mathrm{Zu}$ ihm siehe Josef Hirn, Erzherzog Ferdinand II. von Tirol. Geschichte seiner Regierung und seiner Länder, 2 Bde. (Innsbruck I885-1888); Václav BưŽEK, Ferdinand von Tirol zwischen Prag und Innsbruck. Der Adel aus den böhmischen Ländern auf dem Weg zu den Höfen der ersten Habsburger (Wien/Köln/Weimar 2009).

ÖNB, Handschriftensammlung, Cod. 8228, fol. 203r-223v, 227v, 663v-664r. Jene Passagen des Nachlassinventars, die Objekte des Marstalls erwähnen, sind auszugsweise angeführt in: Wendelin Boeneim, Urkunden und Regesten aus der k. k. Hofbibliothek. In: Jahrbuch der kunsthistorischen Sammlungen des Allerhöchsten Kaiserhauses 7 (I888), S. XCI-CCCXIV und Io (I889), S. 
nur die Wagen, Pferdesänften und Schlitten, die der Erzherzog selbst benutzte, sondern auch die seines Sohnes aus erster Ehe, Markgraf Karl von Burgau (I560-I6I8) ${ }^{31}$, sowie jene seiner zweiten Gemahlin, der aus Mantua stammenden Anna Caterina Gonzaga (I566-I62I). Mit ihrer Ankunft in Tirol hatte sich der Innsbrucker Hof zunehmend italienischen Einflüssen gegenüber geöffnet. ${ }^{32}$ So sind im Fuhrparkinventar von 1596 auch Vehikel aus Italien aufgelistet, etwa eine Pferdesänfte, die der Herzog von Mantua 1583 als Geschenk nach Tirol gesandt hatte, oder ein kleiner Wagen aus Ferrara. ${ }^{33}$ Tragsessel, die damals bereits in mehreren Städten Italiens - allen voran Genua und Neapel - weit verbreitet waren, ${ }^{34}$ sind in diesem Inventar jedoch keine zu finden. Auch in den vollständig vorliegenden Fuhrparkinventaren eines anderen habsburgischen Landesfürsten Tirols, jenen des Erzherzogs Maximilian III. (I558-I6I8)35 aus den Jahren I6I4 und I6I8/I9, sind keine Tragsessel verzeichnet. ${ }^{36}$

Zu den Fuhrparks österreichischer Adeliger können hier nur einige wenige Vergleichsbeispiele angeführt werden. Das Bild, das sich dabei in Hinblick auf Tragsessel zeigt, ist jedoch sehr ähnlich jenem, das sich bei den Mitgliedern der Herrscherfamilie beobachten ließ. Ein von 1587 datierendes Stallinventar des überaus wohlhabenden und politisch einflussreichen Wolf Rumpf zu Wielroß, Geheimer Rat und Oberstkämmerer unter Kaiser Rudolf II., führt unter anderem einen Frauenzimmerwagen, einen spanischen Wagen sowie eine italienische Karosse an, jedoch keinen Tragsessel. ${ }^{37}$ Einen frühen Hinweis auf das

I-XIX, Regest 5556.

3I Von seiner Rüst- und Sattelkammer zu Günzburg existiert ein mit Io. April I6I9 datierendes Nachlassinventar, in dem sich zwar zahlreiche Fahrzeuge befinden, aber kein einziger Tragsessel. TLA, Inventare, $\mathrm{A}$ i/Is $\mathrm{d}$.

32 Elena TAddei, Anna Caterina Gonzaga und ihre Zeit: Der italienische Einfluss am Innsbrucker Hof. In: Heinz Noflatscher/Jan Paul Niederkorn (Hg.), Der Innsbrucker Hof. Residenz und höfische Gesellschaft in Tirol vom I5. bis I9. Jahrhundert (Archiv für österreichische Geschichte I38, Wien 2005), S. 213-239.

33 ÖNB, Handschriftensammlung, Cod. 8228, fol. 2I4r, 2I8v.

34 Siehe dazu die Beiträge von Farida Simonetti sowie von Attilio Antonelli, Stefano Moscatelli und Ilaria Telesca in diesem Band.

$35 \mathrm{Zu}$ ihm siehe Josef Hirn, Erzherzog Maximilian der Deutschmeister. Regent von Tirol, 2 Bde. (Innsbruck 1915-1936); Heinz Noflatscher, Glaube, Reich und Dynastie. Maximilian der Deutschmeister (I558-I6I8) (Quellen und Studien zur Geschichte des Deutschen Ordens II, Marburg 1987).

36 DOZA, Abt. Hochmeister, K. 484, Nr. 4/b, unfol., und K. 485, Konv. „Todesfall und Verlassenschaft. 16I8-1619", unfol.

37 Andrea Schoвer, Das Inventar des Wolf Rumpf zu Wielroß. Ein Beispiel materieller Kultur des Adels in Österreich unter der Enns im 16. Jahrhundert (ungedr. Diplomarbeit, Universität Wien 2002), S. II9-I23. Zur Person des Rumpf zu Wielroß siehe auch Friedrich Edelmayer, „Manus manum lavat“. Freiherr Wolf Rumpf zum Wielroß und Spanien. In: Erwein H. Eltz/Arno Stroh- 
Existieren von Tragsesseln in adeligem Besitz bietet ein Mühlviertler Adelsinventar des Erasmus von Rödern aus dem ersten Viertel des I7. Jahrhunderts. Darin sind neben zahlreichen anderen Vehikeln auch ein mit schwerer Seide überzogener Tragsessel sowie für das Jahr I623 ein Frauentragsessel aufgelistet. ${ }^{38}$ Eine weitere Spur zur Ausstattung eines adeligen Haushalts mit Tragsesseln führt zu Karl I. von Liechtenstein (I569-I627), der Anfang des I7. Jahrhunderts für einige Jahre das Amt des kaiserlichen Obersthofmeisters bekleidet hatte. ${ }^{39}$ Für das Jahr I6I3 erwähnt ein Inventar dieses Adeligen neben einem schwarzsamtenen „sessel zum tragen“ auch einen „grossen neapolitanischen sessel zum tragen, von rotten sammet und damaschketen fürhang ". $4^{\circ}$

Die Tatsache, dass Inventare und Hofstaatsverzeichnisse österreichischer Habsburger des I6. Jahrhunderts und frühen I7. Jahrhunderts keine Hinweise auf Tragsessel und Sesselträger liefern, bedeutet allerdings keineswegs, dass man damals zur Gänze auf Tragsessel verzichtete. Einen möglichen Hinweis auf die Verwendung eines Tragsessels durch Kaiser Ferdinand I. (I503-I564) liefert ein Eintrag im Hofzahlamtsbuch von 1560, der die Anschaffung von Samt für einen „neuen sesl so die kay[serliche] m[ajestä]t auf daß gejaid brauchen"4r dokumentiert. Ob es sich bei dem Sessel nur um eine einfache, für kurze Rasten auf der Jagd dienende Sitzgelegenheit handelte oder vielleicht doch um einen Tragsessel, ist ungewiss. Fest steht, dass Ferdinand I. in den Jahren um I560 häufig krank war und auch seine Kräfte in den Beinen sukzessive nachließen. Da er trotz dieser gesundheitlichen Einschränkungen nicht auf die Jagd verzichten wollte, verwendete er auf seinen Jagdausflügen häufig eine Kutsche. ${ }^{42}$ Es ist also durchaus denkbar, dass er sich dabei im dichten

MEYeR (Hg.), Die Fürstenberger. 800 Jahre Herrschaft und Kultur in Mitteleuropa (Katalog des Niederösterreichischen Landesmuseums, NF 342, Korneuburg 1994), S. 235-252.

38 Laurenz PröLL, Ein Blick in das Hauswesen eines österreichischen Landedelmannes aus dem ersten Viertel des 17. Jahrhunderts. In: 38. Jahres-Bericht über das k. k. Staatsgymnasium im VIII. Bezirke Wiens für das Schuljahr I888 (Wien I888), S. 3-47, 39. Jahres-Bericht [...] für das Schuljahr I889 (Wien I889), S. 3-46, hier 38. Jahres-Bericht, S. 26; 39. Jahres-Bericht, S. 20.

Zu ihm siehe Herbert НАupt, Fürst Karl I. von Liechtenstein. Obersthofmeister Kaiser Rudolfs II. und Vizekönig von Böhmen. Hofstaat und Sammeltätigkeit. Edition der Quellen aus dem liechtensteinischen Hausarchiv, 2 Bde. (Wien/Köln/Graz 1983), Bd. I.

40 Ebenda, Bd. 2, S. I82 f. Zur Gestalt von Tragsesseln aus Neapel siehe den Beitrag von Attilio Antonelli, Stefano Moscatelli und Ilaria Telesca im vorliegenden Band.

4I ÖStA, FHKA, HZAB, Bd. I6, fol. I22r (I560 Juni ro).

42 Vgl. zum Beispiel: Venezianischer Botschafter Leonardo Mocenigo an Doge Lorenzo Priuli, Wien I558 Juli 6, Gustav Turba (Bearb.), Venetianische Depeschen vom Kaiserhofe (Dispacci di Germania), Bd. 3 (Wien I895), S. 44; Toskanischer Botschaftssekretär Iacobo Dani, Wien I56I Juli 30, ASF, MdP, filza 4323, fol. 487r; Toskanischer Botschafter Antonio Albizi, Prag I562 Mai I8, ASF, MdP, filza 4324, fol. I8v; Venezianischer Botschafter Giacomo Soranzo, I563, Joseph Fiedler (Hg.), Relationen venetianischer Botschafter über Deutschland und Österreich im sechzehnten 
Wald oder auf unwegsamen Pfaden, wo es mit Wagen kein Fortkommen gab, in einem Tragsessel transportieren ließ und sich dieser mit dem erwähnten „sesl“ identifizieren lässt.

Durch zahlreiche Quellen gesichert ist hingegen, dass der Sohn und Nachfolger Ferdinands I., Kaiser Maximilian II. (I527-I576) ${ }^{43}$, in seinen letzten Lebensjahren häufig auf Tragsessel zurückgriff. Maximilian hatte sich schon 1553 bei einem Jagdunfall eine schwere Verletzung am Knöchel eines Beines zugezogen. ${ }^{44}$ Diese Läsion war so schwerwiegend, dass sie ihn noch rund ein Jahrzehnt später in seiner Bewegungsfreiheit schwer beeinträchtigte. Zusätzlich machten ihm seit Anfang der I560er Jahre auch noch Herzbeschwerden und erste Symptome einer Gichterkrankung zu schaffen. ${ }^{45}$ Mitte der I56oer Jahre war die Gicht zeitweise schon so stark ausgeprägt, dass Maximilian II. häufig nur noch in der Kutsche den Palast verlassen konnte. ${ }^{46}$ Für seine letzten Lebensjahre ist auch mehrfach dokumentiert, dass er einen Tragsessel verwendete. Als sich der Hof anlässlich der am 25 . September 1572 erfolgten Krönung des späteren Kaisers Rudolf II. zum ungarischen König in Pressburg aufhielt, berichteten diplomatische Vertreter der Toskana vom Krönungsort, dass sich der Kaiser nach einem erlittenen Gichtanfall im Tragsessel transportieren lassen müsse. ${ }^{47}$ Im August 1575 schrieb der toskanische Botschafter aus Prag, dass die Gesundheit des Kaisers nach einer Erkrankung nun erneut so weit hergestellt sei, dass er sich wieder

Jahrhundert (Fontes rerum austriacarum, 2. Abt., Bd. 30, Wien I870), S. 215 f. Zur Krankengeschichte Kaiser Ferdinands I. siehe auch Paula Sutter Fichtner, A community of illness: Ferdinand I and his family. In: Martina Fuchs/Alfred Kohler (Hg.), Kaiser Ferdinand I. Aspekte eines Herrscherlebens (Geschichte in der Epoche Karls V. 2, Münster 2003), S. 203-216, hier S. 203-208; Alfred KoHLER, Ferdinand I. I503-I564. Fürst, König und Kaiser (München 2003), S. IO4-IO7.

43 Zu ihm siehe Viktor Bıbl, Maximilian II. Der rätselhafte Kaiser. Ein Zeitbild (Hellerau bei Dresden 1929); Friedrich Edelmayer/Alfred Kohler (Hg.), Kaiser Maximilian II. Kultur und Politik im 16. Jahrhundert (Wiener Beiträge zur Geschichte der Neuzeit 19, Wien/München 1992); Paula Sutter Fichtner, Emperor Maximilian II (New Haven/London 200I).

44 Martinengo an Monte, Wien I553 November 2I, Nuntiaturberichte aus Deutschland, I. Abt.: I533I559, Bd. I6: Helmut Goetz (Bearb.), Nuntiatur des Girolamo Martinengo (I550-I554) (Tübingen I965), S. 290.

45 Berichte des venezianischen Botschafters Giacomo Soranzo von 1562 beziehungsweise 1563 , Eugenio Albèri (Hg.), Le relazioni degli ambasciatori veneti al senato durante il secolo decimosesto, Serie I, Bd. 6 (Firenze i862), S. I50 f.; Fiedler I870 (wie Anm. 42), S. 217.

46 Toskanischer Gesandter Giulio Ricasoli, Wien I565 März 20, ASF, MdP, filza 4325, fol. 38r, 4or; Costa, Wien 1566 Juni 26, Juli 3 und Juli 30, Norbert Steingress, Die Korrespondenz der Republik Genua mit ihren Gesandten am Kaiserhof (1564-1566) (ungedr. Dissertation, Universität Wien 200I), S. 780,782 und 789.

47 „Et con tutto che s[ua] $m$ [aes] tà si faccia anchora portare in sede [sic] per qualche residuo di podagra, [...]. “ Toskanische Botschafter Lodovico Antinori und Giambatista Concino, Pressburg 1575 September 25. ASF, MdP, filza 4332, fol. 9v-Ior. 
in den Garten tragen lassen könne. ${ }^{48}$ Mehrere Wochen später berichtete der spanische Botschafter Conde de Monteagudo aus Prag, dass die Beine des Kaisers kaum noch einsatzfähig seien und dass er stets im Tragsessel befördert werde. ${ }^{49}$ Als Maximilians II. Sohn Rudolf II. am 27. Oktober 1575 in Regensburg nach erfolgter Wahl zum Römischen König proklamiert wurde, konnte der Kaiser, der bei diesem Ereignis anwesend war, die Kirche nicht zu Fuß verlassen, sondern musste dafür einen Tragsessel zu Hilfe nehmen. ${ }^{50}$ Auch zu einer Messe am Wiener Hof Ende März 1576 musste Maximilian II. laut einem Augenzeugenbericht im Tragsessel gebracht werden. ${ }^{5 \mathrm{I}}$ Kurz nach dem Eintreffen Maximilians II. in Regensburg im Juni desselben Jahres berichtete auch der päpstliche Nuntius, dass der Kaiser sich im Palast tragen lassen müsse, da er nicht mehr fähig sei, selbst zu gehen. ${ }^{22}$ Wenige Monate später verstarb Maximilian II. unter letztlich nicht zur Gänze geklärten Umständen, vermutlich aber an einem chronischen Herzleiden in Zusammenhang mit Tuberkulose..$^{33}$

Welche Personen aber hatten den Kaiser während seiner letzten Lebensjahre getragen? Da in den Quellen jener Jahre keine Hinweise auf am Hof beschäftigte Sesselträger zu finden sind, können dazu nur Vermutungen angestellt werden. Möglicherweise erfüllten andere Hofdiener, zum Beispiel Leiblakaien, diese Aufgabe. Offenbar nahm man damals an, dass die Verwendung eines Tragsessels seitens des Monarchen nur eine vorübergehende Ausnahmeerscheinung sei, die schon in absehbarer Zeit - mit dem Tod des Kaisers - wieder obsolet würde. Man hielt es deshalb anscheinend nicht für nötig, kurzfristig Sesselträger in den festen Personalstand des Hofes zu integrieren.

48 Toskanischer Botschafter Giambatista Concini, Prag 1575 August 7, ASF, MdP, filza 4333, fol. 194r.

49 „[... ${ }^{y}$ hallándose muy impedido de los pies porque siempre lo traen en silla [...]." Conde de Monteagudo an Philipp II., Prag 1575 September 29, Marques de la Fuensanta del Valle (Hg.), Correspondencia de los Príncipes de Alemania con Felipe II y de los embajadores de este en la corte de Viena (I556 á 1576), Bd. 6 (Colección de documentos inéditos para la historia de Espańa II3, Madrid 1895, Reprint Nendeln 1975), S. I94.

50 Burgi KnORR, Die Wahl und Krönung Rudolphs II. zum Römischen König 1575. In: Karl MöSENEDER (Hg.), Feste in Regensburg. Von der Reformation bis in die Gegenwart (Regensburg 1986), S. I24-I27, hier. S. I25.

5I Elena Venturini (Hg.), Le collezioni Gonzaga. Il carteggio tra la corte cesarea e Mantova (I5591636) (Milano 2002), S. 243.

„Et giunto al palazzo, dove sera ridotta tutta la corte, S. M. venne ad incontrare S. S. I., o più tosto si fece portare, non potendo, come lo sa, caminare, fino all'ultima porta della sala appresso la scala, dove ricevè S. S. I. con grandissima allegrezza et cortesia, et toccò la mano a tutta la sua famiglia." Dolfin an Gallio, Regensburg 1576 Juni 20, Nuntiaturberichte aus Deutschland nebst ergänzenden Aktenstücken, 3. Abt.: 1572-1585, Bd. 8: Daniela Neri (Bearb.), Nuntiatur Giovanni Dolfins (I575-1576) (Tübingen 1997), S. 595 .

53 Sutter Fichtner 2003 (wie Anm. 43), S. 208-2io. 
Aus den Jahrzehnten, die auf den Tod Maximilians II. folgten, liegen nur wenige Hinweise auf die Verwendung von Tragsesseln am Kaiserhof vor. Der Sohn und Nachfolger Maximilians II. als Kaiser, Rudolf II. (I552-I6I2) ${ }^{54}$, der sich seit den I590er Jahren in seiner Prager Burg immer mehr den Augen der Öffentlichkeit entzog und seine Residenz nur noch selten verließ, machte allem Anschein nach nur in Ausnahmefällen Gebrauch von derartigen Transportmitteln. ${ }^{55}$ Bislang ist einzig bekannt, dass der Monarch infolge einer langwierigen und äußerst lästigen Erkrankung, die mit einer Entzündung im Genitalbereich einherging und ihm das Gehen zeitweise verunmöglichte, mehrmals in der Prager Burg und deren Garten einen Tragsessel verwendete. Dieses Leiden, das aufgrund

54 Zu ihm siehe unter anderem R(obert) J. W. Evans, Rudolf II and his World. A Study in Intellectual History 1576-I6I2 (Oxford 1973); siehe auch die gekürzte deutsche Übersetzung dieser Biographie mit dem Titel Rudolf II. Ohnmacht und Einsamkeit (Graz/Wien/Köln 1980); Karl VocelKA, Die politische Propaganda Kaiser Rudolfs II. (I576-I6I2) (Veröffentlichungen der Kommission für die Geschichte Österreichs 9, Wien I98I); Karl VocelKa, Rudolf II. und seine Zeit (Wien/Köln/ Graz 1985).

55 Vgl. Anm. 23. Zur Überprüfung, ob Kaiser Rudolf II. Tragsessel verwendete, wurden verschiedenste Quellen herangezogen, unter anderem die unpublizierten Berichte der venezianischen Gesandten am Kaiserhof: ÖStA, HHStA, DdG, Bd. 5-45; außerdem mehrere Schlussrelationen venezianischer Gesandtschaften: Fiedler I870 (wie Anm. 43), S. 355-40I; Albèri I862 (wie Anm. 45), S. 193-248. Auch in den bislang publizierten Nuntiaturberichten vom Hof Rudolfs II. finden sich allein für das Jahr 158I Hinweise darauf, dass der Kaiser Tragsessel verwendete: Nuntiaturberichte aus Deutschland nebst ergänzenden Aktenstücken, 3. Abt.: 1572-I585, Bd. 8: Daniela Neri (Bearb.), Nuntiatur Giovanni Dolfins (I575-I576) (Tübingen 1997); Bd. 9: Alexander Koller (Bearb.), Nuntiaturen des Giovanni Delfino und des Bartolomeo Portia (I577-I578) (Tübingen 2003); Bd. Io: Alexander Koller (Bearb.), Nuntiaturen des Orazio Malaspina und des Ottavio Santacroce. Interim des Cesare dell'Arena (I578-158I) (Berlin/Boston 20I2); Nuntiaturberichte aus Deutschland nebst ergänzenden Aktenstücken 1585 (1584)-1590, 2. Abt: Die Nuntiatur am Kaiserhofe, hg. von d. Görres-Gesellschaft, Bd. i: Robert Reichenberger (Bearb.), Germanico Malaspina und Filippo Sega (Giovanni Andrea Caligari in Graz) (Paderborn 1905); Bd. 2: Joseph SchweIzer (Bearb.), Antonio Puteo in Prag 1587-1589 (Paderborn 1912); Bd. 3: Josef Schweizer (Bearb.), Die Nuntien in Prag: Alfonso Visconte I589-I591, Camillo Caetano I59I-I592 (Paderborn 1919); Natale Mosconi (Hg.), La nunziatura di Praga di Cesare Speciano (I592-I598) nelle carte inedite vaticane e ambrosiane, 5 Bde. (Brescia 1966-1967); Nuntiaturberichte aus Deutschland nebst ergänzenden Aktenstücken, 4. Abt.: Siebzehntes Jahrhundert, Bd. 3: Arnold Oskar Meyer (Bearb.), Die Prager Nuntiatur des Giovanni Stefano Ferreri und die Wiener Nuntiatur des Giacomo Serra (I603-1606) (Berlin I913); Zdeněk KrIsten (Hg.), Epistulae et acta Johannis Stephani Ferrerii 1604-I607, Bd. I/I (Epistulae et acta nuntiorum apostolicorum apud imperatorem I592-I628, Tomus 3, Prag 1944); Milena Linhartová (Hg.), Epistulae et acta Antonii Caetani I607-I6II, 3 Bde. (Epistulae et acta nuntiorum apostolicorum apud imperatorem I592-I628, Tomus 4, Prag I932-1946). In zahllosen weiteren eingesehenen zeitgenössischen Berichten aus der Regierungszeit Rudolfs II., die hier aus Platzgründen nicht im Einzelnen angeführt werden können, finden sich ebenfalls keine Hinweise auf eine Verwendung von Tragsesseln seitens des Monarchen. 
seiner Hartnäckigkeit unter Diplomaten bereits Zweifel an einer Genesung Rudolfs II. aufkommen ließ und Nachfolgefragen aufwarf, hatte sich im März I580 eingestellt und zog sich rund eineinhalb Jahre lang hin, bis schließlich doch schrittweise eine nachhaltige Verbesserung des Gesundheitszustands eintrat. ${ }^{56}$ Der päpstliche Nuntius Ottavio Santacroce berichtete am 23. Juni 158I aus Prag, dass es dem rekonvaleszenten Kaiser inzwischen besser gehe und er sich auch schon wieder in seinen Räumlichkeiten tragen lasse, diese jedoch noch nicht verlassen könne. ${ }^{57}$ Rund einen Monat später teilte er in einem Schreiben nach Rom mit, Rudolf II. lasse sich nun hin und wieder in den Garten tragen und würde manchmal sogar schon wieder selbst Gehversuche unternehmen. ${ }^{8}$ Als seine Mutter, die Kaiserin-Witwe Maria (I528-I603), Anfang August von Prag in Richtung Spanien aufbrach, wo sie ihren Lebensabend in einem Kloster verbringen wollte, ließ sich der Kaiser in ihre Gemächer tragen, um sich von ihr zu verabschieden. Rudolf II. ließ damals alle Personen aus dem Raum schicken. ${ }^{99}$ Unklar ist dabei, ob er dies tat, weil er in diesem intimen Moment - beiden war beim Abschied wohl bewusst, dass sie einander voraussichtlich nie mehr wiedersehen würden - einfach nur allein mit seiner Mutter sein wollte, oder ob es ihm unangenehm war, von anderen Personen in einem Tragsessel in all seiner körperlichen Hinfälligkeit gesehen zu werden. Auch bei diesen Einsätzen von Tragsesseln muss vorläufig die Frage offenbleiben, welche Hofdiener bei Bedarf die Sesselträgerdienste für Rudolf II. erledigten, da in seinem Hofstaat kein eigens dafür abgestelltes Personal vorhanden war.

Aus den Jahren um 1620 ist sowohl von Kaiser Matthias (I557-I6I9) ${ }^{60}$ als auch von Kaiser Ferdinand II. (I578-I637) ${ }^{61}$ überliefert, dass sie sich aufgrund eines Gichtleidens, allgemeiner körperlicher Schwäche beziehungsweise infolge einer Verletzung zumindest in Einzelfällen im Tragsessel transportieren lassen mussten. Kaiser Matthias, der erst in für damalige Verhältnisse - weit fortgeschrittenem Alter zum König von Ungarn (I608), zum böhmischen (I6II) und zum römisch-deutschen König (I6I2) gekrönt wurde, litt

56 Zu dieser Krankheit siehe Koller 2012 (wie Anm. 55), S. XXXIX-XLI.

57 „S. M.tà, per quel che si dice, sta meglio et si fa portar per casa, ma non esce fuori." Santacroce an Gallio, Prag 158I Juni 23, ebenda, S. 483.

58 "L'Imperatore si fa portar alle volte in giardino et camina un pochetto, ma però audienza non è possibile havere, [...]." Santacroce an Gallio, Prag 158I Juli 31, ebenda, S. 52I.

59 "Si è fatto portar l'Imperatore nelle stanze della madre prima della partenza a licentiarsi, ma ha fatto uscir tutti per non esser visto." Santacroce an Gallio, Prag I58I August I, ebenda, S. 522.

$60 \mathrm{Zu}$ ihm siehe Bernd Rill, Kaiser Matthias. Bruderzwist und Glaubenskampf (Graz/Wien/Köln 1999).

6I Zu Kaiser Ferdinand II. siehe unter anderem Franz Christoph KhevenhüLler, Annales Ferdinandei, I2 Bde. (Leipzig I72I-I726); Friedrich von Hurter, Geschichte Ferdinands II. und seiner Eltern, II Bde. (Schaffhausen I850-I864); Johann FranZL, Ferdinand II. Kaiser im Zwiespalt der Zeit (Graz/Wien/Köln $\left.{ }^{2} 1989\right)$. 
während seiner gesamten Regentschaft immer wieder unter heftigen Gichtanfällen, die ihm das Wahrnehmen der Regierungsgeschäfte erheblich erschwerten und ihn oftmals am Reisen hinderten. ${ }^{62}$ Während seines letzten Lebensjahres scheint er sogar ständig auf den Gebrauch eines Tragsessels angewiesen gewesen zu sein. Im Frühling des Jahres I6r8 berichtete der venezianische Botschafter am Wiener Hof in einer Depesche an den Dogen von Venedig, Kaiser Matthias habe zur Gänze die Kontrolle über seine Beine verloren und müsse sich daher stets tragen lassen. Es sei ihm aber höchst unangenehm, in diesem Zustand gesehen zu werden, weshalb er öffentliche Auftritte wie Messfeiern und Zusammentreffen mit ausländischen Gesandten so weit wie möglich vermeide. ${ }^{63}$ Der gesundheitliche Zustand des Monarchen scheint sich auch in den darauf folgenden Monaten nicht verbessert zu haben, denn am Io. November I6I8 berichtete der venezianische Botschafter, Kaiser Matthias sei den Trauerfeierlichkeiten für seinen verstorbenen Bruder, Erzherzog Maximilian III., ferngeblieben, da er nicht im Tragsessel gesehen werden wollte. ${ }^{64}$ Eine vergleichbare Scheu, im Tragsessel gesehen zu werden, zeigte auch Matthias' Nachfolger, Kaiser Ferdinand II. Als sich dieser am 24. Dezember I624 in Wien zur Rorate-Messe begab, zog

62 Dies ist in zahlreichen Gesandtenberichten und anderen Quellen dokumentiert: Venezianischer Botschafter Marin de Cavalli an Doge Leonardo Donà, Prag I608 Dezember 8 und Prag I609 August 17, ÖStA, HHStA, Venedig, DdG, Bd. 4I, S. 139 und Bd. 42, S. 249; Venezianischer Botschaftssekretär Marc' Antonio Padavin an Doge Leonardo Donà, Prag I6ri März 7 und Oktober 3, ÖStA, HHStA, Venedig, DdG, Bd. 45, S. 6, 262; Die böhmischen Landtagsverhandlungen und Landtagsbeschlüsse vom Jahre 1526 bis auf die Neuzeit, hg. vom Landesarchive des Königreiches Böhmen, Bd. I5: Johann Friedrich Novák (Hg.), Die Landtage des Jahres I6II (Prag 1917), S. 465; „Avisos de Praga“, Nr. 28, Prag I6ı2 März io, AGS, Estado, Leg. 2498, unfol.; Venezianischer Botschafter Girolamo Soranzo an Doge Marcantonio Memmo, Prag I6ı2 März 5 und 19, Mai 2I sowie Wien I6r3, Februar 2, März 2, April 20 und 27, ÖStA, HHStA, Venedig, DdG, Bd. 46, fol. 2r, 7r, 28r, I79r und Bd. 47, S. 6, 27, 29; „Avisos de Linz“, Nr. 74, Linz I6I4 Januar 6, AGS, Estado, Leg. 2500, unfol.; Venezianischer Botschafter Zorzi Giustinian an Doge Giovanni Bembo, Prag I6I6 Februar I, August I4, 2I und 28, Wiener Neustadt I6I8 Januar 6, ÖStA, HHStA, Venedig, DdG, Bd. 50, S. 176, Bd. 53, S. 176, I80, 184 und Bd. 54, S. 131.

63 "Si trova l'imp[erato]re in poco buon stato, anzi grandemente declinato da quello di prima, et in molta debolezza, essendosi messo novamente in mano d'un medico che con estratti et altri rimedii chimici lo va mantenendo, et ha perduto affatto l'uso dele gambe, si che convien farsi portar, né in ciò volesser veduto nè accompagnato alla capelle com'era solito et con difficoltà ha admesso li amb [asciato]ri a questo complimento, [... ]." Venezianischer Botschafter Zorzi Giustinian an Doge Nicolò Donà, Wien I6I8 April 2I, ÖStA, HHStA, Venedig, DdG, Bd. 55, S. 102 f.

64 "Il cadavero di Massimiliano fu portato di notte per li corridori del palazzo in una chiesa vicina in deposito per condurlo poi in Tirol accompagnato dal re, amb[asciato]ri et tutta la corte senza l'intervento dell'imperatore il qual facendosi portar in sedia non vol esser veduto; et quando feci l'offitio seco mi parse vederlo molto debole et fiacco. "Venezianischer Botschafter Zorzi Giustinian an Doge Antonio Priuli, Wien I6I8 November Io, ÖStA, HHStA, Venedig, DdG, Bd. 56, S. I75. 
er sich beim Treppensteigen eine Fußverletzung zu und war deshalb gezwungen, sich an den darauf folgenden Weihnachtsfeiertagen im Tragsessel transportieren zu lassen. Zwar nahm er an den Festmessen teil, vermied es jedoch, sich dabei blicken zu lassen. Allein die am Hof weilenden Botschafter und einige andere Personen, die ihm Glückwünsche zu den Feiertagen überbringen wollten, empfing er damals zur Audienz. ${ }^{65}$

Aus diesen Schilderungen geht hervor, dass sowohl Kaiser Matthias als auch Kaiser Ferdinand II. es offensichtlich als Schmach betrachteten, sich in der Öffentlichkeit im Tragsessel zeigen zu müssen. Das Bild des im Tragsessel transportierten Kaisers löste demnach bei Zeitgenossen keinerlei positive Assoziationen aus, wie das damals etwa an anderen europäischen Höfen der Fall war, sondern evozierte bei den Zusehern vielmehr ein Bild der Schwäche, des körperlichen Verfalls und der Vergänglichkeit weltlicher Macht. Vom Bild eines Triumphators auf einem mobilen Thron konnte keine Rede sein. Allerdings erhielten Tragsessel um I620 am Kaiserhof auch eine neue, positive Konnotation. Diese Wende hängt eng mit der Verwendung von Tragsesseln durch Frauen zusammen und führte schließlich dazu, dass in jenen Jahren erstmals Sesselträger in den Hofstaat integriert wurden.

2.2 Ein Geschenk aus Florenz für Kaiserin Anna (1615): Tragsessel als Schutz für schwangere Fürstinnen und ihre ungeborenen Kinder

Wurden bisher nur Fälle erwähnt, in denen männliche Fürsten Tragsessel verwendeten, so sind aus dem Jahr I6I5 auch erstmals Quellen überliefert, die eine - für den Kaiserhof frühe Verwendung von Tragsesseln durch Frauen belegen. In Zusammenhang mit diesbezüglichen Nachrichten steht ein Gerücht, das im Frühling des Jahres I6I5 am Kaiserhof zu kursieren begann: Der venezianische Botschafter Zorzi Giustinian berichtete am 28. März aus Wien, dass seit wenigen Tagen Stimmen im Umlauf seien, Kaiser Matthias' Gemahlin Anna (1585-16I8) erwarte ein Kind und sei bereits im fünften Monat schwanger. ${ }^{66}$ Diese

65 "L'imp[erato]re la vigilia di natale nello scendere alle solite devozione del rorate si suolse super una scala nella pianella un piede dove calo poi un poco d'umore si che in tutte queste feste sè fatto portare in sedia alle cappelle fattesi in corte dove non s'è lasciato vedere in publico, et in sedia hà ricevuto dagl'amb[asciato]re e dà altri il complimento delle buone feste. Sta ora bene e potrà doman l'altro andare a caccia." Toskanischer Botschafter Giovanni Altoviti, Wien 1624 Dezember 28, ASF, MdP, filza 4375, unfol. „Da tre giorni in qua si è data fuori la voce della gravidanza dell'imperatrice, mentre per esser l'imperator quasi sessagenario, lei, se bene giovine, molto grassa, et stati già tre anni insieme, non se n’haveva speranza alcuna, et già la m[aestà] s[ua] si trova nel quinto mese, [...]." Venezianischer Botschafter Zorzi Giustinian an Doge Marcantonio Memmo, Wien I6I5 März 28, ÖStA, HHStA, Venedig, DdG, Bd. 49, S. I3 f. Am selben Tag berichtete auch der toskanische Botschafter am Kaiserhof nach Florenz, dass Hoffnung bestehe, die Kaiserin sei schwanger, äußerte jedoch auch Zweifel, ob 
Nachricht sorgte unter anderem auch deshalb für einiges Aufsehen, weil das Kaiserpaar damals schon seit über drei Jahren verheiratet war und man bis dahin bei Kaiserin Anna vergeblich auf Anzeichen einer Schwangerschaft gewartet hatte. Mit dem aufgeflammten Gerücht war sowohl im Reich als auch in den Erblanden plötzlich die Thronfolgefrage wieder offen, da bis zu diesem Zeitpunkt mit Erzherzog Ferdinand, dem späteren Kaiser Ferdinand II., ein Mitglied der steirischen Familienlinie als Favorit für die Nachfolge des bis dahin kinderlosen Matthias' gegolten hatte, einem Sohn des Kaisers aber womöglich der Vorzug vor Erzherzog Ferdinand gegeben worden wäre.

Die Neuigkeit verbreitete sich rasch an den Höfen Europas und kam unter anderem auch der Großherzogin von Toskana, Maria Magdalena (I589-163I), einer Cousine Annas, zu Gehör. Die Großherzogin beschloss daraufhin - möglicherweise auf ausdrücklichen Wunsch der Kaiserin -, Anna einen Tragsessel als Geschenk überreichen zu lassen. Curzio Picchena, damals Erster Staatssekretär des Großherzogtums, gab dem toskanischen Botschafter am Kaiserhof, Giuliano de' Medici, in einem Schreiben vom ıo. Mai I6ıs präzise Hintergrundinformationen und Anweisungen zu diesem Präsent. ${ }^{67}$ Picchena erklärte dem

dies auch den Tatsachen entspreche. Toskanischer Botschafter Giuliano de’ Medici an Großherzog Cosimo II de' Medici, Wien I6I5 März 28, ASF, MdP, filza 4368, unfol.

67 „[Durchgestrichen: „La maestà dell'imperatrice hà richiesto la“] È venuto pensiero alla ser[enissi] ma arcid[uches] sa $n$ [ost] ra sig[no] ra di provedere e mandare alla maestà dell'imperatrice quattro huomini pratichi a portar seggiola, e perchè qui non ci era da poterla servire et perchè in Genova è questúuso del portar le seggiole più che in altro luogo d'Italia e per poter servir meglio a s[ua] $m$ [aes] tà, se ne scrisse là, a un principal gentilh [uom] o, il quale gli ha mandate, e domani sincamminano per venirsene a cotesta volta. Qui sono stati vestiti all'usanza di quelli che portano le seggiole a loro altezze in campagna; ma parendo conveniente che davanti all'imperatrice comparischino bene in ordine vogliono le altezze loro, che subito al loro arrivo $v$ [ostra] $s$ [ignoria] ill[ustrissi] ma gli faccia rivestire costi speditam[en] te di qualche domaschetto rosso, cioè calzoni e casacca quasi alla uscocca, la qual casacca sia corta, [durchgestrichen: un poco manco che fino] à mezza coscia, e con le maniche del med[esim] o con una frangia d'oro e riscontri come parrà che stia bene. Con essi manda la $d[\mathrm{ett}]$ a ser[enissi] ma arcid[uches] sa una seggiola, la quale $v$ [ostra] $s$ [ignoria] ill[ustrissi] $m a$ ha da presentare of far presentare alla $m$ [aes] tà s[ua], dicendo che è fatta all'usanza di qua che da queste altezze è trovata assai commoda. E perchè le stanghe [durchgestrichen: debbono venir rozze, dicono che $v$ [ostra] $s$ [ignoria] ill[ustrissi] ma le faccia tignere d'un bel rosso, acciò tutto comparisca d'un med[esim] o colore, poichè intendo che la seggiola è rossa] sono tinte di rosso, ma nel viaggio potrebbono patire, $v$ [ostra] $s$ [ignoria] ill[ustrissi] ma faccia ridar lor nuovo colore acciò apparischino nuove. Per portare la $d[\mathrm{ett}]$ a seggiola fino a Inspruch, si mandano di qua certi huomini a posta et uno di essi havrà cura di farla imbarcare per Vienna, se la corte vi sarà, ma quando sia partita per Praga, ha da trovar quelli altri huomini che la portino fin là, et essi tornarsene. [...] Debbo anche dirle, che la seggiola viene ben serrata, e cucita, e con tele, e con incerati, e di più è stata sigillata in alcuni luoghi con cera di Spagna, acciò per il viaggio nessuno la possa aprire, ne entrarvi dentro, e v[ostra] s[ignoria] ill[ustrissi] ma nel riceverla, avvertisca ch'ella sia stata condotta bene condizionata, e con le cuciture, e con i sigilli intatti. "Curzio Picchena an Giuliano de' Medici, Florenz I6I5 Mai Io, ASF, MdP, filza 4954, unpag. 
Botschafter, die Großherzogin wolle der Kaiserin einen Tragsessel samt dem dazugehörigen Bedienungspersonal schicken. Da sich in Florenz aber keine geübten Sesselträger finden ließen, in Genua hingegen, so Picchena, Tragsessel viel mehr als an allen anderen Orten Italiens in Gebrauch stünden, habe man einen hochrangigen Adeligen in Genua kontaktiert, der sogleich vier geeignete Sesselträger nach Florenz habe abgehen lassen, die nunmehr zur Abreise an den Kaiserhof bereitstünden. Am Florentiner Hof wurden diese vier Männer mit Livreen ausgestattet, wie sie auch die Sesselträger des toskanischen Großherzogspaars bei Diensten außerhalb der Stadt trugen. Diese Livreen wurden aber als untauglich für ein Geschenk an die Kaiserin befunden, weshalb an Giuliano de' Medici der Auftrag erging, die vier Sesselträger nach ihrer Ankunft am Kaiserhof mit einer neuen Livree auszustatten. Diese sollte aus Hosen sowie einem kurzen, bis zur halben Schenkelhöhe reichenden Rock nach Uskokenart bestehen, aus rot geblümtem Damaststoff verfertigt und mit Goldfransen besetzt sein. Zum Aussehen des Tragsessels selbst ist von Picchena nur wenig zu erfahren. Wie aus einer Passage seines Schreibens hervorgeht, scheint es sich beim Geschenk um einen geschlossenen Tragsessel gehandelt zu haben, denn das für die Kaiserin bestimmte Objekt wurde für den Transport gut verpackt, in Tücher eingenäht und an mehreren Stellen versiegelt, zum einen, damit sich während der Reise zum Kaiserhof niemand hineinsetzen konnte, und zum anderen, da so auch der Verlust von einzelnen Bestandteilen einfacher zu verhindern war. Weiterhin geben Picchenas Zeilen preis, dass der Sessel und seine Trageholme in roter Farbe gehalten waren. Der toskanische Botschafter erhielt die Anweisung, vor der Übergabe für einen frischen Anstrich der Trageholme sorgen, da die Fassung, so Picchena, während des Transports Schaden nehmen könnte. Bei der Überreichung des Geschenks war der Botschafter angehalten, der Kaiserin mitzuteilen, dass der Tragsessel auf florentinische Art gemacht sei und dass das toskanische Großherzogspaar solche Tragsessel höchst komfortabel finde. Die Überführung des Tragsessels sollte durch vier eigens dafür bestellte Männer auf dem Landweg bis Innsbruck geschehen. Einer von ihnen wurde beauftragt, den Sessel anschließend zu Wasser weiter bis nach Wien zu begleiten. Sollte die Kaiserin sich in der Zwischenzeit jedoch schon nach Prag begeben haben, habe er dafür zu sorgen, dass das Geschenk gleich direkt in die böhmische Hauptstadt gelange.

Dem Präsent der toskanischen Großherzogin an die Kaiserin liegt die damals verbreitete Annahme zugrunde, dass die teils heftigen Erschütterungen, denen Insassen von Kutschen aufgrund der ungenügenden Fahrzeugfederungssysteme ausgesetzt waren, ${ }^{68}$ Fehlge-

68 Zum Fahrkomfort und zur Entwicklung der Fahrzeugfederung siehe Rudolf H. WACKERNAGEL, Fahr- und Fahrzeugsicherheit: Zum Fahrkomfort barocken Reisens. In: Uta Lindgren (Hg.), Naturwissenschaft und Technik im Barock. Innovation, Repräsentation, Diffusion (Bayreuther Historische Kolloquien II, Köln/Weimar/Wien I997), S. I57-I89. 
burten auslösen könnten. Schwangeren Fürstinnen wurde deshalb empfohlen, Kutschenfahrten zu vermeiden und stattdessen lieber einen Tragsessel zu verwenden, dessen sanftes Schaukeln der zu jener Zeit gängigen Meinung zufolge keine Bedrohung für ungeborene Kinder darstelle.

Dass entsprechende Ratschläge damals von Frau zu Frau weitergegeben wurden, belegen Briefe der Großherzogin-Witwe Christine von Lothringen (I565-I636) an ihre Tochter Caterina de' Medici (1593-1629), die I6I7 den Herzog von Mantua geheiratet hatte. Rund zwei Monate nach ihrer Hochzeit, als man bereits hoffen durfte, dass Caterina de' Medici schwanger sei, teilte ihr ihre Mutter brieflich mit, sie solle unbedingt darauf achten, vor Ablauf des „gewissen“ Monats - gemeint ist wohl das Ende des zweiten Schwangerschaftsmonats - Fahrten in Karossen zu meiden. Sie empfahl, sich besser im Tragsessel transportieren zu lassen, denn mit dieser Vorgehensweise habe auch sie selbst gute Erfahrungen gemacht. ${ }^{69}$ Nachdem der Eintritt einer Gravidität aber noch weitere Monate auf sich warten ließ, sprach Christine von Lothringen ihrer Tochter im September I6I7 in einem Schreiben Mut zu. Sie riet ihr, weiterhin gelassen zu bleiben, und lobte sie für die Entscheidung, bereits präventiv von der Kutsche auf den Tragsessel umgestiegen zu sein. ${ }^{70}$ Der I6I5 als Geschenk der Großherzogin Maria Magdalena an den Kaiserhof gelangte Tragsessel ist demnach vor dem Hintergrund der damals praktizierten Strategie zur Vermeidung von Fehlgeburten zu sehen, stellte gleichzeitig aber natürlich auch eine gute Gelegenheit dar, die Kaiserin mittels eines repräsentativen Geschenks zur eingetretenen Schwangerschaft zu beglückwünschen. ${ }^{71}$

Ende Mai I6I5 trafen Kaiser Matthias und seine Gemahlin Anna in Prag ein, wo ein

69 "Avvertisca particolarmente di non andare in carrozza finchè non ha passato quell'altro mese, ma vada in seggiola, come ho fatto io." Christine von Lothringen an Caterina de' Medici, Pisa I6I7 April I3, ASF, MdP, filza 6rio, fol. I6r-v.

70 „[...] et s'ella non habbia ricevuto la gratia della gravidanza hora la riceverà ben presto, et intanto non mi dispiace ch'ella habbia cominciato a usare la seggiola." Christine von Lothringen an Caterina de' Medici, Florenz I6I7 September I2, ASF, MdP, filza 6IIo, fol. 39r-v. Großherzogin Maria Magdalena, die bereits I6I5 der Kaiserin einen Tragsessel als Präsent hatte überreichen lassen, machte I6I7 nun auch Caterina de' Medici einen Tragsessel zum Geschenk. Ebenda, fol. 39v.

7I Ein anderes, wohl noch kostbareres Geschenk gelangte anlässlich der vermuteten Schwangerschaft der Kaiserin damals aus den Spanischen Niederlanden nach Prag. Es bestand unter anderem aus einer Karosse sowie aus zwei besonders reich ausgestatteten Wiegen, eine für den Fall, dass Anna einen Buben zur Welt bringe, die andere passend für ein Mädchen: „Di Fiandra è venuto questa settimana la carozza mandata dall'infante [Infantin Isabella Clara Eugenia] con due cune, l'una da maschio l'altra da femina, benissimo lavorate, con trabacchette, drappi e panni per i bambini, et due casacchini ala framinga per l'imperatrice da tener nel letto, riccamati et tempestati di rubini, diamanti et perle, stimato tutto 20 mila fiorini [...].“ Claudio Sorina an Herzog Ferdinando Gonzaga, Prag i6is Juli 5, Venturini 2002 (wie Anm. 5I), S. 620. 
böhmischer Landtag einberufen worden war. Der Transport des Tragsessels war deshalb rechtzeitig nach Prag umgeleitet worden, wo das Objekt in den ersten Junitagen kurz nach dem Kaiserpaar anlangte. Da der toskanische Botschafter Giuliano de' Medici damals noch in Wien weilte, musste Pietro Ventorini, einer seiner Untergebenen, der in Prag das Quartier des Botschafters vorbereitete, den Tragsessel entgegennehmen. ${ }^{72}$ Giuliano de' Medici traf schließlich rund zwei Wochen später persönlich in Prag ein und ließ den Tragsessel sogleich auspacken. Dabei zeigte sich, dass dieser den Transport vollkommen unbeschadet überstanden hatte. Der Botschafter sah sich somit auch eines lästigen Auftrags entledigt. Die Großherzogin von Florenz, die befürchtet hatte, dass der Transport des Tragsessels viel zu lange dauern würde, hatte Giuliano de’ Medici nämlich angewiesen, in Wien einen anderen Tragsessel nach genauen Vorgaben anfertigen zu lassen und diesen vorläufig der Kaiserin zu überreichen, damit diese sich bis zum Eintreffen des Sessels aus Florenz schon eines Tragevehikels bedienen könne. Dieser Auftrag war durch das zeitgerechte Eintreffen des Tragsessels hinfällig geworden. Nun galt es aber, die zum Ensemble gehörigen Sesselträgerlivreen in aller Eile herstellen zu lassen. Die Zeit drängte nicht nur, weil die Übergabe des Tragsessels rasch vollzogen werden sollte, sondern auch, weil der damals in Prag weilende Herzog von Mantua den Wunsch geäußert hatte, das Geschenk noch vor seiner Überreichung persönlich in Augenschein nehmen zu dürfen. Entgegen den ursprünglichen Plänen ließ Giuliano de’ Medici die Livreen zusätzlich mit Hüten samt Federn sowie mit weißen Schuhen ergänzen. Zufrieden konnte er nach Florenz berichten, dass die Livreen letztlich perfekt mit dem Tragsessel harmonierten und das Geschenk in seiner Gesamtheit bei den Betrachtern einen äußerst positiven Eindruck hinterließ. ${ }^{73}$

Die Überreichung des Tragsessels an die Kaiserin fand schließlich am 2I. Juni statt. ${ }^{74}$ Knapp eine Woche später ließ die beschenkte Monarchin den Botschafter bei einer Messfeier zu sich rufen und teilte ihm mit, dass sie den Sessel sehr schätze. Sie zeigte sich auch begeistert darüber, dass es den mitgeschickten Sesselträgern gelinge, sie beim Tragen so sehr in der Waage zu halten, dass sie dabei fast gar nicht spüre, in Bewegung zu sein..$^{75}$

In Florenz hatte man von Anfang an befürchtet, dass die vier in Genua angeheuerten Sesselträger, mit denen die Kaiserin so zufrieden war, Probleme bereiten könnten. Es war mit ihnen vereinbart worden, dass sie die Reisespesen vorab erhalten und nach ihrer Ankunft am Kaiserhof so lange dort verbleiben sollten, wie dies Kaiserin Anna genehm sei. Für die Zeit ihres Aufenthalts wurden ihnen eine monatliche Besoldung von je 8 Scudi so-

72 Pietro Ventorini an Giuliano de’ Medici, Prag I6I5 Juni 2, ASF, MdP, filza 4368, unfol.

73 Giuliano de' Medici an Curzio Picchena, Prag I6r5 Juni 22, ASF, MdP, filza 4368, unfol.

74 Ebenda.

75 Giuliano de’ Medici an Curzio Picchena, Prag I6r5 Juni 29, ASF, MdP, filza 4368, unfol. 
wie die Übernahme ihrer Verpflegungskosten zugesagt. Auch mit neuen Kleidern für ihre Rückreise nach Italien durften sie rechnen. Da man in Florenz nicht wissen konnte, ob man die Sesselträger am Kaiserhof großzügig bezahlen oder ob man sich ihnen gegenüber knausrig zeigen würde, war vorab die Abmachung getroffen worden, dass der toskanische Botschafter den Sesselträgern den ihnen versprochenen Lohn abzüglich des Geldbetrags, den sie vom Kaiserhof erhielten, ausbezahlen solle. Auf jeden Fall sollte vermieden werden, dass die vier Genuesen, die am Kaiserhof ja für die Handhabung des Geschenkes zuständig waren, sich dort unzufrieden zeigten und damit einen Schatten auf das Präsent fallen ließen. ${ }^{76}$

Die Sorgen um etwaige Unmutsäußerungen der Sesselträger erwiesen sich als begründet. Kaum waren sie gemeinsam mit dem Tragsessel in Prag angekommen, beklagten sie sich, dass sie kein Geld für Essen und Unterkunft mehr übrig hätten, woraufhin sich Pietro Ventorini gezwungen sah, sie vorerst in einem Gasthaus einzuquartieren und dort bis zum Eintreffen des Botschafters zu verköstigen. ${ }^{77}$ Gleich nach seiner Ankunft in Prag beschwichtigte Giuliano de’ Medici die vier Sesselträger und sicherte ihnen zu, dass sie wie abgesprochen den ihnen zustehenden Lohn erhalten würden. Offenbar waren die Sesselträger in Sorge geraten, als sie bemerkt hatten, dass am Kaiserhof das Geld für eine standesgemäße Ausstattung des Marstalls fehlte. ${ }^{78}$ Wie Akten aus jenen Jahren zeigen, befand sich der Hofmarstall damals tatsächlich in einer bedauernswerten Verfassung. Als Beispiel dafür sei nur erwähnt, dass der Oberststallmeister dem Kaiser gegenüber klagte, dass die seit Jahren nicht mehr erneuerten Livreen der Kutscher bereits in einem solch erbärmli-

76 „A questi quattro portaseggiole è stato dato loro tutto il danaro che havranno bisogno fin costà, come anche si sono pagate le spese che hano fatto da Genova fin qui. L'accordo che è stato fatto con loro in Genova, è stato che costì siano pagati loro otto scudi il mese a ragione di piastre fiorentine, e le spese del vitto, per durare fin tanto che alla $m$ [aes] tà s[ua] parrà di servirsene, e che quando siano licenziati, sia dato loro un vestito per ciascuno, e tanti danari quanti basteranno à potersi ricondurre à Genova, e $v$ [ostra] $s$ [ignoria] ill[ [ustrissi] ma potrà darne notizia a quell $m$ [aest] ro di casa di $s$ [ua] $m$ [aes] tà che havrà da haver cura di loro. E per ogni caso, io le mando copia dell'obbligo, ch'essi hanno fatto in Genova per venire a cotesto servitio. Vogliono ben loro altezze, che quando saranno licenziati, se v[ostra] $s$ [ignoria] ill[ustrissi] ma sentisse, che si dolissero, che non fossero forse stati dati loro tanti danari da potersi commodam[en] te condurre a casa loro, e che in effetto ella riscontri, che habbino qualche ragione, in tal caso supplisca con quel più che le paresse conveniente, acciò non habbino occasione di partirsene mal sodisfatti. Et il medesimo vogliono che ella faccia ancora, caso che essi si lamentassero, o di non ricevere le loro paghe à $i$ debiti tempi, è che non fosse dato lor tanto, quanto si è stato promesso loro in Genova, ma faccialo segretamente, acciò s[ua] $m$ [aest] à et i suoi offiziali non se ne tenessero offesi." Curzio Picchena an Giuliano de' Medici, Florenz i6ı5 Mai Io, ASF, MdP, filza 4954, unpag.

77 Pietro Ventorini an Giuliano de' Medici, Prag I6Is Juni 2, ASF, MdP, filza 4368, unfol; Giuliano de' Medici an Großherzog Cosimo II de’ Medici, Wien I6I5 Juni 22, ebenda.

78 Giuliano de’ Medici an Curzio Picchena, Prag I6r5 Juni 22, ASF, MdP, filza 4368, unpag. 
chen Zustand seien, dass diese „vast nackhet und bloß daher gehen“ und bei öffentlichen Auftritten mit ihren „zerrißen, zerflickt und villfärbigen klaidern“ großen Spott auf sich ziehen würden. ${ }^{79}$ Die großen finanziellen Engpässe veranlassten den Kaiser damals dazu, eine Hofreform einzuleiten, die schließlich im Bereich des Marstalls zu einer Reduktion des Pferdestandes auf knapp 200 Tiere und zur Entlassung von Stallpersonal führen sollte. ${ }^{80}$

Das den vier Sesselträgern wiederholt gegebene Versprechen des toskanischen Botschafters, für eine entsprechende Bezahlung zu sorgen, sollten sie diese nicht vom Kaiserhof erhalten, beruhigte die vier Genuesen aber schließlich und bewegte sie sogar dazu, ihre Abreise vom Kaiserhof absichtlich hinauszuzögern. Nachdem auch der kaiserliche Oberststallmeister auf Nachfrage von ihnen erfahren hatte, dass der toskanische Botschafter im Falle einer zu geringen Entlohnung seitens des Hofes mit eigenem Geld einspringen würde, sah auch er - zum Ärger des Botschafters - keinen Grund mehr, die vier Männer vorzeitig nach Genua zurückzuschicken. ${ }^{81}$

Die Illusion, Kaiserin Anna sei in anderen Umständen, blieb noch über den gesamten Sommer des Jahres 1615 am Leben. Da die Kaiserin damals von korpulenter Statur war, ${ }^{82}$ wurde allgemein angenommen, dass die nicht erkennbaren schwangerschaftstypischen Rundungen in Annas beachtlicher Leibesfülle aufgingen. Zudem stimmten Verhärtungen in der Bauchgegend sowie Bewegungen, die sie in ihrem Leib zu verspüren glaubte, sie und den Kaiserhof weiterhin zuversichtlich, dass sie in Kürze ein Kind zur Welt bringen würde. ${ }^{83}$ Noch Anfang Oktober, als auch die letzten Hoffnungen auf eine Gravidität langsam im Begriffe waren zu schwinden, ließ sich die Kaiserin von den vier Sesselträgern in ihrem Tragsessel transportieren. ${ }^{84}$ Etwa zwei Wochen später war es schließlich zur endgültigen Gewissheit geworden, dass die Kaiserin doch kein Kind erwartete. Anna Caterina

79 Oberststallmeister Maximilian von Liechtenstein an Kaiser Matthias, I616 Oktober 4, ÖStA, FHKA, NÖHA, W 6I/a/3, Fasz. „Stallmeister“, fol. 43Ir. Bereits am I6. Dezember I6Is hatte der Oberststallmeister eine entsprechende Klage der Kutscher an den Kaiser weitergeleitet. Ebenda, fol. $4 \mathrm{I} 8 \mathrm{r}$.

80 ÖStA, FHKA, Hoffinanz Österreich, Bd. 657, fol. 378r (I614 September 22); ebenda, Bd. 663, fol. 2v (I6I5 Januar I5); ÖStA, HHStA, HA, Hofakten des Ministeriums des Innern, K. I4, Konv. „I600-I649“, unfol. (Prag I6I5 November 26).

8I Giuliano de' Medici an Curzio Picchena, Prag I6I5 Juli 6, ASF, MdP, filza 4368, unpag.

82 Vgl. Anm. 66.

83 Claudio Sorina an Ferdinando Gonzaga, Herzog von Mantua, Prag i6is September 28, Venturini 2002 (wie Anm. 5I), S. 623.

84 "Per conto di quei porta segiole ho differito di fare l'uffizio che scrissi a $v$ [ostra] s[ignoria] la settimana passata, perche in questa settimana che sono stati bellissimi tempi, l'imperatrice s'è servita di loro piu che mai; intanto ancora dovranno spirare l'ultime speranze del parto." Giuliano de' Medici an Curzio Picchena, Prag I6I5 Oktober 5, ASF, MdP, filza 4368, unpag. 
Gonzaga, die Mutter der Kaiserin, die eigens für die bevorstehende Geburt aus Tirol nach Prag gekommen war, reiste damals verdrossen nach Innsbruck zurück. Ihre Enttäuschung war so groß, dass sie nicht einmal mehr die geplante Krönung ihrer Tochter zur Königin von Böhmen abwarten wollte. ${ }^{85}$ Am 26. Oktober berichtete der toskanische Botschafter nach Florenz, dass man sich am Kaiserhof dazu entschlossen habe, die Sesselträger wieder zurück nach Genua zu schicken. Zwar hätte man sie gerne hier behalten, doch seien ihre Geldforderungen für eine feste Anstellung zu hoch gewesen. ${ }^{86}$ Der Zeitpunkt dieser Entscheidung legt indes nahe, dass beim Entschluss, die vier Männer wieder nach Italien gehen zu lassen, nicht nur finanzielle Aspekte ausschlaggebend waren, sondern dass auch das Ende jeglicher Hoffnung auf eine Schwangerschaft der Kaiserin eine Rolle spielte. Ob der Tragsessel von Kaiserin Anna auch nach I6I5 Verwendung am Kaiserhof fand, ist leider nicht überliefert.

\subsection{Zur Jagd im Tragsessel: Ein Präsent aus Mantua für Kaiserin Eleonora Gonzaga (I.) (1623)}

Ein Beispiel aus dem Jahr I623 zeigt, dass es für eine Kaiserin neben Schwangerschaften auch noch andere Gründe geben konnte, einen Tragsessel zu verwenden. Es unterstreicht auch deutlich, wie bedeutend italienische Einflüsse für die Ausbreitung von Tragsesseln am Kaiserhof waren, da damals erneut ein Tragsessel samt Sesselträgern von einem italienischen Fürstenhof an eine Kaiserin gesendet wurde. Die Adressatin war diesmal Annas Nachfolgerin Eleonora Gonzaga (I.) (I598-1655). Sie war erst im Jahr zuvor als Braut Ferdinands II. an den Kaiserhof gekommen. In Wien hatte sie aber offenbar weder einen für ihre Zwecke passenden Tragsessel noch geeignete Sesselträger vorgefunden. Die Kaiserin wandte sich deshalb im Sommer I623 schriftlich an ihren Bruder Ferdinando (I587-I626), den regierenden Herzog von Mantua. In einem ausführlichen Brief schilderte sie ihm, welch leidenschaftlicher Jäger ihr Gemahl sei und wie gerne sie ihn auf die Jagd begleiten würde. Bislang sei sie jedoch erst wenige Male mit ihm zur Jagd ausgeritten, da sie hinterher stets von starken Rückenschmerzen geplagt worden sei. Als Alternative zu einem Reitpferd kam für sie aber weder eine Karosse noch eine Maultiersänfte in Frage, da beide

85 Zorzi Giustinian an Doge Marcantonio Memmo, Wien I6I5 Oktober 19, ÖStA, HHStA, Venedig, DdG, Bd. 50, S. 3I.

86 "Qui havrebbono volentieri ritenuto i portasedie, ma come sentirno le loro pretensioni conforme all'accordo fatto in Genova si risolvettoro à dargli licenza, con dire di volergli dare sodisfazione di quello hanno servito, [...]." Giuliano de’ Medici an Curzio Picchena, Prag I6Is Oktober 26, ASF, MdP, filza 4368 , unpag. 
Transportmittel für Waldwege ungeeignet seien und darüber hinaus das Wild scheu machten. Aus diesem Grund ersuchte sie ihren Bruder, er möge ihr doch einen Tragsessel bauen lassen und zusammen mit diesem sechs Sesselträger schicken. Diese sollten entweder aus Genua oder aus Neapel stammen, wo Tragsessel besonders stark verbreitet waren. Keinesfalls aber, so die Kaiserin, sollte ein gemischtes Sesselträgerteam, das sowohl aus Genuesen als auch aus Neapolitanern bestünde, an den Kaiserhof gesendet werden, da Streitigkeiten damit bereits vorprogrammiert wären und sie derartige Konflikte nicht ertragen könne. ${ }^{87}$ Gegen Jahresende trafen der gewünschte Tragsessel und die sechs Sesselträger schließlich in Wien ein, wofür sich die Kaiserin bei ihrem Bruder brieflich bedankte. ${ }^{88} \mathrm{Ob}$ sich der Herzog für Sesselträger aus Genua oder Neapel entschied, geht aus dem Schreiben leider nicht hervor. Zu Beginn des Jahres I624 ließ die Kaiserin in Mantua nachfragen, welchen Betrag sie für den Tragsessel und das mitgeschickte Personal schuldig sei ${ }^{89}$ Wir können davon ausgehen, dass sie diese Anfrage nur der Form halber stellen ließ, denn es ist kaum vorstellbar, dass der Herzog von Mantua sich die Gelegenheit entgehen ließ, seiner Schwester mit dem Tragsessel ein Geschenk zu machen. Über die anschließende Verwendung des Präsents durch die Kaiserin liegen keine Informationen vor. Ob sie den Tragsessel nur auf der Jagd oder auch zu anderen Anlässen benutzte, ist unbekannt. Fest steht allein, dass sie ihn nicht während einer Schwangerschaft benötigte, da ihre Hoffnung auf Nachkommenschaft unerfüllt blieb.

Bedauerlicherweise lässt sich den vorliegenden Quellen auch nicht entnehmen, wie der aus Mantua stammende Tragsessel gestaltet war. Wahrscheinlich handelte es sich dabei jedoch um ein geschlossenes Vehikel, hätte doch der Gebrauch eines offenen Tragsessels bei Jagden im Wald durch das dort anzutreffende dornige Gestrüpp oder durch zurückschwingende Äste unberechenbare gesundheitliche Risken für die Insassin mit sich gebracht. Der Verwendungszweck legt weiterhin nahe, dass der Tragsessel zumindest außen

87 "Serenissimo fratello mio amatissimo, di già l'altezza vostra è informata del gusto che ha l'imperatore mio signore nella caccia, et questo se le radoppia quando vede che l'habbino altri, et io in particolare: il che fa che non patisce volontieri chio resti quando egli esce alla campagna ... poiché quelle poche volte chio cavalcato son restata fuor di modo offesa nella schena, hora non potendo io esser seco né in carrozza né in letica per la qualità dé boschi, et perché si smarirebbero gli animali, ho pensato di valermi delle comodità della seggietta, et a questo effetto vivamente prego l'altezza vostra a farmene far una, et provedermi di sei segettarii o napolitani o genovesi come ella stimerà meglio, pure che siano tutti di una natione perché mi daria troppo pena il vederli in contrasto tra loro, come facilmente seguirebbe quando altri fossero genovesi et altri napolitani ....". Eleonora Gonzaga an Ferdinando Gonzaga, Wien 1623 Juli 22, Venturini 2002 (wie Anm. 5I), S. 683.

88 Eleonora Gonzaga an Ferdinando Gonzaga, Wien 1623 Dezember 6, ebenda, S. 687.

89 Vincenzo Zucconi an Alessandro Striggi, Großkanzler von Mantua, Wien I624 Februar 3, ebenda, S. 689. 


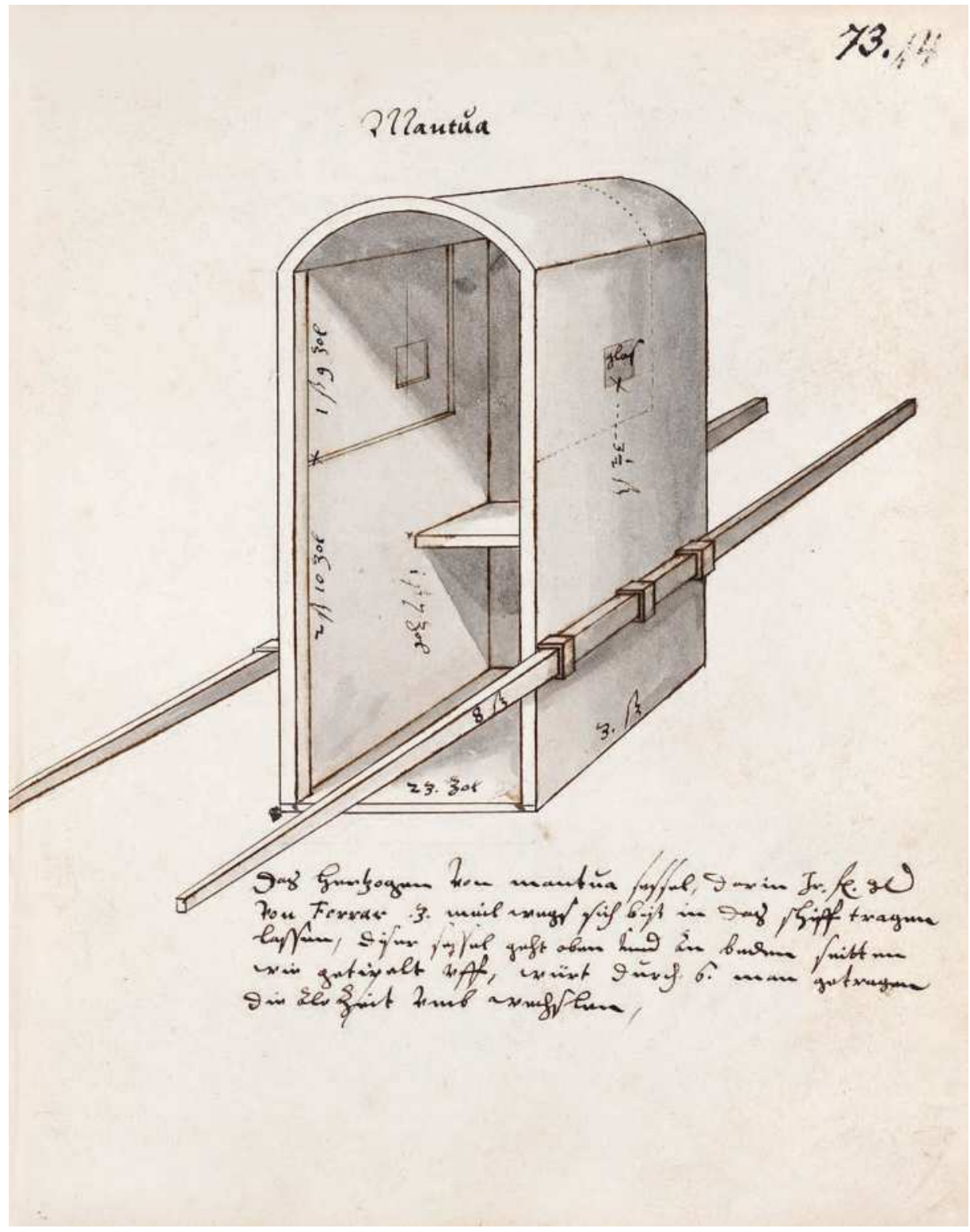

Abb. 5: Heinrich Schickhardt, Zeichnung des Tragsessels von Vincenzo I. Gonzaga, Herzog von Mantua, 1600. Der unter die Zeichnung gesetzte Text lautet wörtlich: „Des hertzogen von Mantua sessel, darin $\operatorname{ir}[e]$ f[ürstliche] g[naden] von Ferrar 3. meil wegs sich biß in das schiff tragen lassen, diser sessel geht oben und zu beden seitten wie getixelt vff, würt durch 6. man getragen die ale zeit umb wechslen."WLB, Handschriften, Cod. hist. qt. 148, b, fol. 73 r. @ WLB 
mit widerstandsfähigem Material - wie etwa Leder - bezogen war. Einen Eindruck davon, wie der mantuanische Tragsessel ausgesehen haben könnte, gibt eine Zeichnung (Abb. 5) des württembergischen Hofbaumeisters Heinrich Schickhardt (I558-I635), die dieser auf einer Italienreise im Jahr 1600 angefertigt hatte. ${ }^{\circ 0}$ Sie zeigt den persönlichen Tragsessel des damals regierenden Herzogs von Mantua, Vincenzo I. Gonzaga (I562-I6I2). Dieses Transportmittel verfügte über ein tonnengewölbtes Dach, war rückwärts und seitlich geschlossen und an der Vorderseite, an der bei später entstandenen, vergleichbaren Tragsesseln meist die Türe zu finden ist, zur Gänze geöffnet. Zusätzlich ließen sich jedoch bei Bedarf auch Teile des Dachs und der seitlichen Wände, die mit kleinen, verglasten Fensteröffnungen versehen waren, entfernen. An den Seitenwänden waren im unteren Bereich jeweils drei Metallbügel befestigt, durch die die Trageholme geschoben werden konnten. Die fix eingebaute Sitzbank, auf der wohl nur eine Person Platz fand, war äußerst schlicht gestaltet und bot keinerlei Komfort für den Passagier. Dies ist wohl darauf zurückzuführen, dass Schickhardt sich nur für die konstruktiven Details interessierte - darauf weisen auch die vielen Maßangaben seiner Zeichnung hin - und auf die bildliche Dokumentation der Polsterung und textilen Ausstattung des Tragsessels völlig verzichtete. Der Zeichnung beigefügte Notizen verraten unter anderem, dass zur Bedienung des Tragsessels insgesamt sechs Männer benötigt wurden, die einander ständig abwechselten, um so Übermüdungen und damit auch Unfällen vorzubeugen.

Die Zahl der Personen, die für die Beförderung des von Schickhardt gezeichneten Tragsessels nötig waren, stimmt mit der Zahl der italienischen Sesselträger überein, die der Herzog von Mantua I623 an den Kaiserhof entsandte. Diese sechs Personen verblieben nach ihrer Ankunft in Wien offenbar dauerhaft in Diensten Eleonora Gonzagas (I.), denn von 1625 datiert die Nachricht, dass die sechs Sesselträger der Kaiserin neu eingekleidet wurden. ${ }^{9 \mathrm{I}}$ Sie waren demnach die ersten Sesselträger, für die am Kaiserhof Planstellen geschaffen wurden. Ihre Anzahl blieb auch in den Jahren nach I625 stabil, denn auch I629 und 1630 ist in Archivalien wiederholt von der Herstellung neuer Livreen für sechs Sesselträger Eleonora Gonzagas (I.) die Rede. ${ }^{22}$ Besonders aufwendig waren die I630 angeschafften Livreen gestaltet, die dem Auftreten des Kaiserpaares auf dem Kurfürstentag von Regensburg besonderen Glanz verleihen sollten. Das Aussehen der damals gelieferten Dienstkleider ist in schriftlicher Form minutiös überliefert. Dabei lässt sich feststellen, dass sich die Livreen der Sesselträger von jenen der übrigen Hofdiener durch eine andersartige Gestaltung abhoben. Nur die Sesselträger wurden mit langen, weitärmeligen, sogenannten

90 Zu dieser Zeichnung siehe auch WaCkernagel 2002 (wie Anm. 20), Bd. I, S. 74, Bd. 2, S. 97.

9I ÖStA, FHKA, HZAB, Bd. 76, fol. 532v (Anno r625).

92 ÖStA, FHKA, Hoffinanz Österreich, Bd. 729, fol. I63v (I629 April 19) und 193v (I629 April 2I) sowie Bd. 73I, fol. $203 v$ (I629 April 2I); ÖStA, FHKA, NÖHA, K. 780, fol. 760v-763v (I630 Mai ıo). 
„französischen“ Flügelmänteln ausgestattet. Diese waren aus gelbem Samt gefertigt, mit schwarzem, feinem englischen Tuch gefüttert und mit gelb-weißen Seidenborten sowie mit gleichfarbigen, großen „französischen“ Seidenknöpfen besetzt. Ähnliche Materialien, Applikationen und Farben wiesen auch die dazugehörigen Kleidungsstücke auf, nämlich ein Rock, ein Wams, Hosen, Strümpfe, Gürtel und ein Gehänge. Komplettiert wurde die Livree durch einen Hut aus Biberfell, auf den ein Federbusch aufgesetzt war. ${ }^{93}$

\subsection{Exkurs I: Nachrichten über frühe Tragsessel am Innsbrucker Hof}

Als Vergleichsbeispiel für den Kaiserhof bietet sich hinsichtlich der Ausbreitung von Tragsesseln der Innsbrucker Hof an, an dem seit 1564 Mitglieder einer Nebenlinie der österreichischen Habsburger als Tiroler Landesfürsten regierten. Wie bereits erwähnt, finden sich Ende des I6. und Anfang des I7. Jahrhunderts noch keine Spuren von Tragsesseln in den Inventaren der Herrscher Tirols. Weder lassen sich solche im Nachlassinventar Ferdinands II. von Tirol von 5966 noch in Inventaren von Erzherzog Maximilian III. von I6I4 und 1618/19 nachweisen. Tragsessel wurden am Innsbrucker Hof allem Anschein nach in der zweiten Hälfte der I620er Jahre eingeführt, also nur wenige Jahre nach ihrer Etablierung am Kaiserhof. Auffallend ist nicht nur diese zeitliche Nähe, sondern auch die Tatsache, dass die ersten archivalisch dokumentierbaren Tragsessel am Innsbrucker Hof gleichfalls italienischer Provenienz waren. Sie wurden von Claudia de' Medici (I604-I648) ${ }^{94}$ I626 aus der Toskana mitgebracht. Im I625 erstellten Inventar der Brautausstattung dieser Florentiner Fürstin, die sich ein Jahr später mit dem Tiroler Landesfürsten Erzherzog Leopold V. (I586-I632) vermählen sollte, finden sich gleich zwei repräsentative Tragsessel. Einer der beiden war mit blauem Samt bezogen, mit vergoldeten Ziernägeln beschlagen und mit einer rotledernen, kuppelartigen Bedachung versehen, die an der Innenseite eine blaue Damastbespannung aufwies. Der Sessel war zudem mit Spitzen sowie mit blauseidenen und goldenen Fransen geschmückt und im Inneren mit reichen Verzierungen ausgestattet. An seiner Außenseite dominierte die Farbe Rot. Alle Eisenbeschläge dieses Tragsessels wie auch die Schnallen der Tragegurte waren vergoldet. ${ }^{95}$ Das andere Objekt der Brautaus-

93 ÖStA, FHKA, NÖHA, K. 780, fol. 760v-763v (I630 Mai ıо).

$94 \mathrm{Zu}$ ihr siehe Sabine Werss, Claudia de' Medici. Eine italienische Prinzessin als Landesfürstin von Tirol (I604-I648) (Innsbruck/Wien 2004); DIEs., Der Innsbrucker Hof unter Leopold V. und Claudia de’ Medici (I619-I632). Glanzvolles Leben nach Florentiner Art. In: Noflatscher/NieDERKorn 2005 (wie Anm. 32), S. 24I-348.

95 "Una seggiola da portare di velluto turchino con bullette dorate, e trine, e frange di seta turchina, et oro, con sua coperta a cupola di sommacchi rossi foderati di domm[asc]o turchino con guarn[izion]e drento d.o e seta turchina, e fuori rossa con tutti ferram [en] ti dorati con sue cigne di fibbie dorate". ASF, 
stattung, das wie der zuvor beschriebene Tragsessel im Inventar als „seggiola“ bezeichnet ist, war der Beschreibung nach zu schließen ein offener Tragsessel ohne Seitenwände und Bedachung. Er war mit rotem Samt bezogen, mit Fransen und Verzierungen aus Gold und roter Seide versehen und gleich dem anderen Tragsessel mit vergoldeten Ziernägeln bestückt. Darüber hinaus verfügte er über ein Kopfpolster und über eine in ihrer Neigung verstellbare Rückenlehne. ${ }^{96}$ Es besteht kein Zweifel daran, dass Claudia de' Medici diese beiden Tragsessel auch tatsächlich nach Tirol mitnahm.

Der zweite, offene Tragsessel der Brautausstattung begegnet uns einige Jahre später erneut in einer anderen Quelle. Zwischen I626 und I628 - der genaue Zeitpunkt lässt sich nicht mehr feststellen - wurde er am Innsbrucker Hof einer Reparatur unterzogen, bei der er unter anderem einen neuen Samtbezug erhielt und 400 seiner vergoldeten Ziernägel ausgetauscht wurden. Die über die durchgeführten Arbeiten gelegte Rechnung gibt außerdem einen Hinweis auf seinen Einsatzbereich: Claudia de' Medici ließ sich in diesem „zusamengelegten“ Sessel für gewöhnlich innerhalb des fürstlichen Palastes tragen. ${ }^{97}$

Die erwähnte Generalüberholung des Tragsessels wurde von Andrea Pandolfini verrichtet, einem Florentiner Sattler, den Claudia de' Medici aus ihrer toskanischen Heimatstadt mitgebracht hatte. Seit 1626 erledigte er am Innsbrucker Hof die anfallenden Sattlerarbeiten, und zwar nicht nur für den Tiroler Landesfürsten und seine Gemahlin, sondern auch für andere hochrangige Personen. Dies erfahren wir aus einem Schreiben Pandolfinis an Erzherzog Leopold V., in dem er darüber klagte, dass seine Kunden mit ihren Zahlungen für bereits geleistete Arbeiten säumig seien. ${ }^{98}$

In den Innsbrucker Quellen jener Jahre taucht noch ein weiterer Tragsessel auf, der sich allerdings nicht mit dem blau tapezierten, geschlossenen Tragsessel der Brautausstattung von Claudia de’ Medici identifizieren lässt. Die Provenienz dieses dritten Tragsessels ist unbekannt. Es handelte sich dabei um einen mit einem Dach versehenen Sessel mit Vorhängen, der mit grün gemasertem Samt bezogen und mit vergoldeten Ziernägeln beschlagen war. Zudem verfügte er über goldene und seidene Fransen und war mit einem Fußbrett aus rotem Corduanleder versehen. Auch dieser Tragsessel wurde von Pandolfini in Stand

Miscellanea Medicea 5/2, fol. 217v.

96 "Una seggiola di velluto rosso con guarnitione d'oro et frango d.o e seta rossa con fullette dorate, et un guanciale del med[esim] o velluto per acconciare la testa sendo la seggiola da ripiegare". Ebenda, fol. 2IOv. „Widerumben ain zusamengelegten tragsessel. Darinnen mann ir für[stliche] d[urchlauch]t, die erzherzogin etc. in der für[stlichen] burg hin- und heer tregt. Zway mal von roten cärmesin samet überzogen, auch von rot seiden unnd gulden fransen mit neuen 400 vergulten negl beschlagen die fuessdrit zu 2 mal von roten cardewan überzogen, ist auch fir mein macherlon, guert, aisen und schwarze nögl 6 f." Rechnung von Andrea Pandolfini aus den Jahren I626-I628, TLA, Kunstsachen I 874, unfol.

98 Ebenda. 
gesetzt. Er versah das Vehikel zudem mit einem „loch in der mitten“, womit vielleicht der Einbau eines Aborts umschrieben ist. ${ }^{99}$ Vermutlich lässt sich dieser grünsamtene Tragsessel mit einem gleichfarbigen Tragsessel identifizieren, den Erzherzog Leopold V. laut einer Augenzeugenbeschreibung im Jahr I628 benutzte. Die diesbezügliche Nachricht stammt von Philipp Hainhofer aus Augsburg, der sich im April und Mai jenes Jahres für mehrere Wochen in Innsbruck aufhielt. Er berichtete von dort, dass sowohl der Tiroler Landesfürst, der nach einem Kuraufenthalt noch rekonvaleszent war, als auch seine zu jener Zeit hochschwangere Gemahlin Claudia de’ Medici längere Wegstrecken innerhalb der Stadt im Tragsessel zurücklegten. Nur den Tragsessel des Erzherzogs beschrieb Hainhofer etwas näher: Er war mit grünem Samt bezogen und verfügte über eine Bedachung. ${ }^{100}$

Obwohl am Innsbrucker Hof seit der zweiten Hälfte der I62oer Jahre Tragsessel in Verwendung standen, sind für diese Zeit noch keine Sesselträger im erzherzoglichen Hofstaat nachweisbar. ${ }^{\text {IoI }}$ Es ist deshalb unklar, wer damals die Tragsessel des Landesfürsten und seiner Gemahlin beförderte und woher das eingesetzte Sesselträgerpersonal kam. Auch in einem Hofstaatsverzeichnis von I645 der damals bereits verwitweten Claudia de' Medici, in dem zahlreiche Stalldiener angeführt sind, finden sich noch keine Sesselträger. ${ }^{102}$ Erst in Verzeichnissen der frühen I66oer Jahre sind mehrere davon im Innsbrucker Hofstaat dokumentiert. ${ }^{103}$

\subsection{Königin und Kaiserin Maria Anna und ihre Tragsessel}

Gelangte eine ausländische Prinzessin als Braut an den Kaiserhof, wurde dies in Wien in der Regel zum Anlass genommen, den Fuhrpark zu überholen und neue, repräsentative Gefährte für die ankommende Fürstin herstellen zu lassen. Gleichzeitig brachte die

99 „Erstens den 29. may anno I626 ainen tragsessl von grien gmussierten samet beschlagen, die anndern firhenng von grien gemussierten samet mit ibergulten nöglen beschlagen, die anlain und armblain mit ybergulten negl beschlagen. Ain loch in der mitten gemacht, auch seideni und guldeni fransen daran beschlagen, den fuessdrit von roten cordewan yberzogen [...]. Mer 6 pfund gesottenes rosshar zu dem sessl gebraucht [...]. "Ebenda. Über derartige in die Sitzpolster eingebaute Aborte verfügen auch die beiden erhaltenen Hofsänften der kaiserlichen Wagenburg (Inv.-Nrn. W 90 und W 9I).

Ioo Oscar Doering, Des Augsburger Patriciers Philipp Hainhofer Reisen nach Innsbruck und Dresden (Wien I90I), S. 35 f.

IOI Vgl. die Hofstaatsverzeichnisse von I626/28, I629 und I632. TLA, Hs. 5157 und TLA, Kunstsachen I 7 I8.

IO2 TLA, Hs. I42O.

I03 Vgl. die Hofpfennigmeisteramtsrechnungen von I660 (TLA, Hs. 1965, fol. I24V-I26r) und das Hofstaatsverzeichnis von 1662 (TLA, Ambraser Memorabilien I 173). 
Braut zuweilen auch Fahrzeuge aus dem Ausland an den Hof ihres Gemahls mit. Derartige Vorgänge lassen sich auch rund um die Hochzeit der spanischen Infantin Maria Anna

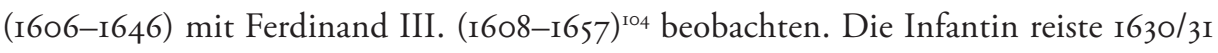
nach Wien, ${ }^{105}$ um mit dem Sohn des damals regierenden Kaisers Ferdinand II. den Bund der Ehe zu schließen. Bereits knapp zwei Jahre vor der von langer Hand geplanten Vermählung hatte man am Wiener Hof damit begonnen, sich mit zahlreichen neuen Fahrzeugen für das bevorstehende Fest auszurüsten. ${ }^{106}$ Eine etwaige Anschaffung von neuen Tragsesseln ist dabei jedoch nicht überliefert. Allerdings benutzte Maria Anna auf ihrer Brautreise von Spanien nach Wien selbst immer wieder Tragsessel, ${ }^{107}$ die ihr fallweise unterwegs zur Verfügung gestellt oder aber auch geschenkweise überlassen wurden. Franz Christoph von Khevenhüller berichtete etwa, dass ihr am 7. Januar I63I beim Eintreffen im römischen Herrschaftsgebiet ein päpstlicher Nuntius im Namen des Kardinalnepoten Francesco Barberini eine vollständige Garnitur verschiedenartiger Transportmittel als Geschenk überreichte. Es handelte sich dabei um einen sechsspännigen Wagen samt Zugtieren, eine rotsamtene Sänfte mit goldenen Borten, venezianischen Spiegelgläsern und drei weißen Trageseln sowie um einen Tragsessel, der ähnlich der Sänfte gestaltet war. ${ }^{108}$

IO4 Zu Ferdinand III. siehe vor allem Lothar НӧвеLt, Ferdinand III. Friedenskaiser wider Willen (Graz 2008); Mark Hengerer, Kaiser Ferdinand III. (I608-I657). Eine Biographie (Veröffentlichungen der Kommission für Neuere Geschichte Österreichs I07, Wien/Köln/Weimar 2012).

Zur Brautreise siehe am umfassendsten Claudia HAм, Die verkauften Bräute. Studien zu den Hochzeiten zwischen österreichischen und spanischen Habsburgern im I7. Jahrhundert, 2 Bde. (ungedr. Dissertation, Universität Wien 1995), Bd. I, S. 74-I43.

I06 Zur Erneuerung des Fuhrparks anlässlich der Hochzeit von I63I siehe: Toskanischer Botschafter Niccolò Sacchetti, Wien I629 April 25, ASF, MdP, filza 4382, unfol.; ÖStA, FHKA, Hoffinanz Österreich, Bd. 729, fol. I69r (1629 April 27) und Bd. 731, fol. 4I3v (I629 August 9); ÖStA, FHKA, NÖHA, K. 773, fol. I035r (I629 März 7), fol. I039-I046 (I629 August 3), fol. I047r (I629 August 7), fol. ıo9ov (I630 März 6); ÖStA, FHKA, NÖHA, K. 774, fol. II57-II75 (163I April 25); ÖStA, FHKA, NÖHA, K. 775, fol. 46-55 (undat., aber I631).

KHeVenhüLler I72I-I726 (wie Anm. 6I), Bd. II, Sp. 959 f., I487, I499, I5OI.

I08 Ebenda, Bd. II, Sp. I487. Der kostspielige Brauch, einen Wagen, eine Sänfte und einen Tragsessel zusammen als Ensemble zu schenken, lässt sich für das 17. Jahrhundert mehrfach belegen. Im Jahr I633 ließ Manuel de Acevedo y Zúńiga, damals Vizekönig von Neapel, dem erst vierjährigen spanischen Infanten Baltasar Carlos drei derartige, alle mit grünem goldbesticktem Samt ausgestattete Prunkvehikel, deren Gesamtwert auf 20.00o Scudi geschätzt wurde, als Präsent übergeben. Francesco di Giovanni de’ Medici an Andrea di Giovanni Battista Cioli, Madrid I633 Dezember I7 und 24, ASF, MdP, filza 4959, fol. 1066, 1074. Zit. nach der Internetplattform „The Medici Archive Project“. Papst Alexander VII. machte der zum Katholizismus konvertierten Christina von Schweden für deren Einzug in Rom im Jahr I655 ebenfalls ein derartiges Ensemble zum Geschenk. Es wurde von Gian Lorenzo Bernini entworfen und bestand aus einem Wagen, einer Sänfte, einem Tragsessel und einem Pferd samt allem erdenklichen Zubehör. Galeazzo Gualdo Priorato, His- 
Aus anderen Quellen geht hingegen eindeutig hervor, dass der eigentliche Geschenkgeber nicht Francesco Barberini, sondern dessen Onkel Papst Urban VIII. war. ${ }^{109}$ Anlässlich der Vorbereitungen für den wenige Wochen später erfolgenden Einzug Maria Annas in Triest wurden in einer Liste ${ }^{\text {Iо }}$ drei Tragsessel erwähnt, die die Braut mit sich führte. Einer davon verfügte über einen verglasten Sitzkasten und stammte aus ihrem eigenen Besitz. Vielleicht hatte Maria Anna ihn aus Spanien mitgenommen. Beim anderen handelte es sich um den Tragsessel, den ihr der Papst verehrt hatte. Beide waren mit Vorhängen und Polstern ausgestattet. Der dritte Tragsessel war klein, mit grünem Damaststoff überzogen ${ }^{\text {III }}$ und stammte möglicherweise ebenfalls aus Spanien. ${ }^{\text {I2 }}$ Es ist anzunehmen, dass diese drei Tragsessel nach Maria Annas Ankunft in Wien dem Oberststallmeister zur Verwaltung überlassen wurden.

Etwas weniger als zwei Jahre nach ihrer Vermählung war Maria Anna guter Hoffnung. Während ihrer Gravidität ließ sie sich zumindest fallweise im Tragsessel befördern. Der toskanische Botschafter Niccolò Sacchetti berichtete im Mai I633 aus Wien, dass die im sechsten Monat schwangere Maria Anna zwar an der Fronleichnamsfeier teilgenommen habe, während der Prozession aber in der Kirche verblieben sei und sich vom Palast zur Kirche und wieder zurück neben dem in der Karosse fahrenden Kaiser im Tragsessel transportieren habe lassen. ${ }^{\text {II3 }}$

Am 8. September I633 erblickte das erste Kind von Maria Anna und Ferdinand III., Erzherzog Ferdinand IV. (1633-1654), das Licht der Welt. Mit ihm schien die Erbfolge lang-

toria della Sacra Real Maestà di Christina Alessandra Regina di Svetia, \&c. (Roma I656), S. 242 f. Für weitere Beispiele siehe den Beitrag von Alejandro López Álvarez im vorliegenden Band.

IO9 „Manda di più s[ua] s[antit] à [Papst Urban VIII., Anm. d. Verf.], otro la carozza, lettiga, e sedia, che ha fatto fare per serv[izio] di s[ua] $m$ [aest] à [Maria Anna, Anm. d. Verf.] un regalo [...]. "Schreiben an Fürst Hans Ulrich von Eggenberg (?), Rom I63o Dezember 28, ÖStA, HHStA, ÄZA, K. 2, Konv. I3, fol. 4v. Siehe dazu auch ÖStA, HHStA, ÄZA, K. 2, Konv. 16, fol. $20 r$.

IIO „Memoria de las caualgaduras de la caualleriza de su mag[esta]d que desembarcaron en Trieste, y se entregaron al conde mi s[eño] r oy sabado I de febrero de I63I [...]. Dos sillas una de su mag[esta]dy otra de su sant $[\mathrm{ida}] d$ con cortinas y almuadas, y la de su mag[esta] d hay una cassa de bidrios. Otra silla pequena de dam [as] co verde de su mag[esta] d“. ÖStA, HHStA, ÄZA, K. 2, Konv. I6, fol. 2or-v.

III Im gleichen Jahr wird ein „grüen sameten trag sessl“ der Königin erwähnt. Ob es sich dabei um denselben Tragsessel handelt, ist unklar. ÖStA, HHStA, OMeA, SR, K. 75, Konv. I, Akten von I63I.

II2 Die Tatsache, dass die Infantin Tragsessel aus Spanien mitbrachte, ist auch vor dem Hintergrund der außerordentlichen Bedeutung zu sehen, die diese Tragevehikel damals bereits am Madrider Hof erlangt hatten. Siehe dazu den Beitrag von Alejandro López Álvarez im vorliegenden Band.

II3 „Tutti lor' mm[aes]tà, et alt[ezz]e se la passano bene, essendo giovedì mattina intervenute alla processione del corpus domini, essendo però la regina rimasta in chiesa, che venne dà palazzo, e tornò in seggetta accanto alla carrozza dell imp[erato]re, rispetto alla sua gravidanza, che dev'essere adesso al principio del sesto mese con buone speranze d'uscire felicemente, [...]. "Toskanischer Botschafter Niccolò Sacchetti, Wien I633 Mai 28, ASF, MdP, filza 4388, unfol. 
fristig gesichert. Noch am Nachmittag desselben Tages wurde der kleine Prinz getauft. Für jene Jahre lässt sich für den Kaiserhof erstmals die Verwendung eines Tragsessels im Rahmen des Taufzeremoniells nachweisen. Es ist jedoch trotz einer anderslautenden Mitteilung eher unwahrscheinlich, dass ein solcher bereits bei der Taufe Ferdinands IV. zum Einsatz kam. Sacchetti berichtete, dass Gräfin Siruela, die Obersthofmeisterin der Königin, in deren Tragsessel in den großen Saal der Wiener Hofburg, in dem die Zeremonie stattfand, getragen worden sei und dass die Gräfin dabei das Neugeborene im Arm gehalten habe. ${ }^{\text {II }}$ Franz Christoph Khevenhüller schreibt hingegen, dass das Kind damals in einem mit Perlen bestickten „Fäsch-Bett" ${ }^{\text {"Is }}$ von Graf Thun, dem Obersthofmeister des Kindsvaters, zur Taufe gebracht worden sei. Dieses „Fäsch-Bett“ sei aber so schwer gewesen, dass auch der Obersthofmeister der Königin, Franz Christoph von Khevenhüller, und der Oberststallmeister des Königs, Maximilian von Waldstein, mit anpacken mussten, um das Kind sicher zum Ort der Taufe zu bringen. ${ }^{116}$ In diesem Fall können wir der Version Khevenhüllers wohl größeres Vertrauen schenken als jener Sacchettis, da Khevenhüller nach eigenen Angaben selbst das Bettchen tragen half, während aus Sacchettis Schreiben nicht einmal hervorgeht, ob er selbst Augenzeuge der Taufe war oder nur aus zweiter Hand vom Ablauf der Zeremonie erfahren hatte. Vermutlich kam bei der Taufe Ferdinands IV. also kein Tragsessel zum Einsatz. Interessant ist dabei jedoch, dass es für Sacchetti - möglicherweise aufgrund von Erfahrungen, die er an anderen Höfen gemacht hatte - offenbar gar nicht denkbar war, dass bei diesem Anlass ein anderes Tragevehikel als ein Tragsessel zu Einsatz gekommen sein könnte.

Als Maria Anna I634 erneut in anderen Umständen war, beschloss sie im Sommer trotz hoher Temperaturen und ihres bereits fortgeschrittenen Schwangerschaftsstadiums, von Wien nach Passau zu reisen, um dort ihren jüngeren Bruder, den Kardinalinfanten Ferdinand, zu treffen. Mit großem Gefolge brach sie am I4. Juli per Schiff von Wien auf. In Klosterneuburg, der ersten Station der flussaufwärts führenden Reise, ließ sich die Königin

II4 Doppo questo le mm[aes] tà, et alt [ezz] e calorno nella gran sala venendo imediatam[en] te dietro all'imp[erato] re et imp[eratri]ce la sedia stessa della regina, nella quale era la contessa di Ziruola sua maiordoma mag[gio] re, che portava la creatura, et avanti in test'alla sala, dove eretto un altare, fu tenuta al sacrofonte dall imp [erato] re, et imp[eratri]ce, in nome del re, et regina catt [oli] ci, et battezzata dal cardinale Dietristain col nome di Ferdinando Francesco; [...]." Toskanischer Botschafter Niccolò Sacchetti, Wien I633 September 20, ASF, MdP, filza 4388, unfol. Keine Einzelheiten zur Taufzeremonie erfahren wir aus den Berichten des päpstlichen Nuntius und des venezianischen Gesandten am Kaiserhof. Vgl. Nuntiaturberichte aus Deutschland nebst ergänzenden Aktenstücken, 4. Abt.: Siebzehntes Jahrhundert, Bd. 6: Rotraut Becker (Bearb.), Nuntiatur des Ciriaco Rocci. Ausserordentliche Nuntiatur des Girolamo Grimaldi. Sendung des P. Alessandro d'Ales (I633-I634) (Berlin/Boston 2016), S. I53; ÖStA, HHStA, Venedig, DdG, Bd. 77.

II5 Khevenhüller I72I-I726 (wie Anm. 6I), Bd. II, Sp. 496. Unter einem „Fäsch-Bett“ ist vermutlich ein Bett für ein Neugeborenes zu verstehen, das in Binden (Faschen) eingewickelt war.

II6 Ebenda. 
in ihrem Tragsessel in die Stiftskirche tragen, wo sie eine Litanei hörte. Der darauf folgende Tag brachte einen Wetterumschwung mit starken Regenfällen. In kurzer Zeit ließen die Niederschläge die Donau anschwellen und über ihre Ufer treten. Um eine akute Gefährdung der Kaiserin und ihrer mitreisenden Hofdamen auszuschließen, beschloss man, die Frauen bei Greifenstein aus den Schiffen zu bergen. Damit sie nicht selbst im tiefen Wasser und Schlamm des überfluteten Auwaldes waten mussten, wurden die schwangere Königin und ihre Hofdamen nacheinander im Tragsessel der Monarchin an Land gebracht. Die sechs mitgereisten königlichen Sesselträger, die vor der Abfahrt noch neu eingekleidet worden waren, zeigten sich in dieser Situation mit ihrer Aufgabe überfordert und mussten deshalb von Khevenhüller, dem Obersthofmeister der Königin, sowie von einigen anderen Kavalieren tatkräftig unterstützt werden. ${ }^{\mathrm{II} 7}$ Nachdem sich das Wetter gebessert hatte und der Pegelstand des Flusses wieder gesunken war, konnte die Reise fortgesetzt werden. Am Io. August trafen die schwangere Königin und ihr Gefolge schließlich wohlauf in Passau ein. ${ }^{\text {II8 }}$ Nach einer Nacht auf dem Schiff wurde die Königin am darauf folgenden Tag im Tragsessel an Land gebracht und unter einem Baldachin in die Domkirche geleitet. ${ }^{119}$ Die Wiedersehensfreude der beiden Geschwister war groß. Kardinalinfant Ferdinand ließ seiner Schwester am I3. August einen „galanten“ Tragsessel als Geschenk überreichen. ${ }^{\text {I20 }}$ Bei einem Besuch der auf einem Hügel bei Passau gelegenen Wallfahrtskirche Mariahilf testete die Königin sogleich ihren neuen Tragsessel. ${ }^{\text {I2I }}$ Sie scheint ihn auch noch in späteren Jahren verwendet zu haben, denn am 4. Mai I637, zu einem Zeitpunkt, als Maria Anna bereits Kaiserin war und gerade wieder ein Kind erwartete, werden in einer Liste von Vehikeln, die für einen Landaufenthalt in Laxenburg bereitgestellt werden sollten, auch „ir. m[ajestä]t drey sessel“ erwähnt. Die Kaiserin benötigte gemäß dieser Liste an Tragsesseln „den von sereniss[i]mo infante“, also jenen, den ihr Bruder ihr I634 in Passau geschenkt hatte, außerdem „den päpstl[ichen]“, also jenen, den sie I63I auf ihrer Brautreise nach Wien von Urban VIII. als Präsent erhalten hatte, und schließlich „den khlain“"122, womit vermutlich der mit grünem Seidendamast bezogene kleine Tragsessel gemeint ist, der uns ebenfalls schon in den Quellen des Jahres I63I begegnete.

II7 Ebenda, Bd. I2, Sp. I446-I45O. Franz Christoph von Khevenhüller an Kaiser Ferdinand II., Tulmb (Tulln) I634 Juli I6, ÖStA, HHStA, ÄZA, K. 2, Konv. I8, fol. 3r. Zu dieser Reise siehe auch Otto Friedrich Winter, Die Donaureise Königin Marias im Sommer I634. In: Mitteilungen des Österreichischen Staatsarchivs 25 (1972), S. 359-373.

II8 Khevenhüller I72I-I726 (wie Anm. 6I), Bd. I2, Sp. I455 f.

II9 Kardinal Dietrichstein an Kaiser Ferdinand II., Passau I634 August I2, ÖStA, HHStA, ÄZA, K. 2, Konv. I8, fol. 76 r.

I20 Khevenhüller I72I-I726 (wie Anm. 6I), Bd. I2, Sp. I457; Franz Christoph Khevenhüller an Kaiser Ferdinand II., Passau I634 August I5, ÖStA, HHStA, ÄZA, K. 2, Konv. I8, fol. 83r.

I2I KheVenhüLleR I72I-I726 (wie Anm. 6I), Bd. I2, Sp. I457.

122 ÖStA, HHStA, OMeA, SR, K. 76, Konv. 8, unfol. 
Für das Jahr I640 lässt sich am Kaiserhof erstmals mit Sicherheit die Verwendung eines Tragsessels bei einer Taufe und auch beim nachfolgenden Hervorgang der Kindesmutter aus dem Kindbett nachweisen. Am 9. Juni I640 wurde frühmorgens Erzherzog Leopold, der spätere Kaiser Leopold I., in Wien geboren. Sein Vater, Kaiser Ferdinand III., hatte die Niederkunft seiner Frau Maria Anna nicht abgewartet, sondern war bereits zuvor nach Regensburg zu einer Reichsversammlung abgereist. Die Taufe des Prinzen fand noch am Abend des Tages der Entbindung Geburt in Anwesenheit des in Wien verbliebenen Hofstaats im eigens für diesen Anlass kostbar ausgestatteten „grossen Saal“ der Hofburg statt. Gräfin Susanna Veronika Trautson, die damals für sämtliche kaiserlichen Kinder das Amt der Obersthofmeisterin versah, kam die Aufgabe zu, den neugeborenen Erzherzog vom Kindbett der Kaiserin, die nur wenige Stunden nach der Geburt nicht selbst an der Taufe teilnehmen konnte, bis zu jenem Saal zu bringen, in dem die Taufzeremonie stattfand. Diese Strecke legte sie in einem „rothsammeten Trag-Sessel“ zurück, wobei sie den kleinen Prinzen im Arm hielt. An der Schwelle zum Saal entstieg sie dem Tragsessel und übergab den Täufling Franz Christoph von Khevenhüller, der in Vertretung des abwesenden kaiserlichen Obersthofmeisters das Kind zu Fuß bis zum Altar trug. Nach vollendeter Taufzeremonie brachte Khevenüller das Neugeborene wieder bis zur Tür des Saals, wo Gräfin Trautson es entgegennahm, sich abermals in den Tragsessel setzte und auf diese Weise den kleinen Erzherzog wieder zu seiner Mutter brachte. ${ }^{\mathrm{I} 3}$

Mit großer Wahrscheinlichkeit ist der bei dieser Tauffeier verwendete Tragsessel mit jenem identisch, der anderen Quellen zufolge nur wenige Monate zuvor neu hergestellt wurde. Im Januar I640 hatte der kaiserliche Oberststallmeister Maximilian Graf Waldstein um die Freimachung von Finanzmitteln zur Herstellung eines neuen Tragsessels für die Kaiserin angesucht, worauf die Finanzbehörden rückfragten, welche Farbe dieser Tragsessel haben solle. ${ }^{124}$ Aus Protokollbucheinträgen der kaiserlichen Hoffinanz vom März und April geht hervor, ${ }^{125}$ dass der Tragsessel schließlich mit rotem Samt bespannt wurde, also in gleicher Farbe und mit gleichem Stoff, wie dies für den Tragsessel, der im Juni desselben Jahres bei der Taufe zum Einsatz kam, überliefert ist. Das erforderliche Material wurde beim in Wien ansässigen Handelsmann Stephan Abiso bestellt und kostete 580 Gulden. ${ }^{26}$ Weiter-

I23 Theatrum Europaeum, Bd. 4 (Frankfurt a. M. I692), S. 274 f. Eine Transkription dieser Quelle findet sich auch in Katrin KelLer, Hofdamen. Amtsträgerinnen im Wiener Hofstaat des 17. Jahrhunderts (Wien/Köln/Weimar 2005), S. $245 \mathrm{f}$.

I24 ÖStA, FHKA, Hoffinanz Österreich, Bd. 774, fol. 6or (1640 Januar 23).

I25 ÖStA, FHKA, Hoffinanz Österreich, Bd. 774, fol. 236r (I640 März I4), fol. 305v (I640 April 3) und fol. 38rv (I640 April 3).

I26 ÖStA, FHKA, HZAB, Bd. 86, fol. 227 (I640 Mai 18); erwähnt auch in E. Schwaighofer, Auszüge aus den Hofzahlamtsrechnungen in der Nationalbibliothek. II. Theil (224-498). In: Jahrbuch der kunsthistorischen Sammlungen in Wien, N. F., Bd. I2 (Wien 1938), S. 227-237, hier Reg. 256. 
hin erfolgten Zahlungen an mehrere Wiener Handwerker, die sich an der Herstellung des Tragsessels beteiligten, nämlich an Hofsattler Hans Pusch (42 Gulden) ${ }^{127}$, an Hofriemer Hans Leüttl (20 Gulden) ${ }^{128}$, an Hofschlosser Daniel Knaupus (26 Gulden) ${ }^{129}$ und an den bürgerlichen Messerschmied Hans Weber (40 Gulden) ${ }^{130}$, was für Material und Arbeitsleistung einen Gesamtbetrag von 708 Gulden ergibt. ${ }^{13 \mathrm{I}}$ Zählt man auch noch die Kosten von I4I6 Gulden für die Livree hinzu, die der kaiserliche Zeltmeister Andreas Heiminger damals für neun kaiserliche Sesselträger neu anfertigte ${ }^{\mathrm{I} 22}$ und die einen Bestandteil des Tragsesselensembles bildete, ergibt dies die beachtliche Summe von 2124 Gulden.

Vermutlich bediente sich die Kaiserin auch bei der solennen Zeremonie des Hervorgangs aus dem Kindbett, ihrem ersten öffentlichen Auftritt vierzig Tage nach der Geburt, erneut ihres neu angefertigten rotsamtenen Tragsessels. Erwähnt ist in einer Quelle zu diesem Ereignis, dass sich Maria Anna damals in einem Tragsessel aus ihren Gemächern über den sogenannten Augustinergang in die Augustinerkirche bringen ließ. Unmittelbar nach ihr folgte die Gräfin Trautson, die den kleinen Prinzen im Arm hielt und ihn über die Treppe hinab in die Kirche trug. In der Kirche übernahm die Kaiserin ihren Sohn und brachte ihn selbst bis zur Loretokapelle, wo sie ihn auf den Altar legte und vom Wiener Bischof segnen ließ. Nach beendeter Messfeier ließ sich die Kaiserin abermals im Tragsessel über die Treppe und den Gang zurück in ihre Räumlichkeiten in der Hofburg transportieren, wobei ihr wie zuvor Gräfin Trautson mit dem Kind folgte. ${ }^{133}$

Zu Beginn des Jahres I642 gab der kaiserliche Oberststallmeister Waldstein erneut den Bau eines Tragsessels für Kaiserin Maria Anna in Auftrag, der diesmal mit schwarzer Seide

I27 ÖStA, FHKA, HZAB, Bd. 86, fol. 226r (I640 Februar 29); erwähnt auch in SchwAighofER I938 (wie Anm. 126), Reg. 253 (hier fälschlicherweise mit Hansen „Puch“ transkribiert).

I28 ÖStA, FHKA, HZAB, Bd. 86, fol. 226v-227r (I640 Februar 29); erwähnt auch in SchwAIGHOFER 1938 (wie Anm. 126), Reg. 255. Biographische Informationen zu Hans Leüttl liefert Herbert Haupt, Das Hof- und hofbefreite Handwerk im barocken Wien I620 bis 1770. Ein Handbuch (Forschungen und Beiträge zur Wiener Stadtgeschichte 46, Innsbruck/Wien/Bozen 2007), S. 543 (dort unter der Namensvariante „Johann Leydl“).

I29 ÖStA, FHKA, HZAB, Bd. 86, fol. 226v (I640 Februar 29); erwähnt auch in SchwAighofer I938 (wie Anm. I26), Reg. 254. Mehr zu Knaupus findet sich bei Haupt 2007 (wie Anm. I28), S. 318 (dort unter der Namensvariante „Daniel Knaufus").

I30 ÖStA, FHKA, HZAB, Bd. 86, fol. 226v (I640 Februar 29).

I3I Diese Gesamtsumme wird auch erwähnt in ÖStA, FHKA, Hoffinanz, Bd. 774, fol. 236r (I640 März I4), fol. 305v (I640 April 3) und fol. 38Iv (I640 April 3).

I32 ÖStA, FHKA, HZAB, Bd. 86, fol. 227r (I640 Mai 19); erwähnt auch in SchwAIGHofer I938 (wie Anm. I26), Reg. 252. Zu Haiminger siehe auch Haupt 2007 (wie Anm. I28), S. 493 f.

I33 ÖStA, HHStA, ÄZA, K. 3, Konv. 2, fol. Ir-v. Eine weniger ausführliche Beschreibung dieses Ereignisses liefert der venezianischen Botschaftssekretär Thadio Vico an Doge Francesco Erizzo, Wien I640 Juli 28, ÖStA, HHStA, Venedig, DdG, Bd. 84, S. 54 f. 
ausgeschlagen war. ${ }^{134}$ Die Herstellungskosten sind in diesem Fall nicht vollständig archivalisch überliefert, allein eine Zahlung von I30 Gulden an den Hofhandelsmann Johann Paul Bartholoti, der vermutlich Materialien für den Bau des Tragsessels bereitstellte, ist schriftlich belegt. ${ }^{135}$ Die Quellen erwähnen zwar nicht, warum die Kaiserin gerade damals einen Tragsessel in der Trauerfarbe Schwarz benötigte, vermutlich steht dessen Herstellung aber in Zusammenhang mit dem Tod von Maria Annas geliebtem jüngeren Bruder, dem Kardinalinfanten Ferdinand, Ende I64I.

Während über die Tragsessel Maria Annas erstaunlich viele Informationen vorliegen, stellt sich die Quellenlage bei ihren unmittelbaren Nachfolgerinnen ungleich schlechter dar. Nach Maria Annas überraschendem Tod 1646 heiratete Kaiser Ferdinand III. noch zweimal, nämlich die bald darauf verstorbene Maria Leopoldine (I632-I649, Kaiserin seit I648) und Eleonora Gonzaga (II.) (I630-I686, Kaiserin seit I65I, seit I657 Witwe). Die wenigen Hinweise auf eine Verwendung von Tragsesseln seitens dieser beiden Kaiserinnen sind schnell aufgezählt. Einige Wochen nach der Hochzeit von Ferdinand III. mit Maria Leopoldine reisten die beiden donauabwärts von Linz nach Wien, wobei auf der Schiffsliste für diese Reise auch eine Plätte angeführt ist, die für Leiblakaien und Sesselträger reserviert war. ${ }^{136}$ Die Sesselträger nahmen vielleicht an dieser Hofreise teil, um die Kaiserin gleich mit einem Tragsessel bedienen zu können, sollten sich schon bald nach der Hochzeit erste Anzeichen einer Schwangerschaft einstellen. Von Eleonora Gonzaga (II.) sind nur zwei Fälle überliefert, nämlich von $1653^{137}$ und ${ }_{1} 656^{138}$, in denen sie sich in einem Tragsessel befördern ließ, wobei die Kaiserin beide Male guter Hoffnung war.

2.6 Exkurs II: Tragsessel bei Tauffeiern und Hervorgängen von der 2. Hälfte des 17. Jahrhunderts bis Anfang der 1740er Jahre. Nachhaltige Änderungen im Hofzeremoniell?

Wenn auch für das Jahr I640 erstmals mit Sicherheit der Gebrauch von Tragsesseln bei einer Taufe und einem Hervorgang am Kaiserhof nachgewiesen werden kann, bedeutete

I34 ÖStA, FHKA, Hoffinanz Österreich, Bd. 782, fol. 49r (I642 Januar I6) und Bd. 784, fol. I8v (I642 Januar I6).

I35 ÖStA, FHKA, HZAB, Bd. 90, fol. I5Ir (I644 April 2); bei Schwaighofer ist der Betrag irrtümlich mit I38 Gulden transkribiert: SChWAighofer 1938 (wie Anm. I26), Reg. 439.

I36 ÖStA, HHStA, ÄZA, K. 3, Konv. I4, fol. Iv.

I37 Die Kaiserin befand sich damals auf dem Reichstag in Regensburg und ließ sich dort zu einem Besuch der Kurfürstin von der Pfalz „über die gassen in einen sessel tragen.“ ÖStA, HHStA, ZA, Prot. I, S. II4 f.

I38 Venezianischer Botschafter Battista Nani an Doge Bertuccio Valier, Wien 1656 August I2, ÖStA, HHStA, Venedig, DdG, Bd. 107, S. 312 f. 
dies nicht zwangsläufig, dass Tragsessel damit fortan ein fester Bestandteil bei derartigen zeremoniellen Ereignissen gewesen wären. ${ }^{139}$ Eher scheint das Gegenteil der Fall gewesen zu sein. Zwar orientierte sich der Ablauf von Zeremonien damals häufig an Vorbildern der Vergangenheit, war aber keineswegs völlig erstarrt, sondern vielmehr in ständiger Entwicklung begriffen. Um feststellen zu können, ob, wann und auf welche Art Tragsessel bei Taufen und Hervorgängen in das Hofzeremoniell integriert wurden, ist es nötig, die einzelnen Beschreibungen von Kindstaufen und Hervorgängen am Kaiserhof auszuwerten. Die beste vorhandene Quellengrundlage bilden hierfür die ab I652 angelegten Hofzeremonialprotokolle. ${ }^{140}$ Doch selbst dort bieten die Schilderungen nicht immer Informationen darüber, ob bei den Feiern Tragsessel zum Einsatz kamen oder ob auf sie verzichtet wurde. Wenden wir uns zunächst den Taufen zu.

Gar keinen Rückschluss auf die Verwendung von Tragsesseln erlauben etwa die äußerst knapp gehaltenen Taufbeschreibungen für die Habsburgerkinder Eleonore Maria Josepha $(\mathrm{I} 653)^{\mathrm{I41}}$, Johann Leopold (I670) ${ }^{\mathrm{I4} 2}$, Anna Maria Sophia (I674) ${ }^{\mathrm{I} 43}$, Christine (I679) ${ }^{\mathrm{I44}}$, Maria Theresia (I684) ${ }^{\mathrm{I} 45}$ und Maria Josepha (I687) ${ }^{\mathrm{I} 46}$. Die Taufen von Maria Anna (I683) und Karl, dem späteren Kaiser Karl VI. (I685), finden in den Zeremonialprotokollen nicht einmal Erwähnung. ${ }^{147}$ Für die Taufe von Maria Anna Josepha $(\mathrm{I} 654)^{148}$ ist dokumentiert, dass der an der Gicht leidende Kindesvater, Kaiser Ferdinand III., sowie die damals bereits etwas betagtere Kaiserin-Witwe Eleonora Gonazaga (I.) in Tragsesseln in die Ritterstube befördert wurden. Hinsichtlich der direkt nachfolgenden Obersthofmeisterin der

I39 Das Taufzeremoniell am Kaiserhof wurde bereits von Irene Kubiska anhand der entsprechenden Zeremonialprotokolleinträge ausgewertet. Kubiska rückt in ihrer Arbeit vor allem idealtypisch verlaufene Taufen in den Vordergrund; dynamischen Prozessen hinsichtlich der im Lauf der Zeit unterschiedlichen Verwendung von Tragsesseln schenkt sie dagegen weit weniger Augenmerk. Irene KuBISKA, „Und ist wegen dieser so glückhlich- und trostreichen geburth ein allgemeines frolockhen und grosse freydt gweesen“. Das Geburten- und Taufzeremoniell am Wiener Hof im Zeitraum von I652 bis i8oo. In: Irmgard Pangerl/Martin Scheutz/Thomas Winkelbauer (Hg.), Der Wiener Hof im Spiegel der Zeremonialprotokolle (I652-I80o). Eine Annäherung (Forschungen zur Landeskunde von Niederösterreich 3I / Forschungen und Beiträge zur Wiener Stadtgeschichte 47, Innsbruck/Wien/Bozen 2007), S. 493-527.

I40 Zu den Hofzeremonialprotokollen siehe vor allem Pangerl/Scheutz/Winkelbauer 2007 (wie Anm. I39).

I4I ÖStA, HHStA, ZA, Prot. I, S. 218.

I42 ÖStA, HHStA, ZA, Prot. 2, S. I482.

I43 ÖStA, HHStA, ZA, Prot. 2, S. I767-I769.

144 ÖStA, HHStA, ZA, Prot. 3, fol. I98v.

I45 ÖStA, HHStA, ZA, Prot. 4, fol. Io8r-v.

I46 ÖStA, HHStA, ZA, Prot. 4, fol. I83r-v.

I47 ÖStA, HHStA, ZA, Prot. 4.

I48 ÖStA, HHStA, ZA, Prot. I, S. 448-45I. 
Prinzessin ist lediglich vermerkt, dass sie die neugeborene Erzherzogin auf einem seidenen Kissen trug und sie an der Schwelle zur Ritterstube dem kaiserlichen Obersthofmeister übergab. Allem Anschein nach ging die Obersthofmeisterin der kleinen Maria Anna Josepha dabei zu Fuß und verwendete selbst keinen Tragsessel. Ganz ähnlich lautet auch die Beschreibung der Taufe von Ferdinand Joseph (I657) ${ }^{\text {I49 }}$, bei der sich offenbar nur Ferdinand III. („weyllen sye mit den Podagra behafft ${ }^{\text {“i5o) }}$ ) in einem Tragsessel transportieren ließ, die Obersthofmeisterin des kleinen Prinzen diesen jedoch abermals - offenbar zu Fuß - auf einem Seidenkissen trug. Die relativ ausführlichen Beschreibungen der Taufen von Ferdinand Wenzel (I667) I51 $^{15 a r i a ~ A n t o n i a ~(I 669) ~}{ }^{152}$ und Maria Anna (I672) ${ }^{153}$ erwähnen keinerlei Tragevehikel für die Obersthofmeisterin der Kinder, die die Täuflinge stets vom Kindbett bis zum Saal, in dem die Zeremonie stattfand, auf einem kostbaren Kissen trug

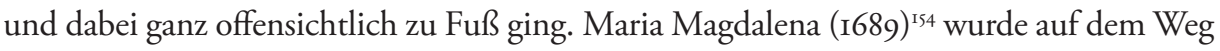
zu ihrer Taufe und auf dem Rückweg in ihr Zimmer streckenweise vom Obersthofmeister, zeitweilig aber auch von ihrer Aja getragen. Beide gingen dabei zu Fuß und bedienten sich keiner Tragsessel. Sonderfälle stellten die Taufen von Maria Josepha Klementine (I675) ${ }^{155}$, bei der die Obersthofmeisterin der Prinzessin unpässlich war und diese deshalb von zwei kaiserlichen Kämmerern zur Taufe getragen wurde, sowie die Taufen von Joseph (I678) ${ }^{156}$, Maria Elisabeth (I680) ${ }^{157}$, Leopold Joseph (I682) ${ }^{158}$ und Maria Margaretha (I690) ${ }^{159}$ dar, bei denen die Herzogin von Pfalz-Neuburg als Großmutter der Kinder anstatt der Obersthofmeisterin beziehungsweise des Obersthofmeisters die Täuflinge auf ihrem Arm halten und zum Altar tragen durfte. In den Beschreibungen dieser fünf letztgenannten Tauffeiern werden ebenfalls keine Tragsessel erwähnt. Die drei Kinder des späteren Kaisers Joseph I. und seiner Frau Amalia Wilhelmine, Maria Josepha (I699) ${ }^{160}$, Leopold Joseph (I700) ${ }^{161}$ und

\footnotetext{
149 ÖStA, HHStA, ZA, Prot. I, S. 63I-634.

I5O ÖStA, HHStA, ZA, Prot. I, S. 632.

I5I ÖStA, HHStA, ZA, Prot. 2, S. I364-I371. Eine ausführliche Beschreibung dieser Tauffeier findet sich auch bei Eucharius Gottlieb RincK, Leopolds des Großen, Röm. Käysers, wunderwürdiges Leben und Thaten, aus geheimen nachrichten eröffnet. Der andere druck, um vieles vermehret, 4 Bde. (Leipzig I709), Bd. 2, S. 546-548.

I52 ÖStA, HHStA, ZA, Prot. 2, S. I432-I438.

I53 ÖStA, HHStA, ZA, Prot. 2, S. 1558-1560.

I54 ÖStA, HHStA, ZA, Prot. 4, fol. 307r-308r.

I55 ÖStA, HHStA, ZA, Prot. 3, fol. 30v-3Iv.

I56 ÖStA, HHStA, ZA, Prot. 3, fol. 158r-I6ov.

I57 ÖStA, HHStA, ZA, Prot. 3, fol. 288v-29Ir.

I58 ÖStA, HHStA, ZA, Prot. 4, fol. 46r-47r.

I59 ÖStA, HHStA, ZA, Prot. 4, fol. 574r-575r.

I60 ÖStA, HHStA, ZA, Prot. 5, fol. 6I2r-6I5v.

I6I ÖStA, HHStA, ZA, Prot. 6, fol. 96r-Ioor.
} 
Maria Amalia (I700) ${ }^{162}$, wurden bei ihren jeweiligen Taufen von der Großmutter der Kinder, Benedicta Henriette von der Pfalz, beziehungsweise vom königlichen Obersthofmeister, Fürst Salm, zur Taufe in die Ritterstube und von dort wieder zurück in das Zimmer transportiert. Auch hier kamen laut den relativ ausführlichen Taufbeschreibungen keine Tragsessel zum Einsatz.

Erst im Jahr I7I6, also rund ein Dreivierteljahrhundert nachdem im Rahmen des Taufzeremoniells am Kaiserhof zuletzt ein Tragsessel Verwendung gefunden hatte, ist erneut der Einsatz eines Tragevehikels bei einer kaiserlichen Tauffeier dokumentiert. ${ }^{163}$ Die Aja ging bei dieser Taufe zu Fuß, wobei sie Erzherzog Leopold Johann, das erstgeborene Kind von Kaiser Karl VI. und seiner Frau Elisabeth Christine, auf ihren Armen hielt und von der Retirade bis zur Ratsstube trug. Bei der Ratsstube angelangt, übergab sie das neugeborene Kind dem kaiserlichen Obersthofmeister, welcher es anschließend zum in der Ritterstube vorbereiteten Altar brachte. Nachdem die Taufzeremonie vollzogen und - was im Fall Leopold Johanns eine Ausnahme war - der kleine Erzherzog als erstgeborener Sohn auch gleich in aller Feierlichkeit in den Vliesorden aufgenommen worden war, übernahm die Aja in der Ratsstube das Kind wieder aus den Armen des Obersthofmeisters und trug es in das Schlafzimmer der Kaiserin, wo das Neugeborene den Segen seiner Eltern erhielt. Erst im Anschluss daran kam ein Tragsessel zum Einsatz, denn nun setzte sich die Aja in einen Tragsessel, nahm das Kind auf ihren Schoß und brachte es auf diese Weise in Begleitung des zu Fuß schreitenden Obersthofmeisters und anderer Hofwürdenträger in das erzherzogliche Kinderzimmer. Die Taufzeremonie von I7I6 sollte für die nächstfolgenden Taufen Vorbildwirkung haben. Genau entsprechend der Zeremonie von I7ı 6 wurde nämlich auch der Ablauf der Tauffeiern von Leopold Johanns Schwestern Maria Theresia $(\mathrm{I} 7 \mathrm{I} 7)^{164}$, Maria Anna (I7I8) ${ }^{165}$ und Maria Amalia (I724) ${ }^{166}$ gestaltet. Auch bei diesen Feierlichkeiten wurde stets am Ende der Feier, als die bereits getauften Kinder von ihrer Aja vom Schlafzimmer der Kaiserin in das erzherzogliche Kinderzimmer gebracht wurden, ein Tragsessel verwendet.

Das Taufzeremoniell unterlag jedoch auch danach weiterhin Modifikationen. So werden in den Beschreibungen der in Wien vollzogenen Tauffeiern der ältesten vier Kinder ${ }^{167}$ des späteren Kaisers Franz I. Stephan und seiner Gemahlin Maria Theresia, nämlich Maria

\footnotetext{
I62 ÖStA, HHStA, ZA, Prot. 6, fol. I64r-I67r.

I63 ÖStA, HHStA, ZA, Prot. 9, fol. 92r-II3v.

I64 ÖStA, HHStA, ZA, Prot. Io, fol. 39r-44r.

I65 ÖStA, HHStA, ZA, Prot. Io, fol. I64r-I7Iv.

I66 ÖStA, HHStA, ZA, Prot. I2, fol. 392r-397v.

I67 Die Taufbeschreibungen der jüngeren, zwischen 1742 und 1756 geborenen Kinder des Kaiserpaares wurden für die vorliegende Arbeit nicht durchgesehen.
} 
Elisabeth (I737) $)^{168}$, Maria Anna (I738) ${ }^{169}$, Maria Karolina (I740) $)^{170}$ und Joseph (II.) (I74I ${ }^{171}$, keinerlei Tragsessel erwähnt.

So lässt sich als Fazit festhalten, dass in schriftlichen Dokumentationen von Taufen am Kaiserhof erstmals für das Jahr I640 mit Sicherheit die Verwendung eines Tragsessels nachweisbar ist, Tragevehikel aber anschließend für lange Zeit bei Taufen nicht mehr zum Einsatz kamen. Erst viele Jahrzehnte später, bei den Taufen der Kinder von Kaiser Karl VI. und Kaiserin Elisabeth, fanden Tragsessel wieder einen - wenn auch nur peripheren Platz im Rahmen des kaiserlichen Taufzeremoniells. Schon Ende der I73oer Jahre hatten sie diesen aber vorläufig erneut verloren.

Etwas anders als bei den Taufen sieht die Situation bei den feierlichen Hervorgängen der Mütter aus dem Kindbett aus. Eleonora Gonzaga (II.), die dritte Frau Kaiser Ferdinands III., brachte insgesamt vier Kinder zur Welt. Für ihre ersten öffentlichen Auftritte nach den jeweiligen Geburten lässt die Quellenlage leider zu wünschen übrig. Ihr Hervorgang nach der Niederkunft mit ihrer ältesten Tochter Therese Maria Josepha (I652) wurde in den Zeremonialprotokollen noch nicht erfasst, ${ }^{172}$ und auch der Hervorgang nach der Geburt von Maria Anna Josepha (1655) ${ }^{173}$ findet keine Erwähnung in dieser bedeutenden Quelle zu zeremoniellen Ereignissen am Kaiserhof. Die Hervorgänge der Kaiserin nach den Geburten von Eleonore Maria Josepha (I653) ${ }^{174}$ und Ferdinand Joseph (I657) ${ }^{175}$ sind in den Zeremonialprotokollen zwar kurz beschrieben, diese bieten aber ebenfalls keinerlei Anhaltspunkte dafür, dass dabei Tragsessel zum Einsatz kamen. Eine dauerhafte Änderung im Zeremoniell lässt sich erst ab den I66oer Jahren konstatieren. Als am 28. September I667 Kaiser Leopold I. und seiner ersten Frau Margarita Teresa mit Ferdinand Wenzel ein Thronfolger geboren wurde, wurde der Hervorgang der Kaiserin am 6. November besonders festlich begangen. Auf dem Weg von ihren Gemächern in der Wiener Hofburg über den Augustinergang in die nahe gelegene Augustinerkirche folgte unmittelbar nach

\footnotetext{
I68 ÖStA, HHStA, ZA, Prot. 16, fol. 205r-207v.

I69 ÖStA, HHStA, ZA, Prot. I6, fol. 383r-386r.

I70 ÖStA, HHStA, ZA, Prot. 17, fol. Io2v-iosr.

I7I ÖStA, HHStA, ZA, Prot. I8, fol. 29v-46r.

172 Die Zeremonialprotokolle des Wiener Hofes setzen erst mit 29. September I652 ein, die Taufe von Erzherzogin Therese Maria Josepha fand aber bereits am 27. März desselben Jahres statt. ÖStA, HHStA, ZA, Prot. I, S. I; Theatrum Europaeum, Bd. 7 (Frankfurt a. M. I685), S. 324.

I73 ÖStA, HHStA, ZA, Prot. I.

174 ÖStA, HHStA, ZA, Prot. I, S. 295 f.

175 ÖStA, HHStA, ZA, Prot. I, S. 634. Etwas ausführlicher ist ein in den sogenannten „Älteren Zeremonialakten" aufbewahrter Bericht über den Hervorgang der Kaiserin am 26. März I657, in dem aber ebenfalls keine Verwendung eines Tragsessels dokumentiert ist. ÖStA, HHStA, ÄZA, K. 3, Konv. 2, fol. Iv.
} 
Margarita Teresa in einem Tragsessel die Gräfin Mansfeld, die den kleinen Prinzen als dessen Obersthofmeisterin in ihren Armen hielt. Bei der Kirche angekommen, erhob sich die Gräfin aus dem Transportmittel und übergab das Kind der Kaiserin, die es in die Loretokapelle brachte, wo es vom Wiener Bischof gesegnet wurde. Nach Beendigung der religiösen Zeremonie wurde Ferdinand Wenzel abermals von Gräfin Mansfeld im Tragsessel zurück in die Hofburg gebracht. Das Kaiserpaar aber wartete das Ende des Gottesdienstes ab und verließ die Kirche zu Fuß. ${ }^{176}$ Dieser Ablauf hatte für die Folgezeit Vorbildwirkung, denn nach genau demselben Muster verliefen auch die Hervorgänge nach den Geburten der kaiserlichen Kinder Maria Antonia (I669) ${ }^{177}$, Anna Maria Sophia (I674) 178 $^{17}$, Maria Josepha Klementine (I675) ${ }^{179}$, Maria Elisabeth (I68I) ${ }^{180}$ und Leopold Joseph (I682) (181 $^{\mathrm{I}}$. Zu anderen Hervorgängen jener Zeit lassen sich keine Aussagen bezüglich der Verwendung eines Tragsessels treffen, weil diese Ereignisse entweder gar nicht oder nur in einem einzigen Satz in den Hofzeremonialprotokollen erwähnt sind. Dies betrifft die Hervorgänge nach den Geburten von Maria Anna (I683), Maria Theresia (I684), Karl (I685) - dem späteren Kaiser Karl VI. -, Maria Josepha (I687) und Maria Magdalena (I689) ${ }^{182}$. Einige Hervorgänge jener Zeit fallen aus der Reihe, so etwa die Hervorgänge nach den Niederkünften mit Johann Leopold (I670) ${ }^{183}$ und Maria Anna (I672) ${ }^{184}$, da diese Kinder zum Zeitpunkt des Hervorganges ihrer Mutter bereits verstorben waren. Die entsprechenden Vorgänge wurden deshalb ohne jeden Pomp begangen und auch in den Zeremonialprotokollen nur kurz erwähnt. ${ }^{185}$ Eine weitere Ausnahme stellte der Hervorgang nach der Geburt von Erzherzog Joseph (I678) - dem späteren Kaiser Joseph I. - dar. Da dieser Zeremonie auch das Herzogspaar von Pfalz-Neuburg - die Großeltern des Täuflings - beiwohnte, befürchtete man am Wiener Hof Präzedenzstreitigkeiten zwischen den Gästen und den ausländischen Botschaftern. Um einem drohenden Konflikt aus dem Weg zu gehen, wurde der Hervor-

I76 ÖStA, HHStA, ZA, Prot. 2, S. I385-I390. Auch im „Theatrum Europaeum“ wird dieser Hervorgang ganz ähnlich beschrieben. Theatrum Europaeum, Bd. Io (Frankfurt a. M. I677), S. 525 f. Dabei wird erwähnt, dass die Obersthofmeisterin mit dem Prinzen „auf einem köstlichen Stul“ getragen wurde. Ebenda, S. 525 .

177 ÖStA, HHStA, ZA, Prot. 2, S. I440-I443.

178 ÖStA, HHStA, ZA, Prot. 3, fol. Ir-2r.

179 ÖStA, HHStA, ZA, Prot. 3, fol. 3Iv-32r.

I80 ÖStA, HHStA, ZA, Prot. 3, fol. 293r-v.

I8I ÖStA, HHStA, ZA, Prot. 4, fol. 48v-5or.

I82 ÖStA, HHStA, ZA, Prot. 4 und ebenda, fol. 207v, $327 \mathrm{v}$.

I83 ÖStA, HHStA, ZA, Prot. 2, S. I489.

I84 ÖStA, HHStA, ZA, Prot. 2, S. I565.

I85 Nach dem am Tag der Geburt, unmittelbar nach einer Nottaufe eingetretenen Tod von Erzherzogin Christine (I679) scheint sogar gänzlich auf den traditionellen Hervorgang verzichtet worden zu sein. Vgl. ÖStA, HHStA, ZA, Prot. 3. 
gang nicht wie üblich in der Hofkirche bei den Augustinern zelebriert, sondern in privatem Rahmen in der kaiserlichen Kammerkapelle. Bei der Beschreibung dieser Zeremonie ist kein Tragsessel erwähnt. ${ }^{186}$ Ungewöhnlich war auch der Hervorgang nach der Geburt von Maria Margaretha (1690) ${ }^{187}$, dem jüngsten Kind von Kaiser Leopold I. und seiner dritten und letzten Gemahlin Eleonore Magdalene, denn dabei ließ sich die Kaiserin selbst und nicht, wie sonst üblich, die Aja in einem Tragsessel zur Augustinerkirche bringen, wo Mutter und Kind vom Wiener Bischof gesegnet wurden.

Die Beschreibungen der Hervorgänge nach den Geburten der drei Kinder des späteren Kaisers Joseph I. und seiner Gemahlin Amalia Wilhelmine lassen hinsichtlich der Verwendung von Tragsesseln keine einheitliche Linie erkennen. Während die beiden Töchter Maria Josepha (I700) ${ }^{188}$ und Maria Amalia (I700) ${ }^{189}$ nach dem bereits erwähnten Vorbild von 1667 von der Aja in einem Tragsessel zur Loretokapelle der Augustinerkirche gebracht wurden, war beim Hervorgang nach der Geburt von Leopold Joseph (I700) ${ }^{190}$ offenbar kein Tragsessel im Einsatz. Möglicherweise stand das Fehlen eines Tragsessels bei letzterem Ereignis in Zusammenhang mit einem reduzierten zeremoniellen Aufwand infolge der Hoftrauer, die damals anlässlich des Ablebens des spanischen Königs Karl II. ausgerufen worden war. Diese Hoftrauer führte auch dazu, dass die am Kaiserhof residierenden Botschafter damals nicht, wie sonst üblich, zur Hervorsegnung geladen wurden. ${ }^{\text {I91 }}$

Einheitlicher war das Zeremoniell bei den Hervorgängen nach den Geburten der vier Kinder von Kaiser Karl VI. und Kaiserin Elisabeth Christine, Leopold Johann (I716) ${ }^{192}$, der späteren Kaiserin Maria Theresia (I7I7) ${ }^{193}$, Maria Anna (I7I8) ${ }^{194}$ und Maria Amalia $(\mathrm{I} 724)^{195}$. Bei allen vier Hervorgängen hielt die in einem Tragsessel sitzende Aja die Neugeborenen nach dem Vorbild von 1667 auf ihrem Schoß und brachte sie auf diese Weise von den kaiserlichen Gemächern bis zur Augustinerkirche und nach der dort vollzogenen Zeremonie wieder zurück.

\footnotetext{
I86 ÖStA, HHStA, ZA, Prot. 3, S. I67v-168v.

I87 ÖStA, HHStA, ZA, Prot. 4, fol. 575r-v.

I88 ÖStA, HHStA, ZA, Prot. 6, fol. Iv-5r.

I89 ÖStA, HHStA, ZA, Prot. 6, fol. I68v-170v.

190 ÖStA, HHStA, ZA, Prot. 6, fol. IoIr-IO2v.

I9I ÖStA, HHStA, ZA, Prot. 6, fol. Iorr.

192 ÖStA, HHStA, ZA, Prot. 9, fol. I49r-I56r. Dieser Hervorgang ist auch im „Theatrum Europaeum“ ausführlich beschrieben. Dabei wird erwähnt, dass die Aja in „einem sehr kostbaren Kayserlichen roth-sammeten und mit Gold gezierten Sessel, [...] von 6. Kayserl. Sessel-Trägern getragen “ wurde. Theatrum Europaeum, Bd. 2I (Frankfurt a. M. I738), S. 92.

193 ÖStA, HHStA, ZA, Prot. Io, fol. $55 \mathrm{v}-59 \mathrm{r}$.

194 ÖStA, HHStA, ZA, Prot. Io, fol. I76v-183v.

I95 ÖStA, HHStA, ZA, Prot. I2, fol. 403r-407v.
} 
Ein Bruch mit dieser Tradition fand bei den Hervorgängen nach den Geburten der ersten drei Kinder der Thronfolgerin Maria Theresias statt. Maria Elisabeth (1737) ${ }^{196}$, Maria

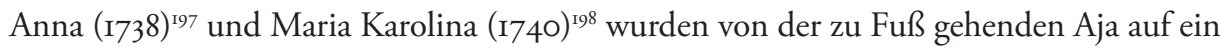
Polster gebettet zur in der Augustinerkirche gelegenen Xaverikapelle und anschließend auf gleiche Weise wieder zurück getragen. Tragsessel kamen bei diesen drei festlichen Ereignissen nicht zum Einsatz. Möglicherweise war der Grund für das geänderte Zeremoniell, dass Maria Theresia damals den Titel einer Herzogin von Lothringen trug, aber noch kein Regierungsamt ausübte. Erst beim Hervorgang nach der Geburt ihres ältesten Sohnes, des späteren Kaisers Joseph II. (I74I) ${ }^{199}$, dem ersten derartigen Ereignis nach ihrer Regierungsübernahme, wurde die Aja mit dem Kind auf dem Schoß erneut in einem Tragsessel zur Hervorsegnung befördert, die nun auch wieder in der Loretokapelle der Augustinerkirche stattfand. Dem freudigen Ereignis entsprechend - nach drei Töchtern hatte Maria Theresia endlich den lang erwarteten Thronfolger zur Welt gebracht - verwendete man bei diesem Hervorgang einen „rodt sammeten reich mit gold bordirten“" 200 Tragsessel, der gleich von sechs mit kostbarer Livree bekleideten königlichen Sesselträgern bedient wurde.

Überblicken wir nun zusammenfassend den gesamten Zeitraum von Mitte des I7. Jahrhunderts bis Anfang der I740er Jahre, so lässt sich feststellen, dass ab I667 Tragsessel mit einer gewissen Regelmäßigkeit bei Hervorsegnungen zum Einsatz kamen. Meist folgte dabei die Aja des erst wenige Wochen alten Kindes dem zu Fuß schreitenden Kaiserpaar in einem Tragsessel bis zur Hofkirche und hielt dabei das Kind im Arm. Nach vollzogener Segnung des Kindes brachte die Aja dieses erneut im Tragsessel sitzend in die kaiserlichen Gemächer zurück.

\subsection{Gebrechliche Kaiser: Ferdinand II. und Ferdinand III. im Tragsessel}

Der Anwendungsbereich von Tragsesseln, der sich für Fürstinnen des Hauses Habsburg im Lauf des I7. Jahrhunderts schrittweise erweiterte, blieb für männliche Mitglieder der Herrscherfamilie auch weiterhin stark eingeschränkt. Für sie war die Verwendung von Tragsesseln nur opportun, wenn gesundheitliche Gründe sie dazu zwangen. Dies lässt sich anhand der Verwendung von Tragsesseln seitens Kaiser Ferdinands II. und seines Sohns Kaiser Ferdinand III. anschaulich demonstrieren.

196 ÖStA, HHStA, ZA, Prot. 16, fol. 213v-216r.

197 ÖStA, HHStA, ZA, Prot. I6, fol. 407r-4Ior.

198 ÖStA, HHStA, ZA, Prot. 17, fol. Io8v-Iogv.

199 ÖStA, HHStA, ZA, Prot. I8, fol. 8ov-9ov.

200 ÖStA, HHStA, ZA, Prot. I8, fol. 84v. 
In der letzten Phase seines Lebens war Kaiser Ferdinand II. bestrebt, die Nachfolge im Reich zugunsten seines ältesten damals noch lebenden Sohnes, Ferdinand III., zu sichern. Obwohl die politischen Rahmenbedingungen dafür zur Zeit des Dreißigjährigen Krieges alles andere als einfach waren, gelang es Ferdinand II. wenige Wochen vor seinem Tod, sein letztes großes politisches Projekt mit Erfolg zu Ende zu führen: Am 22. Dezember I636 wählte das Kurfürstenkollegium im Regensburger Dom Ferdinand III. einstimmig zum Römischen König und damit zum designierten Nachfolger des Kaisers. Unmittelbar nach vollzogener Wahl begab sich der Kaiser, der die Tage zuvor von der Gicht geplagt das Bett hatte hüten müssen, persönlich in den Dom, wo er vom Wahlergebnis offiziell in Kenntnis gesetzt und von den Kurfürsten und seinem Sohn empfangen wurde. Im Anschluss an das „Te Deum“ verließen die Kurfürsten, Ferdinand II. und Ferdinand III. den Dom in Richtung Rathaus, wobei der stark entkräftete Kaiser in einem Tragsessel unter einem Baldachin befördert wurde und der neu gewählte König ihm in kurzem Abstand zu Fuß folgte. ${ }^{201}$ Auch bei der auf den 30. Dezember 1636 angesetzten Krönung selbst musste Ferdinand II. den Weg von seinem Quartier bis zur Krönungskirche und nach beendeter Zeremonie zum Krönungsbankett in einem Tragsessel bestreiten. Auch hierbei wurde über den gebrechlichen Monarchen und seinen ihm zu Fuß folgenden Sohn ein Baldachin gespannt. ${ }^{202}$ Wie der Anblick des hinfälligen Monarchen von den Zuschauern in Regensburg wahrgenommen wurde, ist zwar nicht überliefert. Vielleicht reagierten sie aber ähnlich wie die Bevölkerung Wiens, die sich rund sechs Wochen später beim Einzug Ferdinands II. in der kaiserlichen Residenzstadt angesichts des vom nahenden Tode gezeichneten Kaisers tief ergriffen zeigte, wie der damalige diplomatische Vertreter Venedigs am Kaiserhof berichtete. ${ }^{203}$ Ganz bestimmt aber evozierte der alte und gebrechliche Ferdinand II. im Tragsessel nicht das Bild eines triumphierenden Herrschers auf seinem Thron.

20I Alfons Semler (Bearb.), Die Tagebücher des Dr. Johann Heinrich von Pflummern I633-I643, hg. vom Badischen Landesarchiv (Beiheft zur Zeitschrift für die Geschichte des Oberrheins Bde. 98-IOO, I950-I952), S. 314; Burgi KNorR, Die Wahl von Ferdinand III. zum Römischen König I636. In: MöSENEder I986 (wie Anm. 50), S. 175-178, hier S. 177.

202 Semler 1950-I952 (wie Anm. 20I), S. 316; Khevenhüller i72I-I726 (wie Anm. 6I), Bd. i2, Sp. 1933; Theatrum Europaeum, Bd. 3 (Frankfurt a. M. I670), S. 745; Johann Christian LüNIG, Theatrum ceremoniale historico-politicum, 2 Bde. (Leipzig 1719-1720), Bd. I, S. II50; Christine LindNer, Die Krönung Ferdinands III. zum Römischen König I636. In: Möseneder 1986 (wie Anm. 50), S. 179-183, hier S. 179.

203 „[... [ havendo fatto l'ingresso senźalcuna pompa, ma con insoliti applausi della nobiltà, et del popolo, gravemente commossi del poco buon stato della $m[$ aes] tà sua, deteriorata in estremo [...]." Venezianischer Resident Giovanni Battista Ballarino an Doge Francesco Erizzo, Wien 1637 Februar I4, ÖStA, HHStA, Venedig, DdG, Bd. 8o, S. 572. 


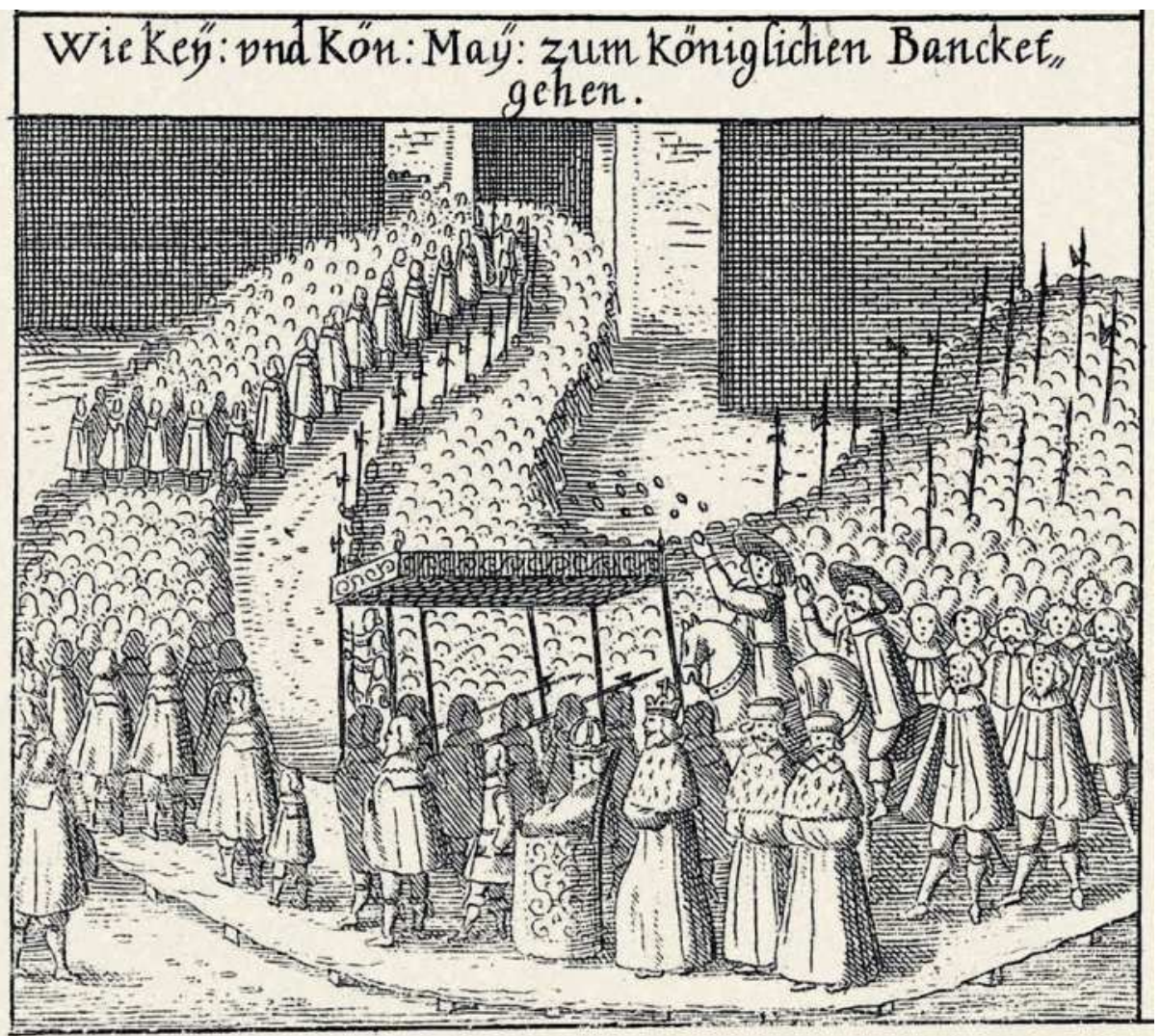

Abb. 6: Kaiser Ferdinand II. im Tragsessel anlässlich der Krönungsfeierlichkeiten für seinen Sohn Ferdinand III. 1636 in Regensburg. Ausschnitt aus dem Einblattdruck „Wie Ihr König: May: Ferdinand III zum Römischen König ist gekrönet worden.“ ÖNB, Bildarchiv, 283572-B. @ ÖNB

Die Prozession der Kurfürsten, des Kaisers und des Römischen Königs zum Krönungsbankett von 1636 ist auch auf einem in mehrere kleine Bildfelder unterteilten Einblattdruck festgehalten (Abb. 6). Es handelt sich dabei um die früheste bisher bekannte bildliche Darstellung eines habsburgischen Kaisers im Tragsessel, wenn auch die schematische, schlichte Art des Kupferstichs stark daran zweifeln lässt, dass der Illustrator selbst Augenzeuge der Regensburger Feierlichkeiten war. Beim dargestellten Tragsessel Ferdinands II. handelt es sich um einen einfachen Armlehnstuhl mit Trageholmen. Die konstruktiven Details des Tragevehikels sind von einem Tuch verdeckt, das von den Armlehnen herabfällt. Es ist mit einer angedeuteten Musterung versehen, die wohl eine kostbare Ausführung des Stoffes verbildlichen soll. Von den beiden Sesselträgern, die den Tragsessel mittels Trageholmen befördern, ist nur der vordere im Bild. 
Nach dem Tod Ferdinands II. am I5. Februar 1637 ging die Kaiserwürde auf seinen Sohn Ferdinand III. über. Die ersten Jahre seiner Regentschaft konnte Ferdinand III. noch ohne erhebliche gesundheitliche Probleme bestreiten. Ab I652 häufen sich allerdings die Nachrichten von der fortschreitenden Gebrechlichkeit des damals erst vierundvierzig Jahre alten Monarchen. ${ }^{204}$ Der venezianische Gesandte am Kaiserhof berichtete damals von der „üblichen Indisponiertheit der Beine ${ }^{{ }_{205}}$, die Ferdinand III. plagte, oder der gewöhnlichen "flussione“ am Fuß, womit wohl von der Gicht herrührende Entzündungen bezeichnet wurden, die den Kaiser immer wieder tagelang ans Bett fesselten. ${ }^{206}$ Ferdinand III. war zeitweilig nicht mehr in der Lage, sich selbstständig auf den Beinen zu halten, und war deshalb darauf angewiesen, sich mit Hilfe von Tragsesseln, Sänften oder Kutschen fortzubewegen. Als beispielsweise der in Prag weilende Kurfürst Johann Georg I. von Sachsen am I3. November I652 seine Abschiedsaudienz beim Kaiser hatte, begleitete ihn dieser gemäß den Gepflogenheiten bis zum Ort, an dem er den Gast zu Beginn seines Besuchs empfangen hatte. Ferdinand III. war damals aber nicht mehr im Stande, die Stufen bis zur Kutsche zu Fuß hinabzusteigen, weshalb er sich bis dorthin tragen lassen musste. ${ }^{207}$

Anfang Dezember des Jahres 1652 brach der Kaiser nach Regensburg auf, wo ein Reichstag einberufen worden war und die Wahl des Römischen Königs vonstattengehen sollte. Am I2. Dezember erfolgte der solenne Einzug in die Stadt. Der Kaiser zog damals jedoch nicht, wie dies bislang üblich gewesen war, zu Pferd in die Reichsstadt ein, sondern bediente sich ebenso wie seine Gemahlin und sein Sohn Ferdinand IV. einer Karosse. Dem Einzug waren Verhandlungen mit den Kurfürsten vorangegangen, die diese Neuerung nicht einfach so hinnehmen wollten, sich dann aber dem Argument, der Kaiser sei unpässlich, beugen mussten. ${ }^{208}$ Damit war ein Präzedenzfall geschaffen, denn von da an fanden bei Wahltagen bis zum Ende des Reiches die feierlichen Einzüge habsburgischer Herrscher stets im Wagen statt. In den Wochen und Monaten nach dem Einzug von I652

204 Mark Hengerer, Die letzten Lebensjahre, Krankheit und Tod Kaiser Ferdinands III. (I608-1657). In: Frühneuzeit-Info I8/I-2 (2007), S. 24-38, hier S. 29.

205 „Attrovandosi la maestà dellimperatore obbligato al letto per l'ordinaria indisposition delle gambe, [...]." Venezianischer Botschafter Girolamo Giustinian an Doge Francesco Molin, Wien I652 März 9, ÖStA, HHStA, Venedig, DdG, Bd. IO2, S. 22.

206 „La maestà dell'imperatore hieri abbandonò il letto ove si è tenuta questi ultimi giorni per la solita flussione nel piede, [...]." Venezianischer Botschafter Girolamo Giustinian an Doge Francesco Molin, Prag I652 November I3, ÖStA, HHStA, Venedig, DdG, Bd. IO2, S. 319.

207 ÖStA, HHStA, ZA, Prot. I, S. 50.

208 ÖStA, HHStA, ZA, Prot. I, S. 56-72; Venezianischer Botschafter Girolamo Giustinian an Doge Francesco Molin, Prag I652 Dezember 25, ÖStA, HHStA, Venedig, DdG, Bd. I02, S. 369 f.; Barbara Stollberg-Rilinger, Des Kaisers alte Kleider. Verfassungsgeschichte und Symbolsprache des Alten Reiches (München 2008), S. I56 f. 
blieb der Gesundheitszustand des Kaisers konstant schlecht. Der venezianische Botschafter berichtete, dass die Wassersucht, die sich an den geschwollenen Beinen Ferdinands III. bemerkbar machte, wenig Hoffnung auf eine Genesung gebe und dass dies auch bei den anwesenden Reichsvertretern mit Schrecken registriert werde. ${ }^{209}$

Die Wahl Ferdinands IV. zum Römischen König fand am 31. Mai I653 in der Augsburger Kirche St. Ulrich statt. Nach Beendigung des Konklaves wurde der Kaiser vom Ausgang der Wahl verständigt und im Tragsessel in die Gregorkapelle von St. Ulrich gebracht, wo man ihm den kaiserlichen Ornat angelegte. Anschließend verließ er gemeinsam mit seinem Sohn, der dem Volk als zukünftiger Kaiser präsentiert wurde, den Kurfürsten und den Gesandten in feierlicher Prozession die Kirche in Richtung kaiserliches Quartier. Dabei wurde Ferdinand III. in einem „roth sameten sessel“ unter einem Baldachin getragen, gefolgt vom zu Fuß schreitenden Ferdinand IV. ${ }^{210}$ Auch diese Prozession wurde auf einem in mehrere Felder geteilten Kupferstich bildlich wiedergegeben (Abb. 7). Zwar ist darauf zu sehen, dass der Kaiser in einem von zwei Sesselträgern bedienten offenen Tragsessel unter einem Baldachin befördert wird, allerdings lassen sich keine weiteren Details des Tragevehikels erkennen.

Auch bei der Krönung Ferdinands IV. am I8. Juni I653 in Regensburg musste sich der Kaiser der „unpässlichkheit halber“ in den Dom und nach vollzogener Krönungszeremonie vom Dom zum Bankett in einem „sessel“ tragen lassen, über den Regensburger Ratsmitglieder einen Baldachin spannten. ${ }^{2 \text { II }}$ Vom Krönungstag existiert ebenfalls ein Einblattdruck samt einer graphischen Darstellung des Kaisers im Tragsessel. Allerdings gibt auch diese Bildquelle, die ähnlich der Illustration auf dem Stich zum Wahltag (Abb. 7) gestaltet ist, nur einen sehr schematischen Eindruck vom Geschehen. ${ }^{212}$

Auf einem weit qualitätvolleren, aber leider weder mit einem Titel noch mit einer Beschreibung versehenen Stich des I7. Jahrhunderts ist gleichfalls ein Kaiser im Tragsessel dargestellt, dem der Römische König als sein designierter Nachfolger im vollen Krönungsornat hinterhergeht (Abb. 8). Da es sich dabei um eine Szene aus einer Krönung

209 „.... [rappresentano la mala dispositione di salute di Sua Maestà aggravata da una specie d'hidropesia nelle gambe e con poca speranza di rimedio, pare che queste rimostranze faccino impressione in Ratisbona, [...]." Venezianischer Botschafter Girolamo Giustinian an Doge Francesco Molin, Prag I653 Februar I9, ÖStA, HHStA, Venedig, DdG, Bd. I02, S. $455 \mathrm{f}$.

2IO ÖStA, HHStA, ZA, Prot. I, S. 200-217. Dass der Kaiser bei dieser Gelegenheit in einem Tragsessel transportiert wurde, ist auch im Theatrum Europaeum, Bd. 7 (Frankfurt a. M. I685), S. 359, festgehalten. Auch eine italienischsprachige Zeitung aus Augsburg vom 6. Juni I653 erwähnt, dass Ferdinand III. aus der Kirche in vollem Ornat "sotto ad un superbissimo baldacchino in seggietta" getragen worden sei. ASF, MdP, filza 4400, unfol.

2II ÖStA, HHStA, ZA, Prot. I, S. 24I, 263 f.

212 John Roger PaAs, The German Political Broadsheet I600-I700, Bd. 8 (Wiesbaden 2005), P-232I. 


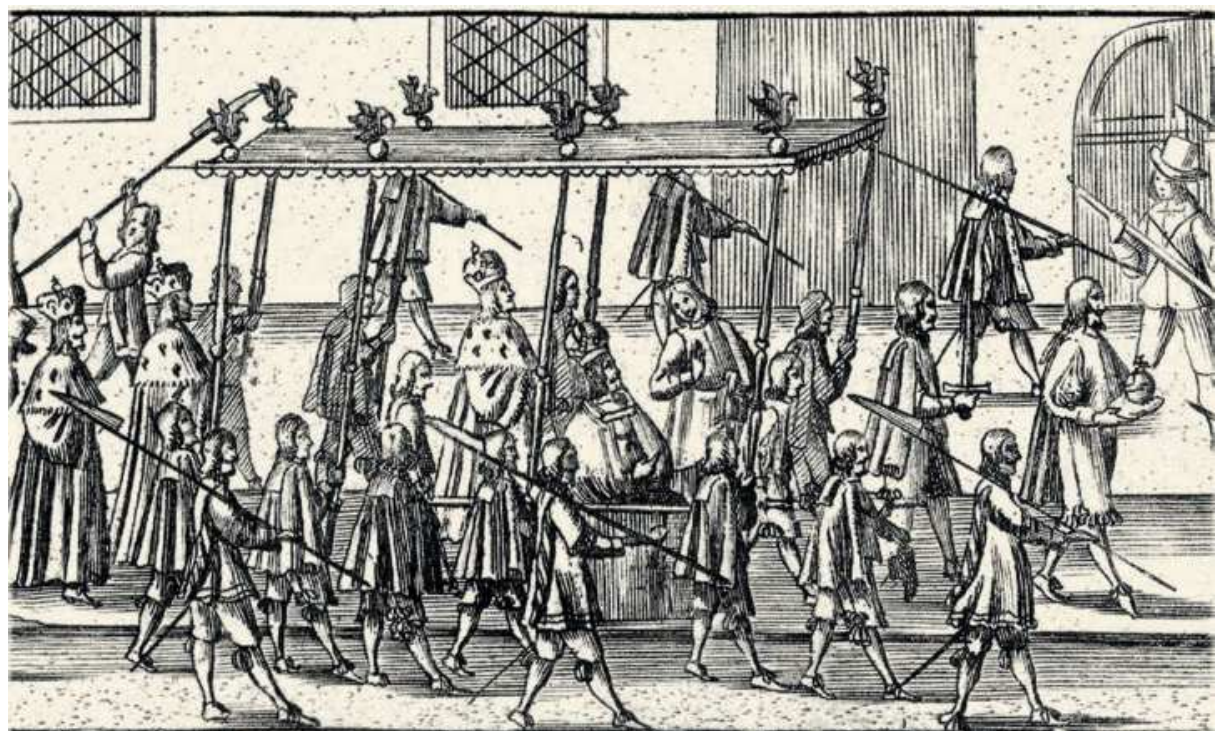

Abb. 7: Kaiser Ferdinand III. im Tragsessel nach der am 31. Mai 1653 in Augsburg erfolgten Wahl seines Sohnes Ferdinand IV. zum Römischen König. Ausschnitt aus dem Einblattdruck „Einzug der Röm: Kays: wie auch der zu Hungarn und Böheimb Königl. May: In dero deß H. Reichsstatt Augspurg / den 20. May Anno 1653. Was sich von dato / biß auff dero abraiß / wider nach Regenspurg / denckwürdiges begeben und sich verloffen." Albertina, Hist. BI. Bd. 5. @ Albertina

vivente imperatore handelt, kommt dafür nur die Krönung Ferdinands III. I636 oder Ferdinands IV. 1653 in Frage. Da bei beiden Krönungen der jeweils regierende Kaiser gezwungen war, einen Tragsessel zu verwenden, und beide Krönungen in Regensburg stattfanden, muss offenbleiben, zu welchem der beiden Anlässe, zur Krönung von I636 oder zu jener von I653, die Graphik entstand. Trotz der detailgenauen Wiedergabe der Szenerie im Hintergrund ist in Hinblick auf die Authentizität der Darstellung auch hier Vorsicht geboten, denn die Gebäude sind weder mit der Topographie von Regensburg noch mit jener Augsburgs, wo die Wahl Ferdinands IV. vollzogen wurde, in Einklang zu bringen und demnach wohl der Phantasie des Vorlagenzeichners entsprungen, was bedauerlicherweise bei zahlreichen ein historisches Ereignis der Frühen Neuzeit illustrierenden Graphiken zutrifft.

Die Gichterkrankung Ferdinands III. verbesserte sich auch in den auf die Krönung von 1653 folgenden Wochen und Monaten nicht, sodass der Monarch bei verschiedenen Zeremonien, wie etwa bei der Eröffnung des Reichstages in Regensburg am I. Juli213 oder

213 Venezianischer Botschafter Girolamo Giustinian an Doge Francesco Molin, Wien I653 Juli 5, ÖStA, HHStA, Venedig, DdG, Bd. I03, S. I53; Katrin Keller/Alessandro Catalano (Hg.), Die Diarien und Tagzettel des Kardinals Ernst Adalbert von Harrach (I598-I667), 7 Bde. (Wien/Köln/ Weimar 20IO), Bd. 3, S. 718. 


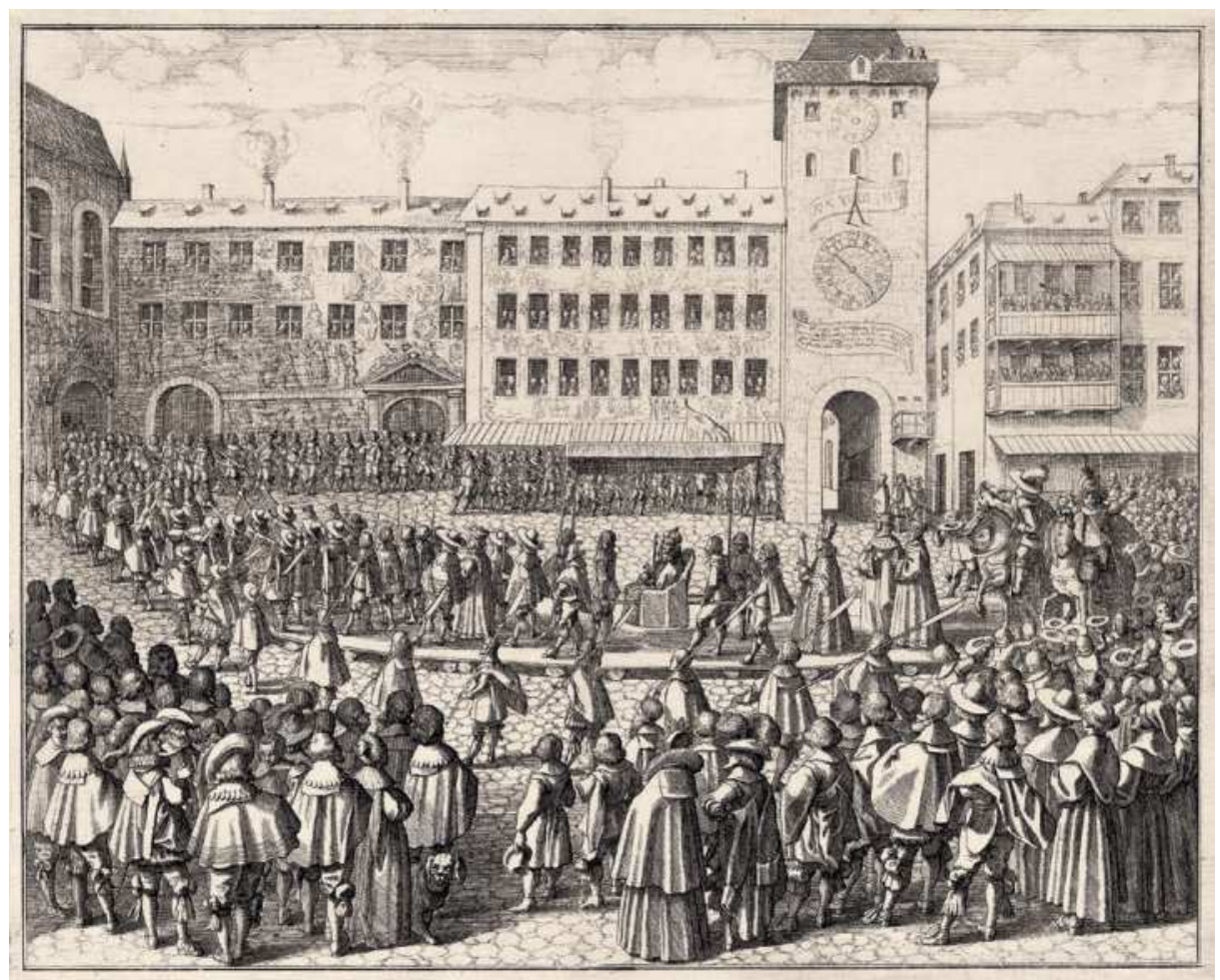

Abb. 8: Kaiser Ferdinand II. oder Kaiser Ferdinand III. im Tragsessel anlässlich der Krönung von Ferdinand III. oder Ferdinand IV. zum Römischen König im Jahr 1636 beziehungsweise 1653 . Germanisches Nationalmuseum, Nürnberg, Inv.-Nr. HB 129, Kapsel 1255. @ Germanisches Nationalmuseum; Foto: Georg Janßen

bei einem Besuch in München am 19. August ${ }^{214}$, auf die Dienste seiner Sesselträger zurückgreifen musste. Der venezianische Botschafter vermeldete gegen Ende des Jahres I653, dass sich der Gesundheitszustand des Kaisers nicht bessere und er sich beim Gehen mehr auf die Arme von Helfern als auf die eigenen Beine verlassen müsse. ${ }^{215}$ Nach Beendigung des Reichstages fuhr die kaiserliche Familie per Schiff von Regensburg nach Wien, wo sie am 24. Mai 1654 ihren feierlichen Einzug hielt. Die Wegstrecke von der Schiffsanlegestelle an der Donau bis zum Stephansdom konnte Ferdinand III. aufgrund seiner Krankheit nicht,

214 ÖStA, HHStA, ZA, Prot. I, S. 337.

2I5 „[...] non può la $m[\mathrm{aes}]$ tà sua tenersi in piedi; marchia più con le bracchia d'altri che colle proprie gambe; [...]."Venezianischer Botschafter Girolamo Giustinian an Doge Francesco Molin, Wien I653 November I, ÖStA, HHStA, Venedig, DdG, Bd. I03, S. 293. 
wie dies sonst bei vergleichbaren Festeinzügen üblich war, reitend zurücklegen. Vielmehr war er so geschwächt, dass er sich aus dem Schiff bis zu seiner Karosse tragen lassen musste und anschließend gemeinsam mit seiner Gemahlin und seinen Söhnen Ferdinand IV. und Leopold (I.) im Wagen bis nach St. Stephan fuhr. ${ }^{216}$ In der Folge ging es mit Ferdinands III. Gesundheit immer weiter bergab. Von einer Audienz gegen Ende des Jahres I654 wird berichtet, dass sich der Kaiser kaum noch aus eigener Kraft von seinem Sessel erheben konnte. ${ }^{217}$ Als die niederösterreichischen Stände im Januar 1655 dem Erzherzog und späteren Kaiser Leopold I. huldigen sollten, verzögerte sich die Zeremonie um einige Tage, da der Kaiser mit Gicht im Bett lag. Der venezianische Botschafter nahm dies in einer Depeche an den Dogen als Anlass zu der Bemerkung, dass der Kaiser nur noch in den eigenen Gemächern einige wenige Schritte mache und selbst dabei auf die Hilfe anderer angewiesen sei; außerhalb seiner Räumlichkeiten aber, so der Botschafter, lasse sich der Kaiser überhaupt nur noch im Tragsessel transportieren. ${ }^{218}$ Natürlich musste Ferdinand III. trotz seiner eingeschränkten Bewegungsfreiheit während seiner letzten Lebensjahre auch weiterhin öffentliche Pflichten wahnehmen. Wenn er bei feierlichen Zeremonien nicht in seiner Karosse fahren konnte, wurde er meist im Tragsessel befördert. So wurde er beispielsweise bei der Ernennung seines Sohnes Leopold (I.) zum Vliesordensritter am 9. Mai 1655 in einem Sessel getragen, ${ }^{219}$ und sowohl für die Krönung seiner dritten Gemahlin Eleonora Gonzaga (II.) zur Königin von Ungarn am 6. Juni 1655 in Pressburg ${ }^{220}$ als auch für ihre Krönung zur böhmischen Königin am II. September I656 in Prag ${ }^{221}$ ist überliefert,

216 ÖStA, HHStA, ZA, Prot. I, S. 400-407; Aigentliche Beschreibung / deß den 24. May Anno I654. Ihrer Kayerlich: und Königlicher Maystätten zu Wienn beschehenen Einzugs (Wien o.J.).

217 Venezianische Botschafter Girolamo Giustinian und Battista Nani an Doge Francesco Molin, Wien 1654 November 28, ÖStA, HHStA, Venedig, DdG, Bd. I04, S. 257.

$2 \mathrm{I} 8$ "La fontione dell'homaggio da farsi al s[igno]r arciduca sè differita sino al 26 del corrente; perchè la podagra ha trettenuto a letto $s[\mathrm{ua}] m$ [aes] tà qualche giorno, et se bene si leva non per anco soffre senza incomodo il moto. Ė però da questi frequenti flussioni la $m$ [aes] tà s[ua] debilitata nè piedi di modo, che per la stanza a pena con appoggio può far qualche passo, et fuori di essa in sedia fa sempre portarsi." Venezianischer Botschafter Battista Nani an Doge Francesco Molin, Wien 1655 Januar 23, ÖStA, HHStA, Venedig, DdG, Bd. I04, S. 329. Bei der am 26. Januar abgehaltenen Erbhuldigungszeremonie benutzte der Kaiser schließlich laut Hofzeremonialprotokoll „einen mit goldt gestickhten wagen“, den der anonyme Autor einer gedruckten Festbeschreibung als „schönen newen Leib-Wagen" bezeichnete. ÖStA, HHStA, ZA, Prot. I, S. 457; Außführliche Erzehlung / Welcher gestalt dem Durchleuchtigen Fürsten und Herrn / Herrn Leopoldo Ignatio Ertz-Hertzogen zu Oesterreich / etc. die Erbhuldigung von allen Vier Ständten deß Löblichen Ertz-Hertzogthumbs Oesterreich gelaistet worden / in der Kays: Residentz-Statt Wien / den 26. Januarij Anno I655 (Augsburg I655), S. 4. ÖStA, HHStA, ZA, Prot. I, S. 484.

220 ÖStA, HHStA, ZA, Prot. I, S. 490. 
dass er dabei zu einem Tragsessel greifen musste, wobei eine Beschreibung der Krönung in Prag erwähnt, dass der Tragsessel des Kaisers „mit gelbem Goldstück überzogen“222 gewesen sei. Auch wenige Wochen vor seinem Tod, bei der Taufe seines Sohnes Ferdinand Joseph am II. Februar I657, musste sich der von seiner körperlichen Hinfälligkeit gezeichnete Monarch tragen lassen. ${ }^{223}$

Trotz seiner stetig zunehmenden Gebrechlichkeit ließ sich Ferdinand III. aber nicht die Freude an der Jagd nehmen. Kardinal Harrach erwähnte 1655, dass der Kaiser auch dabei auf seinen Tragsessel angewiesen war. Beim Besteigen der kleinen Karosse, die er zur Jagd verwendete, ließ er sich in einem Tragsessel sitzend in das Fahrzeug heben. Allein wenn er die Schusswaffe anlege, so Harrach, müsse der Monarch aus eigener Kraft aufstehen und könne nicht auf die Dienste seiner Sesselträger bauen. ${ }^{224}$

\subsection{Reformen im Hofmarstall und ihre Auswirkungen auf die kaiserlichen Sesselträger (1657)}

Im Jahr I657 wurden Reformen im kaiserlichen Hofmarstall umgesetzt, die auch auf die kaiserlichen Sesselträger und ihr Aufgabengebiet gravierende Auswirkungen hatten. Auslöser dafür waren die damals am Kaiserhof vorherrschenden Finanzprobleme sowie Änderungen, die der Regierungsübergang von Ferdinand III. auf Leopold I. mit sich brachte. Den schließlich realisierten Reformen ging eine mehrere Jahre währende Inkubationszeit voran, in der man zwar oftmals strukturelle Änderungen und finanzielle Einschnitte erwog, diese aber letztlich dann doch immer wieder auf unbestimmte Zeit verschob. Besonders großes Einsparungspotential wurde damals bei der Hofkapelle und beim kaiserlichen Marstall vermutet. Vor allem die dem Oberststallmeister unterstellte Jagdabteilung galt als Fass ohne Boden, in dem große Geldsummen versickerten. Felice Marchetti, toskanischer Resident am Kaiserhof, berichtete 1655 aus Wien, dass Gerüchte kursierten, Ferdinand III. wolle mit der Ernennung von Johann Weikhard Fürst von Auersperg zum neuen Obersthofmeister längst überfällige Reformen zur Ausgabensenkung einleiten. Als der ob drohender Einsparungen besorgte Hofkapellmeister bei Auersperg vorfühlte, ob er für seinen eigenen Bereich Einsparungen zu befürchten habe, beruhigte

\footnotetext{
222 Theatrum Europaeum, Bd. 7 (Frankfurt a. M. I685), S. 870.

223 ÖStA, HHStA, ZA, Prot. I, S. 632.

224 „Sua Maestà non camina quasi mai più, ma sempre si fa portare in sedia, et ha un carozzino nel quale entra insieme con la sedia, solo nel carozzino, donde tira alli cervi, bisogna che si facci alzare dentro senza sedia." Kardinal Ernst Adalbert von Harrach, Wien I655 Juli 24, Keller/Catalano 2010 (wie Anm. 213), Bd. 4, S. I37.
} 
ihn dieser mit einer Gegenfrage: Warum nehme er an, der Kaiser wolle die Hofmusik reformieren, wo dieser doch auch von einer Reform seines Stalles Abstand nehme?225 Es hat den Anschein, als seien die Beharrungskräfte damals noch stärker gewesen als der Wille zur Reform.

Etwas mehr als ein Jahr später scheint ein Abrücken vom Status quo jedoch plötzlich unvermeidlich gewesen zu sein. Am I5. Januar I657 beauftragte Ferdinand III. seinen Oberststallmeister Franz Albrecht Graf Harrach, zu dessen Kompetenzen auch die Verwaltung der Tragsessel zählte, Bericht zu erstatten, wo er „bey gegenwertigen schwären zeitten“ und wegen der „allerseits erschöpfften mitln“ in seinem Amtsbereich Streichungen vornehmen könne. ${ }^{226}$ Harrach machte sich daraufhin sogleich an die Ausarbeitung eines Reformkonzepts. Sein Ansatzpunkt für eine mögliche Ausgabenreduktion war der Stand der Pferde und Maultiere des Hofmarstalls, der sich damals auf insgesamt 385 Stück belief und den er in einem ersten relativ unambitionierten Entwurf, der mit 28. Februar I657 datiert ist, um 24 Stück auf 36r Tiere verringern wollte. Weniger Reit-, Zug- und Tragetiere bedeuteten nicht nur niedrigere Futterkosten, sondern auch reduzierte Personalkosten, war doch für die Versorgung von drei Pferden jeweils ein Stallknecht abgestellt. ${ }^{227}$

Für die Tragsessel und deren Bedienungspersonal scheint dieser erste Entwurf Harrachs noch keine Konsequenzen gehabt zu haben. Aus Harrachs Unterlagen geht hervor, dass für den Transport der Tragsessel und der mit Stichtag I. März I657 vorhandenen sechzehn Sesselträger ${ }^{228}$ zum jeweiligen Einsatzort und von dort wieder zurück stets zwei Fahrzeuge mit jeweils vier Zugpferden abgestellt waren. Hinzuzurechnen sind hier noch zwei Kutscher, die den beiden Pferdezügen zugeteilt waren, sowie zwei bis drei Stallknechte für die Pflege der Tiere, was bedeutet, dass für den Tragsesseldienst weit mehr personelle und finanzielle Ressourcen benötigt wurden als allein für das Sesselträgerpersonal und die Tragsessel selbst. Bei Hofreisen zu Wasser mussten zudem für den Transport von Sesselträgern und Tragsesseln eigene Schiffe gemietet werden, was mit weiteren

225 „et il $p[\mathrm{rin}] c[\mathrm{i}]$ pe di Auspergh al $m$ [aest] ro cappella che forse troppo curioso li domandava se era vera la voce di questa riforma, rispose, perche volete veri [?] che s[ua] $m$ [aestà] ces[area] riformi la musica, se non vuole riformar la stalla." Toskanischer Resident Felice Marchetti, Wien 1655 Dezember 4, ASF, MdP, filza 440o, unfol.

226 ÖStA, AVA, FA Harrach, Akten, K. 796, Konv. „Oesterreich, Hofstaat. Gestütte Lippizza und Kladrub und Oberststallmeisteramt.", fol. 83r.

227 Unsigniert, aber wohl Oberststallmeister Franz Albrecht Harrach, Wien I657 Februar 28, ÖStA, AVA, FA Harrach, Akten, K. 796, Konv. „Oesterreich, Hofstaat. Gestütte Lippizza und Kladrub und Oberststallmeisteramt.", fol. 85-94.

228 Siehe Kapitel 6.3. 
Kosten verbunden war. ${ }^{229}$ Harrach sah bei diesen Kostenfaktoren vorerst aber keine Einsparungsmöglichkeiten. ${ }^{230}$

Ferdinand III. ging der erste Reformentwurf Harrachs aber offensichtlich nicht weit genug, da der Oberststallmeister bereits am 3. März I657 ein zweites Konzept vorlegte, das wesentlich tiefere Einschnitte für den Bereich des Hofmarstalls vorsah. Der Pferde- und Maultierstand sollte laut diesem Schriftstück von 385 auf 286 Stück reduziert werden, und für die Tragsessel und Sesselträger waren darin keine eigenen Pferdegespanne mehr vorgesehen. ${ }^{23 \mathrm{I}}$ Die von Harrach vorgeschlagenen Einsparungen konnten jedoch nicht mehr wie geplant zur Ausführung gelangen, da Ferdinand III. am 2. April I657 verstarb und damit etwaige Reformen seinem Sohn Leopold I. vorbehalten blieben.

Leopold I. ersuchte bereits in den ersten Wochen nach seinem Regierungsantritt den scheidenden Oberststallmeister Franz Albrecht Harrach, der noch bis 30. Juni I657 sein Amt versah, ${ }^{232}$ einen Überblick über das Marstallpersonal zu geben. Harrach legte daraufhin dem neuen Herrscher ein Papier vor, in dem er auch seine Einschätzung zu Einsparungsmöglichkeiten ausbreitete. In Hinblick auf das jugendliche Alter des noch unverheirateten Monarchen - Leopold I. wurde am 9. Juni I657 erst siebzehn Jahre alt - meinte Harrach, dass derzeit keine Sesselträger benötigt würden, und stellte die Möglichkeit in den Raum, die vorhandenen Sesselträger der Kaiserin-Witwe Eleonora Gonzaga (II.) für deren neu zu schaffenden Witwen-Hofstaat zu überlassen. Der Oberststallmeisters stellte weiterhin fest, dass viele der Sesselträger schon sehr lange Dienstzeiten hinter sich hätten, was darauf hindeuten könnte, dass er sie nur noch für bedingt einsatzfähig hielt und dem Herrscher in verblümter Weise ihre Entlassung nahelegen wollte. ${ }^{233}$ Leopold I. setzte kurz darauf tatsächlich einige der vorgeschlagenen Reformen

229 Bei der Donaureise von Kaiserin Maria von Linz nach Wien im Jahr 1645 waren insgesamt zweiundfünfzig Schiffe eingesetzt, von denen eines für die Sesselträger und die Tragsessel reserviert war. ÖStA, HHStA, ÄZA, K. 3, Konv. 7, fol. I-4, hier fol. 3r. Als im Jahr I648 Kaiser Ferdinand III. und seine zweite Frau Maria Leopoldine von Linz nach Wien reisten, waren ihr Hofstaat und Gepäck auf neunundvierzig Schiffe und zehn Flöße aufgeteilt. Die Leiblakaien und Sesselträger teilten sich damals eine Plätte. ÖStA, HHStA, ÄZA, K. 3, Konv. I4, fol. I-4, hier fol. Iv.

230 Unsigniert, aber wohl Oberststallmeister Franz Albrecht Harrach, Wien 1657 Februar 28, ÖStA, AVA, FA Harrach, Akten, K. 796, Konv. „Oesterreich, Hofstaat. Gestütte Lippizza und Kladrub und Oberststallmeisteramt.", fol. 87v.

23I Oberststallmeister Franz Albrecht Harrach an Kaiser Ferdinand III., Wien 1657 März 3, ÖStA, AVA, FA Harrach, Akten, K. 796, Konv. „Oesterreich, Hofstaat. Gestütte Lippizza und Kladrub und Oberststallmeisteramt.", fol. I2r-19v.

232 ÖStA, HHStA, OMeA, SR, Bd. I86, fol. I62v.

233 „Sesseltrager, weillen ihr könig[liche] may[estät] [Leopold I., Anm. d. Verf.] der zeit kheine betörfen, stehen zu dero belieben, ob sie hiervon welche behalten, und ob ihr may[estät] die khayserin, villeucht etliche haben wolten, den es sein theils unter ihnen, so schon lang gedienet, und seint die 
um. So verloren etwa alle sechzehn kaiserlichen Sesselträger mit 30. Juni I657 ihre bisherige Stelle. ${ }^{234}$ Sie wurden allerdings nicht, wie dies Harrach angedacht hatte, im Hofstaat der Kaiserin-Witwe mit einem Posten versorgt, denn diese forderte aus dem Hofmarstall zwar zahlreiche Wagen, Sänften, Pferde und Maultiere sowie verschiedenes Stallpersonal an, aber keinerlei Tragsessel oder Sesselträger, für die sie offenbar selbst ebenfalls keine Verwendung hatte. ${ }^{235}$ So fand die Geschichte der Tragsessel und kaiserlichen Sesselträger, die 1657 bereits eine über dreißig Jahre lange, ungebrochene Tradition aufwies, vorläufig ein abruptes Ende.

In den ersten Regierungsjahren Leopolds I. ${ }^{236}$ machte am Kaiserhof allem Anschein nach weder der Monarch selbst noch einer seiner engsten Verwandten Gebrauch von Tragsesseln. ${ }^{237}$ Auch lassen sich für jene Jahre keine Sesselträger im kaiserlichen Hofstaat nachweisen. ${ }^{238}$ Die Tragsessel des Hofes lagerten damals wohl unbenutzt in einem der kaiserlichen

maisten frembte, [...].“ Oberststallmeister Franz Albrecht Graf Harrach an Leopold I., undatiert (aber in den Monaten April, Mai oder Juni 1657), ÖStA, HHStA, HA, Familienakten, K. IoI, Konv. „Berichte des Oberststallmeisters Franz Albrecht von Harrach.“, fol. 3 r.

234 ÖStA, HHStA, OMeA, SR, Bd. I86, fol. I84v-187r.

235 ÖStA, HHStA, HA, Familienakten, K. IOI, Konv. „Berichte des Oberststallmeisters Franz Albrecht von Harrach.“, fol. 7-I4. Zwei spätere Hofstaatsverzeichnisse der Kaiserin-Witwe von 1675 und 1678 beinhalten zwar eine große Zahl an Marstallsdienern, führen aber keine Sesselträger an. Erst gegen Ende ihres Lebens wurden offenbar Sesselträger in ihren Hofstaat integriert, denn unter den Hofdienern, die zum Zeitpunkt ihres Ablebens im Jahr I686 Dienst versahen, befanden sich auch sechs Sesselträger. Siehe dazu die Tabelle in Kapitel 6.3.

$236 \mathrm{Zu}$ diesem Monarchen siehe unter anderem John P. Spielman, Leopold I. Zur Macht nicht geboren (Graz/Wien/Köln 198r); Rouven Pons, „Wo der gekrönte Löw hat seinen Kayser-Sitz.“ Herrschaftsrepräsentation am Wiener Kaiserhof zur Zeit Leopolds I. (Deutsche Hochschulschriften II95, Egelsbach/Frankfurt a. M./München/New York 200I); Friedrich Polleross, „Pro decore Majestatis“. Zur Repräsentation Kaiser Leopolds I. in Architektur, Bildender und Angewandter Kunst. In: Jahrbuch des Kunsthistorischen Museums Wien 4/5 (2002/2003), S. 19I-295; Jutta Schumann, Die andere Sonne. Kaiserbild und Medienstrategien im Zeitalter Leopolds I. (Colloquia Augustana 17, Berlin 2003).

237 Die kaiserlichen Zeremonialprotokolle erwähnen für den Zeitraum zwischen dem Regierungsantritt Leopolds I. im Jahr I657 und der ersten Hochzeit des Monarchen im Jahr I666 keine einzige Verwendung von Tragsesseln durch Mitglieder der Kaiserfamilie. Vgl. ÖStA, HHStA, ZA, Prot. I-2. Gleiches gilt für die Berichte venezianischer Gesandter am Kaiserhof. Vgl. ÖStA, HHStA, Venedig, DdG, Bd. I09-I3rbis.

238 Vgl. dazu die Kapitel 2.8 und 6.3. 
Stallgebäude. Durch langjährige Verwendung unbrauchbar gewordene Tragsessel wurden in jener Zeit vielleicht auch ausgemustert.

Ein Bedarf an Tragsesseln entstand erst wieder, als die langwierigen Verhandlungen rund um die geplante Ehe zwischen Leopold I. und seiner ersten Frau Margarita Teresa ${ }^{239}$ endlich abgeschlossen waren und man die Braut am Kaiserhof erwartete. Im Vorfeld der Hochzeit wurden zahlreiche neue Fahrzeuge für das Kaiserpaar und seinen Hofstaat bestellt. ${ }^{240}$ Den Goldstoff und die kostbaren Stickereien für die hochrangigsten unter den damals angeschafften Transportmitteln ließ der kaiserliche Oberststallmeister in Paris anfertigen. Unter den Prunkvehikeln befanden sich auch zwei Tragsessel ${ }^{241}$, von denen einer gemeinsam mit dem Brautwagen und einer Maultiersänfte, die gleichfalls Pariser Erzeugnisse waren, ein Ensemble bildete. ${ }^{242}$ Die Karosse, die Maultiersänfte und der Tragsessel wurden beim feierlichen Brauteinzug in Wien am 5. Dezember I666 leer mitgeführt. Sie sind auch auf mehreren zeitgenössischen Stichen zur kaiserlichen Vermählung von 1666 dargestellt, darunter auch im Chronikwerk „Theatrum Europaeum“ (Abb. 9). ${ }^{243}$ Der Authentizitätsgrad der dort abgebildeten repräsentativen Transportmittel ist jedoch als äußerst gering einzuschätzen. ${ }^{244}$ So ist die Darstellung des offenen Tragsessels mit seinem überbordenden Muscheldekor offensichtlich der Phantasie des Künstlers entsprungen, handelte es sich dabei laut Fuhrparkinventar von I678 doch tatsächlich um ein mit fünf

239 Zu den zähen Verhandlungen siehe Alfred Francis Pribram, Die Heirat Kaiser Leopold I. mit Margaretha Theresia von Spanien. In: Archiv für österreichische Geschichte 77 (I89I), S. 3I9-375.

240 Siehe dazu vor allem Mario Döвerl, Der Fuhrpark Kaiser Leopolds I. Teiledition der Wiener Hofmarstallinventare von I678. In: Jahrbuch des Kunsthistorischen Museums Wien I2 (20IO), S. 276-309.

24I Siehe dazu Kapitel 6.I.

242 Galeazzo Gualdo Priorato, Historia di Leopoldo Cesare, continente le cose più memorabili successe in Europa dal I656 fino al I670, 3 Bde. (Wien I670-I674), Bd. 3, S. 78.

243 Für andere Darstellungen, auf denen der Tragsessel stets ähnlich dargestellt ist, siehe beispielsweise das Werk von Gualdo Priorato i670-I674 (wie Anm. 242), Bd. 3; und John Roger PaAs, The German Political Broadsheet I600-I700, Bd. 9 (Wiesbaden 2007), P-287I, P-2872, P-2873, P-2890, P-289i.

244 Der Künstler und Verleger Melchior Küsel gestand in seiner an den Kaiser gerichteten Widmung einer weit verbreiteten Darstellung des 1666 erfolgten Brauteinzugs, auf dem auch die Darstellung im „Theatrum Europaeum“ basiert, er habe das Werk bereits zwei Wochen vor dem Ereignis „auß lauter einbildung“ in Kupfer gestochen; vgl. Friedrich KrYZA-Gersch/Barbara Ruck, Ave Claudia Imperatrix. Die Vermählung Kaiser Leopolds I. mit Erzherzogin Claudia Felicitas von Tirol in Graz I673. Schloß Eggenberg als Residenz der kaiserlichen Braut (Ausstellungskatalog, Veröffentlichungen der Abteilung Schloß Eggenberg 3, Graz I983), S. I4. Für ein anderes Beispiel zur mangelnden Authentizität von Kutschendarstellungen auf Stichen zu Festeinzügen siehe auch DöBERL 2010 (wie Anm. 240), S. 279. 


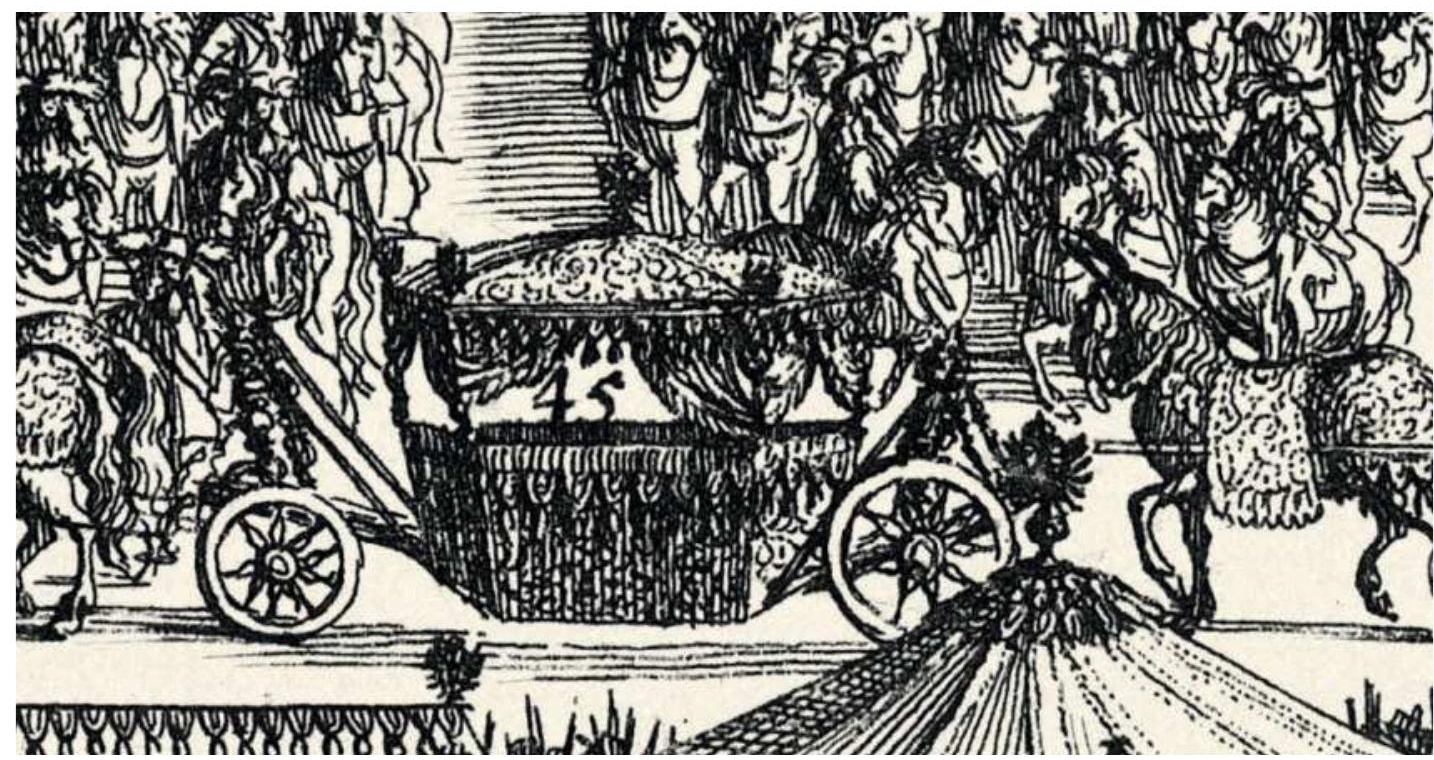

Abb. 9: Einzug der kaiserlichen Braut Margarita Teresa in Wien am 5. Dezember 1666 (Detail). Dargestellt sind die Karosse, die Sänfte und der Tragsessel, die der kaiserliche Oberststallmeister für die Braut in Paris anfertigen ließ. Kupferstich aus Theatrum Europaeum, Bd. 10 (Frankfurt a. M. 1677). KHM, Kaiserliche Wagenburg, Inv.-Nr.Z 263. $\odot$ KHM

venezianischen Gläsern versehenes Vehikel, das zweifellos auch eine Bedachung aufwies. ${ }^{245}$ Der andere Tragsessel, der 1666 für Margarita Teresa in Paris angeschafft wurde, war weit weniger reich ausgestattet, verfügte über keine Gläser und Vorhänge und war offenbar im Jahr I679 bereits in einem solch schlechten Zustand, dass er aus dem kaiserlichen Fuhrpark ausgeschieden und den Hofsesselträgern als Geschenk überlassen wurde. ${ }^{246}$ Neben den beiden Pariser Tragsesseln gelangte I666 auch ein drittes derartiges Tragevehikel in den Hofmarstall. Offenbar hatte es die Kaiserin selbst aus Spanien mitgebracht. Es handelte sich dabei um einen besonders kostbaren Tragsessel, der reich mit Gold und Korallen bestickt war. ${ }^{247}$

Für die darauf folgenden Jahre sind zahlreiche Fälle dokumentiert, in denen die jeweiligen Gemahlinnen Leopolds I., Kaiserin Margarita Teresa, Claudia Felizitas und Eleonore Magdalene, sich eines Tragsessels bedienten. Es waren stets dieselben Riten beziehungsweise Lebensphasen, die den Kaiserinnen die Gelegenheit boten, sich tragen zu lassen,

245 Vgl. die Beschreibung in Kapitel 6.I.

246 Vgl. Kapitel 6.I.

247 Vgl. Kapitel 6.I und DöberL 2010 (wie Anm. 240), S. 286. 


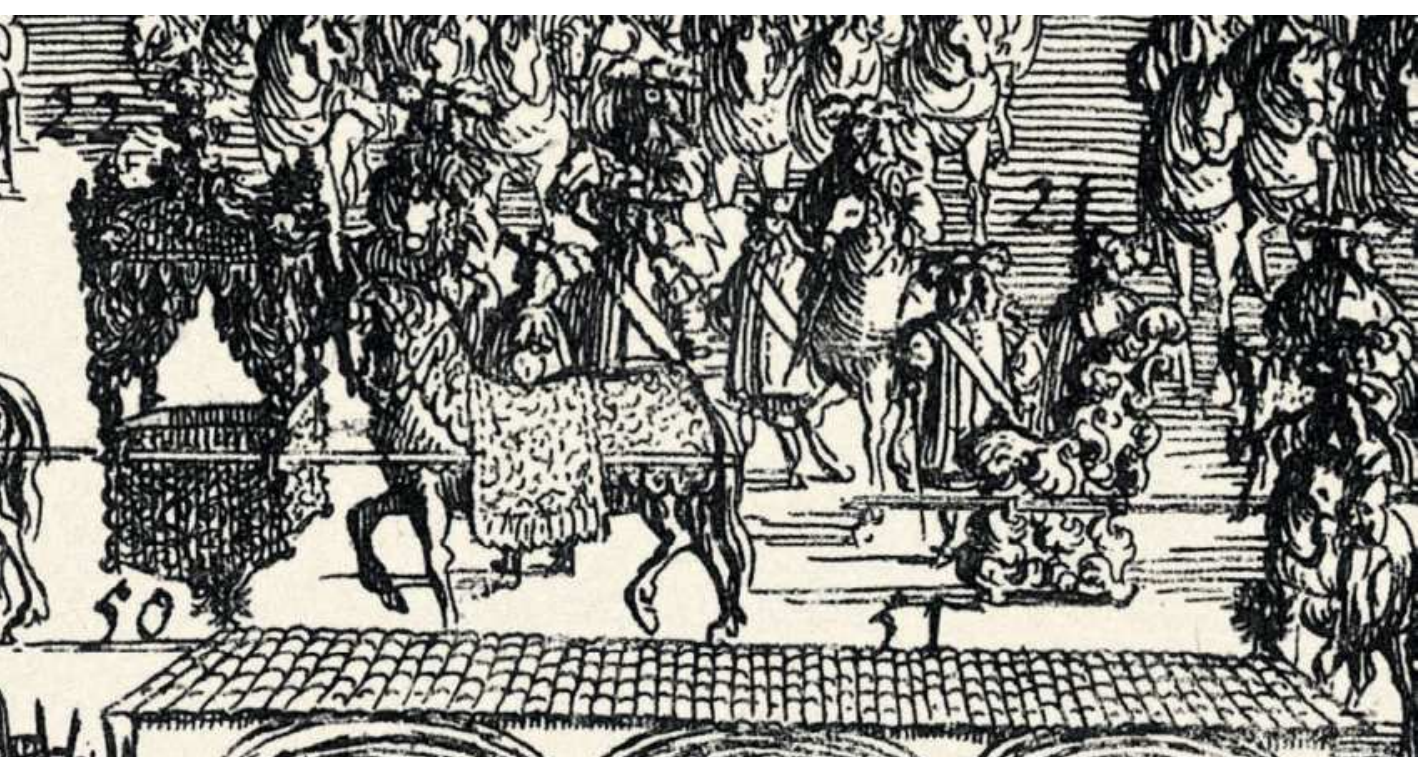

nämlich erstens die Deklaration einer Schwangerschaft im Rahmen einen Kirchgangs, zweitens öffentliche Auftritte und das Zurücklegen von Wegstrecken während einer Gravidität, um das ungeborene Kind vor schädlichen Erschütterungen bei Kutschenfahrten zu schützen, und drittens der Hervorgang aus dem Kindbett ${ }^{248}$.

Kaiserin Margarita Teresa benutzte schon wenige Monate nach ihrem Einzug in Wien erstmals einen Tragsessel. Am 28. März I667 berichtete Kaiser Leopold I. mit Genugtuung an Graf Pötting, seinen Botschafter in Madrid, dass seine Gemahlin drei Tage zuvor, nachdem ihre Menstruation zum zweiten Mal ausgeblieben war, ihren Reifrock abgelegt habe, in einem Tragsessel zur Kirche gebracht worden sei und auf diese Weise öffentlich ihre Schwangerschaft bekannt gegeben habe. ${ }^{249}$

248 Zu den Hervorgängen aus dem Kindbett siehe das Kapitel 2.6.

249 „Der spanische allhier anwesende [Botschafter] hat seiner Schuldigkeit zu sein eracht, por fineza bei diesen Courier, welchen ich ihme ad hunc actum geliehen habe, zu avisiren, dass despues de cumplidas dos faltas mein Gemahlin den 25. dies den Guardinfante abgelegt und sich in der silla in die Kirche tragen lassen." Kaiser Leopold I. an Graf Franz Eusebius Pötting, Wien 1667 März 28, Alfred Francis Přibram/Moritz Landwehr von Pragenau, Privatbriefe Kaiser Leopold I. an den Grafen F. E. Pötting 1662-I673 (Fontes Rerum Austriacarum, 2. Abt., Bde. 56-57, 1903-1904), Bd. 56 (1903), S. 29I. Dieses Ereignis ist auch erwähnt in Theatrum Europaeum, Bd. Io (Frankfurt a. M. 1677), S. 518: „Am I5. 25. Als am Fest Mariae Verkündigung / ließ sich Ihre Majest. die Röm. Käiserin zum ersten male in Teutscher Kleidung [...] in einem roth-Sammeten mit Gold gesticktem / und mit guldenen Borden verpossementirtem Sessel durch die Gallerie in die Augus- 
Die erstmalige Verwendung eines Tragsessels galt als ein allgemein, auch in breiten Bevölkerungsschichten, verstandenes Zeichen dafür, dass das Kaiserpaar Nachwuchs erwartete. Von in Wien stationierten Botschaftern wurde ein solcher symbolischer Hinweis stets umgehend in die eigene Heimat gemeldet. Als Beispiel sei hier nur der venezianische Botschafter Marin Zorzi erwähnt, der am 2. August I670 aus Wien schrieb, dass sich die Kaiserin zwei Tage zuvor öffentlich in einem Tragsessel in die Jesuitenkirche tragen ließ, nachdem die ersten beiden Schwangerschaftsmonate glücklich vorübergegangen waren. Die ganze Stadt, so der Botschafter, habe sich gefreut, die Kaiserin im Tragsessel zu sehen, und hoffe nun auf die Geburt eines Sohnes. ${ }^{250}$ Von der überschwänglichen Freude einfacher Leute beim Anblick einer Kaiserin im Tragsessel berichtete auch Johanna Theresia Gräfin Harrach 1677 in einem ihrer Tagzettel. ${ }^{25 r}$ Andererseits bedurfte es auch keiner Worte, wenn sich die Hoffnungen auf eine eingetretene Schwangerschaft als trügerisch herausstellten oder wenn eine bereits proklamierte Gravidität plötzlich mit einer Fehlgeburt zu Ende ging. In einem solchen Fall reichte es, wenn die Kaiserin wieder den Reifrock anlegte und sich in einer Karosse anstatt in einem Tragsessel transportieren ließ, um jedermann über den neuen Stand der Dinge zu unterrichten. ${ }^{252}$

tiner-Kirch tragen / und dieses geschahe wegen tragender Leibs-Frucht." Interessant ist in diesem Zusammenhang auch, dass der für die Bekanntmachung der Schwangerschaft gewählte Zeitpunkt damals relativ früh lag, nämlich bereits rund sieben Monate vor der Geburt (Erzherzog Ferdinand Wenzel kam am 28. September 1667 zur Welt). Dieser für heutige Verhältnisse frühe Zeitpunkt lässt sich auch in anderen Fällen beobachten. Einen besonders frühen Moment wählte etwa Kaiserin Eleonore Magdalene, als sie am 3. Dezember 1677 durch die erstmalige Verwendung des Tragsessels der Öffentlichkeit kundtat, guter Hoffnung zu sein (ÖStA, AVA, FA Harrach, Hs. 6, fol. 42Iv), und erst am 26. Juli I678 - also erst fast acht Monate danach - ihren Sohn, den späteren Kaiser Joseph I., gebar.

250 "Giovedì sortì publicamente l'imperatore con l'imperatrice la prima volta doppo scoperta la gravidanza, terminati essendo li due mesi felicemente. L'occasione fu di trasferirsi alla chiesa de padri gesuiti per la festa di sant'Ignatio. Tutta la città si rallegrò nel vedere sua maestà portata in sedia per contrassegno delle gratie del cielo, che si sperano col parto fortunato d'un prencipe." Venezianischer Botschafter Marin Zorzi an Doge Domenico II Contarini, Wien 1670 August 2, ÖStA, HHStA, Venedig, DdG, Bd. 135, S. 4I6. Drei Wochen später musste der Botschafter vermelden, dass die Schwangerschaft mit einem Abort zu Ende gegangen war. Venezianischer Botschafter Marin Zorzi an Doge Domenico II Contarini, Wien 1670 August 23, ÖStA, HHStA, Venedig, DdG, Bd. 135, S. 48I.

25I „nacher bin ich zu den augustinern zumb krab und bliben biß daz der keiser komen ist, [...] die keiserin hadt sich daz meist tragen lasen, daz krose freidt verursacht hadt bei den gemein. "Johanna Theresia Gräfin Harrach, Tagzettel von 1677 April 17; Susanne Claudine PiLs, Schreiben über Stadt. Das Wien der Johanna Theresia Harrach 1639-1716 (Forschungen und Beiträge zur Wiener Stadtgeschichte 36, Wien 2002), S. 236.

252 Als Beispiel dafür sei ein Schreiben von Botschafter Zorzi nach Venedig angeführt: „E svanita per hora la speranza, che limperatrice fosse gravida. Di nuovo ha ripreso il guardinfante, et sortendo di 


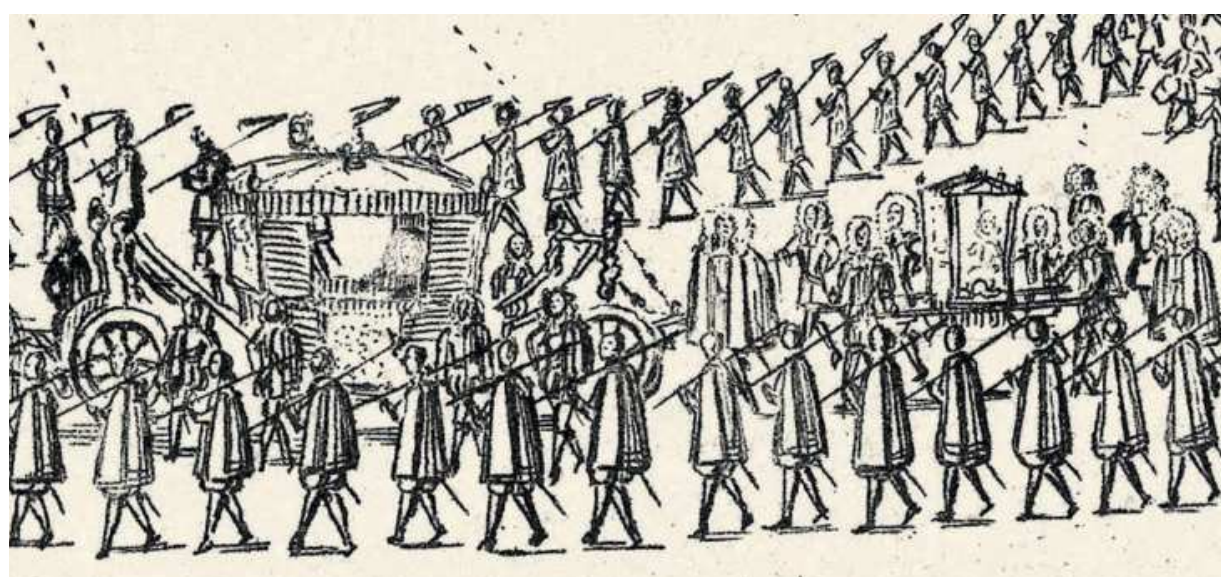

Abb. 10: Ausfahrt aus der Hofburg: im Vordergrund Kaiser Leopold I. in einer von Leibgarden flankierten sechsspännigen Karosse, gefolgt von Kaiserin Margarita Teresa im Tragsessel. Ausschnitt aus dem Kupferstich „Der Kayserliche Burg Platz in Wienn“, in: Georg Matthäus VISCHER, Topographia Archiducatus Austriae inferioris modernae (o.O. 1672). KHM, Bibliothek. @ KHM

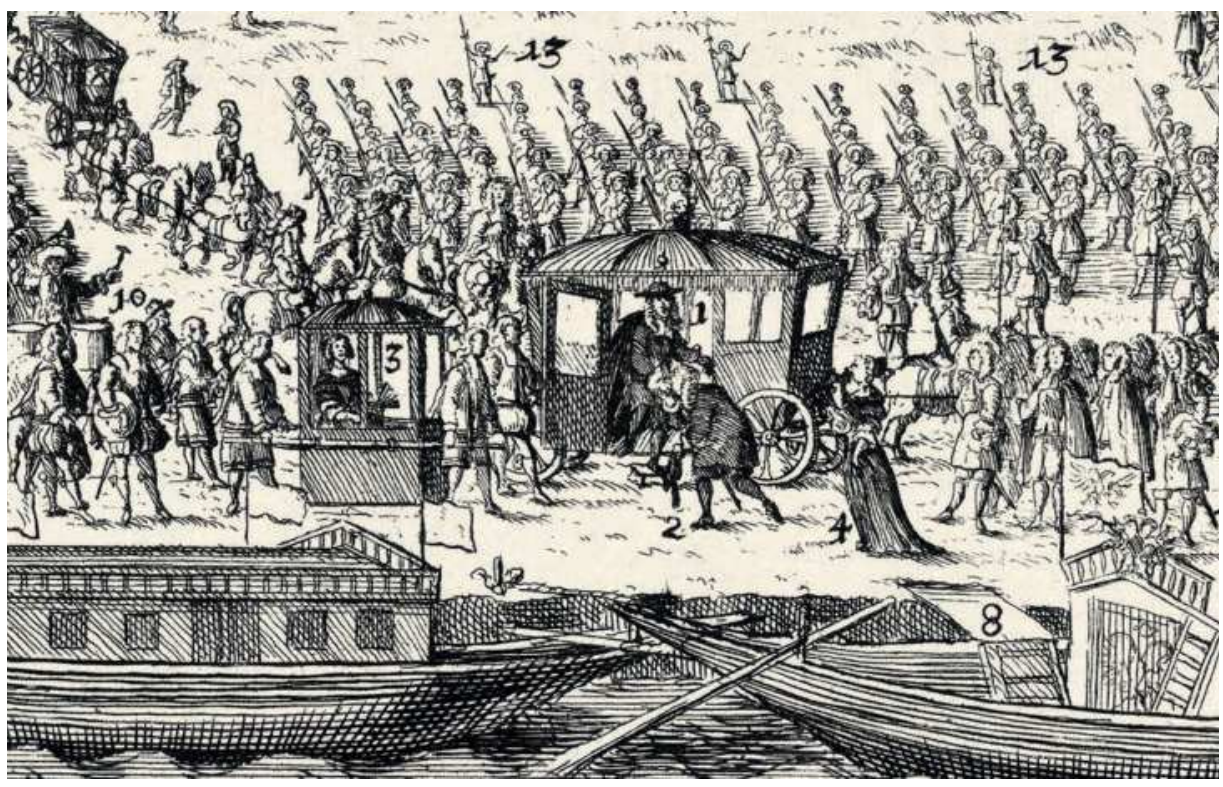

Abb. 11: „Wahre Abbildung der glücklichen Ankunfft beeder Hertzogl. Durchl. von Pfaltz-Neuburg zu Wienn / den 18. Julii [1678] / und wie selbige von denen Kais. Majestäten bewillkommet worden. [...]." Kupferstich (Detail). ÖNB, Bildarchiv, NB 740063. @ ÖNB 
Neben schriftlichen Hinweisen auf die Verwendung von Tragsesseln durch die drei Gemahlinnen Kaiser Leopolds I. existieren auch Bildquellen, die seine erste Frau, Kaiserin Margarita Teresa, und seine dritte Frau, Eleonore Magdalene, im Tragsessel zeigen. Die älteste dieser Darstellungen ist ein Kupferstich aus Vischers I672 publiziertem Werk „Topographia Archiducatus Austriae inferioris modernae“ (Abb. IO). Es zeigt den Inneren Burghof der Wiener Hofburg mit dem 1666 fertiggestellten, zwei Jahre später bei einem Brand zerstörten und anschließend wieder errichteten „Leopoldinischen Trakt“ im Hintergrund. Auf dem Platz ist ein festlicher Aufzug im Gange, bei dem unter anderem eine von Garden flankierte sechsspännige Karosse mit Kaiser Leopold I. zu sehen ist. Unmittelbar dahinter folgt Kaiserin Margarita Teresa in einem von zwei Sesselträgern beförderten verglasten Sessel. Die Kaiserin, die Ende I666 im Alter von fünfzehn Jahren an den Wiener Hof gekommen war und bis zu ihrem Tod I673 gleich sieben, meist unglücklich verlaufende Schwangerschaften durchlebte, ${ }^{253}$ erwartete vermutlich auch während des hier abgebildeten Aufzugs - das genaue Datum und der Anlass des dargestellten Ereignisses sind unbekannt - gerade ein Kind und wird wohl auch deshalb im Sessel getragen. Eine andere Bildquelle (Abb. II) zeigt die Ankunft des Herzogspaars von Pfalz-Neuburg, der Eltern von Kaiserin Eleonore Magdalene, am I8. Juli I678 in Wien. Die Kaiserin war damals hochschwanger und stand unmittelbar vor ihrer ersten Niederkunft. Ihre Eltern waren eigens von Neuburg die Donau stromabwärts angereist, um die Geburt ihres ersten Enkelkindes nicht zu versäumen. Der Kupferstich zeigt den Empfang des Herzogspaars am Donauufer. Kaiser Leopold I., der die Ankunft seiner Schwiegereltern in seiner Karosse abgewartet hatte, ist auf dem Bild gerade im Begriff, aus der Karosse zu steigen. Der ihm entgegengeeilte Herzog, dem mit einigem Abstand die Herzogin folgt, verneigt sich vor dem Kaiser und küsst ihm die Hand. Die Kaiserin selbst verfolgt die Szene etwas weiter links von ihrem geschlossenen Tragsessel aus, der von zwei Sesselträgern befördert wird. Der entsprechende schriftliche Eintrag im Hofzeremonialprotokoll bestätigt, dass sich die Empfangsszene am Donauufer tatsächlich in etwa so ereignete, wie auf dem Kupferstich abgebildet. ${ }^{254}$ Wie authentisch die Darstellung des recht schematisch wiedergegebenen Tragevehikels ist, sei jedoch dahingestellt. Ebenso fragwürdig ist die Authentizität der Darstellung eines Tragsessels auf einem Einblattdruck, der den Festeinzug des Kaiserpaars am 22. Mai I68I in Ödenburg anlässlich eines ungarischen Landtags (Abb. I2) zum Thema hat. ${ }^{255}$ Hinter dem reitenden Kaiser ist dessen Gemahlin

Palazzo, si mette in carozza. "Venezianischer Botschafter Marin Zorzi an Doge Domenico II Contarini, Wien 1670 November 8, ÖStA, HHStA, Venedig, DdG, Bd. 136, S. 158.

253 Alfred A. Strnad, Margarethe, Infantin von Spanien. In: Neue Deutsche Biographie, Bd. I6 (Berlin 1990), S. 155-157, hier S. 156.

254 ÖStA, HHStA, ZA, Prot. 3, fol. I5or-I5Iv.

255 Eine ausführliche Beschreibung dieses Einzugs findet sich auch in den Zeremonialprotokollen: ÖStA, HHStA, ZA, Prot. 3, fol. 318r-320v. 
Eleonore Magdalene zu sehen, die in einem von zwei Sesselträgern transportierten geschlossenen Tragsessel mit weiten Fensteröffnungen und graphisch angedeuteten Stickereien an den Kastenwänden den Einzug hält. Erstaunlich dabei ist, dass die Kaiserin bei diesem festlichen Ereignis einen Tragsessel verwendete, obwohl sie damals kein Kind erwartete. Ein weiterer Stich (Abb. 13) zeigt schließlich erneut die schwangere Eleonore Magdalene im Tragsessel, in Erwartung ihres letzten Kindes, Maria Margaretha. Thema dieser Darstellung ist der am 4. März I690 abgehaltene Einzug der kaiserlichen Familie in Wien nach ihrer Rückkehr aus Augsburg, wo der älteste Sohn des Kaiserpaars zum Römischen König und Eleonore Magdalene selbst zur Kaiserin gekrönt worden waren. Auf der Illustration zu diesem Festeinzug ist der unter einem Baldachin reitende Leopold I. zu sehen. Unmittelbar dahinter folgt ihm die Kaiserin in einem geschlossenen Tragsessel, an dessen von großen Fensteröffnungen durchbrochenen Kastenwänden der Stecher Stickereien andeutete. Laut dazugehöriger Bildlegende wies der Sessel der Kaiserin tatsächlich reiche Goldstickereien auf. ${ }^{256}$ Eine andere gedruckte Einzugsbeschreibung geht etwas näher auf die bei diesem Ereignis verwendeten Fahrzeuge und Tragevehikel ein. ${ }^{257}$ An einer Stelle dieser Beschreibung ist erwähnt, dass die Kaiserin „in dero kostbaren Spanischen Sessel“" “258 getragen worden sei, an anderer Stelle, dass sie bei diesem Ereignis einen „sehr reich gestickten roth-sammeten Sessel (so zu dem Spanischen Leib-Wagen gehörig)“ verwendet habe. ${ }^{259}$ Der erwähnte „spanische“ Leibwagen folgte am Ende des Zugs gemeinsam mit einer gleichartig gestalteten Maultiersänfte. Bei den drei „spanischen“ Prunkvehikeln handelte es sich wahrscheinlich um das Ensemble, dass Leopold I. im Jahr 1666 für seine erste Gemahlin, die spanische Infantin Margarita Teresa, in Paris bestellt hatte. Das Wort „spanisch“ bezieht sich demnach wohl auf die erste Besitzerin des Tragsessels und nicht auf dessen Herkunft.

Obwohl weder eine Schriftquelle noch eine bildliche Darstellung existiert, die die Verwendung eines Tragsessels durch Leopold I. selbst dokumentieren würde, weisen Indizien darauf hin, dass sich der Kaiser zumindest in den Jahren um I680 zeitweise eines Tragsessels bediente. Dafür spricht zum einen die Zahl der kaiserlichen Sesselträger ${ }^{260}$, die zwi-

256 Johann Constantin Feige (Joannem Constantinum Feigium), Wunderbahrer Adlers-Schwung oder fernere Geschichts-Fortsetzung Ortelii redivivi et continuati, Das ist: Eine außführliche Historische Beschreibung deß noch anhaltenden Türcken-Kriegs, [...] von I682 bis I69I [...] Anderter Theil (Wien 1694), S. 599. Auch für diesen Anlass wird der Einsatz eines Tragsessels durch mehrere Schriftquellen, unter anderem durch das Hofzeremonialprotokoll, bestätigt: ÖStA, HHStA, ZA, Prot. 4, fol. 557r-56or.

257 Ausführliche Relation, von dem den 4. Martii, I690. sehr prächtig-gehaltenen Einzug / Ihrer Kayserl. und Königlichen Majestäten / in dero Residentz-Stadt Wienn (o.O., o.J.).

258 Ebenda.

259 Ebenda.

260 Vgl. Kapitel 6.3. 


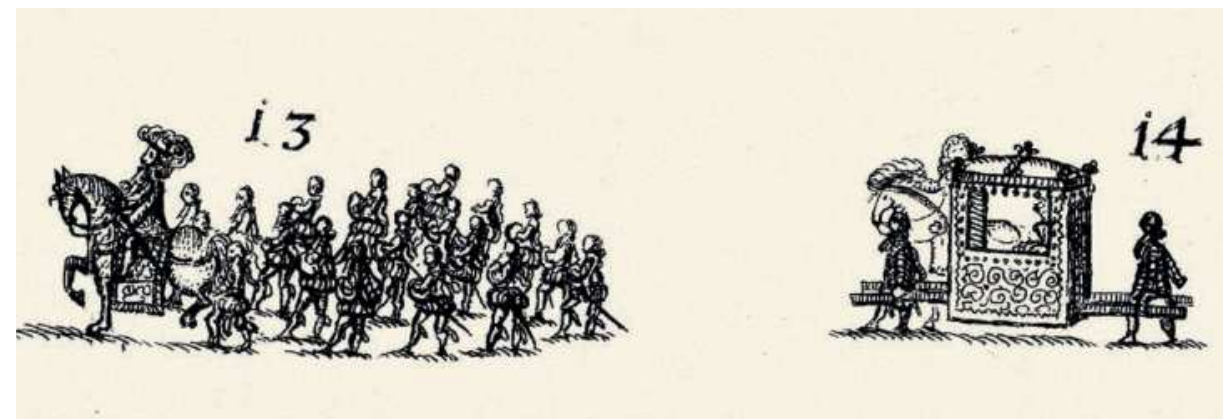

Abb. 12: Kaiserin Eleonore Magdalene im Tragsessel hinter dem reitenden Kaiser Leopold I. Ausschnitt aus dem Einblattdruck „Hochbeglückten einzugs beyder Regierenden Kays. Mayest. in die Königl. Hugarische [sic] Statt Oedenburg, So geschehen, den 22. Monath tags May A 1681. "Magyar Nemzeti Múzeum, Budapest, Inv.-Nr. 2877. @ Magyar Nemzeti Múzeum

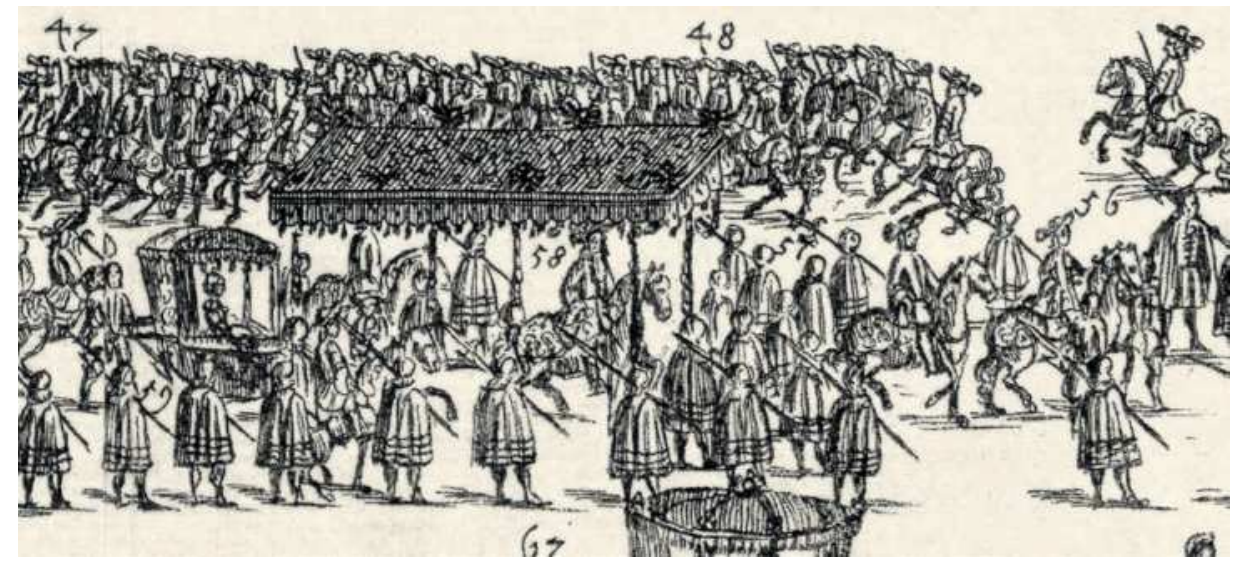

Abb. 13: Einzug der kaiserlichen Familie in Wien am 4. März 169o. Ganz vorne (Nr. 56) ist Joseph I. zu Pferd dargestellt, etwas dahinter folgt inm sein unter einem Baldachin reitender Vater, Kaiser Leopold I., und hinter dem Baldachin ist Kaiserin Eleonore Magdalene in ihrem Tragsessel zu sehen. Ausschnitt aus einem zwischen S. 596 und S. 597 beigebundenen Kupferstich in Feige 1694 (wie Anm. 256). ÖNB, Signatur: Alt Prunk ${ }^{*} 38$. D.29. @ ÖNB

schen I675 und I677 von elf auf fünfzehn stieg und I678 einen Höchststand von sechzehn erreichte. Die Gruppe der kaiserlichen Sesselträger war während des gesamten I7. Jahrhunderts nur ein einziges anderes Mal so groß, nämlich in der Endphase der Regierung Ferdinands III., als sowohl der Kaiser als auch seine Gemahlin regelmäßig auf ihre Tragsessel angewiesen waren. Nach I678 sank die Zahl der kaiserlichen Sesselträger dann wieder 
kontinuierlich. Sie belief sich I682 auf dreizehn, I683 auf elf und sollte anschließend, bis zum Tod Leopolds I. im Jahr I705, nie mehr die Zahl zwölf überschreiten. Ein noch deutlicheres Indiz für die Verwendung von Tragsesseln durch den Monarchen in jenen Jahren sind aber einzelne Passagen des Reglements für kaiserliche Sesselträger von I682. ${ }^{26 \mathrm{I}}$ Darin wird einleitend eigens darauf hingewiesen, dass Leopold I. seit einiger Zeit von den Sesselträgern „ybel bedient“ worden sei. Auch wird darin explizit erwähnt, dass ein Teil der Sesselträger beim Kaiser in Bereitschaft stehen sollte, wenn der andere Teil von ihnen Dienst bei der Kaiserin versah. Zuletzt wird den Sesselträgern in der Ordnung von I682 auch noch explizit untersagt, den Kaiser im Dienst ungefragt anzusprechen. All diese Punkte lassen keinen Zweifel daran, dass sich der Kaiser - zumindest damals - auch selbst im Sessel tragen ließ. Ob er nach I683, als die Zahl der Sesselträger wieder gesunken war, erneut von dieser Gewohnheit abrückte, lässt sich bei derzeitigem Kenntnisstand leider nicht klären. Was aber war der Grund, der Leopold I. um I680 zur Verwendung von Tragsesseln veranlasst haben mag? Obwohl der Kaiser damals erst rund vierzig Jahre alt war, scheint die Ursache auch in diesem Fall in physischen Beschwerden des Monarchen zu liegen. Ein Indiz dafür liefert ein Bericht des schwedischen Gesandten Esaias von Pufendorf über den Monarchen von I675. Pufendorf erwähnte darin, dass Leopold I. „sehr schwach auf den Schenkeln“ sei und deshalb einen torkelnden Gang aufweise. Seine Reitübungen, so der Diplomat, verrichte er aber dennoch mit Kraft und Geschicklichkeit. ${ }^{262}$ Es liegt nahe, dass es dem Kaiser unangenehm war, sich in der Öffentlichkeit mit unsicherem Gang zu zeigen, und er deshalb zu Tragsesseln griff, um diese Schwäche zu kaschieren.

Aus der Regierungszeit Kaiser Leopolds I., nämlich von I678, datiert das älteste bislang bekannte Marstallinventar, das den frühesten Überblick über die am Hof vorhandenen Tragsessel gewährt. ${ }^{263}$ Neben den bereits erwähnten zwei Tragsesseln, die anlässlich der Vermählung des Kaisers mit der spanischen Infantin Margarita Teresa I666 in Paris angeschafft worden waren, sowie dem Tragsessel, den die Braut damals aus Spanien nach Wien mitgebracht hatte, befand sich im Hofmarstall ein einfacher, außen mit schwarzem Leder und innen mit schlichtem Tuch bezogener Tragsessel, der ursprünglich für den Beichtvater des Kaisers, Philipp Miller, angeschafft worden war. Zum Zeitpunkt der Inventarerstellung war der Geistliche bereits verstorben. Im Inventar sind außerdem zwei rotsamtene,

26I Vgl. Kapitel 4 und die Transkription der Ordnung in Kapitel 6.2.

262 „Absonderlich ist er sehr schwach auf den Schenkeln und zeiget solches gnugsam durch seinen vacillierenden Gang; jedoch thut er die Exercitien zu Pferde mit noch ziemlicher Vigueur und Adresse, [...].“ Karl Gustav Helbig (Hg.), Esaias Pufendorf's kngl. schwedischen Gesandten in Wien, Bericht über Kaiser Leopold, seinen Hof und die österreichische Politik I67I-I674 (Leipzig 1862), S. 59 f.

263 Zum Hofmarstallinventar siehe DöBerl 2010 (wie Anm. 240). Die Tragsessel betreffenden Einträge sind in Kapitel 6.I angeführt. 
„reich mit golt verprämbte “ ${ }_{264}$ Tragsessel angeführt, die gleich einem mit schwarzem Tuch ausgeschlagenem Tragsessel im Jahr I678 vom kaiserlichen Rüstmeister verwaltet wurden. Es steht zu bezweifeln, dass diese Tragsessel damals noch im Einsatz standen. Die beiden rotsamtenen Tragsessel wurden zu einem nicht mehr genau zu bestimmenden Zeitpunkt zwischen I678 und I699 den kaiserlichen Sesselträgern als Geschenk überlassen. Der dritte, schwarze Tragsessel, mit seinem „alt schwarz zerfressenem tuech“ und seinen fehlenden Gläsern, wurde im selben Zeitraum ebenfalls aus dem Marstallinventar ausgeschieden. ${ }^{265}$ Die Gesamtzahl von sieben Tragsesseln war für die Größe und Bedeutung des Wiener Hofes keineswegs hoch, waren doch an dem in vielen Belangen vergleichbaren Münchner Hof im Jahr I680 drei Tragsessel mehr als in Wien vorhanden. ${ }^{266}$ Neben den Tragsesseln selbst ist in den kaiserlichen Inventaren von 1678 auch eine einfache Kalesche verzeichnet, ${ }^{267}$ die dafür vorgesehen war, die Tragsessel und Sesselträger bei Bedarf an einen weiter entfernten Einsatzort und anschließend wieder zurück zu transportieren. ${ }^{268}$

Bemerkenswert sind auch Beispiele aus der Regierungszeit Leopolds I., die die Rigidität des Kaiserhofes demonstrieren, wenn Botschafter oder deren Angehörige Tragsessel bei zeremoniellen Abläufen einzuschleusen versuchten, wo der Wiener Hof keinen Platz dafür vorgesehen hatte. So berichtete etwa I66I der venezianische Botschafter am Kaiserhof, dass sich sein spanischer Amtskollege Marqués de Mancera den Unmut des Wiener Hofes zuzog, weil seine Gemahlin darauf bestand, sich zur Audienz bei der Kaiserin-Witwe Eleonora Gonzaga (II.) im Tragsessel bringen zu lassen, obwohl dies in Wien absolut unüblich war. ${ }^{269}$

264 Verzeichnis der Objekte, die unter dem kaiserlichen Oberststallmeister Ferdinand Bonaventura Graf Harrach ausgemustert oder verschenkt wurden, verfasst vom kaiserlichen Rüstmeister „Ignatius Mölzer“. ÖStA, AVA, FA Harrach, Akten, K. 324, Konv. „Ferdinand Bonav. I. Biograph. Oberststallmeister, Allgemeines, I. Partie -I678“, unfol.

265 Ebenda.

266 Döberl 2010 (wie Anm. 240), S. 278.

267 Ebenda, S. 300.

268 Für diese vierspännig gefahrene Kalesche waren stets ein Zug Pferde sowie ein Kutscher abgestellt. Verzeichnis der für eine Reise nach Ödenburg benötigten Zugpferde und Klepper, undat. (aber wahrscheinlich I68I), ÖStA, AVA, FA Harrach, Akten, K. 2528, Konv. „Hoffutteramt, s. d., I678-I686, Rechnungen, Korrespondenz“, unfol.; Verzeichnis des kaiserlichen Klepper- und Kutschenstall im Jahr I684, ebenda, unfol.; zwei undatierte (aber zwischen 1677 und 1699 angelegte) Listen der kaiserlichen Pferdezüge, ÖStA, AVA, FA Harrach, Akten, K. 2528, unfol.

$269,[. .$.$] , e come universalmente disapprovata l'impropria pretentione del sopradetto ambasciatore, il quale$ anco per le elate pretendenze della moglie che ambiva farsi portare in segietta, ciò che non pratica l'imperatrice; haver la precedenza dalla maggiordoma, e nulla conseguitò si è reso non poco odioso a questa corte." Venezianischer Botschafter Giovanni Sagredo an Doge Domenico II Contarini, Wien I66I Oktober 30, ÖStA, HHStA, Venedig, DdG, Bd. II9, S. 92. „Anco alla moglie successe pure un altro incontro perchè fattasi portare in seggietta sopra le scale non fu incontrata dalla maggior donna dell'imperatrice al luoco dove sostiene l'ambasciatore, che fossero accolte le mogli de suoi precessori." Venezia- 
Am 2. März I667 ließ sich auch die spanische Botschaftergattin Condesa de Castillar auf ihrem Weg zur Audienz bei der regierenden Kaiserin Margarita Teresa über weite Strecken im Tragsessel transportieren. Anschließend wurde sie von ihren Dienern im Sessel zur Audienz bei der Kaiserin-Witwe getragen. ${ }^{270}$ Als am darauf folgenden Tag nach einer prächtigen Hofschlittenfahrt zum Tanz und zu einer „Merenda“ in die Hofburg geladen wurde, erweckte die Condesa, wie im „Theatrum Europaeum“ vermerkt wird, zum wiederholten Mal „Dißgust“ am Kaiserhof, da sie sich „in einem Sessel in die Ritter-Stube tragen lassen wollen, welches man ihr aber nicht zugelassen: Worüber sie dann mit Zurücklassung ihres Sessels hinein gangen [...]. “ ${ }^{271}$ Diese Beispiele zeigen anschaulich, dass die an den europäischen Fürstenhöfen unterschiedlichen Gewohnheiten im Gebrauch von Tragsesseln nicht immer harmonierten und deshalb auch zu diplomatischen Zwischenfällen führen konnten.

Die Frauen kaiserlicher Botschafter in Spanien übten ihrerseits übrigens keine Zurückhaltung bei der Verwendung von Tragsesseln, sondern passten sich vielmehr den in Madrid verbreiteten Gepflogenheiten an. Dies mag folgendes Beispiel illustrieren: Kurz nachdem Ferdinand Bonaventura Graf Harrach seinen Botschafterposten am spanischen Hof angetreten hatte, wurde seine Gemahlin Johanna Theresia eingeladen, der spanischen Regentin Maria Anna inkognito einen Besuch abzustatten. Da sie dafür einen Tragsessel benötigte, offenbar aber kein derartiges Tragevehikel aus Wien mitgebracht hatte, musste sie sich einen Tragsessel samt Sesselträgern von der Frau von Graf Pötting, dem scheidenden kaiserlichen Botschafter, ausleihen. ${ }^{272}$ Am Madrider Hof boten sich für die Botschaftergattin Johanna Theresia in den darauf folgenden Jahren offensichtlich zahlreiche Gelegenheiten, Tragsessel zu verwenden ${ }^{273}$, was entsprechende Anschaffungen nötig machte. So befanden sich gegen Ende der diplomatischen Mission Harrachs in Spanien im Jahr I677 gleich drei Tragsessel im Besitz von Ferdinand Bonaventura und Johanna Theresia Harrach. ${ }^{274}$

nischer Botschafter Giovanni Sagredo an Doge Domenico II Contarini, Wien I66r November 6, ÖStA, HHStA, Venedig, DdG, Bd. II9, S. Ior. Auch die Zeremonialprotokolle erwähnen den Konflikt, der am 29. Oktober I66I bei der Audienz der Gemahlin des spanischen Botschafters bei der Kaiserin-Witwe entstand. ÖStA, HHStA, ZA, Prot. 2, S. 983 f.

270 ÖStA, HHStA, ZA, Prot. 2, S. 1333-I335.

271 Theatrum Europaeum, Bd. io (Frankfurt a. M. 1677), S. 198.

272 Miguel Nieto Nuño (Hg.), Diario del Conde Pötting, Embajador del Sacro Imperio en Madrid (I664-I674), 2 Bde. (Madrid I990-I993), Bd. 2, S. 388 f.

273 Dokumentiert ist beispielsweise, dass sie sich, nachdem sie Anfang Februar I674 einen Sohn zur Welt gebracht hatte, am I8. März I674 beim Hervorgang aus dem Kindbett in einem Tragsessel zur Kapelle bringen ließ. Ferdinand MenčıK, Ferdinand Bonaventura Graf Harrach: Tagebuch über den Aufenthalt in Spanien in den Jahren 1673-1674 (Wien 1913), S. 74.

274 Eine Liste jener Mobilien, die der Botschafter und seine Gemahlin vor ihrer Abreise aus Madrid verkaufen wollten, beinhaltet unter anderem drei geschlossene Tragsessel sowie vier zugehörige Laternen, deren Zweck es war, den Sesselträgern den Weg zu leuchten: „4 lattern der pottschaffte- 
Dass Harrach in Spanien auch selbst Tragsessel verwendete, ist unwahrscheinlich, zumindest ist in seinem außergewöhnlich penibel geführten Tagebuch der Jahre 1673 bis 1677, in dem er von ihm benutzte Fahrzeuge häufig erwähnte, keine Rede davon. ${ }^{275}$ Ein solcher Verzicht auf Tragsessel scheint damals durchaus typisch für den männlichen Adel der Habsburgermonarchie gewesen zu sein. Die wenigen Quellen, die den Gebrauch von Tragsesseln durch adelige Herren erwähnen, liefern meist auch gleich den Grund für die Verwendung eines solchen Transportmittels mit, und dieser steht in der Regel in Zusammenhang mit Gesundheitsproblemen oder hohem Alter. Hierfür seien einige Beispiele angeführt. So ließ sich etwa der ehemalige kaiserliche Obersthofmeister Gundaker Fürst Liechtenstein, der schon seit den I630er Jahren unter Gichtattacken litt, im Alter von siebenundsiebzig Jahren vom kaiserlichen Hoftischler einen Tragsessel bauen, da ihm damals sogar das Kutschenfahren schon zu anstrengend geworden war. ${ }^{276}$ Ein anderes Beispiel liefert der ungarische Palatin Franz Wesselényi von Hadad, dem I662 in der Pressburger Franziskanerkirche der Orden vom Goldenen Vlies verliehen wurde, wobei er sich eines Tragsessels bedienen musste, was, wie das Zeremonialprotokoll hierzu vermerkt, „des podagra halber“ geschehen sei. ${ }^{277}$ Auch der böhmische Obersthofmeister Graf Maximilian Valentin Martinitz benutzte nur aus gesundheitlichen Gründen einen Tragsessel: Er brach I665 trotz mehrfacher Warnungen in schlechter körperlicher Verfassung in einer Kutsche von Prag in Richtung Karlsbad auf, musste allerdings schon bei Schloss Stern auf einen Tragsessel umsteigen, da er „daß schüttlen deß wagens nicht erleiden" konnte. ${ }^{278}$ Kardinal Ernst Adalbert von Harrach, dessen Leben durch seine überlieferten Diarien und Tagzettel bis zum Jahr I667 besonders detailreich dokumentiert

rin neben den sessel zu leichten. Einen sessel vor die graffin von blawen silberstuck, auß und einwendig mit guldenen spizen, und vergulden neglen geziert, sambt einen vened[ischen] spieglglaß, fürhangl von silberstuckh, riembe von dergleichen und allr zugehör. [Randvermerk von anderer Hand: „Ist in Teutschlandt das süberstuk verkaufft, die beschlecht udt gestell aber in der almoneda."] Einen anderen sessel inwendig von rothen damasc, fürhängl von eben diesen, außwendig von grawen paracan mit rott seidenen franßl ganz überstickht sambt einen vened[ischen] glaß und allr zuegehör. [Randvermerk von anderer Hand: „Ist in der almoneda verkaufft worden.“] Noch einen anderen sessel inwendig und die fürhängl von rothen damasc, außwendig von leder mit einen weisen gewixt, und mit rothen fränßlen gestickhten überzug sambt allr zugehör.“ „Verzaichnus der jenigen mobilien so ihro hoch gräff. ex.ce herr herr graff von Harrach, alhier lassen werden.", undat. (aber 1677), ÖStA, AVA, FA Harrach, K. 775, Konv. „Tapezereien“, unfol. Vgl. ÖStA, AVA, FA Harrach, Hs. 6/I und 6/2.

276 Thomas Winkelbauer, Fürst und Fürstendiener. Gundaker von Liechtenstein, ein österreichischer Aristokrat des konfessionellen Zeitalters (MIÖG Ergänzungsbd. 34, Wien/München 1999), S. $470 \mathrm{f}$.

277 ÖStA, HHStA, ZA, Prot. 2, S. 998.

278 Keller/Catalano 2010 (wie Anm. 213), Bd. 7, S. 6 I2. 


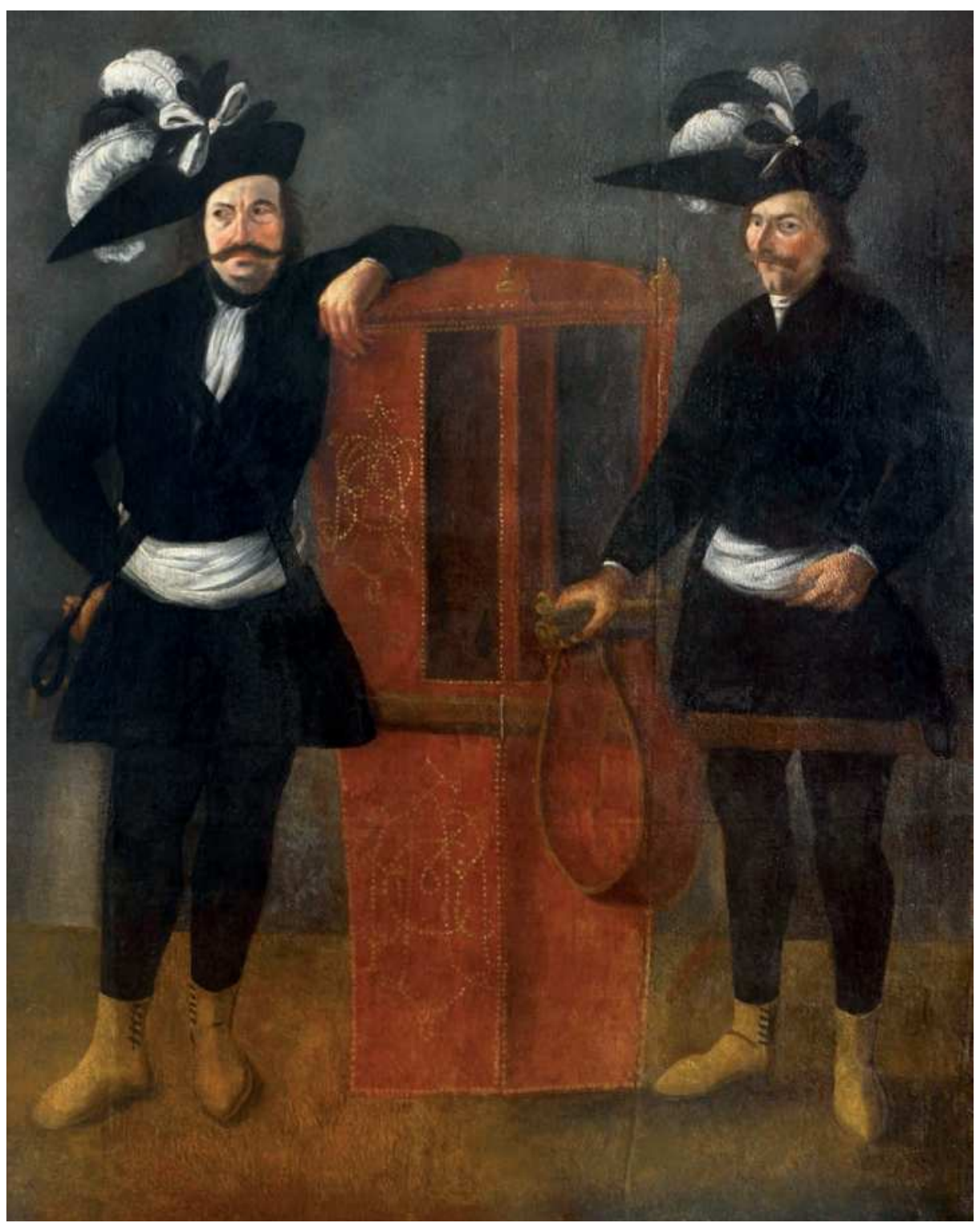

Abb. 14: Tragsessel und Sesselträger von Maria Gabriela Gräfin Lazansky von Bukowa. Václav Dvořák, ca. 1715/17, Staatsschloss Manětín, Inv.-Nr. MA 869. @ The National Heritage Institute (NHI), Prag; Foto: Vaclav Podestát 
ist, griff selbst zwar sehr häufig zu Kutschen und Sänften, benutzte aber offenbar niemals Tragsessel. ${ }^{279}$

Für adelige Damen scheinen hinsichtlich der Verwendung von Tragsesseln keinerlei Restriktionen geherrscht zu haben, solange dabei kein Konflikt mit dem Hofzeremoniell entstand. Von der selbstbewussten Nutzung und Zurschaustellung von Tragsesseln seitens weiblicher Adelsangehöriger zeugt ein außergewöhnliches Gemälde aus dem frühen I8. Jahrhundert (Abb. I4). Es stammt ursprünglich aus dem Besitz von Maria Gabriela Gräfin Lazansky von Bukowa (geb. Czernin) und wurde zwischen I7I5 und I7I7 als Teil der Ausstattung für Schloss Manětín in Böhmen geschaffen. Im Bildzentrum ist der geschlossene, mit rotem Leder überzogene und mit Fenstergläsern und kleinen Dachvasen versehene Tragsessel der Gräfin dargestellt. Auf den sichtbaren Seitenpaneelen ist mittels vergoldeter Ziernägel das Monogramm der Besitzerin in doppelter Ausführung nachgezeichnet. Das über zwei Meter hohe Gemälde zeigt auch in monumentaler Weise zwei äußerst selbstbewusst wirkende, schwarz livrierte Diener, die sich auf Basis erhaltener Schriftquellen als die beiden Sesselträger Johannes Pleistein und Jacob Krummer identifizieren lassen. ${ }^{280}$

\section{Zu Herkunft, Gestalt und Ausstattung der kaiserlichen Tragsessel im 17. Jahr- hundert. Mit einer Besprechung des ältesten erhaltenen Exemplars des Wie- ner Hofes}

Im Folgenden sollen die vorliegenden Informationen zu den in Schrift- und Bildquellen fassbaren kaiserlichen Tragsesseln noch einmal gebündelt präsentiert und der älteste erhaltene Tragsessel des Wiener Hofes besprochen werden. Zum Aussehen jener Tragsessel, die vor I6I5 an den Höfen der österreichischen Habsburger in Verwendung standen, existieren bislang bedauerlicherweise weder schriftliche noch bildliche Hinweise, weshalb sich über ihre Gestalt nur Vermutungen anstellen lassen. Erste gesicherte, wenn auch nur bruchstückhafte Hinweise auf das Aussehen kaiserlicher Tragsessel datieren ab I6I5. Von dem Tragsessel, der damals als Geschenk aus Florenz an Kaiserin Anna gelangte, ist überliefert, dass er einem am Florentiner Hof gängigen Modell folgte. Außerdem ist bekannt, dass er über einen geschlossenen, rot tapezierten Passagierkasten verfügte und seine Trageholme einen roten Anstrich aufwiesen. ${ }^{28 \mathrm{I}}$ Nahezu keine Informationen liegen zu einem Tragsessel

279 Vgl. Keller/Catalano 2010 (wie Anm. 2I3).

280 Jaroslav Sojka (Hg.), Zapřažená krása. Kočáry, saně a nosítka i8.-20. Století (Ausstellungskatalog, Praha 20I4), S. 80. Die Kenntnis dieses Gemäldes verdanke ich Monica Kurzel-Runtscheiner.

28I Siehe hierfür Kapitel 2.2. 
vor, der I623 als Geschenk des Herzogs von Mantua für seine Schwester, Kaiserin Eleonora Gonzaga (I.), an den Wiener Hof gelangte. Da die Kaiserin plante, ihn für Jagdzwecke einzusetzen, ist es wahrscheinlich, dass es sich auch hierbei um einen geschlossenen Tragsessel handelte. Mehr ist aus den Quellen zu diesem Tragevehikel nicht zu erfahren. Eine Vorstellung vom Aussehen dieses Tragsessels kann vielleicht eine aus dem Jahr I6oo stammende Skizze jenes Tragsessels geben, den der damals regierende Herzog von Mantua verwendete (Abb. 5) - allerdings bewegen wir uns hier zugegebenermaßen auf spekulativem Terrain. ${ }^{282}$

Konkretere Angaben sind zu den sechs bis sieben durch mehrere Schriftquellen dokumentierten Tragsesseln der Königin und späteren Kaiserin Maria Anna vorhanden. ${ }^{283}$ Der Papst schenkte ihr I63I auf einer Zwischenstation ihrer Brautreise einen Tragsessel, der einer verglasten, rotsamtenen, mit goldenen Borten versehenen Trageselsänfte ähnlich sah, die ebenfalls Teil des umfassenden päpstlichen Präsents war. Offenbar verfügte der Tragsessel über Vorhänge, was bedingt, dass er auch eine Bedachung aufwies. Allerdings waren die Seitenwände dieses Tragsessels allem Anschein nach nicht mit Gläsern versehen. Ein anderer Tragsessel Maria Annas, den sie aus Spanien mitgebracht hatte, wies hingegen eine Verglasung auf. Bei einem dritten Tragsessel, der ursprünglich vielleicht ebenfalls aus Spanien stammte, handelte es sich um ein kleines, mit grünem Damaststoff überzogenes Tragevehikel. Ob dieser Tragsessel über einen offenen oder geschlossenen Sitzkasten verfügte, ist unbekannt. Für das Jahr I63I wird in den Quellen außerdem ein grünsamtener Tragsessel erwähnt. Es lässt sich nicht mehr mit Sicherheit feststellen, ob es sich dabei um den kleinen Tragsessel mit grünem Damaststoff handelte, der möglicherweise stellenweise auch mit Samt ausstaffiert war, oder etwa um ein anderes Objekt. Über das Aussehen eines weiteren Tragsessels aus Maria Annas Besitz, der in den Quellen als „galant“ bezeichnet wurde und den sie I634 in Passau von ihrem jüngeren Bruder, dem Kardinalinfanten Ferdinand, geschenkt bekam, ist nichts weiter bekannt. Wiener Hofhandwerker stellten für sie im Jahr I640 einen rotsamtenen Tragsessel her, der bei der Taufe des späteren Kaisers Leopold I. zum Einsatz kam. Wahrscheinlich handelte es sich dabei um einen offenen Tragsessel, da diese repräsentative Tragehilfe im Inneren des Palastes verwendet wurde. I642 wurde schließlich ein weiterer, diesmal mit schwarzer Seide bezogener Tragsessel für Maria Anna bei Wiener Handwerkern in Auftrag gegeben.

Von den Tragsesseln, die Kaiser Ferdinand II. I636 und sein Sohn, Kaiser Ferdinand III. I653 bei den Feierlichkeiten rund um die Wahl und Krönung ihrer jeweiligen Nachfolger als Römische Könige benutzten, existieren mehrere Stiche (Abb. 6-8). Zu sehen sind darauf jeweils offene Tragsessel mit textilen Behängen, die im Freien unter einem Baldachin Verwendung fanden. Schriftliche Quellen zur Ausstattung dieser Tragsessel sind

$282 \mathrm{Zu}$ diesem Tragsessel siehe Kapitel 2.3.

283 Siehe dazu Kapitel 2.5. 
äußerst rar. Allein vom Tragsessel, den Ferdinand III. anlässlich der Wahl Ferdinands IV. gebrauchte, ist überliefert, dass er einen roten Samtbezug aufwies, und vom Sessel, in dem sich Ferdinand III. bei der Krönung seiner Gemahlin Eleonora Gonazaga (II.) I656 in Prag tragen ließ, dass er „mit gelbem Goldstück“ ausgeschlagen war. ${ }^{284}$

Die genauesten Beschreibungen kaiserlicher Tragsessel des I7. Jahrhunderts liefern die Hofmarstallinventare von I678. ${ }^{285}$ Einer der beiden kostbarsten Tragsessel dieser Inventare war ein Hochzeitsgeschenk, das Kaiser Leopold I. I666 in Paris für seine Braut Margarita Teresa herstellen ließ. Es handelte sich dabei um ein geschlossenes, mit fünf herausnehmbaren venezianischen Gläsern versehenes Prunkvehikel, das außen reiche Goldstickerei auf rotem Samtuntergrund aufwies und dessen Innenausstaffierung aus blumengemustertem, mit Gold und Silber durchwirktem Stoff bestand. Ebenso reich mit Edelmetallen durchwirkt war das perlfarbene, entlang der Nähte mit Fransen besetzte Sitzpolster. Die drei mit Gold- und Silberfransen versehenen Vorhänge des Tragsessels zeigten kostbare Goldstickereien auf rot- und weißfarbenem Grundstoff. Die Tragstangen und Schulterbänder für die Sesselträger waren ebenso wie die Außenseite des Tragsessels mit rotem, goldbesticktem Samt überzogen. Bemerkenswert ist, dass weder für diesen noch für einen anderen der in den Inventaren von 1678 angeführten Tragsessel farblich auf das Vehikel abgestimmte Livreen existierten, wie das damals etwa bei drei repräsentativen Kutschen des kaiserlichen Fuhrparks der Fall war. ${ }^{286}$

Ähnlich aufwendig, wenn nicht sogar noch kostbarer gestaltet, war ein geschlossener, unverglaster Tragsessel, den Margarita Teresa I666 nach Wien mitgebracht hatte. Während auf dem veilchenfarbenen Samtbezug des Sitzkastenäußeren flächendeckend massive Reliefstickereien aus Gold und Korallen aufgebracht waren, war das Innere des Tragevehikels mit schwerem blassblauem Silberstoff austapeziert. Die drei dazugehörigen Fenstervorhänge sowie die Tragegurte für die Sesselträger waren analog zur Außenbespannung in Samt mit Gold- und Korallenstickereien ausgeführt. Die drei Vorhänge waren zusätzlich mit kostbaren Zierknöpfen besetzt, von denen allerdings sechs Stück entwendet wurden, als der Tragsessel „in der galleria gestanden“. Dieser Vermerk im Inventar weist darauf hin, dass der Tragsessel zwischen I666 und I678 zumindest für eine gewisse Zeit gemeinsam mit anderen Kunstwerken in den Räumlichkeiten der kaiserlichen Galerie ${ }^{287}$ ausgestellt war. Welch hohen Bekanntheitsgrad und welche einzigartige Stellung dieser Tragsessel am Kaiserhof hatte, erhellt sich aus einem im Frühling des Jahres I677 verfassten Schreiben der

284 Siehe dazu Kapitel 2.7.

285 Siehe dazu die Quellentranskriptionen in Kapitel 6.I.

286 Döberl 2010 (wie Anm. 240), S. 297.

287 Zur Galerie in der Stallburg siehe Alphons Lнотsку, Festschrift des Kunsthistorischen Museums zur Feier des fünfzigjährigen Bestandes, 2 Bde. (Wien I94I-I945), Bd. 2/I, S. 358-360, 369-372. 
Johanna Theresia Gräfin Harrach. Sie berichtete darin, dass sie ihren Tragsessel erneuern lassen wollte und zunächst plante, diesen mit einem blauen, silberdurchwirkten Stoff überziehen zu lassen. Schließlich habe sie von diesem Vorhaben aber Abstand genommen, da sie es nicht gewagt habe, für ihren Tragsessel ähnliche Textilien zu verwenden wie die, mit denen einzig der Tragsessel der Kaiserin ausstaffiert war. ${ }^{288}$

Neben diesen beiden prachtvoll ausgestatteten Tragsesseln findet sich in den Inventaren noch ein drittes Exemplar, dessen Textilien ebenfalls anlässlich der Hochzeit von Leopold I. und Margarita Teresa in Paris angeschafft wurden. Es handelte sich hierbei um einen geschlossenen Tragsessel ohne Verglasung und Vorhänge. Das Äußere des Vehikels war mit rotem Samt bezogen und mit goldenen Posamenten und Fransen verziert. Sein Inneres war mit scharlachrotem Damaststoff ausgeschlagen und mit Goldborten verbrämt. Schon im Jahr I679 wurde dieser Tragsessel, wie bereits erwähnt, aus den kaiserlichen Marstallbeständen ausgemustert und den Hofsesselträgern überlassen.

Zur Ausstattung von vier anderen Tragsesseln, die in den Marstallinventaren von I678 aufgelistet sind, ist nur wenig bekannt. Einer davon war für den kaiserlichen Beichtvater angeschafft worden und außen mit schwarzem Leder und innen mit grauem beziehungsweise grobem Tuch ausgeschlagen. Die drei anderen Tragsessel waren zum Zeitpunkt der Inventarerstellung bereits weitgehend unbrauchbar und wurden bis Ende des I7. Jahrhunderts aus dem Hofmarstall ausgeschieden. Zwei davon waren mit rotem Samt bespannt und mit Goldborten reich verbrämt, der dritte war mit schwarzem Tuch ausgeschlagen.

Aus dem Zeitraum zwischen 1666 und 1690 sind auf mehreren Illustrationen historischer Ereignisse kaiserliche Tragsessel abgebildet (Abb. 9-I3). Leider lässt der - zumindest was die Fahrzeuge, Sänften und Sessel betrifft - weitgehend fiktive Charakter dieser Darstellungen es meist nicht zu, die darauf gezeigten Tragevehikel mit Sicherheit konkreten, archivalisch dokumentierten Tragsesseln des Kaiserhauses zuzuordnen. Einzig durch eine Festbeschreibung von I690 scheint erwiesen, dass der damals beim Einzug der kaiserlichen Familie in Wien von Kaiserin Eleonore Magdalene verwendete Tragsessel (Abb. 13) mit jenem zu identifizieren ist, der für den Brauteinzug ihrer Vorgängerin Margarita Teresa I666 in Paris bestellt worden war. ${ }^{289}$

Auf sichererem Boden befinden wir uns bei Betrachtung des ältesten erhaltenen Tragsessels des Wiener Hofes (Kaiserliche Wagenburg Wien, Inv.-Nr. W 96, Abb. 15-I6). Es han-

$288,[\ldots]$ und der Daschner komen, zu segen, was er begerdt, mein sesel zu machen ihnwendich, will ihn lasen den blaben silberstuckh nemen, [...] ist der Daschner komen, da hab ich ein weil mit ihn an sesel gemesen, hab lasen samet derzue suechen außwendig zum iberziegen, da ich trau mir ihn nit silberstuckh außwendig zu machen, weil ihn keine alß die keiserin hadt." PILS 2002 (wie Anm. 25I), S. 243.

289 Siehe dazu Kapitel 2.9. 


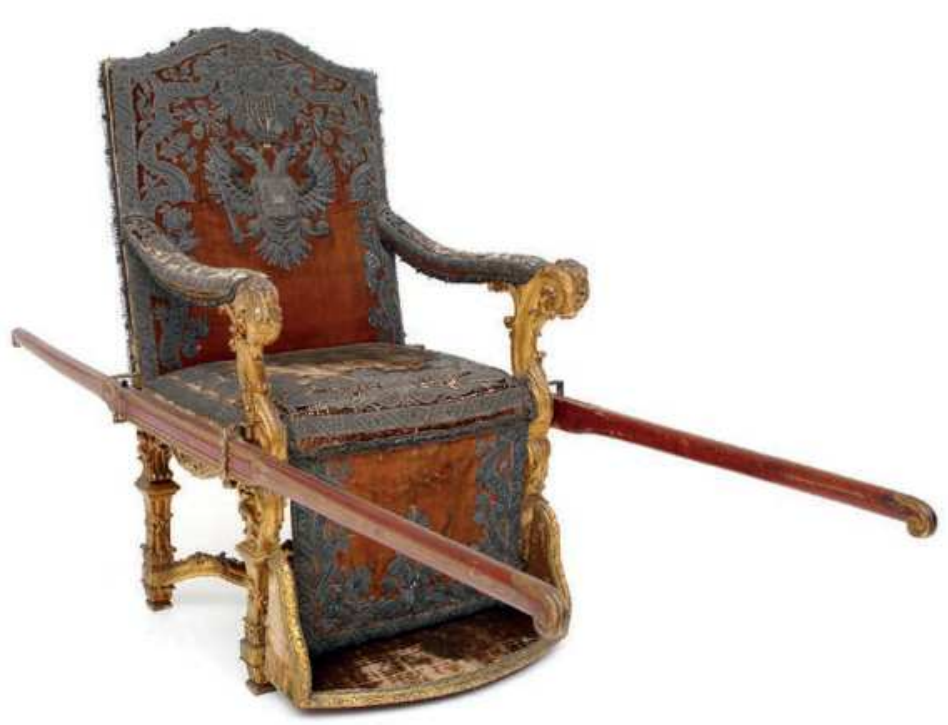

Abb. 15: Offener Gala-Tragsessel des Wiener Hofes. Wien, Holzgestell 1717/18, Samt und Reliefstickerei 1842 erneuert. KHM, Kaiserliche Wagenburg, Inv.-Nr. W 96. @ KHM

delt sich dabei um einen offenen Tragsessel mit Rückenlehne, gepolsterten Armstützen, geraden, mit Diagonalstreben verspreizten Beinen, einem abnehmbaren Fußbrett sowie zwei Trageholmen, die sich in seitlich am Sessel angeschraubte, vergoldete Eisenbügel einschieben lassen. Das in Gold gefasste Holzgestell ist mit reichen Schnitzereien geschmückt, die hauptsächlich Blumen- und Blattwerkmotive zeigen. Während sich die vergoldeten Holzteile in weitgehend gutem Zustand befinden, machen sich die Spuren der Zeit vor allem an der textilen Bespannung des Sessels bemerkbar. ${ }^{290}$ Die ursprünglich in kräftigem Rotton gehaltene Samttapezierung ist inzwischen stark ausgebleicht, und die daraufgesetzten Goldstickereien sowie die Goldposamenterieborten sind stark angelaufen und wirken deshalb silberfarben. Die Vorderseite der Rückenlehne zeigt in Reliefstickerei die Kaiserkrone sowie den Doppeladler, der in seinen Fängen Reichsapfel, Szepter und Schwert hält und an der Brust ein Schild mit dem Wappen der Familie Habsburg-Lothringen trägt. Unterhalb des Wappenschildes sind die Kollane des Ordens vom Goldenen Vlies sowie zwei Ordenskreuze zu sehen, die zwar nicht in aller Deutlichkeit ausgeführt, aber als Dekorationen

290 Dass der Zustand der Textilien und der Stickereien Anfang des 20. Jahrhunderts noch sehr gut war und dass ein großer Teil der Schäden somit wohl erst nach der Übergabe des Tragsessels an das Museum im Jahr 1922 entstand, zeigen zwei Zeitungsillutrationen von 1903 und I908: Österreichs Illustrierte Zeitung, I905 Dezember 3, S. 229; Illustrirte Zeitung (Leipzig), I908 Januar 23, S. I49. 


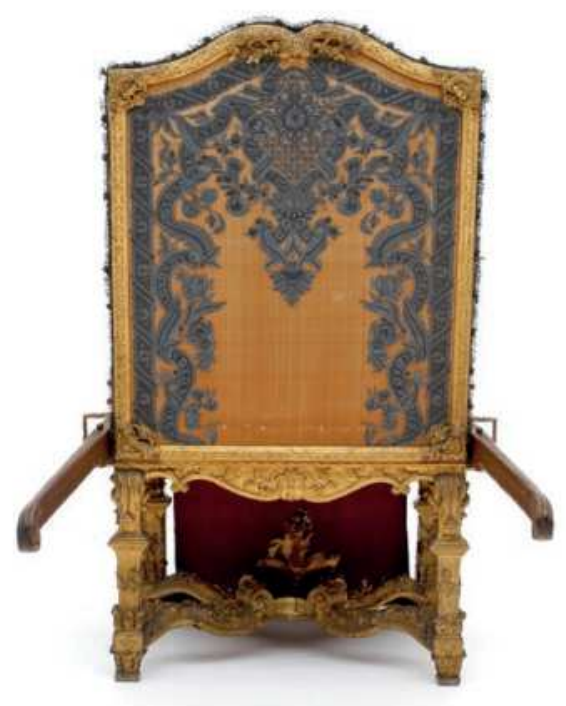

Abb. 16: Offener Gala-Tragsessel des Wiener Hofes, Rückseite (wie Abb. 15). ๑ KHM

des Militär-Maria-Theresien-Ordens sowie des Sankt Stephan-Ordens identifizierbar sind. Der Doppeladler ist von einer breiten Bordüre umrandet, die in Flachstickerei ausgeführt ist und sich aus Blüten, Blättern und Bändern zusammensetzt. Die Motive dieser Bordüre wiederholen sich an verschiedenen Stellen des Sessels, etwa an der Stickerei der Rückwand, der Armlehnen, des Sitzbezugs und jener des Behangs, der von der vorderen Sesselzarge herabfällt. Die beiden Trageholme sind rot lackiert, in Gold beschnitten und verfügen an den Enden jeweils über einen volutenförmigen geschnitzten Knauf.

Aus einem Inventareintrag ist bekannt, dass der Samtbezug und die Goldstickerei des Tragsessels im Jahr I842 erneuert wurden. ${ }^{291}$ Auch wenn wir davon ausgehen können, dass man sich bei diesen Arbeiten an der überlieferten Gestaltung der Stickereien, der Borten und des Farbtons beim Samt orientierte, bietet dennoch der auf die Rückenlehne gestickte Doppeladler mit dem Wappenschild bedauerlicherweise keinen brauchbaren Datierungshinweis für den Sessel. Das Wappen Habsburg-Lothringens war erst ab der Maria-Theresianischen Regierungszeit in Gebrauch, die kaiserlichen Insignien

29I „Ein rothsamtener reich [durchgestrichen: „mit“] Gold gestickter offener Gallatragsessel. (Wurde im Jahre [I]842 mit neuem Samt und Stickerei versehen; [durchgestrichen: „die alte Stickerei zum Ausbrennen vorräthig. “) “ KHM, Kaiserliche Wagenburg, „Inventarium der reichen k. k. Hofsattelkammer" (I825-I854), S. 319. 
verweisen auf die Jahre ab I745, die Kreuze des Militär-Maria-Theresien-Ordens beziehungsweise des Sankt Stephan-Ordens sogar erst auf die Zeit ab 1757 beziehungsweise I764, als diese beiden Orden gestiftet wurden. Gegen eine solch späte Datierung des Tragsessels sprechen aber eindeutig stilistische Gründe, weshalb es wahrscheinlich ist, dass zumindest diese Teile der Stickerei nicht dem Originalzustand der Entstehungszeit entsprechen. ${ }^{292}$

Bislang wurden bereits einige Versuche unternommen, den Tragsessel auch zeitlich einzuordnen. Schon im Katalog der I888 veranstalteten Maria-Theresia-Ausstellung wurde der Tragsessel zeitlich als „Theresianisch“ eingestuft. ${ }^{293}$ In einem 1906 erschienenen Führer durch den Hofmarstall wurde der damals in der Reichen Sattel- und Geschirrkammer ausgestellte Tragsessel zwar nicht datiert, jedoch als „Gala-Tragsessel der Kaiserin Maria Theresia" bezeichnet. ${ }^{294}$ Ein Wagenburg-Führer der Zwischenkriegszeit gab als Entstehungszeit für den Tragsessel die Mitte des I8. Jahrhunderts an, ohne diese Grobdatierung näher zu erörtern. ${ }^{295}$ In seinem monumentalen Werk „Die Kunst des deutschen Möbels“ schreibt Heinrich Kreisel über den Tragsessel: „Er ist die Arbeit eines Bildhauers, der noch ganz in den Formvorstellungen Kaiser Karls VI. lebte, so daß wir dieses seltene Möbel, von dem bekannt ist, daß es schon für die Kaiserin gefertigt worden ist, zu Beginn ihrer Regierungszeit, also nach I740, ansetzen dürfen. " ${ }^{296}$ Christian Witt-Dörring hielt sich in seiner Dissertation über die „Möbelkunst am Wiener Hof zur Zeit Maria Theresias“ eng an Kreisels Analyse und ordnete den Tragsessel in die Zeit nach 1740 ein, wobei auch er konstatierte, dass die „Struktur sowie die geschnitzte Dekoration des Tragsessels [...] zurück in die Zeit Karl VI.“ weisen und es sich dabei um ein typisches Beispiel für ein Möbelstück aus den ersten Regierungsjahren Maria Theresias handle, das „noch ganz im Geist der Zeit Karl VI.“ gearbeitet sei. ${ }^{297}$ Zuletzt wurde der Tragsessel von Monica Kurzel-Runtscheiner in die Jahre um 1740 datiert. ${ }^{298}$ Stilistische Gründe und archivalische Funde lassen annehmen, dass dieses transportable Sitzmöbel älter ist als bislang angenommen und nicht nur im „Geist der Zeit“ Karls VI. gestaltet wurde, sondern tatsächlich während seiner Regierungszeit entstand. So ist etwa die Art der Gestaltung der geraden, vierkantigen Sesselbeine in balusterartiger

292 Die spätere Anbringung eines jüngeren Wappens ist auch für einen aus dem I7. Jahrhundert datierenden Tragsessel der Nymphenburger Wagensammlung dokumentiert. Siehe dazu den Beitrag von Gudrun Szczepanek und Friederike Ulrichs im vorliegenden Band.

293 Katalog der Kaiserin-Maria-Theresia-Ausstellung (Wien ${ }^{2}$ I888), S. 96, Nr. 1065.

294 Kurzer Führer durch die k. und k. Hofmarställe (o.O., o.J., aber Wien 1906), S. I.

295 August Grosz, Führer durch die Wagenburg in Schönbrunn (Wien I93I), S. 37.

296 Heinrich Kreisel, Die Kunst des deutschen Möbels. Bd. 2: Spätbarock und Rokoko (München 1970), S. 22I f. Zum Tragsessel siehe auch ebenda, S. 406, Abb. 661.

297 Witt-Dörring 1978 (wie Anm. 3), S. I82 und Abb. 267.

298 Monica Kurzel-Runtscheiner 2004 (wie Anm. I), S. 95. 
Form $^{299}$ samt den leicht geschwungenen Diagonalstegen, die eine geschnitzte Bekrönung am Kreuzungspunkt aufweisen, mit dem Untergestell zahlreicher Möbel - hauptsächlich Tische - aus dem ersten Drittel des I8. Jahrhunderts, vor allem aber der I7Ioer und I72oer Jahre vergleichbar, ${ }^{300}$ sodass eine Datierung in diesen Zeitraum plausibel erscheint. Für eine Entstehung in jenen Jahren sprechen auch schriftliche Zeugnisse. So erwähnen die Zeremonialprotokolle des Wiener Hofes, dass Kaiserin Elisabeth Christine am 6. Februar I7I8 anlässlich eines Kirchganges in Wien durch die Benutzung eines neuen, kostbaren Tragsessels öffentlich deklarierte, in anderen Umständen zu sein. ${ }^{30}$ Einige Monate später, am 22. Oktober 1718, kam beim Hervorgang der Kaiserin aus dem Kindbett erneut ein Tragsessel zum Einsatz. Laut Eintrag in den Zeremonialprotokollen handelte es sich dabei um einen „käy[serliche]n rot-sammeten, und mit goldenen borden bebramten sessel“302. Wir können davon ausgehen, dass beim Hervorgang derselbe Tragsessel verwendet wurde, der erst wenige Monate zuvor neu gebaut worden war und dessen Beschreibung mit der Ausstattung des ältesten erhaltenen Tragsessels des Wiener Hofes übereinstimmt. Es spricht also einiges dafür, die Entstehungszeit dieses repräsentativen Tragevehikels in die Monate rund um den Jahreswechsel I7I7/I8 anzusetzen.

299 Für Maria-Theresianische Sessel sind bis in die I770er Jahre geschwungene Beine und die meist eingerollten Sesselfüße charakteristisch. Vgl. die zahlreichen Beispiele bei WITt-DöRRING 1978 (wie Anm. 3).

300 Vgl. etwa Beispiele bei Kreisel 1970 (wie Anm. 296), Abb. I, 30, 210, 313, 361, 387; Brigitte LanGer/Alexander Herzog von Württemberg (Bearb.), Die deutschen Möbel des I6. bis I8. Jahrhunderts (Die Möbel der Residenz München 2, München/New York 1996), S. I34 f. Einen auf den ersten Blick zwar schlagenden, tatsächlich aber problematischen stilistischen Vergleich stellt Christian Witt-Dörring bei seiner Behandlung des Tragsessels aus der Wagenburg an. Er bildet in seiner Dissertation als Referenzobjekt einen Armlehnsessel aus dem Neuen Palais in Potsdam $\mathrm{ab}$ und folgt dabei in der Datierung des Sessels (um 1725) Heinrich Kreisel. Witt-DöRring 1978 (wie Anm. 3), Abb. 268; Kreisel 1970 (wie Anm. 296), S. 24 f., Abb. 9. Nach neuerer Erkenntnis scheint der im Krieg verloren gegangene Sessel aus Potsdam aber zu einer neobarocken Gruppe zu gehören, die erst I890 für das Berliner Schloss angefertigt wurde. Für den Hinweis darauf möchte ich mich bei Henriette Graf von der „Stiftung Preußische Schlösser und Gärten“ bedanken.

„6. Februar 1718: Öffentlicher kirchgang nach den stüfft st. Dorothè. [...] Zu welcher andacht ihro may. die kayserin wegen dero gesegneten leibs sich in einen kostbahren neüen trag seßl haben offentlich überbringen lassen. " ÖStA, HHStA, ZA, Prot. Io, fol. IIIv.

ÖStA, HHStA, ZA, Prot. Io, fol. I78r. 


\section{Die kaiserlichen Sesselträger: Sozialer Status, Anzahl, Herkunft, Rekrutierung und Dienstvorschrift}

Im Rahmen des Hofzeremoniells wurden verschiedene körperlich anstrengende oder zumindest vordergründig niederrangig erscheinende Assistenzdienste von Personen erfüllt, die auf den oberen Sprossen der sozialen Leiter standen. Zog beispielsweise ein Kaiser in eine Reichsstadt ein, so galten das Tragen des Baldachins, unter dem der Herrscher einritt, aber auch das Führen der Zügel seines Pferdes als Ehrendienste, die ausgewählten Bürgern und hochrangigen Amtsträgern der durch den kaiserlichen Besuch beehrten Stadt vorbehalten waren..$^{303}$ In der I63I ausgestellten Dienstinstruktion für Franz Christoph Khevenhüller, den Obersthofmeister von Königin Maria Anna, ist festgehalten, derselbe müsse der Königin persönlich behilflich sein, wenn sie auf ihr Reitpferd aufsitzen oder wieder davon absteigen wolle. Gleiches galt für das Besteigen oder Verlassen von Kutschen und Sänften. ${ }^{304}$ Ein besonders mühseliger, gleichzeitig aber auch reputationssteigernder Dienst war das Tragen eines fürstlichen Leichnams zur Begräbnisstätte. Diese Tätigkeit wurde in der Regel nicht von einfachen Hofdienern, sondern von Adeligen durchgeführt. Ein Beispiel von 1596 zeigt, welch enorme Gewichte dabei befördert werden mussten: Die Bahre mit dem Leichnam Erzherzog Ferdinands II. von Tirol wog laut einem zeitgenössischen Bericht rund 400 Kilogramm und wurde von achtundzwanzig Adeligen transportiert. ${ }^{305}$ Dass den vornehmen Leichenträgern nicht nur große Lasten, sondern auch noch andere Unannehmlichkeiten zugemutet wurden, dokumentiert eine Quelle zur Bestattung des habsburgischen Thronfolgers Ferdinand IV. Der Leichnam des jung verstorbenen Fürsten wurde im Juli 1654, drei Tage nach seinem Ableben, in einen Sarg gebettet und von zwölf königlichen und zwölf kaiserlichen Kämmerern zur Kapuzinergruft getragen. Dabei drang ein derart übler Geruch - der wohl einer schlechten Präparierung des Leichnams in Verbindung mit der sommerlichen Hitze zuzuschreiben war - aus dem Sarg, dass den vierundzwanzig Kämmerern ihre Tätigkeit zur kaum erträglichen Qual wurde.. ${ }^{306}$

303 Siehe dazu ausführlich Gerrit Japser Schenk, Zeremoniell und Politik. Herrschereinzüge im spätmittelalterlichen Reich (Forschungen zur Kaiser- und Papstgeschichte des Mittelalters. Beihefte zu J. F. Böhmer, Regesta Imperii 2I, Köln/Weimar/Wien 2003), S. 348 f., 466-469.

304 Keller 2005 (wie Anm. I23), S. 228.

305 „Dann kam die fürstliche Bahre. Sie wog ungefähr sieben Centner, und achtundzwanzig Adelige haben gar hart an ihr getragen." Victor KLARwill (Hg.), Fugger-Zeitungen. Ungedruckte Briefe an das Haus Fugger aus den Jahren I568-I605 (Wien/Leipzig/München 1923), S. I91.

306 „Fu sepelito il Re [Ferdinand IV.] nella capella appresso cappucini, portato da 24 trásuoi proprii e camerieri dell'imperatore [Ferdinand III.], ma imbalsamato cosi puoco bene, che per la puzza stentorno i camerieri a portarlo, e se ne scandalizorno aquanto il nuntio [...] e li ambasciatori [...]." KelLeR/ Catalano 2010 (wie Anm. 213), Bd. 3, S. 829. Über den Ablauf dieses Leichenbegängnisses siehe auch ÖStA, HHStA, ZA, Prot. I, S. 417-420. 
Im Unterschied zu den oben genannten Ehrenämtern war der Sesselträgerdienst am Kaiserhof mit zu wenig Sozialprestige verbunden, um ihn für hochrangige Hoffunktionäre erstrebenswert zu machen. Die Bedienung von Tragsesseln galt als subaltern und wurde deshalb von einfachen Hofdienern übernommen. Nur in Ausnahmefällen unterstützten Adelige die professionellen Sesselträger. Das Tragen von Sesseln war für Angehörige der sozialen Oberschicht auch deshalb nicht opportun, weil Sesselträger nicht nur bei einmaligen, herausragenden Ereignissen herangezogen wurden, wie etwa beim Tragen von Baldachinen im Rahmen des Adventus-Zeremoniells oder beim Transport eines fürstlichen Leichnams, sondern im Bedarfsfall ständig im Einsatz standen. Zudem war das Gewicht von Tragsesseln beachtlich ${ }^{307}$ und stellte in Verbindung mit dem Körpergewicht der zu transportierenden Person eine Last dar, die nur mit der entsprechenden körperlichen Konstitution, Ausdauer und Übung zu bewältigen war. Wohl nicht zuletzt auch aus Sicherheitsgründen griff man am Kaiserhof bei Sesselträgern auf zuverlässige Fachkräfte zurück, die schon seit längerer Zeit in ihrem Metier erprobt waren. Das gesundheitliche Risiko, dem sich etwa eine schwangere Fürstin und ihr ungeborenes Kind durch eine unsachgemäße Bedienung des Tragsessels ausgesetzt gesehen hätten, war zu hoch, um die Beförderung von Tragsesseln ungeübten Amateuren zu überlassen. Allerdings ließen sich auch durch den Einsatz fachkundiger Sesselträger Unfälle nicht zur Gänze ausschließen. Am 5. Januar I656 berichtet Kardinal Ernst Adalbert von Harrach von einem Unfall, der sich kurz zuvor in Wien ereignet hatte. Als sich der damals bereits stark gebrechliche Kaiser Ferdinand III. im Tragsessel zu den Jesuiten bringen ließ, brach plötzlich ein Trageholm seines Transportmittels. Der Kaiser stürzte aus dem Sessel, fiel zuerst auf die Knie, konnte sich mit den eigenen Händen gerade noch rechtzeitig abstützen und kam so mit dem Schrecken und ohne gröbere Verletzungen davon. ${ }^{308}$ Ein anderer überlieferter Unfall mit einem Tragsessel entstand nicht aufgrund von Materialermüdung, sondern durch die Pflichtvergessenheit eines Sesselträgers. Im Jahr I665 besuchte die Frau von Graf Pötting, dem kaiserlichen Botschafter am spanischen Hof, in Madrid eine Verwandte und ließ sich dabei von ihren Sesselträgern transportieren. Einer davon hatte durch übermäßigen Alkoholkonsum seine Sinne so stark benebelt, dass durch sein Verschulden der Tragsessel mitsamt der Gräfin zu Boden stürzte. Der Graf, der den Vor-

307 Erwähnt sei das Gewicht von zwei aus der ersten Hälfte des I8. Jahrhunderts stammenden Tragsesseln des Wiener Hofes. Der eine, ein offener Tragsessel (Kaiserliche Wagenburg Wien, Inv.-Nr. W 96, Abb. 15-16) wiegt samt Trageholmen 24,5 Kilogramm, der andere, ein Exemplar mit geschlossenem Sitzkasten und Verglasung (Kaiserliche Wagenburg Wien, Inv.-Nr. W 92), 78 Kilogramm. KHM, Kaiserliche Wagenburg, Inventar.

308 Keller/Catalano 2010 (wie Anm. 213), Bd. 6, S. i20. Auch der Bruch einer Tragstange einer päpstlichen sedia gestatoria ist überliefert, nämlich beim Einzug von Papst Julius II. I5IO in Bologna. MärTL 2000 (wie Anm. Io), S. I64. 
fall in seinem Tagebuch festhielt, streicht in diesem Zusammenhang nur hervor, dass er den Sesselträger bestrafte und anschließend aus dem Dienst entließ, nicht aber eine etwaige Verletzung seiner Gemahlin. ${ }^{309}$ Der Unfall dürfte demnach glimpflich für sie verlaufen sein.

Die Zahl der Hofsesselträger ${ }^{310}$ war im Lauf der Zeit starken Schwankungen unterworfen und von verschiedenen die Mitglieder der kaiserlichen Familie betreffenden Ereignissen und Faktoren beinflusst, allen voran Hochzeiten, Schwangerschaften, körperliche Gebrechen und Todesfälle. In den I620er und I630er Jahren belief sich die Zahl der kaiserlichen Sesselträger meist auf sechs, wobei nach dem Eintreffen von Infantin Maria Anna am Wiener Hof im Februar I63 I für mehrere Jahre zusätzlich auch für den königlichen Hofstaat die Existenz von fünf bis sechs Sesselträgern dokumentiert ist. Gegen Ende der I63oer Jahre wurde die Zahl der Sesselträger auf neun erhöht und blieb auch in den darauf folgenden Jahren etwa auf diesem Niveau. ${ }^{31}$ Am 3I. Juli I645 wurden drei Sesselträger entlassen, ${ }^{312}$ doch schon sieben Monate später, am I. März I646, als Kaiserin Maria Anna im fortgeschrittenen Stadium schwanger war, wurden sechs Sesselträger neu aufgenommen. Ihre Zahl belief sich im Frühling dieses Jahres auf insgesamt zehn. Nach dem unglücklich verlaufenen Ende der Gravidität - sowohl die Kaiserin als auch das neugeborene Kind überlebten die Geburt nicht - wurden die erst kurz zuvor in die Hofdienste genommenen sechs Sesselträger mit Ende Juli I646 wieder entlassen, da es für sie nun keine Verwendung mehr gab. ${ }^{313}$ Die Zahl der Sesselträger sank daraufhin auf vier und erreichte damit den tiefsten Stand seit Jahrzehnten. ${ }^{314}$ Nachdem der verwitwete Kaiser Ferdinand III. im Sommer des Jahres I648 erneut den Bund der Ehe eingegangen war, entstand schon bald darauf erneut der Bedarf an einer größeren Zahl von Sesselträgern. Mit I. Dezember I648 wurden drei Sesselträger neu aufgenommen, was möglicherweise mit dem Umstand zusammenhängt, dass sich bei der damals erst sechzehnjährigen Kaiserin Maria Leopoldine gegen Ende des Jahres I648 wohl erste Anzeichen einer Schwangerschaft bemerkbar machten. Am 7. August I649 brachte sie Erzherzog Karl Joseph zur Welt, verstarb selbst aber schon einige Stunden danach an den

309 "La condesa visitó a la Marquesa de Mondéjar su parienta, y se cayo con la silla por culpa de un enborrachado sillietero, al qual hiçe castigar y despedir." Nieto Nuño 1990-1993 (wie Anm. 272), Bd. I, S. 88.

3IO Einen Überblick dazu bietet die Tabelle in Kapitel 6.3.

3 II Vgl. ÖStA, HHStA, OMeA, SR, Bd. I86, fol. I84v-187r.

312 Johann Domenico Micajo, Daniele de Lorenzo und Johann Ottino. ÖStA, HHStA, OMeA, SR, Bd. I86, fol. I87r.

313 Die Namen dieser sechs Sesselträger waren Paul Falora, Thoma Prunela, Bartholome Scifano, Paulo Moratore, Francesco Fornaro und Lorentz Ridelo. ÖStA, HHStA, OMeA, SR, Bd. I86, fol. I85r-v.

314 Die in Kapitel 6.3 angegebene Zahl für I647 wird auch durch eine weitere Quelle unterstützt: ÖStA, HHStA, OMeA, SR, Bd. I86, fol. I84v-187r. 
Folgen der Geburt. Die Zahl der damals vorhandenen sieben Sesselträger wurde aufgrund des Ablebens der Kaiserin diesmal nicht reduziert und lag auch in den folgenden Jahren konstant bei sieben bis acht. Erst ab I655 wurden wieder vermehrt Sesselträger benötigt, da nicht nur für die dritte Gemahlin Ferdinands III., Eleonora Gonzaga (II.), Tragsessel bereitgestellt werden mussten, sondern auch für den zunehmend gebrechlicher werdenden Kaiser selbst. Einen vorläufigen Höchststand erreichte die Zahl der Sesselträger kurz vor dem Tod Ferdinands III. im Frühling I657, als insgesamt sechzehn Sesselträger in kaiserlichen Diensten standen. Vermutlich war die eine Hälfte von ihnen für die Bedienung des Kaisers und die andere Hälfte für die seiner Gemahlin abgestellt. Nach dem Tod des Kaisers wurden sämtliche Sesselträger entlassen. Neuaufnahmen fanden aller Wahrscheinlichkeit nach erst wieder statt, als Kaiser Leopolds I. erste Gemahlin, Margarita Teresa, Ende I666 in Wien eintraf. Für den Beginn des Jahres I667 lassen sich bereits wieder sieben Sesselträger im kaiserlichen Hofstaat nachweisen. Ab I675 stieg die Zahl der Sesselträger kontinuierlich an, bis schließlich I678 erneut sechzehn Sesselträger in kaiserlichen Diensten standen. Wie bereits an früherer Stelle ausgeführt wurde, lässt sich dies nur damit erklären, dass sich damals auch der Kaiser selbst im Tragsessel transportieren ließ. Bis I683 sank die Zahl der Sesselträger wieder auf elf und pendelte bis zum Ende des Jahrhunderts stets zwischen neun und zwölf. In den letzten Jahren der Regierung Leopolds I. verrichteten schließlich nur noch sechs bis acht Sesselträger Dienst im kaiserlichen Hofstaat. Seit I. April I699, also wenige Wochen nach der Hochzeit zwischen Joseph I. (I678-I7II) und der hannoveranischen Prinzessin Amalie Wilhelmine (I673-I742), lassen sich auch in einem königlichen Hofstaat erstmals seit vielen Jahrzehnten wieder Sesselträger nachweisen. Kurze Zeit später, nachdem sich bei Amalie Wilhelmine erste Anzeichen einer Schwangerschaft bemerkbar gemacht hatten, erhöhte man die Zahl der königlichen Sesselträger auf neun. Während der kurzen Regentschaft Josephs I. zwischen I705 und I7II lag die Zahl der kaiserlichen Sesselträger schließlich konstant bei elf.

Die starken italienischen Einflüsse bei der Einführung von Tragsesseln am Kaiserhof wurden bereits mehrfach erwähnt. Sie fanden auch bei der Herkunft der kaiserlichen Sesselträger ihren Niederschlag, denn unter ihnen stellten für viele Jahrzehnte Italiener eine dominante Gruppe. Parallelen zu diesem Phänomen finden sich in der Frühen Neuzeit auch in anderen Hofstallabteilungen, etwa bei den Läufern, die in der ersten Hälfte des I8. Jahrhunderts ebenfalls vorwiegend aus Italien rekrutiert wurden, ${ }^{315}$ bei der Gruppe der Kutscher, die in den $1560 e r$ Jahren meist aus Ungarn stammten, ${ }^{316}$ oder bei den Jägern der Vénerieab-

315 Vgl. Irene KubisKa-Schard/Michael Pölzl, Die Karrieren des Wiener Hofpersonals I7II-I765. Eine Darstellung anhand der Hofkalender und Hofparteienprotokolle (Forschungen und Beiträge zur Wiener Stadtgeschichte 58, Innsbruck/Wien/Bozen 2013), S. 394 f.

316 Vgl. Mario DöвERL, Unterwegs mit dem Tafelgeschirr. Der höfische „Marendwagen“, ein verges- 
teilung, deren Mitglieder bis zur Auflösung ihrer Stallpartei im Jahr I788 vor allem französische Namen trugen. ${ }^{317}$ Waren die ersten Sesselträger am Kaiserhof anfangs noch ausschließlich Italiener, reduzierte sich deren Anteil bis Anfang des I8. Jahrhunderts sukzessiv. Im Jahr I639 lassen immerhin acht von neun Namen der damals dienenden kaiserlichen Sesselträger eine italienische Herkunft annehmen, ${ }^{318}$ I 657 war dies immerhin noch bei neun oder zehn von sechzehn Personen der Fall, ${ }^{19}$ Ende der I67oer Jahre bei sechs bis zehn von vierzehn, ${ }^{320}$

sener Fahrzeugtyp der Spätrenaissance. In: Jahrbuch des Kunsthistorischen Museums Wien I3-I4 (2011/12), S. 162-175, hier S. I66 f.

317 Vgl. Obersthofmeister Georg Adam Fürst von Starhemberg, Wien I788 September 19. ÖStA, HHStA, OStA, SR, Bd. 163, 206v-207r.

318 Die Liste der am 31. Mai 1639 in kaiserlichen Diensten stehenden Sesselträger führt folgende Namen an: Johann Dominico Micaro (andernorts auch „Micajo“), Johann Ottino, Jacomo Tromet (andernorts auch „Trompeta“), Pietro Anthoni Daniel, Bartholome Rabalio, Domenico Conteldeno (andernorts auch „Contadino“, „Contarini“, „Conterdini“ beziehungsweise „Contardino“), Anthoni Ridello (andernorts auch „Ridelo“ oder „Ridella“), Bartholome Franzario (andernorts auch „Francoria“, „Francoia“ oder „Fransoria“) und Hans Ritsch (andernorts „Nitsch“). ÖStA, FHKA, NÖHA, W 6r/a/3, Fasz. „Stallmeister“, fol. 465v, 462r.

319 Die Namen der mit Stichtag I. März I657 in kaiserlichen Diensten stehenden Sesselträger lauten: Domenico Contardino (für Namensvarianten siehe Anm. 318), Bartholome Francoria (für Namensvarianten siehe Anm. 318), Johann Fasch (andernorts "Johann Sascia“ - er scheint demnach Italiener gewesen sein), Sebastian Queolo, Augustin Putaro, Nicola Balestraza (auch „Palestrazi“, „Palestrazo“, „Palastraza“, „Ballastraza“, „Baletrazzo“ oder „Bollestras“), Francesco Mercante, Martin Caroza, Johann Falso, Andreas Imperialis (Herkunft unklar), Hans Geörg Hendl, Hans Wahl, Lorentz Raab, Hans Starck, Balthasar Maller und Peter Kaltenbruner. ÖStA, HHStA, OMeA, SR, Bd. I86, fol. $184 \mathrm{~V}-187 \mathrm{r}$.

320 Eine undatierte, aber wohl von 1679 stammende Liste der kaiserlichen Sesselträger erwähnt folgende Namen: Nicola Palestrazi (für Namensvarianten siehe Anm. 319), Nicola Palestrazi der Jüngere, Johann Bapt.a Faggiani (andernorts auch „Giovanni Battista Fagiani“ oder „Fagiano“), Georgio Bianchi (andernorts auch „Georgio Pianca“), Pantelione Remessaro (andernorts auch „Pantaeleo Remerzani“ oder „Remerzale), Valerio Riva, Johann Adami (Herkunft unklar), Johann Dornbihler (andernorts auch „Thurnpüchler“, Herkunft unklar), Franz Adamy (Herkunft unklar), Peter Dornpichler (andernorts auch „Thornpüchler“", Herkunft unklar), Hans Jörg Hendl (andernorts auch „Hans Geörg Hendl“), David Amber (andernorts auch „Dävit Ahamber“), Daniel Seißthal (andernorts auch „Schauställ“ oder „Säustahl“) und Johann Obermayr (andernorts auch „Obermarcher"). ÖStA, AVA, FA Harrach, Akten, K. 2926, unfol. Um I690 stellte ein kaiserlicher Sesselträger namens „Pietro Torre Pillora“ gemeinsam mit vier weiteren Italienern ein Bittgesuch. Möglicherweise handelte es sich beim deutsch klingenden Namen „Peter Dornpichler“ um eine ungelenke Übersetzung des Namens „Pietro Torre Pillora“, was zur Folge hätte, dass nicht nur Peter, sondern auch „Johann Dornbihler" den Italienern zuzurechnen wäre. Kaiserliche Sesselträger Giorgio Bianchi, Gio. Batta Fagiani, Pietro Torre Pillora, Steffano Scrivani und Gio. Batta. Firpo an Oberststallmeister Ferdinand Bonaventura Graf Harrach, undat. (aber um I690). ÖStA, AVA, FA Harrach, Akten, K. 2517, unfol. 
I704 bei drei bis vier von sieben ${ }^{321}$ und in den Jahren I709/IO schließlich nur noch bei vier von elf. ${ }^{322}$

Aus welchen Regionen und Städten der Apenninen-Halbinsel aber stammten die italienischen Sesselträger am Kaiserhof? Die genaue Herkunft lässt sich nur in Einzelfällen eruieren, etwa, wenn in Bittgesuchen von Hofdienern eigens darauf hingewiesen wird. Fallweise wurde die Herkunft von kaiserlichen Sesselträgern auch bereits in vorangegangenen Kapiteln erwähnt. So waren etwa die vier Sesselträger, die I6I5 gemeinsam mit einem Tragsessel aus Florenz an den Kaiserhof gelangten, Genuesen. ${ }^{323}$ Kaiserin Eleonora Gonzaga (I.), die sich I623 von ihrem Bruder einen Tragsessel aus Mantua wünschte, bat ihn, ihr entweder sechs genuesische oder sechs neapolitanische Sesselträger mitzusenden, wobei wir in Unkenntnis darüber sind, woher die sechs nach Wien geschickten Personen letztlich tatsächlich stammten. ${ }^{324}$ Der Hofsesselträger Domenico Contarini ${ }^{325}$ erhielt am 29. Dezember I650 90 Gulden rückerstattet, die er für die Anreise von zwei Männern aus Genua ausgelegt hatte, die als Sesselträger für den Kaiserhof bestimmt waren. ${ }^{326}$ Dabei handelte es sich offenbar um Giovanni Battista Solare und Francesco Fornero, die mit I. Oktober I650

32I Während die Namen der italienischstämmigen Sesselträger im gedruckten Hofstaatsverzeichnis von 1704 in Antiquaschrift vermerkt sind (Gio. Battista Conti, Antonio Pacifici und Francesco Carigeri), wurden die Namen der übrigen Sesselträger in Frakturschrift gedruckt (Daniel Säustahl, Peter Thornpüchler, Johann Matthias Spacirer und Joachim Müller). Peter Thornpüchler, dessen Name ebenfalls in Frakturschrift gesetzt ist, könnte jedoch italienischer Herkunft gewesen sein. Siehe dazu Anm. 320. Käyserlicher und Königlicher wie auch Ertz-Hertzoglicher und dero Residentz-Stadt Wienn Staats- und Stands-Kalender / Auff das jahr M.DCCIV. Mit einem noch nie dergleichen gesehenen Schematismo geziert (Wien o.J.), S. I9I f. Im damaligen königlichen Hofstaat Josephs I. weisen die Namen von vier der sieben Sesselträger auf eine italienische Herkunft hin. Ebenda, S. 205.

322 Keine Italiener waren offensichtlich Frantz Müllauer, Mathias Herschitz, Erhard Wissing, Joachim Müllner, Philipp Dörffler, Johann Mathias Spacirer und Caspar Boschman. Staat des Käyserl. Hoffs / von Jahr 1709. biß I7IO. Ehedessen / unter dem Titl Käyserlichen und Königlichen / wie auch Ertz-Hertzoglichen / dan dero Residenz Stadt Wienn / Staats- u. Stands-Kalender mit einem noch nie dergleichen gesehenen Schematismo, heraus gegeben. Anderter Theil (Wien o.J.), o.S. Zwar sind im gedruckten Verzeichnis für I709/Io nur die Namen von Giovanni Battista und Francesco Fagiani in Antiquaschrift gedruckt und damit als Italiener hervorgehoben, doch dürfte auch Niclas Brandi (andernorts auch „Nicola Brandi“ genannt) und Johann Banquier (in anderen Verzeichnissen ist ein "Giuseppe Banquier" erwähnt, was auf einen italienischen Ursprung der Familie schließen lässt), deren Name im gedruckten Hofstaatsverzeichnis in Frakturschrift gesetzt ist, italienischstämmig gewesen sein. Ebenda.

323 Vgl. Kapitel 2.2.

324 Vgl. Kapitel 2.3.

325 Für Namensvarianten siehe Anm. 318.

326 ÖStA, FHKA, HZAB, Bd. 96 II, fol. 342r (I650 Dezember 29). 
in den kaiserlichen Hofstaat eingetreten waren. ${ }^{327}$ Wir können davon ausgehen, dass nicht nur Solare und Fornero aus Genua stammten, sondern dass dies auch für Contarini zutraf. Ebenso Genuese war Giorgio Bianchi, von dem sich mehrere undatierte Bittgesuche aus der von I677 bis I699 währenden Amtszeit des Oberststallmeisters Ferdinand Bonaventura Graf Harrach erhalten haben. In einem der Schreiben ersuchte Bianchi Kaiser Leopold I., zwei seiner Verwandten aus Genua die Aufnahme in den Hofdienst zu ermöglichen. Diese seien eigens nach Wien gekommen, weil ihnen dort von nicht näher bezeichneten Personen Sesselträgerstellen in Aussicht gestellt worden waren. Letztlich hätten die potentiellen Dienstgeber dieses Angebot aber wieder zurückgezogen, weshalb die beiden Genuesen nun ohne Arbeit und Geld dastünden. Alles, was sie erlernt hätten, so Bianchi, sei der Beruf des Sesselträgers. ${ }^{328}$ Ob Bianchi mit seiner Bitte beim Kaiser Gehör fand, ist nicht überliefert. Zu einem späteren Zeitpunkt bat Bianchi Oberststallmeister Harrach, sich beim Kaiser für ihn selbst einzusetzen, damit er eine Abfertigung in der Höhe von Iooo Gulden erhalte und nach siebzehn langen, kräftezehrenden Jahren als kaiserlicher Sesselträger in seine Heimat zurückkehren dürfe, wo er in Frieden zu sterben wünsche. ${ }^{329}$ Ebenfalls aus Genua stammte der in den I670er Jahren als kaiserlicher Sesselträger dienende Remerzani, der beim kaiserlichen Oberststallmeister vorstellig wurde, weil er fünf Jahre nach seiner Ankunft in Wien noch immer nicht das ihm versprochene Hofquartier erhalten hatte. ${ }^{330}$ Giovanni Battista Conti und Antonio Pacifici hingegen waren Mailänder. In einem Bittgesuch an Kaiser Leopold I. erwähnten sie ihren bisherigen Karriereverlauf. Für sechs Jahre hätten sie beim I682 verstorbenen Kardinal Friedrich von Hessen-Darmstadt als Sesselträger gedient und hätten zuvor bereits achtzehn Jahre lang in Rom als Sesselträger im Dienst habsburgtreuer Kardinäle und anderer hochrangiger Persönlichkeiten gestanden. Nun stellten sie den Antrag, bei der Kaiserin als Sesselträger dienen zu dürfen. ${ }^{331}$ Offenbar wurde dem Verlangen von Conti und Pacifici nachgekommen, denn im gedruckten Hofstaatsverzeichnis für das Jahr I704 sind die beiden unter den kaiserlichen Sesselträgern

327 ÖStA, HHStA, OMeA, SR, Bd. I86, fol. I85v. Fornero (andernorts auch „Fornaro“) hatte bereits I646 für fünf Monate als Sesselträger am Kaiserhof gedient, war am Ende Juli I646 entlassen worden und danach offenbar nach Genua zurückgekehrt. Ebenda, fol. I85r.

328 Kaiserlicher Sesselträger Giorgio Bianchi an Leopold I., undat. (aber zwischen I677 und I699). ÖStA, AVA, FA Harrach, Akten, K. 25I5, unfol.

329 Kaiserlicher Sesselträger Giorgio Bianchi an Oberststallmeister Ferdinand Bonaventura Graf Harrach, undat. (aber wohl knapp nach I690). ÖStA, AVA, FA Harrach, Akten, K. 2528, unfol.

330 Kaiserlicher Sesselträger Pantaleo Remerzani an Oberststallmeister Ferdinand Bonaventura Graf Harrach, undat. (aber zwischen 1677 und I679). ÖStA, AVA, FA Harrach, Akten, K. 25I5, unfol.

33I Giovanni Battista Conti und Antonio Pacifici, „Sediari Milanesi“, an Kaiser Leopold I., undat. (aber zwischen 1682 und I699). ÖStA, AVA, FA Harrach, Akten, K. 25I5, unfol. 
angeführt. ${ }^{332}$ So lässt sich anhand der vorliegenden Informationen zur Herkunft der kaiserlichen Sesselträger zusammenfassend festhalten, dass die Gruppe der Italiener zahlenmäßig von Genuesen dominiert war, auch wenn es vereinzelt Mailänder und möglicherweise auch Neapolitaner unter ihnen gab.

Am zuvor erwähnten Beispiel Giorgio Bianchis war bereits zu sehen, dass sich aus Italien stammende Sesselträger bemühten, Verwandte und Bekannte aus ihrer Heimat nachkommen zu lassen und diese ebenfalls als Sesselträger am Kaiserhof unterzubringen. Für ein derartiges Vorgehen gibt es noch weitere Exempel. ${ }^{333}$ So schrieb etwa Giovanni Battista Fagiani an Oberststallmeister Harrach, dass er am I. Oktober I679 den Kaiser darum gebeten habe, einen seiner Brüder als Sesselträger aufzunehmen. Ihm sei daraufhin beschieden worden, dass dies frühestens nach dem Freiwerden einer derartigen Stelle möglich sei. Nachdem sich nun aber durch den Tod von „Pantaleo Remerzale“, der stets gemeinsam mit Fagiani Sesselträgerdienste verrichtet hatte, eine Vakanz ergeben habe, ersuchte er Harrach, diese Stelle seinem Bruder zu verleihen. Dieser könne, so Fagiani, im Falle einer positiven Erledigung sogleich - vermutlich aus Italien - die Reise nach Wien antreten. ${ }^{334}$ Giovanni Battista Fagianis Intervention für seinen Bruder war vermutlich erfolgreich, denn in den Hofstaatsverzeichnissen schien seit I. Juli I699 unter den Sesselträgern König Josephs I. ein Francesco Fasan beziehungsweise Fagiani auf. ${ }^{335}$ Maria Graf, die aus Italien stammende Witwe des verstorbenen kaiserlichen Wagenmeisters Martin Graf, wurde beim Kaiser vorstellig, da sie vom Plan gehört habe, neue Hofsesselträger aufzunehmen und dafür auch Männer aus Italien kommen zu lassen. Graf empfahl dem Kaiser ihren Schwiegersohn Giovanni Battista Tomasdine. ${ }^{336}$ Da Tomasdine in keinen Sesselträgerlisten aufscheint, ging der Wunsch seiner Schwiegermutter vermutlich nicht in Erfüllung.

Mehr Glück war offenbar Joachim Müller beschieden, der bei der Gemahlin von Oberststallmeister Ferdinand Bonaventura Graf Harrach als Lakai und Sesselträger diente. Sein Beispiel illustriert, dass auch eine Stelle als Bediensteter im privaten Hofstaat des Oberststallmeisters eine Eintrittskarte in den Hofsesselträgerdienst sein konnte. Die verwitwete Maria Susanna Pachern wandte sich schriftlich an Harrach, berichtete ihm von

332 Käyserlicher und Königlicher wie auch Ertz-Hertzoglicher und dero Residentz-Stadt Wienn Staats- und Stands-Kalender / Auff das jahr M.DCCIV. Mit einem noch nie dergleichen gesehenen Schematismo geziert (Wien o.J.), S. 192

$333 \mathrm{Zu}$ diesem Phänomen siehe allgemein Kubiska-Schard/Pölzl 2013 (wie Anm. 315), S. I94-198.

334 Kaiserlicher Sesselträger Giovanni Battista Fagiani an Oberststallmeister Ferdinand Bonaventura Graf Harrach, undat. (aber zwischen 1677 und 1699), ÖStA, AVA, FA Harrach, Akten, K. 2517, unfol.

335 ÖStA, HHStA, OMeA, SR, K. I88, fol. 264v.

336 Maria Graf an Kaiser Leopold I., undat. (aber zwischen I677 und 1699), ÖStA, AVA, FA Harrach, Akten, K. 2515, unfol. 
ihrer finanziellen Notlage und davon, dass Müller ihr versprochen habe, sie zu heiraten, sollte er als Sesselträger am Kaiserhof aufgenommen werden. Da erst kürzlich der Hofsesselträger Hans Georg Hendl verstorben und deshalb ein Planposten frei geworden sei, bat die Witwe den Oberststallmeister, Müller die Aufnahme in den Hofdienst zu ermöglichen. ${ }^{337}$ Offenbar gelang es der Bittstellerin, ihren Wunsch durchzusetzen, da Joachim Müller im kaiserlichen Hofstaatsverzeichnis von I704 als Sesselträger gelistet ist.

Eine andere interessante Berufslaufbahn schilderte der kaiserliche Sesselträger Johann Thurnpüchler ${ }^{338}$ in einem Schreiben an Leopold I., in dem er um finanzielle Unterstützung für eine Wallfahrt nach Tirol ersuchte. Er habe, so Thürnpüchler, seit insgesamt fünfunddreißig Jahren als Sesselträger gedient, lange Zeit davon am Innsbrucker Hof bei Erzherzog Ferdinand Karl (I628-I662), bei dessen Bruder, Erzherzog Sigismund Franz (I630I665) und bei Ferdinand Karls Witwe Anna de' Medici (I6I6-I676), bis er schließlich an den Wiener Hof wechselte, wo er nun seit neun Jahren der Kaiserin zugeteilt sei. ${ }^{339}$ Johann Thurnpüchler war nicht der einzige Sesselträger am Innsbrucker Hof, der nach dem Tod von Anna de' Medici vom Wiener Hof übernommen wurde. Derselbe Ortswechsel und Karrieresprung ist auch für vier andere Sesselträger dokumentiert, nämlich für Johann Adami, Johann Obermarcher, ${ }^{340}$ Franz Adami und Peter Thurnpüchler. ${ }^{34 \mathrm{I}}$ Diese Beispiele demonstrieren, dass Sesselträger auch über Zwischenstationen an Höfen habsburgischer Nebenlinien zu einer Anstellung am Kaiserhof gelangen konnten. Aber auch der Sesselträgerdienst im Hofstaat eines designierten Thronfolgers konnte als relativ sicheres Sprungbrett für einen Aufstieg in den kaiserlichen Hofstaat gelten. So wurden beispielsweise vier der fünf Sesselträger, die I635 im Hofstaat König Ferdinands III. tätig waren, nach dessen Übernahme der Kaiserwürde im Jahr I637 als Sesselträger in den kaiserlichen Hofstaat übernommen. ${ }^{342}$ Ähnliches lässt sich bei der Regierungsübernahme Josephs I. im Jahr I705 beobachten. Alle acht Sesselträger, die sich zuvor in seinem königlichen Hofstaat befunden hatten, wurden nach seiner Regierungsübernahme zu kaiserlichen Sesselträgern ernannt. ${ }^{343}$

337 Maria Susanna Pachnerin an Oberststallmeister Ferdinand Bonaventura Graf Harrach, undat. (aber zwischen 1677 und I699), ÖStA, AVA, FA Harrach, Akten, K. 2517, unfol.

338 Für Namensvarianten siehe Anm. 320.

339 Kaiserlicher Sesselträger Johann Thurnpüchler an Kaiser Leopold I., undat. (aber um I685), ÖStA, AVA, FA Harrach, Akten, K. 25I7, unfol.

340 Andernorts auch „Obermayr".

34I ÖStA, FHKA, NÖHA, K. 790, fol. I356r; ÖStA, AVA, FA Harrach, Akten, 796, Konv. „Oesterreich, Hofstaat. Gestütte Lippizza und Kladrub und Oberststallmeisteramt.", fol. 4Ir.

342 ÖStA, HHStA, OMeA, SR, K. 76, Konv. 5, unfol.; ÖStA, HHStA, OMeA, SR, Bd. I86, fol. I84v-I87r.

343 Käyserlicher und Königlicher wie auch Ertz-Hertzoglicher und dero Residentz-Stadt Wienn Staats- und Stands-Kalender / Auff das jahr M.DCCIV. Mit einem noch nie dergleichen gesehe- 
Gemeinsam ist sämtlichen angeführten Beispielen zu den Karriereverläufen der hohe Spezialisierungsgrad der Sesselträger. Um als solcher am Kaiserhof aufgenommen zu werden, musste man sich offenbar bereits zuvor andernorts in diesem Beruf bewährt haben. Dies galt zumindest bis Anfang des I8. Jahrhunderts. Danach änderte sich das Karrieremodell für Hofsesselträger. Von I7ı6 an wurden diese häufig aus den Reihen der kaiserlichen Heiducken rekrutiert. ${ }^{344}$ Der Grund für diese Umstellung ist bislang nicht erforscht. Es handelte sich dabei jedoch um einen internationalen Trend, denn auch an anderen Höfen, etwa jenen Bayerns, Schwedens, Dresdens oder Weimars, wurden Heiducken als Sesselträger eingesetzt. ${ }^{345}$ Unberührt von dieser offenbar I7I6 am Kaiserhof eingeführten Neuerung blieb jedoch die Tatsache, dass eine Anstellung als kaiserlicher Sesselträger kein Sprungbrett für eine andere Funktion innerhalb des Hofstaates gewesen zu sein scheint. Wer am Kaiserhof einmal als Sesselträger diente, blieb dies bis zu seiner Entlassung, seiner Versetzung in den Ruhestand beziehungsweise bis zu seinem Tod.

Von I682 datiert die einzige bekannte Dienstvorschrift für kaiserliche Sesselträger. ${ }^{346} \mathrm{Im}$ Zentrum dieser sogenannten „Sesseltrager Ordnung“, die von Oberststallmeister Ferdinand Bonaventura Graf Harrach unterzeichnet wurde, stehen organisatorische und disziplinäre Richtlinien, nicht jedoch praktische Anweisungen. Anlass für die Erstellung des Regelwerks war, wie zu Beginn desselben zu lesen ist, die Unzufriedenheit des Kaisers mit seinen Sesselträgern. Um eine Verbesserung der Situation herbeizuführen, sollten die Ses-

nen Schematismo geziert (Wien o.J.), S. 205; Staat des Käyserl. Hoffs / vom Jahr 1706. biß I708. Ehedessen / unter dem Titl Käyserlichen und Königlichen / wie auch Ertz-Hertzoglichen / dan dero Residenz Stadt / Wienn / Staats- u. Stands-Kalender / Mit einem noch nie dergleichen gesehenen Schematismo heraus gegeben. Erster Theil (Wien o.J.), o.S.

344 Vgl. Irene Kubisкa, Der kaiserliche Hof- und Ehrenkalender zu Wien als Quelle für die Hofforschung. Eine Analyse des Hofpersonals in der Epoche Kaiser Karls VI. (I7II-I740), 2 Bde. (ungedr. Diplomarbeit, Universität Wien 2009), Bd. 2, S. 70-I7I.

345 Claus Heinrich BiLl, Kulturgeschichte der Portechaise. Soziale und kulturelle Aspekte des Sänftenwesens (München 2013), S. 9I-93.

346 Eine Transkription der Sesselträgerordnung ist in Kapitel 6.2 abgedruckt. Zu Dienstinstruktionen am Kaiserhof im Allgemeinen siehe vor allem Martin Scheutz/Jakob Wührer, Dienst, Pflicht, Ordnung und "gute policey“. Instruktionsbücher am Wiener Hof im 17. und I8. Jahrhundert. In: Pangerl/Scheutz/Winkelbauer 2007 (wie Anm. 139), S. I5-228; Jakob Wührer/Martin Scheutz, Zu Diensten Ihrer Majestät. Hofordnungen und Instruktionsbücher am frühneuzeitlichen Wiener Hof (Quelleneditionen des Instituts für Österreichische Geschichtsforschung 6, Wien/München 20II). Kutscher bilden eine Dienerkategorie, die jener der Sesselträger in vielerlei Hinsicht vergleichbar ist. Zu Verhaltensregeln für Kutscher im Spanien des frühen I7. Jahrhunderts und zu deren Reputation in literarischen Werken siehe Alejandro López Álvarez, El oficio de cochero en la sociedad cortesana a comienzos del siglo XVII: disciplina e integración social. In: Juan Jesús Bravo Caro/Juan Sanz Sampelayo (Hg.), IX Reunión Científica de la Fundación Española de Historia Moderna. Universidad de Málaga, 2 Bde. (Málaga 2009), Bd. 2, S. 903-92I. 
selträger auf die neue Vorschrift vereidigt werden. Bei Missachtung der darin festgelegten Regeln drohte ihnen eine Bestrafung, die im äußersten Fall die Entlassung bedeutete.

Im Text ist festgelegt, dass „Nicolaus Ballastraza“"347 als Ältester allen übrigen Sesselträgern vorgesetzt sein sollte und diese seinen Dienstanweisungen Folge zu leisten hatten. Ballastraza selbst musste täglich vom Oberststallmeister dessen Anordnungen entgegennehmen und anschließend das ihm unterstellte Personal instruieren. Leisteten einzelne Sesselträger Dienst, so hatte auch Ballastraza stets persönlich anwesend zu sein, damit er den Einsatz beaufsichtigen und gegebenenfalls unverzüglich einschreiten konnte. Vom Tragedienst war er jedoch entbunden und musste nur in Ausnahmefällen selbst Hand anlegen. War Ballastraza krank oder hatte er dienstfrei, ernannte der Oberststallmeister für ihn einen zwischenzeitlichen Stellvertreter unter den Sesselträgern. Zu den zentralen Aufgaben Ballastrazas zählte es, für Disziplin unter den ihm Untergebenen zu sorgen. Bei Streitigkeiten oder auftretendem Ungehorsam oblag es ihm zunächst selbst, eine Ermahnung auszusprechen. Brachte eine solche nicht das gewünschte Ergebnis, hatte er Meldung an den Oberststallmeister zu erstatten, der dann eine angemessene Strafe für die Schuldigen festlegte. Da der Dienst für die Sesselträger mit großen körperlichen Anstrengungen verbunden war, mussten regelmäßige Regenerationsphasen für sie eingeplant werden. Hierfür wurden sie in zwei Gruppen eingeteilt, wobei jeweils alternierend die eine Gruppe für einen Tag im Einsatz war, während die andere dienstfrei hatte und sich erholen konnte. Nahm der Kaiser einen Landaufenthalt, durfte kein Sesselträger verreisen, ohne zuvor die Erlaubnis des Oberststallmeisters und Ballastrazas eingeholt zu haben. In einem solchen Fall musste ein Teil von ihnen den Kaiser auf der Reise beziehungsweise zum Séjourort begleiten und der andere am Hof verbleiben, um gegebenenfalls dort Sesselträgerdienste zu verrichten. Für den Fall, dass die Kaiserin Sesselträgerdienste in Anspruch nehmen wollte, war ganz analog zu verfahren, denn auch da mussten sich sämtliche Sesselträger

347 Sein Name wird in verschiedenen Quellen ganz unterschiedlich geschrieben. Siehe dazu Anm. 319. Ballastraza war am I. Mai I654 als kaiserlicher Sesselträger aufgenommen und am 30. Juni I657, kurz nach dem Ableben Kaiser Ferdinands III., wieder entlassen worden. In den Jahren I660 und I662 ist er als Sesselträger am erzherzoglichen Hof in Innsbruck nachweisbar. TLA, Hs. 1965, fol. I25r; TLA, Ambraser Memorabilien I 173, fol. I8r. Wann genau Ballastraza anschließend wieder in den kaiserlichen Hofdienst eintrat, ist unbekannt. Im Hofzahlamtsbuch von 1685 ist seine Witwe Catarina erwähnt, was bedeutet, dass er spätestens in jenem Jahr verstarb. ÖStA, FHKA, HZAB, Bd. 130, fol. 244v-245r. Von seiner Witwe ist auch ein undatiertes Bittgesuch an den Kaiser erhalten, das sie circa eineinhalb Jahre nach dem Tod ihres Mannes verfasste und in dem sie davon berichtet, dass ihr verstorbener Mann zweiunddreißig Jahre lang dem Kaiserhaus als Sesselträger gedient habe. Sie selbst, so die Witwe, sei arm, alt und krank, habe drei Söhne und drei Töchter, von denen zwei unverheiratet seien und deshalb ihre Unterstützung benötigten. Da sie selbst Italienerin sei, habe sie in Wien keine Verwandten, die ihr helfen könnten. „Catarina Baletrazza“ an Kaiser Leopold I., undat. (aber ca. I685), ÖStA, AVA, FA Harrach, Akten, K. 2517, unfol. 
bereithalten, damit jeweils eine Gruppe der Kaiserin und die andere dem Kaiser zur Verfügung stand. Damit sich die älteren und schwächeren Sesselträger gleichmäßig auf beide Gruppen verteilten, wurde jeweils zwei kräftigen Personen eine nur noch bedingt einsatzfähige zugeteilt, welche die eigentliche Arbeit den stärkeren Männern überließ und nur im Bedarfsfall aushalf. Dabei spielte zwar auch der Gedanke eine Rolle, alternde Sesselträger möglichst lange im Dienst zu halten, im Vordergrund stand dabei aber explizit die Sicherheit der im Tragsessel transportierten Mitglieder der kaiserlichen Familie. Um diese zu gewährleisten, wurde in der Dienstvorschrift auch ausdrücklich darauf hingewiesen, dass den Sesselträgern übermäßiger Alkoholkonsum und das anschließende Fernbleiben vom Dienst bei strenger Strafe verboten sei. Damit die physische Nähe zum Monarchen, die der Sesselträgerdienst zwangsläufig mit sich brachte, nicht ungebührend missbraucht wurde, war es den Sesselträgern untersagt, ungefragt das Wort an den Kaiser zu richten, um persönliche Anliegen vorzubringen oder Dienstanweisungen zu erbitten.

Eine Frage, die sich anhand der Dienstvorschrift von I682 nicht klären lässt, ist, wie viele Personen am Wiener Hof gemeinhin für den Transport eines Tragsessels abgestellt wurden. Während auf mehreren bildlichen Darstellungen (Abb. 6-8, IO-I2) 348 $^{8}$ kaiserlicher Tragsessel jeweils zwei Sesselträger zu sehen sind, weisen schriftliche Quellen darauf hin, dass am Kaiserhof fallweise auch vier ${ }^{349}$ bis sechs ${ }^{350}$ Sesselträger einen einzigen Tragsessel

348 Obwohl auf Abb. 6 nur der vordere Sesselträger zu erkennen ist, beförderten insgesamt wohl zwei Personen den Tragsessel. Auf der Einzugsdarstellung von I666 (Abb. 9) sind gar keine Sesselträger dargestellt. Abb. I3 erlaubt keine sichere Aussage zur Zahl der Sesselträger. Während an den vorderen Trageholmen kein Sesselträger zu sehen ist, lässt die Darstellung unklar, ob an der Rückseite ein oder zwei Sesselträger das Vehikel bedienen.

349 In der im „Theatrum Europaeum“ abgedruckten Beschreibung des Einzugs der kaiserlichen Braut Margarita Teresa in Wien im Jahr 1666 ist festgehalten, dass ihr leerer Tragsessel von vier kaiserlichen Sesselträgern transportiert worden sei. Theatrum Europaeum, Bd. Io (Frankfurt a. M. 1677), S. 193 .

350 Hierfür seien vier Beispiele erwähnt: Der Herzog von Mantua schickte seiner Schwester, Kaiserin Eleonora Gonzaga (I.), im Jahr I623 einen Tragsessel samt sechs Sesselträgern nach Wien. Aus dem Begleittext einer rund zwei Jahrzehnte älteren Zeichnung geht hervor, dass am Hof der Gonzaga stets sechs Männer, „die ale zeit umb wechslen“, den Tragsessel des Herzogs beförderten. Siehe dazu Kapitel 2.3 und Abb. 5. Vermutlich standen auch die sechs Sesselträger der Kaiserin wie jene am Hof der Gonzaga stets gleichzeitig im Einsatz. Ein anderes Beispiel stammt von Ende des 17. Jahrhunderts. Am 19. Februar I697 ersuchte Kaiser Leopold I. seinen Oberststallmeister Graf Harrach, einer im Hoftheater veranstaltete Komödie beizuwohnen. Obwohl Harrach aufgrund heftiger Rückenschmerzen lieber auf diesen Theaterbesuch verzichtet hätte, sah er sich schließlich doch gezwungen, an diesem gesellschaftlichen Ereignis teilzunehmen, und ließ sich „durch 6 kay[serliche] sesseltrager naher hoff tragen“. ÖStA, AVA, FA Harrach, Hs. 134, S. 40. Beim Hervorgang nach der Geburt von Erzherzog Leopold Johann im Jahr 1716 trugen sechs kaiserliche Sesselträger den Tragsessel, in dem die Aja und der junge Prinz befördert wurden (siehe Anm. 192). 
beförderten. Bei einer Zahl von vier Sesselträgern lässt sich noch am ehesten annehmen, dass an jedem der vier Enden der Trageholme jeweils ein Mann anpackte. Fraglich ist hingegen, wie man sich die Arbeitsteilung bei sechs Sesselträgern vorstellen kann. Möglicherweise standen auch in einem solchen Fall nur vier Männer gleichzeitig im Trageeinsatz, während zwei weitere Bedienstete neben dem Sessel hergingen, um der transportierten Person beim Auf- und Absteigen behilflich zu sein und um ihre müde gewordenen Kollegen im Bedarfsfall abzulösen.

\section{Die Einführung von Miettragsesseln in Wien}

Bei der Einführung von Miettragsesseln war die kaiserliche Residenzstadt Wien im internationalen Vergleich ein Nachzügler. In anderen europäischen Machtzentren waren derartige öffentliche Verkehrsmittel schon seit langer Zeit verbreitet, als einem Kammerdiener des Grafen Kaunitz namens Michel de la Place im Jahr I689 das erste kaiserliche Privileg verliehen wurde, Tragsessel in Wien gegen Bezahlung bereitzustellen. Zwar ist weder das Privileg erhalten noch sein genauer Wortlaut bekannt, doch lassen Schreiben ${ }^{351}$, die rund um die Ausstellung dieses Dokuments verfasst wurden, keine Zweifel daran, dass es zu einem unbekannten Zeitpunkt zwischen 5. August und 2I. Oktober I689 tatsächlich in Kraft trat. Aus einem Gutachten, das im Vorfeld vom Bürgermeister und vom Stadtrat Wiens eingefordert wurde, geht deutlich hervor, dass die Widerstände gegen die Einführung von Miettragsesseln beträchtlich waren. Im Gutachten wird einerseits betont, dass die bürgerlichen Wirte und alle anderen Personen, die Mietwagen unterhielten, besorgt seien, dass ihnen durch Miettragsessel finanzielle Nachteile entstehen könnten. Andererseits wird darin aber auch bezweifelt, dass für ein derartiges neues Gewerbe, das bisher „niemahlen alhier practicirt“ wurde, überhaupt die nötige Geschäftsgrundlage vorhanden sei: Die hohen und mittleren Stände würden weiterhin ihre eigenen Wagen verwenden, ausländische Adelige, die in Wien weilten, würden auch in Zukunft auf Mietkutschen zurückgreifen, und schließlich würden sich Bürger sowie Handwerker durch die Neuerung nicht davon abbringen lassen, weiterhin zu Fuß zu gehen. Wenn sich schließlich auch noch der Hofstaat außerhalb Wiens aufhielte, würde das Geschäft vollends zum Erliegen

Ähnliches wird vom Hervorgang Maria Theresias nach der Geburt des späteren Kaisers Joseph II. im Jahr 174I berichtet. Dabei wurden der Erzherzog und seine Aja in einem von sechs königlichen Sesselträgern beförderten Tragsessel von der Retirade zur Augustinerkirche gebracht. ÖStA, HHStA, ZA, Prot. I8, fol. 84v-85r.

35I Einliegend in WStLA, Hauptarchiv - Akten, AI - Hauptarchiv - Akten und Verträge, 32/1689, unfol. 
kommen. Kritisiert wurde im Gutachten weiterhin, dass de la Place Franzose sei, denn dies lasse befürchten, dass er vor allem Landsmänner beschäftigen könnte, was wiederum Unmut in der Bevölkerung hervorrufen würde. Trotz aller in diesem Gutachten geäußerten Vorbehalte wurde Michel de la Place kurze Zeit später die exklusive Erlaubnis erteilt, ein Miettragsesselsystem in Wien zu installieren. Spätestens in den ersten Jahren des I8. Jahrhunderts verlor de la Place seine Monopolstellung am Wiener Miettragsesselsektor aber wieder. Die Gründe dafür sind leider nicht überliefert, könnten aber im I7or ausgebrochenen Spanischen Erbfolgekrieg liegen, in dem die Häuser Habsburg und Bourbon einander feindlich gegenüberstanden. Es ist denkbar, dass die damalige politische Situation die wirtschaftliche Begünstigung eines Franzosen nicht länger opportun erscheinen ließ. Fest steht, dass Kaiser Leopold I. am 20. Juni 1703 nun seinem eigenen Kammerdiener Heinrich Ernst Rauchmüller auf Lebenszeit das Privileg zur Unterhaltung von Miettragsesseln erteilte. ${ }^{352}$

Im Privileg von 1703 sind drei Gründe genannt, die den Kaiser zur Einführung von Miettragsesseln bewegt hatten. Zum einen bestand die Hoffnung, dass damit die hohen Ausgaben für kostspielige Karossen („Kobel-Wägen“353) vermindert werden könnten, zum anderen, dass durch eine Reduktion des Wagenverkehrs das Straßenpflaster der Stadt geschont werde, dem die eisenbereiften Kutschenräder offenbar stark zusetzten, und schließlich versprach man sich durch Miettragsessel eine Erhöhung der Lebensqualität für die Bewohner und Besucher der Stadt, da diesen damit ein zusätzliches bequemes Verkehrsmittel zur Verfügung gestellt werde. Vielleicht um Skeptiker von der Sinnhaftigkeit eines Miettragsesselsystems zu überzeugen, wurde im Text explizit darauf hingewiesen, dass ein solches bereits in London, Paris, Düsseldorf, München, Hannover, Turin und Brüssel eingeführt worden sei und sich an diesen Orten bestens bewährt habe.

Nachdem sich Rauchmüller mit der niederösterreichischen Kammer und Regierung über verschiedene Punkte, die im Privileg festgehalten sein sollten, verständigt hatte, wurde das Verhandlungsergebnis dem Kaiser zur Beschlussfassung vorgelegt. Leopold I. genehmigte schließlich folgende Bestimmungen und Einschränkungen: Erstens durfte Rauchmüller nur Sesselträger „Teutscher Nation“ beschäftigen, wobei im Text nicht weiter ausgeführt wird, welche Gründe zu diesem Passus geführt haben. Vielleicht waren es negative Erfahrungen, die man zuvor mit de la Places französischen Sesselträgern gemacht hatte, möglicherweise versuchte man mit dieser Regelung aber auch Italiener, die in die-

352 Das Privileg ist im vollen Wortlaut in Kapitel 6.4 abgedruckt.

353 Dabei handelte es sich nicht um den im Spätmittelalter und im I6. Jahrhundert weit verbreiteten Wagentypus gleichen Namens, der über ein tonnenförmiges Wagendach verfügte. Vermutlich wurden um I700 auch repräsentative Fahrzeuge mit einem geschlossenen Wagenkasten als Kobelwagen bezeichnet. Nähere Informationen dazu bei DöBerL 20Io (wie Anm. 240), S. 280. 
sem Berufsfeld stark vertreten waren, zugunsten einheimischer Sesselträger zu verdrängen. Zweitens wurde verschiedenen Personengruppen die Benutzung von Tragsesseln explizit verboten. Auf Wunsch Rauchmüllers waren Kranke von der Inanspruchnahme dieser Dienstleistung ausgenommen, wahrscheinlich aus Sorge, gesunde Kunden zu verlieren, die Angst hatten, in einem öffentlichen Tragsessel mit einer gefährlichen Krankheit angesteckt zu werden. Weiterhin war es Lakaien und ähnlichen livrierten Dienern verwehrt, Tragsessel zu mieten, wobei einzig für Edelknaben (Pagen) eine Ausnahme gemacht wurde. Mit dieser einschränkenden Regelung sollte die Befugnis, Tragsessel zu benutzen, wohl als Privileg der oberen sozialen Schichten gewahrt bleiben. Als Ausdruck der antijudaistischen Stimmung, die auch nach der Vertreibung der Juden aus Wien im Jahr 1670 weiterhin in der Stadt herrschte, ist wohl die Tatsache zu werten, dass auch Juden explizit von der Benutzung der Miettragsessel ausgeschlossen waren. Drittens wurden Tarifobergrenzen festgelegt, damit Rauchmüller seine Monopolstellung nicht ungebührend ausnutzen konnte. Interessanterweise handelte es sich dabei um Einheitstarife, die unabhängig von der zurückgelegten Strecke, dem Wetter und der Uhrzeit waren. Für jeden zurückgelegten Weg, wie weit dieser auch immer sein sollte, durften nicht mehr I4 Kreuzer verlangt werden. Der Aktionsradius ging dabei über die Stadttore hinaus und reichte bis in die Vorstädte. Wollte man den Tragsessel auch gleich für den Rückweg reservieren, musste die dabei für die Sesselträger anfallende Wartezeit mit einem Zuschlag von 6 Kreuzer pro Stunde abgegolten werden. Zusätzlich gab es kostengünstigere Zeittarife, die unabhängig von der Zahl der Wegstrecken und eventuell auftretender Wartezeiten waren. So konnten etwa Tragsessel für sechs oder zwölf Stunden gemietet werden, was 45 Kreuzer beziehungsweise I Gulden und 30 Kreuzer kostete. Allen Tarifen war gemeinsam, dass sie im Voraus beglichen werden mussten und nur unterschritten, nicht aber überschritten werden durften.

Analog zu einer damals bereits geltenden Regelung für Mietkutschen ${ }^{354}$ wurden auch für Tragsessel Abgaben festgelegt, die direkt an das Armenhaus vor dem Schottentor fließen sollten. Rauchmüller musste für jeden Tragsessel, den er einsetzte, einen Betrag von monatlich I Gulden 30 Kreuzer bezahlen. Damit ihm während der Aufbauphase seines Gewerbes, in der größere Investitionen zu tätigen waren, keine allzu schweren finanziellen Bürden entstanden, wurde dieser Betrag für die ersten vier Jahre auf I Gulden pro Tragsessel und Monat gesenkt.

354 Mit 2. Dezember 1697 legte Kaiser Leopold I. Abgaben in der Höhe von 3 Gulden pro Monat auf „Lehen-Wägen / Schese / und Kalessen“ fest, die in Wien und Umgebung im Einsatz waren. Das so eingenommene Geld sollte dem Armenhaus vor dem Schottentor zugutekommen. Codex Austriacus (Wien I704), Teil I, S. II4. Mit großer Wahrscheinlichkeit war mit der Bezeichnung "Chaise" ein Wagentyp und nicht ein Tragsessel gemeint. 


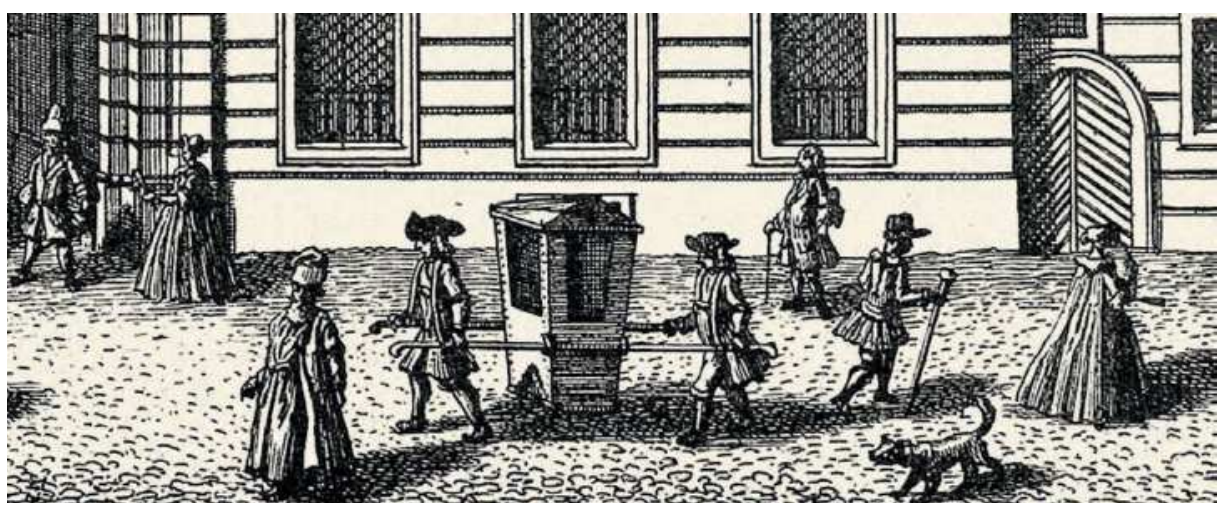

Abb. 17: Miettragsessel (?) mit zwei Sesselträgern vor dem Palais Lamberg-Sprinzenstein in Wien. Ausschnitt aus einem Kupferstich von Johann August Corvinus nach Salomon Kleiner, 1733. ๑ Institut für Kuntstgeschichte, Universität Wien

Eine unmittelbare Reaktion auf die Tragsessel seitens der Wiener findet sich in einem I705 anonym erschienenen Reisebericht über Wien aus der Feder des französischen Benediktiners Casimir Freschot. ${ }^{355}$ Dieser erwähnte die Widerstände, auf die die Einführung von Miettragsesseln anfangs bei der Bevölkerung gestoßen sei, und welch große Akzeptanz diese Transportmittel mittlerweile genössen, nachdem sich ihre Vorteile und große Bequemlichkeit er-

355 „Man hat nichts mehr von der stadt Wien zu erinnern / ausser daß man von wenig zeit her die chaises à porteur oder sänfften eingeführet / wodurch man sich mit geringen unkosten von einem orte zum andern kan tragen lassen / ohne daß man sein geld auf die carossen wenden dörffe / die doch zu winters-zeit schlechter dings nöthig sind / weil man sodann fast unmöglich durch den schnee und morast / womit die gassen angefüllet seyn / kommen kan." (Casimir FrEsCHOT), Relation von dem käyserlichen Hofe zu Wien [...]. Aufgesetzt von einem Reisenden im Jahr I704 (Köln I705), S. 5I. „[...] indem man / wie schon gesaget worden / wegen schnee und morastes / des winters kaum auff denen gassen zu Wien fortkommen kan. Ohne zweiffel hat man deßwegen vor einiger zeit die tragsessel / wie man sie zu Turin und in andern Frantzösischen städten siehet / eingeführet. Anfangs schiene es unmüglich / dieses zu stande zu bringen; Doch hat man mit der zeit erkennen lernen / wie bequehm diese anordnung sey / deßwegen sind sie nunmehr durchgängig im gebrauch / wie man denn an unterschiedenen orten der stadt buden auffgerichtet / worunter sie stehen / ja man findet fast in allen gassen dergleichen träger / die zu allen stunden des tages und der nacht bereit seyn auffzuwarten. Es ist auch ein unterscheid unter denen chaisen selbst / indem einige besser als die andern / solcher gestalt / daß keine person von stande ist / so sich schämet / sich derselben zu bedienen / weil sie es mit aller ihrem stande zukommenden pracht thun kan. Die Dames se[l]bst gebrauchen sie öffters lieber / als ihre carossen / denn weil sie darinne gantz verdecket sind / so können sie desto bequemer und mit weniger aufsehen hingehen / wo sie wollen." Ebenda, S. $159 \mathrm{f}$. 
wiesen hätten (Abb. I7). Vor allem in den kalten Wintermonaten, wenn die Straßen mit Schnee und Morast bedeckt seien, böten sie eine gute und kostengünstige Alternative zu Kutschen. Freschot berichtete weiterhin, dass an vielen Orten Wiens, ja fast in jeder Gasse der Stadt, Unterstandplätze für Miettragsessel errichtet worden seien, wo zu allen Tag- und Nachtzeiten Sesselträger ihre Dienste feilböten. Lobend hob er hervor, dass Kunden zwischen schlichten und äußert prachtvoll ausgeführten Tragsesseln wählen könnten und somit auch für sozial höhergestellte Personen standesgemäße Exemplare vorhanden seien. Besonders bei Damen, so Freschot weiter, seien Miettragsessel äußerst beliebt, ja sie würden sogar lieber auf Sessel als auf ihre eigenen Karossen zurückgreifen, da ihnen Erstere ein höheres $\mathrm{Maß}$ an Anonymität im öffentlichen Raum ermöglichten. ${ }^{356}$ Wenn wir Freschots Einschätzungen folgen - und es besteht kein Grund, dies nicht zu tun ${ }^{357}$-, war die Einführung von Miettragsesseln in Wien ein voller Erfolg. Erst im Lauf des 19. Jahrhunderts geriet dieses öffentliche Verkehrsmittel in der kaiserlichen Residenzstadt aus der Mode, bis schließlich im Jahr I888 der letzte Wiener Sesselträger sein Gewerbe niederlegte. ${ }^{358}$

\section{Quellenanhang}

6.1 Tragsessel in den kaiserlichen Marstallinventaren von 1678

Kurz nach seinem am 23. November 1677 erfolgten Amtsantritt als kaiserlicher Oberststallmeister ließ Ferdinand Bonaventura Graf Harrach eine Generalinventur in seinem

356 Diesen Vorteil von Miettragsesseln hatte bereits der englische Reisende Fynes Moryson bei Aufenthalten in Neapel und Genua im Jahr 1594 erkannt. Zu Neapel bemerkte er: „[...] one fashion pleased me beyond measure, that at the end of many streetes they had chaires, vulgarly called Seggioli di Napoli, which those that are weary doe enter, and they being covered round about, and onely having windowes on the sides, he that is carried therein, cannot be seene of any, and yet himselfe may see all that passe." Fynes Moryson, An Itinerary Containing His Ten Yeeres Travell through the Twelve Dominions of Germany, Bohmerland, Sweitzerland, Netherland, Denmarke, Poland, Italy, Turky, France, England, Scotland \& Ireland, Bd. I (London I617, Nachdruck Glasgow 1907), S. 239. Anlässlich einer Besichtigung Genuas strich Moryson hervor: „The chaires called Seggioli, whereof I spake in the discription of Naples, are also in use here, in which the Citizens of both sexes are carried upon two Porters shoulders, through the streetes lying upon the sides of hils, the chaires being covered with a curtaine drawne, and having glasse windowes, so as they may see all men, and themselves be unseene." Ebenda, S. 360.

357 Auch ein früher Wienführer von I72I zieht ein positives Resümee über die Einführung von Miettragsesseln in Wien: Johann [Valentin] NeIner, Vienna curiosa \& gratiosa, oder deß anjetzo lebende Wienn, Teil 3 (I72I), S. 3I f.

358 Gustav Gugitz, Die Sesselträger in Alt-Wien. In: Jahrbuch des Vereines für Geschichte der Stadt Wien 8 (1949/50), S. 94-I04, hier S. I04. 
neuen Verantwortungsbereich durchführen. Das Ergebnis waren mehrere Inventare, in denen sämtliche mit Stichtag I. Januar I678 aufgefundenen Stallgegenstände aufgelistet sind. Zwar wurden die Fahrzeuge und Tragevehikel, die in diesen ältesten bislang bekannten Inventaren des kaiserlichen Hofmarstalls beschrieben sind, erst vor wenigen Jahren im Rahmen einer Quellenedition veröffentlicht, 359 jedoch finden sich dort die Passagen, in denen Tragsessel Erwähnung finden, teilweise in weit voneinander entfernt liegenden Abschnitten. Der Übersichtlichkeit halber werden deshalb im Folgenden jene Inventareinträge, in denen Tragsessel behandelt werden, noch einmal wörtlich wiedergegeben. ${ }^{360}$

Im Inventar der Untersattelkammer findet sich sich:

Ein tragseßl von schwarzen löder, inwendig mit graben [!] tuech gefüedert, so vor h[errn] p[ater] Müller ${ }^{361}$ gemacht worden. ${ }^{362}$

Das Inventar der sogenannten „Gestickten Sattelkammer“ listet folgende drei Tragsessel auf:

Empfangt er satl camerverwalther ${ }^{363}$ ainen tragseßl, welchen ihr May. die kayserin Margaritha $^{364}$ mit auß Hispanien gebracht, aussenher durchgehent mit feiglfarben sammet überzogen, und allenthalben dickh mit rothen corallen undt goldt gestickht, inwendig mit blumeranfarben silberstuckh gefüedert, wie auch dergleichen drey fürhang, alles wie aussen, nit weniger auch die darzue gehörige zwey tragbender mit corallen und goldt gestickhet, an den fürhängen seind dreyzechen vergulte khnöpf mit corallen eingelegt, darbey ein überdöckhen von gewixter leinwath, und sein hievon, alß der sessl in der galleria gestanden, 6 knöpf entfrembt worden.

[...]

Ein reich mit goldt gestickhter roth sametener tragseßl, inwendig mit silber in golt gebluemten goldtstuckh gefüedert, sambt denen darzue gehörigen drey golt, auff roth und weiß gestickhten fürhängen, die umb und umb mit gold und silberen fransen besezt, mit einem perlfarben goldt in silberstuckh mit kleinen nattfränßl besezten polster, neben mit roth goldt gestickhten sameten tragbendern, und überzogenen tragstangen, wie auch dar-

359 Döberl 2010 (wie Anm. 240).

360 Laufende Nummern und Folioangaben der Quellenedition werden im Folgenden unkommentiert weggelassen.

36I Philipp Miller (1613-1676), Jesuit; ab I653 Lehrer und Beichtvater des Kaisers.

362 Döberl 2010 (wie Anm. 240), S. 300.

363 Nicola Valentin Stoltz. Ebenda, S. 302. Er bekleidete die Stelle des Verwalters der „Gestickten Sattelkammer" seit I. Juli 1653. ÖStA, HHStA, OMeA, SR, Bd. I86, fol. I74r.

364 Kaiserin Margarita Teresa (I65I-1673). 
zue gehörigen fünff Vened[ischen] glössern, so auff die kay. hochzeit, welche a[nn]o I666 gehalten, gemacht worden.

Ein tragseßl von rothen samet mit guldenen posamenten und fransen, inwendig mit carmeßin tamaskh gefüedert und gulden posamenten verbrämbt, ohne glaß und fürhäng, sein außwendig die fransen in etwas entfrembt.

[Randvermerk von zweiter Hand] Dißer sessel ist den 9. Jan[uary] I679 denen sesseltragern gegeben worden. ${ }^{365}$

Das Inventar der Rüstungen und deren Zubehör erwähnt schließlich:

Zwey rotsametene tragseßl mit goldenen porthen brämbt, mit grien überzogen.

Ein tragsessl von schwarz tuech. ${ }^{366}$

6.2 Vorschriften für kaiserliche Sesselträger (1682)

Quelle: ÖStA, AVA, FA Harrach, Akten, K. 2926, unfol. ${ }^{367}$

Sesseltrager ordnung

Dieweillen ihre röm[isch] kay[serliche] may[estät] unser allergnedigster herr etc. eine zeit hero durch dero sessltragern mit unordnung und ybel bedient worden, alß haben sye allergnedigst anbefohlen, denenselben eine rechte ordnung vorzuschreiben, nach welcher sye sich unfehlbahr zuverhalten haben werden.

Erstlichen, wollen allerhöchst gedachte ihre röm[isch] kay[serliche] may[estät], daß Nicolaus Ballastraza ihnen, alß der älteste, vor einen corporalen solle vorgestelt werden, demselben sollen sye in allem und iedem, waß er ihnen in der kay[serlichen] may[estät] diensten ansagen würdet, allen gebüehrenden gehorsamb erzaigen.

Anderten, solle obgedachter Nicolaus alle tag seine ordinanzen von dem herrn obr[isten] stahlmaister abhollen und nach dessen befelch die ordinanz den andern sesseltragern außthailen.

Drittens, müessen khünfftig die sesseltrager in zwey thail gethailt und abgesöndert werden, von welchen allezeit ein thail einen ganzen tag den dienst haben, welche so dan den

365 Döberl 2010 (wie Anm. 240), S. 302.

366 Ebenda, S. 305.

367 Beim hier transkribierten Schriftstück handelt es sich um eine Abschrift. Eine nur fragmentarisch erhaltene Originalausfertigung der Sesselträgerordnung findet sich in ÖStA, AVA, FA Harrach, Akten, K. 797, unfol. 
andern tag die andere helffte ablösen solle; damit nun die abthaillung nicht geschehe, daß allezeit die sterckhesten, und jüngsten beysamben bleiben, solle zu zwey starckhen alzeit ein schwach und alter gegeben werden, damit die schwächesten allein zum helffen und nicht zum tragen kommen, weil leichtlich eine gefahr vor ihr may[estät] dabey vorlauffen khönte.

Viertens, solle er Nicolauß nicht vor ordinary zum tragen, sondern allein zum helffen unnd auf die andern achtung zugeben allezeit gegenwertig sein.

Fünfftens, wan die röm[isch] kay[serliche] may[estät] auf dem landt sein, so sollen alle würckhliche sesseltrager sich allezeit gegenwertig einfinden und ohne herrn obr[ist] stahlmaisters erlaubnuß und des Nicolai vorwissen nicht verraißen, sondern, weylen sye zu sonst nichts anders gebraucht und gehalten werden, iedes mahl zuer stöhl verbleiben, damit wan seine kay[serliche] may[estät] außraisen wollen, allezeit die eine helfft voran khame und die andere helffte zu hauß zum aufwarten verbleibe, und dise ordnung solle auch gehalten werden, wan sich ihre may[estät] die römische kayserin tragen lest, $\mathrm{d}[\mathrm{a}] ß$ die jenige parthey, so d[a]s aufwartten bey ihr may[estät] dem kayser hat, bey dero verbleiben, die andere aber völlig bey der kayserin auf zuwartten haben.

Sechstens, damit Ihr kay[serliche] may[estät] gebührend und ohne gefahr bedient werden, so soll sich kein sesseltrager understehen, mit dem trunckh zu yberladten, und nit zum dienst zukhamben, dan wo ein oder der anderer voller betretten wuerde, solle er ohn alle gnad gestrafft und gahr des dienst entsezt werden.

Sibentens, solle Nicolaus sein fleißige obsicht haben, daß durch seine undergebene sesseltrager allem deme, so hievor geschriben, aller volzug beschehe, und daß sye under ein ander selbsten fridlich und in ruehe leben; soll einer aber sich deme, so ihnen hievor geschriben, sich widersezen und nicht gehorsamben wöllen, so soll nach gethaner ermahnung der Nicolaus solches herrn obr[ist] stahlmaister anzeigen, der wüerdet der gebüehr nach die bestraffung vorzukheren wissen.

Achtens, wan Nicolaus etwan wegen kranckhheit oder sonsten mit herrn obr[ist] stahlmaisters erlaubnuß abwessent sein müsste, solle allezeit durch herrn obr[ist] stahlmaister ein anderer Sesseltrager an dessen stöhl benent werden, welcher biß zu seiner widerkhunfft die obsicht haben solte.

Neundens, damit ihr kay[serliche] may[estät] mit all gebührenden respect bedient werden, alß würd hiemit allen sesseltragern verbotten, das sich keiner understehen solle mit ihrer may[estät] (ohne daß er gefragt werde) zureden etwaß anzubringen, oder einzige ordinanz zunemmen, sondern waß sye anzubringen oder zu fragen haben, bey herrn obr[ist] stahlmaister vorbringen, und die ordinanz zunemmen.

Zechentens, so wöllen seine kay[serliche] may[estät], daß auf dise ordnung die sesseltrager aufs neue angloben sollen und daß ihnen der Niclaus zu dem ende vorgestelt werde, daß 
er die verbrecher anzaige und daß selbige der gebüehr nach gestrafft oder gahr abgeschaffet werden khönen.

Und weillen schließlichen dises der röm[isch] kay[serlichen] may[estät] allergnedigster ernstlicher will und mainung ist, alß habe ich solches auf dero befelch mit meiner aignen hand underschriben und verferttiget. Datum Wienn den $\mathrm{I} 4 .{ }^{368}$ augusti, anno ain tausent sechs hundert zway und achtzig.

Ferdinand Bonaventura graff von Harrach

\section{3 Überblick über die wechselnde Zahl der Hofsesselträger (1615-1711)}

\begin{tabular}{|c|c|c|c|c|}
\hline Datum & 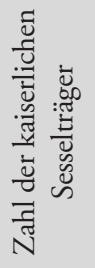 & 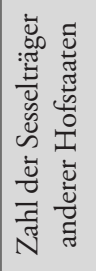 & 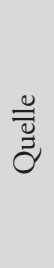 & Anmerkungen \\
\hline 1615 & 4 & & 369 & $\begin{array}{l}\text { Von Juni bis Oktober I6I5 bedienten vier Sesselträger aus } \\
\text { Genua den Tragsessel von Kaiserin Anna }\end{array}$ \\
\hline 1618 & & o & 370 & $\begin{array}{l}\text { Keine Erwähnung von Sesselträgern im hinterlassenen Hof- } \\
\text { staat von Erzherzog Maximilian III. ( } † \text { 2. Nov. I6I8) }\end{array}$ \\
\hline I623 Dez. 6 & 6 & & 371 & $\begin{array}{l}\text { Kaiserin Eleonora Gonzaga (I.) bestätigt, dass sechs von Man- } \\
\text { tua abgesandte Sesselträger in Wien eingetroffen seien }\end{array}$ \\
\hline 1625 & 6 & & 372 & $\begin{array}{l}\text { Beschaffung von Waren für die Livree der „,sechs sessel unnd } \\
\text { sennftentrager“ der Kaiserin" }\end{array}$ \\
\hline I629 April I9 & 6 & & 374 & $\begin{array}{l}\text { Beschaffung von Waren für die Livree der sechs Sesselträger } \\
\text { der Kaiserin }\end{array}$ \\
\hline
\end{tabular}

368 Durchgestrichen: „zwölfften“.

369 Vgl. Kapitel 2.2.

370 DOZA, Abteilung Hochmeister, K. 485, Konv. „Todesfall und Verlassenschaft. I6I8-I6r9.“, unfol.

37I Venturini 2002 (wie Anm. 5I), S. 683, 687.

372 ÖStA, FHKA, HZAB, Bd. 76, fol. 532 r.

373 Es ist unklar, warum hier nicht nur von Sesselträgern die Rede ist. Die für die Maultiersänften zuständigen Bediensteten wurden nämlich damals am Kaiserhof für gewöhnlich als Sänftenknechte bezeichnet.

374 ÖStA, FHKA, Hoffinanz Österreich, Bd. 729, fol. I63v (I629 April I9), fol. 193v (I629 April 2I). 


\begin{tabular}{|c|c|c|c|c|}
\hline Datum & 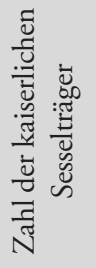 & 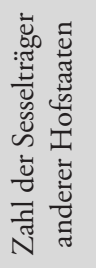 & $\frac{\ddot{g}}{\partial}$ & Anmerkungen \\
\hline I630 Mai Io & 6 & & 375 & $\begin{array}{l}\text { Herstellung der neuen Livree für sechs kais. Sesselträger, } \\
\text { angeschafft für die Reise zum kurfürstlichen Kollegialtag in } \\
\text { Regensburg }\end{array}$ \\
\hline 1632 & 5 & & 376 & Betrag für die Kleidung der fünf Sesselträger der Kaiserin \\
\hline I634 Juli & & 6 & 377 & $\begin{array}{l}\text { Zahl der Sesselträger, die Königin Maria Anna auf ihrer Reise } \\
\text { nach Passau begleiteten }\end{array}$ \\
\hline I634 Sept. 30 & & 5 & 378 & Namensliste der kgl. Sesselträger \\
\hline I635 Juni I & & 6 & 379 & Namensliste der kgl. Sesselträger \\
\hline 1639 & 6 & & 380 & Neujahrsgeld für sechs Sesselträger der Kaiserin \\
\hline I639 März 3I & 9 & & $38 \mathrm{r}$ & $\begin{array}{l}\text { Verzeichnis des kais. Stallpersonals, das im ersten Quartal } \\
1639 \text { in Wien und Prag Dienst versah }\end{array}$ \\
\hline I640 Mai 19 & 9 & & 382 & $\begin{array}{l}\text { Zahlung an den kais. Zeltmeister Andreas Heiminger für die } \\
\text { Anfertigung der Livree für neun kais. Sesselträger }\end{array}$ \\
\hline I646 April 8 & IO & & 383 & $\begin{array}{l}\text { Zahlung an Hofschneider Georg Bohr für Warenlieferung } \\
\text { und Arbeiten zur Livree für zehn kais. Sesselträger }\end{array}$ \\
\hline I647 Okt. 2 & 4 & & 384 & Vier kais. Sesselträger werden von Wien nach Prag beordert \\
\hline
\end{tabular}

375 ÖStA, FHKA, NÖHA, K. 780, fol. 76ov-762r.

376 ÖStA, FHKA, HZAB Bd. 79, fol. 318r.

377 KheVenhüLler I72I-I726 (wie Anm. 6I), Bd. I2, Sp. I448.

378 ÖStA, HHStA, OMeA, SR, K. 76, Konv. 8, Umschlag „I636-I644 Rechnungen für den Hof der Kgn. beziehungsweise Kaiserin Maria Anna", unfol.

379 ÖStA, HHStA, OMeA, SR, K. 76, Konv. 5, unfol.

380 ÖStA, FHKA, HZAB, Bd. 85, fol. $260 v$.

38I ÖStA, FHKA, NÖHA, W 6I/a/3, Fasz. „Stallmeister“, fol. 465v, 462 r.

382 ÖStA, FHKA, HZAB, Bd. 86, fol. 227r. Angeführt auch bei SchwaighofER 1938 (wie Anm. 126), Reg. 252.

383 ÖStA, FHKA, HZAB, Bd. 92, fol. I84.

384 ÖStA, FHKA, HZAB, Bd. 93 II, fol. 388v. Dass damals nicht mehr als vier Sesselträger am Kaiserhof dienten, deckt sich auch mit den Angaben in ÖStA, HHStA, OMeA, SR, Bd. I86, fol. I84v-I87r. 


\begin{tabular}{|c|c|c|c|c|}
\hline Datum & 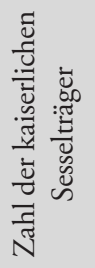 & 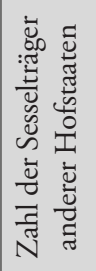 & 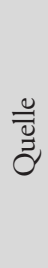 & Anmerkungen \\
\hline I649 Juli I6 & 7 & & 385 & Neujahrsgeld für sieben kais. Sesselträger \\
\hline I650 Juli 8 & 7 & & 386 & Neujahrsgeld für sieben kais. Sesselträger \\
\hline I65I April 20 & 8 & & 387 & Neujahrsgeld für acht kais. Sesselträger \\
\hline I652 Feb. I & 8 & & 388 & Neujahrsgeld für acht kais. Sesselträger \\
\hline 1654 Jan. 15 & 8 & & 389 & Neujahrsgeld für acht kais. Sesselträger \\
\hline 1655 Jan. 13 & IO & & 390 & Neujahrsgeld für zehn kais. Sesselträger \\
\hline 1656 & $\mathrm{I} 2$ & & 391 & Neujahrsgeld für zwölf kais. Sesselträger \\
\hline 1656 Dez. 3I & I5 & o & 392 & $\begin{array}{l}\text { Liste der im letzten Quartal I656 dienenden kais. und kgl. } \\
\text { Stallpartei }\end{array}$ \\
\hline I657 März I & 16 & & 393 & $\begin{array}{l}\text { Liste der kais. Sesselträger während der Regierung Ferdi- } \\
\text { nands III. (1637-1657) }\end{array}$ \\
\hline I660 Jan. I & & 5 & 394 & $\begin{array}{l}\text { Liste der erzherzoglichen Sesselträger, die am Innsbrucker } \\
\text { Hof besoldet wurden }\end{array}$ \\
\hline 1662 & & o & 395 & $\begin{array}{l}\text { Hinterlassener Hofstaat von Erzherzog Leopold Wilhelm } \\
(† 20 \text {. Nov. I662) }\end{array}$ \\
\hline
\end{tabular}

385 ÖStA, FHKA, HZAB, Bd. 95 II, fol. 5 I4v.

386 ÖStA, FHKA, HZAB, Bd. 96 II, fol. 3I9r-v.

387 ÖStA, FHKA, HZAB, Bd. 97 III, fol. 599v.

388 ÖStA, FHKA, HZAB, Bd. 98 II, fol. $523 \mathrm{v}$.

389 ÖStA, FHKA, HZAB, Bd. Ioo, fol. $573 \mathrm{v}$.

390 ÖStA, FHKA, HZAB, Bd. IoI, fol. 494r. Ein I655 gedrucktes Hofstaatsverzeichnis in lateinischer Sprache führt nur acht Sesselträger („Sellarum baiuli“) auf. Möglicherweise sind dort aber nur die Planstellen aufgelistet, die von der Zahl der tatsächlichen Hofdiener abwichen. Gabrielis BuCELINI, Germania topo-chrono-stemmato-graphica sacra et prophana, Bd. I (Ulm I655), S. 28I.

39I ÖStA, FHKA, HZAB, Bd. IO2, fol. 284r.

392 ÖStA, AVA, FA Harrach, Akten, K. 796, Konv. „Oesterreich, Hofstaat. Gestütte Lippizza und Kladrub und Oberststallmeisteramt.“, fol. 78r, 79 r-v.

393 ÖStA, HHStA, OMeA, SR, Bd. 186, fol. I84v-187r.

394 TLA, Hs. 1965, fol. I24V-I26r.

395 ÖStA, FHKA, NÖHA, K. 790, fol. III5r-II22v. 


\begin{tabular}{|c|c|c|c|c|}
\hline Datum & 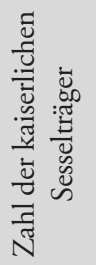 & 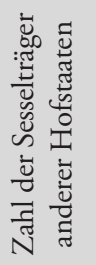 & 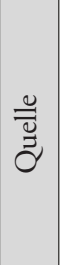 & Anmerkungen \\
\hline I664 Juni 30 & o & & 396 & Liste der im zweiten Quartal I664 dienenden Hofstallpartei \\
\hline 1667 & 7 & & 397 & Neujahrsgeld für sieben kais. Sesselträger \\
\hline 1668 & 8 & & 398 & Neujahrsgeld für acht kais. Sesselträger \\
\hline 1670 & 8 & & 399 & Neujahrsgeld für acht kais. Sesselträger \\
\hline 1673 Jan. 23 & 8 & & 400 & Neujahrsgeld für acht kais. Sesselträger \\
\hline I674 Jan. 28 & 7 & & 401 & Neujahrsgeld für sieben kais. Sesselträger \\
\hline I675 Jan. 3I & II & o & 402 & $\begin{array}{l}\text { Hofstaatsverzeichnisse Kaiser Leopolds I. und der Kaise- } \\
\text { rin-Witwe Eleonora Gonzaga (II.) }\end{array}$ \\
\hline I676 Sept. II & & 5 & 403 & $\begin{array}{l}\text { Hinterlassener Hofstaat von Anna de’ Medici († II. Sept. } \\
\text { I676), Witwe von Erzherzog Ferdinand Karl von Tirol und } \\
\text { Mutter der Kaiserin Claudia Felizitas }\end{array}$ \\
\hline 1677 & 15 & & 404 & Neujahrsgeld für fünfzehn kais. Sesselträger \\
\hline 1678 & 16 & o & 405 & $\begin{array}{l}\text { Hofstaatsverzeichnis Kaiser Leopolds I. und der Kaise- } \\
\text { rin-Witwe Eleonora Gonzaga (II.) }\end{array}$ \\
\hline I679 ca. & I4 & & 406 & Namensliste des kais. Stallpersonals \\
\hline
\end{tabular}

396 ÖStA, FHKA, NÖHA, W 6I/a/3, Fasz. „Stallmeister“, fol. 467-478.

397 ÖStA, FHKA, HZAB, Bd. III, fol. sIIr.

398 ÖStA, FHKA, HZAB, Bd. III, fol. 5I4r.

399 ÖStA, FHKA, HZAB, Bd. II3, S. 679 f.

400 ÖStA, FHKA, Hoffinanz Österreich, Bd. 9II, fol. 25v.

40I ÖStA, FHKA, Hoffinanz Österreich, Bd. 913, fol. $56 \mathrm{r}$.

402 ÖNB, Handschriftensammlung, Cod. I407I, fol. I5r, $73 v$.

403 ÖStA, FHKA, NÖHA, K. 790, fol. I356r.

404 ÖStA, FHKA, HZAB, Bd. I2I, fol. 292v.

405 ÖNB, Handschriftensammlung, Cod. I2388, fol. 24v, 28r-29r. Wohl ebenfalls von I678 stammt eine undatierte Liste des kaiserlichen Stallpersonals, die sechzehn Sesselträger namentlich erwähnt. ÖStA, AVA, FA Harrach, Akten, 796, Konv. „Oesterreich, Hofstaat. Gestütte Lippizza und Kladrub und Oberststallmeisteramt.", fol. 40v-4Ir.

406 Die Namensliste ist zwar undatiert, lässt sich aber aufgrund von am Rand eingetragenen Sterbedaten einzelner Stalldiener auf ca. I679 datieren. ÖStA, AVA, FA Harrach, Akten, K. 2926, unfol. 


\begin{tabular}{|c|c|c|c|c|}
\hline Datum & 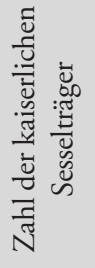 & 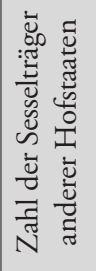 & $\frac{\stackrel{u}{\vec{v}}}{\vec{\partial}}$ & Anmerkungen \\
\hline I68I & 14 & & 407 & Neujahrsgeld für vierzehn kais. Sesselträger \\
\hline 1682 & $\mathrm{I} 3$ & & 408 & Neujahrsgeld für dreizehn kais. Sesselträger \\
\hline 1683 & II & & 409 & Neujahrsgeld für elf kais. Sesselträger \\
\hline 1684 & $\mathrm{I} 2$ & & 410 & Neujahrsgeld für zwölf kais. Sesselträger \\
\hline 1685 & II & & $4 \mathrm{II}$ & Neujahrsgeld für elf kais. Sesselträger \\
\hline 1686 & II & 6 & 412 & $\begin{array}{l}\text { Neujahrsgeld für die kais. Sesselträger beziehungsweise nach- } \\
\text { gelassener Hofstaat von Kaiserin-Witwe Eleonora Gonzaga } \\
\text { (II.) († 6. Dez. I686). }\end{array}$ \\
\hline 1687 & IO & & 413 & Neujahrsgeld für zehn kais. Sesselträger \\
\hline 1688 & 9 & & 414 & Neujahrsgeld für neun kais. Sesselträger \\
\hline 1689 & II & & 415 & Neujahrsgeld für elf kais. Sesselträger \\
\hline 1690 & $\mathrm{I} 2$ & & 416 & Neujahrsgeld für zwölf kais. Sesselträger \\
\hline I69I & $\mathrm{I} 2$ & & 417 & Neujahrsgeld für zwölf kais. Sesselträger \\
\hline 1692 & $\mathrm{I} 2$ & & 418 & Neujahrsgeld für zwölf kais. Sesselträger \\
\hline 1693 & II & & 419 & Neujahrsgeld für elf kais. Sesselträger \\
\hline
\end{tabular}

407 ÖStA, FHKA, HZAB, Bd. 125, fol. 265v.

408 ÖStA, FHKA, HZAB, Bd. 126, fol. 308v.

409 ÖStA, FHKA, HZAB, Bd. 127, fol. 310r-v.

4 IO ÖStA, FHKA, HZAB, Bd. I28, fol. 285v.

4 II ÖStA, FHKA, HZAB, Bd. I29, fol. 226v.

4 I2 ÖStA, FHKA, HZAB, Bd. I3I, fol. 393v-394r; ÖStA, FHKA, HZAB, Bd. I33, fol. 342r-v. Die

Namen der Sesselträger der Kaiserin-Witwe Eleonora Gonzaga (II.) lauteten Francesco Carigari, Johann Baptista Conti, Antonio Pacifici, Matthia Spacierern, Peter Pogniets (†) und Philipp Dörffler.

$4 \mathrm{I} 3$ ÖStA, FHKA, HZAB, Bd. 132, fol. 347r-348r.

4 I4 ÖStA, FHKA, HZAB, Bd. 133, fol. 378r.

415 ÖStA, FHKA, HZAB, Bd. 134, fol. 295r.

416 ÖStA, FHKA, HZAB, Bd. 135, fol. 353v.

417 ÖStA, FHKA, HZAB, Bd. I36, fol. 352 r.

418 ÖStA, FHKA, HZAB, Bd. 137, fol. 357r.

419 ÖStA, FHKA, HZAB, Bd. I38, fol. 325 r. 


\begin{tabular}{|c|c|c|c|c|}
\hline Datum & 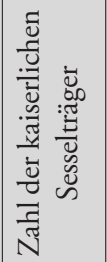 & 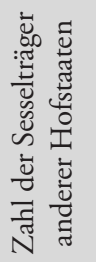 & $\stackrel{\varrho}{\stackrel{\Xi}{\Xi}}$ & Anmerkungen \\
\hline 1694 & II & & 420 & Neujahrsgeld für elf kais. Sesselträger \\
\hline 1697 & IO & & $42 \mathrm{I}$ & Neujahrsgeld für zehn kais. Sesselträger \\
\hline 1698 & 9 & & 422 & Neujahrsgeld für neun kais. Sesselträger \\
\hline 1699 & 9 & & 423 & Neujahrsgeld für neun kais. Sesselträger \\
\hline I699 April I & & 5 & 424 & Hofstaat König Josephs I. ab I685 \\
\hline I699 Juli I & & 8 & 425 & Hofstaat König Josephs I. ab I685 \\
\hline I7OI & 8 & & 426 & Neujahrsgeld für acht kais. Sesselträger \\
\hline I70r April is & & 9 & 427 & Hofstaat König Josephs I. ab I685 \\
\hline 1702 & 8 & & 428 & Neujahrsgeld für acht kais. Sesselträger \\
\hline 1703 & 8 & & 429 & Neujahrsgeld für acht kais. Sesselträger \\
\hline 1704 & $6 / 7$ & 8 & 430 & $\begin{array}{l}\text { Neujahrsgeld für sechs kais. Sesselträger beziehungsweise } \\
\text { gedrucktes Hofstaatsverzeichnis I704 (sieben kais. und acht } \\
\text { kgl. Sesselträger) }\end{array}$ \\
\hline
\end{tabular}

420 ÖStA, FHKA, HZAB, Bd. 139, fol. 292 r.

$42 \mathrm{I}$ ÖStA, FHKA, HZAB, Bd. I40, fol. 345r.

422 ÖStA, FHKA, HZAB, Bd. I4I, fol. 342r-v.

423 ÖStA, FHKA, HZAB, Bd. I42, fol. 4IIv-4I2r.

424 ÖStA, HHStA, OMeA, SR, Bd. 188, fol. 246r.

425 ÖStA, HHStA, OMeA, SR, Bd. I88, fol. 246r-v.

426 ÖStA, FHKA, HZAB, Bd. I43, fol. 4I8v.

427 ÖStA, HHStA, OMeA, SR, Bd. I88, fol. 246r-v.

428 ÖStA, FHKA, HZAB, Bd. I44, fol. 388v-389r. Im gedruckten Hofstaatsverzeichnis von 1702 ist zwar erwähnt, dass zwölf - namentlich nicht genannte - Sesselträger im kaiserlichen Hofstaat vorhanden seien, jedoch scheint es sich hierbei um die Zahl der Planstellen zu handeln, von denen damals offenbar einige vakant waren. Der königliche Hofstaat bleibt in diesem gedruckten Hofstaatsverzeichnis unerwähnt. Käyserlicher und Königlicher wie auch Ertz-Hertzoglicher und dero Residentz-Stadt Wienn Staats- und Stands-Kalender / Auff das Jahr M.DCCII. Mit einem noch nie dergleichen gesehenen Schematismo geziert (Wien o.J.), S. Io.

429 ÖStA, FHKA, HZAB, Bd. I45, fol. 296r.

430 ÖStA, FHKA, HZAB, Bd. I46, fol. 263v; Käyserlicher und Königlicher wie auch Ertz-Hertzoglicher und dero Residentz-Stadt Wienn Staats- und Stands-Kalender / Auff das jahr M.DCCIV. Mit 


\begin{tabular}{|c|c|c|c|c|}
\hline Datum & 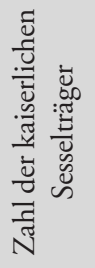 & 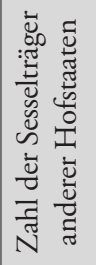 & $\frac{\ddot{v}}{\vec{\partial}}$ & Anmerkungen \\
\hline 1705 & 6 & & $43 \mathrm{I}$ & Neujahrsgeld für sechs kais. Sesselträger \\
\hline $1706 / 08$ & II & & 432 & Gedrucktes Hofstaatsverzeichnis 1706 bis 1708 \\
\hline I709/10 & II & & 433 & Gedrucktes Hofstaatsverzeichnis I709 bis I7IO \\
\hline I7II Juni I & II & & 434 & $\begin{array}{l}\text { Sesselträger im hinterlassenen Hofstaat von Kaiser Joseph I. } \\
(\dagger \text { I7. April I7II })\end{array}$ \\
\hline
\end{tabular}

6.4 Privileg für Miettragsessel in Wien (1703)

Privileg für die Vermietung von Tragsesseln in Wien und Umgebung, ausgestellt am 20. Juni I703 von Kaiser Leopold I. für Heinrich Ernst Rauchmüller. Quelle: Codex Austriacus (Wien I704), Teil 2, S. 342 f.

einem noch nie dergleichen gesehenen Schematismo geziert (Wien o.J.), S. 192, 205.

43I ÖStA, FHKA, HZAB, Bd. I47, fol. 264v. Eucharius Gottlieb Rinck listet in seiner Biographie Kaiser Leopolds I. für das Jahr I70s das kaiserliche Hofpersonal auf. Für den Hofstaat Leopolds I. erwähnt er fünf Sesselträger, für jenen der Kaiserin elf. RincK I709 (wie Anm. I5I), Bd. I, S. I70, 173. Wahrscheinlich handelt es sich dabei um ein Missverständnis. Vielleicht meinte Rinck, dass im Jahr des Todes Leopolds I. in dessen Hofstaat fünf und in jenem seines Sohnes Joseph I. elf Sesselträger dienten.

432 Staat des Käyserl. Hoffs / vom Jahr 1706. biß 1708. Ehedessen / unter dem Titl Käyserlichen und Königlichen / wie auch Ertz-Hertzoglichen / dan dero Residenz Stadt / Wienn / Staats- u. Stands-Kalender / Mit einem noch nie dergleichen gesehenen Schematismo heraus gegeben. Erster Theil (Wien o.J.), o.S.

433 Staat des Käyserl. Hoffs / von Jahr I709. biß I7ı. Ehedessen / unter dem Titl Käyserlichen und Königlichen / wie auch Ertz-Hertzoglichen / dan dero Residenz Stadt Wienn / Staats- u. Stands-Kalender mit einem noch nie dergleichen gesehenen Schematismo, heraus gegeben. Anderter Theil (Wien o.J.), o.S.

ÖNB, Handschriftensammlung, Cod. I4848, fol. IIv-I2r. 
Trag-Sessel-Ordnung.

Bekennen offentlich mit diesem Brieff / und thun kundt allermänniglich / daß Uns Unser Cammer-Diener und getreuer lieber Heinrich Ernst Rauchmüller allergehorsambst zuvernehmen gegeben / was massen Er willens wäre / zu bessern Nutzen deß gemeinen Wesens / Erspahrung der kostbaren Kobel-Wägen / und Verschonung deß Stadt-Pflasters / auch umb mehrer Bequemlichkeit und anderer Ursachen halber dahie / sowohl inn- als auch ausserhalb dieser Unserer Residentz-Stadt Wienn / die Trag-Sessel / allermassen solches in mehr andern Städten: benanntlich zu Londen / Pariß / Düsseldorf / München / Hannover / Turin / Brüssel / und dergleichen vornehmen Orthen mit guter Commodität / und Vortheil practicirt werde / zu introduciren; Solchemnach allerunterthänigst gebetten / daß Wir ihme hierauff Unser Kayserl. und Lands-Fürstl. Privilegium zuertheilen gnädigist geruhen wolten. Wann Wir dann gnädigist angesehen sein Supplicantens unterthängste Bitt / und daß durch solch vorhabende Einführ- und Gebrauchung der Lehen-Trag-Sessel niemanden praejudicirt / sondern hierdurch nur eine mehre Wohlfailkeit in mehr Sachen introducirt wurde / vorhero aber eine Nothdurfft zuseyn erachtet / gleichfalls Unsere N. Oe. Regierung / und Cammer hierüber zuvernehmen / und deß Lohns / Werths / oder Taxa halber: was nemblich von ein oder anderen Tag / Zeit / und Orth zubezahlen seyn mögte / mit dem Supplicanten tractiren / und ein gewisses außsetzen zulassen. Als haben Wir darumben / über von gedacht-Unserer Regierung und Cammer derentwegen abgefordert- und eingelangten Bericht und Gutachten: sodann Uns beschehenen gehorsambsten Vortrag / mit wohlbedachten Muth / guten Rath / und rechten Wissen / in solch sein Rauchmüllers allerunterthänigstes Bitten dergestalten gnädigst bewilliget / daß Er sich bey Außleihung derley Trag-Sessel keiner andern Außländischen / sondern allein Teutscher Nation, und in diesen Landen sich befindenden Leuthen gebrauchen / deßgleichen seinen gehorsambsten Erbieten gemäß keinen Krancken / noch Laggey / und dergleichen ringfügige Liberee-Personen (ausser die Pagen) vil weniger einen Juden tragen lassen. Sovil aber die Satzung: was nemblich von einem Trag-Sessel / oder Mühe / Weite des Weegs / auch allen Umbständen nach / der Billichkeit gemäß zunehmen seye / belanget / demselben jedesmahl von einem Orth / zu dem andern in der Stadt / es seye hernach weit oder nahend / für das Hintragen I4. Kreutzer / und dann auff Verlangen / für das Zuruck- nach Hauß / oder andernwärtiges Hintragen widerumb sovil / id est I4. Kreutzer / und im Fall man auch mehr Stund zuwarten begehrte / für jedwedere Stund auch 6. Kreutzer: wofern aber ein Sessel auff den gantzen tag: nemblich auff I2. Stund verlanget wurde / mehr nicht als I. fl. 30. Kr. folgends auff einen halben Tag pr. 6. Stund 45. Kreutzer inn und vor der Stadt zunehmen passirt: Hingegen jedermann nicht allein den Hin- und Hergang / sondern auch alle Warth-Stunden / wie eben auff den gantzen und halben Tag in allweeg vorhinein bezahlen: benebens 
die Sessel-Trager in allweeg verbunden seyn sollen / dieser Satzung strictè nachzuleben / und auff keine Weiß mehr / wohl aber / da sie freywillig wolten / weniger zunehmen. Thuen das alles auß Kayserl. und Lands-Fürstl. Machts-Vollkommenheit hiemit wissentlich in Krafft dieses Brieffs / bewilligen und erlauben ihme Unserem Cammer-Diener Heinrich Ernst Rauchmüller / daß er allein / sonsten aber niemands anderer / Lebenslang in- und umb diese Unsere Stadt Wienn / seiner Gelegenheit und Gefallen nach / die Trag-Sessel / ungehindert männigliches introduciren und außlehen / gleichwie in andern Städten und Orthen gewöhnlich / und Herkommens / alle und jede / so sich tragen lassen wollen / und vorstehender massen / nichts außgenommen / redlich und ehrlich durch seine / an einem oder andern / mit denen von Wienn umb ein gewisses ad dies vitae verglichen- und darzu bestimbten eigentlichen Platz und Orth hierzu haltende Leuth bedienen: Uber obaußgesetzte Tax oder Satzung aber niemanden beschwären / noch darüber ein mehrers begehren / sondern darmit ohne Unterschied deß Wetters / und der Zeit / man verlange das Sessel-Tragen in oder ausser der Stadt / sich allerdings begnügen lassen. Damit aber auch dem Armen-Hauß hierdurch nichts entgehen möchte / dannenhero von jedem Trag-Sessel / die erste vier Jahr hindurch / immassen die Einrichtung gleichwohlen ein nahmhafftes kosten wird / Monathlich nur I. fl. nach deren Verfliessung aber / von jedem Trag-Sessel das Monath hindurch I. fl. 30 Kr. in das Armen-Hauß ordentlich bezahlt / und abgeführt / auch obberührte Satzung und Tax zu männigliches Wissen und Nachricht ad publicas valvas, oder wenigist an dem / für die Sessel-Trager bestimbten Orth und Platz angeschlagen / und publicirt werden solle. Gebieten etc. 


\section{„In- und außwendig mit Gold vertrefflichist außgeziert". Tragsessel am Münchner Hof}

\section{Tragsessel im Münchner Marstallmuseum}

Zwei prächtige Tragsessel aus dem 17. und I8. Jahrhundert in der Sammlung des Münchner Marstallmuseums in Schloss Nymphenburg zeugen aufgrund ihrer kostbaren Ausstattung noch heute von ihrer repräsentativen Funktion. Dass sie die Jahrhunderte überdauerten, spricht für ihre Wertschätzung durch die nachfolgenden Generationen der Wittelsbacher. Beide Tragsessel, so unterschiedlich sie auch erscheinen, sind äußerst kostbar gefertigt und von herausragender handwerklicher Qualität. Zugleich mag ein genealogischer Aspekt ausschlaggebend für ihre Erhaltung gewesen sein.

\subsection{Gala-Tragsessel von Kurfürstin Maria Antonia, um 1684/85}

Bei dem älteren, um I684/85 in Paris gefertigten Tragsessel (Abb. I) handelt es sich mit großer Wahrscheinlichkeit um den „Churfürst[lichen] Tragsessl“ von Maria Antonia von Österreich (I669-I692). ${ }^{\mathrm{I}}$ Die Habsburger Kaisertochter heiratete am I5. Juli I685 in Wien den bayerischen Kurfürsten Maximilian II. Emanuel (reg. I680-1726). Anlässlich dieser Hochzeit tätigte Max Emanuel umfangreiche Bestellungen in Paris. Eine ins Deutsche übertragene Rechnung, datiert vom 24. Januar I694, fasst die Ausgaben von I685 detailreich zusammen und nennt eine Restsumme, die Max Emanuel zu diesem Zeitpunkt wohl immer noch schuldet. Die Zusammenstellung gibt auch Auskunft über den Tragsessel:

Der khönig[liche] Sadler Saliot hat nit allein die churfürst[liche] Praitgutschen, sonder auch den churfürst[lichen] Tragsessl verferttiget, alles Golt zu dem Stickh [Stück] nit zu der

I Vgl. Rudolf H. Wackernagel (Hg.), Staats- und Galawagen der Wittelsbacher. Kutschen, Schlitten und Sänften aus dem Marstallmuseum Schloß Nymphenburg, 2 Bde. (Stuttgart 2002), Bd. I, S. 8I. 


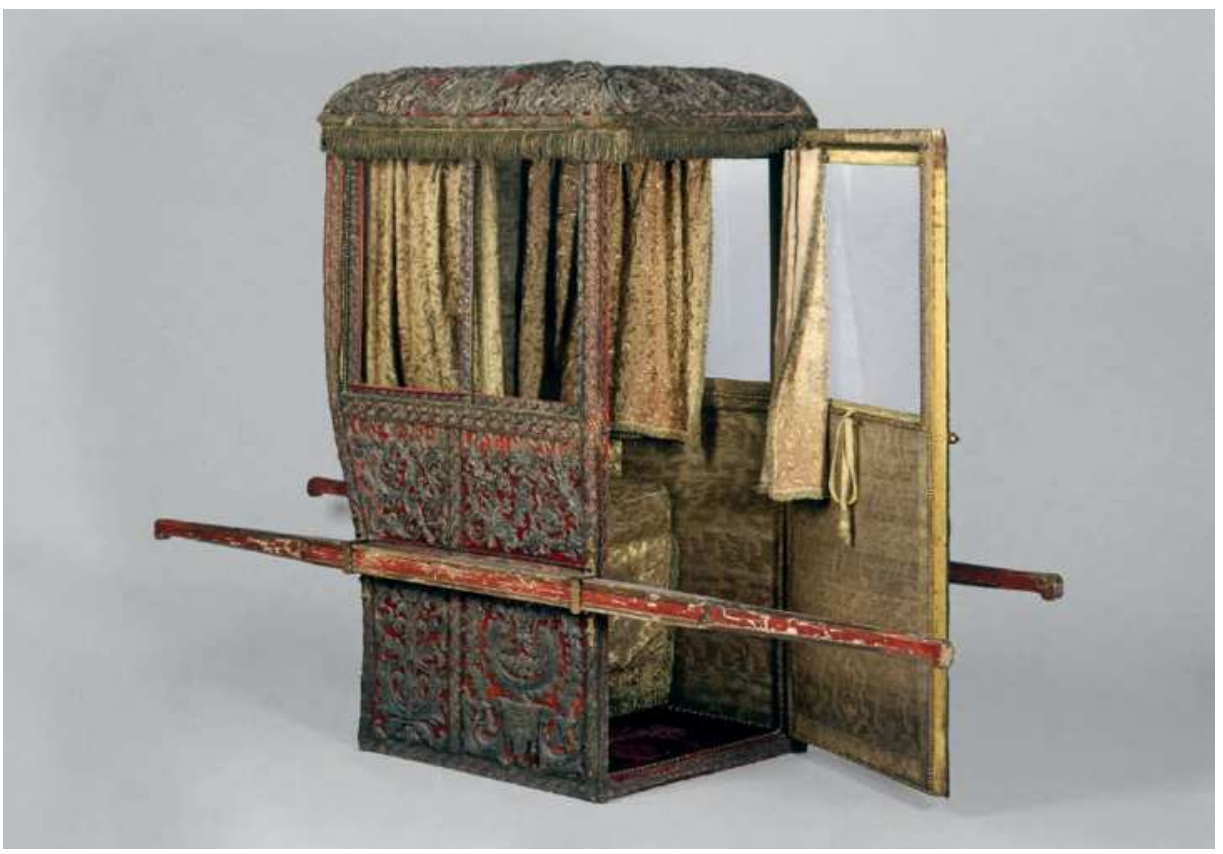

Abb. 1: Tragsessel von Maria Antonia, gefertigt von Saillot in Paris um 1684/85. @ BSV

Gutschen und Sessl sonder auch zu 6 Geschirr, wie nit weniger den Sammet und andere reiche Zeug, herbey geschafft, sonder auch den Maller, Schlosser, Schmidt, Wagner und Pilthauer, selbsten bezalt trifft also dess. Conto. 4I.844 franc. ${ }^{2}$

Der Tragsessel wurde also zusammen mit einer Brautkutsche sowie dem Geschirr für einen Sechsspänner von dem Sattlermeister Saillot, der auch das französische Königshaus belieferte, als Ensemble gefertigt. Die Kutsche war im selben Stil mit Samt kaschiert und mit aufwendigster Gold- und Silberstickerei dekoriert. Die textile Verkleidung von hochrangigen Kutschen, Sänften und Tragsesseln war in Deutschland bis ins späte I7. Jahrhundert

2 BHStA, FS 704, fol. 239v. Die gesamte Rechnung umfasst fol. 237r-25Ir. Für die Transkription danken wir Dr. Magdalena Bayreuther. Vgl. auch Wackernagel 2002 (wie Anm. I), Bd. I, S. 8I, Anm. 8. Für dieses Zitat und sämtliche weiteren Auszüge aus den ungedruckten Quellen gelten folgende Transkriptionsregeln: Die Wiedergabe der Quellen erfolgt buchstabengetreu. Als Ausnahme von dieser Regel werden die Buchstaben u und v ihrem Lautwert entsprechend wiedergegeben. Die Groß- und Kleinschreibung wird den aktuell gültigen Regeln angepasst. Die originale Interpunktion wird hingegen, wenn möglich, beibehalten. Wo es zum besseren Verständnis notwendig ist, wird sie allerdings den heute geltenden Regeln angepasst. 
Abb. 2: Detail von der Rückseite des Tragsessels: Das sächsische Wappen auf der heraldisch linken Seite ersetzte um 1747 das ursprüngliche österreichische Wappen mit dem Bindenschild. (c) BSV

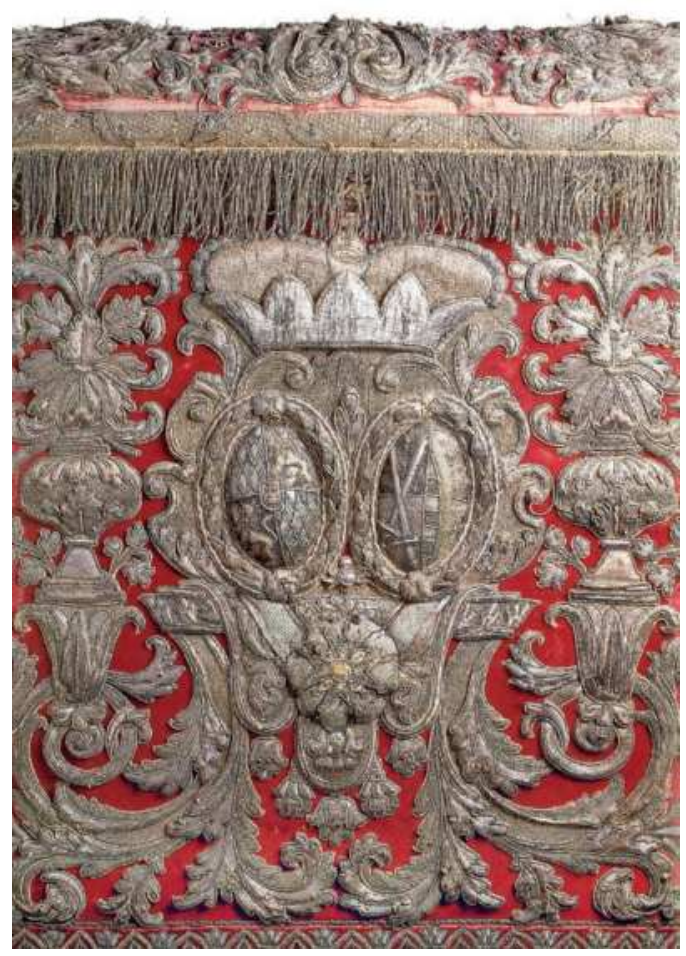

üblich. ${ }^{3}$ Während die Kutsche und das Geschirr nicht erhalten sind, wurde der Tragsessel noch von Kurfürstin Maria Anna Sophie (1728-1797) geschätzt und verwendet, wovon das zeitgenössisch ergänzte Allianzwappen von Bayern und Sachsen auf der Rückwand des Tragsessels zeugt (Abb. 2). Das Wappen könnte auch darauf hinweisen, dass der äußerst repräsentative Tragsessel 1747 bei der Hochzeit der sächsischen Prinzessin mit Kurfürst Max III. Joseph in Dresden Verwendung fand. ${ }^{4}$ Denn Kurfürst Max III. Joseph (reg. I745-I777) hatte Bayern zwei Jahre zuvor von seinem verstorbenen Vater, Kaiser Karl VII., in einem desolaten Zustand übernommen. Um die immense Schuldenlast abzubauen, waren entschiedene Sparmaßnahmen notwendig, die auch eine weitere Verwendung des prächtigen Tragsessels Maria Antonias, der ersten Gemahlin seines Großvaters, begründen könnten. Aufgrund des Wappens galt der Tragsessel lange Zeit als Transportmittel von Maria Anna Sophie. Man nahm sogar an, dass die Stickerei von der Kurfürstin selbst -

3 In Italien bis ins frühe I8. Jahrhundert. Vgl. Wackernagel 2002 (wie Anm. I), Bd. 2, S. IOI.

4 Bei der bayerisch-sächsischen Doppelhochzeit heiratete Maria Anna Sophie von Sachsen den bayerischen Kurfürsten Max III. Joseph, und dessen Schwester Maria Antonia von Bayern vermählte sich mit Kurfürst Friedrich Christian von Sachsen. 


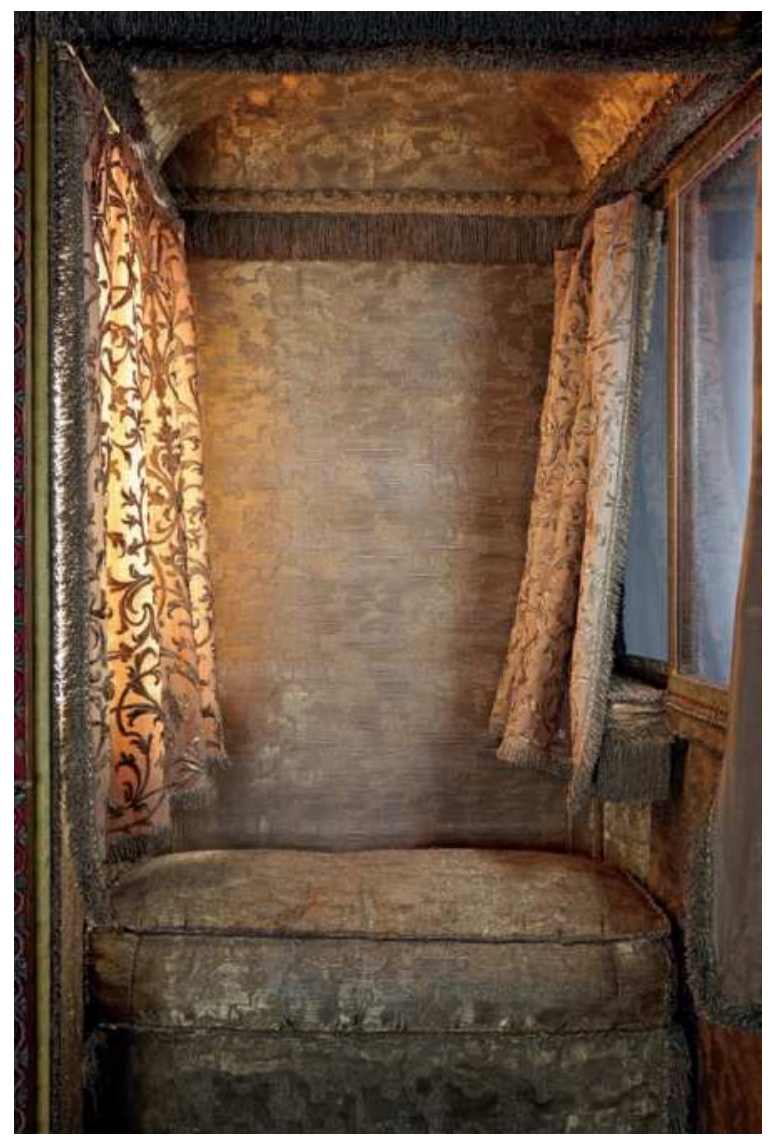

Abb. 3: Innenansicht des Tragsessels von Maria Antonia. Tapezierung mit Goldtuch (Drap d'or). ( BSV

„der Ornamentik nach wohl nach Vorbildern des frühen I8. Jahrhunderts“ - ausgeführt worden war. ${ }^{5}$

Die textile Ausstattung des Tragsessels ist überaus reich und kostbar. Außenwände und Dach sind im damaligen Zeitgeschmack vollständig mit rotem Samt kaschiert, auf dem die goldene Reliefstickerei ein dichtes barockes Muster aus Vasen, Akanthusblättern und Ranken bildet. Textile Goldborten und Goldfransen rahmen den kostbaren Stoff. Trotz der Oxydation und Verfärbung der Goldfäden ist der damalige prachtvolle Eindruck auch heute noch erkennbar. Im Inneren sind die Wände und Sitzpolster mit Gold-Brokatell in zwei unter-

5 Armin Hausladen/Heinrich Kreisel (Bearb.), Marstallmuseum in München. Hofwagenburg und Sattelkammer. Kleiner Führer, hg. von Friedrich H. Hofmann, Direktion der Museen und Kunstsammlungen des ehemaligen Krongutes in Bayern (München I923), S. IO, Nr. 4. Erst 2002 wurde diese Annahme mit den Bestandskatalogen von Rudolf H. Wackernagel korrigiert. 
schiedlichen Webmustern bezogen, wobei die textile Verkleidung des abnehmbaren Daches besonders gut erhalten ist (Abb. 3). Der Innenraum ist - am Boden, um die Fenster-Bordüren und um das Türfeld - mit mehreren Hundert vergoldeten Ziernägeln sehr reich beschlagen. Die Tür des Tragsessels lässt sich nur öffnen, wenn das Dach angehoben wird, wodurch auch das Ein- und Aussteigen erleichtert wird. Die Ausstattung mit sogenanntem Goldtuch oder „drap d'or", einem mit Goldfäden durchwebten Textil, war ein Zeichen kaiserlicher Abstammung. ${ }^{6}$ Maria Antonia hatte als kaiserliche Prinzessin und einzige überlebende Tochter aus der ersten Ehe Kaiser Leopolds I. Anspruch auf dieses Würdezeichen. Für ihren zukünftigen Gatten, Kurfürst Max Emanuel, war die Heirat mit der Kaisertochter ein wichtiger Baustein für das eigene Streben nach Rangerhöhung und Machtzuwachs, um das wichtigste Ziel, die Kaiserwürde, zu erlangen. Die entsprechende Repräsentation seiner Braut kann somit auch als Demonstration der eigenen politischen Ziele und Ansprüche gewertet werden.

Noch im I9. Jahrhundert fand der Tragsessel von Kurfürstin Maria Antonia am Münchner Hof so große Wertschätzung, dass er im kurfürstlichen „Wagen-Inventarium“ von I799-I8II an erster Stelle der „Senften“ genannt wurde:

Ein Tragsessel auswendig von rothem Samet mit Gold gestückt [gestickt], goldenen Franzen, und Crepinen garniert; inwendig aber von goldenem ganz reichen Zeugs ausgemacht nebst solchem Sitzkissen mit goldnen Franzen besetzt, dann Vorhängen von rothem Grosdetour mit Gold gestückt. ${ }^{7}$

Diese einst rötlichen, mit Goldmetallfaden bestickten Vorhänge aus Gros de Tours sind in die zweite Hälfte des I8. Jahrhunderts zu datieren. ${ }^{8}$ Sie ersetzten wohl die erste Vorhanggarnitur aus Goldtuch. Heute sind die Vorhänge aufgrund von Lichteintrag verblichen und erscheinen in einem zarten Gelb. Der einstige Rotton der Vorhänge, die vor die original erhaltenen Schiebefenster gezogen werden konnten, ist lediglich noch im Inneren als helles Rosa zu erkennen. Der Tragsessel war damals laut Inventar in der Sattelkammer deponiert, wo die Kost-

6 Gottfried Stieves „Hoff-Ceremoniel“ von 1723 beschreibt im Kapitel „Was für ein Ceremoniel bey Zusammenkunfft Kayerl. Majestät, und eines Churfüsten gewöhnlich ist" das Audienzzimmer: „In diesem sind die Sessel, und zwar des Kaysers meistens von Gold- oder Silber-Brocat, des Churfürsten aber von Carmesin-Sammet, mit goldenen Frantzen bordieret“. Gottfried STieve, Hoff-Ceremoniel (Leipzig ${ }^{2}$ I723), S. I86. Vgl. auch: Esther Janowitz, Textile Pracht und höfisches Zeremoniell. In: Rudolstädter Forschungen zur Residenzkultur, Bd. 3: Zeichen und Raum (München 2006), S. 325-350, hier S. 340; WaCkernagel 2002 (wie Anm. I), Bd. 2, S. 102.

7 BSV.Invor95, fol. $224 \mathrm{v}$.

8 Gros de Tours ist ein mit Leinen gebundenes Seidengewebe, in dem der Schuss aus jeweils zwei Fäden gebildet wird. Für die zeitliche Einschätzung danken wir sehr herzlich Prof. Dr. Birgitt Borkopp-Restle, Universität Bern. 
barkeiten des königlichen Marstalls aufbewahrt wurden. ${ }^{9}$ Die Qualität der Textilien und Stickereien des Tragsessels wurde so hoch geschätzt, dass er 1876 als Leihgabe König Ludwigs II. in der Kunst- und Industrieausstellung im Münchner Glaspalast zu sehen war. ${ }^{10}$ Neben kostbaren Exponaten des South Kensington Museum (heute Victoria \& Albert Museum) in London war der Tragsessel als Beispiel für herausragendes Kunsthandwerk ausgestellt.

Der zweite erhaltene Tragsessel des Münchner Hofs entstand wohl um 1747 anlässlich der Vermählung von Kurfürst Max III. Joseph mit Maria Anna Sophie von Sachsen. ${ }^{\text {II }}$ Auch bei diesem Tragsessel (Abb. 4) mag die kostbare Ausstattung und insbesondere der aufwendige Lackdekor in Silber und Blau, den heraldischen Farben Bayerns, ausschlaggebend für die Erhaltung gewesen sein. Die hölzerne Kastenwandung ist mit Leinwand kaschiert und außen mit Azurit-Blau und teils poliertem Zinnpulver bemalt. ${ }^{\mathrm{I2}}$ Die Rahmenkonstruktion zeigt ehemals blauen Lüster und Poliment-Versilberung. Sowohl das kleinteilige, zierliche Rautenmuster der Paneele als auch das Schnitzwerk der Rahmen greift das Webmuster des prachtvollen silbernen und blauen Seidenstoffs auf, mit dem der Innenraum ausgestattet ist. Nur bei genauem Hinsehen wird deutlich, dass die Maler das Stoffmuster bis ins kleinste Detail, wie zum Beispiel den Schatten beziehungsweise das Changieren des Gewebes, imitierten (Abb. 5). Die äußere Dekoration des Tragsessels wurde somit nach dem damals kostbarsten Material, dem Textil, angefertigt. Das Muster ist dem Droguet verwandt, einem Seidengewebe mit schmalen Musterrapporten, der aber gewöhnlich in die zweite Hälfte des I8. Jahrhunderts datiert wird (Abb. 6). Hier könnte es sich um ein frühes Beispiel handeln. ${ }^{13}$ Die originalen

9 Johann Michael von Söltl beschreibt I838 in „München mit seinen Umgebungen“ die Sattelkammer, allerdings ohne den Tragsessel zu erwähnen. Johann Michael von SöıtL, München mit seinen Umgebungen historisch, topographisch, statistisch dargestellt (München I838), S. 207. - Vgl. WACKernagel 2002 (wie Anm. I), Bd. 2, S. ioI und IO3, Anm. I4.

Vgl. Wackernagel 2002 (wie Anm. I), Bd. 2, S. IOI, Abb. III. - Der I93I ausgebrannte Glaspalast war ein multifunktionales Ausstellungs- und Veranstaltungsgebäude im Alten Botanischen Garten in München. König Maximilian II. ließ ihn I853/54 nach Plänen von August von Voit (I8OI-I870) erbauen. Als Vorbild diente die Eisen-Glas-Konstruktion des berühmten Crystal Palace in London. Durch den Glaspalast begründete sich der Ruf Münchens als fortschrittlicher Wirtschaftsund Messestandort sowie als Kunststadt.

II Ob er in München gefertigt wurde, wie Wackernagel 2002 (wie Anm. I), Bd. I, S. 82 vermutet, oder doch in Paris, bedarf noch weiterer Forschungen.

I2 Alle technischen Angaben verdanken wir Dipl.-Rest. Hella Huber, Möbelrestaurierung der BSV, die die Lackmalerei des Tragsessels 2015/16 restauriert hat.

Vgl. Wackernagel 2002 (wie Anm. I), Bd. 2, S. IO5. 


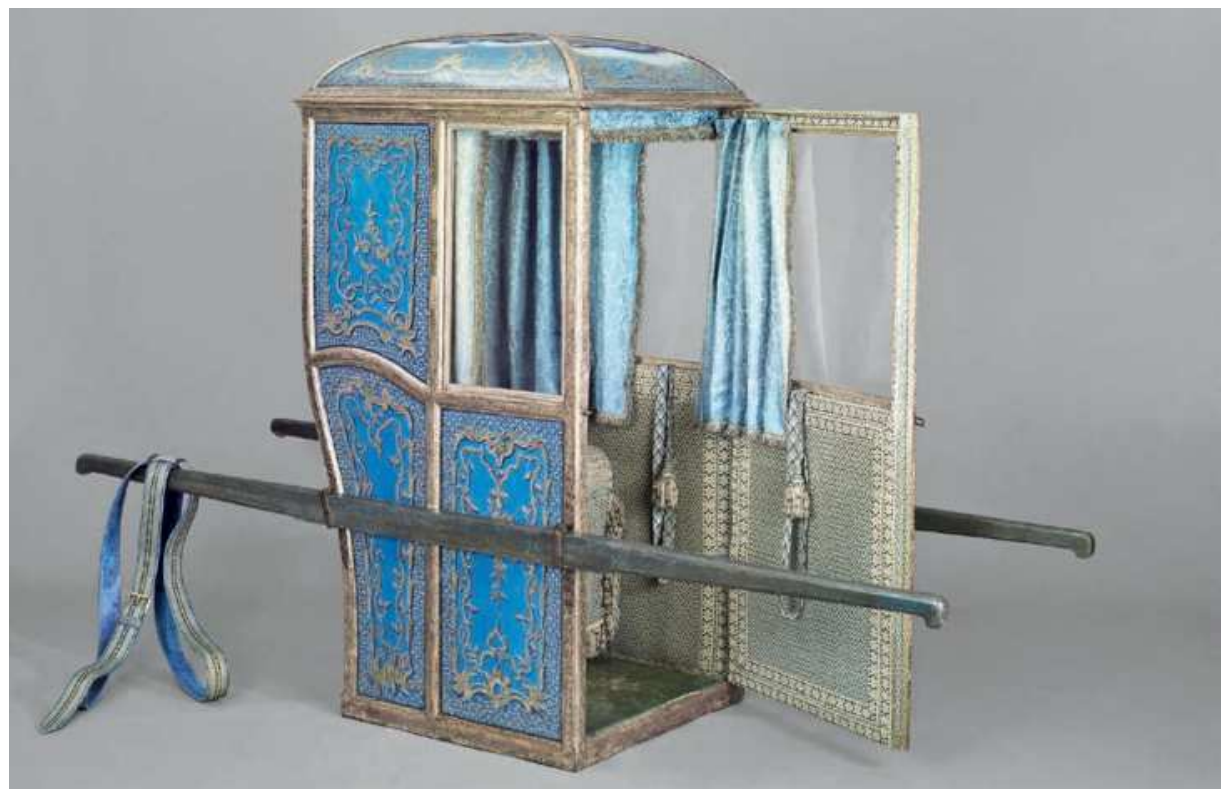

Abb. 4: Tragsessel um 1747 mit silber-blauem Lackdekor (Zustand nach der Restaurierung 2016). ( BSV

Glasfenster, die wahrscheinlich aus Frankreich stammen, ${ }^{14}$ können mittels der gewebten Riemen in den Seitenwänden versenkt werden. Auch dieser Tragsessel besitzt ein abnehmbares Dach, um das Ein- und Aussteigen zu vereinfachen. Erste Ergebnisse der Restaurierung, die eine behutsame Annäherung an das originale Erscheinungsbild darstellt, wurden durch die Abnahme des vergilbten Firnisses deutlich sichtbar. Anstelle der gelb-grünlichen Verfärbung erscheint der Tragsessel wieder in seinem ursprünglichen Farbklang (Abb. 7). Die Feinheit der Malerei tritt stärker hervor, die gesamte Darstellung von silbernen Ranken und Spalierwerk vor blauem Hintergrund gewinnt an Tiefe und Plastizität.

Der Tragsessel befand sich offenbar nie im Marstall, wo er in den Inventaren des I8. Jahrhunderts nicht nachweisbar ist, sondern wurde erst I807 im Inventar der Gardemeuble der Residenz München erwähnt:

Ein blau laquirter und mit silber Blumen gemahlener Tragseßl; der inwendig so wie das hierin befindliche Sitzkiß[en], mit blau geschnürlten Samet ausgemacht, und mit Silber-vermengten Fransen besetzt ist. Die Vorhänge inwendig sind von blauen Damast. ${ }^{15}$

\footnotetext{
I4 Freundlicher Hinweis von Ingrid Thom, Restauratorin des Fachbereichs Kunsthandwerk bei der BSV. Oberfläche und Struktur der Gläser sprechen für eine Herkunft aus Frankreich.

Is BSV.Invoo92: „Inventarium über die in der Gardemeuble aufbewahrten Residenz Meubles so anderen Geräthschaften. Aufgenohmen den 22. July I807. II Theil“ (lose beiliegend, ohne Paginie-
} 


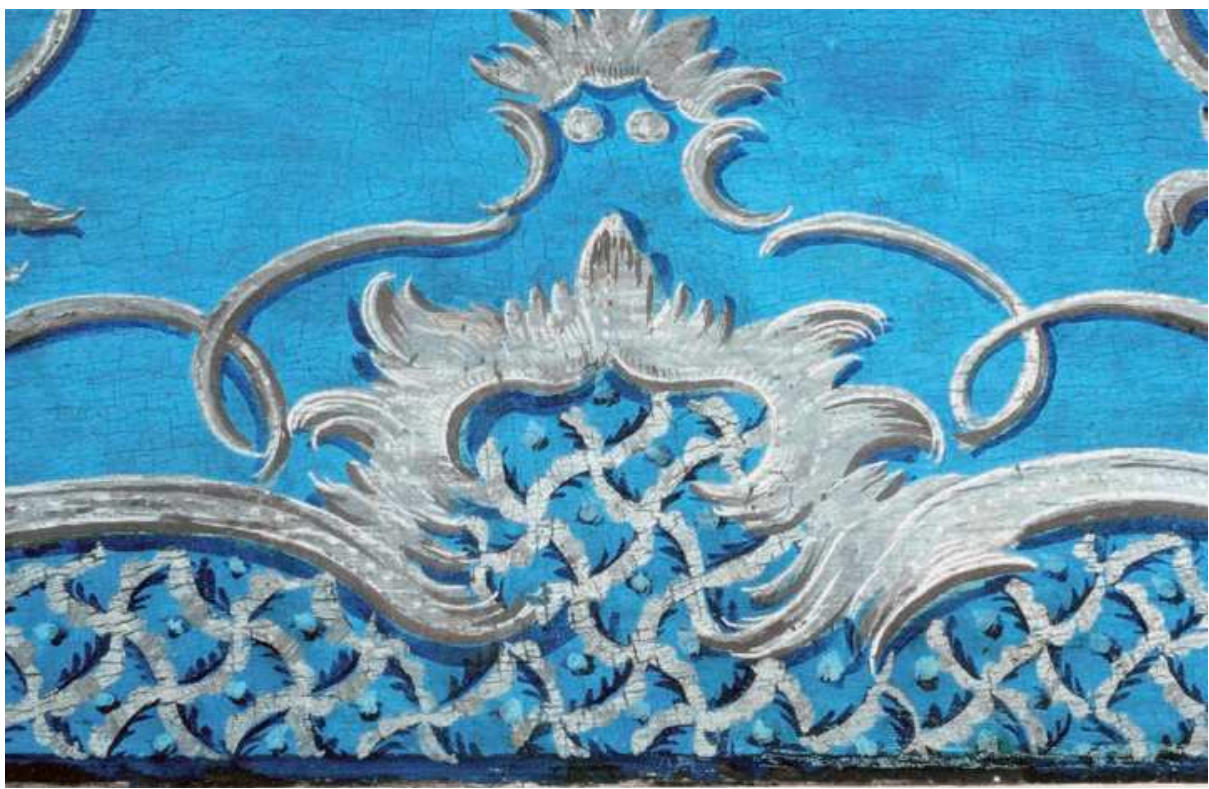

Abb. 5: Ausschnitt des restaurierten Baldachins. Die Malerei imitiert Details des Stoffmusters. Foto: Hella Huber

Wahrscheinlich wurde der lackierte Tragsessel nur in Innenräumen oder bei gutem Wetter im Garten verwendet. Diesen Rückschluss legt der Lackbefund nahe. Es handelt sich bei dem ursprünglichen Lack nicht um einen wasserfesten Harz-Öl-Lack, aus dem auch der berühmte Vernis Martin besteht, sondern um einen empfindlicheren, nicht wetterfesten Weingeist-Firnis. Für eine Verwendung im Garten spricht auch die zierliche, an Gartenspaliere erinnernde Rokoko-Ornamentik der Malerei. Die Sommerresidenz der bayerischen Kurfürsten, Schloss Nymphenburg mit den Parkburgen Amalienburg, Badenburg und Pagodenburg, käme als einstiger Einsatzort des eleganten Transportmittels in Frage. ${ }^{16}$ Möglicherweise handelt es sich wie bei dem Gala-Tragsessel von Maria Antonia auch hier um einen Tragsessel, der vorwiegend von Frauen genutzt wurde. ${ }^{17}$

rung). Vgl. auch Wackernagel 2002 (wie Anm. I), Bd. 2, S. IO4.

I6 Quellen hierzu sind uns bislang nicht bekannt. In den Nymphenburger Inventaren sind nur die ständigen Ausstattungsgegenstände der Schlossräume verzeichnet, nicht jedoch diejenigen, die für die Sommersaison temporär aus der Residenz München mitgebracht wurden.

17 Nach Johann Jakob Schüblers architektonischem Lehrbuch von 1725/1728 „Zweyter Theil / Des Gründlichen Unterrichtes ..." waren die „Frauenzimmer“-Sänften allgemein so beschaffen, dass sie „aussen so wol mit mehr Zierrathen versehen, als auch innenwendig bey den Füssen, wegen der Kleider, mehr Raum haben." Johann Jakob Schüвler, Zweyter Theil / Des Gründlichen Unterrichtes, Der vollständigen Säulen-Ordnung, Nach der heutigen CIVIL-Bau=Kunst (Nürnberg I725-1728), S. 24 

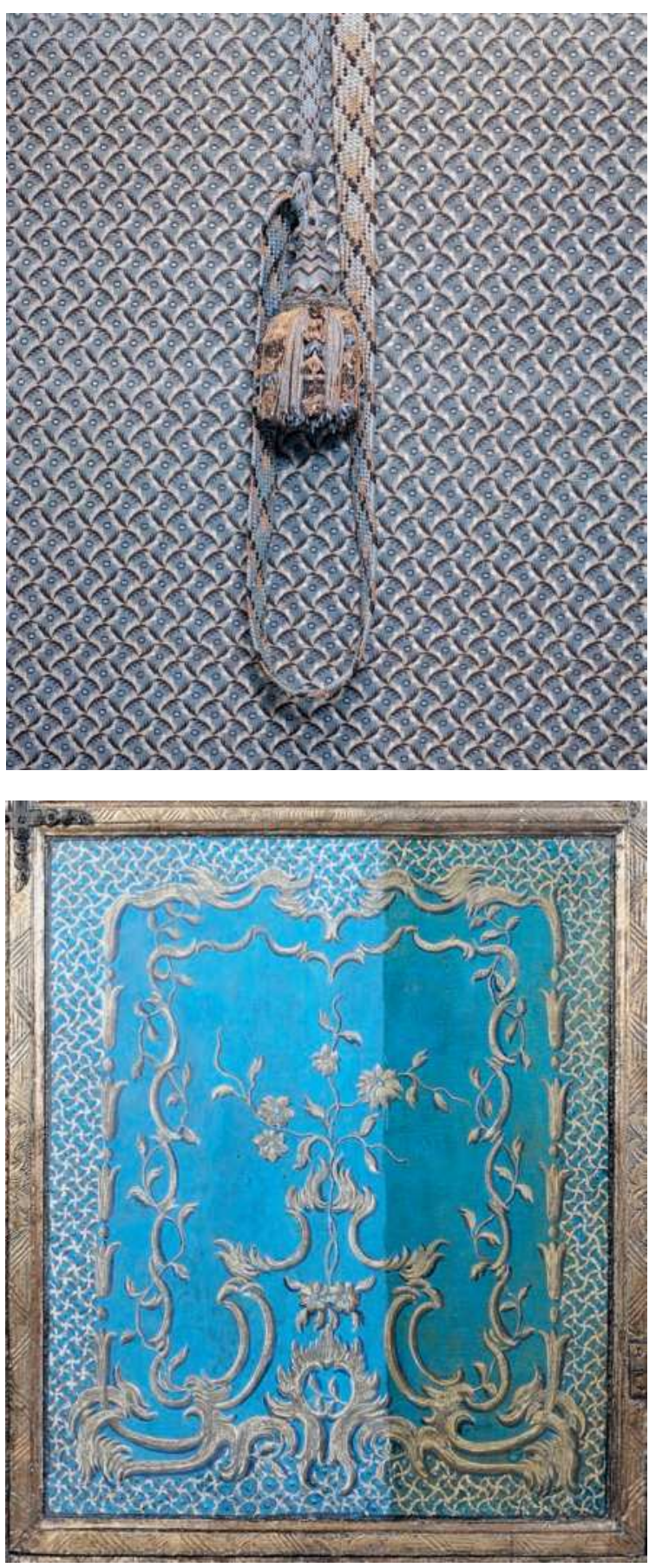

Abb. 6: Detail des „Droguet“-artigen Stoffmusters im Tragsessel um 1747 (c) BSV

Abb. 7: Die Türfüllung des Tragsessels während der Firnisabnahme. Foto: Hella Huber 
Im Gegensatz zu den beiden im Marstallmuseum erhalten gebliebenen Tragsesseln erachtete man andere in den Inventaren verzeichnete Tragsessel als weniger erhaltenswert. Ihre Zerstörung und Umarbeitung zu anderen Zwecken ist beispielsweise im Inventar von 1728 dokumentiert: Ein „plausammeter“ Tragsessel wurde einer Randnotiz zufolge 1729 zerschlagen und der Samt für einen Sattel verwendet. ${ }^{18}$

\section{Quellen zu Gebrauch und Funktion der frühen Tragsessel am Münchner Hof}

So wertvoll die beiden Gala-Tragsessel als bildhafte Zeugnisse für den hohen repräsentativen Anspruch der Wittelsbacher heute sind, so verraten sie uns doch nichts über die einstige Nutzung und die Funktion, die Tragsessel am Münchner Hof der Wittelsbacher hatten. Über die Marstallinventare hinaus sind Bemerkungen zum Gebrauch eines Tragsessels in unterschiedlichsten Kontexten des Münchner Hofes und seines Umfeldes zu finden, wie zum Beispiel in Biographien, Reise- und Festberichten. Leider werden vor allem in der Sekundärliteratur die Begriffe Sänfte und Tragsessel meist synonym verwendet, was weitere Recherchen nach sich zieht.

Aufschlussreich ist zunächst ein Blick in die Teilinventare oder Gesamtverzeichnisse des fürstlichen Marstalls, die sich vom I6. bis zum 20. Jahrhundert nahezu lückenlos erhalten haben. ${ }^{19}$ In den Gesamtverzeichnissen wurden neben den Pferden und Eseln auch die Kutschen, Sänften, Tragsessel, Schlitten und sämtliches Reit- und Fahrzubehör erfasst. Die Auflistung erfolgte meist in hierarchisch absteigender Ordnung. Der Marstall unterstand dem Oberststallmeisteramt, und in der Regel wurde mit jedem Wechsel des Oberststallmeisters ein neues Inventar verfasst. Mitunter gab auch das Ableben eines regierenden Herrschers Anlass für die Erstellung eines neuen Inventars (Quellenanhang 5.I).

Das früheste erhaltene Inventar datiert aus dem Jahr 1560, also in die Regierungszeit von Herzog Albrecht V. (reg. 1550-I579). Dieser hatte 1546 Erzherzogin Anna von Österreich geheiratet, eine Tochter des späteren Kaisers Ferdinand I. und Schwester des nachfolgenden Kaisers Maximilian II. Die enge Verbindung zum Hause Habsburg war für Herzog Albrecht V. Anlass genug, Pracht und Aufwand seiner Münchner Hofhaltung an der Re-

I8 BSV.Invo205, fol. 37v. - Vgl. WACKernagel 2002 (wie Anm. I), Bd. 2, S. IO4.

I9 Vgl. Brigitte VolK-Knüttel, Verzeichnis der Inventare. In: WaCkernagel 2002 (wie Anm. I), Bd. 2, S. 348-35I. - Für die große Unterstützung bei der Durchsicht und Transkription der Inventare danken wir Dr. Magdalena Bayreuther. 


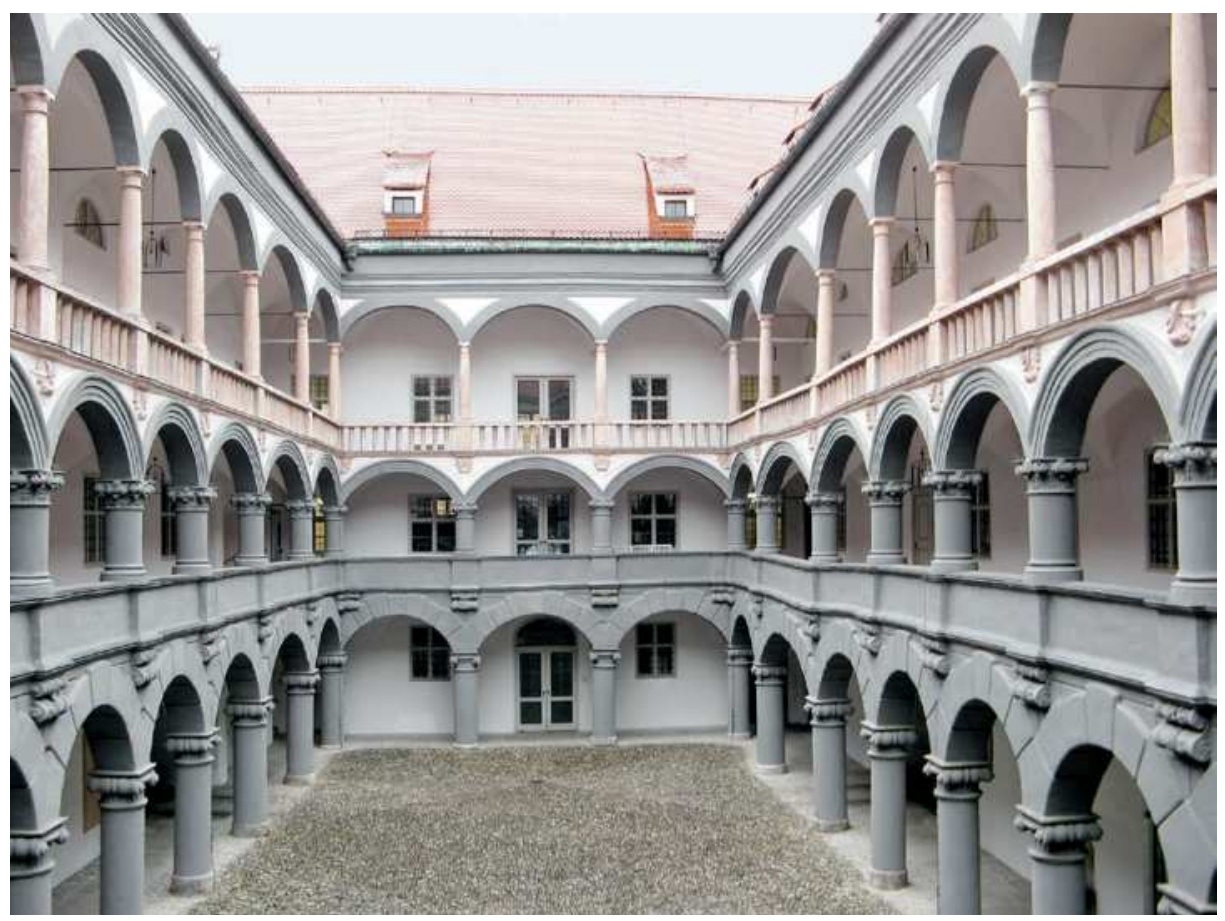

Abb. 8: Innenhof des Marstallgebäudes, das Herzog Albrecht V. 1563-1567 nahe dem Alten Hof erbauen ließ. Foto: Gudrun Szczepanek

präsentation des Habsburger Kaiserhauses zu messen. Von 1563 bis 1567 ließ er nahe dem Alten Hof ein neues Marstallgebäude als große dreigeschossige Vierflügelanlage mit zum Innenhof ausgerichteten Arkadengängen bauen (Abb. 8). Im Erdgeschoss befanden sich die vom Innenhof aus zugänglichen Stallungen. Die Arkadenöffnungen waren teilweise durch heute nicht mehr vorhandene gemauerte Wände zu Depoträumen ausgebaut. ${ }^{20}$ Hier wurden den Inventaren zufolge unter anderem die Sänften und Tragsessel sowie deren Zubehör aufbewahrt. Im ersten Obergeschoss waren die Sattelkammern und Wohnräume des Stallmeisters eingerichtet, und im zweiten, höheren und lichteren Stockwerk befand sich auf rund I200 Quadratmetern die Kunstkammer. Die Verbindung von fürstlichem Marstall im Erdgeschoss und Kunstkammer im Obergeschoss mag auf den ersten Blick erstaunen, doch waren Pferde und Kunstwerke als Luxusgüter gleichermaßen wertvoll und repräsentativ. ${ }^{21}$

Das lediglich zehn beschriebene Blätter umfassende Teilinventar von 1560 nennt keine

20 Vgl. Wackernagel 2002 (wie Anm. i), Bd. 2, S. 55, Abb. 7I.

2I Zur Münchner Kunstkammer mit Marstall siehe: Lorenz SEELIG, Die Münchner Kunstkammer. In: Die Münchner Kunstkammer, Bd. 3: Aufsätze und Anhänge, vorgelegt von Willibald SAUERLÄNDER (München 2008), S. I-I24, hier S. I2-I7 (mit weiterführender Literatur). 
Tragsessel oder Sänften. ${ }^{22}$ Erst zwanzig Jahre später im Inventar von I58I findet sich ein „Verzaichnus waß auf die Esl geherig“. ${ }^{23}$ Im „Ersten [bis] driten Castn“, womit vermutlich die gemauerten Verschläge in den Arkaden gemeint sind, befanden sich sechs zum Teil alte Sänften sowie Zubehör wie Sänftensättel, Eseldecken und Zaumzeug für die Lasttiere. Möglicherweise handelte es sich um ausgediente Sänften, denn einige Seiten weiter folgt noch einmal eine Auflistung von sechs „Senfften“, darunter eine Sänfte „für die junge Herrschafft“. An dieser Stelle handelt es sich um prunkvolle und repräsentative Sänften, die mit schwarzem Samt, rotem Atlas oder Leder überzogen und mit „vergultem Geschmeid“ ausgestattet waren. ${ }^{24}$ Da das Inventar keine Tragsessel nennt, Sänften jedoch an zwei unterschiedlichen Stellen aufgelistet werden, könnte man schließen, dass die beiden Begriffe synonym verwendet wurden. Dies ist jedoch unwahrscheinlich, unterscheidet doch das spätere Gesamtinventar von 1656 eindeutig zwischen Sänften und Tragsesseln, wenn es heißt: „Volgen die Leibsönfften und Tragseßl“. Neben sieben Sänften werden sechs „gedöckt Leibtragsessl“ und fünf „unbedöckhte Tragsessl“ aufgelistet (Quellenanhang 5.I). ${ }^{25}$ Vermerke über Reparaturen an Tragsesseln zeugen von ihrem Gebrauch. So erwähnt das Inventar von 1656 auch, dass ein geschlossener „blausamtener Tragsessel“, der „mit Silber verbrämt“ war, aus Wien an den Münchner Hof kam. Da der blaue Samt vollständig „abganngt gewesen“, also abgewetzt war, wurde er, einer Anmerkung im Inventar zufolge, mit schwarzem „herschei [Hirschleder?]“ neu bezogen. ${ }^{26}$

\subsection{Erste Tragsessel unter Kurfürstin Maria Anna, 1635}

Möglicherweise kam dieser Tragsessel, der in den heraldischen Farben der Wittelsbacher gefertigt war, mit Erzherzogin Maria Anna von Österreich (I6IO-1665) nach München. Sie hatte I635 in Wien den bayerischen Kurfürsten Maximilian I. (reg. I597-I65I, ab I623 als Kurfürst) als dessen zweite Gemahlin geheiratet. Dass der blaue Samt zwanzig Jahre später abgenutzt war, ist selbst bei mäßigem Gebrauch kein Wunder. Bereits I638 werden in den

22 „Verzeichnus aller Rüstung und Varnus so von [...] Herzog Albrechts wegen [...] dem Tristrant Götzengriener jezigen Stalmaister [...] eingeanntworth worden“. München 1560 September 16. BHStA, HR I, Fasz. 9I, Nr. 56 (I).

23 „Inventary uber den fürstl. Stal, was an Pferden, Sätln, Zeugen, Senfften-, Gutschn- Schlittenzeug und anderem verhanden [...]“. I58I August 29. 35 beschriebene Blätter, nachträglich foliert. BHStA, HR I, Fasz. 23, Nr. 67 f.

24 BHStA, HR I, Fasz. 23, Nr. 67 f., fol. 5ov-5Ir (nachträglich foliert).

25 „Inventarium yber die churfürstliche Sadtlcammer und Wagenheuser, waß nach Ableiben ihrer churfürstlichen Durchl. [gemeint ist Kurfürst Maximilian] [...] verhandten auch seither wider darzue gemacht worden [...]“. I656 April 22. BHStA, HR I, Fasz. 91, Nr. 56 (I). In späteren Inventaren auch geschrieben „herisey“ oder „ heristey“. Vgl. auch Inventar vom 5. April I663, BHStA, HR I, Fasz. 9I, Nr. 56 (I). 
Hofzahlamts-Rechnungen explizit Schlosserarbeiten an einem nicht weiter bezeichneten Tragsessel für Kurfürstin Maria Anna genannt, für die 4 fl. 44 kr. bezahlt wurden. ${ }^{27} \mathrm{Ob}$ es sich dabei um eine Reparatur, vielleicht an dem Wiener Tragsessel, handelte oder um Arbeiten für eine Neuanfertigung, geht aus dieser Quelle nicht hervor.

Aus diesen Archivalien kann man jedoch schließen, dass Kurfürstin Maria Anna den ersten Tragsessel aus Wien mitbrachte und den Gebrauch des Tragsessels am Münchner Hof einführte. Sie schien sich zeitlebens gerne des Tragsessels bedient zu haben. So berichtete der Augsburger Patrizier Philipp Hainhofer von seiner Reise nach München, die er im Juni I636 „in Frstl. Braunschweigischen Geschäfften“ unternahm:

Nachmittag vmb 3 Vhren bin ich für die Statt München khommen vnnd Ich von der guardia und den Thorrschreibern verstanden, dass Ihre Churfürstl. Dhlt. mit dero hertzliebsten Churfrstl. Frawen Gemahlin animi gratia in Circa mit 200 Pferdten zue gutschen, vnnd die Churfürstin wegen schwangern leibs im Sessel getragen, nach Starenberg 3 meil von München spatziert seyen $[\ldots] .^{28}$

Hainhofer reiste dem Kurfürstenpaar nach und erfuhr bei seiner Ankunft am nächsten Tag in Starnberg vom eigentlichen Grund der Reise, einer Wallfahrt auf den „Heiligen Berg Andechs“ ${ }^{29}$ Leider enthält sein Reisebericht keine genauere Beschreibung des Tragsessels. Der Leser erfährt lediglich, dass es sich um einen „Bedeckhten Sessel“ handelte, wie ihn Hainhofer selbst im Jahr 1596 in Neapel benutzt hatte. Nebenbei berichtet Hainhofer auch, dass er so einen Tragsessel I628 am Innsbrucker Hof von Erzherzog Leopold und dessen Florentiner Gemahlin gesehen hatte. ${ }^{30}$ Leider beschreibt er keine weiteren Details zur Ausstattung, berichtet jedoch, dass der Tragsessel „durch 2 Laggaien, deren Ihro Dhlt. Io, Alss 6 Deutsche vnnd 4 Italiener in die Bayerische livream gleich geklaidet haben“, getragen wurde. ${ }^{31}$ Weiter erzählt er über das Prozedere des Sesseltragens:

27 Vgl. Wackernagel 2002 (wie Anm. i), Bd. 2, S. 99, Anm. 24: BHStA, HZR 88, i638, fol. 503v.

28 Philipp Hainhofer, Relatio Philippi Hainhoferi Seiner von Augspurg nacher München in Frstl. Braunschweigischen Geschäfften Verrichteten Rayse. Anno I636. Nach der Edition von Christian HäUtle (Hg.), Hainhofers Reisen nach München und Neuburg a/D. in den Jahren I6I3, I6I4 und I636. In: Zeitschrift des Historischen Vereins für Schwaben und Neuburg 8 (I88I), S. 268-3I4, hier S. 273. - Eine Meile bezeichnete um diese Zeit in Bayern rund 7,4 Kilometer. Drei Meilen entsprechen also 22,2 Kilometer. Damit hatte Hainhofer den Weg nach Starnberg etwas zu kurz eingeschätzt, denn es sind 26 Kilometer.

29 Andechs liegt zwischen Starnberg und dem Ammersee. Das Kurfürstenpaar unternahm die Wallfahrt, um für eine glückliche Geburt des Kurprinzen zu bitten. Am 3I. Oktober I636 wurde Ferdinand Maria geboren.

30 Hainhofer i636 (wie Anm. 28), S. 279 f. - Erzherzog Leopold hatte I626 Claudia, eine Tochter des Großherzogs Ferdinand I. von Florenz, geheiratet.

3I Hainhofer i636 (wie Anm. 28), S. 280. 
Vber Lanndt fahren die Laggayen in einem Wagen vnnd wann 2 ain stundt getragen haben, so lösen diese zween andere vom Wagen ab, die lauffen den Gutschen gleich, so dass die Churfürstin Ihnen oft zuesprechen muess, Sie sollen gemacher gehen, damit sie nit über einen hauffen fallen.

Die Beobachtung Hainhofers, dass er diese Art Tragsessel bereits in Italien gesehen hatte und dass der Tragsessel von Maria Anna neben deutschen auch von italienischen Sesselträgern getragen wurde, könnte darauf hinweisen, dass die Mode des Sesseltragens von Italien über den Habsburger Hof nach München importiert wurde.

Auch in späteren Jahren spielte der Tragsessel am Münchner Hof unter Kurfürst Maximilian I. und Kurfürstin Maria Anna immer wieder eine Rolle. So ordnete sie zum Beispiel in einem Schreiben vom 23. Juli I652 an den Richter und Pflegverwalter von Mauerkirchen an, die Straßen und Gehwege wegen einer Hirschjagd in Mattighofen (im Innviertel) reparieren zu lassen:

Als wellen und bevelchen wir dir hiermit, das du nit allain die Strassen sonder auch die Gangstaig dergestalt machen- und cräften lassen sollst, damit man sowol mit Fahren als dem Sesseltrag[en] ohnverhinderlich fort- unnd durchkhomen khan. ${ }^{32}$

Auch Kurfürst Maximilian I. ließ sich, zumindest im Alter, im Tragsessel zum Gottesdienst tragen. ${ }^{33}$ Wie groß die Anzahl der bedeckten und unbedeckten Tragsessel zu seiner Zeit war, lässt sich leider nicht feststellen, da das erste Inventar, das überhaupt explizit Tragsessel nennt, erst I656 verfasst wurde.

\subsection{Die Tragsessel von Kurfürstin Henriette Adelaide, 1650-1676}

In dem Inventar von 1656 sind bereits auch die Tragsessel der bayerischen Kurfürstin Henriette Adelaide (I636-I676) verzeichnet. Erst vierzehnjährig, hatte sie am II. Dezember I650 im Rahmen einer Prokura-Hochzeit in Turin den gleichaltrigen bayerischen Thronfolger Ferdinand Maria (reg. 165I-I679) geheiratet. Am I6. Mai I652 reiste die junge Prinzessin schließlich in Begleitung von Gräfin Felizitas von Wolkenstein, ihrer späteren Obersthof-

32 BHStA, HR I, Fasz. 3I2, Nr. 350/3. Vgl. Wackernagel 2002 (wie Anm. I), Bd. 2, S. 99 und Anm. 26.

33 Roswitha von BarY, Henriette Adelaide von Savoyen. Kurfürstin von Bayern (München 1980), S. 57, Anm. 53 verweist auf das Geheime Hausarchiv: „Diarium“ des Grafen Maximilian Kurz über die Vorgänge am Münchner Hof im Jahre I65I, Korr. Akt 63I/4. 
meisterin, nach Bayern. Vorbereitet wurde die Reise durch den bayerischen Obersthofmeister Maximilian Kurz, Freiherr von Senftenau und Graf von Valley, der die Reise im Auftrag von Kurfürstin Maria Anna in einem ausführlichen tagebuchartigen Bericht dokumentierte. Die „märchenhafte Aussteuer, nämlich Tapezereien, Betten, Baldachine, Sessel, Kutschen, Sänften, Teppiche, Portieren [=Tragsessel], Eseldecken, Silbergeschirr, Kleinodien, Leinwand und Kleidung, insgesamt ein hohes Vermögen“ waren bereits dem bayerischen Gefolge übergeben worden. ${ }^{34}$ Während ihrer fünfwöchigen Reise fuhr Henriette Adelaide meistens zusammen mit Gräfin Wolkenstein in einer Kutsche. An einigen Orten, wie Brescia, Verona, Trient und Kufstein, tauschte sie die Kutsche jedoch gegen eine Sänfte, in der sie festlich in die jeweilige Stadt einzog. Die Sänfte kann hier als besonderes Zeichen der Ehrerbietung und Würde gewertet werden. So ritt ihr der Bischof von Trient mit dreißig Pferden eine Meile vor die Stadt entgegen ,vnd hat Ihre Churfürstl. Durchl. empfangen/ folgends auch vor der Senfften her biß nach Trient begleitet“. ${ }^{35}$ Am I9. Juni I652 kam Henriette Adelaide schließlich in Wasserburg am Inn an, wo ihr Kurfürst Ferdinand Maria beim Aussteigen aus der Sänfte half und sie zur Kutsche seiner Mutter Maria Anna führte. ${ }^{36}$ Eindeutig schreibt der Obersthofmeister von Sänften und nicht von Tragsesseln.

Über die Tragsessel, die Henriette Adelaide aus Turin mitbrachte, informieren uns die Münchner Hofmarstallinventare. Überaus prunkvoll ausgestattet war der sogenannte „Turiner Tragsessel“, der zusammen mit einer gleichermaßen prächtigen Kutsche und einer „Savoyischen Senfften“ ein Ensemble bildete. Das Gesamtinventar von I675 beschreibt den prunkvollen „Turiner Tragsessel“, „der mit Goltt unnd Rotsammet vermengten Plummen, wie selbige Gutschen außstaphirt" war, etwas anschaulicher. ${ }^{37} \mathrm{Da}$ es sich um ein Ensemble handelte, lässt auch die ausführliche Beschreibung der Sänfte im Inventar von I728 weitere Rückschlüsse auf die Ausstattung des Turiner Tragsessels zu:

I Turiner Senfften von rothem Sammeth mit Golt: und silbern Fransen verprämbt, sambt 6 Fürhängen von goldenen Mor unnd goltenen Fränsln besezt [...].38

34 Bary i980 (wie Anm. 33), S. 66 (ohne Angabe einer Quelle).

35 Maximilian Kurz, Relation Der auß gnädigistem Befelch, der Durchleuchtigisten Fürstin vnd Frawen, Frawen Maria Anna, in Obern vnd Nidern Bayrn [...] in Abholung der Durchleuchtigisten Fürstin vnd Frawen, Frawen Henrietta Adelheida, Churfürstin in Bayrn, [...] Durch den Hoch vnd wolgebornen Herrn, Herrn Maximilian Graf Kurtzen, Freyherrn von Senfftenaw, [...] verrichter Raiß nacher Piemont (o.O. I652), S. 36.

36 „Ihr Churfürstl. Durchl. der Churfürst hat der Churfürstl. Princessin von der Senfften herauß geholffen/ vnd Ihr Durchl. zu dero Fraw Mutter Gutschen geführt." Ebenda, S. 45.

37 „Inventarium so über ihr churfürstl. Durchl. in Bayrn etc. Hofmarstall [...] aufgerichtet worden“. I675 Juni. 2. Exemplar. BHStA, HR I, Fasz. 9I, Nr. 56 (I).

38 BSV.Invo205, fol. 37r. - Von dieser Sänfte wurden am „5. Martig I727 nachtszeit inenher sowohl als 
Die Vorhänge waren also aus Goldtuch mit goldenen Fransen gefertigt, einem Material, das in der Hierarchie der Stoffe ganz oben stand und dem höchsten Herrscher und seiner Familie vorbehalten war. ${ }^{39}$ Henriette Adelaide, eine Enkelin des französischen Königs Heinrich IV. und eine Nichte seines Nachfolgers Ludwig XIII., war sich ihrer königlich-bourbonischen Abstammung durchaus bewusst und bestand auf einer entsprechenden fürstlichen Repräsentation. Als bayerische Kurfürstin etablierte sie in München eine prunkvolle, italienisch-französisch geprägte Hof- und Festkultur und stand dabei in regem Austausch mit dem Turiner Hof. ${ }^{40}$ In Turin gefertigt und nach München gebracht wurde noch ein weiterer „schwarzsamtener“ Tragsessel, der mit schwarzer Spitze verbrämt war. Im Gegenzug sollte ein neuer grünsamtener Tragsessel mit goldener Spitze nach Turin geschickt werden. Vermutlich blieb er jedoch in München, da er noch I665 und I668 in den Münchner Marstallinventaren genannt wird. Zudem verrät eine Anmerkung, dass seine Beschläge für einen neuen Sessel verwendet wurden. ${ }^{41}$

Kurfürstin Henriette Adelaide pflegte zeitlebens enge Beziehungen zum italienischen Hof in Turin. So kam, dem Inventar von 1675 zufolge, noch um 1670, neben den beiden oben genannten Tragsesseln, ein großer bedeckter Tragsessel aus rotem Samt nach München, „so der wälsche Tapezierer Aureli gemacht“ ${ }^{42}$ Dieser Tragsessel wird letztmalig im Inventar von $\mathrm{I} 683$ genannt. ${ }^{43}$

\subsection{Tragsessel der Kurfürstinwitwe Maria Anna, 1651-1665}

Neben den aus Wien und Turin stammenden Tragsesseln werden im Inventar von 1656 auch „ein alter grün samten Tragsessl mit gulden Porten verprämbt“ sowie ein Tragsessel mit ähnlichem Erscheinungsbild aufgeführt, der gerade mit schwarzem Tuch „zur Clag“ überzogen worden war. Anlass für die neue Ausstattung mit schwarzem Stoff gab wahrscheinlich der Tod von Kurfürst Maximilian I., der am 27. September I65I in Ingolstadt verstorben war. Neben den geschlossenen Tragsesseln nennt das Inventar von I656 auch fünf kleine unbedeckte Tragsessel. Aus dem Eintrag geht nicht hervor, ob es sich dabei um offene Tragsessel für Kinder handelte oder lediglich um Sessel, die mit Tragstangen versehen waren.

von denen Fürhängen d. silber: unnd golten Parten: dan Fränsl ausgeschniden: und entfrembtet“. Zwei Jahre später hat man sie dann entsorgt.

Vgl. Anm. 6.

40 BARY i980 (wie Anm. 33), S. 254-263.

4I BHStA, HR I, Fasz. 9I, Nr. 56 (I).

42 BHStA, HR I, Fasz. 9I, Nr. 56 (I), 2. Exemplar (ohne Folierung).

43 BSV.Invo204, fol. 29r. 
Kurfürstinwitwe Maria Anna, die einst den ersten Tragsessel aus Wien nach München brachte, schien sich gerade im Alter gerne des Tragsessels bedient zu haben. So besuchte der Münchner Hof in der Karwoche des Jahres I66I die Kranken- und Waisenhäuser in der Stadt, wobei der regierende Kurfürst Ferdinand Maria und seine Gemahlin Kurfürstin Henriette Adelaide mit dem Bruder des Kurfürsten, Herzog Maximilian Philipp, zu Fuß gingen. Die verwitwete Kurfürstin Maria Anna ließ sich jedoch tragen: „Die wittibte Churfürstin hat sich trag lassen [...]“.44 Die Quelle nennt keine weiteren Details, doch kann man wohl davon ausgehen, dass sie sich in einem Tragsessel tragen ließ, da sich die Wege innerhalb der Stadt München befanden und Sänften eher für weitere Strecken verwendet wurden. Am Karfreitag desselben Jahres besuchte der Hof die heiligen Gräber an dreizehn verschiedenen Stellen in der Stadt. Während die Fürsten alle zu Fuß gingen und die Kutschen leer hinterher fuhren, ließ sich die verwitwete Kurfürstin wieder tragen. ${ }^{45}$ Ausschlaggebend dafür waren sowohl repräsentative als auch vermutlich gesundheitliche Gründe der bereits einundfünfzigjährigen Kurfürstinwitwe. Denn Federico Marchese Pallavicino notierte gut ein Jahr später anlässlich seiner Reise nach München im Kontext der Taufe von Max Emanuel in seinem Tagebuch, dass die Kurfürstinwitwe am 19. September I662 „era in cadrèga, si faceva portare havendo male al piede“. ${ }^{46}$ Maria Anna ließ sich also im Tragsessel tragen, da sie fußkrank war.

\subsection{Der „Turinische Tragsessel“ im Kontext der Taufe von Kurprinz Max Emanuel, 1662}

Federico Marchese Pallavicino reiste als Gesandter des Herzogs von Parma und Piacenza, Ranuccio II. Farnese, im September 1662 nach München, um dem regierenden Kurfürstenpaar Glückwünsche zur Geburt des lang ersehnten Thronfolgers Max Emanuel zu überbringen. ${ }^{47}$ Aufgrund der dynastischen Beziehungen zwischen dem Kurfürstentum Bayern und dem Herzogtum Savoyen erhielt Pallavicino Zugang zum unmittelbaren Umfeld von Kurfürstin Henriette Adelaide, ${ }^{48}$ die ihm auch mehrfach Audienz gewährte.

44 StadtA, Historischer Verein von Oberbayern, Manuskripte Nr. 225, fol. $45 \mathrm{v}$.

45 StadtA, Historischer Verein von Oberbayern, Manuskripte Nr. 225, fol. 46.

46 Susan Tipton (Hg.), Diario del March.e Federico Pallavicino, Inviato Ducale a Monaco 1662 Sett.e-Ottobre. Tagebuch des Federico Pallavicino, Gesandter des Herzogs von Parma in München, im September und Oktober 1662, S. 30. Zitiert wird die Online-Version von 20Io: https:// doi.org/IO.II588/artdok.0000I220 (letzter Zugriff: 19.07.2019).

47 Vgl. Tipton 2010 (wie Anm. 46), S. 4: Federico Pallavicino stammte aus der lombardischen Linie der Pallavicino Marchesi di Zibello und war ein entfernter Verwandter von Ranuccio Pallavicino, der 1667 „I trionfi dell'architettura“ verfasste, die erste gedruckte Beschreibung der Münchner Residenz.

48 Ihre ältere Schwester Violanta Margherita von Savoyen war aufgrund ihrer Hochzeit mit Ranuccio II. Farnese Herzogin von Parma. 
Außerdem durfte er die Residenz mit dem Kaisersaaltrakt, dem Antiquarium und den kurfürstlichen Sammlungen sowie die Pferdezucht in Schleißheim besichtigen. Schließlich wurde er auch zur Taufe des kurfürstlichen Prinzen Max Emanuel am 2I. September I662 mit den begleitenden Festlichkeiten wie Jagden, Opern und Turnieren eingeladen. Der Marchese notierte ausführlich die Begebenheiten und seine Eindrücke in einem „Diario", einem tagebuchartigen Bericht, der im Staatsarchiv in Parma aufbewahrt wird. ${ }^{49}$ Ganz besonders interessierte ihn das Zeremoniell am Münchner Hof, wobei sich auch immer wieder Hinweise auf den Gebrauch von Tragsesseln finden. ${ }^{50}$

Zwei Tage vor der Taufe, am 19. September, machte sich der Münchner Hof in mehreren Kompanien auf den Weg, um Herzog Philipp Wilhelm von Pfalz-Neuburg, einen Vetter von Kurfürst Ferdinand Maria, vor den Toren der Stadt zu begrüßen. Dem Marchese Pallavicino selbst wurde ein grauscheckiges, edles Rassepferd zur Verfügung gestellt. Nach den Trompetern und Trommlern folgten rund fünfzig Kavaliere, dann noch einmal Trommler und schließlich auf Pferden Kurfürst Ferdinand Maria, flankiert vom Freisinger Bischof Albrecht Sigismund von Bayern sowie Herzog Maximilian, dem jüngeren Bruder des Kurfürsten. Anschließend folgte die Kurfürstinwitwe in einem schwarzen Tragsessel, der von ihren eigenen Dienern getragen wurde, die gleichfalls ganz in schwarzen Samt gekleidet waren. ${ }^{\text {sI }}$ Neben dem Tragsessel ritt ihr oberster Kammerherr Graf Fugger, gefolgt von der Leibgarde in ihren Livreen mit Tambourinen. Anschließend fuhren drei sechsspännige Kutschen, die alle mit schwarzem Samt ausgekleidet waren. Diese leeren, prächtig ausgestatteten Kutschen vertraten vermutlich den I65I verstorbenen Kurfürsten Maximilian I. Den Abschluss des Zuges bildeten rund dreißig Karossen, in denen die Hofdamen und adligen Damen der Stadt fuhren. Die regierende Kurfürstin Henriette Adelaide war aus gesundheitlichen Gründen nicht anwesend. Nach ungefähr einer Wegstunde machte der Zug halt, der Kurfürst und seine Kavaliere stiegen ab und warteten auf den Herzog von Neuburg. Nach dem Begrüßungszeremoniell gingen der Herzog und die Herzogin von Pfalz-Neuburg auch zur Kurfürstinwitwe, die noch immer in ihrem Tragsessel saß. Sie hatte allerdings „die Bedeckung aufheben lassen und machte Anstalten, sich umständlich von ihrem Sessel zu erheben, blieb dann jedoch die ganze Zeit sitzen, weil sie wegen der Verletzung am Bein nicht laufen konnte“.52

49 Carteggio Farnesiano Estero, Busta 3, Baviera, c. I.

so In der Übersetzung von Susan Tipton werden die Begriffe „Sänfte“ und „Tragsessel“ meist synonym gebraucht. Im italienischen Text heißt es allerdings „cadrega“, also Tragsessel, abgeleitet vom griech. K $\alpha \theta \dot{\varepsilon} \delta \rho \alpha$ oder lat. cathedra=Sitz, Sessel. faceva portare con suoi staffieri a parte, tutti vestiti di veluto nero [...]". 
Am darauf folgenden Tag erwartete man den Fürsterzbischof von Salzburg, Guidobald Graf von Thun und Hohenstein, der den kleinen Max Emanuel taufen sollte. ${ }^{53}$ Am frühen Nachmittag zogen ihm Kurfürst Ferdinand Maria zusammen mit dem Bischof von Freising und Herzog Maximilian in Begleitung von dreiundsechzig Kavalieren, alle zu Pferd, in der gleichen Formation wie am Vortag entgegen. Der Fürsterzbischof wurde von zwölf Kavalieren, sechsundzwanzig sechsspännigen Kutschen, vier vierspännigen Fahrzeugen und vierundzwanzig gesattelten Pferden mit violetten und roten Satteldecken begleitet. ${ }^{54}$ Nach der Begrüßungszeremonie, Kurfürst Ferdinand Maria hatte inzwischen wohl sein Pferd gegen eine Kutsche getauscht, stieg der Fürsterzbischof zum Kurfürsten in den Wagen, und beide fuhren nun dem Zug voran nach München, wo sie von dreiunddreißig Kanonensalven empfangen wurden. In der Residenz erwartete sie bereits die Kurfürstinwitwe auf der obersten Treppenstufe "in sedia scoperta et fatti li loro complimenti“, also in einem unbedeckten Tragsessel, um sie zu begrüßen.5

Am 2r. September traf Marchese Pallavicino den Hofstaat bei der Messe, zu der sich die Kurfürstinwitwe hereintragen ließ und alle in Logen Platz genommen hatten. Nach der Messe versammelte man sich im Kaisersaal zum Speisen. Die Taufe war für I6 Uhr angesetzt, und so traf man sich, allerdings mit einer Stunde Verspätung, in der Residenz, um in Richtung Dom aufzubrechen. Zunächst wurde der Täufling in Begleitung einer Ehrendame in einer Kutsche gebracht, die mit karminrotem Samt und Goldbesatz ausgestattet war. ${ }^{56}$ Der Festzug formierte sich sodann in folgender Ordnung: Den Kavalieren, die zu Fuß gingen, folgten der Bischof von Freising und Herzog Maximilian, danach kamen der Fürsterzbischof von Salzburg, der Herzog von Neuburg und Kurfürst Ferdinand Maria auf Pferden. Anschließend folgte ein prunkvoller Tragsessel, der mit rotem Samt sowie Goldtuch und -borten ausgestattet war. In diesem saß die Obersthofmeisterin der Kurfürstin, Gräfin Wolkenstein, und hielt den Täufling auf dem Schoß. Begleitet wurde der Tragsessel von sechs kleinen Pagen, die in weißen Atlas gekleidet waren und kleine Fackeln trugen. Nach dem Tragsessel folgte eine Kutsche mit ähnlicher Ausstattung, die von sechs schönen Falben gezogen wurde. In dieser prunkvollen Kutsche saßen Kurfürstin Henriette Adelaide mit ihrer Tochter, der zweijährigen Prinzessin Maria Anna Christina, und die Herzogin von Pfalz-Neuburg, Elisabeth Amalie von Hessen-Darmstadt. ${ }^{57}$ Sehr wahrscheinlich han-

53 Guidobald Graf von Thun und Hohenstein (I616-I668) war seit I654 Fürsterzbischof von Salzburg, I662 ernannte ihn Kaiser Leopold I. zum Prinzipalkommissar auf dem Reichstag in Regensburg. 1666 wurde er Bischof in Regensburg und I667 folgte die Kardinalswürde. Vgl. Tipton 2010 (wie Anm. 46), S. 34: „[... 24 cavalli da sella con gualrappe violette et rosse [...]“ bedeutet ,gesattelte Pferde“ und nicht „Pferde mit Sesseln [oder Sänften]“.

55 Ebenda, S. 34, auf S. 90 irrtümlich übersetzt mit ,gedeckter Tragsessel“.

56 Ebenda, S. $36:$ „[... [ ch'era portata in caroza di veluto cremesi con oro“.

57 Bary 1980 (wie Anm. 33), S. I55 und Anm. 192 (GHA: Korr. Akt. 645, Produkt Nr. 73). Unwahr- 
delte es sich bei diesem kostbaren und repräsentativen Tragsessel sowie der Kutsche um das prunkvolle Ensemble aus Savoyen, also den „Tuorinischen [sic] Tragsessl“, der „mit Goltt vnd rotsammet vermengten Pluemmen, wie selbige Gutschen außstaphirt" war. ${ }^{58}$ Auf gleicher Höhe mit der Kutsche ließ sich die verwitwete Kurfürstin in einem schwarz ausstaffierten Tragsessel tragen, der ebenfalls im Inventar von 1656 genannt wird. ${ }^{59}$ Den Münchner Bürgern wurde mit diesem festlichen Aufzug einmal mehr die Pracht des kurfürstlichen Hofes und die dynastische Verbindung nach Italien und zum Hause Pfalz-Neuburg vor Augen geführt.

Am folgenden Tag fand zu Ehren des Täuflings eine Jagd statt, zu der die Herren auf ihren Pferden ritten, die Damen jedoch Kutschen benutzten, da es regnete. Am Samstag, dem 23. September, begab sich Marchese Pallavicino noch einmal in die Residenz, wo ihm der Kurfürst persönlich entgegenkam, die Kurfürstin und die Kurfürstinwitwe jedoch in Tragsesseln getragen wurden. ${ }^{60}$ Gemeinsam begab man sich dann zum Appartement des Herzogs von Neuburg und anschließend mit dem Herzogspaar zum Appartement des Fürsterzbischofs, um zusammen zur Messe in die Hofkapelle zu gehen. Tragsessel fanden also auch im Innenbereich zur zeremoniellen Begrüßung und Ehrbezeugung gegenüber ranghohen Gästen Verwendung, und zwar im Speziellen durch die Damen des Münchner Hofs, die Kurfürstin und die Kurfürstinwitwe.

Federico Pallavicino reiste am 3. Oktober 1662 aus München ab. In seinem „Diario“ berichtet er noch zweimal, dass sich die Kurfürstinwitwe im Tragsessel tragen ließ. ${ }^{61}$ Seine Beschreibungen zeichnen ein lebendiges Bild von der repräsentativen Bedeutung der Tragsessel am Münchner Hof.

Im Inventar von I680 wurden neue Begriffe eingeführt, wie ein „Sede rollanda, ain offene churfürsstl[iche] Leibseza, für unserem g[nädi]gsten Herren “. ${ }^{62}$ Vermutlich handelte es sich dabei um eine sogenannte „Chaise roulante“, eine einachsige Sesselkutsche mit langen, federnden brancards, wie sie seit I660 an den europäischen Fürstenhöfen modern wurde. ${ }^{63}$ Durch die leichte Bauweise und den besseren Fahrkomfort waren derartige

scheinlich erscheint dagegen die Beschreibung Pallavicinos (fol. I6v), wenn er anstelle der Tochter Henriette Adelaides eine Tochter der Herzogin von Neuburg nennt. Vgl. Tipton 2010 (wie Anm. 46), S. 36 und S. 96.

58 Zum Beispiel Marstallinventar von I680, BSV.Inv0203, fol. 28v.

59 Bei Pallavicino ist die Rede von „,adrega“, also Tragsessel (vgl. Tipton 2010 [wie Anm. 46], S. 36, die „cadrega“ jedoch mit Sänfte übersetzt, vgl. ebenda, S. 93).

60 Vgl. Tipton 2010 (wie Anm. 46), S. 40: „[... la Serenissima Elettrice Reggente e la Serenissima Elettrice Vedova in cadrega."

6I Ebenda, S. 43 und 52.

62 BSV.Invo203, fol. $38 \mathrm{r}$.

63 Vgl. Wackernagel 2002 (wie Anm. I), Bd. 2, S. II7, Abb. 127. 
„rollende Sessel“ auch in unwegsamem Jagdgelände beliebt. Der Begriff „Sede rollanda“ würde wortwörtlich übersetzt „Rollstuhl“ bedeuten. Allerdings wäre dieser wohl kaum im Marstalldepot, sondern in der Residenz aufbewahrt worden. Das Inventar von I680 nennt auch einen offenen Tragsessel, der mit blauem Damast ausgestattet war. Dem Eintrag zufolge wurde dieser „offene Seza“ einst von der 1676 verstorbenen Kurfürstin Henriette Adelaide benutzt. Zudem werden ein ähnlicher Tragsessel aus grünem Samt aufgelistet sowie zwei bedeckte Tragsessel: „Ain gläserne mit griennem Damast ausgemachte Seza“ und „Ain Seza, so inwendig mit grien Tuech gefüettert, ohne Stangen“ ${ }^{64}$

\subsection{Der Tragsessel Maria Antonias im Kontext der Taufe von Max III. Joseph, 1727}

I685 wurde anlässlich der Hochzeit von Maria Antonia und Max Emanuel der prächtige Tragsessel angeschafft, der sich heute im Marstallmuseum befindet. Dieser Tragsessel fand noch 1727 anlässlich der Taufe des Kurprinzen Max III. Josef Verwendung. Im Festbericht zur Taufe, der von den beiden kurfürstlichen Kammerfourieren Philipp Blondeau und Joseph Anton Cavallo verfasst wurde, wird er im Kontext des Festzuges zur Frauenkirche ausführlich gewürdigt: Den Mittelpunkt dieses Zuges bildeten sechs kurfürstliche Kutschen. In der ersten Prunkkutsche, deren „gantze[s] Zeug [...] von rothen Sammat [war], alles mit gut Silber im Feuer vergoldet beschlagen, [...]“ saßen „beyde Churfürstl. Durchl.“, also Kurfürst Karl Albrecht und Kurfürstin Maria Amalia. Der Beschreibung nach handelte es sich bei der Kutsche sehr wahrscheinlich um den Brautwagen von Maria Antonia, den Max Emanuel rund vierzig Jahre vorher bei Saillot in Paris bestellt hatte. Die Kutsche war außen „mit rothem Sammat überzohen, auf das allerkostbariste gestickt, innwendig mit reichstem Trap d'Or, goldenen Crepinen und anderen Stickwerck außgemacht“. Neben dieser Kutsche wurde „in einem bedeckt roth sammaten in= und außwendig mit Gold vertrefflichist außgezierten Trag=Sessel getragen Ihro Excellentz die Frau Ana, welche auf einem reichen Kiß den Durchleuchtigisten Chur=Printzen haltete, so mit kostbarist=goldenen Decken bedeckt ware. “" Vermutlich ist mit „Frau Ana“ Maria Anna von Bayern (I696-I750) gemeint, die älteste Schwester Karl Albrechts und einzige Tochter

\footnotetext{
64 BSV.Invo203, fol. $38 \mathrm{r}$.

65 Philipp Blondeau/Joseph Anton Cavallo, Vollständiger Bericht, Von allen Sehens-würdigen Freuden-Festen, Welche Hochfeyerlich begangen worden In- und nahe der Churfürstl. Hauptund Residentz-Stadt München Anno 1727. Vom 28. Mertzen biß den 26. May, als dem Herrn Carolo Alberto, In Ob- und Nider-Bayrn, [...] Herzogen, [...] Auß Der [...] Frauen, Maria Amalia, Regierenden Chur-Fürstin, [...] gebohren worden Ein Durchl. Chur- und Erb-Printz, [...]. Faksimile nach der Ausgabe von Joh. Lucas Straub (1727) (München 2000), S. 7.
} 
Max Emanuels, die I7ı in das Klarissenkloster Sankt Jakob am Anger in München eingetreten war. Sie also saß nun mit dem kleinen Kurprinzen auf dem Schoß in dem Tragsessel, der einst Maria Antonia gehört hatte. Anzumerken bleibt an dieser Stelle noch, dass das bayerisch-österreichische Allianzwappen auf der Rückseite des Tragsessels auch für Karl Albrecht und Maria Amalia passte, war sie doch die jüngste Tochter von Kaiser Joseph I. aus dem Hause Habsburg.

In diesem Zeitraum scheint neben zwei Sänften nur noch ein einziger Tragsessel im „Senfften Cämmerl“ des Hofmarstalls aufbewahrt worden zu sein. Das Inventar von 1726 nennt einen blausamtenen Tragsessel „von ihro churfürstl. Drtl. zu Cölln hechstmildisten Angedenckhens“, der mit einer silbernen Borte verbrämt war. ${ }^{66}$ Der Kurfürst und Erzbischof von Köln, Joseph Clemens Kajetan von Bayern, der zweitgeborene Sohn von Kurfürst Ferdinand Maria, war I723 verstorben. Sein Tragsessel kam wohl als Erbstück nach München in die Sesselkammer des kurfürstlichen Marstalls. Eine Notiz in dem darauf folgenden Inventar von 1728 verrät, dass am 5. März I727 nicht nur „die silbern Porten, sondern auch die Sammeth ab der hintern Anlainwand und Sitzpolster ausgeschnide[n] und entwendtet word[en]“. Zwei Jahre später wurde der Tragsessel dann zerstört und der restliche noch vorhandene Samt für Sättel verwendet. ${ }^{67}$

Diese geringe Anzahl an Tragsesseln mag verwundern, gab es doch immerhin im zweiten Halbjahr 1750 noch fünfzehn Sesselträger am Münchner Hof, die im Besoldungsbuch namentlich aufgeführt werden. ${ }^{68}$ Die Differenz zu nur einem Tragsessel im Marstallinventar könnte darauf verweisen, dass Mitte des I8. Jahrhunderts die Tragsessel nicht mehr in Depots des kurfürstlichen Marstalls aufbewahrt wurden. Vermutlich dienten sie nun weniger als repräsentatives Transportmittel, sondern vielmehr höfischen „Spaziergängen“ in den Lustschlössern, der Sommerresidenz Nymphenburg oder im dortigen Park.

\section{Die Sesselträger}

Aufschlussreich ist auch ein Blickwechsel auf die Sesselträger am Münchner Hof. So fin-

66 BHStA, HR I, Fasz. 9I, Nr. 56/2.

67 BSV.Invo205, fol. 37v. - Vgl. Anm. I8.

68 BHStA, HR I, Fasz. 312, Nr. 350/3, fol. I86r-I87v. Ein Sesselträger verdiente in sechs Monaten 58 fl. 48 kr., während der Oberststallmeister, der das höchste Amt am Hof innehatte, im selben Zeitraum I500 fl. erhielt. - Für den Hinweis auf diese Archivalie danken wir herzlichst Dr. Brigitte Volk-Knüttel. 
den sich in den Akten der Hofamtsregistratur immer wieder Hinweise im Kontext ihrer Stellung am Hof, der Witwenpension oder neuer Livreen. Laut Schreiben vom 2. September 1636 wurden sechs Hofsesselträger in die Leibgarde aufgenommen und ihre Besoldung an die der Fußleibgarde angeglichen. Sie bekamen eine eigene Dienstkleidung, die einer Kostenaufstellung vom 2. Mai I659 zufolge in den Farben Schwarz und Weiß gehalten war. Denn hier werden vor allem schwarzes und weißes Leinen, aber auch schwarzer Samt und schwarze Borten genannt. Die entsprechende Ausstattung der Hofsesselträger war auch sechzig Jahre später noch Thema, denn in einem Brief an Kurfürst Max Emanuel vom März I7I8 beschweren sich die Sesselträger, deren Besoldung zwei Jahre zuvor an die der Hoflakaien angepasst worden war, dass sie schon seit drei Jahren keine neuen Livreen erhalten hätten, während doch die Hoflakaien immerhin mit neuen „Sadut“-Röcken ausgestattet worden seien. Kurz darauf bekamen die Hofsesselträger dann neue Überröcke. ${ }^{69}$ Dass die Anschaffung neuer Livreen hinausgezögert wurde, kann man angesichts der hohen Kosten durchaus verstehen. Laut einer Aufstellung von I7I9 kostete eine Hofsesselträger-Livree 46 fl. 501/4 kr. Das war mehr als ein Eselknecht des kurfürstlichen Marstalls im Jahr 1688 in sechs Monaten verdient hatte. ${ }^{70}$

\subsection{Instruktion für den Sesselmeister der Stadt München, 1688}

Bereits im letzten Viertel des I7. Jahrhunderts war es nicht nur am Hof gebräuchlich, sich eines Tragsessels zu bedienen, sondern auch in der Stadt konnten Tragsessel gemietet werden. Dass den Sesselträgern dabei große Verantwortung zukam, liegt auf der Hand. Über ihre Rechte und Pflichten gibt eine Sesselträgerordnung für den Sesselmeister vom 26. Mai I688 Aufschluss (Quellenanhang 5.2):

Waßmassen sich der yber die nunangerichte Tragsessl, und selbige Trager, aufgestelte Maister namens Christoph Wegerle in seiner Diensts Verrichtungen zuverhalten. ${ }^{71}$

Bestimmt war die Instruktion für den Sesselmeister Christoph Wegerle, der für die neu eingerichteten Tragsessel und die Sesselträger zuständig war. Standort der Miettragsessel war der Münchner Schrannenplatz, der heutige Marienplatz, an der Ecke zur Dienergasse.

69 BHStA, HR I. Fasz. 47, Nr. 6I (3): Hofsesselträger. Die umfangreiche Akte zum I7./I8. Jahrhundert enthält auch Schriftverkehr zur Witwenpension verstorbener Sesselträger.

70 Anton Machomet wurde am I. Januar I688 als Eselknecht am kurfürstlichen Marstall eingestellt und verdiente jährlich 76 fl. Siehe: BHStA, Kurbayern Hofzahlamt, Nr. 726, fol. $158 \mathrm{v}$.

BSB, Cod.germ.2093: „Instruction wie sich der Sesselmaister zuverhalten“. 


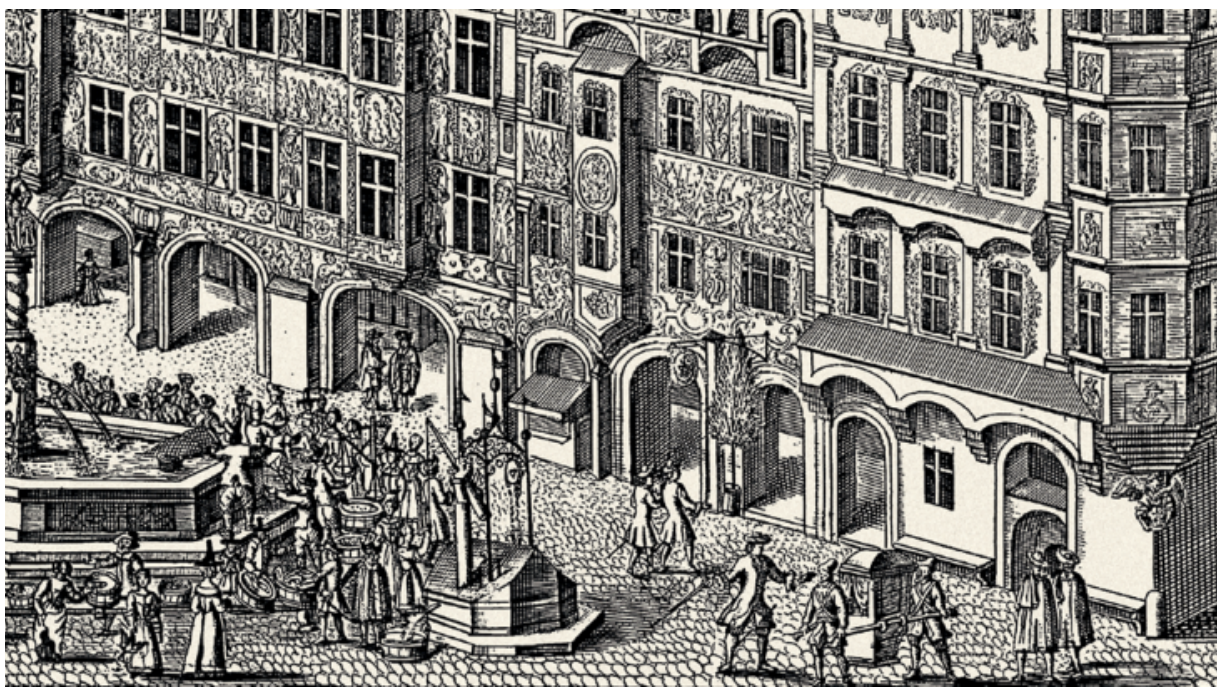

Abb. 9: Ausschnitt aus dem Kupferstich „Der Marcth zu München“ von Michael Wening. Foto: Bayerisches Landesamt für Digitalisierung, Breitband und Vermessung

Der Hofkupferstecher Michael Wening erhielt 1696 von Kurfürst Max Emanuel den Auftrag, detailgenaue Bilder der damaligen bayerischen Städte, Märkte, Klöster, Schlösser, Burgen und Herrenhäuser zu zeichnen und in Kupfer zu stechen. Diese „Historico-Topographica Descriptio“ gibt in rund 85o Bildern nicht nur topographische Darstellungen wieder, sondern auch einen Eindruck vom Alltagsleben. Ein großer Kupferstich stellt den Münchner Schrannenplatz dar, wo rechts unten nahe dem Fischbrunnen die öffentlichen Tragsessel stationiert waren. Der Bildausschnitt zeigt zwei Sesselträger sowie den Sesselmeister, der gestikulierend noch Anweisungen zu geben scheint (Abb. 9). Zur Verfügung standen mehrere Tragsessel, von denen der Sesselmeister einen in seiner Wohnung aufbewahren sollte, die anderen jedoch in einem Gewölbe im Weinstadel und der Trinkstube in der Dienergasse. Dabei gab es unterschiedliche Kategorien von Sesseln, denn der Sesselmeister sollte

denen hochen Standts Persohnen die saubern Sessl vor[...]behalten [...], die schlechtern aber vor die gemainen Leuth zu gebrauch. ${ }^{72}$

Der Sesselmeister oder seine Frau, die nüchtern und höflich zu sein hatten, mussten tagsüber stets vor Ort sein. Zu ihren Aufgaben gehörte auch das Reinigen der Tragsessel. Diese Anweisung galt für alle Tragsessel, auch wenn für Kranke ein spezieller vorgesehen war, der

72 Ebenda, Absatz 5. 
nicht nur gründlich gereinigt, sondern auch ausgeräuchert werden musste. Zudem hatte der Sesselmeister die Aufsicht über die Sesselträger:

Hat er sich auf die Türckhen, so zum tragen gebraucht werden, Obacht zuhalten, d[a]z sye in ihrer Klaidtung nit zerissen, od[er] schlämppisch daher gehen, sonder sich alzeit sauber halten. ${ }^{73}$

Dieser Absatz ist interessant, werden doch ausdrücklich Türken als Sesselträger genannt. Auf dem Kupferstich mögen die Kopfbedeckungen der beiden Sesselträger an Heiducken-Darstellungen aus dem i8. Jahrhundert erinnern. ${ }^{74}$

\subsection{Türken als Sesselträger}

Bereits Ende 1683 kamen die ersten türkischen Kriegsgefangenen nach der Schlacht am Kahlenberg bei Wien nach München. Zwei Türken, die sich beide Achmet nannten, wurden im Januar I684 im Münchner Zuchthaus verhört, da man sich Lösegeld von ihnen versprach. ${ }^{75}$ Weil eine Auslösung nicht zustande kam, versuchte man die beiden Türken in München zu integrieren. Sie konvertierten zum katholischen Glauben und ließen sich taufen. Am 2. Juli I684 nahm ein Achmet den Namen seines Taufpaten, des kurbayerischen Hofrats, Hofoberrichters und Truchsesses Franz Adam Präntl zu Irnsing an. Er nannte sich nun Franz Adam. Laut Matrikeleintrag im Taufbuch von St. Peter wurde die Taufe nicht in der Kirche vollzogen, sondern wegen einer Erkrankung des Türken im städtischen Zuchthaus. ${ }^{76}$ Hier fand am I8. August I684 noch eine zweite Taufe statt, bei der Kurfürst Max Emanuel selbst die Patenschaft übernahm. Vertreten wurde er durch seinen Kammerdiener Kilian Bill. Dieser türkische Kriegsgefangene, der sich gleichfalls Achmet nannte, hieß nun Anton Achmet. ${ }^{77}$ Der in lateinischer Sprache verfasste Eintrag im Taufbuch von St. Peter berichtet, dass Anton Achmet I683 bei Wien gefangen genommen und

73 Ebenda, Absatz 7.

74 Heiducken waren Wehrbauern, die in Südosteuropa im Grenzgebiet zum Osmanischen Reich lebten. Seit dem späten I6. und im frühen I7. Jahrhundert wurden in Österreich und im Königreich Ungarn besoldete Infanteristen als Heiduck bezeichnet.

75 Kurfürst Max Emanuel. Bayern und Europa um I700, 2 Bde. (Ausstellungskatalog, München I976), S. 8I, Nr. 2IO.

76 Archiv des Erzbistums München und Freising, Pfarrmatrikeln, Taufen St. Peter, I683-1689 (Sign. 8953), fol. 67v.; vgl. Markus Krischer, Der Mann aus Babadag. Wie ein türkischer Janitschar I683 nach München verschleppt und dort fürstlicher Sänftenträger wurde (Darmstadt 20I4), S. 82 f.

77 Archiv des Erzbistums München und Freising, Pfarrmatrikeln, Taufen St. Peter, 1683-1689 (Sign. 8953), fol. 7Iv. 
nach München gebracht worden war. Dieser Mann fand sein Auskommen am Hof Max Emanuels, wo er zunächst als kurfürstlicher Sesselträger Anstellung fand. Am I. Januar 1688, kurz vor seiner Trauung mit Kunigunde Ertmann, ${ }^{78}$ wurde er zum Eselknecht im kurfürstlichen Marstall befördert und verdiente nun laut Besoldungsbuch, in dem er als „Anthoni Machomet" geführt wird, jährlich 76 Gulden. ${ }^{79}$

Im Sommer und Herbst 1686 kamen infolge der Eroberungen der ungarischen Städte Pest und Buda zunächst rund 340 türkische Kriegsgefangene und dann noch einmal 296 Türken nach Bayern. Nach der Belagerung und Zerstörung von Belgrad wurden I688 nochmals über 400 türkische Gefangene nach München gebracht. ${ }^{80}$ Sie wurden als Bedienstete am kurfürstlichen Hof und bei Adeligen eingesetzt. Vor allem aber mussten sie in der kurfürstlichen Manufaktur zur Tucherzeugung sowie bei den Kanalbauten von Nymphenburg, Schleißheim und Dachau arbeiten. Einige dieser Türken wurden auch als Träger für die öffentlich zu mietenden Tragsessel ausgebildet. Sie waren dem Sesselmeister unterstellt und hatten seinen Anordnungen Folge zu leisten.

Dass die türkischen Sesselträger zwar hart arbeiten mussten, dabei jedoch ihr Auskommen hatten, belegt die bereits erwähnte Sesselmeisterordnung von 1688. Der Sesselmeister hatte darauf zu achten, dass die Sesselträger ausreichend zu essen und zu trinken bekamen. Während der Woche gab es mittags

guets Oxen: oder Ründtfleisch auch Suppen und Krautt: auf die nacht aber Fleisch, und Reis in der Fleischsuppen od[er] aber Gersten, neben einen Sollat zu speißen, an Fasttägen sollen ihnen guete cräfftige Speißen von Mell und Schmalz gegeben: und solle ihme Sesslmaister vor solche Cost auf die Persohn wochentlich I fl. Costgelt bezalt werden.

Und weiter unter Absatz 9 heißt es:

Den Trunckh betr. hat man ieden Türckhen die Mahlzeit ain halbe Mass Pier zu geben, und solle diser Trunckh aus der Sessl Cassa bezahlt werd[en]. ${ }^{8 \mathrm{r}}$

Zum Waschen sollten sie sich ins Zuchthaus begeben, wo auch ihre Kleidung gereinigt wurde, oder aber eines der öffentlichen Stadtbäder aufsuchen.

78 Archiv des Erzbistums München und Freising, Pfarrmatrikeln, Trauungen St. Peter, 1670-1690 (Sign. 90II), fol. 287r. Die Hochzeit war am I2. Januar I688. Vgl. KRISCHER 2014 (wie Anm. 76), S. 133 .

79 BHStA, Kurbayern Hofzahlamt, Nr. 726, fol. 158v.

80 Vgl. Ausstellungskatalog Max Emanuel (wie Anm. 75), Bd. 2, S. 79 f., Nr. 204 und S. 82, Nr. 2 I2.

8I BSB, Cod.germ.2093: „Instruction wie sich der Sesselmaister zuverhalten“, Absatz 8 und 9. 
Auch die Miete für die Tragsessel war geregelt. So kostete die Beförderung von einer Gasse in die andere 6 kr. (Kreuzer), eine ganze Stunde jedoch 15 kr. Beanspruchte man den Tragsessel für einen halben Tag, das waren $3^{1 / 2}$ Stunden, so musste man $30 \mathrm{kr}$. ausgeben, für einen ganzen Tag jedoch I fl. (Gulden) bezahlen. Zum Vergleich: Ein Eselknecht des Münchner Marstalls verdiente zeitgleich jährlich 76 fl., monatlich also 6 fl. $20 \mathrm{kr}^{82}$ Den Sesselträgern war es strengstens verboten, einen Kunden um Trinkgeld zu bitten. Es war ihnen auch nicht gestattet, Geld anzunehmen. Falls doch Trinkgeld bezahlt wurde, so kam dies in eine Dose, die der Sesselmeister verwahrte. Monatlich wurde dann das Trinkgeld gleichmäßig an die Sesselträger verteilt. Dass das Sesseltragen harte Arbeit war, kann man sich vorstellen, wenn man bedenkt, dass der Tragsessel von Maria Antonia leer bereits ungefähr fünfunddreißig Kilogramm wiegt. Mit einem Passagier mittleren Gewichts hatte jeder der beiden Sesselträger also rund fünfzig Kilogramm zu tragen. Zwei über die Schultern gelegte Gurte, in welche die Tragstangen eingehängt wurden, entlasteten dabei die Arme. Die Sesselmeisterordnung sah auch drastische Strafen vor. So war beispielsweise

Zanckh[en] oder Greinen in kein Weis zu gestatten, und wo es mündtlich nit verhüettet werden kundte, weren nach ihren Verdienst gar die Steckhenstraich zugebrauchen. ${ }^{{ }^{3}}$

Auch mussten die Träger, die einen leeren Sessel trugen, einem Priester auf der Straße ausweichen. Wenn dies nicht möglich war, hatten sie den Tragsessel abzusetzen, die Kopfbedeckung abzunehmen und sich wie ein Christ niederzuknien, bis der Priester vorbei war. Falls sie diese Anweisung nicht befolgen sollten, würden sie „mit würcklicher Straff angesechen werden. " 84

Erst im Rahmen des Friedens von Karlowitz im Januar 1699 wurde ein Austausch der Gefangenen vereinbart. Dabei war Max Emanuel jedoch darauf bedacht, dass die Einrichtung der öffentlichen Tragsessel nicht allzu sehr beeinträchtigt wurde:

Ihro Chf. Durchlaucht wollen diese gefangenen Türken zu hierin vermelten Ende gnädigst loslassen, jedoch ist dahin zu sehen, daß dadurch das Sesseltragen nit gar in Abgang komme. ${ }^{85}$

Im Jahr I70o lebten noch sechsunddreißig „türkische Sklaven“ in München. ${ }^{86}$

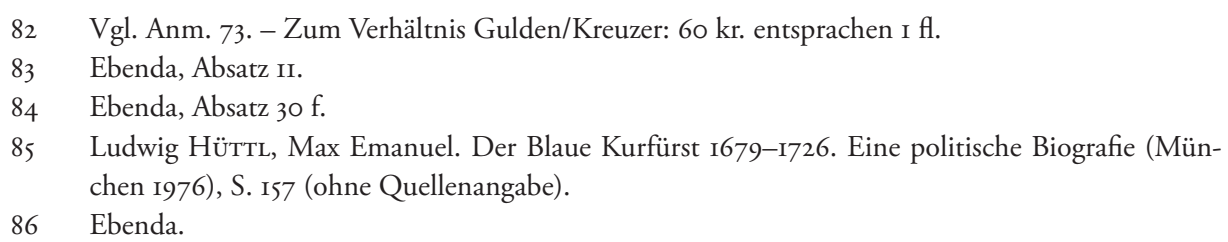




\section{$4 \quad$ Zusammenfassung}

Aus den bisher bekannten Archivalien kann man schließen, dass der Tragsessel erst um I635 durch Kurfürstin Maria Anna am Münchner Hof eingeführt wurde, während Reisesänften bereits im I6. Jahrhundert im Einsatz waren. Die Anzahl der geschlossenen und offenen Tragsessel variierte in den folgenden Jahren nur wenig. So befanden sich 1656 zunächst elf, ab I665 neun oder zehn Tragsessel im kurfürstlichen Marstall und sechs bis sieben Sänften. Reparaturen oder die weitere Nutzung von Beschlägen eines alten, ausgedienten Tragsessels für einen neuen verraten den regen Gebrauch des höfischen Transportmittels. Mit dem Marstallinventar von 1728 wurden Tragsessel und Sänften zwar noch begrifflich unterschieden, jedoch nicht mehr getrennt erfasst. Im „Senfften Cämmerl“ des kurfürstlichen Marstalls existierten in dieser Zeit nur noch zwei Sänften und ein „plausammeter“ Tragsessel. ${ }^{87}$ Rund vierzig Jahre später, im Inventar von 1766 , wurden gar keine Tragsessel mehr aufgelistet. Stattdessen gab es nun eine Rubrik „Jagdsessel“. Diese wendigen einachsigen Sesselkutschen waren komfortabler und passten hinsichtlich Geschwindigkeit und Eleganz zum Geschmack des Rokoko. Diesem Zeitgeist entsprach auch der Tragsessel mit silber-blauem Lackdekor, der allerdings in keinem Marstallinventar genannt wurde, sondern erst 1807 im Gardemeuble-Inventar der Münchner Residenz. Im Inventar von 1799 wurden unter der Rubrik „Senften“ lediglich der im Marstallmuseum erhaltene Gala-Tragsessel von Maria Antonia und zwei nicht erhaltene Maultiersänften verzeichnet. Das Inventar des königlichen Marstalls von I826 führt nur noch diesen Gala-Tragsessel auf, der nach wie vor als Kostbarkeit in der Sattelkammer aufbewahrt wurde, sowie drei „Senften-Wägen“ ${ }^{88}$ Die Verwendung des Tragsessels am Münchner Hof erstreckte sich über einen gut I2O Jahre währenden Zeitraum und war nach Kenntnis der bisher ausgewerteten Quellen vorwiegend eine Angelegenheit der Damen, die sich zu besonderen Festlichkeiten dieses repräsentativen Transportmittels bedienten.

\section{$5 \quad$ Quellenanhang}

\section{1. Übertragung des Marstallinventars von 1656}

BHStA, HR I, Fasz. 9I, Nr. 56 (I), ohne Folierung

Inventarium yber die churfürstl. Sadtlcammer und Wagenheuser, waß nach Ableiben ih[r]er churfürstl. Durchl. [=Kurfürst Maximilian I.] [...] verhandten auch seither wider darzue gemacht worden [...]

87 BSV.Invo205, fol. $37 \mathrm{v}$.

88 BSV.Invor95, fol. 224v und BSV.Invor98, fol. 274v, 282v und $283 \mathrm{r}$. 


\section{April 1656}

\section{„Volgen die gedöckt Leibtragsessl“}

I neuer grünsamtener Tragsessel, mit goldener Spitze verbrämt, „und nacher Turino zuschickhen vermaint gewesen"

I Turinischer Tragsessel, den die Kurfürstin Adelheid mitgebracht hat und der mit der Ausstattung der Kutsche identisch ist

I blausamtener Tragsessel mit Silber verbrämt, der von Wien mitgebracht wurde Nebenbemerkung: da der Samt des Sessels vollständig abgewetzt war („ganz abganngt gewesen“), wurde er mit schwarzem „herschei“ [=Hirschleder?] überzogen

I schwarzsamtener mit schwarzer Spitze verbrämter Tragsessel, der in Turin gemacht und dann nach München geschickt worden war („so nacher Turino gemacht: und entgegen geschickht worden")

I grünsamtener Tragsessel mit goldenen Borten verbrämt, gerade mit schwarzem Tuch „zur Clag" überzogen

I alter grünsamtener Tragsessel mit goldenen Borten verbrämt

„Volgen die clain unbedöckhten Tragsessl“

I schwarzsamtener kleiner Tragsessel

3 andere kleine Tragsessel mit schwarzem Tuch überzogen

I rotsamtener kleiner Tragsessel mit goldenen Fransen verbrämt

\subsection{Sesselträgerordnung von 1688 (Abschrift)}

BSB Handschriftenabteilung, Cod.germ. 2093 (Transkription Dr. Magdalena Bayreuther)

Instruction wie ßich der Sesslmaister zuverhalten

[Seite I]

Instruction.

Waßmassen sich der yber die nunangerichte Tragsessl, und selbige Trager, aufgestelte Maister namens Christoph Wegerle in seiner Diensts Verrichtungen zuverhalten.

I. Werden ihme die Sessl ybergeben, und hat er selbige in gueter Verwahr: ainen in seiner Wohnung: die andern aber in dem darzuegerichten Gewölb in der Dieners Gassen im Weinstadl und der Trünckhstuben zuhalten, damit man ieden Orths gleich darmit dienen kann. 2. Solle er Sesslmaister od[er] sein Weib stetts bey der Stell sein, und beim Tag an dem Orth wo die Sessl stehen, in der Dieners Gassen wartten, zu nachts aber sich alzeit fleissig zu Haus fündten lassen.

3. Hat er sich alzeit nüchter: und gegen meniglich beschaiden, willig und dienstbar zuhalten, sich aber in kein Weiß, es seye fruehe oder spadt, gegen denen, so die Sessl und Trager ver- 
langen, nit ungehorsamb, verdrossen: od[er] unhöflich zu bezaigen.

4. Die Persohnen, welche sich in den Sessln wollen tragen lassen, seint auf Begehrn, so balts imer sein kan, zubefürd[er]n, und zu bedienen, und ist den Tragern alzeit bester Fleiss, und ein sicherer Gang einzebündten, und von ihnen kein Unwillen, od[er] Ungehorsamb zugestatten.

[Seite 2]

5. Hat er Sesslmaister denen hochen Standts Persohnen die saubern Sessl vorzubehalten, und sye darmit zu bedienen, die schlechtern aber vor die gemainen Leuth zu gebrauch[en].

6. Hat er die Sessl alzeit sauber zu halten, und alzeit nachdeme einer od[er] der ander getragen worden, wid[er] aufzukören, und zu säubern.

7. Hat er sich auf die Türckhen, so zum Tragen gebraucht werden, Obacht zuhalten, d[a]z sye in ihrer Klaidtung nit zerissen, od[er] schlämppisch daher gehen, sonder sich alzeit sauber halten.

8. Hat ermelter Sessl[durchgestrichen: Trag]maister die Türckhen, so zum Sessltragen bestelt sein, in der Cosst zuhalten, und ihnen in der Wochen zu mittags guets Oxen: oder Ründtfleisch auch Suppen und Krautt: auf die Nacht aber Fleisch, und Reis in der Fleischsuppen od[er] aber Gersten, neben einen Sollat zu speißen, an Fasttägen sollen ihnen guete cräfftige Speißen von Mell und Schmalz gegeben: und solle ihme Sesslmaister vor solche Cost auf die Persohn wochentlich I Costgelt bezalt werden.

9. Den Trunckh betr. hat man ieden Türckhen die Mahlzeit ain halbe Mass Pier zu geben, und solle diser Trunckh aus der Sessl Cassa bezahlt werd[en].

[Seite 3]

Io. Hat er Sesslmaister sye die Trag[er] bey ihrer ordinarri Fleiss zuhalten, und ihnen im Trunckh ain mehrers nit zuezelassen, als sye wol ertragen könen, damits in ihrem Dienst nit saumbig erscheinen, sonder einen ieden, den sye tragen, den gueten Willen erfüllen.

II. Seint sye die Trag[er] auch stetts in guetter Freundtschafft zuhalten, und ist zwischen ihnen d[a]z Zanckh[en] oder Greinen in kein Weis zugestatten, und wo es mündtlich nit verhüettet werden kundte, weren nach ihren Verdienst gar die Steckhenstraich zugebrauchen.

I2. Aber wan einer ein Verbrechen gethan hette, welche mit 5 od[er] 6 Steckhenstraichen nit gnueg gepüest were, so hete man solches Verbrechen der Commission anzuzaigen, und vor dort aus zuerwartten, wie ein solch[er] Fähler gepüest solle werden.

I3. Sovil die Wösch und d[a]z Padt anlanget, solle ihnen daß Leinwanth im Zuchthaus geseübert werden, und mögen für sich aldorth auch des Padts bedienen oder aber die gemaine Stattpädter brauchen.

I4. Hat Sesslmaister sowol auf die Sessl alß Türckh[en] wie gemelt sein guete Obacht zubehalten, beinebens

[Seite 4]

auch alle Gemainschafft zwischen ihnen und den christlichen Persohnen: sonderbahr denen 
Weibsbildtern zuverhüetten, und keine Ungelegenheiten vorgehn z $[u]$ lass[en], im Gegenfahl hete er alle Verantworttung auf sich zutrag[en], und Straff zugewartten.

15. Hat er Sesslmaister die Türckhen in einer sonderbarn Cammer zuverpflegen, und sye allein zuhalten, dise Cammer aber solle in seinem Zünß nachent bey ihme sein, $d[a] z$ er die Türckhen alzeit heren, also ihr thuen und lassen wissen kan, und hat er weder Mägd noch Knaben zu ihnen hineinzulassen, sonder ihre Ligstatten von ihnen selbst richten: und yberziechen z[u]lass[en].

I6. Solle ihme der Zünß sovil der Türckhen underkhommen importiert, aus der Sessl Cassa zuhilf bezalt werden.

17. Seindt all die jenige welche sich tragen lassen wollen, an den Sesslmaister gewißen, daß er ihnen die Sessl und Trag[er] zuestellen solle, waiß er also wiegemelt, einen ieden auf Begehren, solchen Sessl fürderlich zuverschaffen, und darbey iedes Mahls den Tragern besten Fleiß einzebündten

I8. Hat er von ainem Gang, von ainem Hauß: od[er] Gassen ins ander 6 kr.: von ainer ganzen Stundt I5 kr.:

[Seite 5]

von ainem halben Tag od[er] 3 Stundt 30 kr.: und von ainem ganzen Tag I fl. Tragerlohn einzeford[er]n.

19. Vor wan die Trag[er] und[er] Essenzeit, so lang aufgehalten wurden, daß sye zu Hauß ihre Speiß versaumbten, so hette ihnen der jenige, der sye solang aufgehalten, die Cosst zu geben. 2o. Wan einer od[er] der and[er], die Träger ein oder mehr Stundt auf sich warthen lisse, so hete man ihnen von ieder Stundt, iedem $3 \mathrm{kr}$. Wortgelt zuzallen.

2I. Sollen sye weiter nit ausser der Statt als weith ist bis zu den Herrn Paulinern und nit weither tragen derffen, und solle bis dahin und wider herein 24 kr.: bis zum Rädl in die Au 20 kr.: bis zu den Herrn Capucinern I5 kr.: bis ins Herrn Graff von Tättebachs Gartten am Lechen: oder bis zum Holzschreiber $24 \mathrm{kr}$. und also in anderen Weegen nach Proportion dessen, daß Tragerlohn bezalt werden.

22. Sobaldt sye Sessltrag[er], einen an sein Orth, wohin er d[a]z Tragerlohn bezahlt, werden getragen haben, so haben sye alsobaldt den lahren Sessl widerumb an seine Orth, in die Dieners Gassen zutragen und aldort auf weithern Bevelch zuwarthen.

[Seite 6]

[Nr. 23 fehlt]

24. Hat man den Sesslmaister ein verschlossne Pixen in die Handt gegeben, da sowollen er allen Verdienst, sovil von Sessltragen bezahlt worden, gethreülich einlegen, darbey kein Unthreü spillen, sond[er] alles auf richtig und redlich zur Commission lifern.

25. Aber hat er niemandten tragen $z[u]$ lassen, nach einen Sessl eheund[er] zuschickhen, ehe er vorher $\mathrm{d}[\mathrm{a}] \mathrm{z}$ Tragerlahn empfangen, und ohne vorherige Bezallung hat er nichts herzugeben. 
26. Hat er zwar den Tragern zuverbietten, d[a]z sye bey Straff nüemandten umb ein Trünckhgelt ansprechen noch in ander Weeg yberlestig sein sollen, will aber iedoch nit zuzweiflen, es werde einer: oder der ander ein mehrere Danckhbarkheit erweisen, und den Tragern widers Verbott ein Trünckhgelt bezallen, so hat der Sesslmaister ein sonderbare Pixen zuhalten, und alles Trünckhgelt, es seye vill od[er] wenig, welches den Tragern gegeben wirdt, darein zulegen, und volgents ihnen solches von Monat zu Monat zur gleichen Portion zuverthaillen, sye ins gesambt aber ernstlich dahin halten, $\mathrm{d}[\mathrm{a}] \mathrm{z}$ sye [Seite 7]

solche Trünckhgelter vleissig zu seinen Handten lifern, im Gegenfahl sollen sye gestrafft werden. 27. Auf dem Fahl einer: od[er] der and[er] so getragen wirdt, aus Unachtsambkheit am Sessl ein Glaß oder waß anders verbrechen thette, hete derselb den Schadten, so er gethan ohne Entgelt der Sessl Cassa wider aus seinem Säckhl mach[en] z[u]lassen.

28. Hat man in solchen Sessln keinen Khranckhen tragen z $[\mathrm{u}]$ lassen, sonder vor solche kranckhe Persohnen den vor sye gerichten praun Sessl, und kheinen anderen zunemmen, und nach dem derselb gebraucht worden, ist er wid[er] mit Fleiss zuseübern, und wol auszurauchen.

29. Damit die Leüth nach Belieben wol bedient werden, und auf die Trager nit lang wart$\mathrm{h}$ [en] derffen, so seindt die jenige Trager welche keine Dienst haben, stetts beysammen bey den Sessln zuhalten, und sye nit von einander zulassen.

[Seite 8]

30. Hat sich bishero bezaigt, wan man mit dem höchsten Guett zu den kranckhen Persohnen gangen, und darmit ein oder andern Türckhen begegnet, haben sye demselben, nit allein khein Ehr erwisen, sonder woll sogar daß Gespött darbey getriben, und Gott dem Allmechtig[en] Unehr angethan, welches von ihnen in khein Weis zugedulten, sonder ist der Bevelch, und seindt sye dahin alles Ernsts zuhalten, daß sye Türckhen, wan man mit dem höchsten Guett auf der Gassen gehet, und ihnen darmit begegnet, wan sye lähr gehen, sich aintweders in ein andere Gassen, oder ein Zimmer reterieren: od[er] auf ihre Knie niderfahlen, und gleich wie die catholische Christen thuen: im Gegenfahl sye mit würckhlicher Straff angesechen werden sollen, wurdte sich aber begeben, $d[a] z$ die Sessltrager eben einen gegen dem hochwürdigisten Guett tragen thetten, so hetten sye den Sessl gleich nider zusözen, ihre Khappen abzuziechen, und solang den

[Seite 9]

Sessl nit aufzuheben, bis der Priester würdt voryber sein, $\mathrm{d}[\mathrm{a}] \mathrm{z}$ also einige Örgernus nit gegeben werden solle, darob dan der Sesslmaister alles Ernsts zuhalten, und nach Gestalt des Verbrechens zu straffen, od[er] es der Commission der Abstraffung willen anzuzaigen.

Münch[en] den 26. May Anno I688. 


\section{Französische Tragsessel des späten 17. und frühen 18. Jahrhunderts}

\section{$1 \quad$ Einleitung}

Wiewohl es sich bei Tragsesseln um facettenreiche und äußerst faszinierende Objekte handelt, führen sie in Frankreich sowohl in öffentlichen Einrichtungen als auch in der Wahrnehmung breiter Bevölkerungsschichten ein Schattendasein. Dies zeigt sich etwa in der Tatsache, dass zwischen I9II und 20II lediglich neunundzwanzig aus dem Zeitraum zwischen dem I7. Jahrhundert und der Mitte des I9. Jahrhunderts stammende Tragsessel in das nationale Kulturgüterinventar aufgenommen oder als „historische Denkmale“ klas-

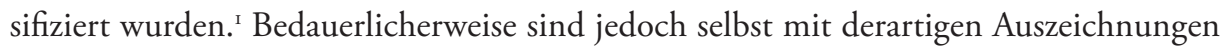
weder wissenschaftliche Erschließungsarbeiten noch Detailuntersuchungen oder gar Restaurierungen verbunden. Erst in jüngerer Zeit erlangten Tragsessel durch die Ausstellung „Roulez carrosses!" in Arras sowie durch eine Publikation, die sich den Tragevehikeln aus dem Schloss Marsillargues bei Montpellier widmet, einige Aufmerksamkeit. ${ }^{3}$

Die Zahl der in Frankreich vorhandenen Tragsessel ist nicht einfach zu ermitteln, da sie bis in jüngste Vergangenheit erheblichen, vor allem durch öffentliche Versteigerungen verursachten Schwankungen unterlag. Schätzungen zufolge existieren innerhalb der Landesgrenzen aber zumindest I50 Objekte französischer Herkunft. Diese Tragsessel weisen eine erstaunliche Formenvielfalt auf, was nicht nur in stilgeschichtlicher Hinsicht von Interesse ist, sondern auch regionale Besonderheiten und unterschiedlichste technische Eigenarten,

I Vgl. die Datenbank Palissy, die von der Direction de l'Architecture et du Patrimoine du ministère de la Culture et de la Communication erstellt wurde: https://www.pop.culture.gouv.fr/search/list?base $=\% 5$ B \%22Patrimoine\%20mobilier\%20\%28Palissy\%29\%22\%5D (letzter Zugriff: 30.09.2019). Béatrix SAule/Jean-Louis Libourel/Hélène Delalex (Hg.), Roulez carrosses! Le château de Versailles à Arras (Ausstellungskatalog, Paris 20I2).

3 La chaise à porteurs du château de Marsillargues, hg. von d. Direction régionale des affaires culturelles (DRAC) du Languedoc-Roussillon / Conservation régionale des monuments historiques (CRMH) (Montpellier 20I2). 
auf die später noch näher eingegangen wird, erkennen lässt. Leider sind die bislang verfügbaren wissenschaftlichen Dokumentationen einzelner bereits registrierter Tragsessel zumeist derart ungenügend, dass die Erstellung einer Chronologie oder einer präzisen Typologie anhand spezifischer Elemente, wie dies beispielsweise Türschnallen oder -angeln sein könnten, zum derzeitigen Zeitpunkt nicht möglich ist. Der vorliegende Beitrag strebt daher auch in keiner Hinsicht Vollständigkeit an, sondern widmet sich vielmehr in eingehender Weise einigen wenigen Tragsesseln, die zwischen Ende des 17. und Anfang des I8. Jahrhunderts in Frankreich hergestellt wurden. ${ }^{4}$

\section{Tragsessel im Machtzentrum der Monarchie}

In der königlichen Residenz und dem Kloster El Escorial wird heute die Replik eines Tragsessels aufbewahrt, in dem sich Philipp II. von Spanien (I527-I598) gelegentlich tragen ließ. Wie er verwendeten auch verschiedene französische Herrscher, von Heinrich II. (I519-I559) bis Ludwig XIV. (I638-I715), derartige Vehikel. Einem Zeitzeugen zufolge waren Tragsessel damals in Frankreich weit verbreitet. ${ }^{5}$ Da ein Mangel an Wagen und Kutschen bestand, galten Tragsessel als "la seule voiture de commodité que l'on avait dans Paris".

Zu den illustren Personen, die Tragsessel benutzten, zählten unter anderem Caterina de' Medici (I519-I589), deren Tochter Margarete von Valois (I553-I6I5) sowie Maria de' Medici (I575-I642), die zweite Gemahlin Heinrichs IV. Anfangs handelte es sich dabei um einfache Stühle, die zu Transportmitteln umfunktioniert wurden. In einer späteren Phase wurden die Vehikel schließlich auch überdacht. Kardinal Mazarin (I602-I66I) sowie La Meilleraye (I602-1664) und Fouquet (I6I5-I680), beide Vorstände der französischen Finanzverwaltung, aber auch der Erzbischof von Bordeaux, Henri de Béthune (I604-I680), besaßen Tragsessel.7 Ludwig XIV. benutzte Tragsessel, wenn er an Gichtanfällen litt, ${ }^{8}$ und seine Mä-

4 Der vorliegende Beitrag beruht auf der unpublizierten Dissertation der Verfasserin: Marie MAGGIANI, La parade citadine aux $\mathrm{I}^{\mathrm{ème}}$ et $\mathrm{I} 8^{\text {ème }}$ siècles. Enquête méridionale sur la chaise à porteurs (ungedr. Dissertation, Universität Toulouse II 2007).

5 Nicolas Delamare, Traité de la police où l'on trouvera l'histoire de son établissement [...], Bd. 4 (Paris 1738), Kapitel 2, Abschnitt 3, S. 449: „Du privilège des chaises portées à bras et des porteurs de chaises".

6 Ebenda.

7 Henry Havard, Dictionnaire de l'ameublement et de la décoration. Depuis le XIII siècle jusqu’à nos jours, 4 Bde. (Paris I894), Bd. I, Artikel „Chaise à porteurs", S. 653-655.

8 Ein königlicher Leibarzt erteilte dem Monarchen den Rat, sich winters vor Kälte und Nässe zu schützen, und zwar "dans une chaise à porteurs devant son feu" - der Kasten würde ihn mit milder Wärme umgeben. Moyens faciles et éprouvés dont M. de Lorme, premier médecin ordinaire de 
tresse Madame de Maintenon (I635-1719) bediente sich ihrer nicht minder häufig. Kurz, es schien damals schlicht unmöglich, auf diese bequemen Transportmittel zu verzichten. ${ }^{9}$

Das Kunstmuseum Petit Palais besitzt einen äußerst prachtvollen Tragsessel, der als Hervorbringung des Pariser Luxusgewerbes des ausgehenden I7. Jahrhunderts gelten kann (Abb. I). Dieses Transportmittel soll sich ursprünglich im Eigentum der Nichte Ludwigs XIV., Élisabeth Charlotte de Bourbon-Orléans, genannt Mademoiselle de Chartres, befunden haben. Im Jahr 1676 geboren, heiratete sie I698 Herzog Leopold Joseph von Lothringen (1679-I729). Die auf den Kastenpaneelen dargestellten Wappen beider Familien sprechen dafür, dass die Vermählung wohl auch den Anlass für die Herstellung des Tragsessels bot. Die Form des Tragsessels gleicht jener von anderen, einfacheren Exemplaren derselben Epoche ${ }^{\mathrm{IO}}$ : gerade Linien, eine leichte Ausbuchtung des Kastens unterhalb der Seitenfenster und ein gewölbtes Dach. Die vergleichsweise strenge Silhouette kontrastiert mit der Fülle an dekorativen Elementen: auf Goldgrund gemalte Arabesken, fein geschnitzte Zier- und Sockelleisten und raffiniert eingesetzte Metallbeschläge, die nicht versteckt, sondern vielmehr mit großer Sorgfalt ausgearbeitet wurden, angefangen von den Bändern, die den Kasten verstärken, über die Bügel zur Fixierung der Trageholme bis hin zu den Fenster- und Türangeln.

Bemerkenswert ist auch die malerische Ausstattung des Tragsessel, die vielfach Anspielungen auf das Haus Lothringen aufweist. Sie zeigt unter anderem Allegorien auf Ruhm, Sieg, Geschichte und Zeit, mythologische Figuren wie Mars und Amor, Arabesken und Girlanden. All diese Elemente sind von einem Netz aus Blattwerkmotiven eingefasst. Der Entwurf für den Dekor wird dem Zeichner und Graveur Sébastien Le Clerc (I637-I7I4)

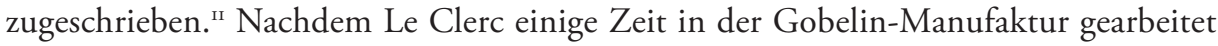
hatte, erhielt er den Ruf der Académie Royale de Peinture et de Sculpture, wo er Perspektive unterrichtete. Er gilt als außergewöhnlich produktiv - mehr als 3000 Tafeln mit Entwürfen von seiner Hand sind erhalten - und wurde von seinen Zeitgenossen für seine technischen Fähigkeiten und sein Talent für gelungene Kompositionen sehr geschätzt, also für Qualitäten, die sich auch in unserem Tragsessel widerspiegeln.

trois de nos rois [...] s' est servi pour vivre près de cent ans (Caen I683), zit. nach HavarD I894 (wie Anm. 7), Bd. I, S. 656.

9 Delamare 1738 (wie Anm. 5), Bd. 4, Kapitel 2, Abschnitt 3, S. 449.

Io Vgl. zum Beispiel die Tragsessel von Schloss Aulteribe in der Auvergne (klassifiziert als „Monument Historique“ - eine historische Reproduktion ist auf der Ministeriumsdatenbank Palissy verfügbar), im Museum Henri-Barré in Thouars, in der Maison Louis XIV in Saint-Jean-de-Luz (Privatsammlung) und im Musée Fenaille in Rodez, abgebildet in Maggiani 2007 (wie Anm. 4), Bd. 2, Tragsessel Nr. 6 und 7.

II Vgl. den Online-Katalog der „Collections patrimoniales de Paris“: http://a8o-musees.apps.paris.fr/ (letzter Zugriff: I6.08.20I6). 


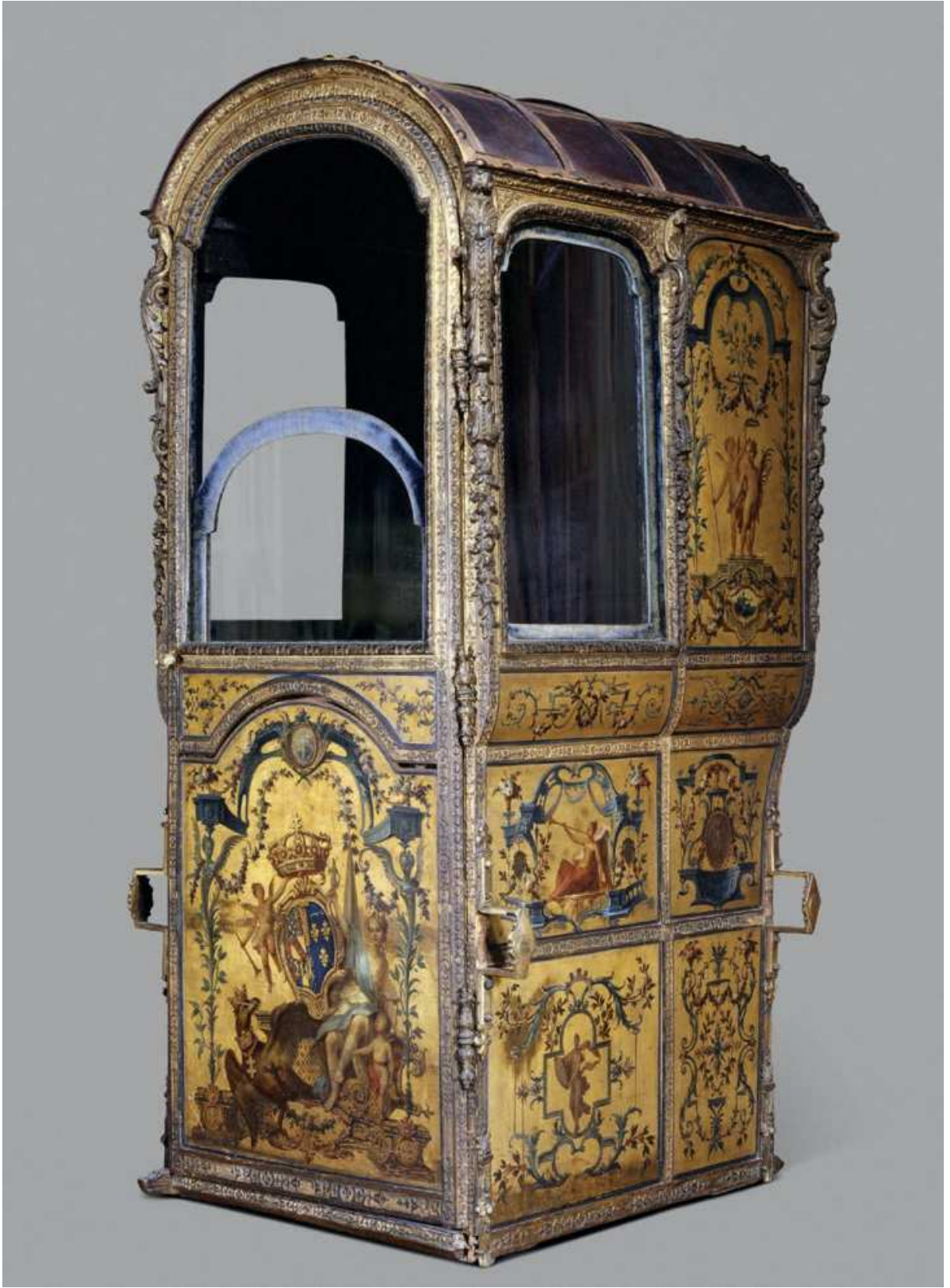

Abb. 1: Sogenannter Tragsessel der Mademoiselle de Chartres, 1698. Petit Palais, Musée des Beaux-Arts de la Ville de Paris. @ Scala Archives 
Der für eine hochrangige Person bestimmte Tragsessel wurde zweifellos bei einer der damals besten Pariser Werkstätten in Auftrag gegeben, möglicherweise bei Saillot (Sattler) und Lepape (Tischler), beide Lieferanten des Hofes von Versailles, die auch für die Hochzeit des Kurfürsten Maximilian II. Emanuel von Bayern im Jahr I685 einen Tragsessel hergestellt hatten, der sich heute im Marstallmuseum Schloss Nymphenburg befindet. ${ }^{\mathrm{I2}}$ Eine Qualitätsstufe, die mit jener des Exemplars aus dem Petit Palais vergleichbar ist, charakterisierte wohl auch den I69I entstandenen Tragsessel der Fürstin von Conti, einer unehelichen Tochter Ludwigs XIV. Für dieses heute nicht mehr erhaltene Tragevehikel erhielt der Maler Jean Lemoyne mit rooo livres den höchsten Teilbetrag der gesamten Herstellungskosten. Der Dekor dieses Vehikels wies ganz offensichtlich Parallelen zum Tragsessel des Petit Palais auf:

Minerve assise dans son trosne tenant les armes de Madame la princesse de Conty, accompagnée d'enfants, de termes, de festons de fleurs, de grotesques et mosaïques, le tout peint de colory sur fond d'or. ${ }^{13}$

Der Entwurf für diesen Tragsessel stammte von Jean Bérain (I640-I7II), einem der renommiertesten Ornamentkünstler seiner Zeit. Bérain wurde I674 als „dessinateur de la Chambre et du Cabinet $d u$ Roi" an den Hof Ludwigs XIV. berufen und war in diesem Amt mit verschiedensten Aufgaben betraut, etwa mit der Gestaltung von Opern, Festen und Bestattungsfeierlichkeiten, mit Goldschmiedearbeiten, Modellen für Wandverkleidungen und Deckenausstattungen, mit Gartenarchitektur, dem Dekor königlicher Schiffe oder mit Tapisseriekartons. Unter seinen Entwürfen finden sich unter anderem Rück- und Seitenansichten eines Tragsessels sowie Modelle für Hofwagen. Bérains Entwürfe, die auch unter der Bezeichnung „Bérinades“ bekannt sind, spielen mit der rhythmischen Gliederung von Architektur, mit Fragen der Symmetrie und mit dem Gleichgewicht zwischen

I2 Zu diesem Tragsessel siehe Rudolf H. WaCKernagel (Hg.), Staats- und Galawagen der Wittelsbacher. Kutschen, Schlitten und Sänften aus dem Marstallmuseum Schloß Nymphenburg, 2 Bde. (Stuttgart 2002), Bd. I, S. 78-8I; sowie den Beitrag von Gudrun Szczepanek und Friederike Ulrichs im vorliegenden Band.

I3 Jérôme de La Gorce, Berain. Dessinateur du Roi Soleil (Paris I986), S. 54. Die nächsthöheren Teilbeträge betrafen mit 700 livres die Stickereien und schließlich mit nur roo livres die Applizierung von vier Schutzschichten über dem Lindenholz sowie die Vergoldung. Für vergleichbare Arbeiten wurden zu jener Zeit fern von Paris wesentlich niedrigere Preise in Rechnung gestellt: Im Jahr 1672 zahlte etwa einer der besten Sattler von Toulouse einem Maler 250 livres für die Arbeiten an einer Karosse. Alain de Beauregard, Parlement de Toulouse. La société parlementaire au Grand Siècle, les expressions profanes de la commande privée (I6IO-I680 principalement) (ungedr. Dissertation, Universität Toulouse II 200I), S. 748. 
Flächen- und Tiefenwirkung. Belebt werden seine Kompositionen durch den Einsatz mythologischer Figuren, durch stilisierte vegetabile Motive, durch Baldachine, Draperien und Kartuschen. ${ }^{14}$ Bérains eleganter Dekorationsstil war in ganz Europa äußerst beliebt, sowohl bei seinen Kunden als auch bei Künstlern und Handwerkern, so etwa auch bei Daniel Marot (I66I-I752). Auf diese Weise entstand eine Vielzahl von Neuschöpfungen, die von Bérain inspiriert waren, dessen Entwürfe imitierten oder für eigene Zwecke adaptierten. Im Bereich des Wagenbaus kam es zu verschiedenen höchst erfindungsreichen, abwandelbaren Entwürfen, etwa von Jean Lepautre (1618-1682) mit seinen „Nouveaux dessins pour orner et embellir les carrosses et les chaises roulantes" und Nicolas-Pierre Loir (1624-1679), der um I650 auf elf Tafeln „Desseins Pour embellir Les Chaires [sic] Roulantes nouvellement inventez par N. Loire, et gravez Par Alexis Loire" publizierte.

Der Tragsessel des Petit Palais hebt sich durch die Pracht seines Dekors, die Qualität der eingesetzten Materialien und die Sorgfalt in der Ausführung selbst kleinster Details von anderen Tragsesseln jener Zeit deutlich ab. Über die damals weit verbreiteten, einfacheren Tragsessel liegen leider nur wenige Informationen vor. Es heißt, die Mitglieder der Hofgesellschaft und andere Vertreter der Oberschicht hätten die Verwendung derartiger Transportmittel rasch übernommen, da diese sich für kurze Strecken innerhalb des Stadtgebiets als äußerst praktisch erwiesen. Auf längeren Strecken blieb die Verwendung von Tragsesseln hingegen die Ausnahme. ${ }^{\text {I5 }}$ Die I644 in Paris veröffentlichten „Lois de la Galanterie“ priesen Tragsessel als

dernière et nouvelle commodité si utile, qu'ayant été enfermé là-dedans sans se gâter le long des chemins, on peut dire qu'on en sort aussi propre, que si on sortait de la boite d'un Enchanteur $[\ldots] .^{16}$

I4 Ein zierliches Laubwerkornament im Stil der „Bérinades“ bedeckt auch den Kasten eines Tragsessels, der heute im Schoss Haroué, nahe Nancy, in einer Privatsammlung zu sehen ist.

I5 In der Regierungszeit Ludwigs XIV. begab sich Maria Anna Victoria von Bayern (I660-1690), die Gemahlin Louis', Dauphin von Frankreich, von Paris nach Fontainebleau. Wie ein Zeitgenosse berichtete, bewältigte sie die etwas mehr als fünfzig Kilometer lange Strecke in einem Tragsessel „à quarante deux porteurs; elle va presque aussi vite qu'en carrosse“. (Felix) Feuillet De Conches (Hg.), Journal du marquis de Dangeau, Bd. I (1684-1686) (Paris 1854), S. 399. Die Herzogin von Nemours reiste auf dieselbe Weise sogar bis in ihr Fürstentum Neuchâtel in der Schweiz. LouisSebastien Mercier, Tableau de Paris (Paris 1994, erstmals 178I-1783), Bd. 2, Kapitel „Chaise à porteurs", S. I29I.

I6 Bei „Les Lois de la galanterie, de nouveau corrigées et amplifiées par l'Assemblée générale des Galants de France" handelt es sich um einen parodistischen Text, der 1644 in der "Nouveau Recueil des pièces les plus agréables de ce temps" in Paris erschien und sich an ein mondänes Publikum richtete. 
Molière (I622-I673) bezeichnete sie I659 in seiner Komödie „Les Précieuses ridicules“ als „un retranchement merveilleux contre les insultes de la boue et du mauvais temps“. Der Marquis von Mascarille vermied in diesem Stück mit Hilfe eines Tragsessels die Exponierung der "l'embonpoint de [ses] plumes aux inclémences de la saison pluvieuse, et [d'] imprimer [ses] souliers en boue ${ }^{\text {"17 }}$.

Vergessen wir nicht, welch schmutziger, übel riechender und gefährlicher Ort die Straßen des Ancien Régime waren. Sie waren zumeist eng und verwinkelt, und häufig versperrten Straßenhändler sowie verschiedene Hindernisse den Weg. Zudem war das Pflaster für gewöhnlich von Abfall übersät und rutschig. Der Schriftsteller und Kritiker Nicolas Boileau (I636-I7II), ein Zeitgenosse Molières, bemerkte in seinem berühmten, I666 veröffentlichten Werk „Embarras de Paris“, die Straßen von Paris seien „si plein de carrosses quion ne peut passer dans une seule rue sans embarras et sans blesser ou tuer quelqu'un "18. Besonders nach dem Ende von Theateraufführungen und ähnlicher Spektakel trat häufig der Fall ein, dass Tragsessel oder Karossen einander den Weg versperrten. Es kam dann zuweilen vor, dass das jeweilige Dienstpersonal aufeinander einschlug, um dem Vehikel des eigenen Herren oder der eigenen Dame freie Bahn zu verschaffen. ${ }^{19}$ Wagen oder Tragsessel boten in solchen Fällen den darin beförderten Personen Schutz vor derartigen außerhalb des Transportgehäuses gewaltsam ausgetragenen Konflikten. Noch wichtiger war aber zweifellos eine andere Funktion der Vehikel: Sie halfen dabei, eine deutlich sichtbare Distanz zwischen dem einfachen Volk und den Mitgliedern der Oberschicht zu schaffen.

Hervorzuheben ist, dass Besitzer von Tragsesseln nicht zwangsläufig Mitglieder der Aristokratie sein mussten. Zwar zeichnete sich die französische Gesellschaft des Ancien Régime durch eine stark hierarchisierte, Ungleichheiten befördernde Sozialstruktur aus, jedoch zählten Tragsessel zu keiner Zeit zu den Privilegien des Adels, ${ }^{20}$ auch wenn die Verwendung von Tragsesseln genauso wie jene von Kutschen einen Lebensstandard voraussetzte, den sich nur Wohlhabende leisten konnten, wie etwa Prälaten, Parlamentarier, Mitglieder kommunaler und königlicher Gremien oder Vertreter des niederen Adels. Gleich dem Wohnsitz oder der Kleidung war auch der Besitz eines Tragsessels ein Indikator für

I7 Molière, Les Précieuses ridicules (I659), Szenen 7 und 9.

I8 Elisabeth-Charlotte DE BAvière, Mélanges historiques, anecdotiques et critiques sur la fin du règne de Louis XIV et le commencement de celui de Louis XV (Neuedition Paris I807), S. 37I.

I9 "Les fêtes nocturnes du Cour", Komödie in einem Akt von Dancourt (I7I4). Zitiert nach Octave Uzanne, La locomotion à travers l'histoire et les mœurs (Paris 1900), S. II3.

20 Während der Revolution war es übrigens stets erlaubt, das eigene Vehikel zu benutzen, vorausgesetzt, die Wappen waren verdeckt. Der 3. Artikel des Dekrets vom 27. September/I6. Oktober I79I behandelt unter anderem Sanktionen für Personen, die „placeraient des armoiries sur leurs maisons ou sur leurs voiture“. Tatsächlich lässt sich an mehreren Tragsesseln beobachten, dass die Wappen mit einer Farbschicht überdeckt wurden, um sie so unsichtbar zu machen. 
den sozialen Status, den eine Person innehatte beziehungsweise anstrebte. In der damals vorherrschenden Kultur des Scheins waren die Menschen gezwungen, hohe Ausgaben für Luxusgüter zu tätigen, um sich allzeit in bestem Licht darzustellen. Das permanente, kollektive Zurschaustellen der eigenen Person, etwa bei Theaterbesuchen, Spazierfahrten oder ähnlichen gesellschaftlichen Ereignissen, nahm mitunter die Gestalt regelrechter Paraden im öffentlichen Raum an.

Entgegen der gängigen Annahme, Tragsessel seien allein für Frauen und kranke oder gebrechliche Geistliche bestimmt gewesen, war die Realität weit komplexer. Zwar trifft es zu, dass hochrangige Kleriker schon sehr früh Tragsessel verwendeten, die ihnen entweder selbst gehörten oder die ihnen zur Ausübung ihres Amtes zur Verfügung gestellt wurden und auf denen in der Regel ihr eigenes Wappen angebracht war. ${ }^{21}$ Und auch wohlhabende verheiratete Frauen, die sich auf eigene Kosten einen Tragsessel beschafften, oder Bräute, die zuweilen einen Tragsessel als Hochzeitsgeschenk erhielten, zählten zu den Nutzern von Tragsesseln. Außer Zweifel steht jedoch auch, dass Tragsessel, die das Allianzwappen eines Ehepaars trugen, auch von beiden Eheleuten verwendet werden konnten. Gelegentlich stand hinter der Bestellung eines neuen Vehikels ein sozialer Aufstieg oder ein Emporkommen auf der Karriereleiter. In Anbetracht der hohen Kosten und des großen Platzbedarfs für Equipagen stellten Tragsessel manchmal auch für Männer eine ernsthafte Alternative zu Kutschen dar.

\section{Beispiele aus sekundären Machtzentren und der Peripherie des Königreichs}

Da die Herstellungsumstände von Pariser Tragsesseln weitgehend im Dunkeln liegen, ist es auch schwierig einzuschätzen, wie und mit welcher Geschwindigkeit sich die in der Hauptstadt entwickelten Modelle im Rest des Königreiches verbreiteten. Wir können jedoch davon ausgehen, dass in Fachkreisen Zeichnungen, Modelle, Graphiken oder gar „Kataloge“ von Tragsesseln zirkulierten. Zudem ist der direkte Austausch unter Berufskollegen in Betracht zu ziehen. Auf diesen Wegen war es mit Hilfe von Entwürfen oder auf dem Wege persönlicher Vermittlung möglich, hinsichtlich Weiterentwicklungen technischer oder stilistischer Natur auf dem Laufenden zu bleiben. Außerdem bestand auch die Option, ein bereits existierendes Vehikel einfach nachzubauen. Ein solches Vorgehen

2I Hierfür existieren nur Beispiele aus dem I8. Jahrhundert, so etwa ein im Museum Duplessis (Carpentras) ausgestellter Tragsessel im Rokokostil. Dieses Vehikel trägt auf der Rückseite das Wappen von Monseigneur Vignoli, der 1757 zum Bischof der Stadt ernannt wurde. Auf den Türen ist das Wappen seines Nachfolgers, Monseigneur Beni (I776-I79I), angebracht. Siehe Maggiani 2007 (wie Anm. 4), Bd. 2, Tragsessel Nr. 24. 
lässt sich beispielsweise für Toulouse gut belegen, die zweite Parlamentsstadt des Königreichs und seit dem I7. Jahrhundert ein florierendes Produktionszentrum für Karossen. Die Auftraggeber von Wagen waren meist in der Stadt ansässige Herren oder Mitglieder des Klerus. Aus einer nicht unbeträchtlichen Zahl von Kaufverträgen geht eindeutig hervor, dass für die Bestellung neuer Fahrzeuge ganz bestimmte, bereits existierende Karossen als Vorbild genommen wurden. Entsprechende Formulierungen lauteten etwa, das neue Fahrzeug solle „ähnlich sein wie [...]“, „,von der gleichen Größe und denselben Proportionen sein wie jenes des Herrn von [...]“ oder „so sein wie jenes, das für Herrn [...] hergestellt wurde“. ${ }^{22}$ Diese Beispiele illustrieren ein hohes Maß an sozialer Anpassung seitens der Auftraggeber. Diese waren bestrebt, Fahrzeuge zu erwerben, die sowohl ihrem eigenen gesellschaftlichen Status als auch dem aktuellen Zeitgeschmack entsprachen. Dafür nahmen sie zuweilen auch die Mühe in Kauf, sich im Umkreis von mehreren Hundert Kilometern nach passenden Fahrzeugen umsehen zu müssen. So gaben etwa der Parlamentsvorsitzende von Bordeaux und einige spanische Herren bei Sattlermeistern in Toulouse den Bau neuer Wagen in Auftrag und trugen damit auch zur Verbreitung aktueller Fahrzeugdesigns bei. ${ }^{23}$ Für Tragsessel ist in dieser Hinsicht nur ein einziges aussagekräftiges Beispiel aus dem I8. Jahrhundert quellenmäßig dokumentiert. ${ }^{24}$ Dennoch lässt sich bei Betrachtung der erhaltenen Objekte feststellen, dass Nachahmungen, Kopien und Abwandlungen existierender Modelle auch bei Tragsesseln verbreitet waren.

Möglicherweise kam dem prachtvollen vergoldeten Sessel der Mademoiselle de Chartres eine derartige Vorbildrolle zu. Sein raffinierter Dekor spiegelt eindeutig den Geschmack jener Zeit wider, was sich durch ähnliche Tragsessel belegen lässt, die wohl ebenfalls in Pariser Werkstätten entstanden sind, so etwa ein Tragsessel aus der Sammlung von

22 De Beauregard 200I (wie Anm. I3), S. 875, 889. Zitiert sei auch die I642 erfolgte Bestellung eines Zuggeschirrs, „bien conditionné de la façon et forme de celui de Monsieur de Calvet". Ebenda, S. 876.

23 Erwähnt sei an dieser Stelle das Beispiel einer kleinen vergoldeten Kalesche, die König Philipp V. von Spanien 1716 auf der Durchreise in Toulouse erstand. Unmittelbar nach dem kurzen Aufenthalt des Königs in der Stadt stellte der Sattler Antoine Rochas, genannt Grenoble, mehrere Kaleschen auf Basis desselben Modells für den lokalen Markt her. De Beauregard 200I (wie Anm. I3), S. 523 .

24 Madame de Tournier, die Gemahlin eines hohen Toulouser Beamten, bestellte 1725 ihren neuen Tragsessel nicht etwa in einer Werkstätte ihres Wohnorts, sondern beauftragte damit einen rund 300 Kilometer entfernt lebenden Meister aus ihrer Geburtstadt Avignon. In seinem Schreiben an Madame de Tournier erwähnte der mit der Herstellung betraute Sattler François Guynaud mehrere seiner Kunden und ging auf deren Tragsessel näher ein, beispielsweise auf jenen von Madame de Toirax: „[...] sur un fond cannelle clair, on peut la faire sur des fonds gris, ou jonquille“. Am Ende seines Briefes versicherte der Sattler, Madame de Tournier „aura lieu d'être plus que contente comme l'ont été tous ceux qui ont agi de cette façon avec moi". ADHG, $3^{\mathrm{E}}$ II990, 1725 Juni 29, Vereinbarung über die Herstellung eines Tragsessels. 


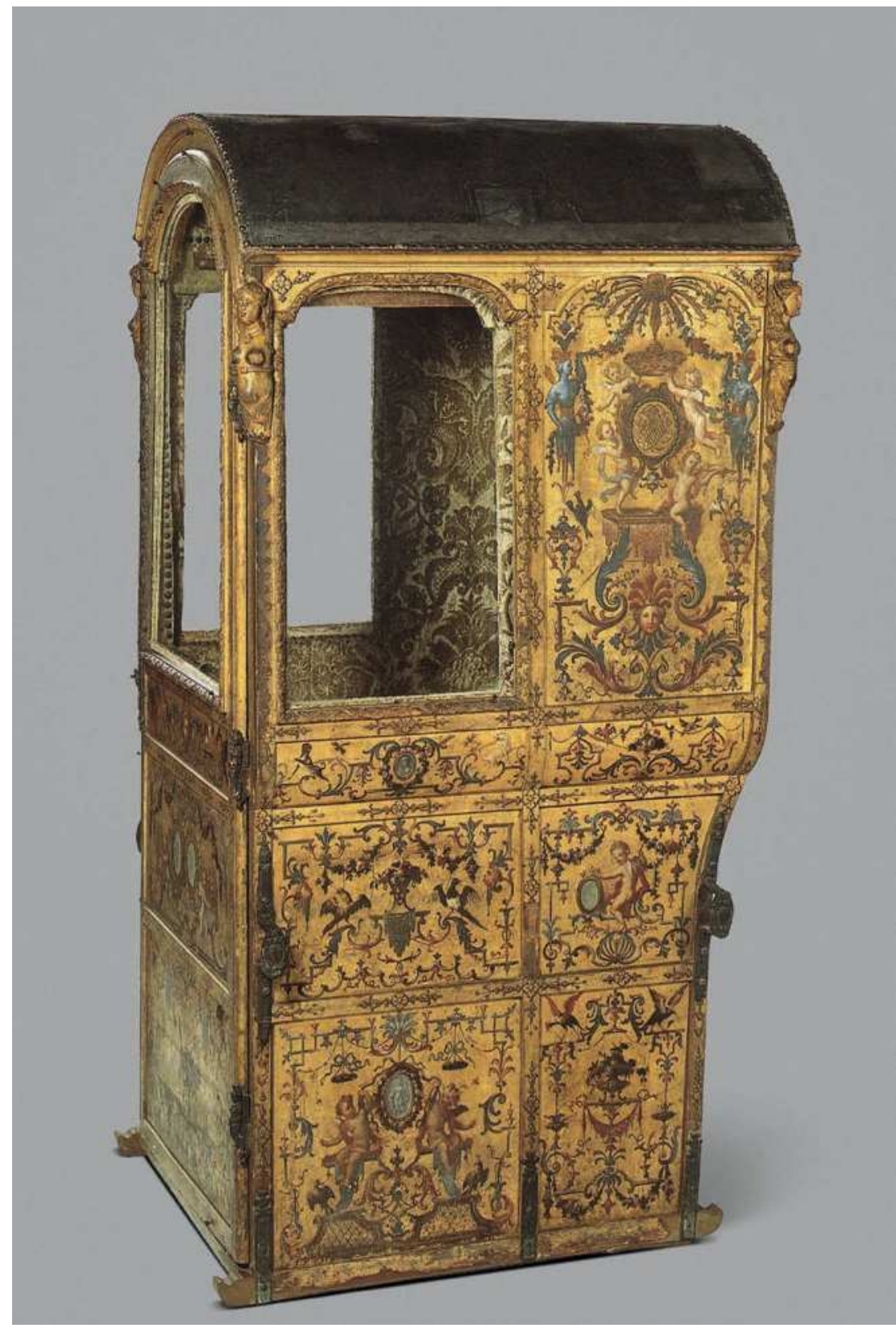

Abb. 2: Tragsessel des kurfürstlichen Hofes zu Hannover, Paris um 1700. @ Erbprinz Ernst August von Hannover 


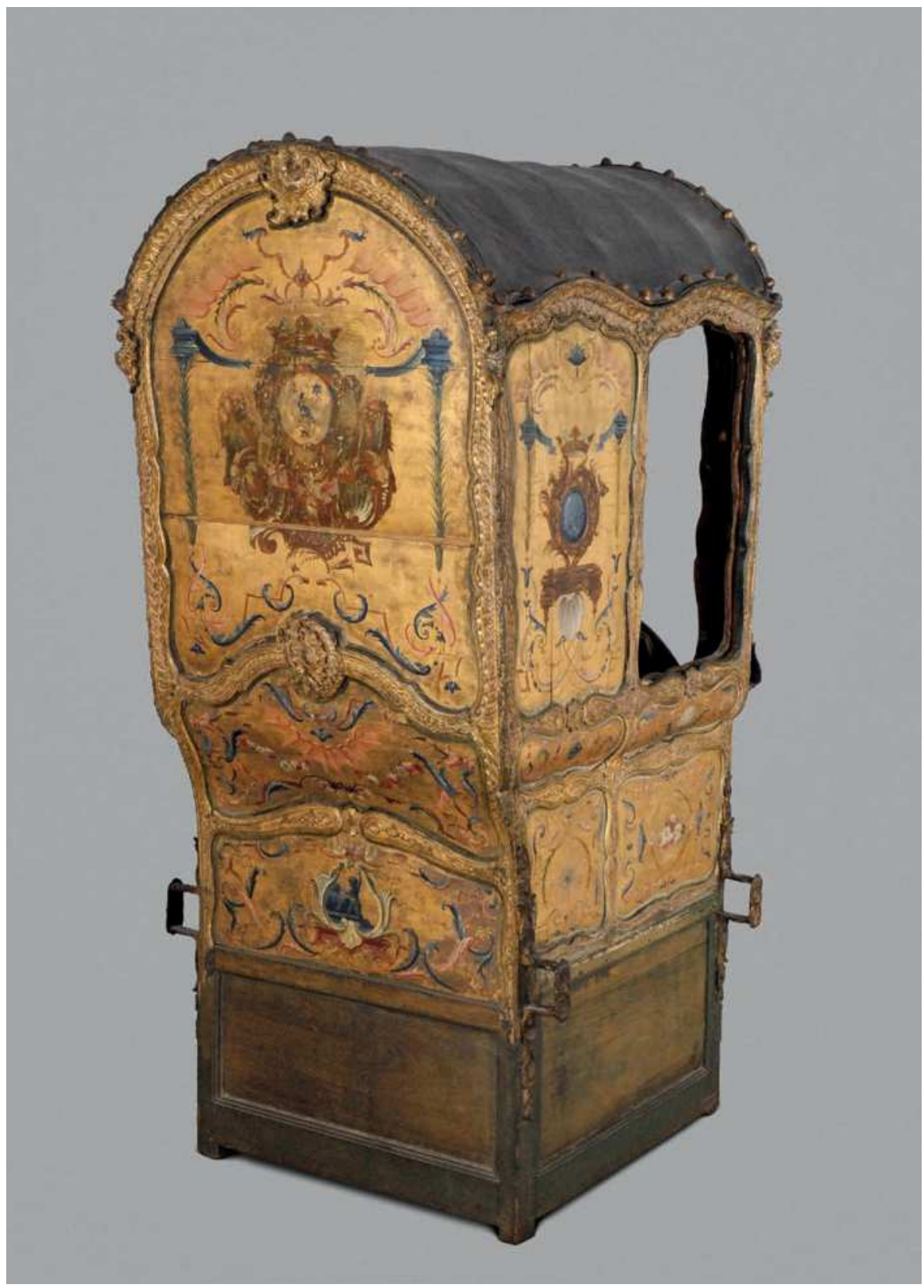

Abb. 3: Tragsessel, einst im Besitz von René Madec, um 1698. Musée départemental breton, Quimper. Foto: Serge Goarin / Musée départemental breton 


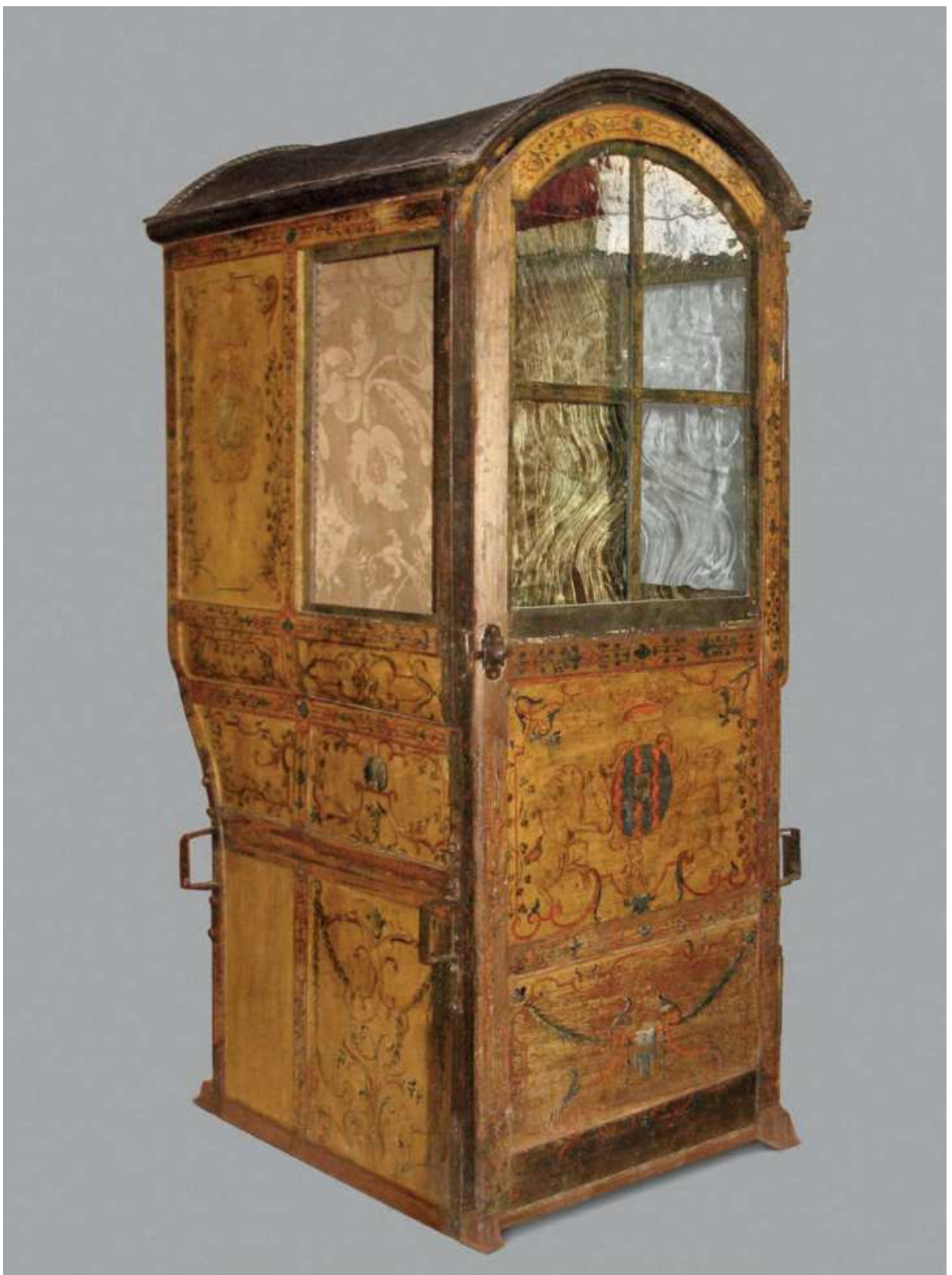

Abb. 4: Tragsessel des Marquis von Calvisson, vor 1700. Musée Paul Pastre, Schloss Marsillargues, Marsillargues. @ Musée Paul Pastre 


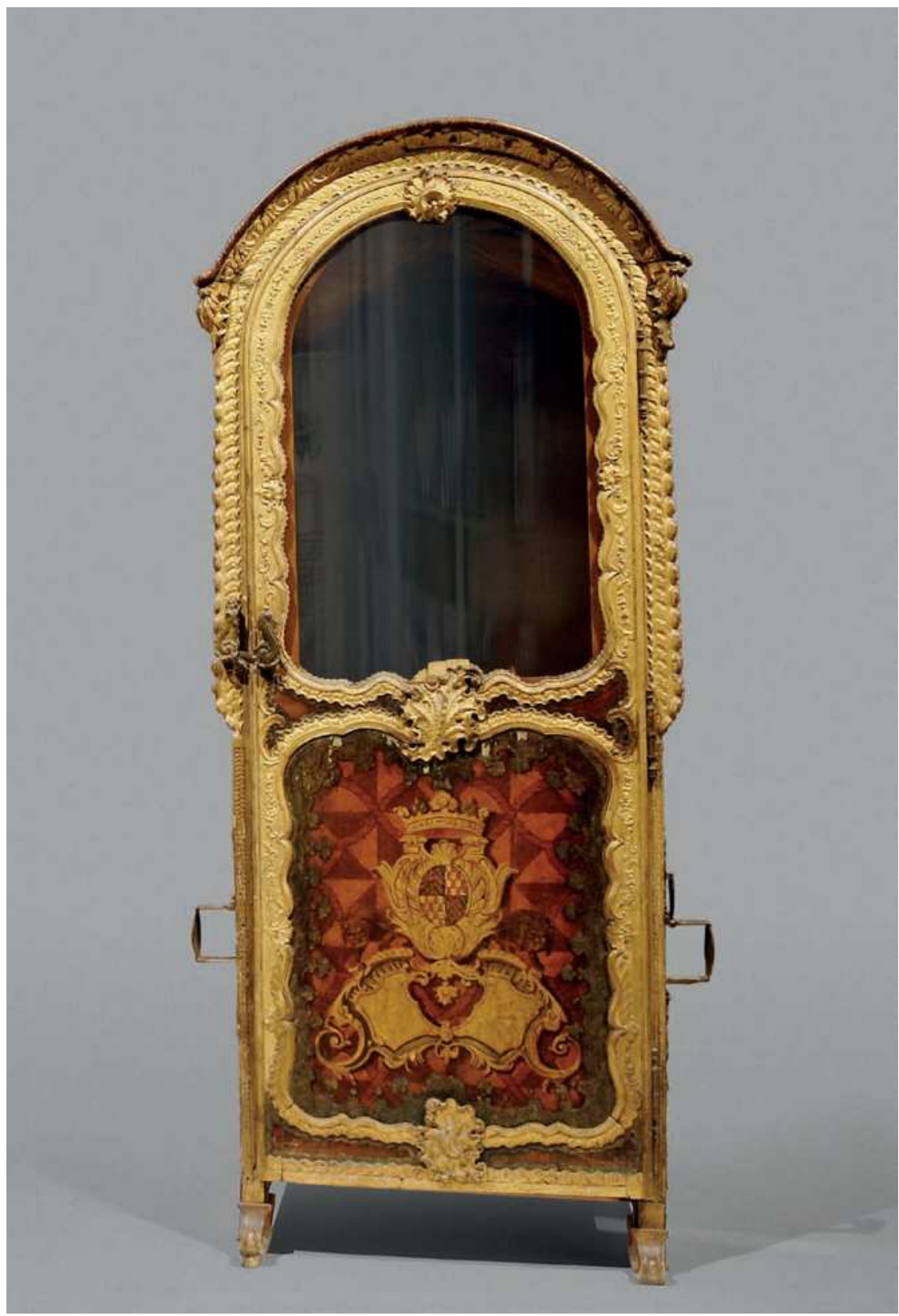

Abb. 5: Tragsessel, um 1690/95. Musée de Vannes. @ Musée de Vannes 


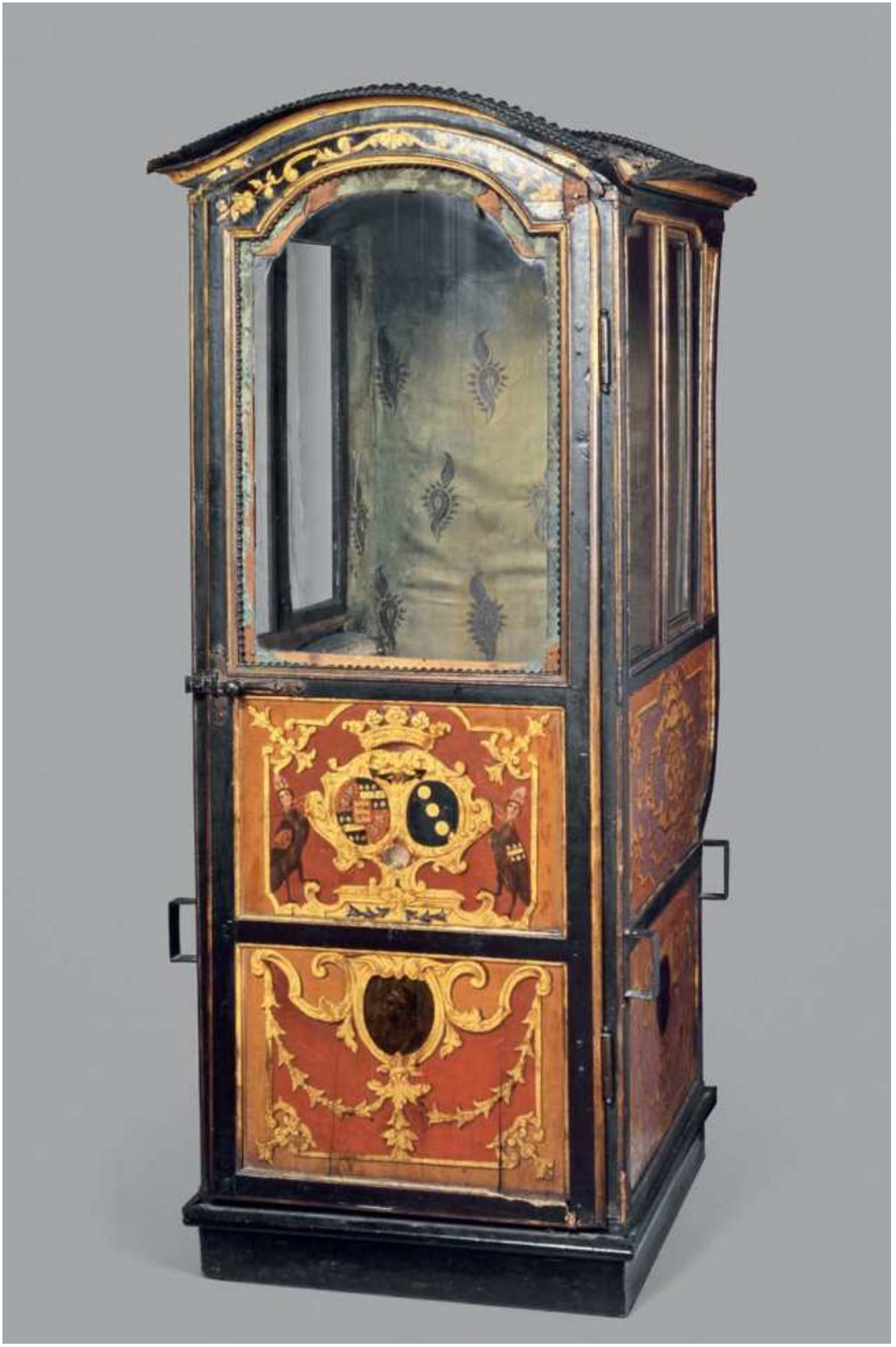

Abb. 6: Tragsessel des Marquis d'Abzac de Ladouze, um 1715? Collections Ville de Périgueux, musée d'art et d'archéologie (Maap), Inv.-Nr. M.48. Foto: Bernard Dupuy. @ Maap 


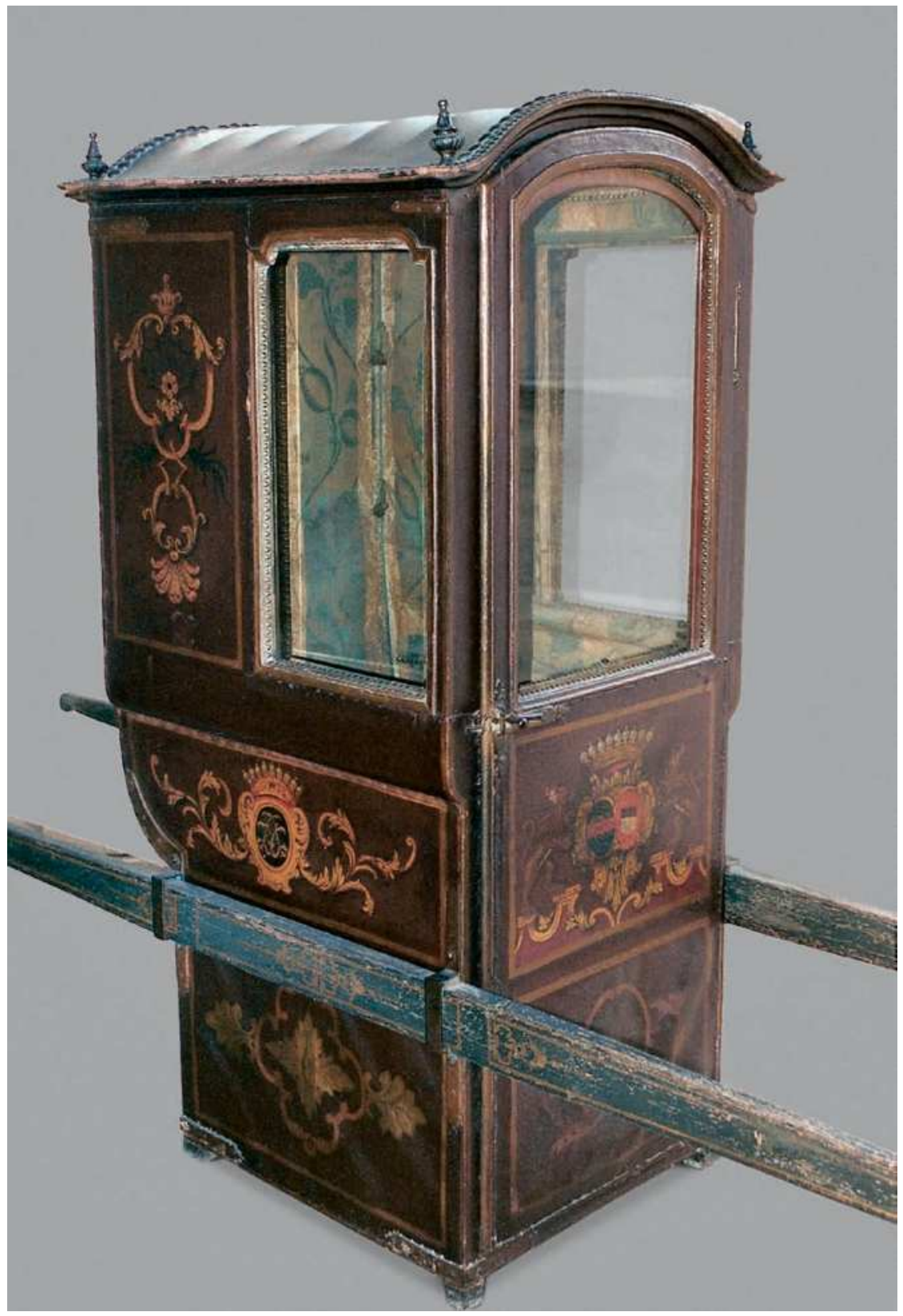

Abb. 7: Tragsessel, um 1715? Collection du musée des Arts décoratifs et du Design, Bordeaux. Foto: Lysiane Gauthier 


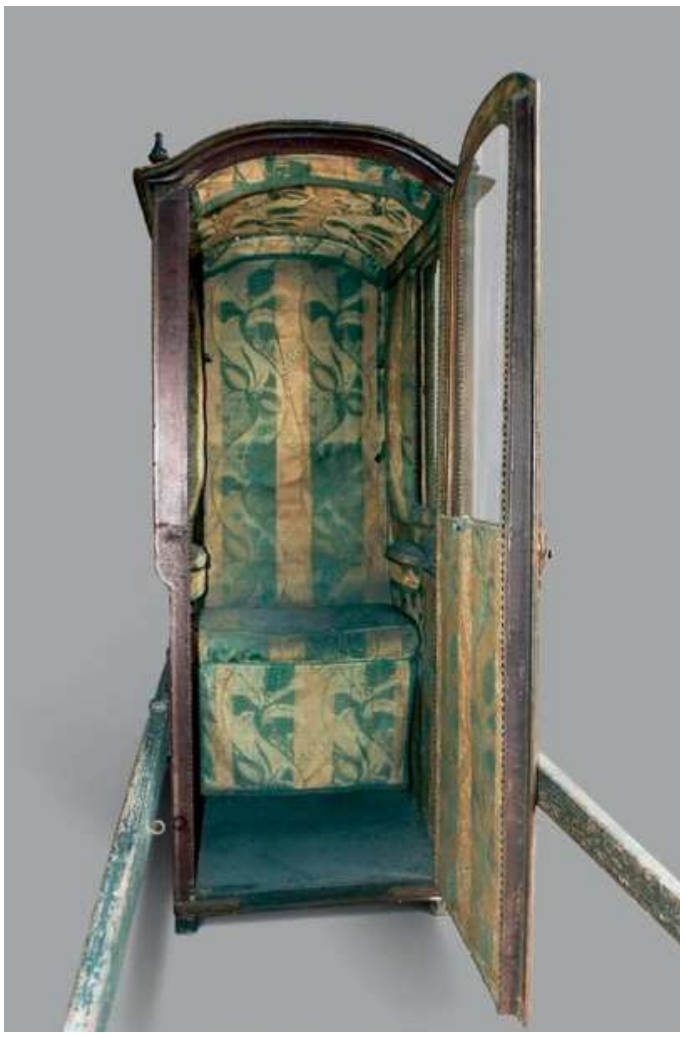

Abb. 8: Wie Abb. 7, Innenansicht.

Foto: Marie Maggiani

Prinz Ernst-August von Hannover (um I700) (Abb. 2), ein Tragsessel des Musée départemental breton in Quimper (um I698?, Abb. 3) ${ }^{25}$ oder ein erst kürzlich restaurierter Tragsessel des Schlosses Marsillargues bei Montpellier (vor I700, Abb. 4). Letzterer weist am Kasten dieselbe Feldunterteilung und auch einen Dekor auf, der stark an die „Bérinades“ erinnert, allerdings sind die vegetabilen und ornamentalen Motive auf goldbraunem Hintergrund hier einfacher als bei Tragsesseln fürstlicher Provenienz. Der Auftraggeber dieses Vehikels

25 Dieser Tragsessel, der im April 2008 als Schenkung in das Museum gelangte, gehörte einst René Madec, einem berühmten Sohn Quimpers. Madec wurde 1736 geboren und lebte über fünfundzwanzig Jahre in Indien, wo er den Titel eines Nawab trug. Nach seiner 1779 erfolgten Rückkehr nach Frankreich wurde er nobilitiert und erwarb diesen Tragsessel von einem Mitglied des bretonischen Parlaments. Das Wappen des Vorbesitzers ließ er mit einem grünen Anstrich verdecken, der 1996 wieder entfernt wurde. Da sich das für lange Zeit unsichtbare Wappen der Familie Bertho de la Villejosse zuordnen lässt, ist es nicht unwahrscheinlich, dass der Tragsessel I698 anlässlich der Hochzeit von Elisabeth Suzanne Bertho de la Villejosse und Charles Gascher hergestellt wurde. 
Abb. 9: Wie Abb. 6, Innenansicht.

Foto: Marie Maggiani

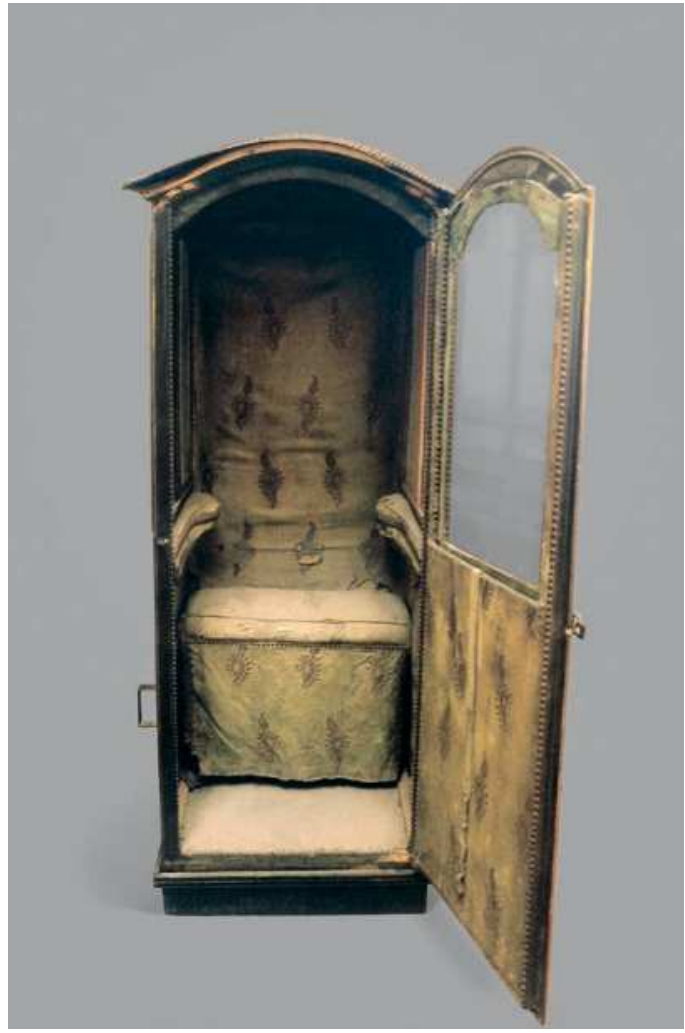

war ein Adeliger aus dem Languedoc ${ }^{26}$, der auch am Hofleben in Versailles teilnahm. Aus diesem Grund scheint auch eine Pariser Herkunft seines Tragsessels plausibel, auch wenn keine diesbezügliche Schriftquelle erhalten ist. Der Tragsessel des Museums in Vannes besitzt wiederum keine „Bérinades“ (Abb. 5); seine auserlesenen Bildhauerarbeiten, die vergoldeten Zierleisten und die sich harmonisch in das Gesamtbild fügenden Metallbeschläge zeugen jedoch von hoher Qualität. Auch der kostbare, Intarsien imitierende Untergrund in Rautenform unterstreicht den hohen Rang dieses Tragsessels. Das auf dem dunklen Farbgrund angebrachte Wappen ermöglicht eine Datierung in den Zeitraum zwischen I690 und $1695 .{ }^{27}$

Derartige Wappen stellen bei vielen Tragsesseln die einzige Verzierung dar. Der Grund für einen solch reduzierten Dekor konnte entweder in persönlichen Vorlieben liegen oder

\footnotetext{
26 Jean Louis II. de Louet de Nogaret (I630-I700), Marquis de Calvisson, hatte das Amt eines Lieutenant général du Languedoc inne. Als solcher vertrat er den König in der gesamten Provinz.

27 Louise Allain ehelichte I690 Nicolas Joseph de Ploeuc, der nur fünf Jahre später verstarb.
} 
aber finanzieller Natur sein. Bei den heraldischen Zeichen, die häufig auf einem einfarbigen, dunklen Untergrund angebracht waren, handelte es sich manchmal um ein einzelnes Familienwappen, zuweilen aber auch um ein Allianzwappen. Gelegentlich war das Wappen von einer Kartusche umfasst, mit einer Krone versehen und von Tieren oder Putten flankiert, die als Schildhalter fungierten. Um den Besitzer des Vehikels eindeutig identifizieren zu können, wurde das Wappen mitunter durch ein Monogramm ergänzt.

Ging der gemalte Dekor über eine einfache Wappendarstellung hinaus, mussten dabei gewisse Konventionen berücksichtigt werden. Zwar konnten Künstler aus dem reichen ornamentalen Repertoire ihrer Zeit schöpfen und den Paneelen entweder einen feierlichen oder einen unbeschwerten Charakter verleihen, jedoch waren sowohl Historienmalereien als auch Porträtdarstellungen verpönt, da diese als inadäquat oder gar trivial erachtet wurden. Geschätzt wurde hingegen die Darstellung von Allegorien und mythologischen Figuren, da derartige Motive gelehrte Verweise mit optischer Gefälligkeit verbanden. So ist beispielsweise auf einem Tragsessel des Kutschenmuseums im Schloss Compiègne ${ }^{28}$ auf dem Türpaneel die auf einer Muschel stehende Venus zu sehen, während die Kastenrückseite Neptun zeigt, der ganz offensichtlich von einem Entwurf Jean Bérains oder Jean Lepautres inspiriert ist. Die übrigen Paneele sind mit verschiedenen zurückhaltend gestalteten maritimen Sujets dekoriert, etwa mit Jakobsmuscheln, Sirenen, in Muschelhörner blasenden Tritonen und so fort. Insgesamt gesehen wirkt die Dekoration des Tragsessels mit seiner verhältnismäßig neutralen Symbolik ausgewogen und geschmackvoll.

Ähnliches lässt sich auch für die Tragsessel von Périgueux (Abb. 6) und Bordeaux (Abb. 7) feststellen, deren Stil von jenem des Petit Palais abweicht. Bei beiden Tragsesseln sind die Seitenpaneele unterhalb der Fensterzone im hinteren Bereich stark eingezogen, und beide verfügen über ein Dach in Form eines „chapeau de gendarme“. Der sorgfältig ausgeführte malerische Dekor, der vermutlich stellenweise nachgebessert wurde, ist weit weniger komplex als die „Bérinades“. Sämtlichen Paneele sind mit Palmetten, Blattranken, Akanthusblättern und Flechtwerkmustern bedeckt, während die Wappen nur an der Kastenvorder- und -rückseite zu sehen sind. Der Luxus entfaltet sich hier vor allem im mit kostbaren Stoffen bezogenen Inneren des Kastens. Die Qualitätsstufe oder Seltenheit der Textilien, die Komplexität der Webart, die bei der Anfertigung eingehaltene Sorgfalt, das Vorhandensein von Gold- und Silberelementen, die Herstellungsdauer sowie die Entfernung des Produktionsortes waren Faktoren, die Einfluss auf den Preis derartiger Stoffe nehmen konnten. Aus diesem Grund stellten Auftraggeber in Frankreich wie auch in anderen Ländern mitunter selbst die Stoffe für ihre Tragsessel bereit. Andernfalls wurden im Kaufvertrag die geforderten Stoffeigenschaften meist präzise festgelegt.

28 Inv.-Nr. MV.6o.D.I. Siehe dazu Maggiani 2007 (wie Anm. 4), Bd. 2, Tragsessel Nr. 2. 
Bei älteren Tragsesseln bevorzugte man allem Anschein nach eher kostbare und elegante Textilien als „bizarr“ anmutende Stoffbezüge, wie etwa jenen, mit dem der bereits erwähnte in Bordeaux aufbewahrte Tragsessel (Abb. 8) tapeziert ist. Mit einer Kombination aus Schlangenlinien und vegetabilen, von chinesischen Ornamenten inspirierten Motiven weist dieser ungewöhnliche Stoff ein eigentümliches, exotisch wirkendes Muster auf. Trotz manchen Schadens und anderer Spuren der Zeit ist das Wechselspiel aus Spitze, Früchten und Blumen auf einem Grund aus grünen und cremefarbenen Vertikalbändern immer noch gut erkennbar. Während es sich hierbei um ein europäisches Erzeugnis handelt, ist der Seidenstoff des Tragsessels von Périgueux (Abb. 9) wohl außereuropäischer Herkunft. Hier heben sich versetzt angeordnete, stilisierte Tulpen in schwarzer Farbe vor einem goldgemaserten, hellen Grund ab, der zusätzlich von feinen Rankenornamenten in persischer Manier belebt ist. Offenbar stammt dieser Stoff, der vermutlich vom - namentlich unbekannten - Auftraggeber bereitgestellt wurde, aus dem Orient, was den Tragsessel als veritables Luxusobjekt kennzeichnet. Äußerst kostbar war wohl auch der schon zuvor erwähnte, I69I nach einem Entwurf von Jean Bérain hergestellte Tragsessel der Fürstin von Conti, dessen Kasten mit einer prunkvollen Reliefstickerei in Gold und Silber auf scharlachrotem Samtgrund bedeckt war. ${ }^{29}$ Zwar waren Tragsessel mit prächtigen Stickereien an den Außenwänden nicht sehr verbreitet, dennoch sind einige außergewöhnlich luxuriöse Exemplare dieser Machart erhalten, etwa in der Eremitage in St. Petersburg (um 1650) ${ }^{30}$ oder im Marstallmuseum Nymphenburg (um I684/85) ${ }^{31}$. Bei einem derart kostbaren Kastendekor konnten die Besitzer davon ausgehen, dass ihr Vehikel alle Blicke auf sich zog. ${ }^{32}$ Wem die finanziellen Mittel für solch

29 LA Gorce 1986 (wie Anm. 13), S. 54. Es handelte sich hierbei um eine „broderie relevée en bas-relief d'or sur doré de Paris, enrichie de guipure de trait d'argent et de trait sur doré double avec un fond tout remply d'or recouvert d'un gros cordon d'or, le tout parfaitement riche".

30 Inv.-Nr. МБ-4I3. Siehe dazu Wladimir TschernYsCHEw, Vom kaiserlichen Marstallmuseum zur Wagensammlung der Eremitage in St. Petersburg - Kostbarkeiten des I8. und 19. Jahrhunderts. Geschichte und Bestand einer der weltweit wichtigsten Marstallsammlungen. In: Achse, Rad und Wagen. Beiträge zur Geschichte der Landfahrzeuge I2 (2004), S. 94-I05, hier S. 94 (Abb.) und IoI.

3 I Vgl. Anm. I2.

32 Im 17. Jahrhundert von Toulouser Meistern für Parlamentarier gebaute Karossen waren fallweise ebenfalls mit Stickereien versehen: „[...] dont les portières seront doublées de bonne vache de Russie et de serge en broderie“ (I6I5), DE BEAuregard 200I (wie Anm. I3), S. 887. In seinem gegen Ende des I8. Jahrhunderts erschienenen Werk erinnerte auch Roubo daran, dass Wagen in früheren Zeiten mit kostbaren Stoffen, Gold und Stickereien ausgestattet waren, allerdings vorrangig innen und seltener an der Außenseite. Jacques-André Roubo, L'art du menuisier (erstmals Paris 1769-1782), Bd. 2: La menuiserie des voitures ou des carrosses (Reprint Meylan 1987), S. 463. 
kostspielige Stickereien fehlten, konnte sich mit kostengünstigerer Posamenteriearbeit behelfen, da sich mit den dabei verwendeten Metallfäden ebenfalls raffinierte Glanzeffekte erzeugen ließen.

Waren damals sämtliche Tragsessel mit aufwendigen Textilien bezogen oder gar mit Stickereien dekoriert? Die Statuten der Sattler von September 1678 erwähnen diesbezüglich „toutes sortes d'étoffes, soit de drap d'or ou d'argent, velours, damas, satin et autres, tant

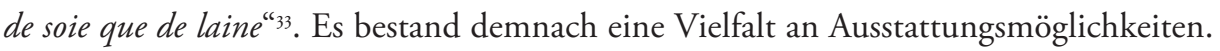
Dies findet auch in Toulouser Nachlassinventaren, die für den vorliegenden Beitrag ausgewertet wurden, Bestätigung. Bei den verwendeten Textilien handelte es sich meist um Seidenstoffe (Brokat, Moiré oder Satinade) beziehungsweise um feines Tuch, in jedem Fall aber um leichte, fragile Materialien. Beispiele wie das folgende aus dem Jahr 1704, in dem die textile Ausstattung eines Tragsessels genau beschrieben ist, sind jedoch äußerst selten: „[...] d'une estoffe de soye a rayes blanches et le fonds jaune avec son [coussin] aussi garny de meme estoffe ${ }^{{ }^{3} 3}$. Ein 1653 inventarisierter Tragsessel Kardinal Mazarins war mit einem aus Genua stammenden scharlachroten Seidendamast mit Blumenmuster ausgeschlagen, und für jenen des Erzbischofs von Bordeaux, Henri de Bétuhne, fand ein violetter Seidendamast Verwendung (I680). ${ }^{35}$ Von exquisiter Qualität ist auch der in Orange- und Rottönen gehaltene und mit einem Muster aus großflächigen Blumen und stilisierten Vögeln versehene Seidendamast eines Tragsessels aus dem Schloss Marsillargues (vor 1700, Abb. 4). Seidendamaste hatten jedoch auch nachteilige Eigenschaften, wie ein Sattler 1725 einer Kundin bestätigte: Ein derartiger Bezug sei „d'un très mauvais usage, il s'engraisse et se coupe bien facilement et tout le monde sén est désabusé [...]". Er riet ihr stattdessen zu einem anderen Material, etwa „velours ou une étoffe bonne et riche ${ }^{\text {"36 }}$. Da Samt tatsächlich widerstandsfähiger und deshalb auch besser für die Ausstaffierung von Tragsesselkästen geeignet war, entwickelte er sich schließlich für diesen Zweck auch zu „dem“ Standardmaterial. Zur Zeit der Régence (1715-1723) verwendete man für die Tapezierung von Tragsesseln gerne Samtstoffe mit großflächigen Motiven (Granatäpfel, Ananas, Sonnenblumen) und symmetrischen Kompositionen. ${ }^{37}$ Die Samtstoffe waren häufig monochrom, wobei während

33 Artikel is des achtundvierzig Artikel umfassenden und von Ludwig XIV. approbierten Sattlerstatuts. Ein bereits älteres, aber äußerst detailliertes Werk hierzu ist René de Lespinasse, Histoire générale de Paris. Collection de documents. Les métiers et corporations de la ville de Paris, $\mathrm{Bd}$. 3: Tissus, étoffes, vêtements, cuirs et peaux, métiers divers (Paris 1892), S. 463.

34 ADHG, $3^{\mathrm{E}}$ II 933, I704 Januar 25.

35 Havard 1894 (wie Anm. 7), Bd. I, S. 654 f.

36 ADHG, $3^{\mathrm{E}}$ II990, Schreiben des Sattlers Guynaud aus Avignon an Madame de Tournier in Toulouse.

37 In dieser Hinsicht sind Tragsessel ungeeignet, um die große Vielfalt französischer Textilien des I8. Jahrhunderts zu demonstrieren, denn Bandwerk- und Spitzenmuster, Chinoiserien, ganze Blumensträuße, 
des gesamten I8. Jahrhunderts die Farben Rot (um genau zu sein, müsste eigentlich von Rottönen die Rede sein ${ }^{38}$ ) und strahlendes Gelb besonders geschätzt und weit verbreitet waren. In den Quellen sind jedoch auch Stoffe in Grün (I692), mit gelb-weißen Streifen $(\mathrm{I} 704)^{39}$ oder in „plusieurs couleurs“, wie etwa ein grün-roter Stoff (I698) ${ }^{40}$, erwähnt. Bei einer Tapezierung mit Samt oder anderen strapazierfähigen Textilien wurde für das gesamte Kasteninnere - also für Sitz samt Polster, Seitenwänden, Rücken- und Armlehnen, Tür und Himmel - meist derselbe Stoff verwendet. Die Vorhänge waren zwar fast immer im gleichen Farbton gehalten, jedoch aus feinem, leichten Seidentaft oder -damast gefertigt. Auf diese Weise ließ sich der Eindruck einer chromatischen Einheit erzielen, der jedoch heute bei vielen Objekten verloren gegangen ist, da häufig die Originaltapezierung durch andere Textilien ersetzt wurde.

Passanten konnten die Innenausstattung des Kastens durch die Kastenverglasung sehen. Meist waren in die Kastenwände drei, seltener fünf Fenster eingelassen. Das Türfenster ließ sich in der Kastenwand versenken, während sich die Fenster der Seitenwände bei älteren Tragsesseln durch eine horizontale Verschiebung der Gläser öffnen ließen und bei jüngeren Modellen ebenfalls vertikal versenkt werden konnten. In Frankreich wurden Fahrzeuge schon sehr früh mit Gläsern versehen. Baron de Bassompierre ließ bereits I599 eine Kutsche mit Fenstern aus Italien importieren, die sich von den bis dahin üblichen Wagen mit einfachen Lederverdecken deutlich abhob. Ein Jahrhundert später „il n'est pas jusqu'à toutes les voitures de remise et la plupart des fiacres, qui par devant ne soient fermés d'une grande glace "4i. Auch Tragsessel wurden mit Glasscheiben ausgestattet, meist mit gewöhnlichem Glas, zuweilen aber auch mit Spiegelglas, das hinsichtlich Strapazierfähigkeit, Regelmäßigkeit und Transparenz eine bessere Qualität aufwies. ${ }^{42}$ Im Jahr ${ }^{6} 665$ gründete Colbert die königliche Glasmanufaktur, um auf diesem Sektor mit Italien konkurrieren zu können. Dennoch bezogen viele Wagenbauer und ihre Kunden auch Glas von anderen der zahlreich vorhandenen Glasmanufakturen des Landes. Der Herzog von Lothringen errichtete etwa im Jahr I667, ein Jahr vor seiner Hochzeit mit der Nichte Ludwigs XIV., ein auf Spiegel- und Wagengläser spezialisiertes Unternehmen, das seine

große Blattwerkmotive und asymmetrische Kompositionen sind dabei nur selten zu finden.

38 In den Quellen sind unter anderem folgende Rottöne erwähnt: cramoisi, rubis und cerise.

39 ADHG., $3^{\mathrm{E}}$ II 892 , I692 Dezember 2O; $3^{\mathrm{E}}$ II9O2, I704 Oktober 29.

40 ADHG, $3^{\mathrm{E}}$ II 982 , I698 November IO.

4I Lister, Voyage en France (I698), zit. nach Claude Pris, La manufacture royale des glaces de Saint-Gobain. Une grande entreprise sous l'Ancien Régime (ungedr. Dissertation, Université Lille III 1975), S. 84 f.

42 Spiegelglas darf nicht mit Spiegeln selbst verwechselt werden. Bei Letzteren handelt es sich um Spiegelgläser mit applizierter Zinnfolie. 
Waren bis nach Holland und Deutschland exportierte. ${ }^{43} \mathrm{Ob}$ wohl auch der Tragsessel seiner zukünftigen Gemahlin mit Gläsern seiner eigenen Manufaktur ausgestattet war? Wer es sich leisten konnte, versah seinen Tragsessel mit großen Scheiben, deren Preis von der Haltbarkeit, Transparenz und dem Grad etwaiger Fehlstellen und Verunreinigungen abhing. Billiger war es, Rahmen mit mehreren rechteckigen Feldern in die Fensteröffnungen zu integrieren, da auf diese Weise kleinere Gläser eingesetzt werden konnten. So sind etwa für I657 Tragsessel „bien et deuement garnyes de leurs chassis a verre“" ${ }^{\text {"4 }}$ dokumentiert. Hierbei handelte es sich um Miettragsessel, die in Aix-en-Provence hergestellt und verliehen wurden.

\section{Miettragsessel}

Auch wenn es in mancher Hinsicht Vorteile hatte, einen eigenen Tragsessel zu besitzen, unter anderem, weil darauf das eigene Wappen angebracht werden konnte, ${ }^{45}$ stand es doch auch jedermann frei, öffentliche Tragsessel zu mieten. Derartige Miettragsessel existierten in Paris offiziell seit dem 22. Oktober 16r7. Damals erhielten drei Personen, die sich zu diesem Zweck zusammengeschlossen hatten, nämlich der Fabrikant Jean Douet, der Finanzier Jean Regnault d'Ezanville sowie der Kapitän der königlichen Leibgarde Pierre Petit, für den Zeitraum von zehn Jahren das Privileg, in Paris, in dessen Vororten und auch in den übrigen Teilen des Königreichs Tragsessel zu unterhalten, ,pour faire porter des rues à autres ceux ou celles qui désireroient sỷ faire porter". Einige Zeit nach Auslaufen dieses Privilegs, im Jahr 1639, erhielten ein gewisser Cavoy, Kapitän der Musketiere, und dessen Geschäftspartner Marquis de Montbrun, der geschlossene Tragsessel aus England eingeführt hatte, dieses Sonderrecht bis zum Jahr 1679 verliehen..$^{46}$ Insgesamt wurde das Privileg zweimal zugunsten Cavoys beziehungsweise dessen Nachkommen für einen Zeitraum von jeweils vierzig Jahren verlängert. ${ }^{47}$ Die Vermietung von Tragsesseln scheint ein profitabler

43 Pris i975 (wie Anm. 4I), S. 784.

44 Jean Boyer, Evocation du Vieil Aix. In: Courrier d‘Aix, Nr. 1795-1797, 7. und 21. April 1979. Bedauerlicherweise gibt der Autor den Standort der von ihm verwendeten archivalischen Quellen nicht bekannt. „[...] ce qui est plus propre et ce qui représente l'avantage de pouvoir y faire peindre ses armes [...]“. Les Lois de la galanterie (wie Anm. I6, Ausgabe Paris i658).

46 Gédéon Tallemant des RÉAux, Les historiettes: mémoires pour servir à l'histoire du $\mathrm{I}^{\text {jème }}$ siècle, Bd. 7 (Paris ${ }^{2}$ I840), S. IO2. Die persönlichen Erinnerungen des Autors blieben für lange Zeit unpubliziert und wurden erst I834 zum ersten Mal veröffentlicht.

47 Die drei Abkommen stammen aus den Jahren 1639, 1679 und I719. Delamare 1738 (wie Anm. 5), Bd. 4, Kapitel 2, Abschnitt 3, S. 449: „Du privilège des chaises portées à bras et des porteurs de chaises“. 
Geschäftszweig gewesen zu sein, da neidische Blicke auf dieses „établissement si commode et si avantageux" fielen und versucht wurde, parallel zu den offiziell genehmigten Tragsesseln illegale Konkurrenzunternehmen aufzubauen. ${ }^{48}$

Tragsessel konnten aber nicht nur in der Hauptstadt gemietet werden. So stand etwa seit März I634 auch den Einwohnern der Parlamentsstadt Aix-en-Provence eine derartige Dienstleistung zur Verfügung. Rund zwei Jahrzehnte später, im Jahr I655, erhielt ein gewisser Paradis, der als Tapissier in der Stadt ansässig war, die Erlaubnis, über einen Zeitraum von vier Jahren zehn selbst gebaute Tragsessel vermieten zu dürfen. Im darauf folgenden Jahr dehnte er dieses Geschäft auf die Stadt Arles aus. I657 überließ er sogar einige von ihm selbst gebaute Tragsessel Sesselträgern, die sie in Monfrein und bei der nur einige Kilometer von Arles entfernten Messe von Beaucoire einsetzen und gegebenenfalls auch verkaufen durften. ${ }^{49}$ Da sich im städtischen Bereich mit derartigen Transportunternehmen offenbar gute Geschäfte machen ließen, überrascht es auch nicht, dass im April I663 auch im nahe gelegenen Marseille ein Tapissier namens Balthazar Bayan einen Tragsesselverleih gründete. ${ }^{50}$

$\mathrm{Zu}$ jener Zeit wurde offiziell bestimmt, dass fortan allein den Tapissiers das Recht zustand, Tragsessel herzustellen, während Sattlern diese Tätigkeit vorerst unter der Androhung von Strafen untersagt wurde. ${ }^{\text {sI }}$ Tatsächlich stellten Sattler eine ernstzunehmende Konkurrenz für Tapissiers dar. Beschränkten sie sich anfangs noch auf die Herstellung von Sätteln und Geschirren, begannen sie später Kutschen und Karossen mit Leder zu beziehen, um schließlich ihren Tätigkeitsbereich noch weiter auszudehnen. Eine Regelung von 1678 bestätigte eine damals bereits verbreitete Praxis, der zufolge nunmehr Sattler und nicht länger Tapissiers für die textile Ausstattung und Fertigstellung von Fahrzeugkästen zuständig sein sollten. In Artikel Is dieser Neuordnung ist explizit festgelegt, dass

48 Ebenda. Unter dem Datum 25. April 1669 erwähnt Nicolas Delamare aus diesem Grund die Verhaftung von Sesselträgern. Ebenda, S. 450.

49 BOYer 1979 (wie Anm. 44).

50 AMM, HH 423, 1663 April I7, „usage des chaises établi à Marseille par Balthazar Payan maître tapissier".

SI „[... que dorénavant aux Tapissiers seuls appartiendra la manufacture desdites chaises à porter par l'homme, et deffenses à tous selliers d'en faire n'y entreprendre, faire faire par qui que ce soit, à peine de confiscation, et de quatre-vingt livres d'amande [...]“. Urteil von Châtelet, I665 September 6. Der Urteilsspruch greift den Wortlaut des 1636 erlassenen und im Jahr 1645 sowie in mehreren Pariser Parlamentssitzungen bestätigten Statuts erneut auf. Zit. nach LeSPINASSE I892 (wie Anm. 33), S. 466. Siehe dazu auch das Beispiel von einem Tapissier in Aix-en-Provence, der I674 anlässlich der Durchreise der Herzogin von Modena den Auftrag zur Herstellung von „une chaise garnie par le dedans de velours cramoisy et par le dehors d'une toille cirée peinte" erhielt. AMAeP, Comptabilité de la ville, CC 649 (I65I-1675), fol. 223. 
les maîtres selliers, exclusivement et privativement à tous les autres, pourront entreprendre de $[\ldots]$ garnir tant dedans que dehors desdits carrosses, coches, litières et autres voitures roulantes et portantes, de toutes sortes d'étoffes, soit de drap d'or ou d'argent, velours, damas, satin et autres, tant de soie que de laine..$^{22}$

Mehr noch, Sattlern wurde schließlich sogar das Exklusivrecht zuteil, die Herstellung von Wagen, Sänften und Tragsesseln im Alleingang zu leiten. Tischlern und Wagnern wurde hingegen ausdrücklich untersagt, in Hinkunft "travailler ni faire travailler aux carrosses, litières, calèches et chaises à porteurs "s3. Sattler standen nun in direktem Kontakt mit den Kunden und koordinierten die Arbeiten der übrigen am Fahrzeugbau beteiligten Gewerke, wie etwa Wagner, Tischler, Bildhauer, Maler, Vergolder oder Lackierer. Im I8. Jahrhundert verstärkten sich diese Tendenzen zunehmend, als die Sattler, die nun sellier-carrossier genannt wurden, sich nicht allein der Herstellung und dem Verkauf von Fahrzeugen widmeten, sondern nunmehr auch Aufgaben wie Reparaturen, den Verleih, gerichtliche Begutachtungen oder Schätzungen von Vehikeln übernahmen. An der Spitze mancher Werkstätte stand damals nicht mehr ein einfacher Handwerksmeister, sondern ein regelrechter Unternehmer.

In stilistischer Hinsicht waren Mittragsessel natürlich wesentlich schlichter gestaltet als Privatvehikel, die für Mitglieder der Hofgesellschaft oder andere wohlhabende Personen bestimmt waren. Damit Miettragsessel auch bei intensiver Nutzung großen Strapazen standhalten konnten, waren sie äußerst solide gebaut. Tischler verwendeten für die Herstellung dieser Tragsessel leichte, gleichzeitig aber auch in hohem Maße belastbare Hölzer von bester Qualität. Wie Schriftquellen belegen, waren Miettragsessel in Aix-en-Provence etwa aus Pinienholz gefertigt. ${ }^{54}$ Anlässlich von Restaurierungsarbeiten konnte bei jüngeren Tragsesseln jedoch auch der Einsatz anderer Hölzer festgestellt werden, wie etwa Buche, Nuss und Erle, die sich aufgrund ihrer langen Haltbarkeit und ihres geringen Gewichts besonders gut für den unteren Kastenbereich eigneten. Für konstruktive Teile und das Dach kam häufig Eiche zur Verwendung, für die Paneele hingegen Pappel- oder Tannenholz. Bei den Trageholmen wurden Hölzer mit hoher Elastizität eingesetzt, um etwaige Stöße gut abfedern zu können.55

Bis Ende des I8. Jahrhunderts war es durchaus nicht unüblich, Tragsessel zur Gänze aus Holz zu fertigen. Um das Kastengewicht zu verringern, wurden viele Objekte jedoch auch

52 Lespinasse i892 (wie Anm. 33), S. 463.

53 Artikel 28. Ebenda, S. 465.

54 Boyer 1979 (wie Anm. 44).

55 In Roubos Werk wird dem Gestell und den Kastenpaneelen leider kaum Aufmerksamkeit geschenkt. Vgl. Roubo 1987 (wie Anm. 32), Bd. 2, S. 558. 
Abb. 10: Aus Versailles stammender Miettragsessel, 3. Drittel des 17. Jahrhunderts. Privatsammlung. Foto: Marie Maggiani

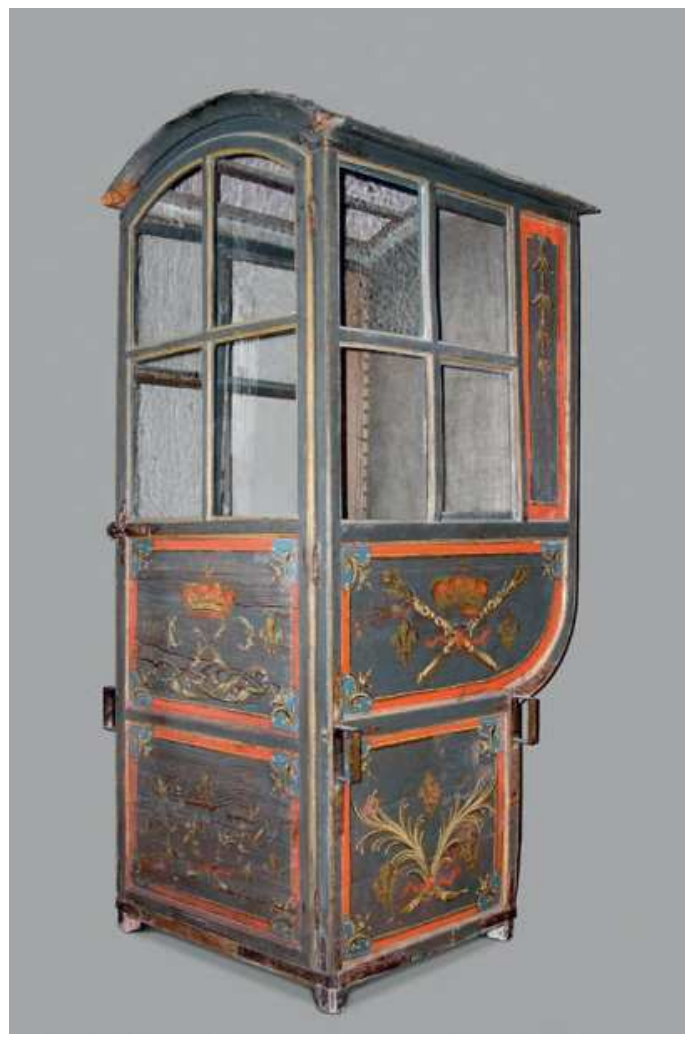

partiell mit Malerleinen bespannt. Der bereits erwähnte Tapissier von Aix-en-Provence hatte zumindest sechs Miettragsessel solcher Bauart in Verwendung, die in den Quellen als "couvertes de toille paincte" oder "chaises toilées" beschrieben sind..$^{66}$ Wahrscheinlich handelte es sich dabei um Leinengewebe in Köperbindung, da diese im Unterschied zur Leinwandbindung auch auf größeren Flächen robuste Stoffe ermöglichte, die auch wechselndem Druck und klimatischen Änderungen gut standhielten. Der Leinenstoff wurde an der Innenseite mit Nägeln befestigt und zwecks Härtung und Straffung mit warmem Hautleim beschichtet. Die Außenseite wurde zur Vorbereitung der später angebrachten Malschicht mit einer Grundierung versehen.

Wie der gemalte Dekor bei Miettragsesseln aussah, ist weitgehend unbekannt. Die Vehikel in Aix-en-Provence waren offenbar mit Verzierungen versehen, denn in Quellen von I656 heißt es, sie seien „couvertes de toille paincte à la grizaille“ gewesen beziehungsweise

56 Verträge von I656 Dezember 9, I657 Juli I4 und I656 Oktober 6. Boyer I979 (wie Anm. 44). 
von „camaieu doutremer“. Der bereits erwähnte Paradis schloss hierfür Verträge mit zwei in Aix-en-Provence ansässigen Malern, zunächst mit François Palme, einem Italiener, der sich in der Stadt niedergelassen und bis zu seinem Tod 1686 vor allem als Innendekorateur gearbeitet hatte, und wenig später mit Ephrem beziehungsweise Meiffren Comte, der damals sechsundzwanzig Jahre alt war und bis heute für seine Stillleben bekannt ist, auf denen er häufig kostbare Goldschmiedearbeiten darstellte. Wir können also davon ausgehen, dass Paradis seinen Kunden nicht nur solide gebaute, sondern auch optisch ansprechende Fahrzeuge zur Verfügung stellen konnte. Sieht man von der obligatorisch anzubringenden Vehikelnummer ab, liefern die Verordnungen für Miettragsessel hinsichtlich des äußeren Erscheinungsbildes kaum Informationen. Offenbar gab es auf diesem Gebiet keine festen Regeln, und es stand den Betreibern frei, ihre Miettragsessel nach eigenem Ermessen zu gestalten. Vermutlich waren damals neben dunklen, in nur einer einzigen Farbe gefassten Miettragsesseln auch auffällige Vehikel mit bunter Bemalung und reicher Verzierung im Umlauf.

Zur Gruppe jener Miettragsessel, die gewiss die Blicke der Passanten auf sich zogen, zählt ein seltenes Exemplar, das sich in einer Privatsammlung erhalten hat (Abb. Io). Der aufgrund formaler Kriterien in das letzte Drittel des 17. Jahrhunderts zu datierende Tragsessel war ein Vorläufer heutiger Taxis und wurde am Hof von Versailles benutzt. Seit I677 wurde in der königlichen Residenz ein Tragsesselservice angeboten, dessen „chaises dorées“ genannte Vehikel die Kunden auf Wunsch bis zu den Gemächern beförderten. Von diesen Tragsesseln unterschieden sich die sogenannten „chaises bleues“, deren Bezeichnung von der Farbe der königlichen Livree herrührte und die für sechs sols gemietet werden konnten. ${ }^{57}$

Besondere Beachtung verdient der Originaldekor des Vehikels, der unter einer Übermalung zum Vorschein kam. Der Tragsessel war ursprünglich mit der Nummer 75 versehen und stammt aus einer Serie, aus der zumindest noch ein weiteres Exemplar erhalten ist. ${ }^{58}$ Auf den Paneelen kamen lediglich drei Farben zum Einsatz, nämlich Rot und ein kräftiges Blau für die Einrahmungen sowie ein Beigeton, der mittels Schattierungen den Eindruck einer Vergoldung erzeugen sollte. Motive wie Palmetten und andere vegetabile Formen sind durch Motive ergänzt, die dem höfischen Ambiente entsprachen, in dem die Tragsessel verwendet wurden: französische Lilien und Palmblätter, gekreuzte Zepter mit Schwurhand beziehungsweise fleur de lys und schließlich das mit einer Königskrone versehene Monogramm des Monarchen, ein „L“ in doppelter Ausführung, gespiegelt und in sich verschlungen. Das hintere Kastenpaneel zeigt auf einer bekrönten Kartusche ein

57 Uzanne 1900 (wie Anm. I9), S. II6.

58 Dieser zweite Tragsessel trägt die Nummer 17 und befindet sich in einer englischen Privatsammlung. 
Wappenschild mit drei goldenen Lilien auf blauem Grund. Der Wappenschild ist seinerseits mit Kollanen der Ritterorden von Saint-Michel und Saint-Esprit behängt. Darüber ist die Vehikelnummer zu sehen. Ende des I7. Jahrhunderts zirkulierten in Versailles wohl Dutzende baugleiche Tragsessel. Die Bemalung des Tragsessels weist auf eine serienmäßige Herstellung hin, für die vermutlich auch schablonenartige Vorlagen Verwendung fanden. Eine Überprüfung dieser Annahme würde jedoch noch eine gesonderte Untersuchung erfordern.

\section{Das Ansehen der Sesselträger}

Einigen Tragsesseln widerfuhr eine überraschend grobe Behandlung. Anlässlich der Geburt des Herzogs von Burgund, des ersten Enkelsohns König Ludwigs XIV., wurden im August I682 Freudenfeste veranstaltet. Damals trugen Sesselträger mit einer unorthodoxen Methode, ihre Vehikel zu beleuchten, zur allgemeinen Erheiterung bei. Um das Freudenfeuer noch weiter zu nähren, rissen sie Bretter aus dem Kastenboden ihrer vergoldeten Tragsessel. Der König war darüber keineswegs erzürnt, da er darin eine Liebesbekundung gegenüber seiner eigenen Person und dem neugeborenen Prinzen erkannte. ${ }^{59}$

Episoden wie diese trugen aber nicht eben zu einer Steigerung des ohnehin stark ramponierten Ansehens der Sesselträger bei. Im I660 erschienenen „Dictionnaire des précieuses" werden sie abwertend als "mulets baptisés“ - getaufte Maultiere - bezeichnet, an anderer Stelle nannte man sie „bricoliers“, abgeleitet von den Schulterriemen, die ihnen den Tragedienst erleichterten. Offenbar verstießen vor allem die Träger von Miettragsesseln häufig gegen geltende Gesetze. Zahlreiche, zumeist aus dem I8. Jahrhundert datierende Polizeiverfügungen liefern Informationen zu den vorgegebenen Haltestellen für Miettragsessel und über verschiedenste Preistarife, die für einfache Wegstrecken beziehungsweise die stunden- oder halbtageweise Nutzung galten. ${ }^{60}$ Derartige Regelungen wurden getroffen, um schon im Vorfeld potentielle Konflikte zwischen den Sesselträgern und ihren Kunden so weit als möglich auszuräumen. Dies zeitigte aber nur bedingt Erfolge: Aus verschiedenen Quellen geht hervor, dass sich Sesselträger häufig strafbarer

\footnotetext{
59 Uzanne 1900 (wie Anm. I9), S. II5.

60 Die ı680 für Marseille festgelegten Statuten bestimmten, dass zwei Träger zwar mit jeweils zwei Tragsesseln arbeiten durften, untersagten jedoch unter Strafe, mehr als nur einen davon pro Tag tatsächlich einzusetzen. Es war ihnen allerdings gestattet, den außer Betrieb stehenden Tragsessel anderen Sesselträgern zur Verfügung zu stellen. Auf keinen Fall durften die Tragsessel aber an einem anderen als dem ihnen zugewiesenen Platz auf Kunden warten. AMM, HH 423, I680 September 4 .
} 
Handlungen schuldig machten, dass sie kontinuierlich Tumulte verursachten, manche Aufträge verweigerten, ihr Gewerbe ohne die dafür nötige Autorisierung ausübten, sich einer unflätigen Sprache bedienten, sich gewaltsam zeigten oder gar betrunken ihren Dienst versahen. ${ }^{61}$

Kunden hatten kaum wirksame Mittel zur Hand, um sich vor derartigen Unannehmlichkeiten zu schützen. Aber auch Besitzer von Tragsesseln waren vor bösen Überraschungen nicht gefeit, ganz gleich, ob sie Sesselträger mit fester Anstellung beschäftigten oder nur fallweise Männer für Tragedienste anwarben. Im Jahr I696 führte etwa ein Geistlicher aus Castres Klage gegen seine Sesselträger. Diese „Vagabunden“, so der betrogene Geistliche, hätten nach Erhalt ihrer Livree und eines Besoldungsvorschusses einfach das Weite gesucht. ${ }^{62}$ Auch auf den Theaterbühnen jener Zeit tummelten sich Sesselträger mit schlechten Manieren, die sich zum Verdruss der von ihnen beförderten Herrschaften aufmüpfig verhielten, so etwa in Molières Stück „Les Précieuses ridicules“, in dem einer der Sesselträger, die vom falschen Marquis de Mascarille wie unverschämte, nichtsnutzige Lumpen behandelt werden, schließlich drohend einen Trageholm gegen den Marquis erhebt, um den ihm zustehenden Lohn gewaltsam einzufordern. ${ }^{63}$

Aus jener Zeit existiert jedoch auch ein rares Dokument, das in einfühlsamer Weise einen zutiefst menschlichen Blick auf die schwierigen Arbeits- und Lebensumstände von Sesselträgern wirft. Im Jahr I7I2 beobachtete ein Arzt namens Valette-Falgous, dass Personen, die diesen Beruf ausübten, überdurchschnittlich oft an Brustschmerzen litten und durch das ständige Heben schwerer Lasten häufig Blut auswarfen. Valette-Falgous war der Ansicht, dass diese Tätigkeit ausschließlich von jungen Männern ausgeübt werden sollte. Tatsächlich wurde sie aber auch von betagten Männern und sogar von Frauen und Mädchen verrichtet, was bei Schwangeren die Gefahr von Fehlgeburten mit sich brachte. ${ }^{64}$ Ähnliches gilt für Tragsessel, die mit zwei Rädern versehen waren und die als „brouettes“ oder „vinaigrettes“ bezeichnet wurden. ${ }^{65}$ Zwar durften diese nur von zwei Männern beför-

6I So verursachten etwa 1736 in Versailles die Sesselträger ,journellement beaucoup de désordres, se querellent et maltraitent même le public [...]; les uns sont d'une conduite très dérangée, les autres très violents et emportés; qu'ils cassent et brisent leurs chaises, soit en les trainant avec violence, soit en les laissant dans le milieu des cours du château ou des rues de la ville; que les uns se reposent et passent la nuit et le jour dans leurs chaises [...], que d'ailleurs la plupart desdits porteurs sont généralement malpropres, vêtus de mauvais habits de différentes couleurs [...]“. Uzanne I900 (wie Anm. I9), S. II6 f.

62 ADT, B 249, 23 juin 1696: Beschwerde von Louis de Fosse, Herr von Roques und Scarlens, Erzdiakon von Castres.

63 Molière, Les Précieuses ridicules (1659), Szene 7.

64 Marcel Gausseran, L'état sanitaire de Montauban en 1712. In: Bulletin Archéologique et Historique de la Société Archéologique de Tarn-et-Garonne 84 (1958), S. 92-99, hier S. 93-95.

65 Zu diesem Vehikeltypus siehe Jean-Pierre Ducastelle, Se déplacer en vinaigrette! Mobilité et 


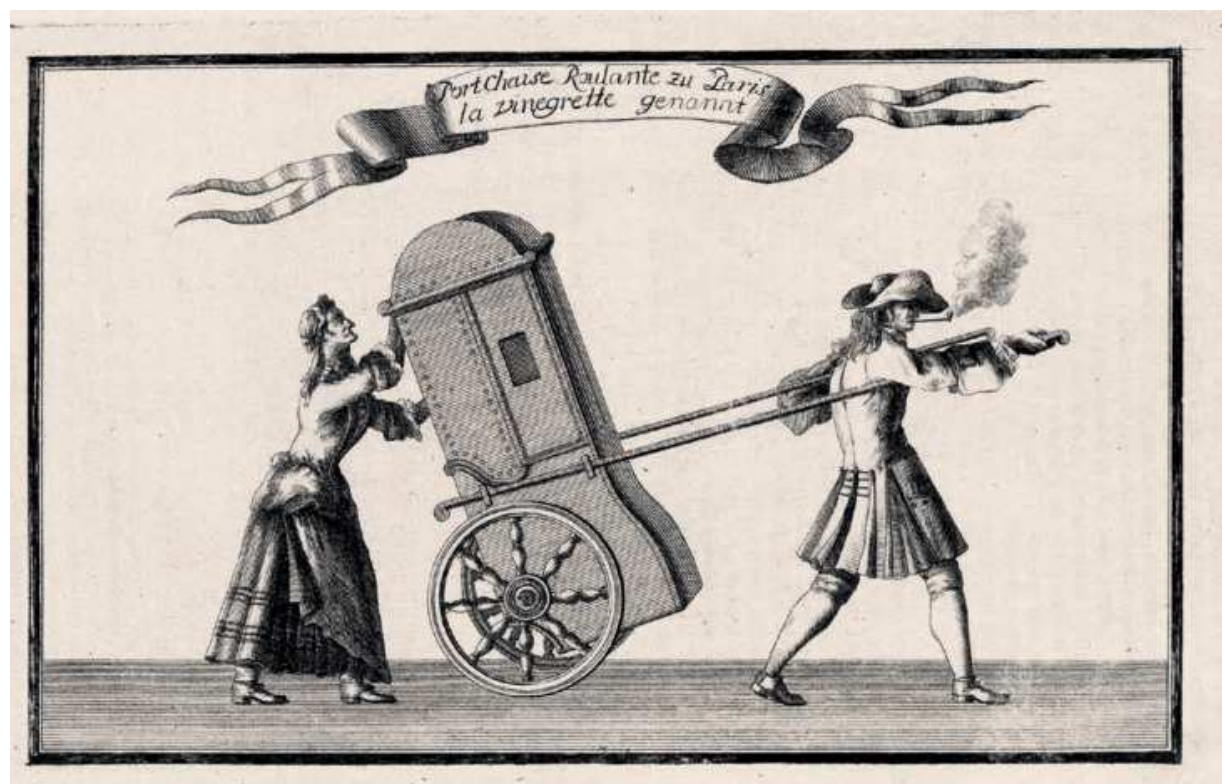

Abb. 11: Pariser „vinaigrettes“. Carl Christian Schramm, Abhandlung der Porte-Chaises oder Trage-Sänfften durch Menschen oder Thiere, in allen vier Theilen der Welt, nach der Critic, Mechanic, Historie, dem Recht, wie auch Cammer- und Policey-Wesen (Nürnberg 1737), zwischen S. 48 und 49. ÖNB, Sign. 260544-C Fid. @ ÖNB

dert werden ${ }^{66}$ jedoch ist auf einer deutschen Bildquelle von $1737 \mathrm{zu}$ erkennen, dass offenbar auch Frauen für solche Dienste herangezogen wurden (Abb. II).

Es sei in diesem Zusammenhang darauf hingewiesen, dass Darstellungen von Tragsesseln und „vinaigrettes“ in Pariser Vedutenwerken äußerst selten sind. Wenn sie in Einzelfällen aber doch gezeigt werden, dann meist nur schemenhaft, häufig inmitten belebter Straßenszenen oder als Staffageobjekte vor bedeutenden Bauwerken. Solche zuweilen dargestellten Tragsessel verfügten nur über schlichte Holzkästen, waren ohne jeglichen malerischen Dekor und nur in Ausnahmefällen mit Ziernägeln versehen, weshalb wir davon ausgehen können, dass es sich hierbei um Miettragsessel handelt.

transport du $\mathrm{I} 7^{\mathrm{e}}$ au $\mathrm{I} 9^{\mathrm{e}}$ siècle. In: Études et documents du Cercle royal d'histoire et d'archéologie d'Ath et de la région 20 (2009), S. 349-388. 
Gegen Ende der Herrschaft Ludwigs XIV. (1715) hatten Tragsessel neben anderen Transportmitteln ihren festen Platz in den urbanen Landschaften Frankreichs gefunden. Sowohl in Paris als auch in anderen großen Städten des Königreichs wollten Angehörige der Oberschicht auf diese Luxusgegenstände, die ein integraler Bestandteil des städtischen Lebensstils geworden waren, nicht mehr verzichten.

Die wenigen erhaltenen Exemplare aus der Frühzeit ihres Bestehens geben noch heute eine gute Vorstellung vom reichen sozialen und künstlerischen Kontext, in dem Tragsessel entstanden und Verwendung fanden. Sie sind bis heute ein oftmals verkanntes Kulturgut und müssen aufgrund ihres häufig prekären Erhaltungszustands als gefährdet gelten. Es wäre deshalb an der Zeit, gemeinsam dafür zu sorgen, dass man diesen schlafenden Schönheiten größere Aufmerksamkeit schenkt und sie derart zu neuem Leben erweckt.

Übersetzung aus dem Französischen: CATHARINA Dietrich 


\section{Résumé}

\section{Etablierung, Verbreitung, Einsatzgebiete und rechtliche Restriktionen}

Nach heutigem Kenntnisstand war Rom der erste europäische Fürstenhof, an dem Tragsessel in das höfische Zeremoniell integriert wurden. Bislang dominierte in der Forschungsliteratur die Ansicht, dass die Wurzeln der päpstlichen sedia gestatoria in der römischen Antike lägen und sich eine kontinuierliche Verwendung dieses Transportmittels über das gesamte Mittelalter bis in die Frühe Neuzeit belegen ließe. Diese Vorstellung beruhte hauptsächlich auf den 1578/88 publizierten Darstellungen des aus Spanien stammenden Klerikers José Estefan, der damit protestantischen Stimmen entgegentreten wollte, die im Tragethron den Ausdruck eines dekadenten Papsttums sahen. Spätere Autoren, allen voran Mitte des I9. Jahrhunderts Gaetano Moroni, folgten und vertieften Estefans Thesen und sorgten für deren Verbreitung. Wie im vorliegenden Band dargelegt wird, hält die im I6. Jahrhundert entwickelte Argumentationsstrategie zur Geschichte der sedia gestatoria jedoch einem kritischen Blick auf die Quellen nicht stand. Die Tradition, Päpste bei feierlichen Anlässen in einem Tragsessel zu transportieren, ist vielmehr eine „Erfindung“ des Spätmittelalters.

Der Anfang dieser Tradition liegt im Pontifikat von Pius II. (I458-I464), der im Jahr I459 aus pragmatischen Gründen, zu denen auch sein prekärer Gesundheitszustand zählte, in mehreren italienischen Städten seinen feierlichen Einzug auf einem Tragsessel sitzend und nicht, wie bis dahin üblich, zu Pferd hielt. Pius II. erkannte die hohe Symbolkraft der sedia gestatoria und verwendete auch in den darauf folgenden Jahren bei zahlreichen Gelegenheiten einen Tragethron. Er verstand es geschickt, ein Symbol der Schwäche in eine neue Insignie des päpstlichen Triumphs umzudeuten, die in den darauf folgenden Pontifikaten vollends ihren Platz im römischen Hofzeremoniell fand. Ende des I5. Jahrhunderts war die häufige Verwendung von Tragsesseln durch den Papst im Rahmen von zeremoniellen Ereignissen bereits so selbstverständlich geworden, dass sie in den Quellen häufig schon gar nicht mehr als erwähnenswert erachtet wurde.

Die päpstlichen Zeremonienmeister begannen allmählich zwischen verschiedenen Typen von päpstlichen Tragsesseln zu differenzieren: Bei der sedia (gestatoria) maior, die allein bei Anlässen von höchster Bedeutung zum Einsatz kam, handelte es sich um eine von 
mehreren Sesselträgern geschulterte Plattform, auf der ein Thron befestigt war, während die Päpste bei anderen Gelegenheiten eine sedia minor oder parva benutzten, bei welcher der Sessel selbst seitlich mit Tragstangen versehen war. Das genaue Aussehen der verschiedenen Typen früher päpstlicher Tragsessel, die sich allesamt nicht erhalten haben, ist uns vor allem durch mehrere repräsentative Fresken des I6. Jahrhunderts überliefert, die von Pinturicchio, Raffael und Vasari geschaffen wurden. Die protestantische Bildpropaganda griff fallweise ebenfalls zu Darstellungen des Papstes auf der sedia gestatoria, um derart den ausufernden weltlichen Prunk des Heiligen Stuhls anzuprangern.

Über von Rom ausgehende Verbreitungswege für Tragsessel im Rahmen des Hofzeremoniells beziehungsweise für den privaten Gebrauch liegen bislang keine konkreten Informationen vor. Bei Betrachtung der weiteren Entwicklungen auf der Apenninen-Halbinsel fällt jedoch auf, dass sich auch in anderen Städten Tragsessel verhältnismäßig früh etablierten, so etwa in Genua und Neapel. Leider liegen die Anfänge hierfür im Dunkeln. Im Jahr I560 finden sich im Nachlassinventar des damals verstorbenen Genuesen Andrea Doria bereits acht zum Teil reich ausgestattete Tragsessel. Dabei handelte es sich gewiss um keinen Einzelfall. Wahrscheinlich waren zu jenem Zeitpunkt Tragsessel in Genua schon weit verbreitet. Aus den letzten Jahren des I6. Jahrhunderts stammende Reiseberichte schildern die dort unter Männern und Frauen vorherrschende Angewohnheit, sich im urbanen Raum im Tragsessel transportieren zu lassen. Als Grund dafür wurde in den Relationen meist auf die topographischen Eigenheiten der Stadt mit ihrer Hanglage und den engen Gassen verwiesen.

Ähnlich wie in Genua stellt sich die Situation für Neapel dar. Wie mehrere Quellen eindrücklich demonstrieren, hatten sich auch dort bis Ende des I6. Jahrhunderts Tragsessel als unverzichtbare städtische Transportmittel durchgesetzt. Der in Mailand weilende Marchese Gioan Battista del Tufo gedachte 588 in Versform seiner fernen Heimat Neapel und der Liebe seiner Landsleute zu luxuriösen Tragsesseln. In diesem Zusammenhang äußerte er die Ansicht, dass in der süditalienischen Metropole anlässlich bedeutender Ereignisse „tausend“ derartige Tragevehikel für die Vertreter der oberen sozialen Schichten bereitstünden. Bei dieser Angabe handelte es sich aber wohl um eine poetische Übertreibung. Realistischer scheint die Zahl, die ein zwischen 1594 und 597 in Neapel residierender Botschafter nannte. Er schätzte die Zahl der damals in der Stadt vorhandenen Tragsessel immerhin auf etwa 300 Stück. Auch verschiedene Bildquellen belegen eindrücklich die große Bedeutung, die Tragsessel in Neapel damals bereits erlangt hatten. Auf topographischen Ansichten und in volkskundlichen Werken aus dem letzten Viertel des I6. Jahrhunderts stand die formelhafte Wiedergabe einer Dame im Tragsessel in beinahe schon stereotyper Weise für die Stadt Neapel selbst. Diese Bilder, auf denen die Dame entweder einen den Passagierbereich verdeckenden Vorhang zur Seite schiebt oder bei denen dieser vom Be- 
trachter mittels einer aufklappbaren Papierlasche geöffnet werden kann, veranschaulichen in trefflicher Weise den ambivalenten Charakter von Tragsesseln. Sie boten den Insassen einerseits die Möglichkeit, mit Hilfe eines prachtvollen Vehikels den eigenen sozialen Status zur Schau zu stellen, waren aber andererseits mit geschlossenen Vorhängen auch Rückzugsorte, die es Passagieren erlaubten, sich unwillkommenen Blicken von Passanten zu entziehen und sich bei Bedarf unerkannt im urbanen Raum zu bewegen.

Für die Einführung von Tragsesseln am französischen Hof liegen derzeit bedauerlicherweise nur bruchstückhafte Nachrichten vor. Allem Anschein nach nahm dieser Prozess aber Mitte des I6. Jahrhunderts seinen Anfang. Weit besser sind wir nunmehr über die entsprechenden Entwicklungen in Spanien informiert. Aus den I550er Jahren stammen erste Nachrichten über die Verwendung von Tragsesseln durch einen spanischen Monarchen. Im darauf folgenden Jahrzehnt begannen auch die Königinnen Spaniens diese Transportmittel zu verwenden. Relevanz erlangten Tragsessel im Rahmen des Hofzeremoniells jedoch erst Anfang des 17. Jahrhunderts. Im Jahr I602 wurden die ersten beiden Sesselträger in den spanischen Hofstaat integriert. Bis I607 war ihre Zahl bereits auf zwölf angewachsen. Dabei ist festzuhalten, dass damals sowohl am Hof als auch in adeligen Kreisen Spaniens Tragsessel vorrangig als Transportmittel für Frauen galten. Griffen männliche Fürsten zu Tragsesseln, so stand dies zunächst meist in Zusammenhang mit körperlichen Gebrechen. Erst allmählich entwickelten sich Tragsessel auch für Männer zum bewusst gewählten Mittel der Repräsentation und Prachtentfaltung. Im Zuge eines gesellschaftlichen Hierarchisierungsprozesses betrachteten Fürsten und Hofleute Tragsessel vermehrt als adäquates Instrument, um die physische und symbolische Distanzierung der eigenen Person von niederrangigen Vertretern der Gesellschaft zu manifestieren und weiter voranzutreiben.

Wie für kein anderes europäisches Herrschaftsgebiet lässt sich für Spanien die Ausbreitung und Verwendung von Tragsesseln auch im Spiegel gesetzlicher Maßnahmen nachvollziehen. Bereits um I550 waren auf den Straßen Kastiliens des Öfteren Tragsessel anzutreffen. Zu einer schlagartigen Vermehrung dieser Transportmittel kam es aber erst im Anschluss an eine 1578 in Kastilien erlassene Verordnung, deren Ziel es war, die Verwendung von Kutschen auf adelige Schichten zu beschränken. Dies hatte zur Folge, dass zahlreiche Personen, die bis dahin Kutschen benutzt hatten, denen dies nun aber verwehrt wurde, auf Tragsessel umstiegen, um sich auch weiterhin im öffentlichen Raum in einem repräsentativen Vehikel zeigen zu können. Als Reaktion auf diese Entwicklung erhoben sich in Parlamentsversammlungen von 1583 und 1585 kritische Stimmen, die die ausufernde Verwendung von Tragsesseln anprangerten. Sie verhallten aber offenbar ohne Konsequenzen, denn in den I580er und I590er Jahren kamen Tragsessel in den Städten und Dörfern Kastiliens immer stärker in Mode. Dieses Phänomen blieb damals keines- 
wegs auf das Kerngebiet des spanischen Imperiums beschränkt. Eine parallele Entwicklung fand in den letzten Jahrzehnten des I6. Jahrhunderts auch in den spanischen Überseebesitzungen statt.

Als I593 der Gebrauch von Kutschen in Kastilien mittels einer restriktiven Verordnung erneut eine starke Einschränkung erfuhr, beförderte dies abermals die Verbreitung von Tragsesseln. Um deren Verwendung besser kontrollieren zu können, wurde 1594 zunächst versucht, die Zahl der Sesselträger zu beschränken sowie Preistarife festzusetzen, bevor schließlich 1604 ein „Institutionalisierungsprozess“ in Gang gesetzt wurde, der fortan nur noch jenen Männern den Gebrauch von Tragsesseln gestattete, die sich im Besitz einer entsprechenden Lizenz befanden. Die in den darauf folgenden Jahrzehnten ausgestellten Lizenzen geben einen guten Eindruck davon, welche sozialen Gruppen tatsächlich Tragsessel verwenden durften. Knapp drei Viertel der Lizenzempfänger waren entweder Funktionsträger im Verwaltungsapparat der Monarchie, Mitglieder königlicher Hofstaaten, Vertreter klerikaler Eliten oder lokale Machthaber. Der Transport eines Mannes im Tragsessel unterstrich somit eindeutig seinen gehobenen sozialen Status und war ein Zeichen seiner guten Verbindungen zum Königshof und den Zentralbehörden, war es doch der Kastilische Rat, der die Lizenzen vergab.

Die Verwendung von Tragsesseln durch Frauen unterlag hingegen vorerst keinerlei Einschränkungen, sieht man von Verordnungen ab, die Prostituierten den Gebrauch dieser Transportmittel untersagte. Mit Beginn des 17. Jahrhunderts entwickelten sich Tragsessel auch zu beliebten Vehikeln der Hofdamen, die damit dem Beispiel der spanischen Königinnen folgten. Die in Tragsesseln transportierten Damen wurden auf den Straßen nicht nur von ihren Sesselträgern, sondern auch von zahlreichen Dienern begleitet und beschützt, was den Glanz ihrer öffentlichen Auftritte vergrößerte, ihren hohen sozialen Status unterstrich und ihre Unnahbarkeit steigerte.

Das Bemühen zentraler und lokaler Regierungsbehörden, Kontrolle über die Verwendung von Tragsesseln zu erlangen, führte im Lauf des 17. Jahrhunderts zu gesetzlichen Maßnahmen unterschiedlichster Art. Ab 1635 wurde der Gebrauch von Tragsesseln mit Abgaben verbunden, was de facto einer Besteuerung gleichkam. Andere gesetzliche Einschränkungen betrafen Miettragsessel, die Regulierung der Anzahl und die amtliche Registrierung der Sesselträger sowie besonders luxuriöse Ausstattungsmerkmale der Tragevehikel. All diese Maßnahmen konnten die Ausbreitung von Tragsesseln sowie Entwicklungen hinsichtlich ihrer zunehmend prunkvollen Gestaltung jedoch nur phasenweise eindämmen beziehungsweise verzögern, letztlich jedoch nicht aufhalten. Langfristig erfolgreich blieben die rechtlichen Bestimmungen jedoch in ihrem Bestreben, Tragsessel als ein weitgehend exklusives Transportmittel und Symbol der sozialen und höfischen Elite Spaniens zu etablieren. 
Ein bedeutendes Herrschaftszentrum im Machtbereich des spanischen Imperiums stellte Neapel dar, wo ein Vizekönig als Stellvertreter der auf der Iberischen Halbinsel residierenden Monarchen regierte. Im vorliegenden Band wurde untersucht, welche Rolle Tragsessel im Laufe des 17. Jahrhunderts in den Hofzeremonialschriften Neapels spielten. Dabei belegen unzählige Passagen, dass Tragsessel sowohl vom Vizekönig, von seiner Gemahlin, von Mitgliedern der Hofgesellschaft als auch anderen vornehmen Personen zu unterschiedlichsten Anlässen benutzt wurden. Mit Hilfe eines Tragsessels war es dem Vizekönig möglich, in kurzer Zeit verschiedenste Ziele im städtischen Bereich und in der näheren Umgebung Neapels zu erreichen. Da er bestrebt war, in der Stadt Fußwege so weit als möglich zu vermeiden, und da sich große, behäbige Karossen in den engen und teils unwegsamen Straßen der Stadt oftmals nicht für ein würdevolles Fortkommen eigneten und mit ihnen häufig auch langwierige Umwege genommen werden mussten, griff der Vizekönig selbst bei festlichen Anlässen religiöser wie auch profaner Art gerne zu Tragsesseln. Diese waren aufgrund ihrer geringen Größe und guten Manövrierbarkeit nicht nur von großem praktischem Nutzen, sondern ermöglichten bei entsprechender Ausstattung auch einen imposanten Auftritt. Sogar für den Empfang von hohem Besuch schrieb das Zeremoniell die Bereitstellung von Tragsesseln vor. Mit ihrer Hilfe wurden die Gäste zuweilen nicht nur bis zum königlichen Palast gebracht, sondern dort sogar die Treppen hinaufgetragen. Aus den Zeremonialschriften geht weiterhin hervor, dass sich ortsansässige Adelige und Regierungsmitglieder, denen das Stufensteigen aus Altersgründen oder gesundheitlichen Motiven zu beschwerlich war, innerhalb der Palastmauern von Sesselträgern transportieren lassen durften.

Auch die Vizekönigin Neapels griff sowohl bei ihren öffentlichen als auch bei ihren privaten Ausgängen häufig zu Tragsesseln. Dabei gab es feine Unterschiede zwischen den Wegstrecken, die der Vizekönig einerseits und seine Gemahlin andererseits in den Tragevehikeln zurücklegten. Die Vizekönigin ließ sich meist in die Beletage der Paläste oder zumindest in das Gebäudeinnere tragen, selbst dann, wenn das Zeremoniell für den Vizekönig ein früheres Aussteigen aus dem Tragsessel vorsah.

Die ausschweifende Nutzung von Tragsesseln hatte am vizeköniglichen Hof von Neapel jedoch nicht nur Befürworter. Der Hofzeremoniär José Renao lässt in seinen Schriften mehrmals durchblicken, dass er die Verwendung von Tragsesseln durch den Vizekönig eigentlich für unschicklich hielt und zumindest bei hochrangigen zeremoniellen Anlässen ein Ritt zu Pferd, eine Fahrt in der Karosse oder ein kurzer Weg zu Fuß einem Transport im Tragevehikel stets vorzuziehen sei. Renaos ablehnende Haltung gegenüber Tragsesseln blieb jedoch ein isoliertes Phänomen. Tragsessel zählten bis Anfang des I8. Jahrhunderts zu den wichtigsten Transportmitteln am Hof Neapels. Dies sollte sich erst mit der Machtübernahme durch die österreichischen Habsburger ändern, 
unter deren Herrschaft die Rolle von Tragsesseln im Rahmen des Hofzeremoniells stark zurückgedrängt wurde.

Für den Familienzweig der in Mitteleuropa regierenden Mitglieder des Hauses Habsburg lässt sich die Verwendung von Tragsesseln oder ähnlichen Tragevorrichtungen punktuell seit dem I4. Jahrhundert nachweisen. Der Grund für die Nutzung derartiger Vehikel lag dabei stets im prekären Gesundheitszustand oder dem fortgeschrittenen Alter der jeweiligen Fürsten. Eine Regelmäßigkeit beziehungsweise Systematik in der Nutzung ist dabei nicht zu erkennen, weshalb die Verwendung von Tragsesseln vorerst auch ohne Folgen für den Hofstaat und das Hofzeremoniell blieb. Für die definitive Einführung von Tragsesseln am Kaiserhof in den Jahren um 1620 waren schließlich Einflüsse aus Italien maßgeblich, wo Tragsessel zu diesem Zeitpunkt schon längst etabliert waren; in geringerem Umfang fanden in diesem Prozess auch Entwicklungen in Spanien, wo ebenfalls Habsburger regierten, ein Echo. Während in früheren Zeiten am Kaiserhof das Bild des im Tragsessel transportierten Fürsten keinerlei positive Assoziationen bei den Zeitgenossen auslöste, sondern vielmehr den Eindruck des körperlichen Verfalls und der Vergänglichkeit weltlicher Macht hinterließ, erhielten Tragsessel um 1620 durch die Verwendung seitens der Kaiserinnen eine neue, positive Konnotation. Der erste repräsentative Tragsessel, der sich am Kaiserhof nachweisen lässt, war ein Geschenk aus Florenz für Kaiserin Anna, bei der - wie sich herausstellen sollte, fälschlicherweise - eine Schwangerschaft vermutet wurde. Er wurde I6I5 gemeinsam mit vier Genueser Sesselträgern nach Prag geschickt. Wenige Monate nach der Übergabe, als sich die letzten Hoffnungen auf eine Schwangerschaft bereits verflüchtigt hatten, wurden die Genuesen schließlich wieder in ihre Heimat zurückbeordert. Der kostbare Tragsessel aber verblieb offenbar bei der Kaiserin. Das Beispiel von I6Is führt deutlich vor Augen, wo fortan ein zentraler Einsatzbereich von Tragsesseln am Kaiserhof liegen sollte: War die Kaiserin oder ein anderes weibliches Mitglied der Herrscherfamilie schwanger, so deklarierten sie öffentlich ihren Zustand der guten Hoffnung durch die Verwendung eines Tragsessels. Da damals allgemein die Meinung vorherrschte, dass heftige Stöße schlecht gefederter Kutschen Fehlgeburten hervorrufen könnten, benutzten Fürstinnen bis zur Geburt stets Tragsessel.

Das Jahr 1623 kann als Zeitpunkt angesehen werden, an dem sich Tragsessel endgültig am Kaiserhof etablierten. Damals erhielt Kaiserin Eleonore von ihrem in Mantua regierenden Bruder einen Tragsessel zu Jagdzwecken zugesandt. Sechs italienische Sesselträger begleiteten das wertvolle Vehikel, wobei unklar ist, ob sie aus Genau oder aus Neapel stammten. Alle sechs Männer erhielten nach ihrer Ankunft in Wien eine dauerhafte Anstellung am Kaiserhof. Fortan befanden sich, abgesehen von einer kleinen zeitlichen Lücke, stets mehrere Sesselträger im kaiserlichen Hofstaat. 
Kurz darauf, nämlich I626, wurden auch am Hof der habsburgischen Nebenlinie in Tirol Tragsessel eingeführt. Diese Neuerung stand in Zusammenhang mit der Ankunft von Claudia de' Medici in Innsbruck, die damals Tragsessel aus ihrer Heimat Florenz mitbrachte. Ungefähr zeitgleich, nämlich im ersten Viertel des I7. Jahrhunderts, sind für den österreichischen Herrschaftsbereich auch erstmals Tragsessel in Inventaren adeliger Familien dokumentiert. Es scheint sich hier demnach um eine Entwicklung zu handeln, welche die gesamte Elite der Habsburgermonarchie etwa zur gleichen Zeit erfasste.

Bei mehreren Tragsesseln der spanischen Infantin Maria Anna, die r63I als Königin an den Wiener Hof gelangte und seit I637 auch Kaiserin war, liegen detaillierte Informationen zur Entstehungs- und Nutzungsgeschichte sowie zu ihrer Gestaltung vor. Maria Anna erhielt vom Papst zur Hochzeit ein gleichförmig gestaltetes Transportset zum Geschenk, das aus einer Karosse samt Geschirren und Zugpferden, einer Sänfte samt Trageseln und einem Tragsessel bestand. Derartige Garnituren entwickelten sich zu jener Zeit zu beliebten Geschenken für Fürstinnen, aber auch für Thronfolger im Kindesalter. Mit Kaiserin Maria Anna tauchte zudem ein neues Phänomen im Wiener Hofzeremoniell auf, das vermutlich aus Spanien übernommen wurde. Anlässlich der Geburt ihres Sohnes Leopold, des späteren Kaisers Leopold I., im Jahr I640 kam nämlich am Kaiserhof mit einiger Wahrscheinlichkeit zum ersten Mal ein Tragsessel bei einer Tauffeier zum Einsatz. Wenige Wochen später wurde auch beim Hervorgang der Kindesmutter, das heißt bei ihrem ersten öffentlichen Auftritt vierzig Tage nach der Geburt, erstmals ein Tragsessel verwendet. Diese Neuerungen im Hofzeremoniell blieben jedoch vorerst nicht nachhaltig. Erst im frühen 18. Jahrhundert sollten bei Taufen von Mitgliedern der Kaiserfamilie wieder Tragsessel zum Einsatz kommen. Bei Hervorgängen etablierte sich die Verwendung von Tragsesseln hingegen schon etwas früher. Sie standen dabei bereits ab I667 mit einer gewissen Regelmäßigkeit in Verwendung.

Während im Laufe des 17. Jahrhunderts der Gebrauch von Tragsesseln durch Habsburgerinnen und adelige Damen immer üblicher wurde, stand ihre Verwendung sowohl seitens männlicher Herrscher als auch adeliger Herren stets in Verbindung mit Krankheiten und Gebrechlichkeit. Dies demonstrieren nicht nur zahlreiche Schriftstücke, sondern auch mehrere Bildquellen, welche die damals gesundheitlich bereits schwer angeschlagenen Kaiser Ferdinand II. und Ferdinand III. bei den jeweiligen Krönungszeremonien ihrer Söhne im Tragsessel zeigen. Die Entwicklung in Mitteleuropa unterschied sich damit deutlich von jener im Süden Europas, etwa in italienischen Städten wie Genua oder Neapel, wo es für gesunde Männer selbstverständlich war, sich im Tragsessel transportieren zu lassen, oder in Spanien, wo so viele Männer zu Tragsesseln griffen, dass die Behörden die Verwendung derselben gesetzlich limitierten. Gründe für diese augenfällige Differenz konnten bisher noch nicht gefunden werden. Kaiser Leopold I. entließ nach seiner Thronbestei- 
gung im Jahr I657 zunächst alle Sesselträger des kaiserlichen Hofstaates, da er damals selbst unverheiratet war und deshalb kein Grund zur Verwendung von Tragsesseln bestand. Erst anlässlich seiner ersten Eheschließung 1666 wurden wieder Sesselträger aufgenommen. In den Jahren um I680 griff auch Leopold I. selbst regelmäßig auf die Dienste von Sesselträgern zurück. Vermutlich lagen auch in diesem Fall gesundheitliche Motive dafür vor. Fest steht jedenfalls, dass Tragsessel keinen Einfluss auf Leopolds I. Herrscherikonographie hatten, sind doch keinerlei Bildquellen erhalten, die ihn im Tragsessel zeigen würden. In seine Regierungszeit datiert auch das derzeit älteste bekannte Marstallinventar von I678, das den frühesten kompletten Überblick samt detaillierter Beschreibungen von den am Wiener Hof vorhandenen Tragsesseln gibt. Die dort dokumentierte Gesamtzahl von sieben Tragsesseln war für die Größe und Bedeutung des Wiener Hofes allerdings keineswegs hoch, existierten doch beispielsweise an dem in vielen Belangen vergleichbaren Münchner Hof im Jahr I680 drei Tragsessel mehr als in Wien.

Nicht lange nach ihrer Etablierung am Kaiserhof tauchten Tragsessel auch erstmals am bayerischen Hof auf. Die zeitliche Nähe war wohl kein Zufall, denn bei dieser Neuerung scheint Wien tatsächlich eine entscheidende Rolle gespielt zu haben. Den historischen Hintergrund für diesen Kulturtransfer bildete offenbar eine Eheschließung zwischen den Häusern Wittelsbach und Habsburg: Schon im Jahr nachdem Erzherzogin Maria Anna I635 den bayerischen Kurfürsten Maximilian I. geheiratet hatte und ihrem Bräutigam nach München gefolgt war, ließ sie sich aufgrund einer eingetretenen Schwangerschaft im Tragsessel befördern. Schriftquellen zufolge hatte die Braut ihr Tragevehikel aus Wien in ihre neue Heimat mitgebracht. Für I636 lassen sich am Hof der Wittelsbacher bereits zehn Sesselträger nachweisen, von denen vier Italiener waren. Dies könnte darauf hindeuten, dass möglicherweise auch der am Kaiserhof gepflegte Brauch, italienische Sesselträger anzustellen, von Wien nach München gelangte. Das erste nach der Hochzeit von I635 angelegte Münchner Marstallinventar stammt aus dem Jahr I656. Es ist gleichzeitig auch das erste, in dem Tragsessel verzeichnet sind, nämlich sechs geschlossene und fünf unbedeckte Exemplare. Dies demonstriert deutlich, wie rasch und umfassend die Einführung von Tragsesseln am Münchner Hof vonstattenging. Die Kufürstin verwendete Tragsessel offenbar auch auf der Jagd. Ebenso griff ihr Gemahl Maximilian I. zumindest im fortgeschrittenen Alter auf dieses Transportmittel zurück. Dennoch scheinen Tragsessel auch am Hof der Wittelsbacher vornehmlich von Frauen benutzt worden zu sein.

Kurfürstin Henriette Adelaide, die I652 aus Turin an den bayerischen Hof gelangte, brachte ebenfalls Tragsessel aus ihrer italienischen Heimat nach München mit. Ein äußerst prachtvolles Exemplar war der sogenannte „Turiner“ Tragsessel, der gemeinsam mit einer Kutsche und einer Sänfte ein gleichartig gestaltetes, in rot-goldenen Farben gehaltenes Ensemble bildete. 
Zu den zentralen zeremoniellen Einsatzgebieten von Tragsesseln zählten auch in München Taufen. So kam etwa der erwähnte rot-goldene „Turiner“ Tragsessel höchstwahrscheinlich bei der Taufe von Max Emanuel im Jahr I662 zum Einsatz. Damals wurde die Obersthofmeisterin der Kurfürstin mit dem Täufling auf ihrem Schoß im Tragsessel zum Münchner Dom befördert. In ganz ähnlicher Art fand 1727 ein um I684/85 in Paris hergestellter Tragsessel, der sich glücklicherweise erhalten hat und der heute im Nymphenburger Marstallmuseum ausgestellt ist, bei der Taufe des Kurprinzen Max III. Josef Verwendung. Auch in diesem Fall wurde beim feierlichen Zug zur Münchner Frauenkirche das Kind in weiblicher Begleitung - diesmal der Tante des Säuglings - im Tragsessel zur Taufe gebracht.

Ab dem zweiten Viertel des I8. Jahrhunderts sind Tragsessel in den Münchner Marstallinventaren kaum noch greifbar. Offenbar standen Tragsessel am bayerischen Hof jedoch auch danach noch in Verwendung. Darauf deutet die Tatsache hin, dass 1750 immerhin noch fünfzehn Sesselträger am Hof tätig waren. Vermutlich wurden Tragsessel damals kaum mehr als repräsentative Transportmittel eingesetzt, sondern dienten vielmehr Mitgliedern der Herrscherfamilie zum reinen Vergnügen in den Parks der Residenzen und Lustschlösser.

\section{Typen, Ausstattungsvarianten und Verbreitungswege neuer Modelle}

Da sich für den langen Zeitraum vom ersten Aufkommen repräsentativer Tragsessel in Rom im Jahr I459 bis etwa zur Mitte des I7. Jahrhunderts keine Tragsessel erhalten haben, sind wir für die Rekonstruktion der damals existierenden Typen, ihrer Bauweise und ihres Aussehens allein auf Bild- und Schriftquellen angewiesen. Der grundsätzliche Aufbau päpstlicher Tragstühle des I6. Jahrhunderts wurde bereits ansatzweise erörtert. Es handelte sich dabei um massive, gepolsterte, in rot-goldener Farbe gehaltene und teilweise mit Fransen versehene Armlehnstühle, die mittels Trageholmen transportiert wurden. Die Holme wurden entweder durch am Sesselgestell angebrachte Metallbügel geschoben, die meist seitlich der Sitzfläche fixiert waren (sedia minor), oder aber mit einer Plattform verbunden, auf welcher der Sessel stand (sedia maior). Bei beiden Varianten wurden die Holme von Sesselträgern geschultert, was dazu führte, dass der sitzende Papst hoch über den Köpfen der anwesenden Personen erschien und derart große Sichtbarkeit genoss. Fallweise wurde über diesen mobilen Thronsesseln auch ein Baldachin getragen. Die in ihrem Aufbau Sitzmöbeln stark ähnelnden Objekte existierten später in mehr oder weniger opulenter Ausstattung auch in anderen Herrschaftsgebieten Europas. Quellenmäßig lassen sich frühe Beispiele davon etwa für den spanischen Hof dokumentieren. Ein schlichtes Exemplar 
eines solchen offenen Tragsessels verwendete beispielsweise Karl V. in seinen letzten Lebensjahren, die er nach seiner Abdankung im Kloster Yuste verbrachte.

In seiner Konstruktionsweise weit anspruchsvoller war ein tragbarer Gichtsessel seines Sohnes Philipp II. Von diesem technisch komplexen Vehikel, dessen Aussehen und Funktionsweise in Form einer Zeichnung samt Beschreibung aus dem Jahr I595 überliefert ist, existiert heute eine moderne Nachbildung.

Wie einzelne Stiche sowie Inventareinträge des 17. Jahrhunderts belegen, standen offene, mit Samt oder Damaststoffen tapezierte Tragsessel auch an den Höfen von Wien und München im Einsatz. Sie dienten sowohl dem Transport kranker oder gehbehinderter Fürsten und Fürstinnen als auch repräsentativen Zwecken. Ein besonders prunkvoller offener Tragsessel hat sich in der Wiener Kaiserlichen Wagenburg erhalten. Er weist aufwendige, in Gold gefasste Schnitzereien auf, ist mit rotem Samt bezogen sowie mit opulenten Goldstickereien und -borten verziert. Anhand bislang unbeachtet gebliebener Schriftquellen und stilistischer Vergleiche lässt sich nunmehr belegen, dass dieser Tragsessel nicht, wie bisher meist angenommen, um 1740 hergestellt wurde, sondern bereits um I717/18 entstand. Er wurde offenbar erstmals für die Taufe von Erzherzogin Maria Anna und den darauf folgenden feierlichen Hervorgang ihrer Mutter, Kaiserin Elisabeth Christine, verwendet.

Wesentlich weiter verbreitet als offene waren aber geschlossene Tragsessel, die in vielfältigen Ausführungsarten existierten. So konnte etwa der Passagierkasten aus einem einfachen Holzgestell und vorhangartigen textilen Seitenwänden bestehen oder aber er verfügte über Wände aus Holzpaneelen, die bemalt, mit Leder, einfacher Wachsleinwand oder kostbaren Textilien bespannt waren. Die meist an der Vorderwand sowie an den Seitenwänden angebrachten Fensteröffnungen waren entweder unverglast oder mit mehr oder weniger großen Scheiben versehen. In jedem Fall aber konnten die Fensteröffnungen mit Vorhängen verschlossen werden. Vor allem anfangs erfolgte der Einstieg des Öfteren durch eine seitlich angebrachte Öffnung, später aber meist durch eine an der Vorderseite des Kastens positionierte Türe.

Der Variantenreichtum hinsichtlich Form, Ausstattung, Materialien und Farbe ist durch zahlreiche Festbeschreibungen und Inventareinträge dokumentiert und wurde durch lokale Vorlieben, Moden, gesetzliche Vorschriften sowie den angestrebten oder tatsächlichen sozialen Status der Besitzer und ihre finanziellen Möglichkeiten beeinflusst. Ein bereits erwähnter überaus prachtvoller geschlossener Tragsessel des ausgehenden I7. Jahrhunderts befindet sich in den Beständen des Münchner Marstallmuseums. Er wurde um I684/85 vom Pariser Sattlermeister Saillot für Kurfürstin Maria Antonia hergestellt. Seine mit verglasten Fensteröffnungen versehenen Kastenwände wurden vollständig mit rotem Samt kaschiert, auf den eine äußerst aufwendige Gold- und Silberstickerei sowie dekora- 
tive Goldborten und -fransen appliziert sind. Das Kasteninnere ist mit Goldtuch tapeziert und mit Hunderten Ziernägeln geschmückt. Um die vorne positionierte Tür öffnen zu können, muss das Dach angehoben werden, was einst auch das Ein- und Aussteigen erleichterte.

Eine weitere herausragende Hervorbringung des Pariser Luxusgewerbes ist ein geschlossener Tragsessel, der wohl 1698 für eine Nichte Ludwigs XIV., Mademoiselle de Chartres, hergestellt wurde. Er ist heute im Kunstmuseum Petit Palais in der französischen Hauptstadt ausgestellt. Dieses höchste Qualitätskriterien erfüllende Objekt weist in Form und Dekor mehrere Charakteristiken auf, die sich teils abgewandelt und meist in schlichterer Ausführung auch bei anderen erhaltenen französischen Tragsesseln feststellen lassen, die ebenfalls um 1700 entstanden, jedoch nicht im Zentrum der Monarchie, sondern in sekundären Machtzentren beziehungsweise in der Peripherie des Königreichs. Vom Tragsessel der Mademoiselle de Chartres ausgehend, setzt sich der Frankreich gewidmete Beitrag des vorliegenden Bandes unter anderem mit der Frage auseinander, welche unterschiedlichen Verbreitungswege für neueste, im Zentrum der Monarchie entwickelte Modelle existierten und wie rasch die neuesten Pariser Designs fernab der Hauptstadt rezipiert wurden. Mit Sicherheit waren in Fachkreisen Vorlagen für den Bau von Tragsesseln in Form von Zeichnungen, Stichen, Modellen oder gar „Katalogen“ im Umlauf. Auch der persönliche Austausch unter Berufskollegen spielte bei der Verbreitung von Entwürfen gewiss eine Rolle. Formulierungen in manchen Rechnungstexten belegen zudem den Wunsch von Kunden, dass ein in Auftrag gegebenes Vehikel einem Vorbild entsprechen sollte. Auch Bestellungen bei Sattlermeistern, die Hunderte Kilometer entfernt vom Auftraggeber ansässig waren, trugen zur Diffundierung aktueller Moden bei. All diese Wege führten dazu, dass sich besonders gelungene Tragsesseldesigns, wie beispielsweise jenes, das dem Tragsessel der Mademoiselle de Chartres zugrunde liegt, zumindest in wesentlichen Zügen relativ rasch auf dem gesamten französischen Territorium und auch darüber hinaus verbreiteten.

Ein weiterer Schwerpunkt des Kapitels über französische Tragsessel liegt auf deren Dekor und deren Ausstattung. Die untersuchten Tragsessel weisen an den hölzernen Kastenwänden fein geschnitzte oder aber auch einfach gehaltene Zierleisten auf und sind mehr oder weniger aufwendig bemalt. Stets ist das Wappen des Besitzers dargestellt, für Ehepaare häufig auch ein Allianzwappen. Bei den gemalten Dekorationen wurden zudem verschiedenste ornamentale Formen, mythologische Darstellungen oder Allegorien geschätzt, nicht aber Historienmalereien oder Porträtdarstellungen. In die Kastenvorderwand und die beiden Seitenwände waren meist drei, seltener fünf Fenster eingelassen, die sich durch ein Versenken der Scheiben in einen unterhalb des Fensters gelegenen Hohlraum der Kastenwand öffnen ließen. Bei älteren Modellen wurden die Seitenfenster hingegen durch ein horizontales Verschieben der Scheiben geöffnet. Auch qualitative Abstufungen in der 
Ausstattung lassen sich an der Art der Verglasung beobachten. Während luxuriöse Tragsessel mit kostspieligen Spiegelgläsern und großflächigen Scheiben versehen waren, wiesen schlichtere Exemplare billigere Glasscheiben gewöhnlicher Machart auf. Um Kosten zu sparen, wurden die Fensterflächen zuweilen durch Sprossen unterteilt und mit mehreren kleinformatigen Glasscheiben bestückt.

Manche der in die Betrachtung einbezogenen französischen Tragsessel offenbaren ihre Kostbarkeit jedoch nicht an ihrem Äußeren, sondern an der Qualität und Herkunft der im Kasteninneren verwendeten Textilien, auf die - analog zu Kutschen - häufig der größte Kostenanteil entfiel. Eine Rolle spielten dabei unter anderem die Rarität der Stoffe, die Komplexität ihrer Webart, die Frage, ob Gold oder Silberfäden eingearbeitet waren, aber auch die Herkunft der Textilien. In Einzelfällen wurden diese von außerhalb Europas bezogen, was dem Vehikel zusätzlich exotischen Glanz verleihen konnte. Eine Auswertung von Toulouser Nachlassinventaren erhellt, dass im Lauf des I7. Jahrhunderts im Inneren der Tragsessel meist leichte Textilien wie Seidenstoffe beziehungsweise feines Tuch zum Einsatz kamen. In der ersten Hälfte des I8. Jahrhunderts wurden diese fragilen Materialien, die sich rasch abnutzten, leicht rissen und schwer zu säubern waren, meist von Samt oder anderen widerstandsfähigen Textilien abgelöst. Allein die Vorhänge wurden weiterhin aus feinem, leichtem Seidenstoff gefertigt, der in der Regel jedoch die gleiche Farbe wie der Rest der Tapezierung aufwies. Oftmals waren die Samtstoffe monochrom gehalten, wobei verschiedene Rottöne dominierten. Daneben zählte auch ein strahlendes Gelb zu den am meisten geschätzten Farben. Bedauerlicherweise ging bei manchen erhaltenen Vehikeln der ursprüngliche Farbeindruck durch eine spätere Auswechslung der Textilien verloren.

\section{Miettragsessel}

Mehrere Beiträge des vorliegenden Bandes informieren über die Einführung und Entwicklung von Miettragsesselsystemen in unterschiedlichen urbanen Zentren Europas. Besonders viele und reichhaltige Quellen liegen hierzu für die spanische Monarchie vor. Unter den Stadtbewohnern Kastiliens breitete sich im letzten Viertel des I6. Jahrhunderts die Nutzung von Tragsesseln in solch rasanter Weise aus, dass sich die Behörden im Jahr I594 angehalten sahen, diesem Phänomen durch eine Verordnung entgegenzuwirken. Als Grund dafür wurde ein problematisches Überangebot an Miettragsesseln vorgebracht. Sesselträger mussten ihr Gewerbe fortan anmelden und sich einem festgesetzten Tarifsystem unterwerfen. Die getroffenen Maßnahmen führten vorerst zu einer Verknappung des Angebots an Miettragsesseln und erschwerten Personen, die sich keinen eigenen Tragsessel samt zugehörigem Personal leisten konnten, den Zugang zu diesen Vehikeln. Die Ver- 
ordnung von 1594 wurde in den darauf folgenden Jahrzehnten mehrfach erneuert und den veränderten Gegebenheiten angepasst. Für Madrid wurde zudem im Jahr I6o9 festgelegt, dass Inhaber einer Miettragsessellizenz nur noch auf einem einzigen Platz ihre Dienste anbieten durften und die Sesselträger ihre Tragriemen gut sichtbar über der Schulter tragen mussten, was ihre Identifizierung erleichtern sollte. Dies führte zu heftigen Protesten seitens der Sesselträger. Sie gaben an, dass durch den Wegfall von Standplätzen eine rasche Beförderung ihrer Kunden nicht mehr zu gewährleisten sei. Außerdem erachteten sie das vorgeschriebene Vorweisen der Tragegurte als demütigend. Trotz der manifestierten Widerstände hielten die Behörden davon Abstand, die einmal beschlossene Maßnahme wieder rückgängig zu machen, da sie einerseits fest entschlossen waren, Kontrolle über die Sesselträger und ihr Gewerbe zu erlangen, und sie andererseits auch versuchten, die Sesselträger aus Stadtvierteln zu vertreiben, in denen sich zahlreiche Prostituierte und Schauspieler aufhielten.

Über die Einführung von Miettragsesseln im spanischen Vizekönigreich Neapel, in Rom und in Genua liefern die entsprechenden Beiträge im vorliegenden Band aufgrund anderer Schwerpunktsetzungen keine konkreten Anhaltspunkte. Es wäre aber verwunderlich, wäre auch dort diese Entwicklung nicht bereits im I6. Jahrhundert vonstattengegangen.

Für Paris lässt sich die Existenz von Miettragsesseln erstmals für I6ı7 dokumentieren. Damals wurde drei Personen, nämlich einem Fabrikanten, einem Finanzier und dem damaligen Kapitän der königlichen Leibgarde, die sich eigens für diesen Zweck zusammengeschlossen hatten, das Privileg zugesprochen, zehn Jahre lang in Paris, dessen Vororten und in den übrigen Gebieten des Königreiches Miettragsessel zu unterhalten. Im Jahr I639 wurde dasselbe Privileg einem Musketier-Kapitän namens Cavoy und dessen Geschäftspartner für die Dauer von vierzig Jahren zuteil. Im Anschluss daran kamen Cavoy beziehungsweise dessen Nachkommen noch zwei weitere Male, nämlich I679 und I719, in den Genuss eines langjährigen Tragsesselprivilegs.

Auch abseits des französischen Machtzentrums entstanden neue Miettragsesselunternehmen. So wurde beispielsweise ab I634 in der Parlamentsstadt Aix-en-Provence ein Miettragsesselsystem eingeführt. Im Jahr 1655 erhielt ein dort ansässiger Tapissier die Konzession, über einen Zeitraum von vier Jahren zehn selbst gebaute Tragsessel zu vermieten. Ein Jahr später baute derselbe Mann auch in Arles ein entsprechendes System auf, um im darauf folgenden Jahr schließlich bestimmten Sesselträgern die Erlaubnis zu erteilen, ihre Dienste mit von ihm selbst gefertigten Tragsesseln in Monfrein und bei der Messe von Beaucoire feilzubieten. Das Beispiel zeigt deutlich, dass sich mit Miettragsesseln gute Geschäfte machen ließen. Sie boten manchen Handwerkern die Gelegenheit, in entferntere Gegenden zu expandieren und dort fallweise auch Subunternehmer zu beschäftigen. 
Miettragsessel waren in der Regel natürlich weniger aufwendig ausgestattet als Tragsessel, die sich im Besitz wohlhabender Privatpersonen befanden. Dafür mussten Miettragsessel widerstandsfähiger sein und größeren Belastungen standhalten. Nähere Aufschlüsse dazu geben Schriftquellen aus Aix-en-Provence, aus denen unter anderem hervorgeht, welche Hölzer beim Bau von Miettragsesseln eingesetzt wurden. Bei manchen Miettragsesseln bestanden nicht nur die konstruktiven Elemente, sondern auch die Wandpaneele des Passagierkastens aus Holz. Um das Gewicht zu verringern, wurde das Gerüst anderer Miettragsessel hingegen mit Malerleinen bespannt. Hinsichtlich des malerischen Dekors von Miettragsesseln gab es - abgesehen von einer obligatorisch anzubringenden Erkennungsnummer - offenbar keine Vorgaben, was eine große Vielfalt in der Ausgestaltung der Tragevehikel vermuten lässt. Überliefert ist, dass auch renommierte Künstler Dekorationsaufträge erhielten.

In Privatsammlungen Frankreichs und Englands haben sich bis heute zwei gleichartige Miettragsessel erhalten, die aus dem letzten Drittel des I7. Jahrhunderts stammen und einst am Hof von Versailles im Einsatz standen. Ihre Bemalung enthält mehrfache Verweise auf die französische Monarchie und König Ludwig XIV. Die angebrachten Nummern lassen darauf schließen, dass neben den beiden erhaltenen Exemplaren noch eine große Zahl identischer Vehikel existierte. Zudem legt die Ausführung ihrer Bemalung die Vermutung nahe, dass diese mit Hilfe von Schablonen in serienmäßiger Herstellung angebracht wurde.

Wesentlich später als in anderen Teilen Europas kamen Miettragsessel in München und am Kaiserhof in Gebrauch. Eine erste Instruktion für einen Münchner Sesselmeister ist aus dem Jahr I688 überliefert. Als Standort für seine Miettragsessel wurde damals der Schrannenplatz, heute Marienplatz, festgelegt. Die Instruktion listet verschiedene Regeln für den Sesselmeister auf, unter anderem etwa, wo die Tragsessel, so sie nicht im Dienst stünden, aufzubewahren seien. Die Tragsessel wiesen unterschiedliche Qualitätsstufen auf, wobei die „saubern“ für sozial höherstehende Personen eingesetzt werden sollten. Präzise festgelegt waren auch die Preistarife für einfache Beförderungen sowie für eine stundenoder tageweise Inanspruchnahme von Miettragsesseln. Selbst der korrekte Umgang mit von Kunden überreichtem Trinkgeld war in der Instruktion genau vorgeschrieben. Der Sesselmeister war auch für die Disziplin und die Verpflegung der ihm unterstehenden Sesselträger zuständig, wobei aus der Instruktion recht genaue Rückschlüsse auf die Ernährung dieser Dienersparte gezogen werden können.

Von besonderem Interesse scheint, dass im Rahmen des Münchner Miettragsesselsystems offenbar zahlreiche Türken als Träger zum Einsatz kamen. Im Zuge der in den I68oer Jahren mit dem Osmanischen Reich ausgetragenen kriegerischen Konflikte gelangten mehrere Hundert Türken als Gefangene nach München. Von einem Türken, der 
I683 bei der Belagerung von Wien in feindliche Hände geriet, ist überliefert, dass er nach seiner Konversion zum Christentum für einige Jahre als Sesselträger am kurfürstlichen Hof diente. Andere Türken wurden hingegen dem Sesselmeister zugeteilt und beförderten Miettragsessel. Auf sie wird in der Instruktion des Sesselmeisters im Besonderen eingegangen. So wird darin kritisch erwähnt, dass mehrmals türkische Sesselträger, deren Weg ein Priester mit dem Allerheiligsten kreuzte, diesem nicht nur die angemessene Ehrerbietung verwehrt, sondern sogar über ihn gespottet hätten. In der Instruktion wurden sie deshalb dazu angehalten, sich fortan in Fällen, in denen sie mit leerem Tragsessel einem Priester mit dem Allerheiligsten begegneten, in eine andere Gasse beziehungsweise eine nahe gelegene Räumlichkeit zurückzuziehen oder aber wie die Christen die Knie zu beugen. Sollten sie aber während der Beförderung eines Passagiers einen Priester mit dem Sakrament antreffen, so hätten sie in Hinkunft den Tragsessel abzustellen, ihre Kopfbedeckung abzunehmen und abzuwarten, bis der Kleriker vorübergegangen sei.

Kurze Zeit nach München führte auch Wien im Jahr I689 ein Miettragsesselsystem ein. Als der Franzose Michel de la Place damals das kaiserliche Privileg erhielt, Tragsessel zu vermieten, stieß er allerdings auf Ablehnung seitens der Stadtverwaltung. Der Wiener Bürgermeister und der Stadtrat hoben in einem Gutachten hervor, dass Personen, die Mietwagen unterhielten, durch die Einführung von Miettragsesseln finanzielle Einbußen zu befürchten hätten. Außerdem wurde im Gutachten bezweifelt, dass für diese Neuerung in Wien überhaupt die nötige Geschäftsgrundlage vorhanden sei. Kritik wurde zudem an der Herkunft von Michel de la Place laut, da man argwöhnte, er würde vornehmlich Landsleute beschäftigen, was wiederum Unmut in der Wiener Bevölkerung hervorrufen könnte. Trotz der Widerstände entwickelte sich das Wiener Miettragsesselsystem wie auch jenes anderer Städte Europas mit Erfolg. Im Jahr I703, zu einem Zeitpunkt, als de la Place das ihm erteilte Privileg offenbar schon wieder verloren hatte, bekam der kaiserliche Kammerdiener Heinrich Ernst Rauchmüller das Sonderrecht zugesprochen, zeitlebens ein Miettragsesselsystem in Wien zu unterhalten. Die lokalen Behörden sahen sich damals offenbar immer noch gezwungen, die Existenz von Miettragsesseln zu rechtfertigen. Sie führten mehrere Gründe für deren Sinnhaftigkeit an: Miettragsessel würden hohe Ausgaben für kostspielige Karossen reduzieren, das Straßenpflaster würde durch eine Verminderung von Kutschen geschont und nicht zuletzt stünde den Stadtbewohnern ein zusätzliches, höchst praktisches Verkehrsmittel zur Verfügung. Rauchmüller wurden mit dem Privileg auch unterschiedliche Pflichten auferlegt: So wurde ihm etwa untersagt, Diener und Juden als Kunden zu akzeptieren. Kranke blieben auf Rauchmüllers eigenen Wunsch hin von seiner Dienstleistung ausgeschlossen, vermutlich, um keine gesunden Kunden zu verlieren, die sich vor einer Ansteckung mit einer gefährlichen Krankheit fürchteten. Damit Rauchmüller keine überzogenen Preise für die Beförderung im Miettragsessel verlangen konnte, wur- 
den differenzierte Tarifobergrenzen festgesetzt. Dem Betreiber der Miettragsessel wurde zudem eine Steuerleistung auferlegt, die gleichzeitig karitativen Charakter hatte: Analog zu einer bereits auf Mietkutschen angewendeten Regelung musste er für jeden in Verwendung stehenden Tragsessel eine finanzielle Abgabe leisten, die direkt an das Armenhaus vor dem Schottentor fließen sollte.

\section{Sesselträger: Herkunft, Karriereverläufe, Reputation und gesundheitliche Aspekte}

Hinsichtlich der Herkunft von Sesselträgern fand bereits Erwähnung, dass gegen Ende des I7. Jahrhunderts in München Türken und in Wien offenbar Franzosen zur Beförderung von Miettragsesseln herangezogen wurden. Vergleichbare Phänomene lassen sich auch für andere Teile Europas beobachten. In manchen Fällen standen hinter der Entscheidung, Ausländer als Sesselträger zu beschäftigen, wohl nicht nur pragmatische Gründe, sondern auch der Wunsch, durch fremdländisches, ja teilweise exotisch anmutendes Personal das Sozialprestige der Beförderten zu heben beziehungsweise zu bestätigen. Dies belegen entsprechende Beispiele aus dem Bereich der sozialen Eliten. Auf der Iberischen Halbinsel etwa sandte der Duque de Braganza seiner Braut zum Einzug in Elvas einen kostbaren Tragsessel entgegen, der von zwei groß gewachsenen Männern schwarzafrikanischer Abstammung getragen wurde. Vereinzelte Nachrichten weisen darauf hin, dass Mitglieder des spanischen Königshofs wie auch spanische Vizekönige auf die Dienste maurischer Sesselträger zurückgriffen. So führte etwa Infantin Maria Anna auf ihrer Brautreise ins Reich I630/3I einen Tragsessel mit zwölf Mauren mit sich. Auch der Duque de Montalto setzte Mauren als Sesselträger ein: Als er I652 als neuer Vizekönig in Valencia einzog, waren vier von ihnen dafür abgestellt, seinen leeren Tragsessel zu befördern. An den Höfen Mitteleuropas erfreuten sich hingegen italienische Sesselträger großer Beliebtheit. Ab dem Auftauchen erster Sesselträger am Kaiserhof in den Jahren um I620 dominierten Italiener diese Dienersparte. Sie verloren dort erst gegen Ende des I7. Jahrhunderts an Bedeutung und Einfluss. Verschiedene Schriftquellen belegen, dass kaiserliche Sesselträger italienischer Herkunft bemüht waren, Verwandte aus ihrer Heimat an den Kaiserhof zu holen, um auch ihnen eine Stelle als Hofsesselträger zu verschaffen. Vereinzelte Nachrichten liegen auch über die genaue Herkunft der italienischen Sesselträger am Kaiserhof vor. Unter ihnen befanden sich nachweislich zahlreiche Genuesen, vereinzelt Mailänder und vermutlich auch Neapolitaner. Mit Wien vergleichbare Entwicklungen gab es offenbar auch in München, denn unter den ersten zehn Sesselträgern am bayerischen Hof befanden sich, wie schon an früherer Stelle erwähnt, gleich vier Italiener. Mancherorts wurde die Tatsa- 
che, dass es sich bei Sesselträgern häufig um Ausländer handelte, jedoch negativ gesehen. Um die Mitte des 17. Jahrhunderts häuften sich etwa in Spanien entsprechende Klagen über dieses Phänomen. Pérez del Barrio merkte damals kritisch an, dass jährlich mehr als 20.000 Ausländer aus aller Herren Länder in Spanien einträfen, von denen viele als Sesselträger arbeiten würden. Ein anderer Autor, Martínez de Mata, beanstandete zu jener Zeit, dass über I20.000 Franzosen nach Spanien gekommen seien und verschiedene Dienersparten - darunter auch jene der Sesselträger - unter Kontrolle genommen und Spanier daraus verdrängt hätten. In Wien wurde 1703 gar festgelegt, dass überhaupt keine Ausländer mehr Miettragsessel transportieren durften.

Für die Sesselträger, die im kaiserlichen Hofstaat der österreichischen Habsburger beschäftigt waren, geben zahlreiche Quellen Einblick in die Möglichkeiten und Grenzen ihrer Berufskarrieren. Grundsätzlich ist ein hoher Spezialisierungsgrad für diese Dienersparte kennzeichnend. Es erhielten nur jene Personen eine Stelle als kaiserlicher Sesselträger, die sich schon andernorts in diesem Beruf bewährt hatten. „Quereinsteiger“ hat es allem Anschein nach dabei keine gegeben. Hofsesselträger konnte etwa werden, wer bereits langjährige facheinschlägige Diensterfahrungen im In- oder Ausland vorweisen konnte oder wer bereits in einem anderen habsburgischen Hofstaat Dienst als Sesselträger verrichtet hatte. Andererseits war eine Anstellung als kaiserlicher Sesselträger aber kein Sprungbrett für eine prestigeträchtigere oder körperlich weniger belastende Position bei Hof. Hofsesselträger dienten als solche bis zu ihrer Entlassung, ihrer Pensionierung beziehungsweise bis zu ihrem Tod. Um die Sesselträger möglichst lange im Dienst zu halten, wurden die älteren und schwächeren unter ihnen jeweils in ein Team mit zwei jüngeren, kräftigeren Sesselträgern eingeteilt. Der Älteste der Dreiergruppe begleitete zwar stets den Tragsessel, half aber nur im Bedarfsfall als Träger aus. Die anstrengende Tätigkeit erforderte auch regelmäßige Regenerationsphasen. Die Hofsesselträger wurden deshalb zwei Großgruppen zugeordnet, von denen alternierend die eine einen Tag im Einsatz war, während die andere dienstfrei hatte. Für den Münchner Hof ist hingegen aus dem Jahr I636 überliefert, dass bei Überlandtransporten zwei Sesselträger das Tragevehikel beförderten, während ihnen Ersatzsesselträger auf einem Wagen folgten. Nach einer Stunde Dienst erfolgte die Ablöse durch jene Sesselträger, die sich in der Zwischenzeit auf dem Wagen ausgeruht hatten.

Für Spanien, besonders aber auch für Frankreich sind zahlreiche Zeugnisse überliefert, die das weit verbreitete negative Image der Sesselträger dokumentieren. In einer französischen Quelle von I660 werden sie etwa despektierlich als „getaufte Maultiere“ tituliert. Sie standen im Ruf, geltende Gesetze zu missachten, strafbare Handlungen zu begehen, Tumulte zu verursachen, sich eines unflätigen Wortschatzes zu bedienen sowie trunksüchtig und gewalttätig zu sein. Diese Charakterisierung spiegelte sich auch in französischen Theaterstücken jener Zeit wider, so etwa in Molières Stück „Les Précieuses ridicules“. Trotz 
solcher negativer Zuschreibungen, die wohl auch auf tatsächlich gemachten Erfahrungen und Beobachtungen beruhten, sollte nicht vergessen werden, dass das Leben von Sesselträgern von einer heute kaum vorstellbaren Härte gekennzeichnet war und ihre Tätigkeit häufig gravierende gesundheitliche Auswirkungen hatte. Ein französischer Arzt namens Valette-Falgous beobachtete I7I2, dass Sesselträger überdurchschnittlich oft an Brustschmerzen litten und als Folge ihrer anstrengenden Arbeit häufig Blut auswarfen. Er zog daraus den Schluss, dass nur junge Männer diesen Beruf ausüben sollten. Die Realität war jedoch eine andere. Häufig sahen sich auch alte Männer und fallweise sogar Frauen und Mädchen gezwungen, ihren Broterwerb als Sesselträger beziehungsweise Sesselträgerinnen zu bestreiten, auch wenn ihre Konstitution für diese Tätigkeit gänzlich ungeeignet war. 


\section{Abkürzungsverzeichnis}

$\begin{array}{ll}\text { ADGG } & \text { Archivio Durazzo Giustiniani, Genua } \\ \text { ADHG } & \text { Archives Départementales de la Haute-Garonne, Toulouse } \\ \text { ADMS } & \text { Archivo Ducal de Medina Sidonia, Sanlúcar de Barrameda (Cádiz) } \\ \text { ADP } & \text { Archivio Doria Pamphilj, Rom } \\ \text { ADT } & \text { Archives Départementales du Tarn, Albi } \\ \text { AGI } & \text { Archivo General de Indias, Sevilla } \\ \text { AGP } & \text { Archivo General de Palacio, Madrid } \\ \text { AGS } & \text { Archivo General de Simancas, Simancas } \\ \text { AGS CC } & \text { Archivo General de Simancas, Cámara de Castilla, Simancas } \\ & \text { (Valladolid) } \\ \text { AHN } & \text { Archivo Histórico Nacional, Madrid } \\ \text { AHN Nobleza } & \text { Archivo Histórico Nacional, Sección Nobleza, Toledo } \\ \text { AHMC } & \text { Archivo Histórico Municipal de Córdoba, Córdoba } \\ \text { AHMV } & \text { Archivo Histórico de los Marqueses de Viana, Córdoba } \\ \text { AMAeP } & \text { Archives Municipales, Aix-en-Provence } \\ \text { AMM } & \text { Archives Municipales, Marseille } \\ \text { AMV } & \text { Archivo Municipal de Valladolid, Valladolid } \\ \text { AS } & \text { Archivio Spinola, Genua (Galleria Nazionale di Palazzo Spinola) } \\ \text { ASCG } & \text { Archivio Storico del Comune di Genova, Genua } \\ \text { ASF } & \text { Archivio di Stato, Florenz } \\ \text { ASG } & \text { Archivio di Stato, Genua } \\ \text { ASN } & \text { Archivio di Stato, Neapel } \\ \text { ASR } & \text { Archivio di Stato, Rom } \\ \text { AVA } & \text { Allgemeines Verwaltungsarchiv (eine Abteilung des ÖStA) } \\ \text { AVM } & \text { Archivo de Villa, Madrid } \\ \text { AZA } & \text { Ältere Zeremonialakten } \\ \text { BHStA } & \text { Bayerisches Hauptstaatsarchiv, München } \\ \text { BL } & \text { British Library, London } \\ \text { BNE } & \text { Biblioteca Nacional des España, Madrid } \\ \text { BPR } & \text { Biblioteca del Palacio Real, Madrid } \\ \text { BSB } & \text { Bayeriatsbibliothek, München } \\ & \end{array}$


BSV Bayerische Schlösserverwaltung, München

BZ Biblioteca Zabálburu, Madrid

CA Colección Juan Abelló, Madrid

DdG Dispacci di Germania

DOZA Deutschordens-Zentralarchiv, Wien

FA Familienarchiv

FHKA Finanz- und Hofkammerarchiv (eine Abteilung des ÖStA)

GHA Geheimes Hausarchiv, München

HA Hausarchiv

HHStA Haus-, Hof- und Staatsarchiv (eine Abteilung des ÖStA)

HZAB Hofzahlamtsbücher

IVDJ Instituto Valencia de Don Juan, Madrid

KHM Kunsthistorisches Museum Wien

MA Museo de América, Madrid

MdP Mediceo del Principato

$\mathrm{ME}$

Real Monasterio de San Lorenzo de El Escorial, Madrid

MNP Museo Nacional del Prado, Madrid

MSC Museo de Santa Cruz, Toledo

NÖHA Niederösterreichische Herrschaftsakten

OMeA Obersthofmeisteramt

ÖNB Österreichische Nationalbibliothek, Wien

OStA Oberststallmeisteramt

ÖStA Österreichisches Staatsarchiv, Wien

RACMyP Real Academia de Ciencias Morales y Políticas, Madrid

RAE Real Academia Española, Madrid

RAH Real Academia de la Historia, Madrid

SR Sonderreihe

StadtA Stadtarchiv, München

TLA Tiroler Landesarchiv, Innsbruck

WLB Württembergisches Landesbibliothek, Stuttgart

WStLA Wiener Stadt- und Landesarchiv, Wien

ZA Zeremonialabteilung 


\section{Verzeichnis der gedruckten Quellen und der Forschungsliteratur}

\section{Gedruckte Quellen}

Actas de las Cortes de Castilla. Publicadas por acuerdo del Congreso de los Diputados, a propuesta de su Comisión de Gobierno Interior, 68 Bde. (Madrid I86I-2006).

Aigentliche Beschreibung / deß den 24. May Anno I654. Ihrer Kayerlich: und Königlicher Maystätten zu Wienn beschehenen Einzugs (Wien o.J.).

Albèri, Eugenio (Hg.): Le relazioni degli ambasciatori veneti al senato durante il secolo decimosesto, Serie I, Bd. 6 (Firenze I862).

Alcocer, Pedro de: Relación de algunas cosas que pasaron en estos reinos desde que murió la reina Católica Dońa Isabel, hasta que se acabaron las Comunidades en la ciudad de Toledo, um I539 (Sevilla I872).

Altoviti, Giovanni: Essequie della Sacra Católica e Real Maestà di Marguerita d'Austria Regina di Spagna, celebrate dal Serenísimo don Cosimo II, Gran Duca di Toscana III (Firenze I6r2).

Antithesis figurata Vitae Christi et Antichristi (Wittenberg I52I).

Antonelli, Attilio (Hg.): Cerimoniale del viceregno spagnolo e austriaco di Napoli, I650I7I7 (I ceremoniali della corte di Napoli I, Soveria Mannelli 20I2).

Antonelli, Attilio (Hg.): Cerimoniale del viceregno austriaco di Napoli, I707-I734 (I ceremoniali della corte di Napoli 2, Napoli 20I4).

Aquí se contiene un milagro que el glorioso San Diego hizo con una devota suya, a los 25 de febrero de este presente año de mil y quinientos y noventa y quatro, juntamente de la gran justicia que en la ciudad de Lisboa se hizo de un inglés luterano y de otras personas, y lleva al cabo una letrilla nueva al tono de la zarabanda sobre la nueva premática. Compuesto en verso castellano por Benito Carrasco, vecino de Ávila. In: Gallardo, Bartolomé José: Ensayo de una biblioteca española de libros raros y curiosos [...], 4 Bde. (Madrid I863-I889), Bd. 2, S. 239 f.

Astrana Marín, Luis: Epistolario completo de D. Francisco de Quevedo. Edición crítica 
(con anotaciones, apéndices, documentos inéditos y una acabada bibliografía) (Madrid I946).

Ausführliche Relation, von dem den 4. Martii, I690. sehr prächtig-gehaltenen Einzug / Ihrer Kayserl. und Königlichen Majestäten / in dero Residentz-Stadt Wienn (o.O., o.J.).

Außführliche Erzehlung / Welcher gestalt dem Durchleuchtigen Fürsten und Herrn / Herrn Leopoldo Ignatio Ertz-Hertzogen zu Oesterreich / etc. die Erbhuldigung von allen Vier Ständten deß Löblichen Ertz-Hertzogthumbs Oesterreich gelaistet worden / in der Kays: Residentz-Statt Wien / den 26. Januarij Anno I655 (Augsburg 1655).

Balbuena, Bernardo de: Grandeza mexicana, I604, hg. von González Boixo, José Carlos (Roma I988).

Barrionuevo de Peralta, Jerónimo: Avisos, hg. und kommentiert von Paz y Meliá, Antonio, 2 Bde. (Biblioteca de Autores Españoles 22I-222, Madrid I968-1969).

Bassompierre, François de: Memoires du Mareschal de Bassompierre contenant l'histoire de sa vie de ce qui s'est fait de plus remarquable à la cour de France pendant quelques années, 3 Bde. (Cologne I665).

Bentura Beleña, Eusebio: Recopilación sumaria de todos los autos acordados de la Real Audiencia y Sala del Crimen de esta Nueva España, y Providencias de su superior Gobierno, 2 Bde. (México 1787).

Bertelli, Pietro: Diversarum nationum habitus centum et quattuor iconibus in aere incisis diligenter expressi, 3 Bde. (Padova I594).

Blondeau, Philipp/Cavallo, Joseph Anton: Vollständiger Bericht, Von allen Sehens-würdigen Freuden-Festen, Welche Hochfeyerlich begangen worden In- und nahe der Churfürstl. Haupt- und Residentz-Stadt München Anno I727. Vom 28. Mertzen biß den 26. May, als dem Herrn Carolo Alberto, In Ob- und Nider-Bayrn, [...] Herzogen, [...] Auß Der [...] Frauen, Maria Amalia, Regierenden Chur-Fürstin, [...] gebohren worden Ein Durchl. Chur- und Erb-Printz, [...]. Faksimile nach der Ausgabe von Joh. Lucas Straub (I727) (München 2000).

Boeneim, Wendelin: Urkunden und Regesten aus der k. k. Hofbibliothek. In: Jahrbuch der kunsthistorischen Sammlungen des Allerhöchsten Kaiserhauses 7 (I888), S. XCICCCXIV und Io (I889), S. I-XIX.

Borghese, Camillo: Diario in Relation del viaggio di Monsigr Camillo Borghese auditore della Rev. Camera da Roma in Spagna mandatovi Nuntio alla Corte straordinario da Papa Clemente Ottavo l'anno I594 al Re Philippo Secondo, I594. In: Morel-Fatio, Alfred: L'Espagne au XVI e et au XVII ${ }^{\mathrm{e}}$ siècle. Documents historiques et littéraires (Heilbronn I878), S. I6I-I93.

Braun, Georg/Hogenberg, Franz: Civitates Orbis Terrarum, Urbium Praecipuarum Totius Mundi: Liber Tertius (Köln I593). 
Bucelini, Gabrielis: Germania topo-chrono-stemmato-graphica sacra et prophana, Bd. I (Ulm I655).

Cabrera de Córdoba, Luis: Relaciones de las cosas sucedidas en la corte de España, desde I599 hasta I6I4 (Madrid I857).

Cáncer y Velasco, Jerónimo de: Relación del nacimiento y bautismo de la Serenísima Infanta Doña Ana María Antonia de Austria, I635. In: Jerónimo de Cáncer y Velasco, poesía completa, hg. von González Maya, Juan Carlos/Cervera Baño, José/Garau Amengual, Javier (Tesis doctorales „cum laude“, Serie L, Literatura 4I, Madrid 2007), S. I8I-I9I.

Capaccio, Giulio Cesare: Il forastiero, hg. von De Mieri, Stefano/Toscano, Maria (Napoli i634, Memofonte 2007).

Capmany y Montpalau, Antonio de: Museo histórico, que comprende los principales sucesos de España y el extrangero, como asimismo toda la parte artística y monumental de los principales países, 2 Bde. (Madrid ${ }^{2}$ I862).

Carrillo, Alonso: Origen de la dignidad de Grande de Castilla (Madrid I657).

Celani, Enrico (Hg.): Johannis Burckardi Liber Notarum ab anno MCCCCLXXXIII usque ad annum MDVI, 2 Bde. (Rerum Italicarum Scriptores², 32, Città di Castello I906-I9IO).

Cieza de León, Pedro de: Las guerras civiles peruanas, ca. I553-I584 (Obras Completas 2, hg. und kommentiert von Sáenz de Santamaría, Carmelo, Madrid 1985).

Codex Austriacus (Wien I704).

Colección de cánones y de todos los concilios de la Iglesia española traducida con notas é ilustraciones por Tejada y Ramiro, D. Juan, 5 Bde. (Madrid I849-I862).

Corral, Fray Hernando del: Historia breve y sumaria de cómo el emperador don Carlos V, nuestro señor, trató de venirse a recoger al monasterio de San Jerónimo de Yuste. In: Sánchez Loro, Domingo: La inquietud postrimera de Carlos V, 3 Bde. (Biblioteca Extremeña 17, Cáceres 1957-I958), Bd. 2, S. 7I-I54.

Curiel Méndez, Gustavo: El efímero caudal de una joven noble. Inventario y aprecio de los bienes de la marquesa Doña Teresa Francisca María de Guadalupe Retes Paz Vera. (Ciudad de México, I695). In: Anales del Museo de América 8 (2000), S. 65-Ior.

(Cuspinianus, Johannes): Der nambhaftigen kay. Ma. und dreyer Kunigen zu Hungern Beham und Poln zamenkumung und versamlung so zu Wienn in dem Heymonat [...] MDXV. jar geschehen [...] (o.O. o.J., aber Wien I5I5).

DE BAvière, Elisabeth-Charlotte: Mélanges historiques, anecdotiques et critiques sur la fin du règne de Louis XIV et le commencement de celui de Louis XV (Neuedition Paris 1807).

Delamare, Nicolas: Traité de la police où l'on trouvera l'histoire de son établissement [...], Bd. 4 (Paris I738). 
Della Tuccia, Nicola: Cronache di Viterbo e di altre città. In: Ciampi, Ignazio (Hg.): Cronache e statuti della città di Viterbo (Documenti di storia italiana publicati a cura della R. deputazione sugli studi di storia patria per le provincie di Toscana, dell'Umbria e delle Marche 5, Firenze I872), S. I-272.

DEL Tufo, Gioan Battista: Ritratto o modello delle grandezze, delizie e maraviglie della nobilissima città di Napoli (I588), hg. von Casale, Olga Silvana/Colotti, Mariateresa (Roma 2007).

Descripción del magestuoso aparato, con que se celebró el Bautismo del Príncipe Don Carlos Ioseph, nuestro señor (que Dios guarde) el Lunes 2i de Noviembre de I66I. In: Varela Hervías, Eulogio: Gazeta Nueva I66I-I663 (Notas sobre la historia del periodismo español en la segunda mitad del siglo XVII, Madrid i960), S. XCV-CI.

Die böhmischen Landtagsverhandlungen und Landtagsbeschlüsse vom Jahre 1526 bis auf die Neuzeit, hg. vom Landesarchive des Königreiches Böhmen, Bd. I5: NovÁk, Johann Friedrich (Hg.): Die Landtage des Jahres I6II (Prag 19I7).

DöBerl, Mario: Der Fuhrpark Kaiser Leopolds I. Teiledition der Wiener Hofmarstallinventare von I678. In: Jahrbuch des Kunsthistorischen Museums Wien I2 (20I0), S. 276-309.

Documentos inéditos relativos a Hernán Cortés y su familia (Publicaciones del Archivo General de la Nación 27, México 1935).

Doering, Oscar: Des Augsburger Patriciers Philipp Hainhofer Reisen nach Innsbruck und Dresden (Wien I90I).

Duchesne, Louis (Hg.): Le Liber pontificalis, 2 Bde. (Paris I886-I892).

Ebendorfer, Thomas: Chronica Austriae, hg. von Lhotsky, Alphons (Monumenta Germaniae Historica, Scriptores rerum Germanicarum, Nova series I3, Berlin/Zürich 1967).

Eleonorae Römischer Kayserin, Königl. Crönung in Böheimb (Prag 1656).

Elliott, John H./Peña, José F. de la: Memoriales y cartas del Conde Duque de Olivares, 2 Bde. (Madrid 1978).

Escobar, Antonio de: Recopilación de la felicíssima iornada que la Cathólica Real Magestad del Rey don Phelipe nuestro señor hizo en la conquista del Reyno de Portugal ansí en las cosas de la guerra como después en la paz antes que boluiesse a Castilla (Valencia 1586).

(Estefan, José): Iosephi Stephani Valentini episcopi Vestani de osculatione pedum Romani Pontificis ad Sanctissimum Dominum Nostrum Sixtum V. Pontificem Optimum Maximum, adiecta eiusdem auctoris disputatione de coronatione et levitatione seu portatione papae. Omnia nunc ex repetita praelectione multis ex partibus locupletata et aucta et ab haereticorum calumniis pluribus argumentis, patrum testimoniis et traditione defensa (Rom I588). 
FeIge, Johann Constantin (Joannem Constantinum Feigium): Wunderbahrer Adlers-Schwung oder fernere Geschichts-Fortsetzung Ortelii redivivi et continuati, Das ist: Eine außführliche Historische Beschreibung deß noch anhaltenden Türcken-Kriegs, [...] von I682 bis I69I [...] Anderter Theil (Wien I694).

Fellner, Thomas/Kretschmayr, Heinrich: Die österreichische Zentralverwaltung I/2 (Veröffentlichungen der Kommission für neuere Geschichte Österreichs 6, Wien 1907). Fernández de Navarrete, Martín/Salvá, Miquel/Sáinz de Baranda, Pedro: Colección de Documentos Inéditos para la Historia de España, iız Bde. (Madrid I842-I895).

Fernández de Navarrete, Pedro: Conservación de Monarquías, i626, hg. von Gordon, Michael D. (Madrid I982).

Fernández de Oviedo, Gonzalo: Historia general y natural de las Indias (Biblioteca de Autores Españoles desde la formación del lenguaje hasta nuestros días I2I, Madrid I846-I999).

Feuillet de Conches, (Felix) (Hg.): Journal du marquis de Dangeau, Bd. I (I684-I686) (Paris I854).

FIEDLER, Joseph (Hg.): Relationen venetianischer Botschafter über Deutschland und Österreich im sechzehnten Jahrhundert (Fontes rerum austriacarum, 2. Abt., Bd. 30, Wien I870).

FLórez, Enrique: Memorias de las reinas Católicas, 2 Bde. (Valladolid 2002, erstmals Madrid I76I).

Foxe, John: Acts and Monuments, Auflage von 1576. Elektronische Edition: The Unabridged Acts and Monuments Online or TAMO (The Digital Humanities Institute, Sheffield 20II); verfügbar unter https://www.dhi.ac.uk/foxe/ (letzter Zugriff: I9.07.2019).

Freitas, Fray Nicolás de: Relación del descubrimiento del País y ciudad de Quivira, hecho por D. Diego Dionisio de Peñalosa, Briceño y Verdugo, Ocampo y Valdivia, señor de las villas de Guarina y de Farara y sus once pueblos, I662. In: Memorias de la Real Academia de la Historia, I4 Bde. (Madrid I796-I9I4), Bd. Io (I885), S. 33-4I.

(Freschot, Casimir): Relation von dem käyserlichen Hofe zu Wien [...]. Aufgesetzt von einem Reisenden im Jahr I704 (Köln I705).

Fuensanta del Valle, Marques de la (Hg.): Correspondencia de los Príncipes de Alemania con Felipe II y de los embajadores de este en la corte de Viena (I556 á I576), Bd. 6 (Colección de documentos inéditos para la historia de España Iı3, Madrid I895, Reprint Nendeln 1975).

GACHARD, Louis Prosper: Retraite et mort de Charles-Quint au monastére de Yuste: lettres inédites d'aprés les originaux conservés dans les archives royales de Simancas, 3 Bde. (Bruxelles I854-I855). 
García, Genaro: Documentos inéditos o muy raros para la historia de México (México I975, erstmals 1907).

García Matamoros, Alfonso: Pro adserenda hispanorum eruditione, I553, hg., übersetzt und kommentiert von López de Toro, José (Revista de Filología Española, Anejo 28, Madrid I943).

García Mercadal, José: Viajes de extranjeros por Espańa y Portugal desde los tiempos más remotos hasta comienzos del siglo XX, 6 Bde. (Valladolid 1999, erstmals Madrid 1952-1962).

GonzÁlez de Eslava, Francisco: Coloquios espirituales y sacramentales, ca. 1578, hg. von Rojas Garcidueñas, José, 2 Bde. (Colección de escritores mexicanos 74 und 75, México 1958$)$.

GonzÁlez Palencia, Ángel: La Junta de Reformación. Documentos procedentes del Archivo Histórico Nacional y del General de Simancas transcritos por Ángel González Palencia publicados por la Academia de Estudios Histórico-Sociales de Valladolid (Colección de documentos inéditos para la historia de España y de sus Indias 5, Valladolid I932).

GotTfried, Joh. Ludw.: Historische Chronica, Oder Beschreibung der fürnehmsten Geschichten / so sich von Anfang der Welt / biß auf das Jahr Christi I6r9 zugetragen (Frankfurt a. M. I7IO, erstmals Frankfurt a. M. 1630).

Granada, Fray Luis de: Epistolario, hg. von Huerga, Álvaro (Obras completas de Fray Luis de Granada I9, Madrid 1998).

Gröbl, Lydia/Haupt, Herbert: Kaiser Rudolf II. Kunst, Kultur und Wissenschaft im Spiegel der Hoffinanz. Teil I: Die Jahre I576 bis I595. In: Jahrbuch des Kunsthistorischen Museums Wien, Bd. 8/9 (2006/2007), S. 205-353.

Gualdo Priorato, Galeazzo: Historia della Sacra Real Maestà di Christina Alessandra Regina di Svetia, \&c. (Roma I656).

Gualdo Priorato, Galeazzo: Historia di Leopoldo Cesare, continente le cose più memorabili successe in Europa dal I656 fino al 1670, 3 Bde. (Wien I670-1674).

Guevara, Rodríguez de: In pluribus ex ijs quibus Galenus impugnatur ab Andrea Vesalio in constructione \& vsu partium corporis humani, defensio (Conimbricae 1559).

Guzmán, Diego de: Reyna católica. Vida y muerte de D. Margarita de Austria Reyna de Espanna (Madrid I6I7).

Hainhofer, Philipp: Relatio Philippi Hainhoferi Seiner von Augspurg nacher München in Frstl. Braunschweigischen Geschäfften Verrichteten Rayse. Anno 1636. Nach der Edition von Häutle, Christian (Hg.): Hainhofers Reisen nach München und Neuburg a/D. in den Jahren I6I3, I6I4 und I636. In: Zeitschrift des Historischen Vereins für Schwaben und Neuburg 8 (I88I), S. 268-3I4. 
Haupt, Herbert: Fürst Karl I. von Liechtenstein. Obersthofmeister Kaiser Rudolfs II. und Vizekönig von Böhmen. Hofstaat und Sammeltätigkeit. Edition der Quellen aus dem liechtensteinischen Hausarchiv, 2 Bde. (Wien/Köln/Graz I983), Bd. I.

Haupt, Herbert: Kaiser Rudolf II. Kunst, Kultur und Wissenschaft im Spiegel der Hoffinanz. Teil II: Die Jahre I596 bis I6I2. In: Jahrbuch des Kunsthistorischen Museums Wien, Bd. Io (2008), S. 227-399.

Hausenblasová, Jaroslava: Der Hof Kaiser Rudolfs II. Eine Edition der Hofstaatsverzeichnisse 1576-I6I2 (Fontes Historiae Artium 9, Prag 2002).

Helbig, Karl Gustav (Hg.): Esaias Pufendorf's kngl. schwedischen Gesandten in Wien, Bericht über Kaiser Leopold, seinen Hof und die österreichische Politik I67I-I674 (Leipzig I862).

Huarte y Echenique, Amalio (Hg.): Relaciones de los reinados de Carlos V y Felipe II, 2 Bde. (Sociedad de Bibliófilos Españoles. Segunda época I2, 25, Madrid I94I-I950).

Karajan, Th[eodor] G. von (Hg.): Johannes Tichtel's Tagebuch MCCCCLXXVII bis MCCCCXCV, Sigmunds von Herberstein Selbstbiographie MCCCCLXXXVI bis MDLIII, Johannes Cuspinian's Tagebuch MDII bis MDXXVII und Georg Kirchmair's Denkwürdigkeiten MDXIX bis MDLIII (Fontes rerum austriacarum I/I, Wien I855).

Käyserlicher und Königlicher wie auch Ertz-Hertzoglicher und dero Residentz-Stadt Wienn Staats- und Stands-Kalender / Auff das Jahr M.DCCII. Mit einem noch nie dergleichen gesehenen Schematismo geziert (Wien o.J.).

Käyserlicher und Königlicher wie auch Ertz-Hertzoglicher und dero Residentz-Stadt Wienn Staats- und Stands-Kalender / Auff das jahr M.DCCIV. Mit einem noch nie dergleichen gesehenen Schematismo geziert (Wien o.J.).

Keller, Katrin/Catalano, Alessandro (Hg.): Die Diarien und Tagzettel des Kardinals Ernst Adalbert von Harrach (I598-1667), 7 Bde. (Wien/Köln/Weimar 2010).

Khevenhüller, Franz Christoph: Annales Ferdinandei, I2 Bde. (Leipzig I72I-I726).

KLARWILl, Victor (Hg.): Fugger-Zeitungen. Ungedruckte Briefe an das Haus Fugger aus den Jahren I568-I605 (Wien/Leipzig/München 1923).

Kristen, Zdeněk (Hg.): Epistulae et acta Johannis Stephani Ferrerii I604-I607, Bd. I/I (Epistulae et acta nuntiorum apostolicorum apud imperatorem I592-I628, Tomus 3, Prag 1944).

Kurz, Maximilian: Relation Der auß gnädigistem Befelch, der Durchleuchtigisten Fürstin vnd Frawen, Frawen Maria Anna, in Obern vnd Nidern Bayrn [...] in Abholung der Durchleuchtigisten Fürstin vnd Frawen, Frawen Henrietta Adelheida, Churfürstin in Bayrn, [...] Durch den Hoch vnd wolgebornen Herrn, Herrn Maximilian Graf Kurtzen, Freyherrn von Senfftenaw, [...] verrichter Raiß nacher Piemont (o.O. I652).

LAssels, Richard: The Voyage of Italy, or a Compleat Journey through Italy (Paris I670). 
Le Jumel de Barneville d'Aulnoy, Marie Catherine: Relation du Voyage d'Espagne (Paris I69I).

Les Lois de la galanterie, de nouveau corrigées et amplifiées par l'Assemblée générale des Galants de France. In: Nouveau Recueil des pièces les plus agréables de ce temps (Paris I658).

Lespinasse, René de: Histoire générale de Paris. Collection de documents. Les métiers et corporations de la ville de Paris, Bd. 3: Tissus, étoffes, vêtements, cuirs et peaux, métiers divers (Paris 1892).

Lewin, Boleslao: Descripción del virreinato del Perú. Crónica inédita de comienzos del siglo XVII (Rosario 1958).

Lhermite, Jean: Le passetemps, hg. von Ruelens, Charles, 2 Bde. (Maatschappij der Antwerpsche Bibliophilen I7 und 20, Antwerpen 1890-1896).

(Lhermite, Jean): El pasatiempos de Jehan Lhermite: memorias de un gentilhombre flamenco en la corte de Felipe II y Felipe III, mit einem Kommentar von Sáenz de Miera, Jesús, Übersetzung von Checa Cremades, José Luis (Aranjuez 2005).

Libro primero de la triunfante jornada q el ynbentísimo enperador Don Carlos hizo contra el turco Solimán en Biena, quando le hizo retirar (o.J.).

LincK, Wenzeslaus: Bapsts gepreng, auß dem Ceremonien Buch (Nürnberg 1565).

Linhartová, Milena (Hg.): Epistulae et acta Antonii Caetani I607-I6II, 3 Bde. (Epistulae et acta nuntiorum apostolicorum apud imperatorem I592-1628, Tomus 4, Prag 1932-I946).

Lisón y Biedma, Mateo de: El Tapaboca que azotan. Respuesta del bachiller ignorante, al Chitón de las taravillas, que hizieron los Licenciados Todo se sabe, y Todo lo sabe, I630. In: Astrana Marín, Luis: La vida turbulenta de Quevedo (Madrid 1945), S. 583-620.

Lorea, Fray Antonio de: El siervo de Dios Fr. Pedro de Tapia, de la Orden de Predicadores, Obispo de Segovia, Siguenza, Córdova y Arzobispo de Sevilla istoria de su apostólica vida y prodigiosa muerte (Madrid I676).

LüNIG, Johann Christian: Theatrum ceremoniale historico-politicum, 2 Bde. (Leipzig I7I9-I720).

Luther, Martin: An den christlichen Adel deutscher Nation von des christlichen Standes Besserung, I520, bearbeitet von Blaschke, Karlheinz (Luther, Martin, Studienausgabe, hg. von Delius, Hans-Ulrich, Bd. 2, Leipzig I982).

Mantuano, Pedro: Casamientos de Espańa y Francia, y viage del Duque de Lerma llevando la Reyna Christianíssima Doña Ana de Austria al paso de Beobia, y trayendo la princesa de Asturias nuestra señora (Madrid 16ı8).

Marqués de Careaga, Gutierre: Invectiva en discursos apologéticos contra el abuso público de las guedejas (Madrid I637). 
Martínez de Mata, Francisco: Memorial en razón de la despoblación, i65o. In: Anes, Gonzalo: Memoriales y discursos de Francisco Martínez de Mata (Madrid i97I), S. 287-330.

Martínez Salazar, Antonio: Colección de memorias, y noticias del gobierno general, y político del Consejo (Reproduktion der I. Auflage, Madrid I764, Madrid 2002).

Matute y Gaviria, Justino: Noticias relativas á la Historia de Sevilla que no constan en sus anales, recogidas de diversos impresos y manuscritos (Sevilla I886).

Menčık, Ferdinand: Ferdinand Bonaventura Graf Harrach: Tagebuch über den Aufenthalt in Spanien in den Jahren I673-1674 (Wien I913).

Mercier, Louis-Sebastien: Tableau de Paris (Paris I994, erstmals I78I-I783).

Misson, Maximilien: Nouveau voyage d'Italie, avec un mémoire contenant des avis utiles à ceux qui voudront faire le mesme voyage (La Haye $\left.{ }^{4} \mathrm{I} 7 \mathrm{O} 2\right)$.

Molière: Les Précieuses ridicules (1659).

Monconys, Balthasar de: Les Voyages De Monsieur De Monconys. Quatrieme Partie: En Espagne: Avec une Relation exacte sur la mort du Sultan Hibraim, Traitté pour connoître le poids des Liqueurs, Traitté de l'Algebre, un Recüeil de Poésies, \& un autre de Lettres; \& les Indices pour toutes les 4 Parties: Enrichie de Figures en taille douce (Paris I695).

Morga, Antonio de: Relación hecha por el Dr. Antonio de Morga para S. M. de lo que se le ofrece sobre el estado de las Islas Filipinas, tanto en lo secular como en lo eclesiástico, I598. In: Morga, Antonio de: Sucesos de las Islas Filipinas, hg. von Retana, Wenceslao Emilio (Madrid 1909), S. I-588.

Moryson, Fynes: An Itinerary Containing His Ten Yeeres Travell through the Twelve Dominions of Germany, Bohmerland, Sweitzerland, Netherland, Denmarke, Poland, Italy, Turky, France, England, Scotland \& Ireland, Bd. I (London I6I7, Nachdruck Glasgow 1907).

Mosconi, Natale (Hg.): La nunziatura di Praga di Cesare Speciano (I592-I598) nelle carte inedite vaticane e ambrosiane, 5 Bde. (Brescia 1966-1967).

Mugaburu, Josephe de/Mugaburu, Francisco de: Diario de Lima: I640-I694, hg. von Romero, Carlos A. (Lima 1935).

Muro Orejón, Antonio: Cedulario americano del siglo XVIII. Colección de disposiciones legales indianas desde 1680 a I80o, contenidas en los Cedularios del Archivo General de Indias, 3 Bde. (Publicaciones de la Escuela de Estudios Hispano-Americanos de Sevilla 99, I85 und 242, Sevilla 1956-1977).

Narbona, Eugenio de: Doctrina política civil, escrita por Aphorismos: sacados de la doctrina de los Sabios, y exemplos de la experiencia (Madrid I62I).

NeIner, Johann [Valentin]: Vienna curiosa \& gratiosa, oder deß anjetzo lebende Wienn, Teil 3 (I72I). 
Nieto Nuño, Miguel (Hg.): Diario del Conde Pötting, Embajador del Sacro Imperio en Madrid (I664-I674), 2 Bde. (Madrid I990-I993).

Noticias de Madrid. I621-I627, hg. von González Palencia, Ángel (Madrid 1942).

Novísima Recopilación (Madrid 1775 und I805).

Novoa, Matías de: Historia de Felipe III, rey de España. In: Fernández de Navarrete, Martín/Salvá, Miquel/Sáinz de Baranda, Pedro: Colección de Documentos Inéditos para la Historia de España, II3 Bde. (Madrid I842-I895), Bd. 6I.

Nueva Recopilación (Madrid I775).

Núñez de Pineda y Bascuñán, Francisco: Cautiverio feliz, hg. von Podestá, Mario Federico/Kordic Riquelme, Raïssa, 2 Bde. (Biblioteca antigua chilena 5, Santiago de Chile 200I).

Nuntiaturberichte aus Deutschland, I. Abt.: I533-I559, Bd. I6: GoEtz, Helmut (Bearb.): Nuntiatur des Girolamo Martinengo (I550-I554) (Tübingen 1965).

Nuntiaturberichte aus Deutschland nebst ergänzenden Aktenstücken, 3. Abt.: 1572-1585, Bd. 8: Neri, Daniela (Bearb.): Nuntiatur Giovanni Dolfins (I575-I576) (Tübingen I997).

Nuntiaturberichte aus Deutschland nebst ergänzenden Aktenstücken, 3. Abt.: 1572-1585, Bd. 9: Koller, Alexander (Bearb.): Nuntiaturen des Giovanni Delfino und des Bartolomeo Portia (I577-I578) (Tübingen 2003).

Nuntiaturberichte aus Deutschland nebst ergänzenden Aktenstücken, 3. Abt.: 1572-1585, Bd. Io: Koller, Alexander (Bearb.): Nuntiaturen des Orazio Malaspina und des Ottavio Santacroce. Interim des Cesare dell'Arena (I578-I58I) (Berlin/Boston 20I2).

Nuntiaturberichte aus Deutschland nebst ergänzenden Aktenstücken I585 (I584)-I590, 2. Abt: Die Nuntiatur am Kaiserhofe, hg. von d. Görres-Gesellschaft, Bd. r: ReichenBerger, Robert (Bearb.): Germanico Malaspina und Filippo Sega (Giovanni Andrea Caligari in Graz) (Paderborn 1905).

Nuntiaturberichte aus Deutschland nebst ergänzenden Aktenstücken I585 (I584)-I590, 2. Abt: Die Nuntiatur am Kaiserhofe, hg. von d. Görres-Gesellschaft, Bd. 2: Schweizer, Joseph (Bearb.): Antonio Puteo in Prag 1587-1589 (Paderborn I9I2).

Nuntiaturberichte aus Deutschland nebst ergänzenden Aktenstücken I585 (I584)-I590, 2. Abt: Die Nuntiatur am Kaiserhofe, hg. von d. Görres-Gesellschaft, Bd. 3: SchweIZER, Josef (Bearb.): Die Nuntien in Prag: Alfonso Visconte I589-I59I, Camillo Caetano I59I-I592 (Paderborn I919).

Nuntiaturberichte aus Deutschland nebst ergänzenden Aktenstücken, 4. Abt.: Siebzehntes Jahrhundert, Bd. 3: Meyer, Arnold Oskar (Bearb.): Die Prager Nuntiatur des Giovanni Stefano Ferreri und die Wiener Nuntiatur des Giacomo Serra (1603-1606) (Berlin 1913). Nuntiaturberichte aus Deutschland nebst ergänzenden Aktenstücken, 4. Abt.: Siebzehntes 
Jahrhundert, Bd. 6: Becker, Rotraut (Bearb.): Nuntiatur des Ciriaco Rocci. Ausserordentliche Nuntiatur des Girolamo Grimaldi. Sendung des P. Alessandro d'Ales (I633I634) (Berlin/Boston 2016).

Olmo, José del: Relación histórica del auto general de fe que se celebró en Madrid este año de I680 (Madrid I820).

PAAs, John Roger: The German Political Broadsheet I600-I700, Bd. 8 (Wiesbaden 2005), Bd. 9 (Wiesbaden 2007).

Pacheco, Joaquín F./Cárdenas, Francisco de/Torres de Mendoza, Luis: Colección de documentos inéditos relativos al descubrimiento, conquista y organización de las antiguas posesiones españolas en América y Oceanía, sacados de los Archivos del Reino, y muy especialmente del de Indias, 42 Bde. (Madrid I864-I884).

Pacheco y de Leyva, Enrique (Hg.): Carlos V y los turcos en I532. La jornada de Viena. Según un manuscrito inédito del siglo XVI existente en la Biblioteca de El Escorial, y otros datos y documentos (Madrid 1909).

Parrino, Domenico Antonio: L'ossequio tributario della fedelissima città di Napoli per le dimostranze giulive nei Regii Sponsali del monarca Carlo secondo colla principessa Maria Anna di Neoburgo [...] (Napoli I690).

PAschetti, Bartolomeo: Del conservare la sanità e del vivere dei genovesi (Genova I602).

PeÑA, Juan Antonio de la: Relación de las fiestas reales, y juegos de cañas, que su Magestad Católica del Rey nuestro señor hizo a los veynte y uno de Agosto deste presente año, para honrar y festejar los tratados desposorios del sereníssimo Príncipe de Gales, con la señora Infanta doña María de Austria, I623. In: Simón DíAz, José, Relaciones breves de actos públicos celebrados en Madrid de I54I a I650 (El Madrid de los Austrias, Reihe: Documentación I, Madrid I982), S. 24I-247.

Pérez del Barrio Angulo, Gabriel: Secretario y consegero de señores y ministros: cargos, materias, cuydados, obligaciones y curioso agricultor de quanto el Gouierno y la Pluma piden para cumplir con ellas (Madrid I645).

Pinheiro da Veiga, Tomé: Fastiginia. Vida cotidiana en la Corte de Valladolid, i605, hg. von Alonso Cortés, Narciso (Valladolid 1973, I. Auflage i9i6).

Piozzi, Hester Lynch: Observations and Reflections made in the course of a journey through France, Italy and Germany (London 1789).

Platynae historici Liber de vita Christi ac omnium pontificum (aa.I-I474), hg. von GAIDA, Giacinto (Rerum Italicarum Scriptores²; III,I, Città di Castello I9I3-I932).

Portugal, Francisco de: Arte de galantería (Lisboa i670).

Pragmática que su magestad manda publicar para que se guarde, execute, y observe la que se publicó el año de I674 sobre la reforma en el Excesso de Trages, Lacayos, y Coches, y otras cosas en esta contenidas (I684). 
Pragmática que su magestad manda publicar, para que se guarde y execute y observe la que se publicó el año de i684 sobre la reformación en el excesso de Trages, Coches, y otras cosas en esta contenidas (I69I).

Pragmática que su Magestad manda publicar sobre la reformación en el excesso de Traxes, lacayos, y coches, y prohibición del consumo de las mercadurías de Francia [...] y otras cosas (I674).

Pragmática sanción, que su magestad manda observar, sobre Trages, y otras cosas (I723).

Pragmática, y nueva orden, cerca de las colgaduras de casas, y hechura de joyas de oro, y piedras, y pieças de plata, y en la forma que se han de hazer labrar, y traer, y otras cosas (I6II).

Pregón general para la gobernación desta corte (Valladolid I6or).

Premática en que se prohibe andar a los hombres en silla de mano (Valladolid I604).

Premática en que se prohíben colgaduras y adereços de casas de brocados, y telas de oro y plata y bordado, y hechura de joyas de oro y pieças de plata, y se da la forma en ella contenida, y se permite traer cuellos de ochava con almidón (I600).

Premática que su Magestad manda publicar sobre conservacion del contravando, revocación de las permissiones, prohibición del uso de las mercaderías, y frutos de los Reynos de Francia, Inglaterra, y Portugal, y reformación de trajes, vestidos, y otras cosas (I657).

Přibram, Alfred Francis/Landwehr von Pragenau, Moritz: Privatbriefe Kaiser Leopold I. an den Grafen F. E. Pötting I662-I673 (Fontes Rerum Austriacarum, 2. Abt., Bde. 56-57, 1903-1904).

Quintana, Gerónimo de: A la muy antigua, noble y coronada villa de Madrid. Historia de su antigüedad, nobleza y grandeza, 2 Bde. (Reproduktion der Auflage Madrid I626, Madrid 1980).

Ramusio, Girolamo: Relazione del Regno di Napoli (Venezia 1597). In: Rullo, Alessandra (Hg.): Tre relazioni del Regno di Napoli composte da diplomatici veneziani (Memofonte 2013), S. 58-105.

Relación de capitulaciones de los señores Marqueses de Toral, y boda del señor Condestable de Castilla, máscara, y acompañamiento de su Magestad. In: Simón DíAz, José: Relaciones breves de actos públicos celebrados en Madrid de I54I a I650 (El Madrid de los Austrias, Reihe: Documentación I, Madrid 1982), S. 294-302.

Relación de la forma en que salió desta Corte, e Imperial Villa de Madrid el Excelentíssimo Sr Marqués de Velada, y Astorga, Mayordomo Mayor de la reyna nuestra señora D. María Luisa de Borbón, en 26 de Setiembre deste año i679. llevando la Real Casa de su Magestad al Viaje de Irún, por la Reyna nuestra Señora (Madrid 1679). 
Relación de la iornada que hizo a España el excelentíssimo señor Príncipe Duque de Montalto, quando vino por virrey, y capitán general del reyno de Valencia, el año M.DC.LII. In: Alenda y Mira, Genaro: Relaciones de solemnidades y fiestas públicas de España, 2 Bde. (Madrid I903), Bd. I, Nr. II28.

Relación de la Jornada de las entregas de las Sereníssimas Señoras Doña Ana Reyna de Françia, y Doña Isabel Prinçesa de España, hechas en los meses de Otubre y Noviembre de este año de i6ıs (I6I5).

Relación que trata de la entrada que su magestad del rey, don Felipe nuestro señor y reina hicieron en la ciudad de Leon con el recibimiento y fiestas que se les hizo, en este año de mil y seiscientos y dos, en primero deste mes de febrero (Sevilla I602).

Relación verdadera de todo lo sucedido el día del Bautismo de la sereníssima Infanta, I638. In: Simón Díaz, José: Relaciones breves de actos públicos celebrados en Madrid de I54I a I650 (El Madrid de los Austrias, Reihe: Documentación I, Madrid I982), S. 45I-453.

Renao, José: Etiquetas de la Corte de Nápoles, hg. von Paz y Meliá, A. In: Revue Hispanique 27 (I912), S. I-284.

Renao, José: Libro donde se trata de los vireyes [...], hg. von Fernández de Navarrete, Eustaquio (Colección de documentos inéditos para la historia de España 23, Madrid I853 und Madrid ${ }^{2}$ I966).

Rinck, Eucharius Gottlieb: Leopolds des Großen, Röm. Käysers, wunderwürdiges Leben und Thaten, aus geheimen nachrichten eröffnet. Der andere druck, um vieles vermehret, 4 Bde. (Leipzig I709).

Rioja, Francisco de: Poesías de Francisco de Rioja corregidas con presencia de sus originales, añadidas e ilustradas con la biografía y la bibliografía del poeta por BARRERA y LEIRAdo, D. Cayetano Alberto de la (Sociedad de Bibliófilos Españoles 2, Madrid I867).

Roubo, Jacques-André, L'art du menuisier (erstmals Paris I769-I782), Bd. 2: La menuiserie des voitures ou des carrosses (Reprint Meylan 1987).

Rufo, Juan: Las seiscientas apotegmas y otras obras en verso, hg. von BlecuA, Alberto (Clásicos Castellanos I70, Madrid 1972).

SaAvedra Fajardo, Diego de: Empresas políticas (I642), hg., eingeleitet und kommentiert von Díez de Revenga, Francisco Javier (Clásicos universales Planeta i6ı, Autores hispánicos, Barcelona 1988).

Sánchez Cantón, Francisco Javier: Inventarios reales. Bienes muebles que pertenecieron a Felipe II, 2 Bde. (Archivo documental español publicado por la Real Academia de la Historia IO-II, Madrid I959).

Santa Cruz, Melchor de: Floresta española, I574, hg. von Cabañas, Maximiliano (Madrid 1996).

SAnuto, Marino: I Diarii, Bd. 20 (Venezia I887). 
S. C.: Documentos históricos pertenecientes al reinado de Felipe IV. Manuscritos inéditos. In: Revista mexicana. Periódico científico y literario I (I835), S. IO7-I2I.

Schickhart von Herrenberg, Heinrich: Beschreibung einer Reiß, welche [...] Friderich Herztog zu Würtemberg unnd Teck, [...] im Jahr I599 [...] auß dem Landt zu Würtemberg, in Italiam gethan (Mömpelgard I602).

SchneIder, Fedor (Hg.): Iohannis abbatis Victoriensis. Liber certarum historiarum, 2 Bde. (Scriptores rerum Germanicarum in usum scholarum ex Monumentis Germaniae Historicis separatim editi, Hannover/Leipzig 1909-1910).

Schoвer, Andrea: Das Inventar des Wolf Rumpf zu Wielroß. Ein Beispiel materieller Kultur des Adels in Österreich unter der Enns im I6. Jahrhundert (ungedr. Diplomarbeit, Universität Wien 2002).

Schramm, Carl Christian: Abhandlung der Porte-Chaises oder Trage-Sänfften durch Menschen oder Thiere, in allen vier Theilen der Welt, nach der Critic, Mechanic, Historie, dem Recht, wie auch Cammer- und Policey-Wesen (Nürnberg 1737).

Schüвler, Johann Jakob: Zweyter Theil / Des Gründlichen Unterrichtes, Der vollständigen Säulen-Ordnung, Nach der heutigen CIVIL-Bau=Kunst (Nürnberg I725-I728).

Schwaighofer, E.: Auszüge aus den Hofzahlamtsrechnungen in der Nationalbibliothek. II. Theil (224-498). In: Jahrbuch der kunsthistorischen Sammlungen in Wien, N. F., Bd. I2 (Wien 1938), S. 227-237.

Segundas tres relaciones diferentes de las que han salido de la Entrada del Duque de Guastala, Embaxador del Rey de Hungría. Nombrando los nombres de los cavalleros, que le salieron a recibir, y joyas que presentó a la Reyna de Ungría. Con las estaciones que anduvo la Reyna Nuestra señora, por el feliz parto que tuvo. Fiestas y Máscaras, que se han hecho al nacimiento, y Bautismo del Príncipe nuestro señor, nombrando por sus nombres las damas, y Grandes de Espańa, que le acompañaron, con las ceremonias de la iglesia. In: Simón DíAz, José: Relaciones breves de actos públicos celebrados en Madrid de I54I a I650 (El Madrid de los Austrias, Reihe: Documentación I, Madrid 1982), S. 379-38I.

Segunda y más verdadera relación del Bautismo del Príncipe de España nuestro señor, Baltasar Carlos Domingo, con todos los nombres de los caballeros, y títulos que ivan en el acompañamiento. In: Simón DíAz, José: Relaciones breves de actos públicos celebrados en Madrid de I54I a I650 (El Madrid de los Austrias, Reihe: Documentación I, Madrid I982), S. 38I-383.

Semler, Alfons (Bearb.): Die Tagebücher des Dr. Johann Heinrich von Pflummern I633I643, hg. vom Badischen Landesarchiv (Beiheft zur Zeitschrift für die Geschichte des Oberrheins Bde. 98-100, 1950-1952).

Sepúlveda, Juan Ginés de: Historia de Carlos V, hg., bearb. und übersetzt von Rodrí- 
guez Peregrina, Elena, mit einer historischen Untersuchung von Cuart Moner, Baltasar, 6 Bde. (Obras completas I, Pozoblanco [Córdoba] I995-20I0).

Simón DíAz, José: Relaciones breves de actos públicos celebrados en Madrid de I54I a I650 (El Madrid de los Austrias, Reihe: Documentación I, Madrid 1982).

Sínodo diocesana del arzobispado de Toledo celebrada en Abril de I682 por el Excelentisímo Señor Don Luis Manuel de Portocarrero añadida con varios edictos (Madrid I849).

SöLTL, Johann Michael von: München mit seinen Umgebungen historisch, topographisch, statistisch dargestellt (München i838).

SorApÁn De Rieros, Juan: Medicina española contenida en proverbios vulgares de nuestra lengua (I6I6), hg. von CAstillo de Lucas, Antonio (Biblioteca clásica de la medicina española i6, Badajoz i99i [Faksimile der Erstausgabe, Madrid I6I6]).

Staat des Käyserl. Hoffs / vom Jahr I706. biß I708. Ehedessen / unter dem Titl Käyserlichen und Königlichen / wie auch Ertz-Hertzoglichen / dan dero Residenz Stadt / Wienn / Staats- u. Stands-Kalender / Mit einem noch nie dergleichen gesehenen Schematismo heraus gegeben. Erster Theil (Wien o.J.).

Staat des Käyserl. Hoffs / von Jahr I709. biß ı7ıo. Ehedessen / unter dem Titl Käyserlichen und Königlichen / wie auch Ertz-Hertzoglichen / dan dero Residenz Stadt Wienn / Staats- u. Stands-Kalender mit einem noch nie dergleichen gesehenen Schematismo, heraus gegeben. Anderter Theil (Wien o.J.).

SteIngress, Norbert: Die Korrespondenz der Republik Genua mit ihren Gesandten am Kaiserhof (1564-1566) (ungedr. Dissertation, Universität Wien 200I).

Stieglecker, Maria: „Wir haben dein gehorsames schreiben empfangen.“ Die Korrespondenz Rudolfs II. mit Johann Khevenhüller, seinem Gesandten in Spanien, I595-I598 (Dissertation, Universität Wien 2002).

StiEve, Gottfried: Hoff-Ceremoniel (Leipzig ${ }^{2}$ I723).

Suardo, Juan Antonio: Diario de Lima: 1629-1634, hg. von Vargas Ugarte, Rubén, 2 Bde. (Lima 1936).

SuÁrez de Deza, Vicente: Romance. In: Borrego Gutiérrez, Esther: Un poeta cómico en la corte: vida y obra de Vicente Suárez de Deza (Teatro del siglo de oro. Estudios de literatura 70, Kassel 2002), S. 26-29.

Suetonius Tranquillus, Caius: Vidas de los doce césares [De vita Caesarum], übersetzt und kommentiert von Agudo Cubas, Rosa María, 2 Bde. (Biblioteca clásica Gredos I67-I68, Madrid 1992).

TALLEMANT DEs RÉAuX, Gédéon: Les historiettes: mémoires pour servir à l'histoire du $\mathrm{I}^{\text {ème }}$ siècle, Bd. 7 (Paris ${ }^{2}$ I840).

Theatrum Europaeum, Bd. 3, 4, 7, I0, 2I (Frankfurt a. M. I670-I738). 
Tipton, Susan (Hg.): Diario del March.e Federico Pallavicino, Inviato Ducale a Monaco I662 Sett.e-Ottobre. Tagebuch des Federico Pallavicino, Gesandter des Herzogs von Parma in München, im September und Oktober I662. Online-Version von 20IO: https://doi.org/IO.II588/artdok.0000I220 (letzter Zugriff: 19.07.2019).

Turba, Gustav (Bearb.): Venetianische Depeschen vom Kaiserhofe (Dispacci di Germania), Bd. 3 (Wien I895).

Valladares de Sotomayor, Antonio: Semanario erudito, que comprende varias obras inéditas críticas, morales [...] y jocosas de nuestros mejores autores antiguos, y modernos, 34 Bde. (Madrid I787-I79I).

Vando del Rey para que se cumpla la pragmática el 8 de marzo de I674 que se había contravenido sobre la reforma de trajes, lacayos y coches, tanto en esta corte como fuera de ella, y para que se ejecuten sentencias a los trangresores (I677).

Venida de Madama Chevrosa a estos reinos, in Cartas de algunos Padres de la Compañía de Jesús sobre los sucesos de la Monarquía entre los años de i634 y i648. In: Memorial histórico español: colección de documentos, opúsculos y antigüedades que publica la Real Academia de la Historia, 50 Bde. (Madrid I85I-I963), Bd. I4, S. 263-266.

Venturini, Elena (Hg.): Le collezioni Gonzaga. Il carteggio tra la corte cesarea e Mantova (I559-1636) (Milano 2002).

Vita Gregors IX. In: Fabre, Paul/Duchesne, Louis (Hg.): Le Liber Censuum de l'Église Romaine, Bd. 2 (Paris I9IO).

Voltelini, Hans von: Urkunden und Regesten aus dem k. und k. Haus-, Hof- und Staatsarchiv (Fortsetzung). In: Jahrbuch der kunsthistorischen Sammlungen des Allerhöchsten Kaiserhauses, Bd. II (I890), S. I-LXXXIII.

Wittelsbach, Adalbert/Maura Gamazo (Duque de Maura), Gabriel: Documentos inéditos referentes a las postrimerías de la Casa de Austria en España, 4 Bde. (Madrid I929-1935).

Wo und wie Ro. Kay. Maiestat und die Kunig von Hungern, Poln und Peham zusammen kumen und zu Wienn eingeritten sendt (o.O. o.J., aber Wien I5I5).

WüHrer, Jakob/Scheutz, Martin: Zu Diensten Ihrer Majestät. Hofordnungen und Instruktionsbücher am frühneuzeitlichen Wiener Hof (Quelleneditionen des Instituts für Österreichische Geschichtsforschung 6, Wien/München 20II).

Yelgo de Vázquez, Miguel: Estilo de servir a Príncipes con exemplos morales para servir a Dios (Madrid I6I4).

Zapata de Chaves, Luis: Miscelánea. In: Memorial histórico español: colección de documentos, opúsculos y antigüedades que publica la Real Academia de la Historia, 50 Bde. (Madrid I85I-1963), Bd. II, S. 33.

ZedLer, Johann Heinrich: Universal-Lexicon, Bd. 33 (Leipzig/Halle I742). 
2 Forschungsliteratur

Addesso, Cristina Anna: „Voler descrivere il sito di Napoli in una lettera non è egli cosa temeraria?" Alcune descrizioni epistolari della città di Napoli tra Quattro e Cinquecento. In: Studi rinascimentali 7 (2009), S. 89-106.

Additionen. Neuerwerbungen des Kunsthistorischen Museums 1990-2008 (Ausstellungskatalog, Milano 2008).

Alisio, Giancarlo/Spinosa, Nicola (Hg.): Vedute Napoletane della Fondazione Maurizio e Isabella Alisio (Napoli 200I).

Álvarez-Ossorio Alvariño, Antonio: El favor real: liberalidad del príncipe y jerarquía de la república (I665-I700). In: Continisio, Chiara/Mozzarelli, Cesare: Repubblica e virtù. Pensiero politico e Monarchia Cattolica fra XVI e XVII secolo (Biblioteca del Cinquecento 67, Roma 1995), S. 393-453.

Амato, Pietro: Museum of the Papal Carriages in the Vatican (Recent Restorations of the Vatican Museums 5, Vatikanstadt 2006).

Ballesteros Rodríguez, Juan: La peste en Córdoba (Colección de estudios cordobeses 24, Córdoba 1982).

BARY, Roswitha von: Henriette Adelaide von Savoyen. Kurfürstin von Bayern (München I980).

BELlONi, Luigi: La carozza nella storia della locomozione (Torino/Milano/Roma I9oI).

Bennassar, Bartolomé: Valladolid au siècle d'Or. Une ville de Castille et sa campagne au $\mathrm{XVI}^{\mathrm{e}}$ siècle (Civilisations et Sociétés 4, Paris 1967).

Berns, Jörg Jochen: Die Herkunft des Automobils aus Himmelstrionfo und Höllenmaschine (Kleine kulturwissenschaftliche Bibliothek 54, Berlin 1996).

Berthod, Bernard/Blanchard, Pierre: Trésors inconnus du Vatican. Cérémonial et liturgie (Paris 200I).

Bessone, Silvana: Le musée national des carrosses Lisbonne (o.O. I993).

Bessone, Silvana: National Coach Museum. Guide (Lissabon 2002).

BıвL, Viktor: Maximilian II. Der rätselhafte Kaiser. Ein Zeitbild (Hellerau bei Dresden 1929).

BILl, Claus Heinrich: Kulturgeschichte der Portechaise. Soziale und kulturelle Aspekte des Sänftenwesens (München 20I3).

Boccardo, Piero: Andrea Doria e le arti (Roma 1989).

Boccardo, Piero: Nota su Gregorio De Ferrari e Filippo Parodi: I progetti per la tomba del doge Francesco Morosini e alcuni inediti. In: Bollettino dei Musei Civici Genovesi 43-45 (gennaio-dicembre 1993), S. 39-52.

Borteux, Martine: Parcours rituels romains à l'époque moderne. In: Visceglia, Maria 
Antonietta/Brice, Catherine (Hg.): Cérémonial et rituel à Rome (XVI $-\mathrm{XIX}^{\mathrm{e}}$ siècle) (Collection de l'École française de Rome 231, Rome i997), S. 27-87.

Böllıng, Jörg: Das Papstzeremoniell der Hochrenaissance. Normierungen - Modifikationen - Revisionen. In: Schmidt, Bernward/Wolf, Hubert (Hg.): Ekklesiologische Alternativen? Monarchischer Papat und Formen kollegialer Kirchenleitung (I5.20. Jahrhundert) (Symbolische Kommunikation und gesellschaftliche Wertesysteme. Schriftenreihe des Sonderforschungsbereichs 496, 42, Münster 2013), S. 273-307.

Borgia, Luigi, u.a.: Le Biccherne. Tavole dipinte delle magistrature senesi (secoli XIIIXVIII) (Roma I984).

Boyer, Jean: Evocation du Vieil Aix. In: Courrier d'Aix, Nr. I795-I797, 7. und 2I. April I979.

Bravo Lozano, Cristina/Quirós Rosado, Roberto (Hg.): En tierra de confluencias: Italia y la Monarquía de Espańa. Siglos XVI-XVII (Valencia 20I3).

BŮŽEK, Václav: Ferdinand von Tirol zwischen Prag und Innsbruck. Der Adel aus den böhmischen Ländern auf dem Weg zu den Höfen der ersten Habsburger (Wien/Köln/Weimar 2009).

CAffiero, Marina: La maestà del papa. Trasformazioni dei rituali del potere a Roma tra XVIII e XIX secolo. In: Visceglia, Maria Antonietta/Brice, Catherine (Hg.): Cérémonial et rituel à Rome (XVI ${ }^{\mathrm{e}}-\mathrm{XIX}{ }^{\mathrm{e}}$ siècle) (Collection de l'École française de Rome 23I, Rome 1997), S. 28I-316.

Cámara Muñoz, Alicia: Pasadizos del Siglo de Oro: la arquitectura del símbolo. In: Revista de Occidente 73 (1987), S. 97-IO8.

Carrozze regali. Cortei di gala di papi, principi e re (Ausstellungskatalog, Reggia di Venaria, Milano 2013).

Castelló Yturbide, Teresa/Martínez del Río de Redo, Marita: Biombos mexicanos (México 1970).

Cataldi Gallo, Marzia: Rosso, oro e nero: colori e simboli di potere nella Repubblica di Genova. In: El siglo de los genoveses (Ausstellungskatalog Genua, Milano I999), S. 78-87.

Catálogo do museu nacional dos coches (Lisboa ${ }^{4}$ I964).

Cavarzere, Marco: Rituale und Zeremonien zu Beginn der Reformation - zwischen Kritik und Innovation. In: Schмidt, Bernward/Wolf, Hubert (Hg.): Ekklesiologische Alternativen? Monarchischer Papat und Formen kollegialer Kirchenleitung (I5.20. Jahrhundert) (Symbolische Kommunikation und gesellschaftliche Wertesysteme. Schriftenreihe des Sonderforschungsbereichs 496, 42, Münster 2013), S. 309-335.

Cervera Vera, Luis: Bienes muebles en el palacio ducal de Lerma (Estudios de Urbanismo, Arquitectura y otras Artes I, Madrid 1967). 
Cervera Vera, Luis: El conjunto palacial de la villa de Lerma (Estudios de Urbanismo, Arquitectura y otras Artes I, Madrid 1967).

Charles-Gaffiot, Jacques: Trônes en majesté. L'Autorité et son symbole (Ausstellungskatalog, Paris 2OII).

Chenot, Beatriz/Chevalier, Maurice: Cuentos recogidos por Juan de Arguijo y otros (Publicaciones de la Excelentísima Diputación Provincial de Sevilla, Sección Literatura 3/2, Sevilla 1979).

Civar, Mauro: La decorazione della Sala del Capitano del Popolo. In: Ferri, Roberta (Hg.), Il Governo di Siena (Siena 2008), S. I29-I62.

Collections patrimoniales de Paris: http://a8o-musees.apps.paris.fr/ (letzter Zugriff: I6.08.2016).

Dannecker, Klaus Peter: Sedia gestatoria. In: Lexikon für Theologie und Kirche, Bd. 9: San bis Thomas (Freiburg/Br. u.a. ${ }^{3} 2000$ ), Sp. 365.

de Beauregard, Alain: Parlement de Toulouse. La société parlementaire au Grand Siècle, les expressions profanes de la commande privée (I6IO-I680 principalement) (ungedr. Dissertation, Universität Toulouse II 200I).

De Cunzo, M. A.: Palazzo Reale di Napoli. In: Il Palazzo Reale di Napoli (Napoli 1995).

Díaz Rodríguez, Antonio José: Las casas del deán don Juan de Córdoba: lujo y clientela en torno a un capitular del Renacimiento. In: Hispania Sacra 6I/I23 (2009), S. 77-IO4.

Diphros. In: Der Neue Pauly, hg. von Cancik, Hubert/Schneider, Helmuth, Bd. 3 (Stuttgart/Weimar 1997), Sp. 682.

DöBerl, Mario: Unterwegs mit dem Tafelgeschirr. Der höfische „Marendwagen“, ein vergessener Fahrzeugtyp der Spätrenaissance. In: Jahrbuch des Kunsthistorischen Museums Wien I3-I4 (2011/I2), S. I62-I75.

Domínguez Ortiz, Antonio: Aspectos del vivir madrileño durante el reinado de Carlos II. In: Anales del Instituto de Estudios Madrileños 7 (I97I), S. 229-252.

Dresken-Weiland, Jutta/Drews, Wolfram: Artikel Kathedra. In: Reallexikon für Antike und Christentum, Bd. 20 (Stuttgart 2004), Sp. 600-682.

Ducastelle, Jean-Pierre: Se déplacer en vinaigrette! Mobilité et transport du $17^{\mathrm{e}}$ au $19^{\mathrm{e}}$ siècle. In: Études et documents du Cercle royal d'histoire et d'archéologie d'Ath et de la région 20 (2009), S. 349-388.

Edelmayer, Friedrich: „Manus manum lavat“. Freiherr Wolf Rumpf zum Wielroß und Spanien. In: Eltz, Erwein H./StrohmeYer, Arno (Hg.): Die Fürstenberger. 800 Jahre Herrschaft und Kultur in Mitteleuropa (Katalog des Niederösterreichischen Landesmuseums, NF 342, Korneuburg 1994), S. 235-252.

Edelmayer, Friedrich/Kohler, Alfred (Hg.): Kaiser Maximilian II. Kultur und Politik im I6. Jahrhundert (Wiener Beiträge zur Geschichte der Neuzeit I9, Wien/München I992). 
Eloga, Erika: Albrecht II. Herzog von Österreich. Eine Monographie (ungedr. Dissertation, Universität Wien 1952).

Емісн, Birgit: Besitz ergreifen von der Kirche. Normen und Normkonflikte beim Zeremoniell des päpstlichen Possesso. In: Wassılowsky, Günther/Wolf, Hubert (Hg.): Werte und Symbole im frühneuzeitlichen Rom (Symbolische Kommunikation und gesellschaftliche Wertesysteme. Schriftenreihe des Sonderforschungsbereichs 496, II, Münster 2005), S. 83-99.

Enciso Alonso-Muñumer, Isabel: Linaje, poder y cultura. El virreinato de Nápoles a comienzos del XVII. Pedro Fernández de Castro, VII conde de Lemos (ungedr. Dissertation, Universidad Complutense de Madrid 2002).

Evans, R(obert) J. W.: Rudolf II and his World. A Study in Intellectual History 1576-I6I2 (Oxford I973); gekürzte Übersetzung ins Deutsche: DERs.: Rudolf II. Ohnmacht und Einsamkeit (Graz/Wien/Köln I980).

FAgioli, Marcello: La festa a Roma dal Rinascimento al I870 (Torino 1997).

Felipe II un monarca y su época. Un príncipe del Renacimiento (Ausstellungskatalog, Madrid 1998).

Firpo, Massimo/Biferali, Fabrizio: „Navicula Petri“. L'arte dei Papi nel Cinquecento (Roma 2009).

Fosi, Irene: Court and City in the Ceremony of the Possesso in the Sixteenth Century. In: Signorotto, Gianvittorio/Visceglia, Maria Antonietta (Hg.): Court and Politics in Papal Rome, I492-I700 (Cambridge 2002), S. 3I-52.

Fraenger, Wilhelm: Altdeutsches Bilderbuch. Hans Weiditz und Sebastian Brant (Leipzig I930).

FranZL, Johann: Ferdinand II. Kaiser im Zwiespalt der Zeit (Graz/Wien/Köln ${ }^{2}$ I989).

Freire, Luciano: Museu Nacional dos côches. Catálogo descritivo e ilustrado (Lisboa ${ }^{2}$ I 928$)$.

Fubini, Riccardo: Flavio Biondo. In: Dizionario Biografico degli Italiani, Bd. Io (Roma I968), S. 536-559.

Furger, Andres: Die Kutschensammlung Heinz Scheidel Mannheim. Der Überblick: Fuhrwerke, Wagen, Reiten, Accessoires und Dokumente (Mannheim 20II).

Furger-Gunti, Andres: Kutschen und Schlitten aus dem alten Basel (Basel 1982).

Galán Domingo, Eduardo: El carruaje ceremonial y ciudadano en Espańa: de I700 al triunfo del automóvil. In: Historia del Carruaje in Espana (o.O. 2002).

GÁlvez, José: Estampas limeñas (Lima 1966).

GARRY, Mary Anne: Sedan chairmen in eighteenth-century London. In: The Journal of Transport History 37/I (2016), S. 45-63. 
Garzón Pareja, Manuel: Diezmos y tributos del clero de Granada (Granada 1974).

GatT, Anneliese: Der Innsbrucker Hof zur Zeit Kaiser Maximilians I. I493-I5I9 (ungedr.

Dissertation, Universität Innsbruck 1943).

Gausseran, Marcel: Létat sanitaire de Montauban en I7I2. In: Bulletin Archéologique et Historique de la Société Archéologique de Tarn-et-Garonne 84 (1958), S. 92-99.

Ginzrot, Johann Christian: Die Wagen und Fahrwerke der Griechen und Römer und anderer alten Völker nebst der Bespannung, Zäumung und Verzierung ihrer Zug-, Reitund Last-Thiere, 2 Bde. (München I8r7, Nachdruck Hildesheim/New York 1975).

Ginzrot, Johann Christian: Die Wagen und Fahrwerke der verschiedenen Voelker des Mittelalters und der Kutschen-Bau neuester Zeiten nebst der Bespannung, Zäumung und Verzierung ihrer Zug-, Reit- und Last-Thiere, 2 Bde. (München I830, Nachdruck Hildesheim/New York 1979).

Glorias efímeras. Las exequias florentinas de Felipe II y Margarita de Austria (Ausstellungskatalog, Madrid 1999).

GodART, Louis (Hg.): Le carrozze del Quirinale (Ancona 2009).

GonZalez-Palacios, Alvar: Il mobile in Liguria (Genova 1996).

GonzÁlez Sánchez, Carlos Alberto: Dineros de ventura: la varia fortuna de la emigración a Indias (siglos XVI-XVII) (Universidad de Sevilla, Geografía e historia 9, Sevilla 1995).

Göres, Burkhardt: Berliner Prunkschlitten, Kutschen und Sänften des Barock, Berlin, Kunstgewerbemuseum (1987).

Grendi, Edoardo (Hg.): Inventione di Giulio Pallavicino di scriver tutte le cose accadute alli tempi suoi (1583-1589) (Genova 1975).

Grosso, Orlando: Le carrozze a Genova. In: Genova 22/I2 (I942).

Grosz, August: Führer durch die Wagenburg in Schönbrunn (Wien 193I).

Gugitz, Gustav: Die Sesselträger in Alt-Wien. In: Jahrbuch des Vereines für Geschichte der Stadt Wien 8 (1949/50), S. 94-IO4.

Guiard y Larrauri, Teófilo: Historia de la noble villa de Bilbao (I300-I60o), Bd. I (Bilbao I905).

Gussone, Nikolaus: Thron und Inthronisation des Papstes von den Anfängen bis zum I2. Jahrhundert. Zur Beziehung zwischen Herrschaftszeichen und bildhaften Begriffen, Recht und Liturgie im christlichen Verständnis von Wort und Wirklichkeit (Bonner Historische Forschungen 4I, Bonn 1978).

HACK, Achim Thomas: Das Empfangszeremoniell bei mittelalterlichen Papst-Kaiser-Treffen (Forschungen zur Kaiser- und Papstgeschichte des Mittelalters. Beihefte zu J. F. Böhmer, Regesta Imperii I8, Köln/Weimar/Wien 1999).

Haidacher, Anton: Geschichte der Päpste in Bildern (Heidelberg 1965).

Ham, Claudia: Die verkauften Bräute. Studien zu den Hochzeiten zwischen österreichi- 
schen und spanischen Habsburgern im 17. Jahrhundert, 2 Bde. (ungedr. Dissertation, Universität Wien 1995).

Haupt, Herbert: Der „goldene Wagen“ der österreichischen Herzogin Katharina (I420I493). In: Livrustkammaren I4/7-8 (1977), S. I73-194.

Haupt, Herbert: Das Hof- und hofbefreite Handwerk im barocken Wien I620 bis I770.

Ein Handbuch (Forschungen und Beiträge zur Wiener Stadtgeschichte 46, Innsbruck/ Wien/Bozen 2007).

Hausladen, Armin/Kreisel, Heinrich (Bearb.): Marstallmuseum in München. Hofwagenburg und Sattelkammer. Kleiner Führer, hg. von Hofmann, Friedrich H., Direktion der Museen und Kunstsammlungen des ehemaligen Krongutes in Bayern (München 1923).

Hautsch, Ernst: Der Nürnberger Zirkelschmied Johann Hautsch (I595-I670) und seine Erfindungen. In: Mitteilungen des Vereins für Geschichte der Stadt Nürnberg 46 (I955), S. 533-556.

Havard, Henry: Dictionnaire de l'ameublement et de la décoration. Depuis le XIII ${ }^{e}$ siècle jusqu'à nos jours, 4 Bde. (Paris 1894).

Helas, Philine: Der Triumph von Alfonso d'Aragona I443 in Neapel. Zu den Darstellungen herrscherlicher Einzüge zwischen Mittelalter und Renaissance. In: JoHANEK, Peter/ Lampen, Angelika (Hg.): Adventus. Studien zum herrscherlichen Einzug in die Stadt (Köln/Weimar/Wien 2009), S. I33-228.

Hengerer, Mark: Die letzten Lebensjahre, Krankheit und Tod Kaiser Ferdinands III. (I608-I657). In: Frühneuzeit-Info I8/I-2 (2007), S. 24-38.

Hengerer, Mark: Kaiser Ferdinand III. (I608-1657). Eine Biographie (Veröffentlichungen der Kommission für Neuere Geschichte Österreichs I07, Wien/Köln/Weimar 2012).

Hirn, Josef: Erzherzog Ferdinand II. von Tirol. Geschichte seiner Regierung und seiner Länder, 2 Bde. (Innsbruck I885-I888).

Hirn, Josef: Erzherzog Maximilian der Deutschmeister. Regent von Tirol, 2 Bde. (Innsbruck 1915-1936).

HöвELT, Lothar: Ferdinand III. Friedenskaiser wider Willen (Graz 2008).

HöDL, Günther: Albrecht II. Königtum, Reichsregierung und Reichsreform I438-I439 (Forschungen zur Kaiser- und Papstgeschichte des Mittelalters. Beihefte zu J. F. Böhmer, Regesta Imperii 3, Wien/Köln/Graz 1978).

HöDL, Günther: Habsburg und Österreich I273-I493. Gestalten und Gestalt des österreichischen Spätmittelalters (Wien/Köln/Graz 1988).

Hoensch, Jörg K.: Kaiser Sigismund. Herrscher an der Schwelle zur Neuzeit I368-I437 (München 1996). 
Hoorn, Esther van der: A Seventeenth-Century Drawing for a Chaise à Porteurs. In: The Rijksmuseum Bulletin 64/2 (2016), S. IOO-II9.

Hörber, Fritz: Auf Kufen und Rädern. Die Geschichte des Krankentransports und der Krankenfahrzeuge (München 1976).

Howe, Eunice D.: Art and Culture at the Sistine Court. Platina’s „Life of Sixtus IV“ and the Frescoes of the Hospital of Santo Spirito (Studi e Testi 422, Città del Vaticano 2005).

Hruza, Karel/KaAr, Alexandra (Hg.): Kaiser Sigismund (I368-I437). Zur Herrschaftspraxis eines europäischen Monarchen (Forschungen zur Kaiser- und Papstgeschichte des Mittelalters. Beihefte zu J. F. Böhmer, Regesta Imperii 3I, Wien/Köln/Weimar 20I2).

Hurter, Friedrich von: Geschichte Ferdinands II. und seiner Eltern, II Bde. (Schaffhausen I850-I864).

Hütтl, Ludwig: Max Emanuel. Der Blaue Kurfürst I679-I726. Eine politische Biografie (München 1976).

Janowitz, Esther: Textile Pracht und höfisches Zeremoniell. In: Rudolstädter Forschungen zur Residenzkultur, Bd. 3: Zeichen und Raum (München 2006), S. 325-350.

Juderías, Julián: España en tiempo de Carlos II el Hechizado (Madrid I9I2).

Jufrè del Aguila, Melchor: Compendio historial del descubrimiento i conquista del Reino de Chile seguido de dos discursos: Avisos prudenciales de Govierno i Guerra, de la Astrología judiciaria (Santiago de Chile i897).

Kamen, Henry: Felipe de España (Madrid 1997 [I. Auflage auf Spanisch]).

Katalog der Kaiserin-Maria-Theresia-Ausstellung (Wien ${ }^{2}$ I888).

Keller, Katrin: Hofdamen. Amtsträgerinnen im Wiener Hofstaat des I7. Jahrhunderts (Wien/Köln/Weimar 2005).

Kirillova, Lyubov: Royal Carriages. Treasures of the Armoury (Moskau 2000).

KNORR, Burgi: Die Wahl und Krönung Rudolphs II. zum Römischen König 1575. In: MöSENEDER, Karl (Hg.): Feste in Regensburg. Von der Reformation bis in die Gegenwart (Regensburg 1986), S. I24-I27.

Knorr, Burgi: Die Wahl von Ferdinand III. zum Römischen König I636. In: Möseneder, Karl (Hg.): Feste in Regensburg. Von der Reformation bis in die Gegenwart (Regensburg 1986), S. I75-I78.

KoHLer, Alfred: Ferdinand I. I503-I564. Fürst, König und Kaiser (München 2003).

Koller, Gerda: Princeps in Ecclesia. Untersuchungen zur Kirchenpolitik Herzog Albrechts V. von Österreich (Archiv für österreichische Geschichte I24, Graz/Wien/Köln 1964).

Kordic Riquelme, Raïssa/Goic, Cedomil: Testamentos coloniales chilenos (Biblioteca indiana 5 / Biblioteca antigua chilena 6, Madrid/Frankfurt a. M. 2005). 
Kreisel, Heinrich: Die Kunst des deutschen Möbels. Bd. 2: Spätbarock und Rokoko (München 1970).

Kreuzer, Georg: Sedia (Sella) gestatoria. In: Lexikon des Mittelalters, Bd. 7: Planudes bis Stadt (Rus') (München I995), Sp. I665 f.

Krischer, Markus: Der Mann aus Babadag. Wie ein türkischer Janitschar I683 nach München verschleppt und dort fürstlicher Sänftenträger wurde (Darmstadt 20I4).

KryZA-Gersch, Friedrich/Ruck, Barbara: Ave Claudia Imperatrix. Die Vermählung Kaiser Leopolds I. mit Erzherzogin Claudia Felicitas von Tirol in Graz I673. Schloß Eggenberg als Residenz der kaiserlichen Braut (Ausstellungskatalog, Veröffentlichungen der Abteilung Schloß Eggenberg 3, Graz 1983).

KuвisKa, Irene: „Und ist wegen dieser so glückhlich- und trostreichen geburth ein allgemeines frolockhen und grosse freydt gweesen“. Das Geburten- und Taufzeremoniell am Wiener Hof im Zeitraum von I652 bis I80o. In: PANgerl, Irmgard/Scheutz, Martin/ Winkelbauer, Thomas (Hg.): Der Wiener Hof im Spiegel der Zeremonialprotokolle (1652-1800). Eine Annäherung (Forschungen zur Landeskunde von Niederösterreich 3I / Forschungen und Beiträge zur Wiener Stadtgeschichte 47, Innsbruck/Wien/Bozen 2007), S. 493-527.

Kubiska, Irene: Der kaiserliche Hof- und Ehrenkalender zu Wien als Quelle für die Hofforschung. Eine Analyse des Hofpersonals in der Epoche Kaiser Karls VI. (I7II-I740), 2 Bde. (ungedr. Diplomarbeit, Universität Wien 2009).

Kubiska-Scharl, Irene/Pölzl, Michael: Die Karrieren des Wiener Hofpersonals I7III765. Eine Darstellung anhand der Hofkalender und Hofparteienprotokolle (Forschungen und Beiträge zur Wiener Stadtgeschichte 58, Innsbruck/Wien/Bozen 2013).

Kugler, Georg: Die Wagenburg in Schönbrunn. Hofwagenburg, Reiche Sattel- und Geschirrkammer der Kaiser von Österreich (Graz 1977).

Kurfürst Max Emanuel. Bayern und Europa um I700, 2 Bde. (Ausstellungskatalog, München 1976).

Kurzel-Runtscheiner, Monica: Die historischen Fahrzeuge der Schausammlung. In: Bresciani, Elisabetta/Kurzel-Runtscheiner, Monica/Samsonow, Elisabeth von (Hg.): Schwanenhals und Goldkrepine. Höfischer Prunk und zeitgenössische Kunst eine Konfrontation (Ausstellungskatalog, KHM, Wagenburg 2004), S. 89-105.

Kurzer Führer durch die k. und k. Hofmarställe (o.O., o.J., aber Wien 1906).

Labrador Arroyo, Félix/López Álvarez, Alejandro: Lujo y representación en la Monarquía de los Austrias: la configuración del ceremonial de la caballeriza de las reinas, 1570-1600. In: Espacio, Tiempo y Forma. Historia Moderna 23 (2012), S. 19-39.

La chaise à porteurs du château de Marsillargues, hg. von d. Direction régionale des affai- 
res culturelles (DRAC) du Languedoc-Roussillon / Conservation régionale des monuments historiques (CRMH) (Montpellier 2OI2).

Ladner, Gerhart B.: Die Papstbildnisse des Altertums und des Mittelalters, 3 Bde. (Città del Vaticano I94I, I970, I984).

La Gorce, Jérôme de: Berain. Dessinateur du Roi Soleil (Paris 1986).

Langer, Brigitte/Württemberg, Alexander Herzog von (Bearb.): Die deutschen Möbel des I6. bis I8. Jahrhunderts (Die Möbel der Residenz München 2, München/New York 1996).

Lectica. In: Paulys Realencyclopädie der classischen Altertumswissenschaft. Neue Bearbeitung begonnen von Wissowa, Georg, Bd. XII, I (23. Halbband, Stuttgart 1924), Sp. IO56-II28.

Leonardo de Argensola, Bartolomé: Sátira del incógnito. In: Cortés VÁzQuez, Luis: La vida estudiantil en la Salamanca clásica (Salamanca 1996), S. 23.

Levati, Luigi: I dogi di Genova e Vita genovese (dal I746 al I77I) (Genova 1915).

Levillain, Philippe: Sedia gestatoria. In: Ders. (Hg.): Dictionnaire historique de la papauté (Paris 1994), S. I559 f.

Lнотsку, Alphons: Festschrift des Kunsthistorischen Museums zur Feier des fünfzigjährigen Bestandes, 2 Bde. (Wien I94I-I945).

Lнотsкy, Alphons: Geschichte Österreichs seit der Mitte des I3. Jahrhunderts (I28I-I358) (Veröffentlichungen der Kommission für Geschichte Österreich I, Wien 1967), S. 3IO375.

Libourel, Jean-Louis: Une chaise à porteur du XVIII ${ }^{\text {meme }}$ siècle enrichit le Musée Georges Borias à Uzès. In: Uzès. Musée vivant 46 (2012), S. I5-24.

Lindner, Christine: Die Krönung Ferdinands III. zum Römischen König I636. In: MöSENEDER, Karl (Hg.): Feste in Regensburg. Von der Reformation bis in die Gegenwart (Regensburg I986), S. I79-I83.

Lohman Villena, Guillermo/Vila Vilar, Enriqueta: Juana de Rojas: una mujer emigrante empresaria y matriarca del siglo XVII. In: Gonzalbo Aizpuru, Pilar/Ares Queija, Berta (Hg.): Las mujeres en la construcción de las sociedades iberoamericanas (Sevilla/ México 2004), S. 87-IOI.

López Álvarez, Alejandro: Carricoche. In: Alvar, Carlos (Hg.): Gran Enciclopedia Cervantina, bisher Io Bde. (Madrid 2005-2017), Bd. 2, S. I892-1895.

López Álvarez, Alejandro: Sillas de mano. In: Alvar, Carlos (Hg.): Gran Enciclopedia Cervantina, bisher Io Bde. (Madrid 2005-2017). Im Druck.

López Álvarez, Alejandro: Coches, carrozas y sillas de manos en la Monarquía de los Austrias entre I600 y I700: evolución de la legislación. In: Hispania 66/224 (2006), S. 883-908. 
López Álvarez, Alejandro: Poder, lujo y conflicto en la Corte de los Austrias. Coches, carrozas y sillas de mano, I550-I700 (Madrid 2007).

López Álvarez, Alejandro: Los vehículos representativos en la configuración de la Corte virreinal: México y Lima, I590-I700. In: García SAnto-Tomás, Enrique (Hg.): Materia crítica: formas de ocio y de consumo en la cultura áurea (Biblioteca áurea hispánica 58, Madrid/Frankfurt a. M. 2009), S. 269-29I.

López Álvarez, Alejandro: El oficio de cochero en la sociedad cortesana a comienzos del siglo XVII: disciplina e integración social. In: Bravo Caro, Juan Jesús/SAnz SAmpeLAYO, Juan (Hg.): IX Reunión Científica de la Fundación Española de Historia Moderna. Universidad de Málaga, 2 Bde. (Málaga 2009), Bd. 2, S. 903-92I.

López Állvarez, Alejandro: La introducción de los coches en la corte hispana y el Imperio. Transfers tecnológicos y culturales, I550-I580. In: MARTínez Millán, José/GonZÁLEZ Cuerva, Rubén (Hg.): La dinastía de los Austria: las relaciones entre la Monarquía Católica y el Imperio, 3 Bde. (Madrid 20II), Bd. 3, S. I885-I928.

López Álvarez, Alejandro: Some reflections on the ceremonial and image of the kings and queens of the House of Habsburg in the sixteenth and seventeenth centuries. In: Vermeir, René/Raeymaekers, Dries/Hortal Muñoz, José Eloy (Hg.): A Constellation of Courts. The Courts and Households of Habsburg Europe, 1555-1665 (Avisos de Flandes I5, Leuven 2014), S. 267-32I.

López Álvarez, Alejandro: Algunas notas sobre La ronda de pan y huevo de Luis Tristán (I624) y su copia anónima (I660). In: Laboratorio de Arte 3I (2019), S. 287-304.

López NovoA, Saturnino: Historia de la muy noble y muy leal ciudad de Barbastro y descripción geográfico-histórica de su diócesis, 2 Bde. (Faksimile der Ausgabe von Barcelona I86I, Barbastro 198I).

López Pérez, María del Pilar: El objeto de uso en las salas de las casa de habitación de españoles y criollos en Santafé de Bogotá. Siglos XVII y XVIII en el Nuevo Reino de Granada. In: Anales del Instituto de Investigaciones Estéticas 2I/74-75 (I999), S. 99-I34.

Maggiani, Marie: La parade citadine aux $17^{\text {ème }}$ et I $8^{\text {ème }}$ siècles. Enquête méridionale sur la chaise à porteurs (ungedr. Dissertation, Universität Toulouse II 2007).

Maggiani, Marie: Les belles oubliées de la carrosserie: les chaises à porteurs. In: SAUle, Béatrix/Libourel, Jean-Louis/Delalex, Hélène (Hg.): Roulez carrosses! Le château de Versailles à Arras (Ausstellungskatalog, Paris 20I2).

Magnani, Lauro: L'intaglio tra apparato e statuaria: l'idea di scultura di Filippo Parodi. In: La scultura a Genova e in Liguria dal Seicento al primo Novecento (Genova 1988), S. I27-I34.

Mainfränkisches Museum Würzburg. Neuerwerbungen 1973-I978 (Würzburg 1978). 
Majorca Mortillaro, Luigi Maria: Letthige, portantine e personaggi del Settecento. Ricerche storico-artistiche (Palermo ${ }^{3}$ I906, erstmals Palermo i897).

Manso Porto, Carmen: Don Diego Sarmiento de Acuña, conde de Gondomar (I567I626). Erudito, mecenas y bibliófilo (Santiago de Compostela 1996).

Martínez Millán, José/Fernández Conti, Santiago (Hg.): La monarquía de Felipe II: la casa del rey, 2 Bde. (Madrid 2005).

MärtL, Claudia: Papst Pius II. (I458-I464) in der Kapelle des Palazzo Medici Riccardi zu Florenz. Ein Beitrag zu Ikonographie und Zeremoniell der Päpste in der Renaissance. In: Concilium medii aevi. Zeitschrift für Geschichte, Kunst und Kultur des Mittelalters und der Frühen Neuzeit 3 (2000), S. I55-183.

MärTL, Claudia: Alltag an der Kurie: Papst Pius II. (I458-I464) im Spiegel zeitgenössischer Berichte. In: Martels, Zweder von/Vanderjagt, Arjo (Hg.): „Pius II, el più expeditivo pontifice“. Selected Studies on Aeneas Silvius Piccolomini (I405-I464) (Leiden/Boston 2003), S. 107-I45.

Märtl, Claudia: Pius II. (I458-I464), Offensive und defensive Strategien seiner Selbstdarstellung als Papst. In: Matheus, Michael/Kuinkhammer, Lutz (Hg.): Eigenbild im Konflikt. Krisensituationen des Papsttums zwischen Gregor VII. und Benedikt XV. (Darmstadt 2009), S. 63-87.

Maura Gamazo, Gabriel: Carlos II y su corte, 2 Bde. (Madrid i9II-I9I5).

Meckel, Claudia: Kutschen, Schlitten, Sänften (Stiftung Preußische Schlösser und Gärten Berlin-Brandenburg, Bestandskatalog der Kunstsammlungen, Berlin 2013).

Merli, A[ntonio]: Gio. Andrea III Doria Landi e Anna Panfili (Nozze Giglioli Masi) (Genova I87I).

Merli, A[ntonio]/Belgrano, L[uigi] T[ommaso]: Il Palazzo del Principe Doria (Genova I874).

Metz, Jörg Heinrich: Inventarverzeichnis der Metz v. Tessin’schen Kutschensammlung (Tübingen 2002).

Millán, Augusto: Historia de la minería del oro en Chile (Santiago de Chile 200r).

Molina, Raúl A.: Antón Higueras de Santana. El andaluz de las cuatro estancias. Vecino fundador de Buenos Aires. In: Genealogía. Revista del Instituto Argentino de Ciencias Genealógicas I2 (1957), S. 2I-46.

Molina, Raúl A.: Historia de los divorcios en el período hispánico. La familia porteña en los siglos XVII y XVIII (Buenos Aires I99I).

Montemayor, Julián: Una ciudad frente a la peste: Toledo a fines el XVI. In: Sáez, Emilio/Segura Graíño, Cristina/Cantera Montenegro, Margarita (Hg.): La Ciudad hispánica durante los siglos XIII al XVI. Actas del coloquio celebrado en La Rábida y Sevilla del I4 al I9 de septiembre de I98I, 3 Bde. (Madrid I985-I987). 
Morazzoni, Giuseppe: Carrozze e portantine a Napoli nel '700. In: Dedalo. Rassegna d'arte 8/3 (I927/28), S. 752-78I.

Moroni, Gaetano: Lectica. In: DERs.: Dizionario di erudizione storico-ecclesiastica, Bd. 38 (Venezia I846), S. I47-I52.

Moroni, Gaetano: Sedia e sedie de' papi. In: Ders.: Dizionario di erudizione storico-ecclesiastica, Bd. 63 (Venezia I853), S. I95.

Moulin, Jean-Marie: Guide du musée national du château de Compiègne (Paris I992).

Mraz, Gerda: Albrecht IV. In: Hamann, Brigitte (Hg.): Die Habsburger. Ein biographisches Lexikon (Wien I988), S. 38 f.

MüLLER, Richard: Wiens höfisches und bürgerliches Leben im ausgehenden Mittelalter. In: Geschichte der Stadt Wien, hg. vom Alterthumsvereine zu Wien, Bd. II/2 (Wien 1907), S. 626-757.

Murray, Hugh: Sedan Chairs in York. In: York Historian 17 (2000), S. 30-45.

Navarrete, María Cristina: Génesis y desarrollo de la esclavitud en Colombia. Siglos XVI y XVII (Cali 2005).

Niederstätter, Alois: Die Herrschaft Österreich. Fürst und Land im Spätmittelalter (Österreichische Geschichte I278-I4II, Wien 200I).

NiEto SÁnchez, José Antolín: Artesanos y mercaderes. Una historia social y económica de Madrid, I450-I850 (Ciencia 297, Serie „Sociología“, Madrid 2006).

Noflatscher, Heinz: Glaube, Reich und Dynastie. Maximilian der Deutschmeister (I558-I6I8) (Quellen und Studien zur Geschichte des Deutschen Ordens II, Marburg I987).

Ottillinger, Eva B.: Kaiserliches Hofmobiliendepot (Wien 2000).

Pacheco Bustillos, Adriana: Historia del Convento del Carmen Alto (Quito 2000).

Pagano, Denise Maria (Hg.): Museo delle carrozze a Villa Pignatelli (Napoli 20I4).

Pangerl, Irmgard/Scheutz, Martin/Winkelbauer, Thomas (Hg.): Der Wiener Hof im Spiegel der Zeremonialprotokolle (I652-1800). Eine Annäherung (Forschungen zur Landeskunde von Niederösterreich 3г / Forschungen und Beiträge zur Wiener Stadtgeschichte 47, Innsbruck/Wien/Bozen 2007).

Paravicini Bagliani, Agostino: Il corpo del papa (Torino 1994). Deutsche Übersetzung: DERs.: Der Leib des Papstes. Eine Theologie der Hinfälligkeit (München 1997).

Paravicini Bagliani, Agostino: La mobilità della corte papale nel secolo XIII. In: CAROCCI, Sandro (Hg.): Itineranza pontificia. La mobilità della curia papale nel Lazio (secoli XII-XIII) (Nuovi studi storici 6I, Roma 2003), S. 3-78.

Paravicini Bagliani, Agostino: Le Chiavi e la Tiara. Immagini e simboli del papato medievale. Nuova edizione riveduta e aggiornata (Roma 2005). 
Paravicini Bagliani, Agostino: Der Papst auf Reisen im Mittelalter. In: Ders.: Il potere del papa. Corporeità, autorappresentazione, simboli (Firenze 2009), S. 315-333.

Paravicini Bagliani, Agostino: Morte e elezione del papa. Norme, riti e conflitti. Il Medioevo (La corte dei papi 23, Roma 20I3).

Pauly, Michel/Reinert, François (Hg.): Sigismund von Luxemburg. Ein Kaiser in Europa. Tagungsband des internationalen historischen und kunsthistorischen Kongresses in Luxemburg, 8.-IO. Juni 2005 (Mainz 2006).

PaZ y Meliá, Antonio de: Un jurisconsulto del siglo XVI pintado por el mismo. Extractos de la autobiografía del Lic. Gregorio Tovar y Pizarro, su ascendencia y descendencia. In: Revista de Archivos, Bibliotecas y Museos I2 (1908), S. I8-36.

Pellegrini, Marco: Leone X. In: Enciclopedia dei papi, Bd. 3 (Roma 2000), S. 42-64.

Pfandl, Ludwig: Felipe II. Bosquejo de una vida y de una época (Madrid I942; Originalausgabe: Philipp II. Gemälde eines Lebens und einer Zeit [München 1938]).

Piendl, Max: Der fürstliche Marstall in Regensburg (Thurn und Taxis-Studien 4, Kallmünz I966).

Pietrangeli, Carlo: Die Gemälde des Vatikan (München i996).

Pillich, Walter: Königin Katharina von Polen in Linz. In: Historisches Jahrbuch der Stadt Linz 1966 (1967), S. I69-I98.

Pils, Susanne Claudine: Schreiben über Stadt. Das Wien der Johanna Theresia Harrach I639-I716 (Forschungen und Beiträge zur Wiener Stadtgeschichte 36, Wien 2002).

Piro, Nicholas de: The Sedan Chair in Malta - Is-Sugg getta. Great Exhibitions Revisited (Valetta 2007).

Polleross, Friedrich: „Pro decore Majestatis“. Zur Repräsentation Kaiser Leopolds I. in Architektur, Bildender und Angewandter Kunst. In: Jahrbuch des Kunsthistorischen Museums Wien 4/5 (2002/2003), S. I9I-295.

Polo, Lucio: C'era una volta una carrozza ... Il museo delle carrozze della Villa di Maser (Cittadella 1978).

Pons, Rouven: „Wo der gekrönte Löw hat seinen Kayser-Sitz.“ Herrschaftsrepräsentation am Wiener Kaiserhof zur Zeit Leopolds I. (Deutsche Hochschulschriften II95, Egelsbach/Frankfurt a. M./München/New York 200I).

Pribram, Alfred Francis: Die Heirat Kaiser Leopold I. mit Margaretha Theresia von Spanien. In: Archiv für österreichische Geschichte 77 (I89I), S. 319-375.

PRIs, Claude: La manufacture royale des glaces de Saint-Gobain. Une grande entreprise sous l'Ancien Régime (ungedr. Dissertation, Université Lille III 1975).

PRÖlL, Laurenz: Ein Blick in das Hauswesen eines österreichischen Landedelmannes aus dem ersten Viertel des I7. Jahrhunderts. In: 38. Jahres-Bericht über das k. k. Staats- 
gymnasium im VIII. Bezirke Wiens für das Schuljahr I888 (Wien I888), S. 3-47, 39. Jahres-Bericht [...] für das Schuljahr I889 (Wien I889), S. 3-46.

Prosperi Valenti Rodinò, Simonetta: L'immagine degli anni santi nelle stampe. In: La storia dei Giubilei, Bd. 2: I450-1575 (Roma 1997), S. 282-293.

Purroy Turrillas, Carmen: Las ordenanzas de Martín Enríquez de Almansa, virrey de México. In: Memoria del X Congreso del Instituto Internacional de Historia del Derecho Indiano, 2 Bde. (Instituto de Investigaciones Jurídicas, Reihe C, Estudios Históricos 50, México 1995), Bd. 2, S. 1285-1323.

Quintero González, Adriana del Carmen: Repertorio léxico en testamentos merideños del siglo XVII (Mérida 2006).

Raffaelo e il ritratto di papa Leone. Per il restauro del Leone X con due cardinali nella Galleria degli Uffizi (Milano I996).

Raupp, Hans-Joachim: Die Illustrationen zu Francesco Petrarca, „Von der Artzney bayder Glueck des guten vnd widerwertigen“ (Augsburg 1532). In: Wallraf-Richartz-Jahrbuch 45 (I984), S. 59-II2.

Reissinger, Elisabeth/Wackernagel, Rudolf H.: Kutschenmuseum Auerstedt. Die historischen Wagen der Großherzöge von Sachsen-Weimar und Eisenach (Berlin/München 2OII).

RÉTHelYi, Orsolya: „... Maria regina ... nuda venerat ad Hungariam ...“. The Queen’s Treasures. In: Réthelyi, Orsolya/RomhánYi, Beatrix F./Spekner, Enikö/VÉGH, András (Hg.): Mary of Hungary. The Queen and Her Court I52I-I53I (Ausstellungskatalog, Budapest History Museum/Slovenská národná galéria, Budapest 2005), S. I2I-I27.

RÉThelYI, Orsolya: Die Anfänge der Ofener Hofhaltung der Königin Maria von Ungarn. In: Fuchs, Martina/RÉTHeLYI, Orsolya (Hg.): Maria von Ungarn (I505-I558). Eine Renaissancefürstin (Geschichte in der Epoche Karls V. 8, Münster 2007), S. 22I-243.

Rickert, Yvonne: Triumph. In: Handbuch der politischen Ikonographie, hg. von Fleckner, Uwe/Warnke, Martin/Ziegler, Hendrik, Bd. 2: Imperator bis Zwerg (München 20II), S. 456-464.

RILl, Bernd: Kaiser Matthias. Bruderzwist und Glaubenskampf (Graz/Wien/Köln I999).

Río BArredo, María José del: Madrid, urbs regia. La capital ceremonial de la Monarquía Católica (Madrid 2000).

Rio BARredo, María José del: Imágenes para una ceremonia de frontera: el intercambio de las princesas entre las Cortes de Francia y España en I6I5. In: PALOs, Joan Lluís/CARrióInvernizzI, Diana (Hg.): La historia imaginada: construcciones visuales del pasado en la Edad Moderna (Madrid 2008), S. I53-I84.

Rodrigo Zarzosa, Carmen: Carruajes del Palacio de los Marqueses de dos Aguas. Museo Nacional de Cerámica. Catalogo (Valencia I99I). 
Rodrigo Zarzosa, Carmen: Evolución y tipología del carruaje desde i70o. In: Historia del Carruaje in Espana (o.O. 2002).

Rodríguez Pérez, Raimundo A.: Un linaje aristocrático en la España de los Habsburgo: los marqueses de los Vélez (I477-I597) (Dissertation, Universidad de Murcia, 20IO).

Rodríguez Villa, Antonio: Dos viajes regios (I679 y i666). In: Boletín de la Real Academia de la Historia 42 (1903), S. 379 f.

Rohlmann, Michael: „Dominus mihi adiutor“. Zu Raffaels Ausmalung der Stanza d'Eliodoro unter den Päpsten Julius II. und Leo X. In: Zeitschrift für Kunstgeschichte 59 (I996), S. I-28.

Rohlmann, Michael: Repräsentation von Künstler und Auftraggeber in den Fresken der Stanzen, der Madonna di Foligno und der Sixtinischen Kapelle. In: SANder, Jochen (Hg.): Raffael und das Porträt Julius' II. Das Bild eines Renaissance-Papstes (Frankfurt a. M. 2013), S. 25-37.

Rojo Vega, Anastasio: El Siglo de Oro. Inventario de una época (Valladolid I996).

Rosa Olivera, Leopoldo de la: Una familia aventurera luso-canaria en el Nuevo Mundo. In: Morales Padrón, Francisco (Hg.): II Coloquio de historia Canario-Americana, 2 Bde. (Ediciones del Excelentísimo Cabildo Insular de Gran Canaria III Geografía e Historia, Las Palmas de Gran Canaria 1977), Bd. I, S. 99-II8.

ROSE-DE VIEJO, Isadora: „A honor y gloria del pan“: una silla de manos eucarística del siglo XVIII español. In: Archivo Español de Arte 67 (I994), S. 323 f.

Ruyssinck, Micheline: Les voitures attelées aux XVIII et XIX ${ }^{\mathrm{e}}$ siècles (Bruxelles 2002).

SÁnchez Gómez, Rosa Isabel: Delincuencia y seguridad en el Madrid de Carlos II (Dissertation, Universidad Complutense, Madrid I994).

SÁnchez Loro, Domingo: La inquietud postrimera de Carlos V, 3 Bde. (Biblioteca Extremeña I7, Cáceres I957-I958).

SAnder, Jochen (Hg.): Raffael und das Porträt Julius' II. Das Bild eines Renaissance-Papstes (Frankfurt a. M. 20I3).

SANGuineti, Daniele: Scultura genovese in legno policroma (Torino 2013).

Santamaria, Roberto: Palazzo Doria Spinola. Architettura e arredi di una dimora aristocratica genovese da un inventario del 1727 (Recco 20II).

SARmiento Ramírez, Ismael: Cuba entre la opulencia y la pobreza. Población, economía y cultura material en los primeros 68 años del siglo XIX (Madrid 2004).

SAUle, Béatrix: A Guided Tour of the Coach Museum (Versailles 1997).

Saule, Béatrix/Libourel, Jean-Louis/Delalex, Hélène (Hg.): Roulez carrosses! Le château de Versailles à Arras (Ausstellungskatalog, Paris 20I2).

Schäfer, Thomas: Imperii Insignia. Sella curulis und fasces. Zur Repräsentation Römi- 
scher Magistrate (Mitteilungen des Deutschen Archaeologischen Instituts. Römische Abteilung, Ergänzungsheft 29, Mainz 1989).

Scheidig, Walther: Die Holzschnitte des Petrarca-Meisters zu Petrarcas Werk: von der Artzney bayder Glück des guten und widerwärtigen - Augsburg I532 (Berlin 1955).

Schenk, Gerrit Japser: Zeremoniell und Politik. Herrschereinzüge im spätmittelalterlichen Reich (Forschungen zur Kaiser- und Papstgeschichte des Mittelalters. Beihefte zu J. F. Böhmer, Regesta Imperii 2I, Köln/Weimar/Wien 2003).

Scheutz, Martin/WüHrer, Jakob: Dienst, Pflicht, Ordnung und „gute policey“. Instruktionsbücher am Wiener Hof im 17. und i8. Jahrhundert. In: PANGERL, Irmgard/ Scheutz, Martin/Winkelbauer, Thomas (Hg.): Der Wiener Hof im Spiegel der Zeremonialprotokolle (I652-I800). Eine Annäherung (Forschungen zur Landeskunde von Niederösterreich 3I / Forschungen und Beiträge zur Wiener Stadtgeschichte 47, Innsbruck/Wien/Bozen 2007), S. 15-228.

Schimmelpfennig, Bernhard: Johannes Burckard. In: Deutscher Humanismus I480I520. Verfasserlexikon, hg. von Worstвrock, Franz Josef, Bd. I (Berlin/New York 2008), Sp. 299-307.

Schmitz-Kallenberg, Ludwig: Hierarchia catholica medii et recentioris aevi, Bd. 3 (Münster 1923).

Schulze, Tonio: Kutschenmuseum Schloss Augustusburg (Coburg o.J.).

Schumann, Jutta: Die andere Sonne. Kaiserbild und Medienstrategien im Zeitalter Leopolds I. (Colloquia Augustana I7, Berlin 2003).

SeELIG, Lorenz: Die Münchner Kunstkammer. In: Die Münchner Kunstkammer, Bd. 3: Aufsätze und Anhänge, vorgelegt von SAUErLÄNder, Willibald (München 2008), S. I-I24.

Sella. In: Paulys Realencyclopädie der classischen Altertumswissenschaft. Neue Bearbeitung begonnen von Wissowa, Georg, Bd. II, 4 (Stuttgart I923), Sp. I310-I315.

Sella curulis. In: Der Neue Pauly, hg. von Cancik, Hubert/Schneider, Helmuth, Bd. II (Stuttgart/Weimar 200I), Sp. 37i f.

Simonetti, Farida/Cataldi Gallo, Marzia (Hg.): Farsi Portare in carega, Portantine e livree per la nobiltà genovese (Ausstellungskatalog, Genova 1995).

SojkA, Jaroslav (Hg.): Zapřažená krása. Kočáry, saně a nosítka I8.-20. Století (Ausstellungskatalog, Praha 20I4).

Soler García, José María: El polifonista villenense Ambrosio Cotes (Publicaciones del Instituto de Estudios Alicantinos I/49, Alicante 1979).

Sommariva, Giulio: „Coronationi“ e solenni esequie, visite e „segni di allegrezza“: il potere in scena alla corte dei dogi. In: El siglo de los genoveses (Ausstellungskatalog, Milano I999), S. I30-I37. 
Spielman, John P.: Leopold I. Zur Macht nicht geboren (Graz/Wien/Köln I98I).

Spielmann, Heinz (Hg.): Reiseleben - Lebensreise. Zeugnisse der Kulturgeschichte des Reisens. Sammlung P.-J. van Tienhoven (Schleswig 1994).

STAGno, Laura: Sovrani spagnoli a Genova: apparati trionfali e „hospitaggi“ alla corte dei

Doria. In: Boccardo, Piero/Colomer, José Luis/Di Fabio, Clario (Hg.): Genova e la Spagna. Opere, artisti, committenti, collezionisti (Genova/Cinisello Balsamo [MI] 2002), S. 73-87.

StAGno, Laura: Feste barocche e „segni di allegrezza“: le nozze Doria-Pamphilj nel I67I nel Palazzo del Principe a Genova. In: Fagiolo, Marcello (Hg.): Atlante tematico del Barocco in Italia. Le capitali della festa. Italia Settentrionale (Roma 2007), S. I49-162.

Stagno, Laura: Committenze artistiche per il matrimonio di Anna Pamphilj e Giovanni Andrea III Doria Landi (I67I). In: Leone, Stephanie C. (Hg.): The Pamphilj and the Arts: Patronage and Consumption in Baroque Rome (Chestnut Hill [Massachusetts] 20II), S. 55-75.

Stagno, Laura: L'attività di Filippo e Domenico Parodi per i Doria principi di Melfi. In: Rivista d'arte 5 (Juni 20I2), S. 353-386.

Starcky, Emmanuel, u.a.: Le Palais impérial de Compiègne (Paris 2008).

Staubach, Nikolaus: „Honor Dei“ oder „Bapsts Gepreng“? Die Reorganisation des Papstzeremoniells in der Renaissance. In: DERs. (Hg.): Rom und das Reich vor der Reformation (Tradition - Reform - Innovation. Studien zur Modernität des Mittelalters 7 , Frankfurt a. M. u.a. 2004), S. 91-136.

Stelzer, Winfried: Albrecht II., „der Weise“, der „Lahme“. In: Hamann, Brigitte (Hg.): Die Habsburger. Ein biographisches Lexikon (Wien I988), S. 34-35.

Stollberg-Rilinger, Barbara: Des Kaisers alte Kleider. Verfassungsgeschichte und Symbolsprache des Alten Reiches (München 2008).

Straus, Ralph: Carriages and Coaches. Their History \& their Evolution (London 19I2). STrnad, Alfred A.: Margarethe, Infantin von Spanien. In: Neue Deutsche Biographie, Bd. I6 (Berlin 1990), S. I55-I57.

Sucheni-Grabowska, Anna: Zu den Beziehungen zwischen den Jagiellonen und den Habsburgern. Katharina von Österreich, die dritte Gemahlin des Königs Sigismund August. Ein Forschungsbeitrag. In: Historisches Jahrbuch der Stadt Linz I979 (I980), S. 59-100.

Sutter Fichtner, Paula: Emperor Maximilian II (New Haven/London 200I).

Sutter Fichtner, Paula: A community of illness: Ferdinand I and his family. In: Fuchs, Martina/Kohler, Alfred (Hg.): Kaiser Ferdinand I. Aspekte eines Herrscherlebens (Geschichte in der Epoche Karls V. 2, Münster 2003), S. 203-2I6.

TAdDEI, Elena: Anna Caterina Gonzaga und ihre Zeit: Der italienische Einfluss am Inns- 
brucker Hof. In: Noflatscher, Heinz/Niederkorn, Jan Paul (Hg.): Der Innsbrucker Hof. Residenz und höfische Gesellschaft in Tirol vom I5. bis I9. Jahrhundert (Archiv für österreichische Geschichte I38, Wien 2005), S. 213-239.

TAgliaferro, Laura: La magnificenza privata. „Argenti, gioie, quadri e altri mobili“ della famiglia Brignole Sale, secoli XVI-XIX (Collana di saggistica 66, Genova 1995).

Tellechea Idígoras, José Ignacio: El ocaso de un rey: Felipe II visto desde la nunciatura de Madrid, I594-I598 (Monografías 79, Madrid 200I).

The Royal Armoury. The assembling of royal relics, costumes arms, armour, uniforms and coaches from about 1500 to the present (Stockholm 1978).

Traeger, Jörg: Der reitende Papst. Ein Beitrag zur Ikonographie des Papsttums (Münchner kunsthistorische Abhandlungen I, München/Zürich 1970).

Traeger, Jörg: Raffaels Stanza d'Eliodoro und ihr Bildprogramm. In: Römisches Jahrbuch für Kunstgeschichte I3 (I97I), S. 29-99.

Traeger, Jörg: Die Begegnung Leos des Grossen mit Attila. Planungsphasen und Bedeutungsgenese. In: Bibliotheca Hertziana - Musei Vaticani, Raffaello a Roma. Il convegno del I983 (Roma i986), S. 97-II6.

Traeger, Jörg: Studien zur Renaissance, hg. von Christoph Wagner (Regensburger Studien zur Kunstgeschichte 2, Regensburg 2008).

Tschernyschew, Wladimir: Vom kaiserlichen Marstallmuseum zur Wagensammlung der Eremitage in St. Petersburg - Kostbarkeiten des I8. und 19. Jahrhunderts. Geschichte und Bestand einer der weltweit wichtigsten Marstallsammlungen. In: Achse, Rad und Wagen. Beiträge zur Geschichte der Landfahrzeuge I2 (2004), S. 94-I05.

Turmo, Isabel: Museo de Carruajes (Madrid ${ }^{2}$ I977).

Unterkircher, Franz: Die datierten Handschriften der Österreichischen Nationalbibliothek von I5OI bis I600 (Katalog der datierten Handschriften in lateinischer Schrift in Österreich 4, Wien I976).

Uzanne, Octave: La locomotion à travers l'histoire et les mœurs (Paris I900).

Vázquez Fernández, Luis: Memoria de Gracias que Puede otorgar Don Fernando Pizarro, del Consejo de Castilla, en Virtud de la Comisión que de su Majestad Felipe IV tiene (De un documento inédito). In: Coloquios Históricos de Extremadura (2000), Weblink: http://www.chdetrujillo.com/memoria-de-gracias-que-puede-otorgar-donfernando-pizarro-del-consejo-de-castilla-en-virtud-de-la-comision-que-de-su-majestadfelipe-iv-tiene-de-un-documento-inedito/ (letzter Zugriff: I6.08.20I6).

VIÑas y MeY, Carmelo: El problema de la tierra en la España de los siglos XVI-XVII (Madrid I94I).

Visceglia, Maria Antonietta: Cerimoniali romani: il ritorno e la trasfigurazione dei trionfi 
antichi. In: Fiorani, Luigi/Prosperi, Adriano (Hg.): Roma, la città del Papa (Storia d'Italia. Annali I6, Torino 2000), S. II3-I70.

Vocelka, Karl: Die politische Propaganda Kaiser Rudolfs II. (I576-I6I2) (Veröffentlichungen der Kommission für die Geschichte Österreichs 9, Wien I98I).

VocelKa, Karl: Rudolf II. und seine Zeit (Wien/Köln/Graz 1985).

Volk-Knüttel, Brigitte: Verzeichnis der Inventare. In: Wackernagel, Rudolf H. (Hg.): Staats- und Galawagen der Wittelsbacher. Kutschen, Schlitten und Sänfte aus dem Marstallmuseum Schloß Nymphenburg, 2 Bde. (Stuttgart 2002), Bd. 2, S. 348-35I.

Wackernagel, Rudolf H.: Fahr- und Fahrzeugsicherheit: Zum Fahrkomfort barocken Reisens. In: Lindgren, Uta (Hg.): Naturwissenschaft und Technik im Barock. Innovation, Repräsentation, Diffusion (Bayreuther Historische Kolloquien II, Köln/Weimar/ Wien 1997), S. 157-189.

Wackernagel, Rudolf H. (Hg.): Staats- und Galawagen der Wittelsbacher. Kutschen, Schlitten und Sänfte aus dem Marstallmuseum Schloß Nymphenburg, 2 Bde. (Stuttgart 2002).

Warncke, Carsten-Peter: Bildpropaganda der Reformationszeit. In: STOLlberG-Rilinger, Barbara/Weissbrich, Thomas (Hg.): Die Bildlichkeit symbolischer Akte (Symbolische Kommunikation und gesellschaftliche Wertesysteme. Schriftenreihe des Sonderforschungsbereichs 496, 28, Münster 2010), S. I85-197.

Wassılowsky, Günther/Wolf, Hubert (Hg.): Päpstliches Zeremoniell in der Frühen Neuzeit. Das Diarium des Zeremonienmeisters Paolo Alaleone de Branca während des Pontifikats Gregors XV. (I62I-I623) (Symbolische Kommunikation und gesellschaftliche Wertesysteme. Schriftenreihe des Sonderforschungsbereichs 496, 20, Münster 2007).

WeIss, Sabine: Claudia de' Medici. Eine italienische Prinzessin als Landesfürstin von Tirol (I604-I648) (Innsbruck/Wien 2004).

Weiss, Sabine: Der Innsbrucker Hof unter Leopold V. und Claudia de’ Medici (I6I9-I632). Glanzvolles Leben nach Florentiner Art. In: Noflatscher, Heinz/Niederkorn, Jan Paul (Hg.): Der Innsbrucker Hof. Residenz und höfische Gesellschaft in Tirol vom I5. bis I9. Jahrhundert (Archiv für österreichische Geschichte I38, Wien 2005), S. 24I-348.

Whitley, Antonia: Mind over matter. Living with ill health: the case of Pius II. In: Nevola, Fabrizio (Hg.): Pio II Piccolomini: il Papa del Rinascimento a Siena. Atti del Convegno Internazionale di Studi, 5-7 maggio 2005 (Siena 2009), S. 269-279.

Wiesflecker, Hermann: Kaiser Maximilian I. Das Reich, Österreich und Europa an der Wende zur Neuzeit, 5 Bde. (Wien I97I-1986).

Wilson, Geoffrey: Poles Apart. The Public Sedans of Bygone London (Colchester 2002). Winkelbauer, Thomas: Fürst und Fürstendiener. Gundaker von Liechtenstein, ein österreichischer Aristokrat des konfessionellen Zeitalters (MIÖG Ergänzungsbd. 34, Wien/ München 1999). 
Winter, Otto Friedrich: Die Donaureise Königin Marias im Sommer I634. In: Mitteilungen des Österreichischen Staatsarchivs 25 (1972), S. 359-373.

WitT-Dörring, Christian: Die Möbelkunst am Wiener Hof zur Zeit Maria Theresias I740-I780 (ungedr. Dissertation, Universität Wien 1978).

Wostry, Wilhelm: König Albrecht II. (I437-I439), 2 Bde. (Prager Studien aus dem Gebiete der Geschichtswissenschaft I2-I3, Prag 1906-1907).

Wüthrich, Lucas Heinrich: Johann Ludwig Gottfried. In: Neue Deutsche Biographie, Bd. 6 (Berlin 1964), S. 677 f.

Żurawski, Jerzy/PostęPski, Zdzisław: Łańcut (Warszawa 1969). 
